\title{
Análisis de la respuesta frente al fuego de puentes mixtos multijácena
}

José Alós Moya

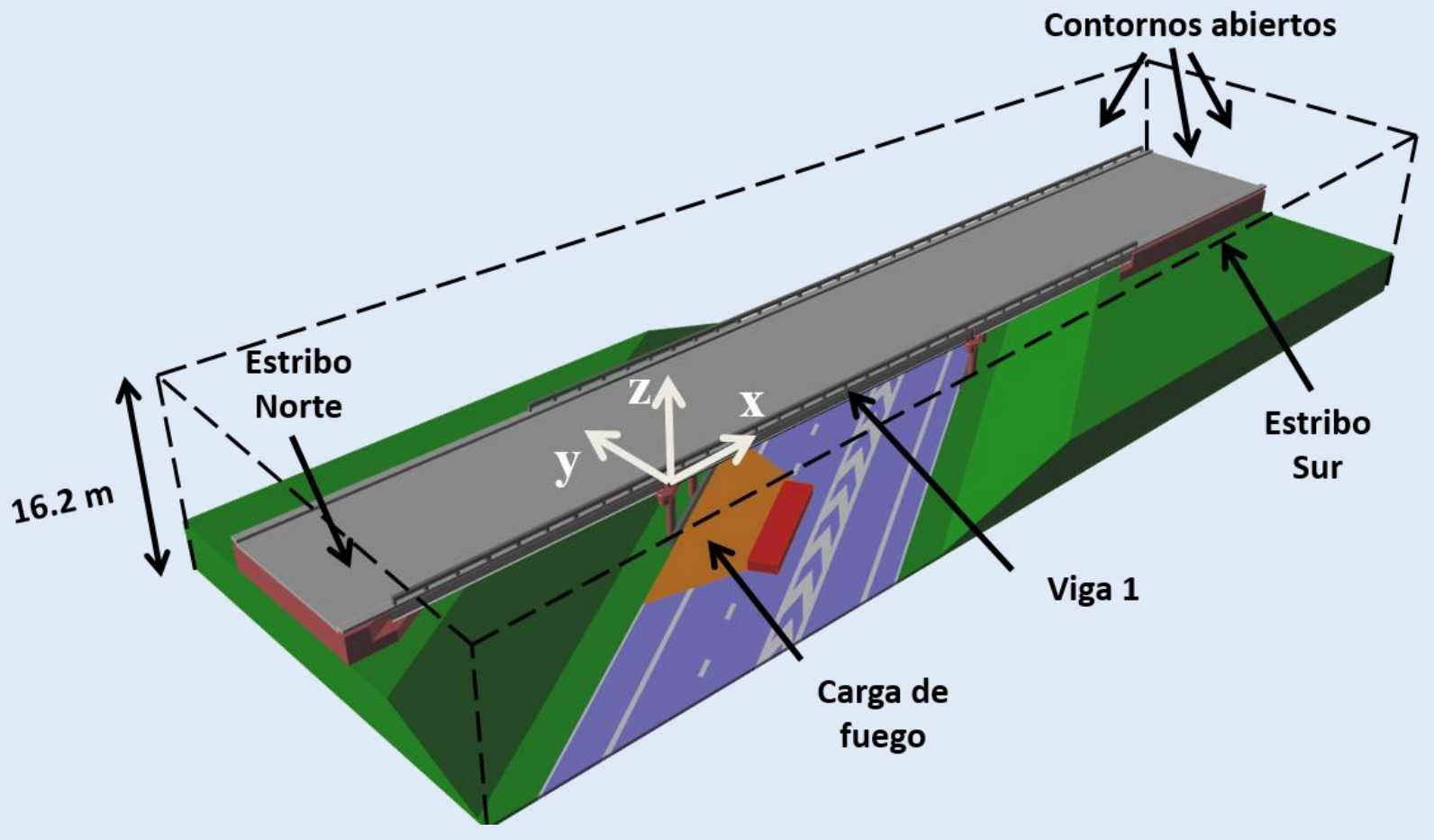

Tesis Doctoral dirigida por: Ignacio Payá Zaforteza

UNIVERSIDAD Antonio Hospitaler Pérez 

Departamento de Ingeniería de la Construcción y Proyectos de Ingeniería Civil

\title{
Análisis de la respuesta frente al fuego de puentes mixtos multijácena
}

\author{
Autor \\ José Alós Moya
}

Tesis Doctoral dirigida por

Dr. Ignacio Payá Zaforteza

Dr. Antonio Hospitaler Pérez

Universitat Politècnica de València

Noviembre de 2018 

A mis padres, a mi tío y, sobre todo, a mi hermano. 

Esta Tesis se presenta en la modalidad de compendio de artículos. A continuación, se muestran las publicaciones que constituyen el cuerpo de esta tesis.

\section{Artículos de Revista:}

i. (2018) Alós-Moya J, Payá-Zaforteza I, Hospitaler A, Loma de Osorio E. "Valencia bridge fire tests: Validation of simplified and advanced numerical approaches to model bridge fire scenarios", Advances in Engineering Software (Accepted in November 2018)

ii. (2017) Alós-Moya J., Payá-Zaforteza I., Hospitaler A., Rinaudo P. "Valencia bridge fire tests: Experimental study of a composite bridge under fire", Journal of Constructional Steel Research (138) pp538-554

iii. (2014) Alós-Moya J., Payá-Zaforteza I., Garlock M.E.M., Loma de Osorio E., Schiffner E., Hospitaler A. "Analysis of a bridge failure due to fire using computational fluid dynamics and finite element models", Engineering Structures (68) pp96-110

Fuera del alcance de la tesis han quedado las siguientes participaciones en congresos:

\section{Participaciones en congresos:}

i. (2016) Alós-Moya J, Marco-Espinosa F, Payá-Zaforteza I, Peris-Sayol G. "Analysis of several strategies for the monitoring of bridges under fire", 19th IABSE Congress. Challenges in Design and Construction of an Innovative and Sustainable Built Environment, pp. 1825-32, Stockholm, 21-23 Sep.

ii. (2014) Alós-Moya J, Payá-Zaforteza I, Peris Sayol G, Hospitaler-Pérez A. "Consideración del fuego en el diseño de puentes multiviga mixtos", IIIrd Fire Engineering Conference, Valencia, 24 Oct.

iii. (2014) Alós-Moya J, Payá-Zaforteza I, Hospitaler-Pérez A, Aguado JV. "Analysis of the structural response of a mid-span multi-girder composite bridge submitted to different fire scenarios", 37th IABSE congress, Madrid, 3-5th Sep.

iv. (2014) Alós-Moya J, Payá-Zaforteza I, Hospitaler-Pérez A, Peris-Sayol G. "Incendios en puentes. Estudio paramétrico de la respuesta termo-mecánica de un puente multiviga mixto", VI Congreso de la Asociación Científico-Técnica del Hormigón Estructural (ACHE), Madrid, 3-5 Jun. 
Durante el periodo iniciado comprendido en el desarrollo de los trabajos el autor además ha contribuido en las siguientes publicaciones:

\section{$\underline{\text { Artículos de Revista (colaboraciones con otras investigaciones) }}$}

i. (2018) Garlock M, Quiel SE, Alós-Moya J, Wang PY, Glassman JD "Postbuckling mechanics of a square slender steel plate in pure shear", American institute of steel construction. Engineering Journal (Accepted in June 2018)

ii. (2017) Peris-Sayol G, Payá-Zaforteza I, Balasch-Parisi S, Alós-Moya J. "Detailed analysis of the causes of bridge fires and their associated damage levels", Journal of Performance of Constructed Facilities 31 (3)

iii. (2015) Peris-Sayol G, Alós-Moya J, Payá-Zaforteza I, Hospitaler I. “Analysis of the influence of geometric, modeling and environmental parameters on the fire response of steel bridges subjected to realistic fire scenarios", Computers \& Structures (158) pp333-345

iv. (2014) Peris-Sayol G, Alós-Moya J, Payá-Zaforteza I, Hospitaler I. "Estudio paramétrico de la respuesta termo-estructural de un puente metálico multijácena sometido a incendios reales", Informes de la Construcción (66), EXTRA 1, m002

Para terminar, el autor también ha colaborado con otros investigadores en la realización de los siguientes estudios:

\section{Participaciones en congresos (colaboraciones con otras investigaciones):}

i. (2017) Garlock MEM, Alós-Moya J, Payá-Zaforteza I. "Alternative designs to improve behavior of thin steel plates in pure shear under fire", 2nd International Fire Safety Symposium, Naples, 7-9 July

ii. (2017) Garlock MEM, Quiel SP, Alós-Moya J, Glassman J. "Postbuckling mechanics of square slender steel plates in pure shear: Examining the role of second order effects", 2017 SSRC Annual Stability Conference Call for Papers, Texas, 21-24 Mar.

iii. (2016) Pardo E, Payá-Zaforteza I, Alós-Moya J. "Análisis de los efectos del fuego en la cubierta del salón columnario de la lonja de Valencia", IVth Fire Engineering Conference, Valencia, 13-14 Dec.

iv. (2016) Barberá A, Payá-Zaforteza I, Alós-Moya J, Glassman J. "Estudio de los daños causados por el fuego en el puente sobre la autopista SR-60 en Montebello, California (USA)", IVth Fire Engineering Conference, Valencia, 13-14 Dec.

v. (2016) Peris-Sayol G, Payá-Zaforteza I, Balasch-Parisi S, Alós-Moya J. "Analysis of the Factors that Influence the Maximum Adiabatic Temperatures 
in I-girder Bridges", 9th International Conference on Structures in Fire, pp. 74350, Princeton, 8-10 June

vi. (2015) Peris-Sayol G, Paya-Zaforteza I, Alos-Moya J, Hospitaler A. "Analysis of the Influence of Structural Models in Fire Responses of Steel Girder Bridges", ASCE Structures Congress 2015, pp. 160-71, Portland, 23-25th Apr.

vii. (2014) Peris Sayol G, Payá-Zaforteza I, Alós-Moya J, Hospitaler-Pérez A. "Análisis de la influencia del tipo de elemento finito empleado en la respuesta frente al fuego de un puente metálico", IIIrd Fire Engineering Conference, Valencia, 24 Oct.

viii. (2014) Peris-Sayol G, Payá-Zaforteza I, Alós-Moya J. "Analysis of the response of a steel girder bridge to different tanker fires depending on its structural boundary conditions", 8th International Conference on Structures in Fire, pp. 11-18, Shangai, 11-13th Jun.

ix. (2013) Peris-Sayol G, Alós-Moya J, Payá-Zaforteza I, Hospitaler-Pérez A. "Analysis of the response of a steel girder bridge under real fire conditions", IInd International Congress on Mechanical models in structural engineering, Granada, 20-21st Jun.

x. (2012) Payá-Zaforteza I, Alós-Moya J, Hospitaler A. "Puentes y fuego, análisis de una problemática", IInd Fire Engineering Conference, Valencia, 25-26 Oct.

\section{Dirección de trabajos fin de máster}

i. (2017) Jia Wei Zheng Lu, "Estudio de la resistencia residual de tableros de puente de sección mixta. Aplicación al puente experimental construido en el campus de la Universitat Politècnica de Valencia", Universitat Politècnica de València.

ii. (2017) Alejandro Barberá Carpio, "Análisis de la capacidad resistente del paso superior del boulevard san Gabriel sobre la carretera interestatal 60 en Montebello, California, Estados Unidos, tras el incendio causado por el accidente de un camión cisterna, Universitat Politècnica de València.

\section{Dirección de proyectos fin de carrera}

i. (2013) Guillem Peris Sayol, "Análisis del colapso del paso superior situado entre los cruces Hodge y Bayard en la localidad de Princeton, New jersey, Estados Unidos", Universitat Politècnica de València. 



\section{RESUMEN}

Lo bueno, si breve, dos veces bueno

Baltasar Gracián 

El diseño de puentes, a diferencia de lo que ocurre con el diseño de edificios o con el diseño de túneles ha dejado de lado la consideración de la acción del fuego hasta la fecha. Este vacío normativo, combinado con la gran repercusión económica y social de colapsos de puentes en el pasado como consecuencia de incendios, ha motivado un rápido incremento del número de estudios relativos a la ingeniería frente al fuego en el ámbito de los puentes. Aunque la acción del fuego no resulta del todo desconocida en el ámbito de las estructuras, sí que existen una serie de singularidades que impiden la trasposición directa de recomendaciones o de modelos de fuego simplificados ya desarrollados en otros campos que ya incorporan la acción del fuego en el diseño.

En este contexto, el trabajo que a continuación se expone parte de un incendio ocurrido en el estado de Alabama en 2002, cuyas consecuencias fueron la demolición de un puente mixto de 37 metros de vano central, para plantear y validar una metodología que aborda el problema de forma numérica mediante tres modelos acoplados secuencialmente: modelo de incendios, modelo térmico y modelo mecánico

Realizada una validación a nivel general se descubre que, aunque la configuración geométrica final obtenida se ajustan bastante a la realidad, la definición del incendio ha supuesto un gran número de hipótesis. Es por ello que se decide, en una segunda parte, realizar una campaña experimental que permita registrar la potencia del fuego, las temperaturas del gas y del acero y las flechas en un puente construido ad-hoc en el campus de la Universitat Politècnica de València. Este puente experimental tenía un vano único de $6 \mathrm{~m}$ de luz y fue sometido a cargas de fuego de hasta 1.3 MW.

Mediante el empleo de los registros realizados en la campaña experimental se ha validado el modelo de incendio, el modelo térmico y el modelo mecánico. Con todo ello se ha puesto en evidencia la importancia del viento en la acción del fuego, la magnitud de los gradientes térmicos espaciales y la urgencia de desarrollar procedimientos simplificados que permitan la incorporación del fuego como acción en el ámbito de los puentes Las validaciones específicas de cada modelo han permitido además llegar a una serie de conclusiones de gran interés para la realización de futuras campañas experimentales en puentes a mayor escala. 



\section{RESUM}

L'única manera d'entendre un pròleg és llegir-lo després del llibre Joan Fuster i Ortells 

El disseny de ponts, a diferència del que passa amb el disseny d'edificis o amb el disseny de túnels ha deixat de banda la consideració de l'acció del foc. Aquest buit normatiu, combinat amb la gran repercussió econòmica i social de col-lapses de ponts com a conseqüència d'incendis, ha motivat un ràpid increment del nombre d'estudis relatius a l'enginyeria del foc del foc en l'àmbit dels ponts. Encara que l'acció del foc no resulta del tot desconeguda en l'àmbit de les estructures, sí que hi ha una sèrie de singularitats que impedeixen la transposició directa de recomanacions o de models de foc simplificats ja desenvolupats en altres camps que ja incorporen l'acció del foc al disseny.

En aquest context, el treball que a continuació s'exposa part d'un incendi ocorregut a l'estat d'Alabama en 2002 i que va provocar la demolició d'un pont mixt de 37 metres de va, per plantejar i validar una metodologia que aborda el problema de forma numèrica mitjançant tres models acoplats seqüencialment: model d'incendis, model tèrmic i model mecànic

Realitzada una validació a nivell general es descobreix que, encara que la configuració geomètrica final obtinguda s'ajusta en gran mesura a la realitat, la definició de l'incendi ha suposat un gran nombre d'hipòtesis. És per això que es decideix, en una segona part, realitzar una campanya experimental que permeta registrar la potència del foc, les temperatures del gas i de l'acer i les fletxes en un pont construït ad hoc al campus de la Universitat Politècnica de València. Aquest pont experimental presenta un va únic de 6 $\mathrm{m}$ de llum i va ser sotmès a càrregues de foc de fins a $1.3 \mathrm{MW}$.

Mitjançant l'ús dels registres realitzats a la campanya experimental s'ha validat el model d'incendi, el model tèrmic i el model mecànic. Amb tot això s'ha posat en evidència la importància del vent en l'acció del foc, la magnitud dels gradients tèrmics espacials i la urgència de desenvolupar procediments simplificats que permetin la incorporació del foc com a acció en l'àmbit dels ponts Les validacions específiques de cada model han permès a més arribar a una sèrie de conclusions de gran interès per a la realització de futures campanyes experimentals en ponts a major escala. 



\section{ABSTRACT}

Writing is 1 percent inspiration, and 99 percent elimination

Louise Brook 

To date, the fire action has been left aside in the bridge design despite this action has been widely considered in other structures such as building and tunnels. This regulatory vacuum, combined with the great economic and social impact of bridge collapses in recent times as a result of fires, has led to a rapid increase in the number of studies related to fire engineering in the field of bridges. Although the action of fire is not entirely unknown in the field of structures, there are a number of singularities that prevent the direct transposition of recommendations or simplified fire models from such fields.

In this context, the study started by using a real fire which occurred in the state of Alabama in 2002 and led to the demolition of the 37-meter main span of a composite concrete and steel bridge to introduce and validate a methodology that numerically addresses the problem by uncoupling the problem in three different models: fire model, thermal model and mechanical model.

Once the validation was accomplished at a general level, it was discovered that, although the geometrical data were quite adjusted to reality, the definition of the fire had involved a large number of hypotheses. That is why carrying out an experimental campaign to record the power of the fire, the gas and steel temperatures and the vertical deflections of a bridge built ad-hoc on the campus of the Universitat Politècnica de València became a priority. This 6-meter single span experimental bridge was subjected to fire loads of up to $1.3 \mathrm{MW}$.

Through the use of the information recorded during the experimental campaign, the fire model, the thermal model and the mechanical model were validated. Moreover, the importance of wind in the action of fire, the magnitude of spatial thermal gradients and the urgency of developing simplified procedures which allow the consideration of fire as an action in the field of bridges were also highlighted. Last but not least, the validation of the different models allowed the author to include useful guidelines in order to define future experimental campaigns with more powerful fires and longer span bridges. 



\section{AGRADECIMIENTOS}

Recordar es fácil para el que tiene memoria. Olvidar es difícil para el que tiene corazón

Gabriel García Márquez 

Quisiera aprovechar la oportunidad para agradecer a todos aquellos que, en mayor o menor medida, han contribuido al desarrollo y a la conclusión del presente documento.

Dicen que la vida se divide en periodos de siete años. Y siete son los años que han pasado desde que me inicié en el campo de la ingeniería del fuego en puentes.

El presente documento no hubiera sido posible si Ignacio Payá no me hubiera brindado la magnífica oportunidad de unirme a su línea de investigación. En él no solo he podido encontrar una referencia profesional, sino también personal. Porque en la vida, como en la ingeniería, la disciplina no está enfrentada con el juego.

Este camino tampoco habría sido lo mismo sin Antonio Hospitaler, apasionado de la ingeniería y fuente inagotable de grandes ideas. Porque si buscas resultados distintos no puedes hacer siempre lo mismo y si has de pensar igual, ¿por qué no hacerlo a lo grande?

No podría escribir estas líneas sin mencionar el apoyo incondicional de mis padres, mi tío y mi hermano. A mis padres porque siempre lo han dado todo por mí. A mi tío por su generosidad y paciencia. Y a mi hermano, porque para mí siempre ha sido y será un ejemplo a seguir.

No podría olvidar tampoco la inestimable contribución de grandes profesionales y buenos amigos. Entre ellos se encuentran Eduardo Loma, Jose Vicente Aguado, Juan Hidalgo, Julio Garzón, Leticia Bonal, Francisca Molina, Javier Pereiro, Luke Bisby, Cristian Maluk, Mohamed Kiari, María Garlock, Jonathan Glassman, Spencer Quiel, Camilla Presicce, Alba Martínez, Elaine Canals y Naiara Guardado.

Especial atención merecen Guillem Peris, Manolo Buitrago y Carlos Meléndez. A Guillem, por la historia del boli "bic" y por estar en Oporto cuando más lo necesitaba. A Manolo, por nuestras conversaciones y por sus puntos de vista. A Carlos, por su honestidad, porque siempre encuentra las palabras adecuadas para cada momento y por su gran corazón.

Finalmente, quisiera citar a Amparo Blázquez. Porque, aunque no salió bien, mereció la pena cada momento. Porque fue ella quien le dio sentido a este trabajo. Y porque recordar es fácil para el que tiene memoria, y olvidar es difícil para el que tiene corazón.

Feliz cumpleaños

José Alós Moya 



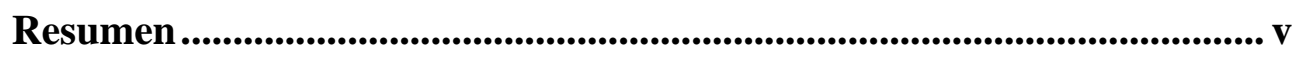

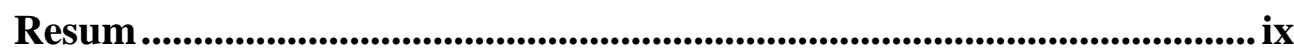

Abstract ............................................................................................... xiii

Agradecimientos ............................................................................................. Xvii

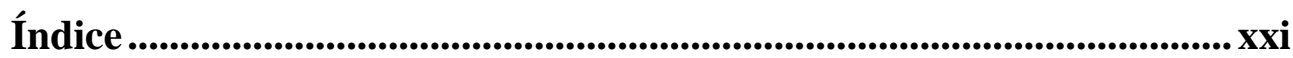

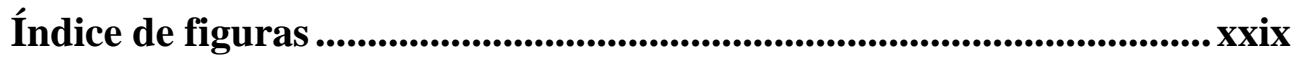

Índice de tablas ......................................................................................xxxvii

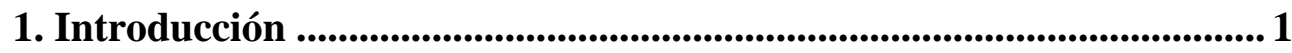

1.1. Motivación..................................................................................................................... 3

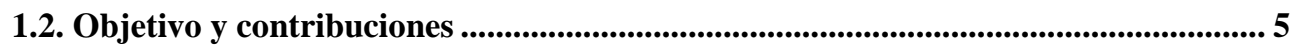

1.3. Mención de "Doctor Internacional"................................................................................... 7

1.4. Estructura de la tesis ....................................................................................... 7

1.5. Referencias.......................................................................................................................... 9

2. Estado del arte ......................................................................................................... 13

2.1. Origen de la disciplina.................................................................................................. 15

2.2. Bloques temáticos y líneas de investigación................................................................... 15

2.3. Definición del problema ....................................................................................................... 16

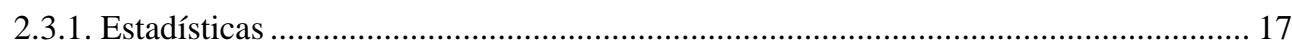

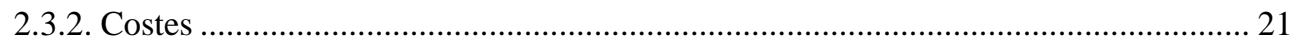

2.3.3. Singularidades respecto a otras disciplinas .......................................................... 22

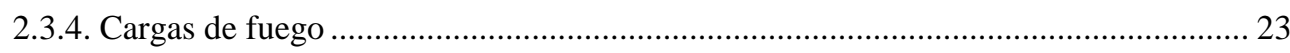

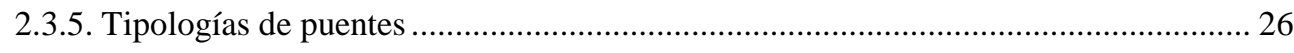

2.4. Estudio del problema ............................................................................................................ 27

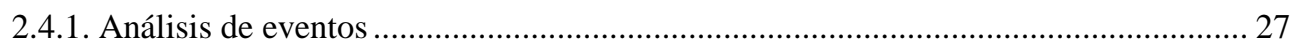

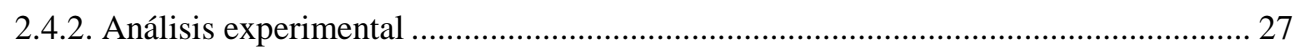

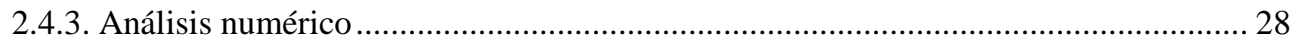


2.5. Resolución del problema .......................................................................................................28

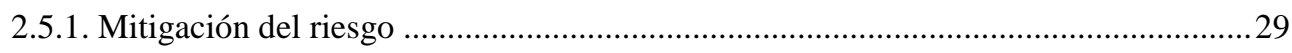

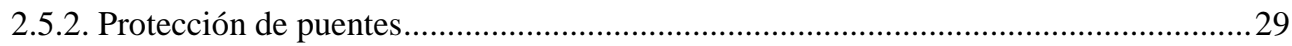

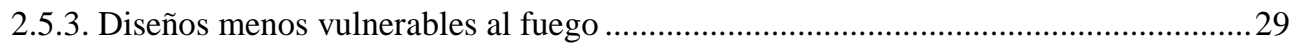

2.5.4. Comprobación de diseño ...................................................................................... 30

2.6. Aplicación de soluciones ..................................................................................................31

2.7. Referencias.................................................................................................................................31

3. Metodología ........................................................................................................... 37

3.1. Introducción ..........................................................................................................................39

3.2. Software empleado ................................................................................................................40

3.2.1. Fire dynamics simulator (FDS) ....................................................................... 40

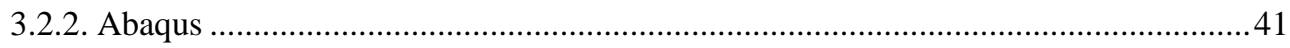

3.3. Superficie adiabática...............................................................................................................41

3.4. Estudio de un evento real ................................................................................................43

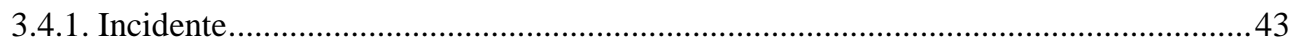

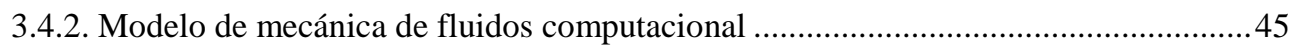

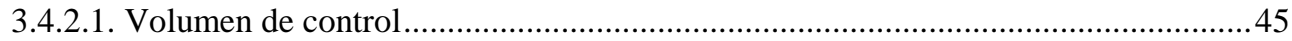

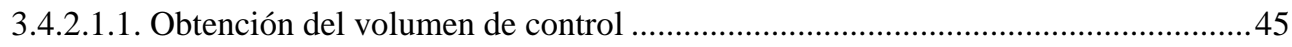

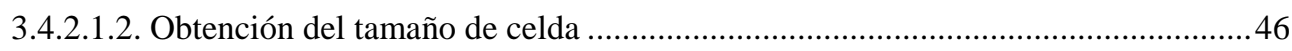

3.4.2.1.3. Comprobación del tamaño de celda .......................................................................46

3.4.2.2. Carga de fuego ................................................................................................ 47

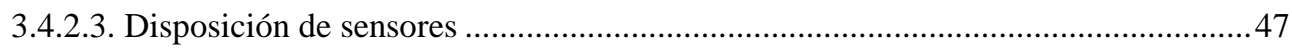

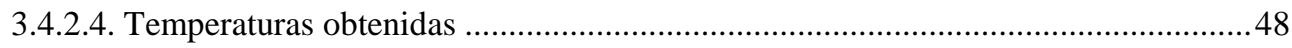

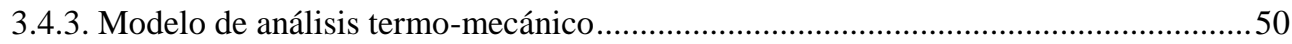

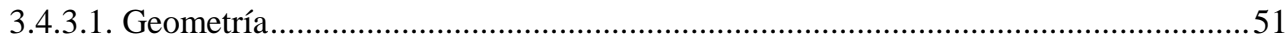

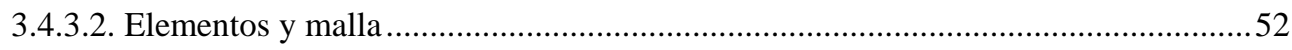

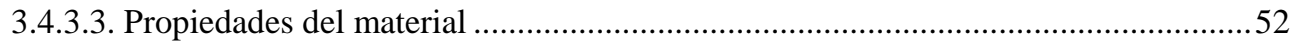

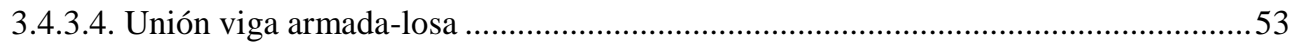

3.4.3.5. Condiciones de contorno............................................................................... 53

3.4.3.6. Cargas gravitatorias..................................................................................... 54 


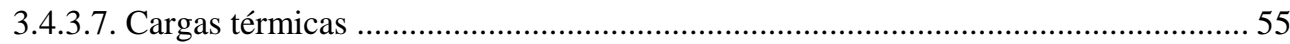

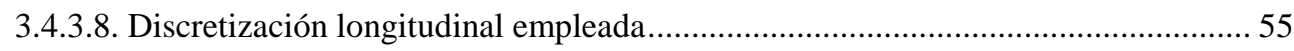

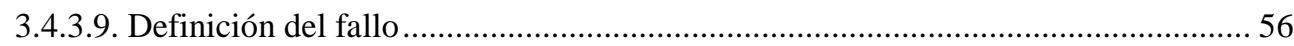

3.4.4. Estudio paramétrico para la validación del modelo .................................................... 56

3.4.4.1. Estudio de la tasa de liberación de calor del derrame ............................................ 57

3.4.4.2. Estudio de la restricción longitudinal al movimiento ......................................... 59

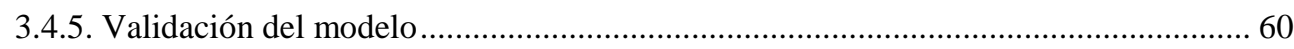

3.5. Conclusiones del estudio de validación de la metodología ..................................... 61

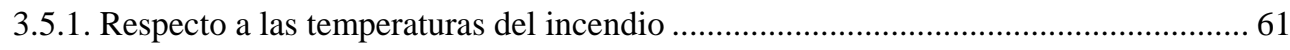

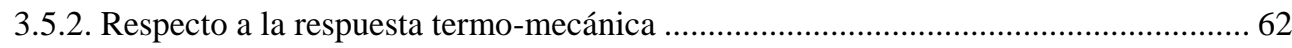

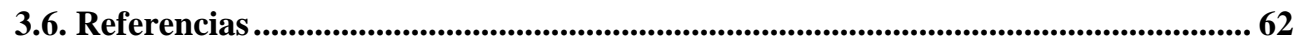

4. Campaña experimental.................................................................................... 65

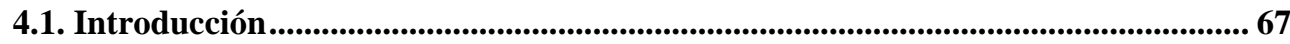

4.2. Descripción del puente experimental ............................................................................... 69

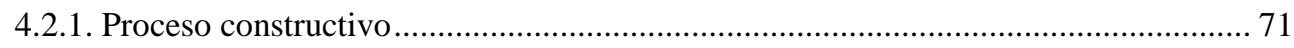

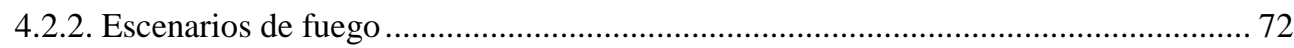

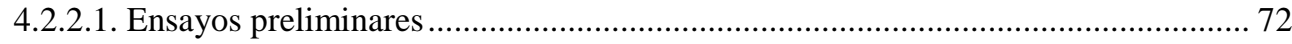

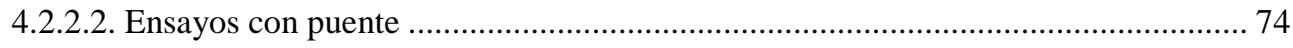

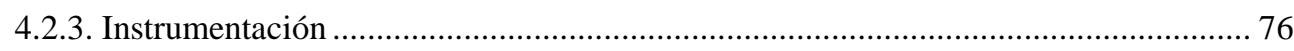

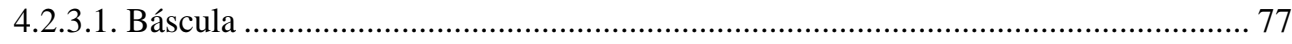

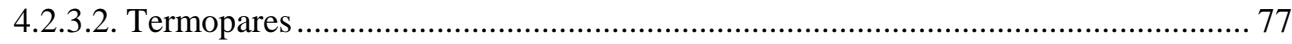

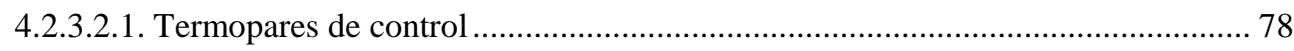

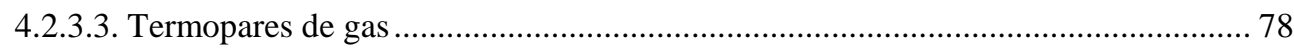

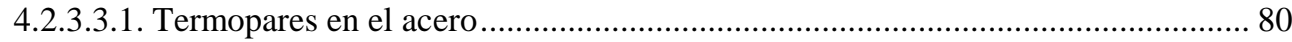

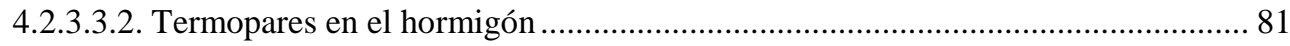

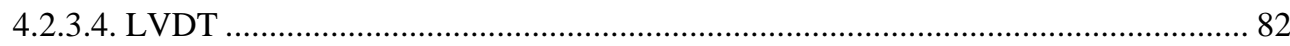

4.2.3.5. Sensores de fibra óptica de altas temperaturas ................................................. 82

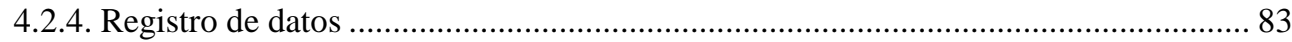

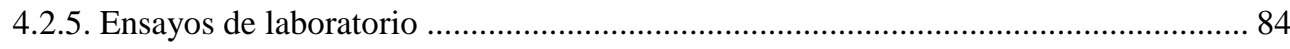

4.3. Resultados y discusión.............................................................................................................. 84 


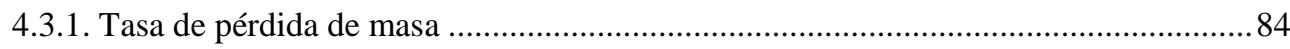

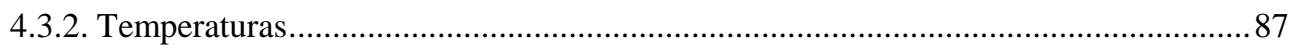

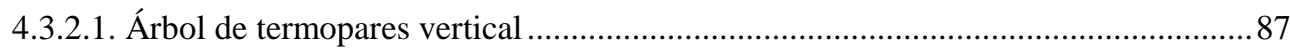

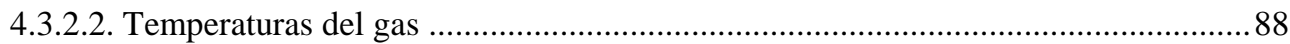

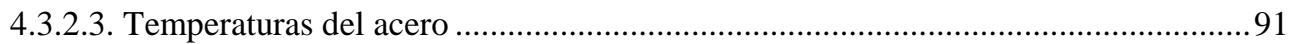

4.3.2.4. Temperaturas en la losa de hormigón armado.................................................. 95

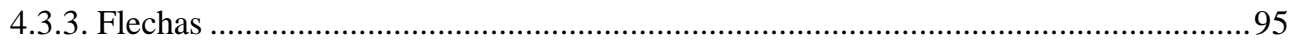

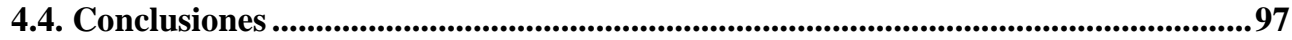

4.4.1. Aportaciones cuantitativas de los ensayos ......................................................... 98

4.4.2. Aportaciones cualitativas de la campaña experimental .........................................99

4.5. Futuras líneas ..............................................................................................................................100

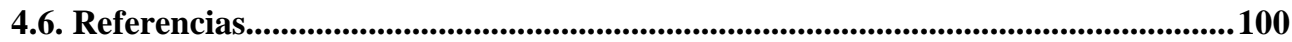

5. Validación del modelo de incendios.................................................. 105

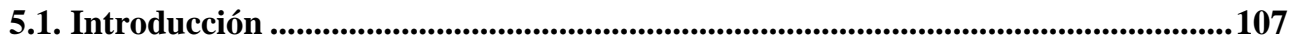

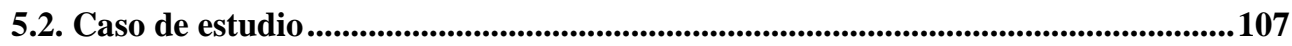

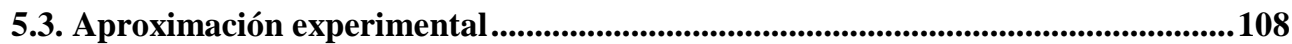

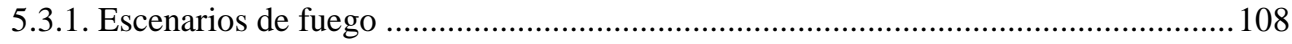

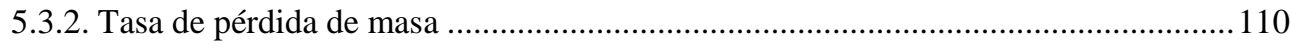

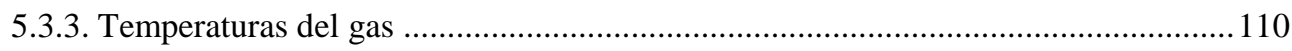

5.4. Modelo simplificado. Correlación de Heskestad \& Hamada ..................................112

5.4.1. Modelos empleados en la ingeniería frente a incendios ....................................... 112

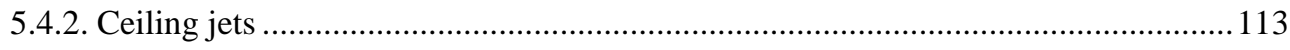

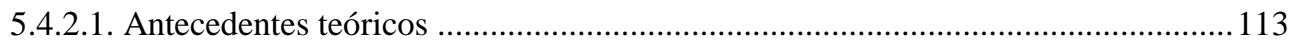

5.4.3. Correlación de Heskestad \& Hamada ....................................................................... 115

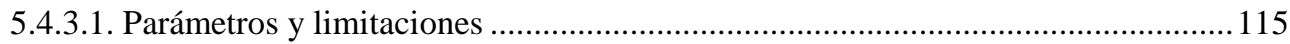

5.4.3.2. Aplicación a los ensayos "Valencia bridge fire tests"...................................... 116

5.5. Modelo avanzado. Fire dynamics simulator (FDS) ........................................118

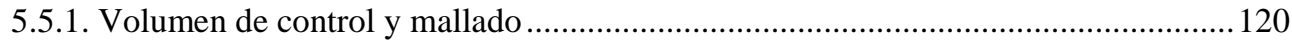

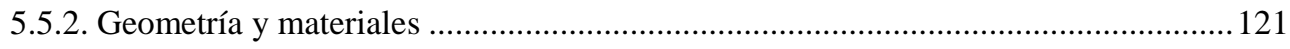

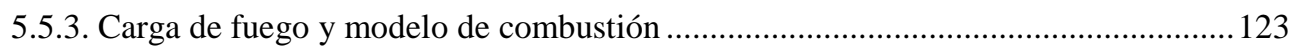


5.5.4. Distribución y tipo de sensores

5.5.5. Resultados

5.6. Análisis de incertidumbre de los resultados obtenidos con FDS.

5.6.1. Incertidumbre experimental.

5.6.2. Incertidumbre del modelo

5.6.3. Aplicación a los ensayos "Valencia bridge fire tests"

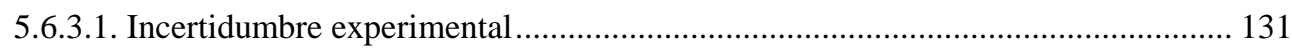

5.6.3.2. Incertidumbre del modelo................................................................................ 131

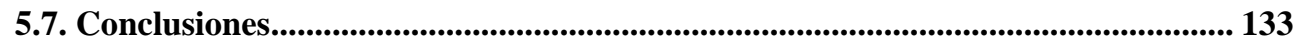

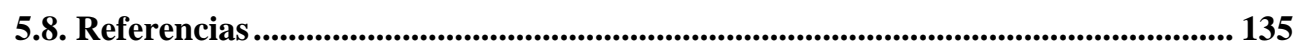

6. Validación del modelo termo-mecánico .............................................. 139

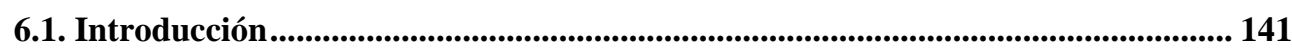

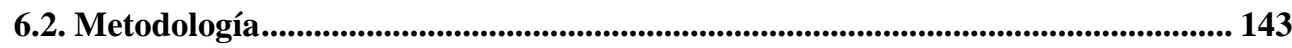

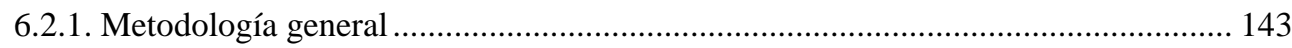

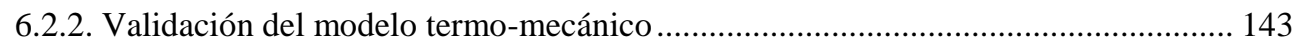

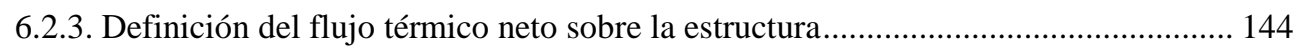

6.2.4. Validación mixta del modelo termo-mecánico ......................................................... 145

6.2.5. Validación mixta iterativa del modelo termo-mecánico........................................ 145

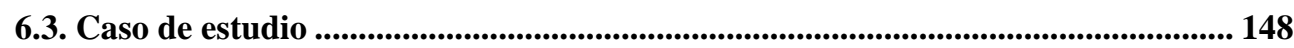

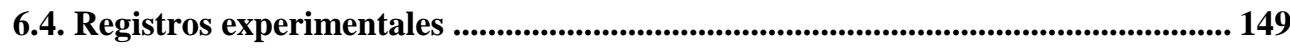

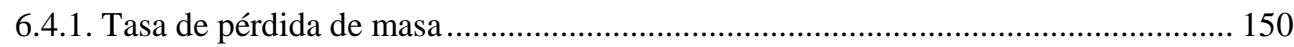

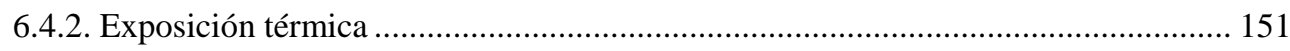

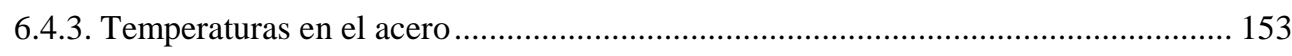

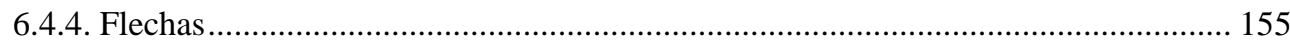

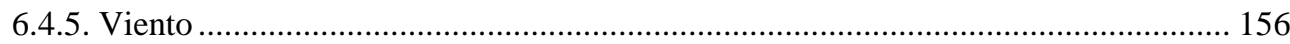

6.5. Modelo de simulación de incendios ............................................................... 157

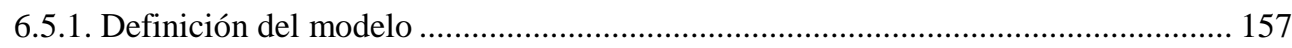

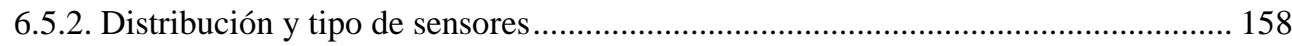

6.6. Modelo de elementos finitos termo-mecánico ..................................................... 160

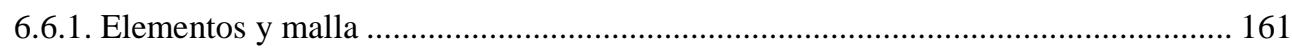




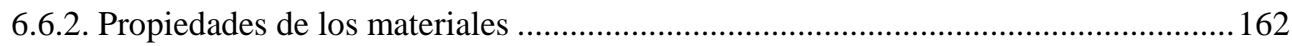

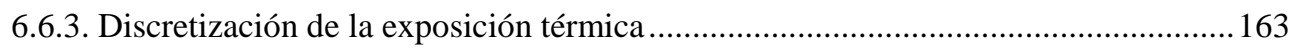

6.6.4. Restricciones y condiciones de contorno y simetría ................................................. 164

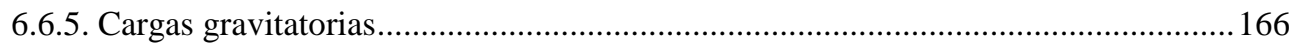

6.7. Validación termo-mecánica....................................................................................166

6.7.1. Paso 1. Iteración inicial con hipótesis de viento nulo ..............................................167

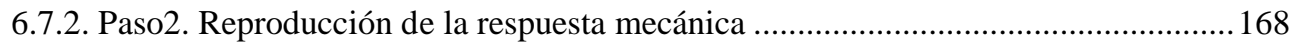

6.7.3. Paso3. Validación del modelo mecánico...................................................................... 170

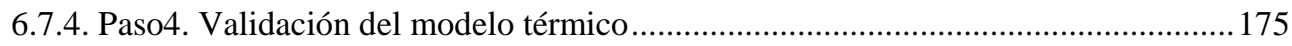

6.8. Metodologías predictivas ...................................................................................................177

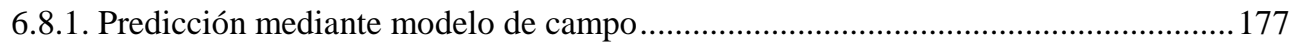

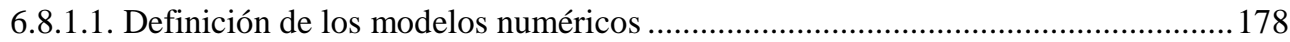

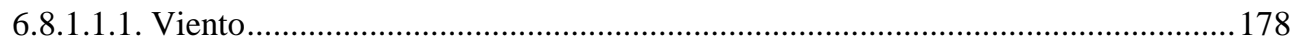

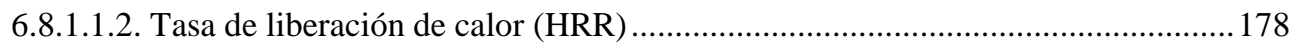

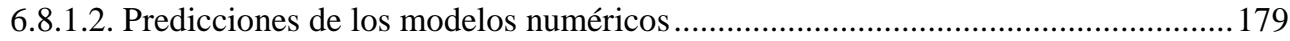

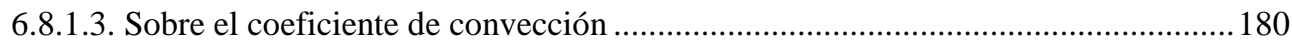

6.8.2. Predicción mediante modelo de fuego localizado .................................................... 181

6.8.2.1. Planteamiento del método de Hasemi .................................................................... 181

6.8.2.2. Limitación relativa a la posición relativa entre el fuego y elemento estructural ...183

6.8.2.3. Limitación relativa al fallo global de la estructura .................................................. 184

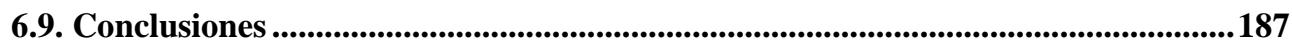

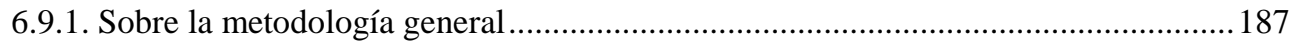

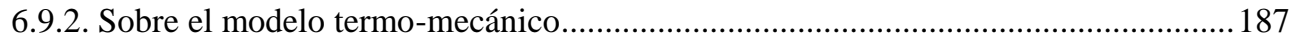

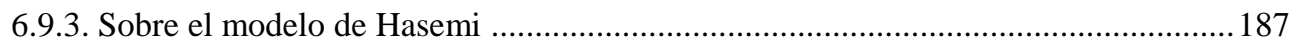

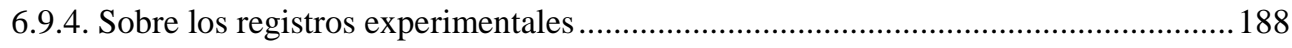

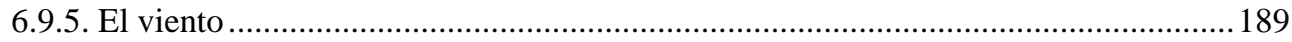

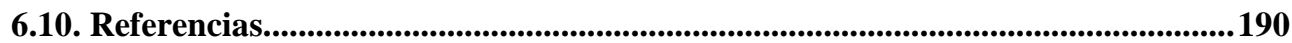

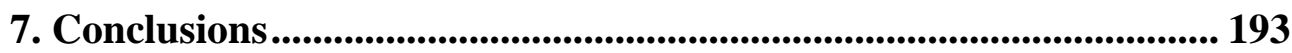

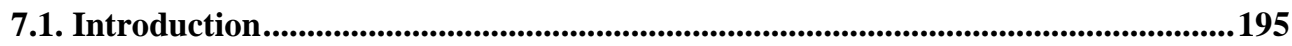

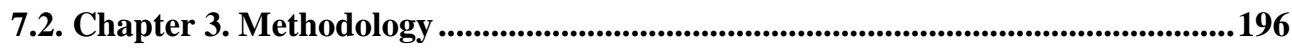


7.3. Chapter 4. Valencia bridge fire tests............................................................................... 197

7.4. Chapter 5. Fire model validation .............................................................................. 199

7.5. Chapter 6. Thermo-mechanical model .......................................................................... 200

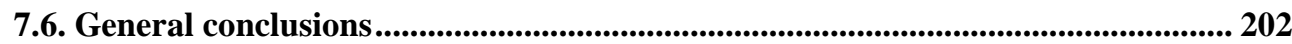

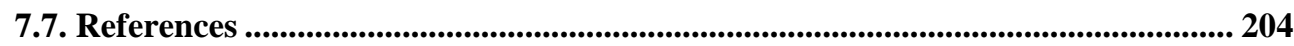

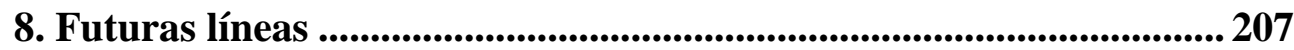

8.1. Futuras líneas........................................................................................................................ 209

9. Glosario y Notación..................................................................... 211

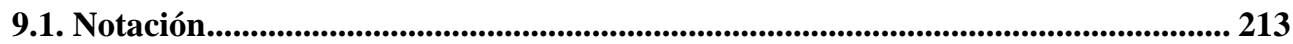

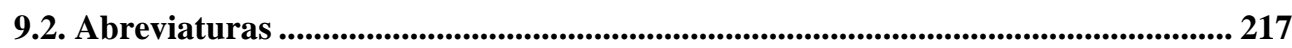

9.3. Términos anglosajones ................................................................................................. 218

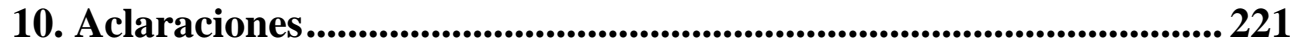

10.1. Introducción .................................................................................................................. 223

10.2. Limitación del sistema estructural considerado ....................................................... 223

10.3. Formulación de la condición de contorno térmica .................................................. 223

10.4. Empleo de la superficie adiabática...................................................................... 225

10.5. Consideración de aplicación de la superficie adiabática .......................................... 227

10.6. Versiones de FDS empleadas ....................................................................................... 228

10.7. Densidad del hormigón .......................................................................................... 228

10.8. Tasa de liberación de calor por unidad de superficie .............................................. 229

10.9. Justificación de curvas de HRRPUA sin fase de enfriamiento .............................. 229

10.10. Detalles sobre los termopares empleados en la campaña experimental........... 230

10.11. Descarte de la hipótesis de temperatura de radiación asimilable a la temperatura del gas............................................................................................................. 232

10.12. Distribuciones y tipos de sensores empleados en las distintas validaciones de los modelos numéricos ............................................................................................................. 232

10.13. Tipos de validaciones numéricas ............................................................................ 233

11. Anexo 1. Conclusiones ................................................................................ 237

11.1. Introducción ..................................................................................................................... 239

11.2. Capítulo 3. Metodología .................................................................................................. 240 
11.3. Capítulo 4. Campaña experimental ...............................................................241

11.4. Capítulo 5. Validación del modelo de incendios ..................................................243

11.5. Capítulo 6. Validación del modelo termo-mecánico...........................................244

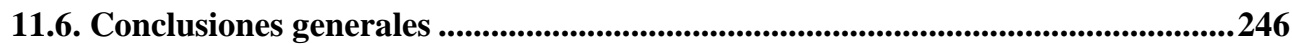

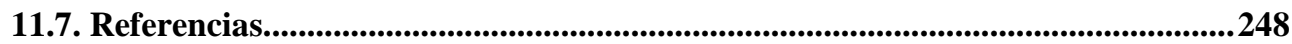

12. Anexo 2. Justificación de impacto ..................................................... 249

13. Anexo 3. Cartas de aceptación y artículos publicados.................. 257

14. Anexo 4. Artículos ......................................................... 267 


\section{ÍNDICE DE FIGURAS}

Figura 1-1. Líneas de investigación en el campo del fuego en puentes. Objetivos de la tesis.

Figura 2-1. Esquema de la publicación Garlock et al [ref2.01]. Situación en 2011 ....15 Figura 2-2. Bloques temáticos y líneas de investigación en el ámbito de fuego en puentes. Situación en 2018

Figura 2-3. Tipo de causas de colapso y cantidad [ref2.03] ..................................... 17

Figura 2-4. Distribución de accidentes en función del tiempo [ref2.06]......................18

Figura 2-5. Colisiones en puentes registradas por la base de datos FARS [ref2.11]....18

Figura 2-6. Número de incidentes con camión de combustible implicado por año

[ref2.12].

Figura 2-7. Relación entre nivel de daño y tipo de combustible implicado en el incendio [ref2.12].

Figura 2-8. Cantidad de puentes con un sistema estructural concreto que han soportado niveles de daño superiores [ref2.12].

Figura 2-9. Intervalos de tukey. Relación entre tipo de material del tableo y nivel de daño registrado [ref2-12].

Figura 2-10. Intervalos de tukey. Relación entre la posición del fuego y nivel de daño registrado [ref2-12]

Figura 2-11. Colapso del Intercambiador MacArthur Maze en Oakland, CA, USA.

Fuente: Noah Berger.....

Figura 2-12. Relación entre el nivel de daño del puente y la causa del fuego. Peris et

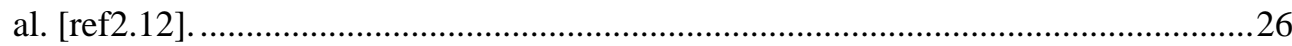

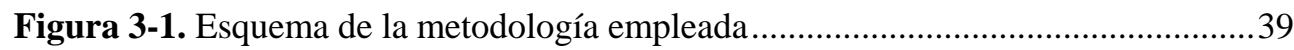

Figura 3-2. Esquema de la resolución del problema...............................................42

Figura 3-3. Bomberos apagando el fuego originado. Cortesía del Alabama Department of Transportation (ALDOT en adelante) ................................................................43

Figura 3-4. Deformada tras el incidente desde el lado Norte. Cortesía del ALDOT....44

Figura 3-5. Detalle de las pilas tras el incidente desde el lado Sur. Cortesía del

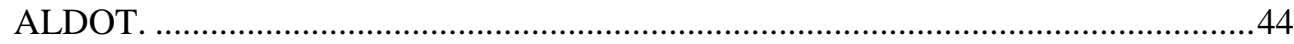

Figura 3-6. Modelo FDS. Vista general y en planta del volumen de control. ..............46

Figura 3-7. Localización de la carga de fuego y definición geométrica.......................47

Figura 3-8. Sensores de temperaturas adiabáticas en una sección tipo. .......................48

Figura 3-9. Temperaturas registradas en sección a $7.5 \mathrm{~m}$ y vista del modelo de incendios 48 
Figura 3-10. Temperaturas promedio a lo largo de las 7 vigas en (a) la zona Oeste, (b) la zona Este y (c) la diferencia Oeste-Este.

Figura 3-11. (a) Vista general, (b) Perfil ongitudinal y (c) Sección transversal del paso

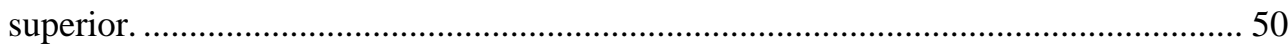

Figura 3-12. Definición geométrica de la viga en el modelo termo-mecánico............ 51 Figura 3-13. Modelo de elementos finitos de la Viga 1. (a) vista general, (b) vista frontal y (c) vista de perfil.

Figura 3-14. Croquis de los posibles desplazamientos en u3 de la losa a la altura de la

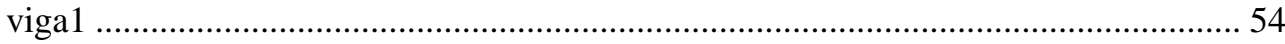

Figura 3-15. Discretización de las cruvas en 16 tramos. Caso de $1000 \mathrm{KW} / \mathrm{m}^{2} \ldots \ldots \ldots . . .55$

Figura 3-16. Variación de las temperaturas en la zona Oeste de la Viga 1................. 57

Figura 3-17. Evolución de la flecha máxima para distintos valores de HRRPUA del

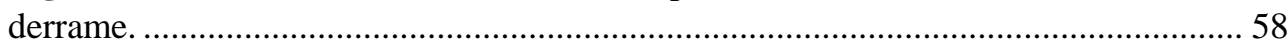

Figura 3-18. Evolución de la deformada para el análisis 1000-16-fix.......................... 58

Figura 3-19. Comparativa para distintas HRRPUA de: (a) Evolución del desplazamiento longitudinal del extremo norte y (b) deformación transversal a media altura del alma.

Figura 3-20. Efecto de limitación del desplazamiento longitudinal: (a) Evolución del desplazamiento longitudinal en extremo norte y vertical máximo y (b) deformación

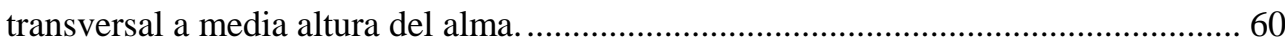

Figura 3-21. Comparativa entre el modelo validado "1000-16-fix" y el evento real... 61 Figura 4-1. Estructura de la tesis. Capítulo 4

Figura 4-2. Puente experimental: (a) Alzado, (b) Detalles del estribo y (c) Detalles del tablero. Todas las dimensiones se expresan en mm y todas las cotas se expresan en

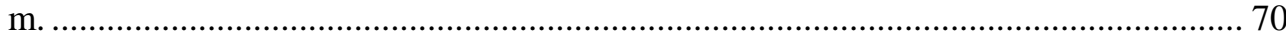

Figura 4-3. Proceso constructivo del puente experimental ....................................... 73

Figura 4-4. Ensayos preliminares: (a) Elementos y (b) vista de uno de los ensayos ... 73

Figura 4-5. Vistas frontales de cada escenario de fuego............................................ 76

Figura 4-6. (a) Báscula antes de incluir la protección para los Ensayos preliminares.

(b) Protección de la báscula con manta aislante, tablones aislantes, ladrillos y papel de

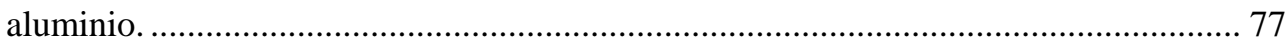

Figura 4-7. Distribución de termopares en el gas. Dimensiones en m........................ 79

Figura 4-8. Distribución de termopares en el acero. Dimensiones en m. .................... 80

Figura 4-9. Distribución de termopares en la losa de hormigón. Dimensiones en m. . 81

Figura 4-10. Distribución de LVDT. Dimensiones en m............................................. 82

Figura 4-11. (a) Nueve "dataloggers" de termopares de ocho canales y (b) 22

extensiones de LVDT conectadas a un módulo de adquisición de 32 canales. 84

Figura 4-12. Registros de pérdida de masa para (a) ensayos con bandejas de $50 \mathrm{~cm}$ de

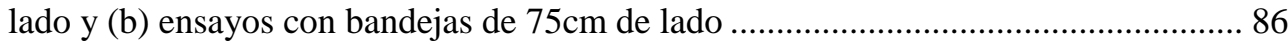


Figura 4-13. Registros de pérdida de masa para (a) escenario "Fire 1" y (b) escenario "Fire 2",

Figura 4-14. Temperaturas registradas mediante el árbol de termopares vertical: (a) Ensayo "Test 7" y (b) Ensayo Test 8.

Figura 4-15. Temperaturas registradas en la región central (entre las dos vigas): (a) Ensayo "Test 7" y (b) Ensayo "Test 8".

Figura 4-16. Temperaturas máximas registradas por región: (a) Escenario "Fire 2" y

(b) cuatro escenarios de fuego.

Figura 4-17. Temperaturas del gas por regiones registradas 20 minutos tras la ignición de los ensayos: (a) Test 7 y (b) Test 8.

Figura 4-18. Temperaturas del acero en la sección (medida) más caliente: (a) Test 7 (sección S6) y (b) Test 8 (sección S4).

Figura 4-19. Temperaturas del acero en el ala inferior de la viga sur para los ensayos: (a) Test 7 y (b) Test 8 . 93

Figura 4-20. Máximas temperaturas del acero en cuatro ensayos representativos: (a) por región y (b) por sección....

Figura 4-21. Flechas en centro-luz (CL) $(x=3.0 \mathrm{~m})$ para: (a) Viga Norte y (b) Viga Sur.

Figura 4-22. Máxima flecha vertical alcanzada por el puente en el ensayo "Test 8": (a) vista en perspectiva y (b) vista frontal.

Figura 5-1. Estructura de la tesis: Capítulo 5. 107

Figura 5-2. Puente experimental: (a) Alzado y (b) Sección BB' con detalles de la distribución de termopares del gas.

Figura 5-3. Vistas de los escenarios de fuego con HRR promedio de cada escenario.

Figura 5-4. Tasa de pérdida de masa registrada durante los ensayos. 110

Figura 5-5. Ceiling jet con impacto de la llama: (a) Esquema conceptual y (b) Caso experimental.

Figura 5-6. Temperaturas en la zona central para (a) todos los escenarios de fuego y (b) escenarios de fuego Fire 1, Fire 2 y Fire 3. Valores experimentales máximos en línea continua y procedentes de la correlación de H\&H en línea a trazos. 118 Figura 5-7. Dispersión en la región central entre las temperaturas obtenidas mediante la correlación de Heskestad y Hamada y las temperaturas máximas registradas experimentalmente.

Figura 5-8. Ocho mallas no uniformes empleadas en el modelo FDS. 120

Figura 5-9. Geometría del puente en FDS: (a) Alzado y (b) Estribo y detalles del tablero. Dimensiones expresadas en $\mathrm{m}$.

Figura 5-10. Definición del modelo FDS: (a) Materiales y superficies, (b)

Dimensiones de las bandejas y (c) Área inerte. 122 
Figura 5-11. Curva tiempo-HRR para los cuatro escenarios de fuego: (negro) definido como el input y (coloreado) el registrado durante las simulaciones de FDS.

Figura 5-12. Modelo FDS. Vista en planta de los distintos escenarios. La superficie del quemador se representa en rojo y las vigas de acero en gris (losa de hormigón no se ha incluido en la figura).

Figura 5-13. Comparativa entre resultados experimentales (exp) y numéricos (num). Todos los valores numéricos son promedios mientras que los valores experimentales son promedios (gráficas a y c) y máximos (gráficas b y d).

Figura 5-14. Efecto del viento en el escenario de fuego Fire 4: (a) Ensayo Test 8 con viento, (b) Simulación numérica sin viento y (c) Ensayo Test 8 sin viento. 126

Figura 5-15. Curvas tiempo-temperatura en la sección S4: (a) Fire 2 en la Zona Central, (b) Fire 4 en la Zona Central, (c) Fire 2 en la Zona Sur y (d) Fire 4 en la Zona Sur.

Figura 5-16. Fuentes de error e incertidumbre.

Figura 5-17. Dispersión entre las temperaturas registradas experimentalmente y las obtenidas en el modelo para (a) el chorro de techo y (b) penacho de fuego............... 132

Figura 6-1. Estructura de la tesis: Capítulo 6........................................................ 141

Figura 6-2. Metodología general en tres etapas..................................................... 143

Figura 6-3. Esquema de la validación mixta iterativa del modelo termo-mecánico .. 146 Figura 6-4. Puente experimental: (a) Alzado, (b) Sección transversal, (c)

Nomenclatura de los termopares e (d) imagen del ensayo Test 8.............................. 149

Figura 6-5. Registros experimentales del ensayo Test 8......................................... 150

Figura 6-6. Comparativa de valor experimental con valor teórico de: (a) Tasa de liberación de calor por unidad de área y (b) Tasa de liberación de calor.

Figura 6-7. Registros de temperaturas realizados mediante termopares de acero inoxidable de $1.5 \mathrm{~mm}$ situados en el gas en la sección S3 en torno a la viga sur en el modelo de FDS empleado para reproducir el ensayo Test 8 en la validación del modelo de incendios.

Figura 6-8. Validación directa del modelo termo-mecánico a partir de registros experimentales de la exposición térmica y de la flecha en centro-luz del tablero. Procedimiento descartado por la ausencia de registros necesarios.

Figura 6-9. Imágenes tomadas mediante la cámara termográfica durante el ensayo Test 8.

Figura 6-10. Comparativa de temperaturas registradas en el ensayo Test 8 mediante termopares situados en el acero e imágenes procedentes de la cámara termográfica. 154 Figura 6-11. Validación directa del modelo termo-mecánico a partir de registros experimentales de la temperatura en el acero y de la flecha en centro-luz del tablero. Procedimiento descartado por la ausencia de registros necesarios. 155 
Figura 6-12. Evolución en el tiempo de (a) la flecha en CL en las vigas norte y sur y (b) la diferencia de flechas entre la viga norte y la viga sur para las secciones $x=1 \mathrm{~m}$, $\mathrm{x}=3 \mathrm{~m}$ y $\mathrm{x}=5 \mathrm{~m}$

Figura 6-13. Evolución del efecto del viento durante el ensayo Test 8 .

Figura 6-14. Modelo de incendios del ensayo Test 8: (a) Materiales y superficies, (b) Vista en planta y (c) Dimensiones de la bandeja.

Figura 6-15. Simulación de incendios del ensayo Test 8: (a) Vista general y (b) Distribución de sensores en sección.

Figura 6-16. Modelo de elementos finitos de la viga sur en Abaqus: (a) Vista 3D, (b) Sección AA’ y (c) Alzado.

Figura 6-17. Discretización de las temperaturas de exposición en el modelo termomecánico: (a) Sección de la viga sur (zonas de exposición) y (b) Alzado (tramos longitudinales de exposición).

Figura 6-18. Temperaturas adiabáticas: (a) registradas en la sección $\mathrm{S} 3$ en el modelo de incendios de FDS e (b) introducidas en el tramo 3 en el modelo térmico de ABAQUS.

Figura 6-19. (a) Temperaturas en el centro de las alas superiores de las vigas y (b) Apoyos elastoméricos empleados en el estibo este. 165

Figura 6-20. Condiciones de contorno (apoyo: $\mathrm{u} 1=\mathrm{u} 2=0$, carito: $\mathrm{u} 2=0$ ) y condición de simetría (u3=0): (a) Vista general y (b) Vista inferior. 166

Figura 6-21. (a) Tasa de liberación de calor por unidad de área (HRRPUA) calculada a partir de la pérdida de masa registrada experimentalmente y (b) flecha en CL obtenida mediante el modelo termo-mecánico a partir de la HRRPUA mostrada en (a). 167

Figura 6-22. (a) Tasa de liberación de calor por unidad de área (HRRPUA) con meseta hasta minuto 22 y (b) flecha en CL obtenida mediante el modelo termo-mecánico a partir de la HRRPUA mostrada en (a). 168

Figura 6-23. (a) Tasas de liberación de calor por unidad de área (HRRPUA) con meseta hasta minuto 13 y (b) flechas en CL obtenidas mediante el modelo termomecánico a partir de las HRRPUA mostradas en (a).

Figura 6-24. (a) Tasas de liberación de calor por unidad de área (HRRPUA) con meseta hasta minuto 13 y doble pendiente en decay y (b) flechas en CL obtenidas mediante el modelo termo-mecánico a partir de las HRRPUA mostradas en (a)........170

Figura 6-25. Esquema resumen sobre la segunda condición a cumplir para la validación del modelo mecánico.

Figura 6-26. Esquema ilustrativo de la generación de una exposición térmica equivalente a la correspondiente al ensayo "Test 8 " a partir de un modelo sin viento y una tasa de liberación de calor reducida respecto a la registrada experimentalmente. 172 Figura 6-27. Comparativa entre temperaturas experimentales (ensayo Test 8) y temperaturas numéricas (modelo "plateau2000-decay4") en las secciones S1 (x = $0.5 \mathrm{~m}), \mathrm{S} 2(\mathrm{x}=1.5 \mathrm{~m})$ y $\mathrm{S} 3(\mathrm{x}=2.5 \mathrm{~m})$. 
Figura 6-28. Diferencia entre las temperaturas registradas por termopares en el gas (FDS) y las temperaturas registradas en el acero (FDS) en el escenario de fuego "plateau2000-decay4"a la altura del alma: (a) Sección S1 ( $x=0.5 \mathrm{~m})$, (b) Sección S2 (x $=1.5 \mathrm{~m})$ y $(\mathrm{c})$ Sección $\mathrm{S} 3(\mathrm{x}=2.5 \mathrm{~m})$.

Figura 6-29. Comparativa entre las temperaturas del acero registradas experimentalmente (ensayo Test 8) corregidas por el efecto de la temperatura del gas de las proximidades y las temperaturas del acero en el modelo "plateau2000-decay4" en (a) la sección S1 ( $\mathrm{x}=0.5 \mathrm{~m})$, (b) la sección S2 (x = 1.5m) y (c) la sección S3 (x = $2.5 \mathrm{~m})$

Figura 6-30. Comparativa entre las temperaturas del gas registradas experimentalmente (ensayo Test 8 ) y numéricamente (modelo "plateau2000-decay4") por termopares de $1.5 \mathrm{~mm}$ de espesor en las zonas central (fila superior) y sur (fila inferior) en torno a la viga sur.

Figura 6-31. (a) Tasa de liberación de calor por unidad de área (HRRPUA) asumiendo crecimiento lineal hasta valor máximo en 1 minuto y decay a partir del 70\% del combustible consumido y (b) flecha en CL obtenida mediante el modelo termomecánico a partir de la HRRPUA mostrada en (a).

Figura 6-32. (a) Sensibilidad de la respuesta mecánica a los parámetros de convección empleados y (b) Valores de coeficientes de convección empleados para cada escenario.

Figura 6-33. Esquema de la obtención del flujo total recibido por cada superficie expuesta al fuego de acuerdo con el Eurocódigo 1. 182

Figura 6-34. Posición relativa de elementos estructurales respecto al fuego: (a) Fuego bajo losa, (b) Fuego bajo viga y (c) Configuración del ensayo Test 8. 184

Figura 6-35. Vista en planta del tablero mostrando esquema de la obtención de la distancia radial $r$ desde cada una de las seis secciones de la viga sur al eje vertical del penacho de fuego.

Figura 6-36. Temperaturas adiabáticas (a) calculadas a partir del modelo de Hasemi considerando la exposición a lo largo del eje de la losa y considerando la exposición a la altura del alma (b) comparadas con las temperaturas adiabáticas registradas por zonas en la simulación de incendios "prediction" realizada mediante FDS. .............. 186

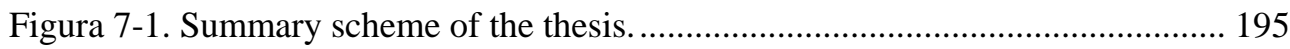

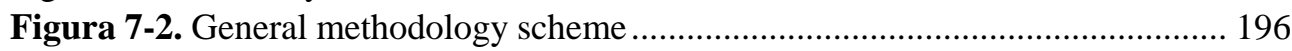

Figura 7-3. Views of fire tests corresponding to each fire scenario ......................... 198 Figura 7-4. Wind effect in Fire 4: (a) Test 8 with wind, (b) Fire simulation without wind and (c) Test 8 without wind.

Figura 7-5. South girder finite element model in Abaqus: (a) 3D view, (b) Section AA' y (c) Elevation. 201

Figura 8-1. Bloques temáticos y líneas de investigación en el ámbito del fuego en puentes. Situación en 2018 209 
Figura 10-1. Esquema explicativo de la superficie adiabática

Figura 10-2. Esquema explicativo de la definición de la superficie adiabática en FDS. 228

Figura 10-3. Imágenes de la instrumentación empleada en la campaña experimental. 231

Figura 10-4. Puente experimental: (a) Alzado, (b) Detalles del estribo y (c) Detalles del tablero. Todas las dimensiones se expresan en $\mathrm{mm}$ y todas las cotas se expresan en m.

Figura 10-5. Simulación de incendios del ensayo Test 8: (a) Vista general y (b)

Distribución de sensores en sección. .234

Figura 11-1. Esquema resumen del contenido de la tesis. 239

Figura 11-2. Esquema de la metodología empleada 240

Figura 11-3. Vistas frontales de cada escenario de fuego 242

Figura 11-4. Efecto del viento en el escenario de fuego Fire 4: (a) Ensayo Test 8 con viento, (b) Simulación numérica sin viento y (c) Ensayo Test 8 sin viento. 243

Figura 11-5. Modelo de elementos finitos de la viga sur en Abaqus: (a) Vista 3D, (b) Sección AA’ y (c) Alzado.

Figura 12-1. Factor de impacto de Engineering Structures. .251

Figura 12-2. Métricas de Scopus para el primer artículo de la tesis. .252

Figura 12-3. Factor de impacto del Journal of Constructional Steel Research. 253

Figura 12-4. Factor de impacto del Journal of Advances in Engineering Software...254 



\section{ÍNDICE DE TABLAS}

Tabla 2-1. Diferencias del fuego en puentes con el fuego en túneles y el fuego en edificación. .24

Tabla 2-2. Tasas de liberación de calor máximas según tipo de vehículos implicados [ref2.16] . .24

Tabla 2-3. Cargas de fuego propuestos por Kotsovinos et al. [ref2.19]. 25

Tabla 3-1. Parámetros y resultados de los análisis llevados a cabo para la validación del modelo.

Tabla 4-1. Escenarios de fuego de la campaña experimental "Valencia bridge fire tests"

Tabla 4-2. Distribución de termopares

Tabla 4-3. Posición vertical de los termopares del árbol de termopares vertical. .79

Tabla 4-4. Valores de tasa de pérdida de masa en los ensayos y diferencias expresadas en $\%$ de los valores teóricos.

Tabla 4-5. Valores de tasa de pérdida de masa promedios y diferencias expresadas en $\%$ de los valores teóricos.

Tabla 4-6. Máximas temperaturas registradas por el árbol de termopares vertical. .....87

Tabla 4-7. Máximas temperaturas registradas en el gas entre las dos vigas.................88

Tabla 4-8. Máximas temperaturas en ${ }^{\circ} \mathrm{C}$ registradas en la viga norte..........................91

Tabla 4-9. Máximas temperaturas en ${ }^{\circ} \mathrm{C}$ registradas en la viga sur. ............................92

Tabla 4-10. Máximas flechas (en $\mathrm{mm}$ ) para los ocho ensayos con puente...................95

Tabla 5-1. Escenarios de fuego empleados en la validación. ......................................... 109

Tabla 5-2. Temperatura promedio (Tprom $\left({ }^{\circ} \mathrm{C}\right)$ ) y máximas $\left(\operatorname{Tmax}\left({ }^{\circ} \mathrm{C}\right)\right)$ registradas

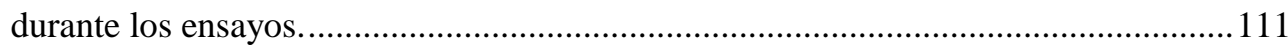

Tabla 5-3. Intervalos considerados para obtener las temperaturas promedio..............112

Tabla 5-4. Resumen de la obtención de las ratios Lf/H...........................................115

Tabla 5-5. Propiedades térmicas del material. Base de datos de Pyrosim [ref5.018]. 122 Tabla 5-6. Temperaturas promedio $\left(\mathrm{T}\right.$ prom. $\left({ }^{\circ} \mathrm{C}\right)$ ) obtenidas a partir de las simulaciones de incendios realizadas con FDS

Tabla 5-7. Parámetros de incertidumbre para ceiling jets. 70 medidas consideradas. 133

Tabla 5-8. Parámetros de incertidumbre para penachos de fuego. 20 medidas consideradas

Tabla 6-1. Número de elementos finitos organizados por partes del modelo .161

Tabla 7-1. Comparison between data sources 196

Tabla 11-1. Diferencias entre las dos fuentes de información empleadas en las validaciones 


\section{INTRODUCCIÓN}

No hay segunda oportunidad para generar una primera impresión

Oscar Wilde 



\subsection{Motivación}

Como ocurre con otras estructuras, no es posible diseñar un puente con riesgo cero de colapso. Esto es debido fundamentalmente a dos motivos. El primero no es otro que la incertidumbre existente con respecto a algunas de las acciones que actuarán sobre la estructura en servicio (desconocimiento), mientras que el segundo es el presupuesto limitado del que se dispone para diseñar y construir la estructura (recursos limitados).

Conforme se profundiza sobre las acciones, las causas y los mecanismos de fallo de las estructuras, se reduce el riesgo de fallo de las mismas mediante la incorporación de nuevos criterios de dimensionamiento. Aunque algunas de las acciones suelen considerarse en el diseño con independencia de las singularidades de la estructura, existen acciones que tan solo se consideran (o tan solo se realiza un estudio exhaustivo más allá de modelos simplificados y procedimientos de cálculo estandarizados) para estructuras cuya singularidad o emplazamiento exige su consideración. Este sería el caso del efecto dinámico del viento y el sismo para el ámbito de los puentes.

En 2008, un estudio realizado por el Departamento de Transportes de Nueva York [ref1.01] pone de manifiesto la importancia relativa del fuego con respecto a otras causas de fallo en lo que respecta a puentes. En el estudio se tuvieron en cuenta 1746 colapsos totales y parciales de puentes de 18 estados atendiendo al tipo de puente, al material y a las causas del fallo. Algunas de los datos más relevantes del estudio son:

1. La principal causa de fallo es la hidráulica (incluyendo tanto inundaciones como socavaciones), con 1001 colapsos (57\% del total).

2. Un $30 \%$ de los colapsos (520) se deben a colisiones, sobrecargas o deterioro de la estructura.

3. El fuego resulta ser la quinta causa de fallo de mayor importancia con 52 colapsos (3\% del total) por delante del sismo, con 19 colapsos (en torno al 1\% del total)

El hecho de que el número de colapsos por fuego triplique el número de colapsos por sismo indica que, dado el marco normativo actual (todavía a fecha de 2018 no se ha considerado seriamente el fuego en normativa) y a pesar de que la probabilidad de ocurrencia de sismo es muy superior a la probabilidad de ocurrencia de un incendio, es más probable que colapse un puente por fuego que como consecuencia a un sismo.

Según afirma la National Fire Protection Association (NFPA) [ref1.02]: 
"Los elementos estructurales críticos deberán ser protegidos de las colisiones y la exposición a altas temperaturas que podrían desembocar en el debilitamiento peligroso o colapso total del puente o la carretera elevada".

queda claro que los puentes deben protegerse frente al fuego, aunque no lo queda tanto como hacerlo (puesto que el documento no proporciona recomendaciones o modelos simplificados que permitan llevar a cabo la exigencia).

Cuando un puente sufre los efectos de un incendio de cierta magnitud, generalmente se demuele y reconstruye si los daños se extienden a lo largo de todo el vano o se repara y/o refuerza si los daños son localizados. En ambos casos se interrumpe la circulación sobre y bajo la estructura hasta asegurar que la misma no supondrá un riesgo para la seguridad de las personas. El periodo de cierre del servicio, en el que el tráfico se desvía (evaluación de daños y actuación sobre la estructura), suele provocar pérdidas económicas de magnitud muy superior a la correspondiente al coste de la propia actuación. Con motivo de reducir este coste indirecto asociado al colapso de un puente con afección directa sobre un volumen determinado de tráfico diario se pone sobre la mesa la consideración del fuego como acción a considerar en el diseño de los puentes.

Aunque el hecho de que el fuego ya haya sido considerado en normativa en ámbitos como la edificación y los túneles supone un punto de partida que otras acciones no han tenido, no hay que olvidar que las particularidades del ámbito de los puentes exigen una maduración previa del problema antes de comenzar a regular como diseñar puentes más resistentes al fuego. Aunque en el Capítulo 2 se realiza una comparativa exhaustiva entre los tres ámbitos (puentes, edificación y túneles) en relación a la consideración de la acción del fuego en el diseño de las estructuras a continuación se plantean las diferencias entre el ámbito de la edificación y el ámbito de los puentes que Payá-Zaforteza et al [ref1.03] dieron a conocer en 2010:

1. En el caso de edificios el combustible habitual es el mobiliario y la madera mientras que en un fuego próximo a un puente se alimentará esencialmente de combustibles basados en hidrocarburos procedentes de los vehículos que circulen por las vías.

2. El incendio al que se verá sometido un puente se producirá al aire libre mientras que en edificaciones suele tratarse de un fuego confinado.

3. Los elementos estructurales que soportan la acción del fuego presentan cantos superiores a los existentes con mayores esbelteces del alma (vigas con rigidizadores) lo que acentúa el peligro de pandeo del alma de las mismas al calentarse los materiales a altas temperaturas. 
4. Las conexiones en puentes suelen realizarse bajo el ala inferior de los perfiles sobre apoyos de neopreno, mientras que en edificación resulta común que se realicen a través de toda la sección.

5. A diferencia de lo que ocurre en edificación, en los puentes no existe ningún tipo de protección, ni activa ni pasiva, de cara a afrontar un incendio potencial.

Por estas y otras diferencias que se presentarán en el Capítulo 2 se hace indispensable entender las singularidades del fenómeno de fuego y su interacción con el puente. Es por ello que la investigación planteada en la presente Tesis Doctoral incluirá el estudio en profundidad de una campaña experimental de ensayos de fuego sobre un puente multiviga mixto a pequeña escala que permita no solo un mejor entendimiento del campo térmico en el entorno de la estructura, sino que supondrán la base para el estudio termomecánico de este tipo de puentes, además de para la definición de ensayos a mayores escalas.

\subsection{OBJETIVO Y CONTRIBUCIONES}

El objetivo principal de esta Tesis Doctoral es el de proporcionar una mayor comprensión del problema del fuego en puentes para la casuística de puente multiviga mixto con carga de fuego bajo el tablero.

Está mayor comprensión del problema se proporciona a través de seis líneas de investigación principales:

1. Planteamiento de metodología en tres etapas que permite estudiar cualquier tipo de escenario de fuego en el que un puente se encuentre implicado.

2. Estudio numérico de un incendio real con daños significativos sobre un puente mixto de $37 \mathrm{~m}$ de vano principal empleando la metodología propuesta.

3. Realización de una campaña experimental de 8 ensayos con un puente experimental sometido a la acción de cargas de fuego de entre 0.7 y $1.3 \mathrm{MW}$.

4. Validación del modelo FDS empleado en la simulación de incendios mediante los datos obtenidos en 4 de los ensayos de la campaña experimental.

5. Validación del modelo ABAQUS empleado en el problema de transmisión de calor y respuesta mecánica mediante el ensayo de mayor severidad realizado en la campaña experimental.

6. Valoración de los registros obtenidos mediante la instrumentación empleada en la campaña experimental y recomendaciones para ensayos con cargas de fuego más severas y para ensayos con puentes y cargas de fuego a escalas reales.

A través de ellas el presente documento contribuye al estado del arte actual del fuego en puentes: 
1. Planteando y aplicando una metodología en tres etapas que desacopla el problema de un puente sometido a la acción del fuego en tres modelos numéricos resolubles de forma independiente. Esta metodología no había sido aplicada previamente en el ámbito del fuego en puentes, suponiendo un paso adelante en la búsqueda de respuestas en este campo mediante la simulación numérica tato de incendios como mediante elementos finitos.

2. Definiendo y realizando una campaña experimental de ensayos de fuego con un puente a pequeña escala diseñado y construido ex profeso para la presente investigación. Los resultados de los ensayos suponen de ahora en adelante la primera referencia de ensayos de fuego bajo puente multiviga que servirán a otros investigadores validar sus modelos numéricos.

3. Validando modelos numéricos de simulación de incendios y de elementos finitos mediante los registros realizados en la campaña experimental. De esta forma el autor no solo pone a disposición de otros investigadores modelos numéricos ya validados, sino que sienta las bases para la estimación de la respuesta termo-mecánica de puentes de vigas de similares características mediante el empleo de estos modelos numéricos. En base a las validaciones, los modelos resultantes se emplearán posteriormente para definir otras campañas experimentales a superiores escalas, tanto de fuegos como de puentes.

4. Presentando una serie de comentarios relativos a los registros realizados en la campaña experimental y su utilidad final en las citadas validaciones. De esta forma el autor proporciona información de gran interés para la definición de la instrumentación en futuras campañas.

5. Aportando una nueva visión del problema mucho más realista de lo que es habitual en el campo del fuego en puentes, donde abundan los análisis numéricos en base a accidentes con pocos registros disponibles y donde generalmente se desprecian variables como el viento precisamente por falta de registros durante los ensayos. En este sentido, el trabajo que aquí se presenta podría suponer el primer paso firme hacia un mayor entendimiento del problema que nos ocupa.

Aunque la categorización en bloques temáticos y líneas de investigación considerada de forma arbitraria por el autor en base a la información consultada y recopilada durante los últimos siete años se explicará en la Sección 2.2, en la Figura 1-1, se ha querido dejar claro desde un principio que el contenido del presente documento se vincula principalmente al bloque temático de "2. Estudio del problema" en sus tres subapartados ("1. Análisis de eventos", "2. Análisis experimental” y "3. Análisis numérico"). Por ello los resultados de esta Tesis Doctoral serán de utilidad no solo para futuros estudios dentro del mismo bloque temático, sino también para los bloques temáticos de "3. Resolución del problema” y “4. Aplicación de soluciones"." 


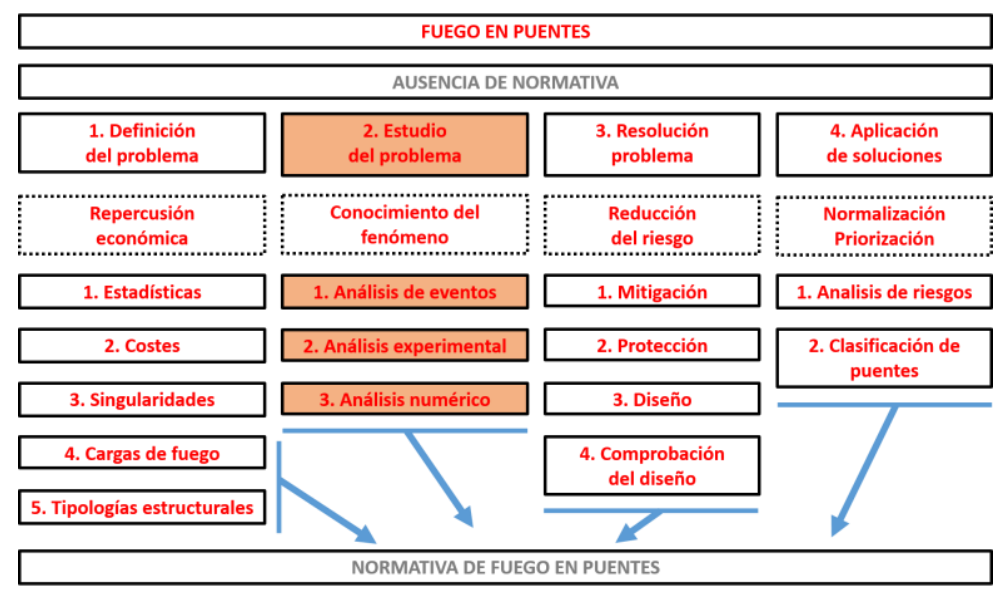

Figura 1-1. Líneas de investigación en el campo del fuego en puentes. Objetivos de la tesis

\subsection{MENCIÓN DE "DOCTOR INTERnACIONAL"}

El Artículo 22 del R.D. 1393/2007 de 29 de octubre, que regula la obtención de la mención de "Doctor Internacional", exige entre otros aspectos, que "parte de la tesis doctoral, al menos el resumen y las conclusiones, se haya redactado y sea presentado en una de las lenguas habituales para la comunicación científica en su campo de conocimiento, distinta a cualquiera de las lenguas oficiales en España".

Con objeto de obtener dicha mención, el Capítulo 7 correspondiente a las conclusiones ha sido redactado e incluido en la presente Tesis en Inglés, lengua habitual de uso en el ámbito científico de la Ingeniería Civil.

\subsection{ESTRUCTURA DE LA TESIS}

Esta Tesis se presenta en la modalidad de compendio de publicaciones (ver lista de publicaciones en la página i). Estos trabajos han sido publicados de forma separada, pero conformando todos parte de una investigación única. Los capítulos de esta Tesis se describen a continuación y describen los métodos empleados, los resultados obtenidos y las conclusiones mostradas en las distintas publicaciones.

1. Capítulo 1. Introducción

2. Capítulo 2. Estado del arte

3. Capítulo 3. Metodología 
4. Capítulo 4. Campaña Experimental

5. Capítulo 5. Validación del modelo de incendios

6. Capítulo 6. Validación del modelo termo-mecánico

7. Capítulo 7. Conclusiones

8. Capítulo 8. Futuras líneas

9. Capítulo 9. Glosario y notación

10. Capítulo 10. Aclaraciones

11. Anexo 1. Conclusiones

12. Anexo 2. Justificación de impacto

13. Anexo 3. Cartas de aceptación

14. Anexo 4. Artículos

En el Capítulo 1 se realiza una introducción general al campo del fuego en puentes, se plantean los objetivos y las contribuciones de la Tesis Doctoral y se detalla la estructura de la misma.

En el Capítulo 2 no solo se realiza una recopilación de la situación actual general del fuego en puentes, sino que también se plantea una subdivisión de la disciplina en cuatro (4) bloques temáticos y catorce (14) líneas de investigación.

En el Capítulo 3 se plantea la metodología en tres etapas que desacopla el problema general en 3 partes. De esta forma se plantea por un lado un modelo de incendios que se definirá mediante un software CFD (en este caso FDS) y por otro los modelos de transmisión de calor en la estructura y de análisis mecánico en el tiempo mediante un software de elementos finitos (en este caso ABAQUS). La transmisión de información entre ambos modelos se realizará mediante la superficie adiabática [ref1.04] mientras que el caso de estudio empleado para aplicar la citada metodología será el incendio ocurrido en Alabama en 2002 y que obligó a demoler el puente tras verse expuesto al efecto del fuego de un camión cisterna que transportaba material inflamable

En el Capítulo 4 se detalla la campaña experimental constituida por 8 ensayos de fuego con potencias entre 0.6 y $1.3 \mathrm{MW}$ realizada en la Universitat Politècnica de València durante los años 2015 y 2016. En ella se diseña y construye el puente experimental a pequeña escala que servirá de referencia tanto para realizar validaciones numéricas posteriores como para proponer recomendaciones de cara a futuros ensayos a escala real. Los resultados experimentales presentados en este capítulo no solo servirán para cuantificar los gradientes térmicos asociados a este tipo de eventos, sino que incluirán el registro en el tiempo de otras variables como la tasa de liberación de calor a partir de la pérdida de masa y las flechas registradas por las vigas metálicas

En el Capítulo 5, con las temperaturas registradas en los gases y la pérdida de masa, se realiza la validación numérica del modelo de incendios con FDS. Para ello se emplean 4 
de los 8 ensayos realizados en la campaña experimental. Durante la validación se comparan los resultados con un modelo de fuego localizado y se ve la influencia del viento sobre los resultados

En el Capítulo 6, se emplea el único ensayo de la campaña experimental que ha provocado flechas superiores a los $120 \mathrm{~mm}$ en centro-luz (CL) para realizar la validación termo-mecánica del modelo de elementos finitos. Para ello se ha recurrido a un procedimiento iterativo de corrección de la carga de fuego que podrá ser empleado en futuros estudios para determinar la carga de fuego equivalente de un incendio. Durante el estudio se hace un repaso de los distintos registros llevados a cabo durante el ensayo que permite además fijar una serie de recomendaciones de utilidad para próximas campañas experimentales.

En el Capítulo 7 se exponen las conclusiones de la Tesis Doctoral. Este capítulo se incluye en inglés como parte de las condiciones requeridas para la mención internacional.

En el Capítulo 8 se exponen las futuras líneas de investigación

En el Capítulo 9 se incluye un glosario de términos y la notación empleada

En el Capítulo 10 se incorporan una serie de aclaraciones que contribuyen a mejorar el entendimiento del documento

En el Anexo 1 se incluyen las conclusiones del Capítulo 7 en español, por si resultasen de utilidad al lector hispanohablante.

En el Anexo 2 se realiza una justificación del impacto de cada uno de los artículos considerados para la realización de la presente tesis doctoral.

En el Anexo 3 se incluyen las cartas de aceptación de los artículos ya publicados, así como los encabezamientos de los mismos en las revistas respectivas.

En el Anexo 4 se adjuntan los textos de los artículos en su versión inglesa.

\subsection{REFERENCIAS}

[ref1.01] Garlock ME, Paya-Zaforteza I, Kodur V, Li G. Fire hazard in bridges: Review, assessment and repair strategies. Engineering Structures 35:89-98. 2012.

[ref1.02] National Fire Protection Association. NFPA 502: Standard for road tunnels, bridges and other limited access highways. 2008.

[ref1.03] Paya-Zaforteza I, Garlock ME. A numerical investigation on the fire response of a steel girder bridge. Journal of Constructional Steel Research 75:93-103. 2012. 
[ref1.04] Wickström D, Duthinh D, McGrattan K. Adiabatic surface temperature for calculating heat transfer to fire exposed structures. Interflam 2:943. 2007. 



\section{ESTADO DEL ARTE}

Ningún problema puede ser resuelto desde el mismo nivel de conocimiento que lo creó

Albert Einstein 



\subsection{ORIGEN DE LA DISCIPLINA}

En 2012 Garlock et al. [ref2.01] publicaron lo que muchos considerarán el inicio formal de la disciplina del fuego en puentes. Aunque existen estudios anteriores [ref2.02ref2.10] el artículo publicado por Garlock et al. [ref2.01] ha sido referenciado en torno al centenar de veces (105 según Google Scholar y 80 según Scopus) en tan solo 6 años, lo que le convierte en una referencia indiscutible en el campo.

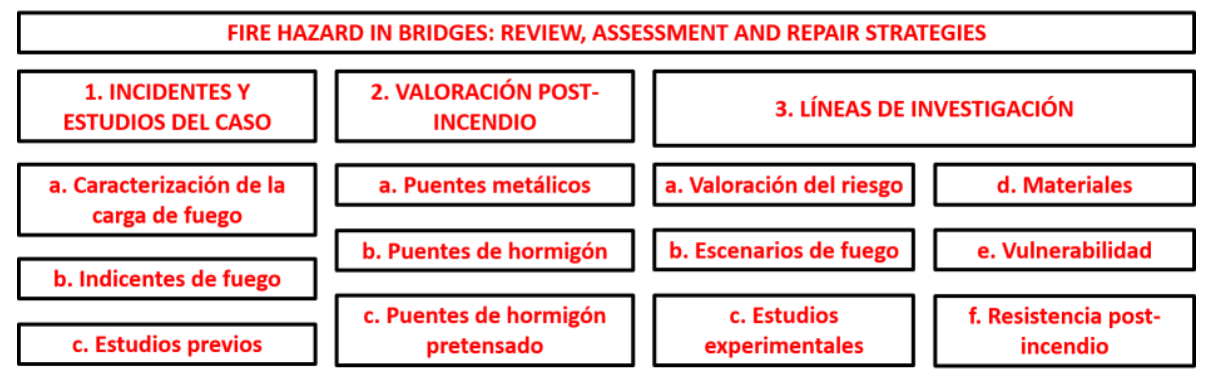

Figura 2-1. Esquema de la publicación Garlock et al [ref2.01]. Situación en 2011.

En la Figura 2-1 se han recogido los apartados tratados por Garlock et al. [ref2.01]. En ella se puede ver cómo la publicación consta de tres secciones claramente diferenciadas. En ellas se trata respectivamente qué incendios se han producido, qué estudios se han hecho al respecto y qué líneas de investigación se proponen para aumentar el grado de conocimiento del problema y reducir así la vulnerabilidad de los puentes frente al fuego.

\subsection{BLOQUES TEMÁTICOS Y LÍNEAS DE INVESTIGACIÓN}

A fecha de 2018, seis años después de la publicación del artículo que supuso las bases del fuego en puentes, la situación accidental de fuego sigue sin considerarse en normativa para este tipo de estructuras. Aunque este tipo de aplicación práctica lleva su tiempo, bien es cierto que la falta de un enfoque integral no ha ayudado a su implementación precisamente. Es por ello que, a partir del método científico, se plantea la siguiente estructura de bloques temáticos:

1. Definición del problema

2. Estudio del problema

3. Resolución del problema

4. Aplicación de soluciones

Para resolver una problemática el primer paso es el de su correcta definición. Si no se define adecuadamente se corre el riesgo de dirigir nuestros esfuerzos en la dirección 
incorrecta. Una vez definido el problema llega el momento de entender las causas que lo motivan, que lo agravan y que lo mitigan. Sólo así se podrá llegar a una adecuada resolución del mismo. Finalmente, y como habitualmente ocurre, tanto en ingeniería como en otros campos, existen diversas soluciones que convendrá aplicar o no según cada caso particular.

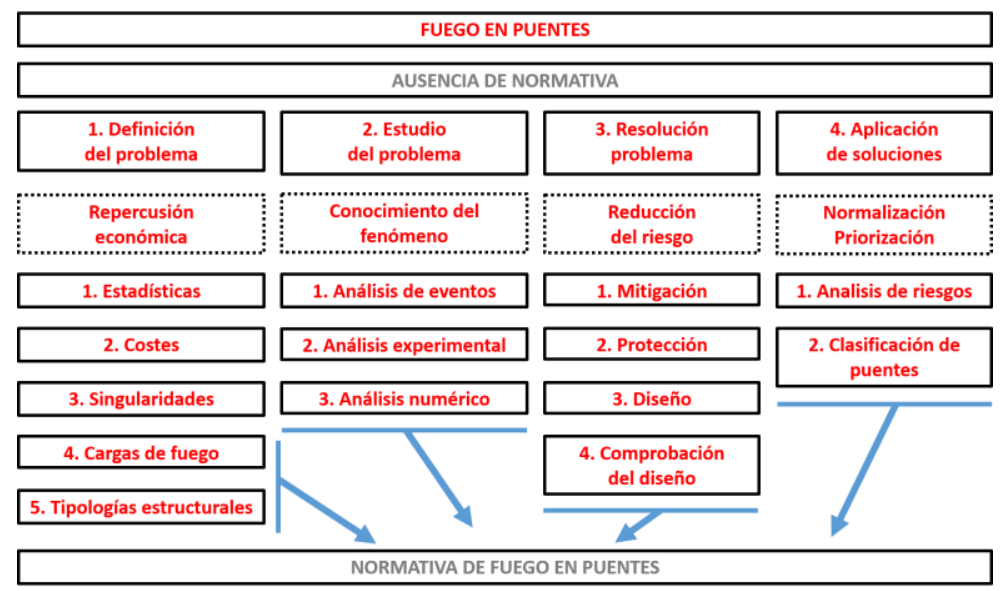

Figura 2-2. Bloques temáticos y líneas de investigación en el ámbito de fuego en puentes. Situación en 2018

Definidos los bloques temáticos, un estudio en profundidad de las publicaciones ha permitido definir un total de catorce líneas de investigación que se organizan según la Figura 2-2. Llegado a este punto es importante remarcar que cada publicación y/o estudio puede formar parte de dos o más de cualquiera de estas líneas de investigación.

\subsection{DEFINICIÓN DEL PROBLEMA}

Como se puede ver en la Figura 2-2, el bloque temático "1. Definición del problema" se subdivide a su vez en las siguientes líneas de investigación:

1. Estadísticas

2. Costes

3. Singularidades

4. Cargas de fuego

5. Tipologías estructurales 


\subsubsection{ESTADÍSTICAS}

En lo que respecta a las estadísticas cabe destacar algunos datos. Wardana et al. [ref2.03] remarcan en 2003 que de más de 500 colapsos de puentes estudiados entre 1989 y 2000 se detectó que en 16 de ellos (un $3.18 \%$ del total de la muestra) la causa del colapso fue un incendio (ver Figura 2-3). Resulta notable en este caso ver como el sismo presenta un valor muy similar (17 colapsos con un 3.38\% del total de la muestra).

En 2008, Oggero et al. [ref2.06], en un estudio de 1932 accidentes ocurridos durante el transporte de sustancias peligrosas por carretera y ferrocarril desde el principio del siglo XX hasta julio de 2004 (ver Figura 2-4), destacan el incremento del número de accidentes a lo largo de las décadas. Adicionalmente indican que en torno al $63 \%$ de los accidentes se producen en carreteras siendo los más frecuentes los derrames (78\%) y los fuegos $(28 \%)$.

Table 5. Type and Number of Failure Causes

\begin{tabular}{lcc}
\hline Failure causes and events & Number of occurrences & Percentage of total \\
\hline Hydraulic & 266 & 52.88 \\
Flood & 165 & 32.80 \\
Scour & 78 & 15.51 \\
Debris & 16 & 3.18 \\
Drift & 2 & 0.40 \\
Others & 5 & 0.99 \\
Collision & 59 & 11.73 \\
Auto/truck & 14 & 2.78 \\
Barge/ship/tanker & 10 & 1.99 \\
Train & 3 & 0.60 \\
Other & 32 & 6.36 \\
Overload & 44 & 8.75 \\
Deterioration & 43 & 8.55 \\
General & 22 & 4.37 \\
Steel deterioration & 14 & 2.78 \\
Steel-corrosion & 6 & 1.19 \\
Concrete-corrosion & 1 & 0.20 \\
Fire & 16 & 3.18 \\
Construction & 13 & 2.58 \\
Ice & 10 & 1.99 \\
Earthquake & 17 & 3.38 \\
Fatigue-steel & 5 & 0.99 \\
Design & 3 & 0.60 \\
Soil & 3 & 0.60 \\
Storm/hurricane/tsunami & 2 & 0.40 \\
Miscellaneous/other & & 4.37 \\
Total & 5.00 \\
\hline & 5 & \\
\hline & 3 & \\
\hline
\end{tabular}

Figura 2-3. Tipo de causas de colapso y cantidad [ref2.03]. 


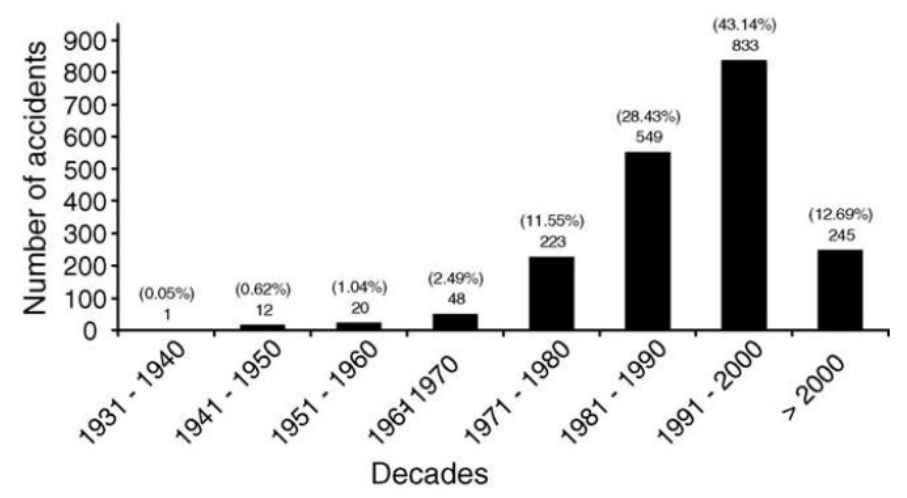

Fig. 2. Distribution of accidents as a function of time.

Figura 2-4. Distribución de accidentes en función del tiempo [ref2.06].

En 2013 Woodworth et al. [ref2.011] (ver Figura 2-5), en un estudio en el que empleó la base de datos de la "Fatal accident reporting service" (FARS) entre 1994 y 2008, muestran cómo se producen 5209 colisiones con puentes cada año, de los cuales 536 terminan en un incendio (que no siempre es fatal para la estructura). Destacable es el hecho de que el primer impacto para la mayoría de las colisiones (52\%) lo reciben los componentes de la subestructura (pilas y/o estribos), siendo otros elementos susceptibles de recibir la colisión las barreras metálicas o de hormigón cuando el impacto se produce sobre el puente.

Table 1. Bridge collisions recorded in the FARS database.

\begin{tabular}{|c|c|c|c|}
\hline & $\begin{array}{c}\text { Bridge } \\
\text { Collisions }\end{array}$ & $\begin{array}{c}\text { No Fire } \\
\text { Occurrence }\end{array}$ & $\begin{array}{c}\text { Fire } \\
\text { Occurrence }\end{array}$ \\
\hline Accidents & 5,209 & 4,672 & 536 \\
\hline Average Per Year & 347.3 & 311.5 & 35.7 \\
\hline Standard Deviation & 52.9 & 46.9 & 8.8 \\
\hline Variance & $2,794.1$ & $2,201.6$ & 76.8 \\
\hline 95\% Confidence (+/-) & 26.7 & 23.7 & 4.4 \\
\hline
\end{tabular}

Figura 2-5. Colisiones en puentes registradas por la base de datos FARS [ref2.11].

En 2016 Peris et al. [ref2.12] presentan un estudio exhaustivo (de rango temporal comprendido entre 1997 y 2015) donde se recopilan 154 casos de fuegos que han afectado en mayor o menor medida a puentes existentes a lo largo de todo el mundo. 
Este estudio es el primero centrado únicamente en incendios en puentes por lo que arroja algunos datos de gran interés desconocidos hasta la fecha. Se indica que un total de 58 incidentes ( 3 incidentes/año) estuvieron causados por un camión cisterna cargado de combustible (ver Figura 2-6) siendo el volumen de combustible transportado de 30$35 \mathrm{~m}^{3}$. En la Figura 2-7 se muestra como la gasolina suele provocar niveles de daño superiores al de otros combustibles estudiados. En la Figura 2-8 se puede ver como los sistemas estructurales multiviga en I y en cajón han sido los que con mayor frecuencia han sufrido niveles de daño superiores. Este dato no necesariamente implica que el sistema estructural sea más vulnerable al fuego, sino que se puede deber también al hecho de que un gran número de puentes emplean este tipo de tipología estructural. En la Figura 2-9 se puede ver como el nivel de daño registrado por puentes de madera es superior a los puentes de hormigón, de acero o mixtos de hormigón y acero. Adicionalmente se puede ver como los puentes mixtos registran en promedio un nivel de daño superior al de los puentes de hormigón y de los puentes de acero. Que los puentes mixtos presenten un nivel de daño superior al de los puentes metálicos se atribuye a que los puentes metálicos son habitualmente empleados para mayores luces (cruzando un río o incluso un valle), donde la magnitud de la carga de fuego potencial es muy inferior a la que podría presentarse en emplazamientos donde la tipología mixta es más frecuente. Este hecho justificaría que los daños ocasionados por un fuego de las mismas dimensiones tuvieran un impacto mucho menor en un puente de una luz muy superior. En este mismo artículo se remarca el hecho de que mientras no se había encontrado (hasta 2015) ningún incidente en el que un puente de hormigón colapsara, si se habían recopilado 9 eventos en los que puentes metálicos o mixtos de acero-hormigón habían colapsado. Finalmente, en la Figura 2-10, Peris et al. [ref2.12] ponen en evidencia la importancia de la posición relativa del fuego respecto al puente, destacando como posiciones más desfavorables "debajo del puente" y "encima del puente con derrame en la zona inferior del puente", lo que introduce el sistema de drenaje del puente como un factor a tener en cuenta en la definición de escenarios

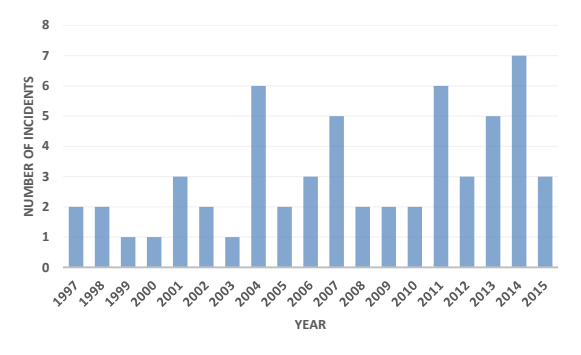

Figura 2-6. Número de incidentes con camión de combustible implicado por año [ref2.12]. 


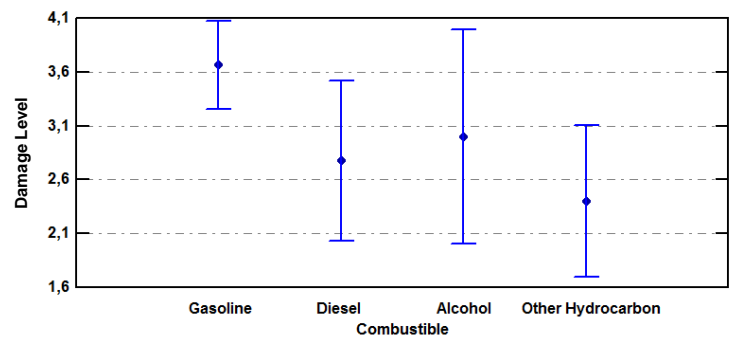

Figura 2-7. Relación entre nivel de daño y tipo de combustible implicado en el incendio [ref2.12].

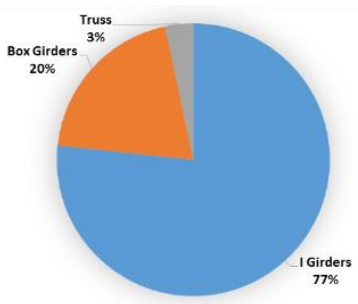

w Girders $=$ BoxGirders $=$ Truss

Figura 2-8. Cantidad de puentes con un sistema estructural concreto que han soportado niveles de daño superiores [ref2.12].

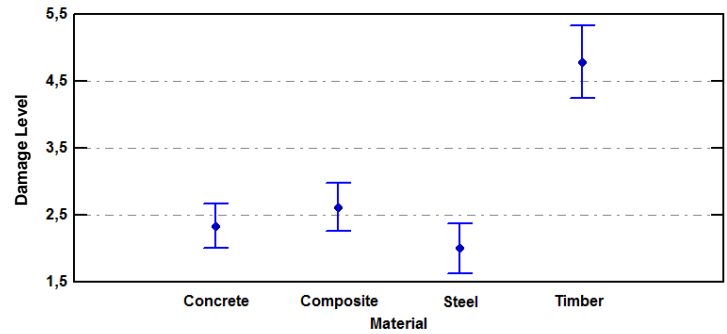

Figura 2-9. Intervalos de tukey. Relación entre tipo de material del tableo y nivel de daño registrado [ref2-12]. 


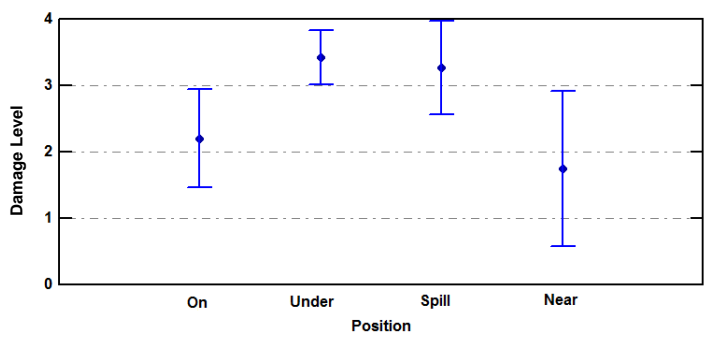

Figura 2-10. Intervalos de tukey. Relación entre la posición del fuego y nivel de daño registrado [ref2-12].

En 2016 Deng et al. [ref2.13], referenciando las estadísticas de Wardana et al. [ref2.03] realiza la observación de que el fuego se debería contemplar como una acción, además de accidental, de naturaleza humana, como ocurre con una colisión o una sobrecarga excesiva de la estructura. Esta caracterización de la acción resulta de gran interés, puesto que permite considerar una reducción del daño potencial sobre las estructuras desde la propia reducción de la probabilidad de ocurrencia, como se indicará más adelante.

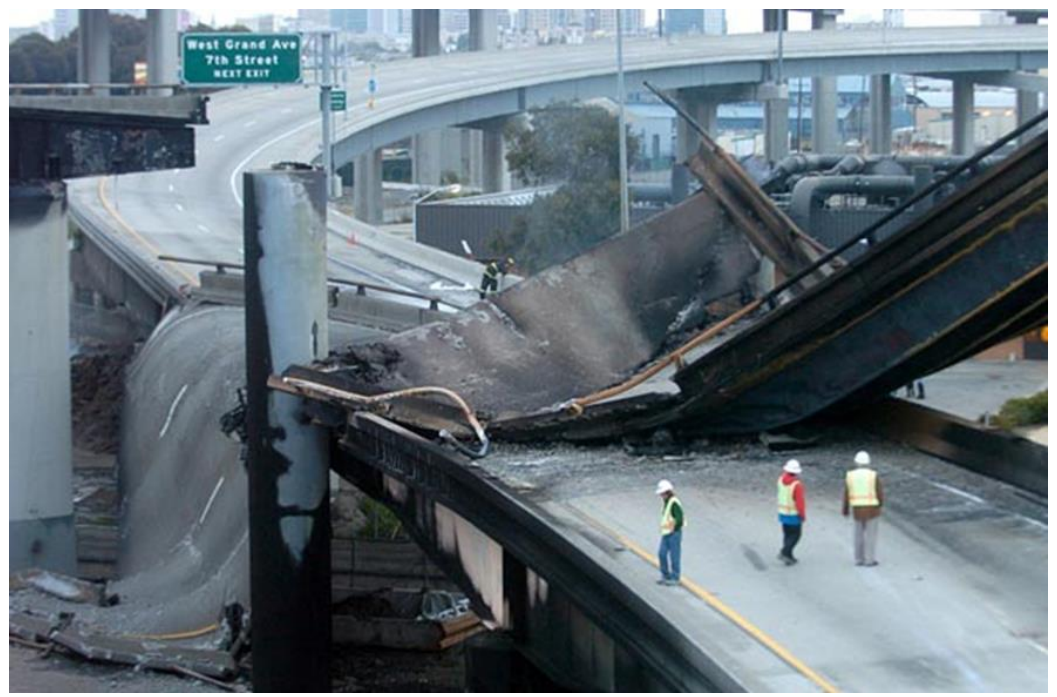

Figura 2-11. Colapso del Intercambiador MacArthur Maze en Oakland, CA, USA. Fuente: Noah Berger.

\subsubsection{COSTES}

Hasta el momento se han presentado algunos datos que permiten admitir que el problema del fuego en los puentes es una realidad. Sin embargo, la mera existencia de un problema 
no justifica la necesidad de resolverlo. En el campo de la ingeniería de la protección frente a incendios, como ocurre con el campo de la aeronáutica, siempre se busca una mejora continua de los distintos diseños frente al fallo. Sin embargo, para poder implementar mejoras se requieren inversiones y para que éstas lleguen debe existir una justificación económica (o moral si se permite la consideración). Puesto que en el campo del fuego en puentes rara vez se producen victimas mortales, es la repercusión económica provocada por este tipo de eventos la que sirvió de "detonante" para comenzar a destinar recursos a esta joven disciplina. Es por ello que raro es el estudio de fuego en puentes que no cite uno o dos ejemplos de repercusión económica de incendios previos que llevaron al colapso o demolición del puente afectado.

Entre ellos está presente el colapso del intercambiador MacArthur Maze registrado el 29 de abril de 2007 en Oakland (ver Figura 2-11). Este evento ha sido recurrentemente empleado en innumerables estudios y conferencias porque pone en evidencia la vulnerabilidad de los puentes frente a eventos de fuego. Durante el desarrollo del incendio $160 \mathrm{~m}$ del intercambiador colapsaron en cuestión de minutos. Se trataba de un tablero mixto acero-hormigón multiviga, una tipología comúnmente empleada en los EEUU. La reposición de la estructura afectada supuso un coste de 9 millones de dólares [ref2.10], mientras que los costes indirectos se cuantificaron en 6 millones de dólares diarios (156 millones de dólares en total por los 26 días que la estructura permaneció fuera de servicio) [ref2.14].

\subsubsection{SINGULARIDADES RESPECTO A OTRAS DISCIPLINAS}

Detectado el problema y evaluadas las consecuencias del mismo cabe preguntarse ¿por qué no aplicar los criterios de diseño y seguridad estructural empleados en ámbitos como los túneles o las edificaciones? En primer lugar, hay que admitir que se está tratando el mismo problema básico de una estructura siendo afectada por una acción de fuego. Desde este punto de vista serán aprovechables muchos de los conceptos desarrollados en el ámbito de la ingeniería frente a incendios. En segundo lugar, habrá que tener en cuenta las particularidades del campo de estudio que nos ocupa. Estas diferencias con otros campos serán clave a la hora no sólo de entender el problema, sino también de plantear recomendaciones de diseño. En la Tabla 2-1 se ha incluido una comparativa del fuego en puentes con respecto al fuego en edificación y al fuego en túneles. Para ello se ha jerarquizado el problema a 2 niveles constituidos por cuatro bloques y trece secciones respectivamente. La comparativa ha tomado como punto de partida la propuesta por Payá et al. [ref2.15] y se ha complementado con la experiencia adquirida a lo largo del periodo que abarca la investigación que aquí se presenta. 


\subsubsection{Cargas de fuego}

Respecto a las cargas de fuego implicadas, pocos estudios se han realizado. En $2012 \mathrm{Li}$ et al. [ref2.16] plantean emplear como curvas de calentamiento para puentes las propuestas por Ingason [ref2.17-ref2.18] para túneles. De los tres modelos matemáticos (lineal, cuadrático y exponencial) propuestos por Ingason para representar la evolución de la tasa de liberación de calor (HRR: Heat Release Rate) a lo largo de las etapas de crecimiento, meseta y descrecimiento, Li et al. [ref2.16] comentan que:

1. El modelo lineal es intuitivo y claro, pero presenta la mayor desviación frente a las cargas de fuego registradas experimentalmente

2. El modelo experimental, más complejo, requiere un mayor número de parámetros difíciles de caracterizar.

Para finalmente terminar proponiendo el modelo cuadrático, con una fase de crecimiento cuadrático, una fase estable de HRR máxima constante según los valores de la Tabla 2-2 $\mathrm{y}$ una fase de decrecimiento exponencial.

En 2016 Kotsovinos et al. [ref2.19], tras revisar y analizar incidentes notables con efecto en puentes de carretera, destacaron que en su gran mayoría fueron originados por la colisión o impacto de un camión portador de material combustible como la gasolina o el gasóleo. A partir del estudio se definieron cuatro cargas de fuego (ver Tabla 2-3) en los que se incluye un camión contenedor, un camión cisterna de transporte de combustibles inflamables, una piscina de combustible que representa el combustible derramado y un camión de gas natural licuado. Como se puede ver para cada carga de fuego se definieron unos valores específicos, salvo para el caso de la potencia y la duración del incendio, que suponen las dos variables más importantes de la caracterización del incendio. Los valores presentados se obtuvieron a partir de eventos concretos y no son necesariamente conservadores. En el caso del camión de gas licuado Kotsovinos et al. [ref2.19] realizan un apunte interesante indicando que el escenario más desfavorable no tiene por qué ser el de mayor potencia de fuego, ya que, según el nivel de protección, un fuego de mayor duración podría generar una situación más desfavorable que un fuego muy intenso, pero de corta duración.

En 2016 también, Kotsovinos et al. [ref2.20] realizan una recopilación de causas potenciales de incendios a nivel cualitativo que se incluye a continuación:

3. Camión contenedor

4. Camión cisterna

5. Locomotora diésel

6. Vagón de mercancías

7. Barco
8. Vehículo de carga

9. Depósitos de madera

10. Almacenamiento fertilizantes

11. Incendios forestales

12. Incendios en edificios 


\begin{tabular}{|c|c|c|c|c|c|}
\hline Bloque & Sección & Puentes & Edificación & Túneles & Observaciones \\
\hline \multirow{5}{*}{ 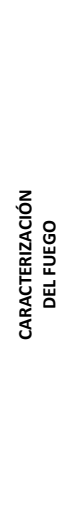 } & Causa de fuego & $\begin{array}{l}\text { Colisión } \\
\text { Ignición de materiales } \\
\text { acopiados } \\
\text { Ignición de encofrados en } \\
\text { construcción }\end{array}$ & $\begin{array}{l}\text { Ignición de materiales } \\
\text { dentro del sector }\end{array}$ & Colisión & $\begin{array}{l}\text { Distintos combustible } \\
\text { conllevan } \\
\text { distintas cargas de fuego }\end{array}$ \\
\hline & Nivel de ventilación & $\begin{array}{l}\text { Controlado por } \\
\text { combustible }\end{array}$ & $\begin{array}{l}\text { Controlado por } \\
\text { ventilación }\end{array}$ & $\begin{array}{l}\text { Controlado por } \\
\text { combustible o ventilación }\end{array}$ & $\begin{array}{l}\text { No hay restricción de } \\
\text { potencia } \\
\text { por ausencia de oxígeno }\end{array}$ \\
\hline & Intensidad del fuego & $\begin{array}{l}\text { Fuegos de hidrocarburos } \\
\text { Rápidos calentamientos } \\
\text { Altas intensidades de fuego }\end{array}$ & $\begin{array}{l}\text { Fuegos celulósicos } \\
\text { Calentamientos más lentos }\end{array}$ & $\begin{array}{l}\text { Fuegos de hidrocarburos } \\
\text { Rápidos calentamientos } \\
\text { Altas intensidades de fuego }\end{array}$ & $\begin{array}{l}\text { Fuegos de hidrocarburos } \\
\text { implican mayores } \\
\text { temperaturas en los } \\
\text { primeros minutos }\end{array}$ \\
\hline & Entorno & Al aire libre & Compartimentado & $\begin{array}{l}\text { Obra lineal con una } \\
\text { dimensión notablemente } \\
\text { superior a las otras dos. } \\
\text { Ventilación limitada }\end{array}$ & $\begin{array}{l}\text { Se evita la acumulación de } \\
\text { gases tóxicos } \\
\text { y el viento cobra } \\
\text { importancia }\end{array}$ \\
\hline & $\begin{array}{l}\text { Retroaliminetación de la } \\
\text { superficie de combustible }\end{array}$ & $\begin{array}{l}\text { Depende del volumen de la } \\
\text { llama, } \\
\text { la posición de la superficie } \\
\text { de combustible } \\
\text { y la geometría del puente }\end{array}$ & $\begin{array}{l}\text { Depende del volumen de la } \\
\text { Ilama, } \\
\text { la distribución de la carga } \\
\text { de fuego } \\
\text { y la geometría del sector }\end{array}$ & $\begin{array}{l}\text { Depende del volumen de la } \\
\text { llama, } \\
\text { la geometría del túnel } \\
\text { y la ventilación del túnel. }\end{array}$ & $\begin{array}{l}\text { Se reduce notablemente } \\
\text { en el caso de los puentes }\end{array}$ \\
\hline \multirow{2}{*}{ 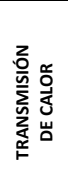 } & $\begin{array}{l}\text { Curvas de exposición } \\
\text { (Curvas de fuego) }\end{array}$ & No existen & $\begin{array}{l}\text { Curvas nominales: } \\
\text { ISO-834 } \\
\text { ASTM E119 } \\
\text { Curvas paramétricas } \\
\text { (Eurocódigo1) }\end{array}$ & $\begin{array}{l}\text { Curvas disponibles (según } \\
\text { ITA): } \\
\text { HCM, RWS, RABT ZTV }\end{array}$ & $\begin{array}{l}\text { Las curvas de exposición } \\
\text { sirven de referencia para la } \\
\text { aplicación de normativas. } \\
\text { No existen en puentes. }\end{array}$ \\
\hline & $\begin{array}{l}\text { Variabilidad espacial de la } \\
\text { exposición térmica }\end{array}$ & $\begin{array}{l}\text { No se puede asumir } \\
\text { uniforme }\end{array}$ & Se considera uniforme & Se considera uniforme & $\begin{array}{l}\text { Se requieren estudios } \\
\text { específicos }\end{array}$ \\
\hline \multirow{3}{*}{ 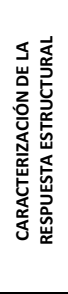 } & Geometría estructural & $\begin{array}{l}\text { Mayor canto de los perfiles } \\
\text { de acero } \\
\text { Almas más esbeltas } \\
\text { Presencia de rigidizadores }\end{array}$ & $\begin{array}{l}\text { Perfiles conformados } \\
\text { Almas menos esbeltas } \\
\text { Sin rigidizadores }\end{array}$ & $\begin{array}{l}\text { Infraestructura lineal de } \\
\text { gran dimensión, } \\
\text { generalmente de hormigón } \\
\text { in situ o prefabricado }\end{array}$ & Mayor sensibilidad al fuego \\
\hline & Conexiones & $\begin{array}{l}\text { Se apoya el ala inferior de } \\
\text { las vigas } \\
\text { sobre apoyos } \\
\text { elastoméricos }\end{array}$ & $\begin{array}{l}\text { Se realizan las uniones en } \\
\text { el alma } \\
\text { y/o en las alas }\end{array}$ & $\begin{array}{l}\text { Suelen emplearse dovelas } \\
\text { prefabricadas de hormigón }\end{array}$ & $\begin{array}{l}\text { Condiciones de contorno } \\
\text { específicas del campo }\end{array}$ \\
\hline & Tipos de fallo (en vigas) & $\begin{array}{l}\text { Cortante, flexión, } \\
\text { pandeo del alma, } \\
\text { pandeo global }\end{array}$ & Flexión & No procede & $\begin{array}{l}\text { Pueden existir otros } \\
\text { elementos estructurales } \\
\text { expuestos al fuego }\end{array}$ \\
\hline \multirow{3}{*}{ 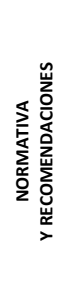 } & $\begin{array}{l}\text { Normativa de protección } \\
\text { frente a incendios }\end{array}$ & No existe & $\begin{array}{l}\text { Se especifica la resistencia } \\
\text { al fuego de cada elemento } \\
\text { frente a una curva nominal }\end{array}$ & $\begin{array}{l}\text { Algunas directrices de } \\
\text { diseño (ITA y NFPA) } \\
\text { han propuesto criterios de } \\
\text { diseño }\end{array}$ & $\begin{array}{l}\text { La metodología empleada } \\
\text { en edificación no es } \\
\text { extrapolable } \\
\text { sin estudios previos }\end{array}$ \\
\hline & Protección frente al fuego & No se emplea & $\begin{array}{l}\text { Pasiva: Cobertura } \\
\text { mediante } \\
\text { materiales resistentes al } \\
\text { fuego } \\
\text { Activa: Rociadores }\end{array}$ & $\begin{array}{l}\text { Pasiva: Cobertura } \\
\text { mediante } \\
\text { materiales resistentes al } \\
\text { fuego } \\
\text { Activa: Rociadores }\end{array}$ & $\begin{array}{l}\text { Se descartan los sistemas } \\
\text { de protección activa en } \\
\text { favor } \\
\text { de la protección pasiva }\end{array}$ \\
\hline & $\begin{array}{l}\text { Objetivo principal de } \\
\text { diseño }\end{array}$ & Mantenimiento del servicio & Evitar la pérdida de vidas & Evitar la pérdida de vidas & $\begin{array}{l}\text { Objetivos distintos implican } \\
\text { restricciones diferentes }\end{array}$ \\
\hline
\end{tabular}

Tabla 2-1. Diferencias del fuego en puentes con el fuego en túneles y el fuego en edificación.

\begin{tabular}{cccccc}
\hline Potencia & Tipo de vehículo & Potencia & Tipo de vehículo & Potencia & Tipo de vehículo \\
\hline $3 \mathrm{MW}$ & Coche & $20 \mathrm{MW}$ & Bus & $100 \mathrm{MW}$ & Camión de carga \\
$5 \mathrm{MW}$ & Coche con plásticos & $30 \mathrm{MW}$ & Camión & $300 \mathrm{MW}$ & Camión de combustible \\
\hline
\end{tabular}

Tabla 2-2. Tasas de liberación de calor máximas según tipo de vehículos implicados [ref2.16]. 


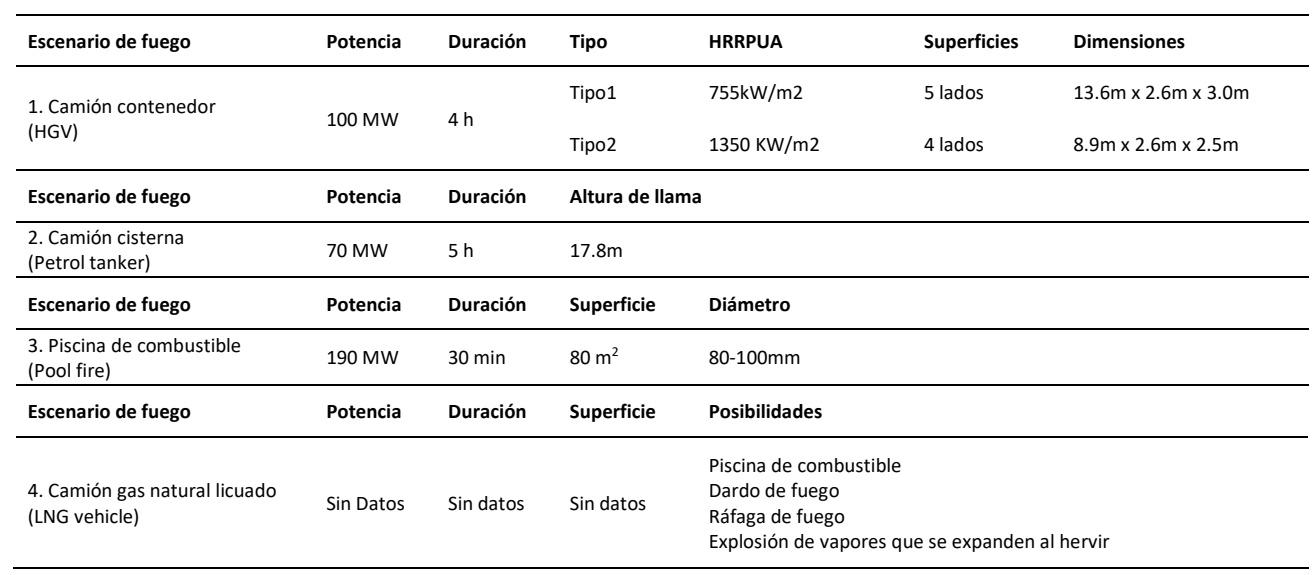

Tabla 2-3. Cargas de fuego propuestos por Kotsovinos et al. [ref2.19].

En el estudio cabe destacar algunos puntos. En primer lugar, se remarca la necesidad de que el fuego permanezca bajo la estructura durante un tiempo suficiente para que ésta se vaya calentando y deteriorando. Para que esto ocurra, no solo se requiere una cantidad de combustible mínima, sino que la carga de fuego se mantenga en la misma posición ( sin sobrepasar la estructura como ocurriría con un barco incendiado, por ejemplo). En segundo lugar, se destaca el hecho de que, aunque haya materiales que no sean inflamables a temperatura ambiente, si pueden contribuir a aumentar la potencia de un incendio ya iniciado. En tercer y último lugar, mediante la consideración de los incendios forestales y de edificios como potenciales amenazas, los autores ponen en evidencia la necesidad de tener en cuenta todo aquello que exista o vaya a existir (temporal o de forma continuada) bajo el puente.

Ya en 2017, en el estudio estadístico de Peris-Sayol et al. [ref2.12], se registraron como causas de fuego las siguientes:

1. Coches

2. Camiones contenedores.

3. Camiones cisterna con líquidos inflamables

4. Problemas eléctricos

5. Materiales almacenados

6. Incendios forestales o incendios deliberados

7. Otros. Incendios en los encofrados o con causa sin identificar

Este último estudio supone una aportación interesante en lo que respecta a la definición de las cargas de fuego en el fuego en puentes por cuatro motivos: 
1. Ofrece una lista de causas reales de incendios con daños en puentes (en contrapartida a la lista de amenazas potenciales propuesta por Kotsovinos [ref2.19] por ejemplo).

2. Permite relacionar el nivel de daño registrado en puentes reales con cada una de las causas del fuego mencionadas (ver Figura 2-12)

3. Remarca la importancia de la consideración de los camiones cisterna cargados de combustibles inflamables como carga de fuego de referencia para próximos estudios.

4. Deja en evidencia el hecho de que no todos los fuegos tienen origen en vehículos que circulan por vías inferiores, sino que también se han registrado eventos con daños no despreciables en los que las causas de fuego son de origen eléctrico, consecuencia de almacenamientos de materiales bajo puentes o incluso de origen desconocido.

El cuarto punto es importante puesto que permite reducir el riesgo mediante otro tipo de medidas más allá de las del diseño de las estructuras o evitando colisiones de vehículos en las proximidades a las mismas

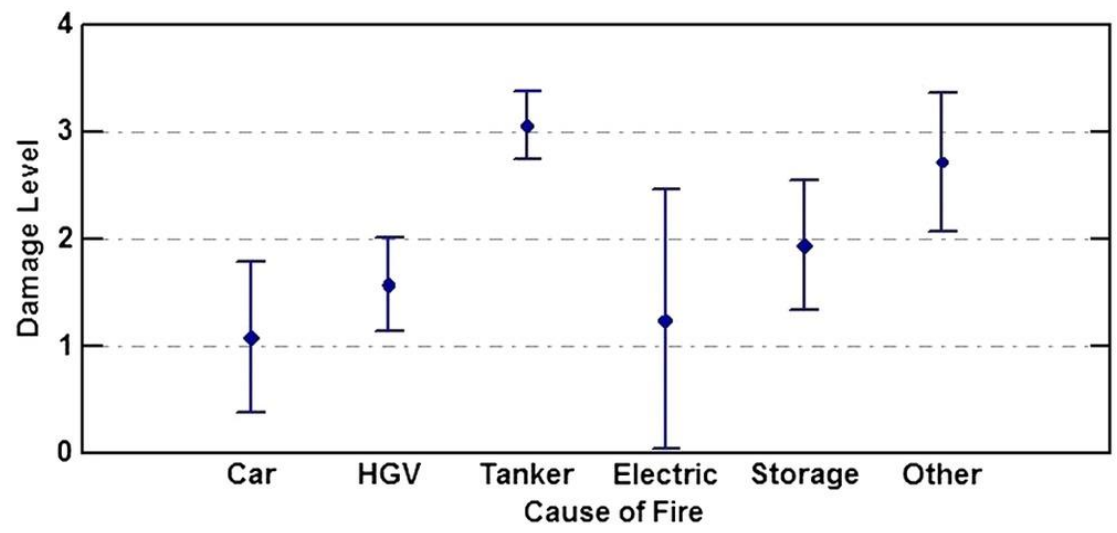

Figura 2-12. Relación entre el nivel de daño del puente y la causa del fuego. Peris et al. [ref2.12].

\subsubsection{TIPOLOGÍAS DE PUENTES}

Caracterizada la acción deberá tenerse en cuenta que no todos los puentes se comportaran de igual manera frente al fuego. En este sentido los estudios existentes se podrían clasificar los puentes según dos parámetros: por los materiales del puente afectado (hormigón y/o acero generalmente) y por las tipologías estructurales (en su mayoría puentes multiviga para incendios bajo pasos superiores y atirantados para incendios con la carga de fuego sobre el propio tablero del puente). 


\subsection{ESTUDIO DEL PROBLEMA}

La urgencia asociada a la necesidad de reabrir al tráfico (dada la gran repercusión económica indirecta relativa a los desvíos de circulación de vehículos) suele generar soluciones de compromiso en las que frecuentemente se decide demoler estructuras que podrían seguir dando un servicio con un margen de seguridad más que aceptable. Si se quiere permitir al equipo de ingenieros encargado de evaluar la seguridad de la estructura la posibilidad de realizar una evaluación del estado de la estructura más realista (no tan del lado de la seguridad) en un tiempo razonable (dada la magnitud del impacto económico) se requiere de un estudio exhaustivo previo del problema que permita plantear una serie de procedimientos de actuación concretos a aplicar durante la emergencia para evaluar el estado del puente.

Para ello cabe realizarse las preguntas adecuadas. Pasar del "¿Debe reforzarse el puente antes de la reapertura?" al "¿Se puede evitar?”, “Cómo?”, “ise puede mitigar el daño estructural?", ¿¿cómo?”, ¿qué puentes son críticos en la red de transportes?, ¿qué diseños son los más resistentes al fuego?, ¿qué sistemas de protección pueden emplearse en puentes ya existentes? En definitiva, pasar de afrontar las consecuencias a reducir o evitar el riesgo. Incluso en el caso de que no se reduzca ni elimine el riesgo y el incendio afecte a la estructura, disponer de un procedimiento claro de actuación que permita determinar el estado del puente de una manera sistemática supondría una herramienta de gran valor para cualquier departamento de transporte.

La respuesta a estas preguntas requiere de buen entendimiento del fenómeno a partir del bloque temático "2. Estudio del problema”, que según la Figura 2-2 se subdivide en las siguientes líneas de investigación:

1. Análisis de eventos

2. Análisis experimental

3. Análisis numérico

\subsubsection{ANÁLISIS DE EVENTOS}

Cuando se habla de análisis de eventos se hace referencia al estudio detallado de un incendio ocurrido con repercusión sobre un puente. En el análisis de eventos interesa considerar las cargas de fuego de eventos en los que se hayan producido daños estructurales de gran magnitud e incluso el colapso total o parcial de las estructuras.

\subsubsection{ANÁLISIS EXPERIMENTAL}

En lo que respecta al análisis experimental se incluyen todo tipo de ensayos, tanto de puentes reales que han sufrido el efecto del fuego como el de ensayos correspondientes 
a los materiales empleados en las estructuras (aunque se hayan hecho dentro del contexto de otras disciplinas). Tanto de la reproducción de incendios a escala real como de otras escalas buscando alcanzar el conocimiento que nos permita llegar a responder las preguntas inicialmente planteadas.

\subsubsection{ANÁLISIS NUMÉRICO}

El análisis numérico servirá tanto para tratar de reproducir eventos reales como para la variación de condicionantes y parámetros del fuego o de la propia estructura. Permitirá, según casos, prescindir de la realización de ensayos con estructuras a escala real, que en general requerirán de una mayor inversión económica. Por si esto fuera poco, los ensayos numéricos permiten una mayor flexibilidad en lo que respecta a la definición de eventos y permiten alcanzar resultados de gran interés en un intervalo temporal menor.

En relación al estudio del problema se podrían citar innumerables (se incluyen algunas sólo) publicaciones relativas tanto al análisis de eventos [ref2.02, ref2.04, ref2.06ref2.09] como al análisis numérico [ref2.04, ref2.06-ref2.08, ref2-10, ref2-15], siendo habitual que se traten de forma generalizada ambos temas conjuntamente. Sin embargo, el tema del análisis experimental (en su vertiente de ensayos de fuego con puentes a escala real o reducida) debido a la gran inversión económica que estos requieren, está todavía inexplorado.

\subsection{RESOLUCIÓN DEL PROBLEMA}

Llegados a este punto cabe recordar que, para resolver un problema, el planteamiento del mismo debe tener en cuenta una correcta definición de los objetivos. En la Figura 2-2, aunque el objetivo general es reducir la repercusión económica de este tipo de eventos, los objetivos específicos son las líneas de investigación incluidas en el bloque temático "3. Resolución del problema":

1. Mitigación del riesgo

2. Protección

3. Diseño

4. Comprobación de diseño

Aunque estos objetivos han sido necesariamente considerados para un adecuado planteamiento de los bloques temáticos "1. Definición del problema" y "2. Estudio del problema", su adecuada resolución está supeditada al adecuado desarrollo de los dos primeros bloques temáticos. 


\subsubsection{MitigaCIÓN DEL RIESGO}

El hecho de que en el bloque temático de "1. Definición del problema" se hable de "reducción del impacto económico sobre una región determinada" en lugar centrar la atención en el "incremento de resistencia frente al fuego de los puentes" permite abordar el problema desde una perspectiva más general. Este matiz es relevante si se atiende al comentario de Deng et al. [ref2.13] en el que indica que el fuego es una acción, además de accidental, de naturaleza humana. La naturaleza "humana" de esta acción permite reducir el impacto económico potencial actuando tanto sobre la vulnerabilidad (resistencia termo-mecánica de un puente al fuego) como sobre la probabilidad de ocurrencia.

Se entenderá como mitigación la reducción del riesgo mediante la propia reducción de la probabilidad de ocurrencia (actuando sobre la acción). Esto se puede conseguir mediante medidas de gestión del tráfico y del espacio encaminadas a evitar directamente que el incendio ocurra. En el primer caso las recomendaciones y/o regulaciones irían enfocadas a la priorización de eliminación de zonas de concentración de accidentes en las proximidades de las intersecciones multinivel (como podría ser el caso de zonas de trenzado donde se producen incorporaciones y salidas de la vía principal en un tramo de longitud excesivamente reducida). En el segundo caso se estaría hablando de la restricción de almacenamiento de materiales inflamables y/o combustibles bajo los puentes (admitiendo por ejemplo almacenar pales de ladrillos con nula contribución sobre un incendio potencial pero no permitiendo la acumulación de materiales como bidones de combustible o depósitos de madera). Hasta la fecha ya ha habido algunos estudios con en esta línea, como es el caso de los publicados por Kotsovinos et al. [ref220] y por Wright et al [ref2-21].

\subsubsection{Protección de PUENTES}

Cuando se habla de protección se están considerando aquellas medidas destinadas a puentes ya existentes o cuyo diseño no pueda ser modificado. Estas medidas podrían ser activas (de extinción del incendio) o pasivas (de incremento del tiempo de la resistencia al fuego de la estructura). En esta línea resulta se puede estudiar la viabilidad del empleo de medidas ya testeadas en otros ámbitos como la edificación o los túneles. Algunos ejemplos de este tipo de medidas se pueden encontrar en [ref2.21-ref2.25].

\subsubsection{DISEÑOS MENOS VULNERABLES AL FUEGO}

Se habla de definición de diseños menos vulnerables frente a la acción del fuego. Los estudios enfocados en este tipo de medidas deberán ir en la línea de comparar la resistencia frente al fuego de puentes con vanos y cargas similares con el fin de poder 
añadir al criterio económico el de resistencia al fuego sin necesidad de que el proyectista tenga que realizar un análisis avanzado para considerar la acción del fuego. Este tipo de estudios, al tener que considerar más de un tipo de diseño estructural son menos frecuentes, aunque ya se han publicado algunos resultados [ref2.26, ref2.27].

\subsubsection{COMPROBACIÓN DE DISEÑO}

Aunque no se trata de una actuación que reduzca el riesgo al colapso de la estructura frente al fuego, la comprobación del diseño se ha decidido incluir en este bloque temático puesto que sirve como experiencia acumulada de cara a la propuesta de recomendaciones futuras.

Si bien es cierto que la acción de fuego debe considerarse en la elección del diseño, ni siempre será posible emplear la tipología más resistente al fuego, ni ello nos garantizará que el puente sea seguro frente a una carga de fuego específica. Por ello, sería recomendable para todos los puentes (y en especial para aquellos puentes de naturaleza singular) que se compruebe su resistencia al fuego (a una carga de fuego todavía indefinida) previamente a su construcción.

Esta comprobación, cuando se exija, deberá realizarse mediante:

1. Modelos avanzados de cálculo

a. En caso de puentes singulares (tipologías arco, atirantado y colgante) o con características excepcionales (cuyo comportamiento a fuego no pueda suponerse dadas otras comprobaciones a fuego previamente realizadas)

b. En caso de puentes críticos (cuyo cierre o reconstrucción suponga una repercusión económica sobre la zona superior a un determinado umbral)

c. En caso de puentes convencionales y no críticos que no dispongan de recomendaciones o métodos simplificados de comprobación

2. Métodos simplificados

a. En caso de puentes convencionales y no críticos que dispongan de recomendaciones o métodos simplificados de comprobación

Un ejemplo de este tipo de estudios se puede consultar en [ref2-28] donde se analiza la respuesta estructural de un puente singular metálico con arcos superpuestos de $85 \mathrm{~m}$ de vano y 3000 toneladas frente a distintas hipótesis de fuego (empleando curvas de fuego y modelos CFD) empleando el software SAFIR para resolver el modelo de elementos finitos termo-mecánico. 


\subsection{APLICACIÓN DE SOLUCIONES}

Como se puede ver en la Figura 2-2, el bloque temático "4. Aplicación de soluciones" se subdivide a su vez en las siguientes líneas de investigación:

1. Análisis de riesgos

2. Clasificación de puentes

Una vez definidas las diversas soluciones al problema cabría estudiar la necesidad de su aplicación tanto para puentes en fase de diseño como para puentes ya en servicio. Como ocurre en el caso del sismo, no todos los puentes serán igualmente vulnerables a una misma acción de fuego. Adicionalmente, se debe tener en cuenta el hecho de que cada casuística concreta admitirá un tipo de soluciones concretas. Siendo habitual que la consideración de un nuevo estado de carga (ELU de fuego en este caso) conlleve un incremente del coste económico del puente objeto de la aplicación surge la necesidad de establecer criterios objetivos de priorización de las actuaciones. En este sentido ya se han realizado algunos estudios relativos al análisis de riesgos [ref2.29-ref2.33] llegando incluso a algunas propuestas de clasificaciones de los puentes en función de su riesgo [ref2.32, ref2.34-ref2.35].

\subsection{REFERENCIAS}

[ref2.01] Garlock ME, Paya-Zaforteza I, Kodur V, Li G. Fire hazard in bridges: Review, assessment and repair strategies. Engineering Structures 35:89-98. 2012.

[ref2.02] Stoddard R. Inspection and repair of a fire damaged prestressed girder bridge. 2004.

[ref2.03] Wardhana K, Hadipriono FC. Analysis of recent bridge failures in the United States. Journal of Performance of Constructed Facilities. ASCE. 2003.

[ref2.04] Dotreppe JC, Majkut S, Franssen JM. Failure of a tied-arch bridge submitted to a severe localized fire. IABSE Symposium Lisbon. 2005.

[ref2.05] Oggero A, Darbra RM, Muñoz M, Planas E, Casal J. A survey of accident during transport of hazardous substances. Journal of Hazardous Materials. 2006.

[ref2.06] Choi J. Concurrent fire dynamics models and thermomechanical analysis of steel and concrete structures. Georgia Institute of Technology. 2008.

[ref2.07] LeAnn Moore W. Performance of fire-damaged prestressed concrete bridges. Missouri University of Science and Technology. 2008. 
[ref2.08] Noble CR, Wemhoff AP, McMichael LD. Thermal-structural analysis of the MacArthur maze freeway collapse. ASME Summer Heat Transfer Conference. Jacksonville, FL, USA. 2008.

[ref2.09] Bennetts I, Moinuddin K. Evaluation of the Impact of Potential Fire Scenarios on Structural Elements of a cable-stayed bridge. Journal of Fire Protection Engineering 19. 2009.

[ref2.10] Paya-Zaforteza I, Garlock ME. A numerical investigation on the fire response of a steel girder bridge. Journal of Constructional Steel Research 75:93-103. 2012.

[ref2.11] Woodworth M, Wright W, Lattimer B, Sotelino E. Fire risks for highway bridges: A statistical investigation. ASCE Structures Congress. 2013.

[ref2.12] Peris-Sayol G, Paya-Zaforteza I, Balasch-Parisi S, Alos-Moya J. Detailed analysis of the causes of bridge fires and their associated damaged levels. ASCE Journal of Performance and Constructed Facilities 31 (3). 2017.

[ref2.13] Deng L, Wang W, Yu Y. State-of-the-art. Review on the causes and mechanisms of bridge collapse. ASCE Journal of Performance and Constructed Facilities 30 (2). 2016.

[ref2.14] www.sfgate.com. San Francisco Gate - The Maze Meltdown. 12 de Diciembre de 2016.

[ref2.15] Chung P, Wolfe RW, Ostrom T, Hida S. Accelerated bridge construction applications in California - Lessons learned. Report issued by the California Department of transportation. .

[ref2.16] Li L, Hu Z, Liu Q. Study on heat release rate model in steel bridge highway fire. Applied Mechanics and Materials 170-173:2535-2540. 2012.

[ref2.17] Ingason $\mathrm{H}$. Fire growth rate is more important than maximum heat release rate in tunnel fires. Tunnel Management International. 2006.

[ref2.18] Ingason H. Design fires in tunnels. 2nd International Symposium. Safe \& Reliable Tunnels Innovative European Achievements, Lausanne. 2006.

[ref2.19] Kotsovinos P, Walker G, Flint G, Lane B. Assessing the fires on the deck of cable stayed Bridges. 9th International Conference on Structures in Fire. Princeton, NY, USA. 2016.

[ref2.20] Kotsovinos P, Flint G, Walker G, Lane B. Qualitative assessment of the fire hazards beneath bridges. 14th International Conference and Exhibition on Fire Science and Engineering. Royal Holloway College, UK. 2016. 
[ref2.21] Wright W, Lattimer B, Mahammad N, Sotelino E. Highway bridge fire hazard assessment draft. Guide specification for fire damage evaluation in steel bridges. 2013.

[ref2.22] Davidson M. Assessment of passive fire protection on steel-girder bridges. Masters Theses and Specialist Projects. 2012.

[ref2.23] Davidson MT, Harik IE, Davis DB. Fire impact and pasive fire protection on infrastructure: state of the art. Journal of Performance of Constructed Facilities. ASCE. 2013.

[ref2.24] Quiel SE, Yokoyama T, Mueller KA, Bregman LS, Marjanishvili S. Mitigating effects tanker truck fire cable stayed bridge. 9th International Conference on Structures in Fire. Princeton, NY, USA. 2015.

[ref2.25] Aziz EM. Enhancing fire resistance of steel bridge girders using external fire insulation. Kurdistan Journal of Applied Research 2(3). 2017.

[ref2.26] Whitney R, Braxtan NL, Wang Q. Analysis of curved weathering steel box girder bridges in fire. 2016.

[ref2.27] Nahid MNH, Sotelino ED, Lattimer BY. Thermo-structural response of highway bridge structures with tub girders and plate girders. Journal of Bridge Engineering 22 (10). 2017.

[ref2.28] Tonicello E, Desanghere S, Vassart O, Franssen JM. Fire analysis of a new steel bridge. 7th International Conference on Structures in Fire. Zurich, Switzerland. 2012.

[ref2.29] Cook W. Bridge failure rates, consequences, and predictive trends. All graduate theses and dissertations. Utah State University. 2014.

[ref2.30] Kim W, Jeoung C, Gil H, Lee I, Yun SH, Roh H. Fire risk assessment on the highway bridge in South Korea. Transportation Research Record: Journal of the Transportation Research Board. 2014.

[ref2.31] Joo S, Kim S, Kim Y, Park C. Fire risk evaluation of bridge underneath conditions based on field investigation. 6th International Workshop on Performance. Protection and Strengthening of Sructures under Extreme Loading. 2017.

[ref2.32] Kodur VK, Aziz EM, Naser MZ. Strategies enhancing fire performance of steel bridges. Engineering Structures 131:446-458. 2017.

[ref2.33] Liu X, Zhang L, Guo S, Fu M. A simplified method to evaluate the fire risk of liquid dangerous chemical transport vehicles passing a highway bridge. Journal of Loss Prevention in the Process Industries 48:111-117. 2017. 
[ref2.34] Kodur VKR, Naser MZ. Importance factor for design of bridges against fire hazard. Engineering Structures 54: 207-220. 2013.

[ref2.35] Naser MZ, Kodur VKR. A probabilistic assessment for classification of bridges against fire hazard. Fire Safety Journal. 2015. 



\section{MetodoloGíA}

Si no puedes explicarlo de forma sencilla, no lo entiendes lo suficiente

A. Einstein

El contenido de esta sección ha sido tomado directamente del paper

"Analysis of a bridge failure due to fire using computational fluid dynamics and finite element models"

publicado en 2014 en el volumen 68 (p96-110) del

Engineering Structures Journal 



\subsection{INTRODUCCIÓN}

En este capítulo se va a presentar la metodología a emplear para estudiar numéricamente el problema del fuego en puentes. La metodología propuesta divide el problema del puente sometido a la acción del fuego en tres etapas (ver Figura 3-1). En la primera etapa se realiza una simulación de incendios en la que se obtienen las temperaturas de exposición de la estructura, en la segunda se lleva a cabo la transferencia de calor dentro de la estructura a partir de las temperaturas de exposición y los coeficientes de transmisión de calor y en la tercera, a partir de la evolución en el tiempo de las temperaturas de los materiales, se analiza la respuesta mecánica de la estructura con el tiempo.

La citada metodología se validará a dos niveles. En el presente capítulo se validará a nivel general dada la naturaleza de los datos empleados, mientras que la segunda validación tendrá lugar en los Capítulos 5 y 6 , donde se realizará una validación específica de cada uno de los modelos empleados, así como del empleo de la transmisión de información entre ambos modelos.

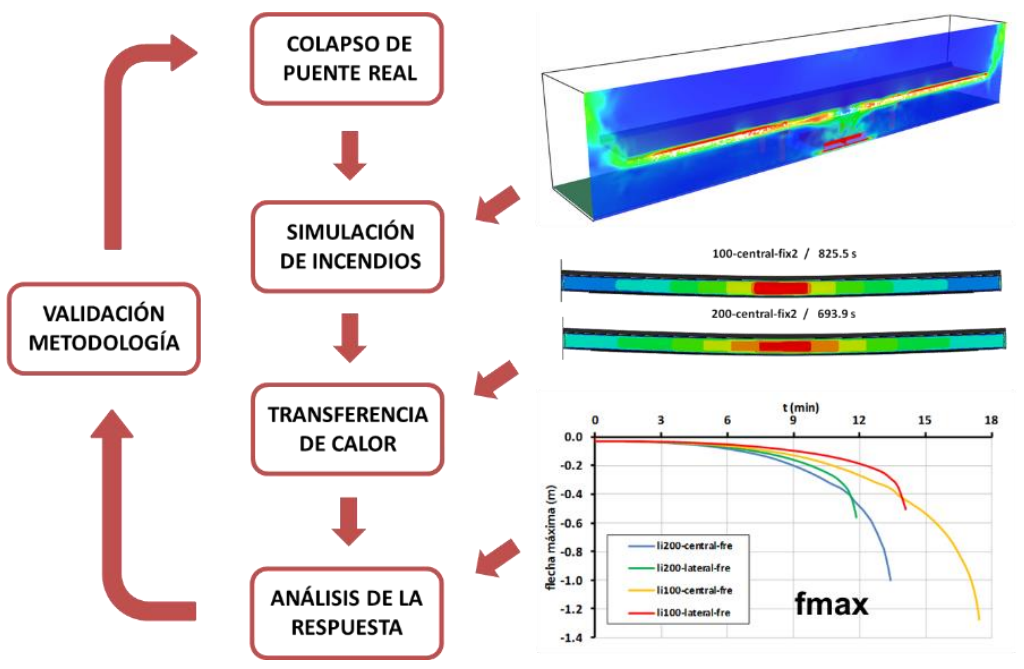

Figura 3-1. Esquema de la metodología empleada

Para ello se requiere de la utilización de dos programas que permitirán abordar el problema en dos fases. La simulación de incendios se realizará mediante el programa "Fire Dynamics Simulator" (en adelante FDS) en su versión 5 [ref3.01]. Por otro lado, 
la transferencia de calor y el cálculo mecánico en el tiempo serán abordados mediante el programa de elementos finitos "Abaqus" en su versión 6.11.

Llegado este punto, cabe matizar que el problema de incendio y el problema termomecánico se abordarán a escalas distintas de trabajo. Mientras que el modelo de incendio (modelado mediante FDS) abarcará tanto el modelado del puente como el de su entorno, el modelo termo-mecánico (modelado mediante Abaqus) abarcará únicamente una de las vigas del puente junto con la losa tributaria a la viga. En el modelo de FDS la precisión geométrica se ajustará a superficie sin espesor o a volúmenes ajustables a celdas no inferiores a $20 \mathrm{~cm}$. En el modelo de Abaqus se empleará precisión milimétrica para la definición de los diversos elementos que conforman la viga mixta. Para realizar la transmisión de información entre ambos modelos se recurrirá a la "superficie adiabática" propuesta por Wickström [ref3.02].

\subsection{SOFTWARE EMPLEADO}

\subsubsection{FIRE DYNAMICS SIMULATOR (FDS)}

FDS es una aplicación informática libre de simulación computacional de incendios desarrollada por el "National Institute of Standards and Techonolgy" (NIST en adelante) de los EEUU ampliamente conocida y que ha sido validada experimentalmente en numerosas ocasiones [ref3.01]. Concebida para predecir el valor de variables y parámetros propios de los incendios, la aplicación está basada en técnicas de dinámica de fluidos computacional (CFD en adelante) que relacionan las variables termodinámicas y aerodinámicas de un sector de incendio determinado. La aplicación resuelve las ecuaciones de Navier-Stokes, de conservación de la masa, de la cantidad del movimiento y de la energía para velocidades de flujo propias de los incendios.

Aunque $F D S$ se desarrolló para el estudio de los efectos de los incendios en industrias, su aplicación se extiende a todo tipo de incendios, tanto en interiores como en exteriores. A diferencia de los modelos de zona, utilizados actualmente para predecir los efectos del fuego en los conocidos sectores, los modelos de campo proporcionan información detallada sobre los movimientos de los fluidos en los incendios y de cómo evolucionan sus características. De esta forma se ofrecen nuevas posibilidades de aplicación, como es el caso de la investigación de incendios en puentes.

Cabe distinguir, cuando se habla de FDS, entre pre-procesador, procesador y postprocesador. Mientras que FDS se limita al cálculo en sí, la caracterización del modelo se realiza empleando el pre-procesador Pyrosim y la visualización se lleva a cabo mediante el programa Smokeview. No obstante, si así lo desea el usuario, puede generar el modelo directamente escribiendo el script de forma manual. 
Para realizar una simulación de incendios mediante $F D S$ se requiere de una correcta definición del problema que incluye (1) la geometría del mismo (sólidos y superficies), (2) la carga de fuego (la acción), (3) las características de los materiales (interacción térmica con los sólidos), (4) el volumen de control, (5) el mallado, (6) las condiciones de contorno (sustituyen el entorno no incluido en el modelo) y el modelo de combustión (7). Habrá que incluir (8) sensores y rebanadas que permitan obtener mediciones puntuales y superficiales dentro del volumen de control.

\subsubsection{AbaQuS}

Abaqus es un programa destinado a resolver problemas de ciencias e ingeniería basado en el método de los elementos finitos (MEF en adelante) que puede resolver una gran variedad de problemas entre los que se incluyen los análisis termo-mecánicos que van a emplearse en el presente trabajo. Para ello admite la definición de diversos tipos de no linealidades y tiene a disposición del usuario una extensa librería de elementos finitos que permite modelar virtualmente cualquier geometría.

Se ha decidido utilizar Abaqus dado el gran número de estudios numéricos calibrados con resultados experimentales que justifican una experiencia probada de su aplicabilidad en elementos estructurales sometidos al fuego [ref3.03-ref3.06].

Para realizar una simulación por elementos finitos mediante Abaqus se requiere de una correcta definición del problema que incluye (1) la geometría del mismo (partes del modelo y su interacción mutua), (2) los materiales (que caracterizan el medio deformable y sobre el que se realizará la transmisión de calor), (3) los pasos en que se dividirá el proceso (transmisión de calor y respuesta mecánica), (4) las cargas (gravitatorias y térmicas), (5) la imposición de condiciones (iniciales, de contorno y de contacto) y (6) la definición del trabajo (procedimiento de resolución y número de procesadores a empelar). De nuevo, y como se ha indicado para FDS, se deben indicar (7) las variables de interés que el programa guardará para su análisis.

\subsection{SUPERFICIE ADIABÁtICA}

La superficie adiabática, introducida por Wickström [ref2.02] como "Adiabatic Surface Temperature”, es una herramienta de gran utilidad en la resolución de problemas de estructuras sometidas al fuego. El motivo fundamental es que permite desacoplar el problema inicial en dos etapas (la simulación del incendio y el problema termo-mecánico asociado a la estructura) que pueden abordarse de forma independiente. Obtenidas las temperaturas adiabáticas, en la primera etapa, se emplean como carga térmica para resolver el problema termo-mecánico asociado (ver Figura 3-2). 
$\mathrm{Al}$ adoptar el recurso de la superficie adiabática se desacopla la transferencia de calor del medio a la estructura imponiendo la condición de flujo nulo. De esta forma, como ocurre con el método por flexibilidad utilizado en estructuras hiperestáticas sencillas, se resuelve el problema real con una pequeña modificación para seguidamente, deshaciendo la modificación, terminar de definir el problema y llegar a la solución.

La superficie adiabática permite que la variable calor transferido se considere nula en el problema de simulación de incendios y por tanto queda trasladada al problema de caracterización estructural. De esta forma la temperatura que se obtiene en el programa FDS es una temperatura que no está incluyendo transferencia de calor medio-estructura de ningún tipo. Es por tanto una temperatura intermedia entre la temperatura promedio de radiación y la temperatura del medio que envuelve a la estructura a una distancia suficiente de la superficie para evitar incluir parte del gradiente térmico que se produce entre gas y estructura en el problema real.

Cuando se habla de temperatura adiabática se está hablando de una temperatura asociada al gas y no a la superficie del material. De hecho, para la obtención de la misma no se están empleando las propiedades del mismo. Por este motivo, cuando se introduce la temperatura en el problema termo-mecánico, debe saberse que la condición de contorno es una condición de flujo (de Neumann) que se impone mediante la definición de la temperatura equivalente (adiabática) del gas en cada punto y la definición de los parámetros de convección y radiación correspondientes. En conclusión, se puede afirmar que la transmisión de calor medio-estructura mediante estos dos mecanismos se produce en el cálculo termo-mecánico y no en la simulación de incendios.

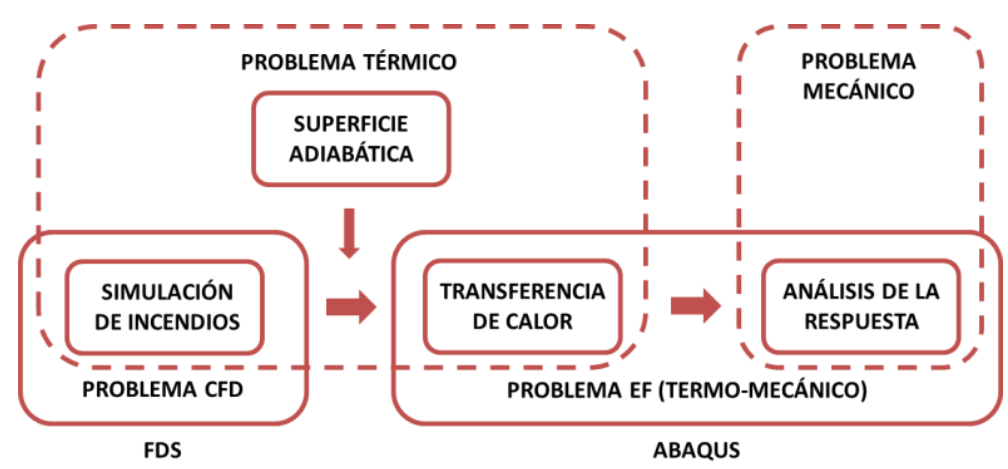

Figura 3-2. Esquema de la resolución del problema 


\subsection{ESTUDIO DE UN EVENTO REAL}

\subsubsection{INCIDENTE}

El día 5 de enero de 2002, en torno a las 10:15 de la mañana, se produjo un accidente de tráfico en el intercambiador entre las interestatales I-65 e I-20/59. En el accidente murió el camionero Tim Dyson como consecuencia del cruce de un turismo que realizó una maniobra imprevista para tratar de evitar pasarse la salida. El conductor del camión, tratando de evitar el choque, perdió el control del vehículo y colisionó contra el murete de protección bajo el paso superior de la I-65S sobre la I-65N en el ramal sur del intercambiador entre la I-65 y la I-20/59.

El camión cisterna, que portaba $37.5 \mathrm{~m}^{3}$ (9900 galones) de gasolina, estalló en llamas y permaneció ardiendo bajo el puente, junto con el combustible derramado, hasta que los bomberos extinguieron el incendio (ver Figura 3-3). Aunque para el presente trabajo se consiguieron los planos originales del proyecto de construcción del paso superior de 1966, desafortunadamente para el estudio que se va a llevar a cabo, no se registraron datos sobre la duración del incendio ni las temperaturas alcanzadas.

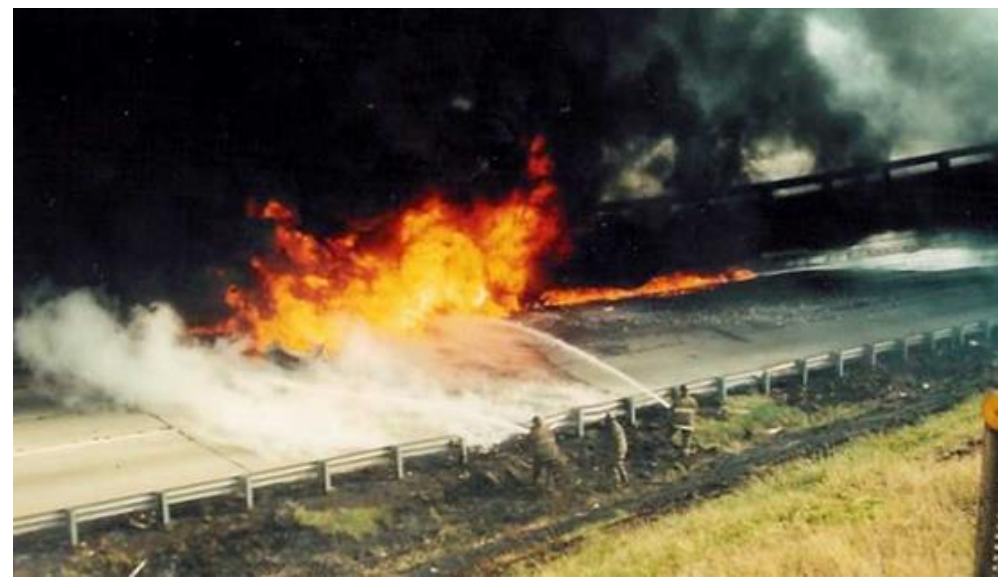

Figura 3-3. Bomberos apagando el fuego originado. Cortesía del Alabama Department of Transportation (ALDOT en adelante)

Aunque el departamento de bomberos local extinguió el incendio antes de que la estructura se derrumbara, como ocurrió en el incidente de Oakland (ver Figura 2-11) en el año 2008, resultó inevitable evitar daños severos en elementos primarios de la estructura. El vano principal de 37.32 metros de longitud quedó totalmente inservible (ver Figura 3-4) dadas deformaciones que según fuentes de informaciones locales se 
sitúan entre 2 y 3 metros ( 7 y 10 pies). Además, parte del hormigón de la losa y de las propias presentaba signos claros de deterioro por desprendimiento (ver Figura 3-5).

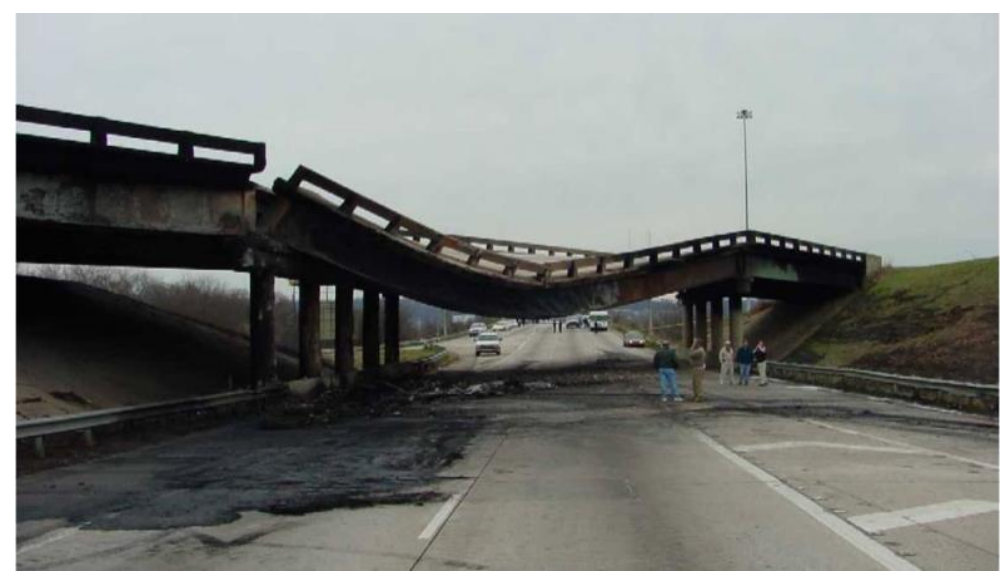

Figura 3-4. Deformada tras el incidente desde el lado Norte. Cortesía del ALDOT.

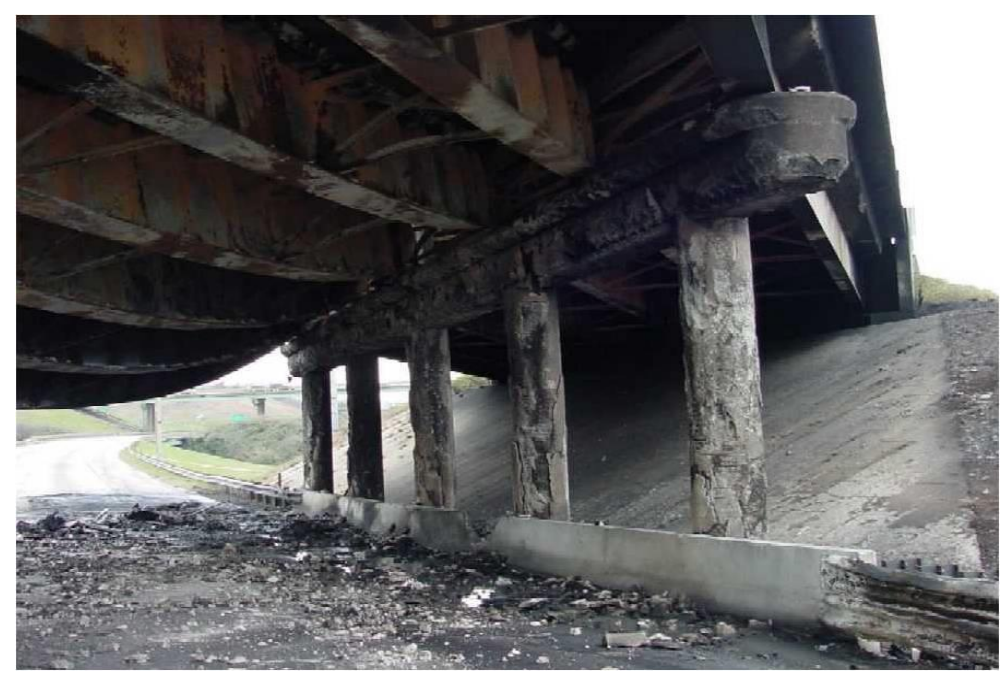

Figura 3-5. Detalle de las pilas tras el incidente desde el lado Sur. Cortesía del ALDOT.

El puente, con evidentes daños debidos a la acción del fuego, tuvo que demolerse y reconstruirse completamente. Según el departamento de transportes de Alabama (ALDOT en adelante) 140.000 vehículos diarios se verían afectados por el cierre temporal de la vía lo que costaría a los usuarios en torno a 100.000 dólares diarios. Por este motivo el ALDOT decidió incluir una cláusula en el contrato de la reconstrucción 
del puente en la que se bonificaría a la empresa encargada con 25.000 dólares por cada día que se adelantara su finalización respecto a un plazo dado de 90 días y se penalizaría con 25.000 dólares por cada día de retraso. De esta forma se consiguió reducir el trabajo de construcción del puente a tan solo 37 días por "The Morris Group and Brasfield \& Gorrie" [ref2.07].

\subsubsection{MODELO DE MECÁNICA DE FLUIDOS COMPUTACIONAL}

\subsubsection{VOLUMEN DE CONTROL}

El volumen de control debe ser lo suficientemente amplio como para representar adecuadamente el volumen afectado por el fuego, pero lo suficientemente pequeño como para que el modelo se ejecute en un tiempo de cálculo razonable. En la Figura 3-6 se muestra el volumen de control empleado en el presente capítulo, así como sus condiciones de contorno.

El recinto definido contiene el paso elevado de la interestatal I-65, así como sus accesos y el entorno, y presenta unas dimensiones en planta de $115,2 \mathrm{~m}$ por $39,6 \mathrm{~m}$ y una altura de $16,2 \mathrm{~m}$. El volumen cuenta con un total de 6.998 .400 celdas ortoédricas de dimensiones $0,24 \mathrm{~m}$ por $0,22 \mathrm{~m}$ por $0,20 \mathrm{~m}$. La geometría del paso superior se obtuvo a partir de los planos de construcción originales del puente proporcionadas por ALDOT y se simplifica como se detalla en [ref2.07].

El tamaño del volumen de control y el tamaño de la malla FDS se obtuvieron a través de un estudio de sensibilidad en tres pasos. En primer lugar, fijando el tamaño de celda se obtuvo el tamaño del volumen de control mínimo (paso 1). En segundo lugar, dado el volumen de control obtenido en el paso anterior se refinó el tamaño de celda (paso 2). Y finalmente se comprobó cómo el volumen de control seguía siendo suficiente para el tamaño de celda finalmente fijado

\subsection{OBTENCIÓN DEL VOLUMEN DE CONTROL}

Las dimensiones iniciales del volumen de control fueron $115,2 \times 32 \times 12 \mathrm{~m}$ en las direcciones $\mathrm{X}, \mathrm{Y}$ y $\mathrm{Z}$ respectivamente. La dimensión en $\mathrm{X}$ se fijó así para incluir la totalidad del puente de los estribos. El ancho de $32 \mathrm{~m}$ en la dirección Y implicaba una distancia mínima de $3 \mathrm{~m}$ desde el borde del volumen de control hasta la estructura (en el lado este) o hasta la carga de fuego (en el lado oeste). Finalmente, la cota máxima (coordenada $\mathrm{Z}$ ) quedó fijada originalmente para estar al menos $4 \mathrm{~m}$ por encima de la cara superior de la losa de puente de hormigón lo que dio el control de volumen de una altura inicial de $12,0 \mathrm{~m}$. 
Estas dimensiones se incrementaron hasta que las temperaturas en cuatro puntos de control no cambiaron en dos iteraciones sucesivas. Las dimensiones resultantes del volumen de control fueron 115,2 $\mathrm{m}$ de largo, 38,4 m de ancho y 16,0 m de altura. En todos los modelos fueron empleadas celdas cúbicas de $0,40 \mathrm{~m}$ de lado.

\subsection{OBTENCIÓN DEL TAMAÑO DE CELDA}

Obtenido el tamaño del volumen de control llegó el momento de comprobar el tamaño de celda. Para ello se emplearon tres mallas diferentes con celdas cúbicas de 0,40, 0,30 y $0,20 \mathrm{~m}$ de lado respectivamente. Tras verificar que las temperaturas en los puntos de control eran las mismas para las mallas con celdas de 0,30 y $0,20 \mathrm{~m}$ de lado se decidió ajustar las distintas dimensiones para respetar lo máximo posible la geometría del paso superior. El resultado fueron celdas de tamaño 0,24 m (en dirección X), 0,22 m (en dirección Y) y 0,20 m (en dirección Z). Este ajuste en el tamaño de las celdas supuso que las dimensiones del volumen de control se modificasen a 115,2 $\mathrm{m}$ de largo, 39,6 m de ancho y 16,2 m de alto como se puede apreciar en la Figura 3-6. En ella además se puede ver la geometría del modelo y la carga de fuego.

\subsection{COMPROBACIÓN DEL TAMAÑO DE CELDA}

Finalmente se verificó que los cambios en el tamaño de malla FDS introducidos en los pasos previos no influían en el tamaño del volumen de control.

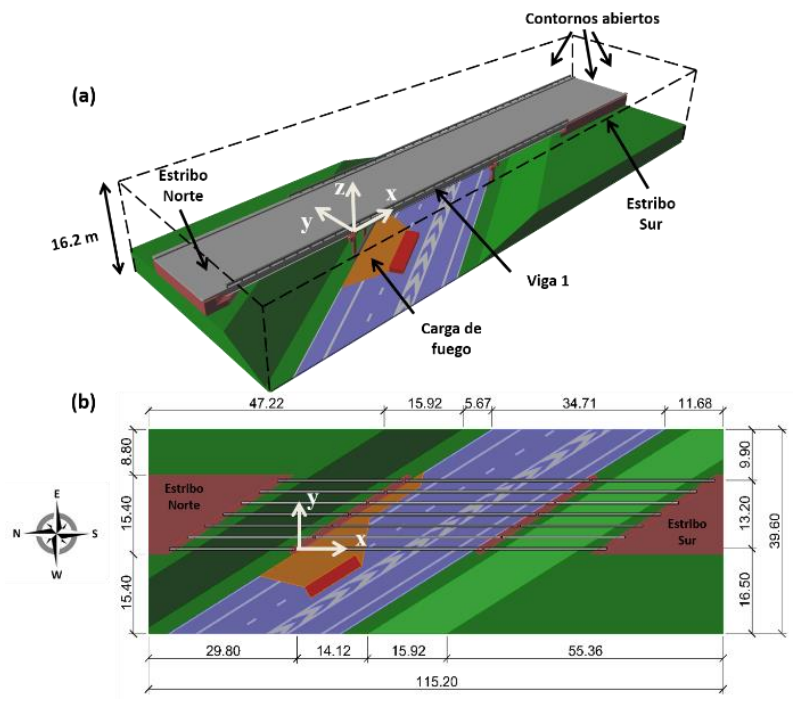

Figura 3-6. Modelo FDS. Vista general y en planta del volumen de control. 


\subsubsection{CARGA DE FUEGO}

La carga de fuego quedó definida tal como se detalle en [ref2.07] en una superficie total de $185,13 \mathrm{~m}^{2}$ (ver Figura 3-7). Se ha empleado un modelo de combustión de fracción de mezcla con una tasa de hollín de 0.018 de acuerdo con [ref2.08]. Esta superficie presenta dos componentes. La superficie coloreada en rojo, de $30 \mathrm{~m}^{2}$, se corresponde con el camión ardiendo después del choque. En marrón, de $155,13 \mathrm{~m}^{2}$, se ha indicado el combustible derramado en la vía como consecuencia del siniestro. Puesto que no se logró encontrar ningún informe oficial que detallase la extensión de las áreas, éstas se estimaron sobre la base del análisis de las imágenes del evento de incendio y de los daños observados en las vigas del paso superior.

La tasa de liberación de calor por unidad de área (HRRPUA en adelante) de cada una de las dos regiones se ha definido mediante un crecimiento lineal hasta alcanzar su valor máximo a los 20 segundos manteniéndose constante hasta el colapso de la estructura. Para el camión se adoptó un valor máximo de HRRPUA de $2.500 \mathrm{~kW} / \mathrm{m}^{2}$ [ref2.09]. En lo que respecta al derrame se esperaba que su HRRPUA máxima se encontrase entre 500 $\mathrm{KW} / \mathrm{m}^{2}$ (quinta parte de la HRRPUA del propio combustible [ref2.10]) y $2.500 \mathrm{KW} / \mathrm{m}^{2}$ en función del espesor del charco del incidente real.

El hecho de que las curvas de HRRPUA no presenten fase de enfriamiento se debe a que, como se comprobó al finalizar el estudio, el colapso se producía antes de que el fuego consumiese el $15 \%$ de la energía disponible.

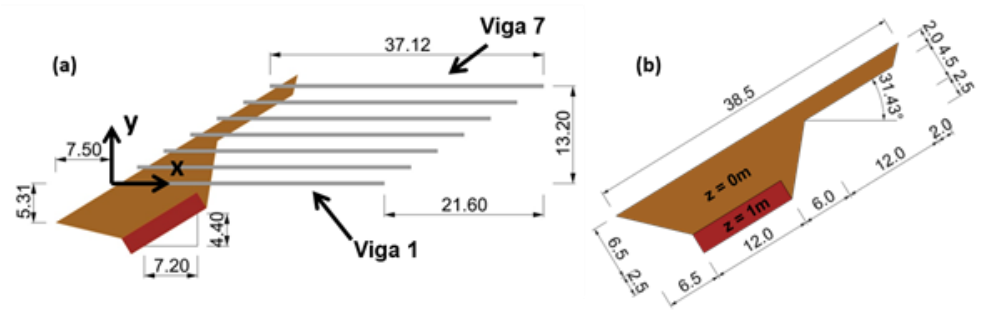

Figura 3-7. Localización de la carga de fuego y definición geométrica.

\subsubsection{DISPOSICIÓN DE SENSORES}

En la Figura 3-8 se muestra la distribución de sensores en sección. En ella se puede ver como las temperaturas adiabáticas fueron registradas disponiendo catorce sensores por sección. En las secciones transversales situadas sobre pilas y estribos tan solo se 
dispusieron doce sensores (excluyendo los sensores 1 y 1' al estar la viga apoyada en esa zona). En el modelo se incluyeron 417 secciones transversales con un total de 5754 sensores de temperatura adiabática.

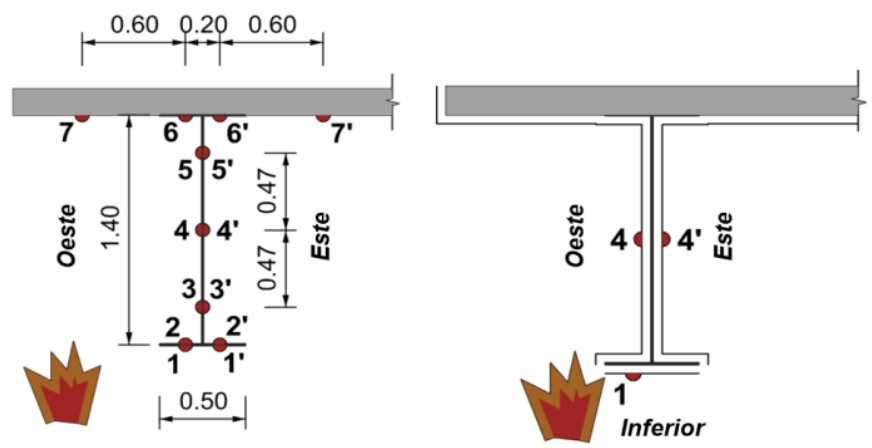

Figura 3-8. Sensores de temperaturas adiabáticas en una sección tipo.

\subsubsection{TEMPERATURAS OBTENIDAS}

En la Figura 3-9 se muestra el escenario de incendio tres minutos después del comienzo del evento, así como la evolución de temperaturas adiabáticas (en adelante también denominadas "temperaturas en el gas" o simplemente "temperaturas") en la sección de la viga 1 situada a $7.5 \mathrm{~m}$ de su extremo norte. En aras de una mayor claridad tan solo se han incluido en la figura los sensores del 1 a 7 correspondientes a la zona Oeste del puente.

En vista de que los sensores del 2 a 7 de cada una de las dos zonas (Este y Oeste) presentan temperaturas muy similares entre sí (diferencias inferiores al 5\%) la transición entre FDS y Abaqus se realizará únicamente mediante el empleo de los sensores 4 y 4'. La temperatura correspondiente a la zona Inferior quedará definida por el sensor 1 (ver Figura 3-8).
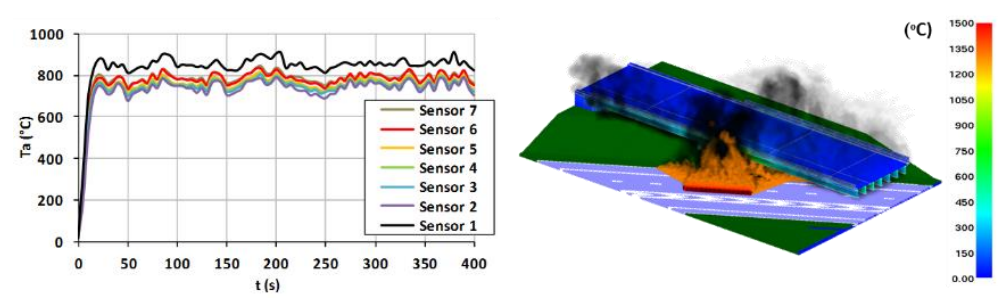

Figura 3-9. Temperaturas registradas en sección a 7.5 m y vista del modelo de incendios. 
En la Figura 3-10 se muestran las temperaturas que se alcanzan en las zonas Oeste (sensores 4) y Este (sensores 4') de la viga así como la diferencia (Oeste-Este) entre ambas. Las temperaturas se han obtenido promediando el periodo comprendido entre los 50 y los 400 s de exposición. Las temperaturas se han representado a lo largo del eje longitudinal que tiene su origen en el extremo norte de la Viga 1 (se puede consultar el origen de coordenadas en la Figura 3-7).

En la Figura 3-10 se muestra la gran variación térmica longitudinal existente, sobre todo, en las vigas 1 y 2 . Por dar algunas cifras, las temperaturas adiabáticas varían entre 841 ${ }^{\circ} \mathrm{C}$ y $185^{\circ} \mathrm{C}$ en la zona Oeste y entre $867^{\circ} \mathrm{C}$ y $495^{\circ} \mathrm{C}$ en la zona Este de la Viga 1 ; entre $381{ }^{\circ} \mathrm{C}$ y $238^{\circ} \mathrm{C}$ en la zona Oeste de la Viga 7 , y entre $166^{\circ} \mathrm{C}$ y $73^{\circ} \mathrm{C}$ en la zona Este de la Viga 7. Adicionalmente se puede ver como las temperaturas máximas se producen en las regiones de afección directa de las llamas.
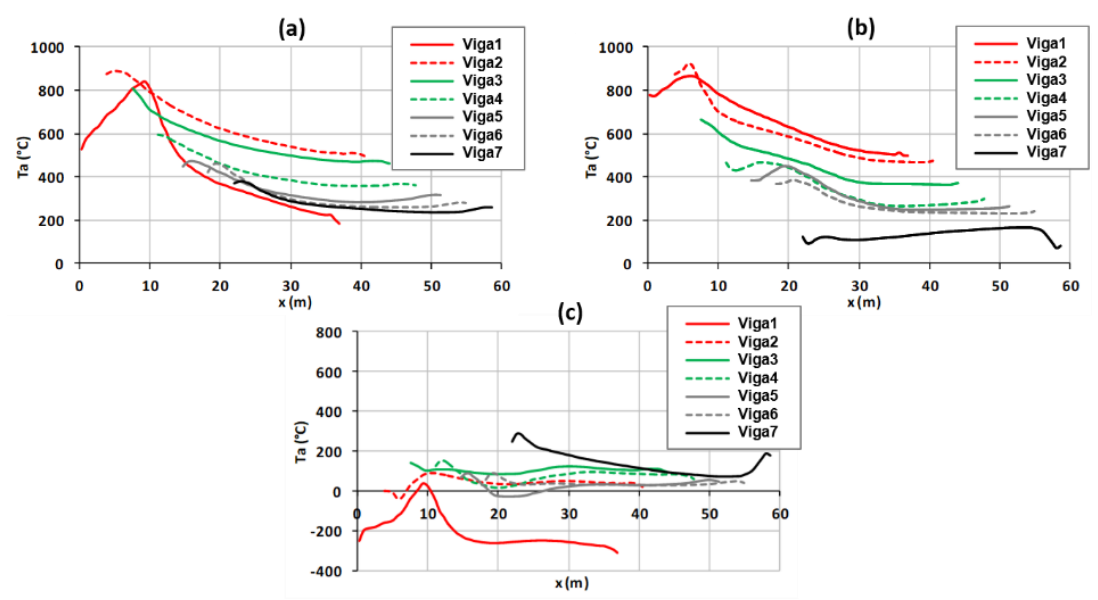

Figura 3-10. Temperaturas promedio a lo largo de las 7 vigas en (a) la zona Oeste, (b) la zona Este y (c) la diferencia Oeste-Este

Se ha querido mostrar la diferencia de temperaturas entre las zonas oeste y este con el fin de remarcar su magnitud. Si se tiene en cuenta que valores positivos en la gráfica (c) indican mayores temperaturas en la zona este se ve que para las vigas exteriores ( 1 al oeste y 7 al este) las temperaturas presentan diferencias de hasta $300^{\circ} \mathrm{C}$. La diferencia máxima de temperaturas varía desde $-311^{\circ} \mathrm{C}$ en la viga 1 a $284^{\circ} \mathrm{C}$ en la viga 7 . Estos valores representan $36 \%$ y $19 \%$ de las temperaturas máximas adiabáticas de cada viga.

Como el incendio se produjo en el lado oeste de la luz, cerca de la viga 1, las temperaturas en la cara oeste de las vigas son generalmente más altas que en su cara este con la excepción de la viga 1. El motivo es que su zona oeste no presenta ningún obstáculo 
(equivalente a la losa como el resto de casos) que evite la elevación libre de gases calientes.

Se observa que, a pesar de los análisis que se presentan en la Figura 3-10 se realizaron suponiendo una HRRPUA máxima para el derrame igual a $1.000 \mathrm{KW} / \mathrm{m}^{2}$ (valor que se validará en la Sección 0), las tendencias son similares y, aunque los valores se modifiquen en cierta medida, los comentarios siguen siendo válidos.

\subsubsection{MODELO DE ANÁLISIS TERMO-MECÁNICO}

Obtenidas las temperaturas en los gases en el entorno del puente es el momento de definir el modelo de análisis termo-mecánico. En esta sección se caracterizará el conjunto vigalosa asociada que sufrió más daños durante el fuego. En la Figura 3-11 se indica la mencionada viga con otro color así como la posición aproximada del incendio. Adicionalmente se incluye una sección transversal en la que se aprecia como la numeración de las vigas se incrementa de oeste a este (de viga más próxima al incendio a más alejada).

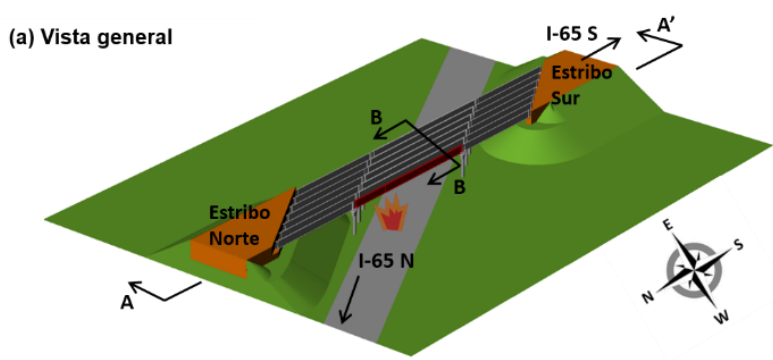

(b) Sección A-A'

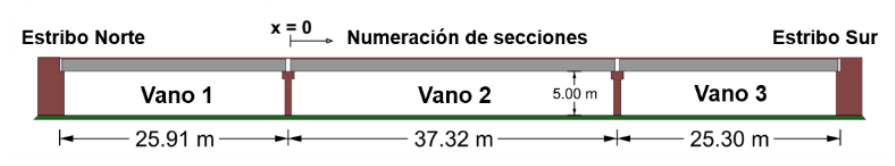

(c) Sección B-B'

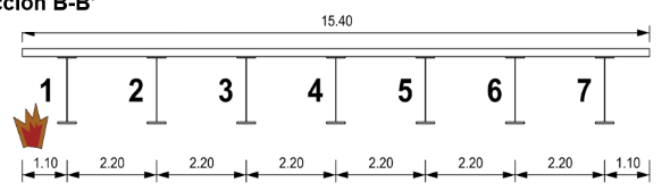

Figura 3-11. (a) Vista general, (b) Perfil ongitudinal y (c) Sección transversal del paso superior.

Adicionalmente, la Figura 3-11 muestra dimensiones globales del puente empleadas en el modelo de incendios expuesto en la Sección 3.4.2 como son el intereje de $2.2 \mathrm{~m}$ y los 
voladizos de $1.1 \mathrm{~m}$ o las dimensiones de los 3 vanos del puentes de 25.91, 37.32 y 25.30 m.

\subsubsection{GEOMETRÍA}

La viga a estudiar es una viga armada mixta de $37.16 \mathrm{~m}$ de longitud total y una luz entre apoyos de $36.13 \mathrm{~m}$. Como corresponde a este tipo de vigas, presenta una serie de rigidizadores a lo largo de la misma, que evitan la abolladura del alma sin necesidad de emplear espesores de la misma tan elevados. La magnitud de la viga hizo que en su momento se proyectara con una variación de los espesores de las alas metálicas que permitiese resistir mayores esfuerzos flectores en la región de centro-luz sin penalizar el peso de la estructura (lo que habría ocurrido en caso de extender los espesores más desfavorables a lo largo de toda la longitud).

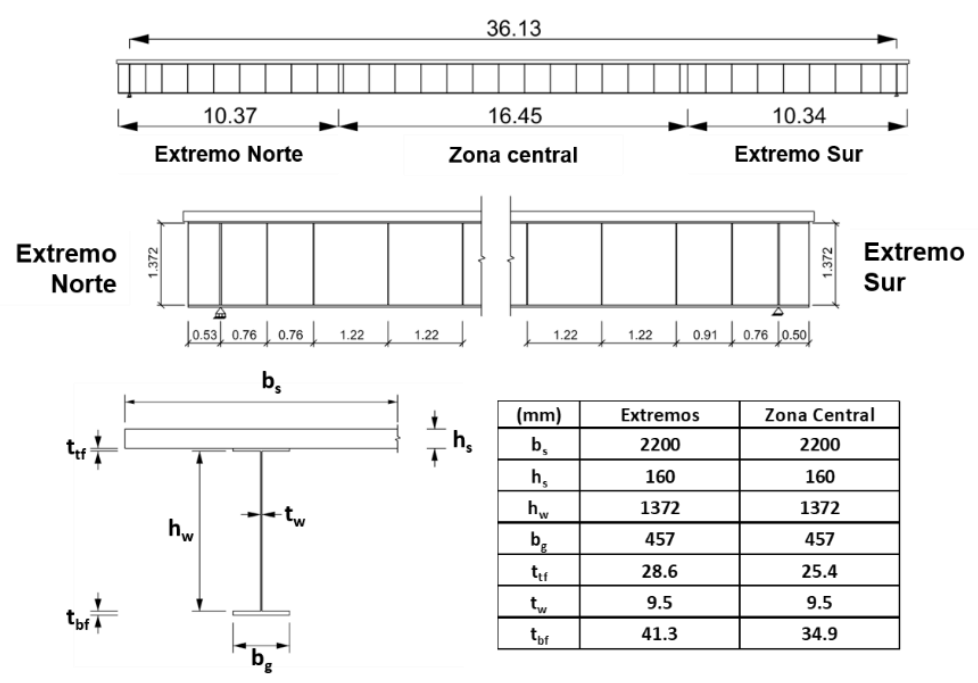

Figura 3-12. Definición geométrica de la viga en el modelo termo-mecánico.

En la Figura 3-12 se muestran las dimensiones de las secciones en la zona de centro de vano así como en las zonas laterales. Las diferencias entre ambas secciones son los espesores de las alas. El resto de parámetros son compartidos a lo largo de toda la pieza. En lo que respecta a los rigidizadores, existen dos tipos. Por un lado existen cuatro rigidizadores a la altura de los apoyos de $25.4 \mathrm{~mm}$. Por otro lado existen otros 30 rigidizadores intermedios de $11 \mathrm{~mm}$ de espesor distribuidos a lo largo de la cara este de la viga con las separaciones indicadas en la Figura 3-12. La cara oeste de la viga, al ser 
extrema, y de acuerdo con los planos de proyecto, no incluye rigidizadores intermedios, como se puede comprobar en la Figura 3-4.

\subsubsection{ELEMENTOS Y MALLA}

Para el análisis térmico se ha empleado un elemento tipo DC3D8. Se trata de un elemento tipo sólido de tres dimensiones con ocho nodos lineal de transferencia de calor con un grado de libertad por nodo. Para el análisis estructural, el elemento finito empleado ha sido el C3D8. Éste es un elemento sólido de ocho nodos tridimensional con tres grados de libertad por nodo.

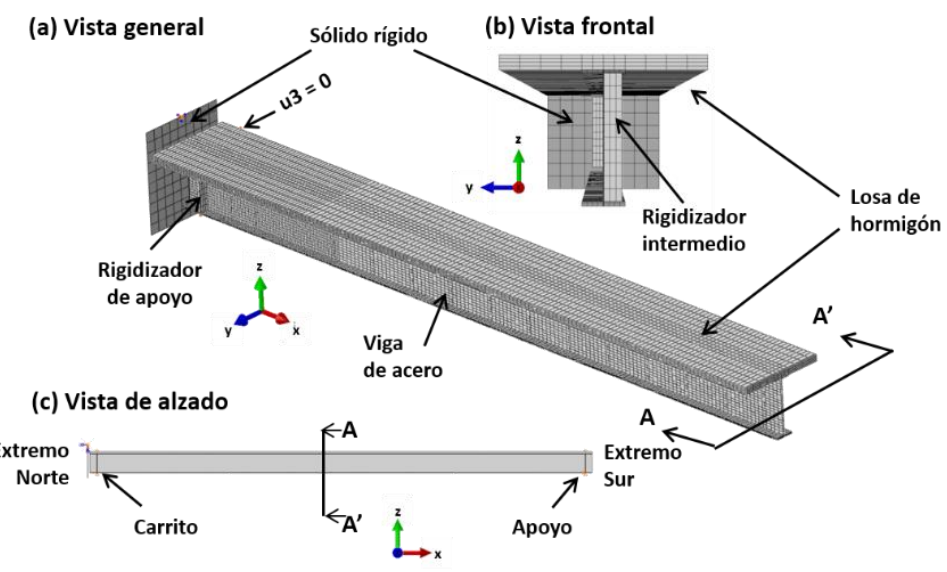

Figura 3-13. Modelo de elementos finitos de la Viga 1. (a) vista general, (b) vista frontal y (c) vista de perfil.

Se decidió realizar un modelo tridimensional de la viga más afectada por el incendio en lugar de un modelo más simple para capturar fenómenos locales como la abolladura del alma entre rigidizadores. En la Figura 3-13 se puede apreciar el refinamiento de la malla en la proximidad de los apoyos. Este hecho se justifica por la concentración de esfuerzos que se produce en las regiones de apoyo que implican una mayor susceptibilidad a la abolladura. El modelo de elementos finitos presenta 87791 nodos y 61620 elementos sólidos.

\subsubsection{PropiedadeS DEL MATERIAL}

El modelo térmico ha requerido de la definición de calor específico y conductividad de los materiales. El modelo mecánico ha precisado de la definición del coeficiente de dilatación térmica y de las curvas tensión-deformación en función de la temperatura. La densidad se ha empleado tanto en el modelo térmico como en el modelo mecánico. 
La caracterización de las variables mencionadas, tanto a temperatura ambiente como a altas temperaturas, se ha definido siguiendo las indicaciones propuestas por el Eurocódigo 4 relativo a estructuras mixtas de acero y hormigón. Se ha asumido que los áridos del hormigón eran calcáreos y que densidad del hormigón $\left(\rho_{c}\right)$ es de $2500 \mathrm{~kg} / \mathrm{m}^{3}$. De acuerdo con los planos del proyecto, se estableció una resistencia a compresión $\left(\mathrm{f}_{\mathrm{c}}\right)$ y un módulo de elasticidad a temperatura ambiente $\left(\mathrm{E}_{\mathrm{c}}\right)$ del hormigón de $27.58 \mathrm{MPa}$ (4000 psi) y de $16.54 \mathrm{GPa}$ respectivamente. En lo que respecta al acero, se empleó una densidad $\left(\rho_{\mathrm{s}}\right)$ de $7850 \mathrm{~kg} / \mathrm{m}^{3}$, así como unas curvas de tensión-deformación con endurecimiento por deformación y un límite elástico $\left(\mathrm{f}_{\mathrm{y}}\right)$ y módulo de elasticidad $\left(\mathrm{E}_{\mathrm{a}}\right) \mathrm{a}$ temperatura ambiente de $248.21 \mathrm{MPa}$ (36 ksi) y $200 \mathrm{GPa}$ respectivamente.

Finalmente cabe indicar que las curvas tensión-deformación propuestas para el acero a distintas temperaturas se convirtieron en leyes de tensión-deformación verdaderos $\left(\sigma_{n^{-}}\right.$ $\left.\varepsilon_{n}\right)$ mediante las expresiones que se indican a continuación.

$\sigma_{\mathrm{n}}=\sigma(1+\varepsilon)$

$\varepsilon_{\mathrm{n}}=\ln (1+\varepsilon)$

\subsubsection{UNIÓN VIGA ARMADA-LOSA}

El puente estudiado es de naturaleza mixta, por lo que las vigas de acero y la losa de hormigón están unidas mediante conectores para garantizar el trabajo conjunto de ambos elementos soportando las cargas actuantes sobre el puente.

Esta unión solidaria entre acero y hormigón puede ver comprometida su resistencia conforme se incrementen las temperaturas de los materiales. Por este motivo se ha comprobado que todos los análisis realizados en el presente capítulo presentan temperaturas en la interfaz viga-losa menores de $500{ }^{\circ} \mathrm{C}$ en todo momento. $\mathrm{Si}$ a este hecho le añadimos que no hubo evidencia alguna que mostrase un fallo de conexión acero-hormigón con posterioridad al incendio ocurrido en 2002 resulta razonable suponer que la adherencia perfecta entre ambos materiales se ha mantenido también durante la exposición al fuego.

\subsubsection{CONDICIONES DE CONTORNO.}

Los desplazamientos transversales de la viga ( $\mathrm{u} 3$ en la Figura 3-13) en los apoyos ( $\mathrm{x}=$ $0.53 \mathrm{~m} \mathrm{y} \mathrm{x}=35.66 \mathrm{~m}$ ) se fijaron al nivel de la losa de hormigón para tener en cuenta la influencia de la región de losa no incluida en el modelo de elementos finitos. No se ha fijado la coordenada transversal "u3" en toda la longitud de la losa, puesto que, dadas las grandes deformaciones y rotaciones transversales alcanzadas por la viga estudiada, no 
se puede asegurar que no se produjese cierto desplazamiento lateral (u3) de la losa (ver Figura 3-14).
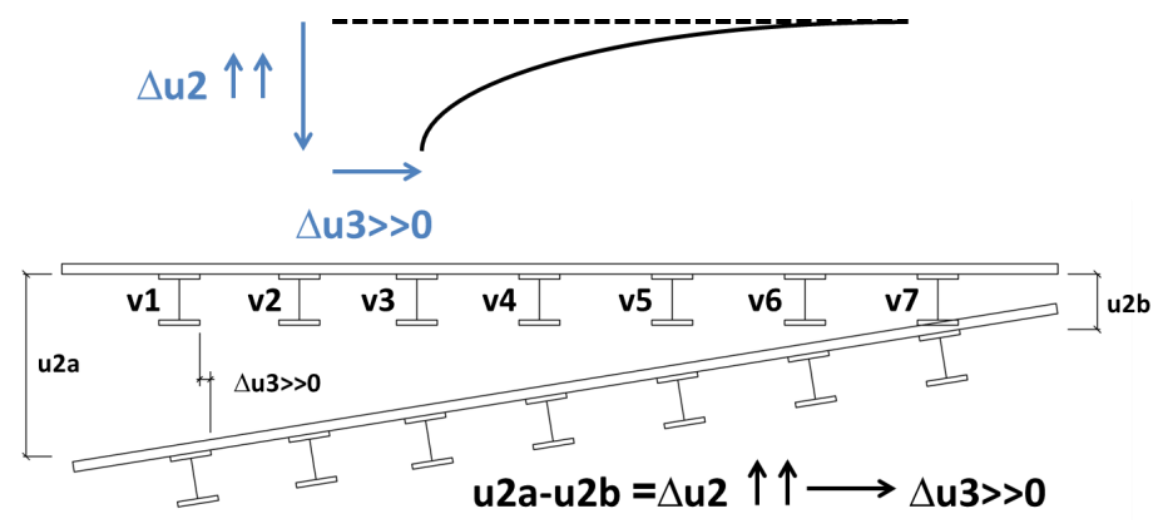

Figura 3-14. Croquis de los posibles desplazamientos en u3 de la losa a la altura de la vigal

Las condiciones en los extremos de la viga 1 fueron de apoyo $(\mathrm{u} 1=\mathrm{u} 2=0)$ en el extremo sur y de apoyo deslizante o carrito $(\mathrm{u} 2=0)$ en el extremo norte.

Adicionalmente se decidió estudiar la influencia de fijar (o no) una limitación al desplazamiento longitudinal que representaría la existencia de los vanos adyacentes oponiéndose al desplazamiento libre de la viga más allá del espesor de la suma de las dos juntas (de $152.4 \mathrm{~mm}$ en este caso). Esta limitación se materializó mediante la incorporación de un sólido rígido fijado en el espacio $(\mathrm{u} 1=\mathrm{u} 2=\mathrm{u} 3=0)$ a esa distancia y un contacto que impide que la cara extrema de la viga traspase el mencionado sólido.

\subsubsection{CARGaS GRAVITATORIAS}

Las cargas gravitatorias correspondientes al peso propio de la viga de acero de (130.6 $\mathrm{KN})$ y la losa de hormigón (327.98 KN) se calcularon automáticamente por el software mediante la densidad y el volumen ocupado por los materiales. Adicionalmente se incorporó el peso de la capa de rodadura $(121.2 \mathrm{KN})$ sobre toda la losa y el peso del pretil $(83.6 \mathrm{KN})$ en una franja de $0.2 \mathrm{~m}$ de ancho sobre el lateral oeste de la losa.

No se encontró ninguna evidencia de vehículos que cruzaran el paso elevado durante el incendio por lo que no se consideraron sobrecargas de uso en el estudio. 


\subsubsection{CARGAS TÉRMICAS}

Se han empleado las temperaturas adiabáticas registradas en el modelo de incendios junto con los coeficientes necesarios para la definición de los flujos de radiación (emisividad) y de convección (coeficiente de convección) propuestos por los Eurocódigos 1 y 4 [ref3.11-ref3.12]. Para definir la transmisión de calor por radiación se ha decidido adoptar la emisividad correspondiente al acero $(\varepsilon=0.7)$ mientras que para caracterizar la convección se ha decidido adoptar el valor propuesto para el empleo de modelos avanzados de incendio $\left(\mathrm{h}=35 \mathrm{~W} \cdot \mathrm{m}^{-2} \cdot{ }^{\circ} \mathrm{C}-1\right)$.

\subsubsection{DISCRETIZACIÓN LONGITUDINAL EMPLEADA}

Aunque habitualmente las cargas térmicas tienden a ser una acción más a tener en cuenta en el diseño, su magnitud (en general reducida si no se considera la acción del fuego) suele hacer que el efecto de su consideración, salvo en estructuras singulares, quede en un segundo plano.

En el presente estudio, al considerar la situación de incendio, las cargas térmicas presentan una magnitud muy superior a la considerada en la normativa para tener en cuenta diferencias de temperatura a lo largo del año (motivadas únicamente por variables ambientales). Cuando los gradientes térmicos en el gas superan el centenar de ${ }^{\circ} \mathrm{C}$ entre zonas de exposición, resulta necesario definir a nivel espacial una serie de tramos a lo largo de los cuales la evolución de temperaturas sea homogénea.
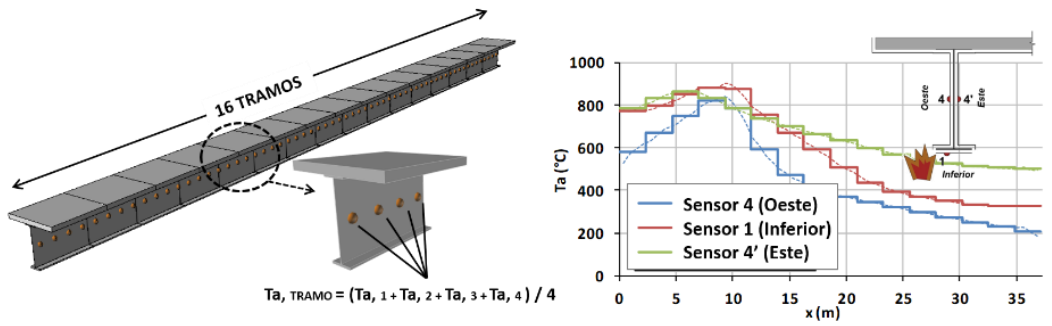

Figura 3-15. Discretización de las cruvas en 16 tramos. Caso de $1000 \mathrm{KW} / \mathrm{m}^{2}$.

En la Figura 3-15 se presenta la discretización longitudinal en 16 tramos empleada finalmente con el fin de reproducir con cierta precisión el perfil térmico longitudinal en cada una de las tres zonas definidas en la Figura 3-8. Las temperaturas mostradas en la Figura 3-8 corresponden a la etapa estacionaria donde las temperaturas se mantienen a partir de los 20s. Se pueden consultar las conclusiones relativas a un estudio del número de tramos mínimo aceptable en [ref2.07] y [ref2.13] para mayor información. 


\subsubsection{DEFINICIÓN DEL FALLO}

De acuerdo con [ref2.04] se asume que la estructura falla cuando se cumple una de las siguientes condiciones: (1) Se rompe el material en el momento en que se alcanzan las deformaciones unitarias máximas admisibles por el material $\left(\varepsilon_{n}=0.14\right)$ o (2) la estructura se vuelve inestable en el momento en que se produce un aumento drástico de la velocidad de deformación o un movimiento hacia el interior del apoyo deslizante hacia el centro del vano.

\subsubsection{ESTUDIO PARAMÉTRICO PARA LA VALIDACIÓN DEL MODELO}

El objetivo último de la reproducción del incendio ocurrido en 2002 en Alabama y su efecto sobre la respuesta estructural del puente es el de validación de la metodología. Para concluir con la definición del modelo de incendio quedarían por definir la tasa de liberación de calor por unidad de área del charco de combustible (en el modelo de incendios) y la incorporación o no de la limitación longitudinal al desplazamiento igual a la suma de los espesores de las juntas.

\begin{tabular}{|c|c|c|c|c|c|c|}
\hline \multirow{2}{*}{ Estudio } & \multirow{2}{*}{ Análisis } & \multirow{2}{*}{$\begin{array}{c}\text { HRRPUA } \\
\text { derrame } \\
\left(\mathrm{kW} / \mathrm{m}^{2}\right)\end{array}$} & \multirow{2}{*}{$\begin{array}{l}\text { Dilatación } \\
\text { máxima }\end{array}$} & \multicolumn{3}{|c|}{ Fallo } \\
\hline & & & & tiempo (min) & Modo $^{\mathrm{a}}$ & Flecha máxima (m) \\
\hline \multirow{5}{*}{$\begin{array}{l}\text { HRRPUA } \\
\text { Derrame } \\
\left(\mathrm{KW} / \mathrm{m}^{2}\right)\end{array}$} & $2500-16$-fix & 2500 & 152.4 & 1.6 & $\mathrm{P}, \mathrm{D}, \mathrm{S}, \mathrm{A}$ & 0.54 \\
\hline & $2000-16$-fix & 2000 & 152.4 & 2 & $\mathrm{P}, \mathrm{D}, \mathrm{A}$ & 0.57 \\
\hline & $1500-16$-fix & 1500 & 152.4 & 3.8 & $\mathrm{P}, \mathrm{D}, \mathrm{A}$ & 0.86 \\
\hline & $1000-16-f i x$ & 1000 & 152.4 & 13.1 & $\mathbf{P}, \mathbf{D}, \mathbf{A}$ & 1.91 \\
\hline & $500-16-$ fix & 500 & 152.4 & $>30$ & $\mathrm{P}, \mathrm{S}$ & 0.67 \\
\hline Restricción u1 & $1000-16$-fre & 1000 & Libre & 12.3 & $\mathrm{~A}, \mathrm{~S}$ & 1.36 \\
\hline
\end{tabular}

Tabla 3-1. Parámetros y resultados de los análisis llevados a cabo para la validación del modelo.

En la Tabla 3-1 se presentan los parámetros del modelo estudiados así como los nombres de análisis. La nomenclatura empleada se detalla a continuación. El primer parámetro indica la tasa de liberación de calor por unidad de superficie del derrame de combustible en $\mathrm{kW} / \mathrm{m}^{2}$. El segundo indicador representa el número de tramos en dirección longitudinal empleados para caracterizar las temperaturas en las tres zonas. Para el caso concreto de los modelos presentados en la tabla se mantiene en 16. El tercer parámetro indica si existe (para el caso "fix") o no (para el caso "free") valor máximo de dilatación longitudinal en el modelo. Los tiempos de fallo, junto con la respuesta estructural de los distintos modelos se comentarán brevemente en las secciones 0 y 3.4.4.2. 


\subsubsection{ESTUDIO DE LA TASA DE LIBERACIÓN DE CALOR DEL DERRAME}

Como se muestra en la Tabla 3-1, se consideraron cinco valores de la tasa máxima de liberación de calor por unidad de área (HRRPUA $\mathrm{A}_{\mathrm{MAX}}$ ) en el combustible derramado: 500, $1000,1500,2000$ y $2500 \mathrm{~kW} / \mathrm{m}^{2}$ respectivamente. Para escoger que valor se ajusta más a la realidad se decidió comparar con la respuesta mecánica del caso real

La Figura 3-16 permite evaluar el efecto de la consideración de distintas potencias de fuego para el derrame sobre las temperaturas alcanzadas en la zona oeste de la viga 1 (para las zonas inferior y este los resultados varían de forma similar). En la figura se aprecia como esta variable presenta una fuerte influencia sobre las temperaturas. Por dar una cifra, al pasar de un valor de 500 a $2.500 \mathrm{~kW} / \mathrm{m}^{2}$ multiplica las temperaturas adiabáticas máximas por $1,73\left(724\right.$ a $\left.1251^{\circ} \mathrm{C}\right)$. En las zonas Este e Inferior, no representadas gráficamente, el factor multiplicativo es de $2,67\left(549\right.$ a $\left.1469^{\circ} \mathrm{C}\right)$ y de 1,54 $\left(811 \mathrm{a} 1251^{\circ} \mathrm{C}\right)$ respectivamente.

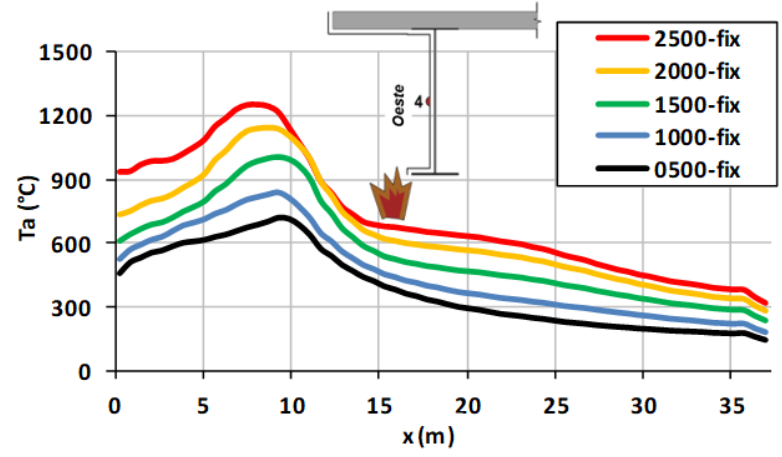

Figura 3-16. Variación de las temperaturas en la zona Oeste de la Viga 1.

Estas diferencias en las temperaturas adiabáticas tienen consecuencias directas sobre la respuesta estructural de la Viga 1. Si se consulta la Tabla 3-1 se puede comprobar como si se eleva la tasa de liberación de calor por unidad de superficie de 1000 a $2500 \mathrm{~kW} / \mathrm{m}^{2}$ el tiempo de fallo se verá reducido drásticamente (de 13,1 a 1,6 minutos). Este hecho confirma la preocupación preexistente por caracterizar adecuadamente esta variable. 


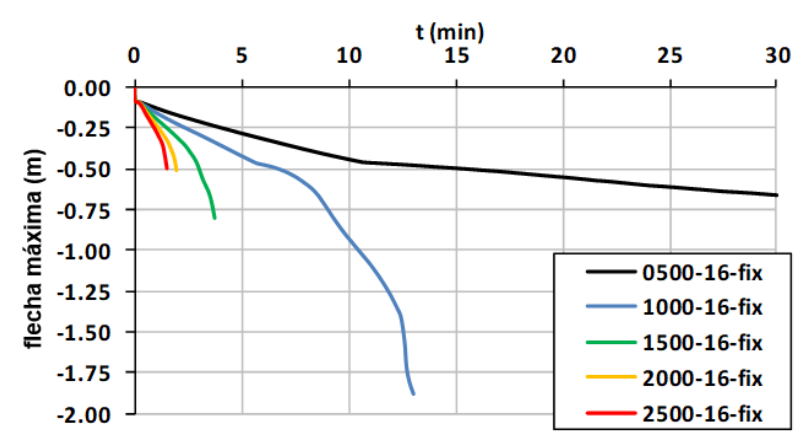

Figura 3-17. Evolución de la flecha máxima para distintos valores de HRRPUA del derrame.

En la Figura 3-17 se puede ver, además del tiempo de fallo y la flecha máxima registrada mostradas en la Tabla 3-1, la evolución de la flecha durante el incendio. En ambas se puede comprobar como la máxima flecha alcanzada por el caso de $1000 \mathrm{KW} / \mathrm{m}^{2}$ igual a $1,91 \mathrm{~m}$ es la más cercana al valor realmente registrado de en torno a $2,5 \mathrm{~m}$ facilitado por el ALDOT.

En la Figura 3-18 se presenta la evolución de la deformada de la viga 1 con el tiempo para el análisis 1000-16-fix (con HRRPUA del derrame igual a $1000 \mathrm{~kW} / \mathrm{m} 2$ ). En ella se aprecia cómo, debido a que la carga de fuego no es simétrica, la respuesta termomecánica tampoco lo es. También se puede ver, para el caso 1000-16-fix, como la máxima flecha se va desplazando hacia el extremo norte llegando a posicionarse a 11,6 $\mathrm{m}$ de distancia de este extremo. A solo 3,4 $\mathrm{m}$ (un 9\% de la longitud de la viga) de la posición estimada a partir de las imágenes facilitadas por el ALDOT (a $15 \mathrm{~m}$ de distancia del extremo norte).

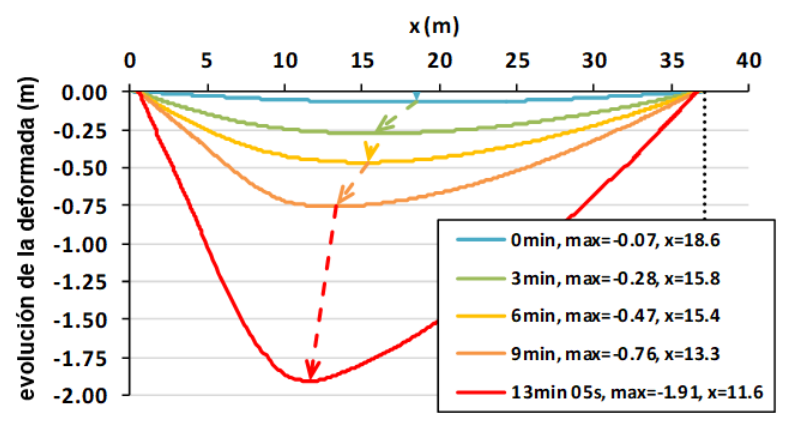

Figura 3-18. Evolución de la deformada para el análisis 1000-16-fix. 
La Figura 3-19 muestra (a) el desplazamiento horizontal del extremo norte de la viga a lo largo del tiempo, así como (b) el desplazamiento transversal del centro del alma. En la gráfica de la izquierda se puede comprobar como la existencia de la junta de $152.4 \mathrm{~mm}$ de espesor solo tiene influencia limitando el desplazamiento longitudinal en los casos de HRRPUA del derrame entre 500 y $1000 \mathrm{~kW} / \mathrm{m}^{2}$. En la Figura 3-19b se registra, salvo para el caso de $500 \mathrm{~kW} / \mathrm{m}^{2}$ en que la viga no colapsa, una abolladura del alma en la región de mayor exposición del fuego (de 0 a 10 m comenzando desde el extremo norte).
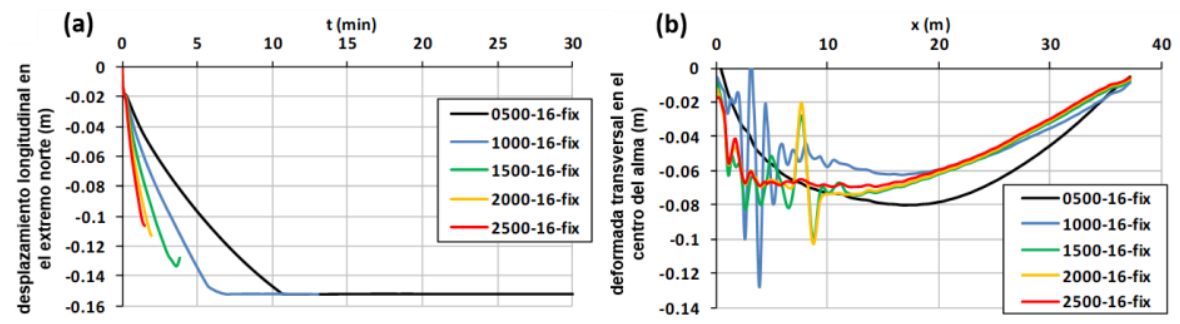

Figura 3-19. Comparativa para distintas HRRPUA de: (a) Evolución del desplazamiento longitudinal del extremo norte y $(b)$ deformación transversal a media altura del alma.

\subsubsection{ESTUDIO DE LA RESTRICCIÓN LONGITUDINAL AL MOVIMIENTO}

Tal como se indica en la Tabla 3-1, se han considerado dos tipos de condiciones en lo que respecta a la dilatación de la pieza en su extremo norte. El caso "fix" representa una limitación del desplazamiento longitudinal máximo de $152.4 \mathrm{~mm}$ respecto de la posición original mientras que el caso "fre" representa una dilatación totalmente libre.

Hasta el momento se han presentado resultados correspondientes al caso con limitación del desplazamiento (fix), llegando a la conclusión de que el modelo de $1000 \mathrm{~kW} / \mathrm{m}^{2}$ es el que mejor ajusta al evento real. Aunque tres de los análisis (con HRRPUA entre 1500 y $2000 \mathrm{~kW} / \mathrm{m}^{2}$ ) no han alcanzado el nivel máximo de desplazamiento longitudinal admitido (ver Figura 3-19) si lo ha hecho el modelo "1000-16-fix" con mejor ajuste. Por ello se plantea el modelo "1000-16-fre" (ver Tabla 3-1) sin coacción y con la misma HRRPUA y discretización longitudinal de temperaturas con el fin de determinar cuál de los dos casos representa mejor la respuesta mecánica de la estructura. 

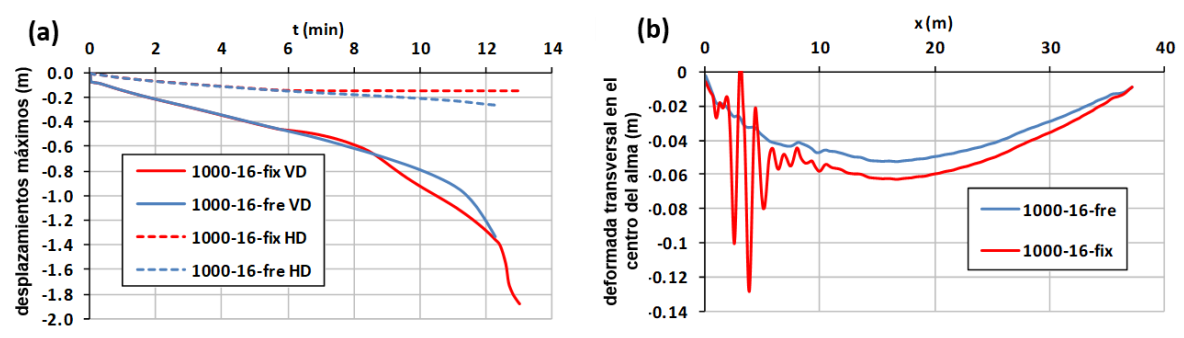

Figura 3-20. Efecto de limitación del desplazamiento longitudinal: (a) Evolución del desplazamiento longitudinal en extremo norte y vertical máximo y $(b)$ deformación transversal a media altura del alma.

La Tabla 3-1 y la Figura 3-20 presentan los resultados de este estudio. La Figura 3-20a representa la máxima flecha (VD) y el desplazamiento horizontal del extremo norte (HD) en función del tiempo para los análisis "1000-16-fix" y "1000-16-fre". La Figura 3-20b presenta los desplazamientos transversales del alma a media altura permitiendo apreciar cuándo se produce la abolladura.

La Figura 3-20a muestra una misma tendencia en la evolución de la flecha máxima con un fallo previo del análisis 'fre'. Por este motivo se alcanza una flecha máxima mayor en el caso coaccionado. En lo que respecta a los desplazamientos transversales existe una clara diferencia entre el caso libre (sin abolladura) y el coaccionado (con aparición de abolladura en la región próxima al extremo norte). Al detectarse en el evento real (ver Figura 3-21) la aparición de una leve abolladura en esta zona se consideró que el análisis "fix" era el que mejor ajustaba con el suceso de 2002.

\subsubsection{VALIDACIÓN DEL MODELO}

Se puede concluir que la respuesta que mejor se ajusta a la observada en el evento real es el análisis "1000-16-fix". La HRRPUA para el derrame que mejor ajusta a la respuesta real es la de $1000 \mathrm{~kW} / \mathrm{m}^{2}$ (con $1.91 \mathrm{~m}$ de flecha máxima frente a los $2.5 \mathrm{~m}$ estimados por el ALDOT) dadas las flechas alcanzadas en el resto de casos. La existencia de abolladura en el alma de la viga de estudio correspondiente al puente real sugiere que un modelo con restricción al desplazamiento horizontal de $152.4 \mathrm{~mm}$ (representando la suma de las dos juntas de dilatación del vano central) representa mejor la condición de contorno de la viga durante el incendio. En la Figura 3-21 se comparan deformadas de la viga de estudio y modos de fallo obtenidos con este análisis, apreciando cierta similitud, tanto a nivel global de la pieza como a nivel de detalle (en el extremo norte).

Llegados a este punto, es importante remarcar que el hecho de no considerar en el modelo termo-mecánico todas las vigas del puente supone no tener en cuenta las posibles 
redistribuciones de carga de la viga estudiada (viga 1) hacia el resto de vigas durante el evento de fuego (a mayor redistribución mayor HRRPUA se requerirá para obtener la misma deformada en la viga 1). Tampoco se ha tenido en cuenta la modificación de la geometría durante el evento en el modelo de incendios puesto que éste no admite la incorporación de elementos deformables en el tiempo (si se considera el incremento de flecha del puente en el modelo de incendios la viga se aproximará al fuego exponiéndose a flujos de calor mayores). La consideración de estas dos limitaciones puede suponer un incremento o disminución de la HRRPUA del derrame estimada en función de cuál de las dos consideraciones afecte más a la respuesta mecánica.
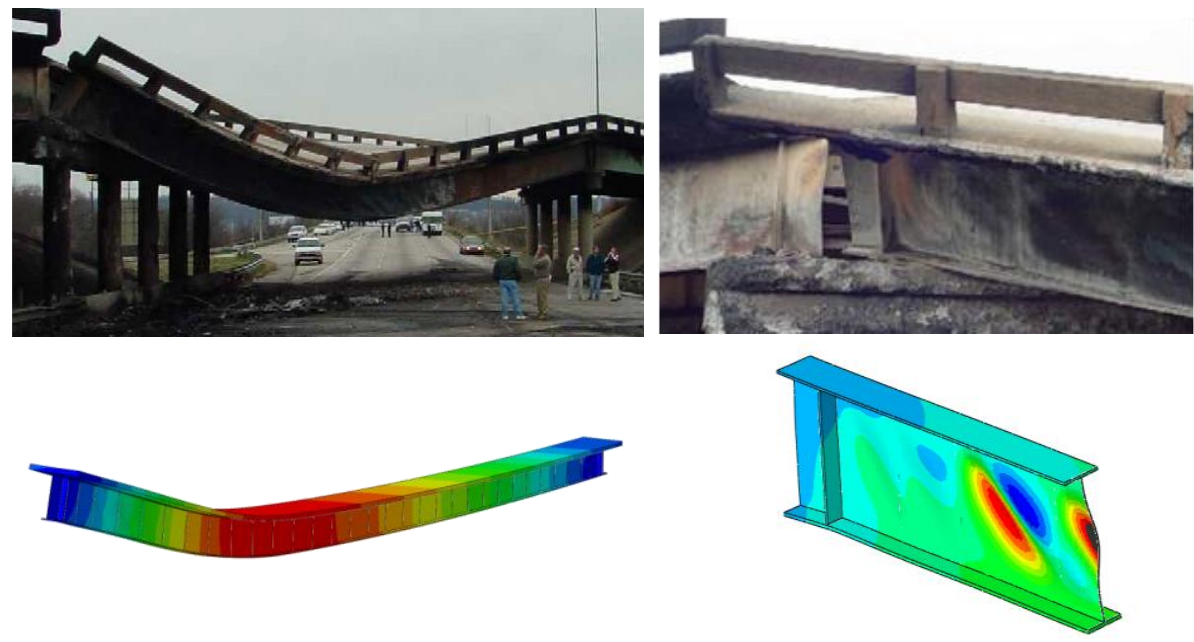

Figura 3-21. Comparativa entre el modelo validado "1000-16-fix" y el evento real.

\subsection{CONCLUSIONES DEL ESTUDIO DE VALIDACIÓN DE LA METODOLOGÍA}

\subsubsection{RESPECTO A LAS TEMPERATURAS DEL INCENDIO}

Los incendios en puentes no solo generan una fuerte exposición térmica desde el foco del incendio hacia la estructura, sino que también provocan fuertes gradientes térmicos longitudinales y entre zonas de exposición. Por este motivo, se recomienda establecer un número mínimo de tramos en dirección longitudinal y transversal que permita tener en cuenta esas diferencias espaciales en lo que a las temperaturas de exposición respecta. La variación a lo largo del tiempo de las temperaturas deberá tenerse en cuenta igualmente, como se viene haciendo en ámbitos como el de los túneles y la edificación. 
Se descarta el empleo de una única curva de calentamiento para el caso de vigas de puente de cierta magnitud (por encima de $30 \mathrm{~m}$ al menos) como ocurre en el campo de la edificación donde la existencia de recintos posibilita esta simplificación. Puesto que las temperaturas no experimentan grandes cambios en la región directamente afectada por las llamas (entre 5 y $12 \mathrm{~m}$ del extremo norte), se plantea que para luces de vano cortas podría resultar razonable el empleo de una sola curva de fuego a lo largo de toda la viga. Para determinar que luces podrían considerarse "cortas" deberían considerarse, al menos, la potencia del incendio de estudio y la geometría de estribos y tablero.

Aunque se han registrado importantes gradientes entre las tres zonas de exposición, también se ha podido comprobar como dentro de cada zona las variaciones térmicas han sido despreciables. Por este motivo se recomienda, para futuros estudios, incorporar un único sensor por sección y zona de exposición. Dado un puente multiviga se definirían tres zonas de exposición por viga y una separación entre secciones de $0.6 \mathrm{~m}$.

\subsubsection{RESPECTO A LA RESPUESTA TERMO-MECÁNICA}

La consideración de la limitación de la dilatación máxima de la viga resulta un parámetro de gran importancia en la respuesta estructural dada la magnitud de la acción térmica. Resulta razonable, y así lo demuestra la consideración de la restricción longitudinal al movimiento, que la influencia del vano adyacente resulta una variable a considerar en este tipo de análisis.

Los modelos numéricos propuestos y validados en este trabajo son complejos, pero se pueden utilizar para realizar un análisis de ingeniería forense de un puente dañado por un incendio y para estudiar cómo mejorar el comportamiento del puente frente a eventos de fuego.

Si se llevan a cabo investigaciones experimentales complementarias, así como estudios paramétricos, estos modelos numéricos podrían emplearse para desarrollar metodologías de diseño simplificadas para evaluar los efectos del fuego en los puentes metálicos y mixtos.

\subsection{REFERENCIAS}

[ref3.01] Mc Grattan K, Hostikka S, Floyd J, Baum H, Rehm R, Mell W. Fire dynamics simulator (version 5). Technical reference guide. 2010.

[ref3.02] Wickström D, Duthinh D, McGrattan K. Adiabatic surface temperature for calculating heat transfer to fire exposed structures. Interflam 2:943. 2007. 
[ref3.03] Choi J. Concurrent fire dynamics models and thermomechanical analysis of steel and concrete structures. Georgia Institute of Technology. 2008.

[ref3.04] Paya-Zaforteza I, Garlock ME. A numerical investigation on the fire response of a steel girder bridge. Journal of Constructional Steel Research 75:93-103. 2012.

[ref3.05] Peris-Sayol G, Paya-Zaforteza I, Alos-Moya J, Hospitaler A. Analysis of the influence of geometric, modeling and environmental parameters on the fire response of steel bridges subjected to realistic fire scenarios. Computers and Structures Journal. 2015 .

[ref3.06] Gong X, Agraval AK. Numerical simulation of fire damage to a long-span truss bridge. ASCE Journal of Bridge Engineering 20 (10). 2015.

[ref3.07] Alos-Moya J. Análisis del colapso frente al fuego del paso superior de la interestatal I-65 dirección sur sobre la I-65 dirección norte en el ramal sur del intercambiador con la interestatal I-20/59 situado en Birmingham, Alabama, Estados Unidos. Proyecto final de carrera. Universitat Politècnica de València. 2012.

[ref3.08] Tewarson A. Generation of heat and chemical compounds in fires. SFPE Handbook of Fire Protection Engineering, Section 3, Chapter 4, 4th Edition, Quincy, MA. 2008.

[ref3.09] Karlson B, Quintiere JG. Enclosure Fire Dynamics. CRC Press. 1999.

[ref3.10] Quintiere JG. Surface flame spread. SFPE Handbook of Fire Protection Engineering, Section 2, 4th Edition, Quincy, MA. 2008.

[ref3.11] European Committee for Standardization (CEN). EN 1991-1-2:2002. Eurocode 1: Actions on structures - Part 1-2: General Actions - Actions on structures exposed to fire. Brussels, Belgium. 2002.

[ref3.12] European Committee for Standardization (CEN). EN 1994-1-2:2005. Eurocode 4: Design of composite steel and concrete structures - Part 1-2: General Actions - Actions on structures exposed to fire. Brussels, Belgium. 2005.

[ref3.13] Alós-Moya J, Paya-Zaforteza I, Garlock MEM, Loma-Ossorio E, Schiffner D, Hospitaler A. Analysis of a bridge failure due to fire using computational fluid dynamics and finite element models. Engineering Structures 68: 96-110. 2014. 


\section{CAMPAÑA EXPERIMENTAL}

El aprendizaje es experiencia. Todo lo demás es información

A. Einstein

El contenido de esta sección ha sido tomado directamente del paper

"Valencia bridge fire tests:

Experimental study of a composite bridge under fire"

publicado en 2017 en el volumen 138 (p538-554) del

Journal of Constructional Steel Research 



\subsection{INTRODUCCIÓN}

Una vez se ha realizada una primera validación de la metodología a nivel general se plantean dos opciones. La primera consistiría en aprovechar la propia metodología para, mediante el empleo de modelos numéricos, de incendios y de elementos finitos, conocer cuáles son las variables, estructurales y relativas al incendio, que participan en menor o mayor medida en el problema del puente sometido a la acción del fuego. Conocidas estas variables se pueden proponer y evaluar medidas de protección, evaluar modificaciones del diseño o simplemente comprobar cómo se comportarían otros puentes con otras tipologías frente a un mismo incendio de diseño. Esta opción se ha adoptado en la gran mayoría estudios que han modelizado la respuesta estructural de un puente determinado frente una acción de fuego específica (procedente de un accidente real o no y partiendo generalmente de un número considerable de suposiciones de partida) [ref4.01-ref4.04].

La segunda opción, que es la que se va a abordar en este caso, pretende realizar una aproximación experimental al problema. Se trata de una elección que, de acuerdo con las publicaciones disponibles a fecha de enero de 2018, no ha sido abordada por otros equipos de investigación. Las causas que se barajan para ello son dos: (1) la suposición de que este tipo de ensayos son prescindibles si se recurre al análisis numérico y (2) la enorme inversión económica que supone la realización de una campaña experimental con puentes a escala real.

Respecto a la primera, no hay que olvidar que al final una simulación de incendios o un análisis termo-mecánico mediante elementos finitos no es más que una reproducción simplificada de la realidad. Por su propia naturaleza, por desconocimiento de algunas de las variables requeridas para el análisis o por la restricción del tiempo de cálculo, en el caso de modelos de grandes dimensiones, impuesta según el número de nodos de la malla de elementos finitos o el número de celdas en una simulación de incendios el modelo llevará asociadas una serie de simplificaciones. ¿Quiere decir esto que no se pueden emplear modelos numéricos para plantear recomendaciones de diseño sin recurrir antes a la realización de experimentos de fuego? Ni mucho menos. De hecho, como ya se ha indicado previamente, los estudios publicados hasta la fecha así lo han hecho. Sin embargo, cabe tener en cuenta que si lo que se busca es el desarrollo de una normativa de protección de puentes frente al fuego con modelos y criterios de toma de decisiones simplificados cabe asegurarse al menos de dos cuestiones:

1. Que los modelos y las metodologías sean validados con registros continuos tomados a lo largo de los eventos de fuego. Solo así será posible asegurar que la validación puede considerarse válida durante el periodo de exposición al fuego. El nivel de validación alcanzable mediante la 
información recopilada en un evento real se limita a la comparación con variables como flechas residuales, estado de los materiales, flechas residuales e imágenes de los eventos. Y una validación de esta naturaleza suele estar limitada a registros post-incendio y/o medidas estimadas con cierto nivel de error.

2. Que no se está omitiendo ninguna variable con impacto sustancial en la transmisión de calor o en la propia respuesta termo-mecánica. Este es el caso de la acción del viento durante el incendio. Aunque muchos de los incidentes empleados en validaciones lo han experimentado en menor o mayor medida, no suele considerarse en las simulaciones. El hecho de que se obtengan validaciones aceptables sin tenerlo en cuenta puede deberse a tres motivos:

a. Su efecto en la dinámica del incendio y/o la transmisión de calor es despreciable

b. Su efecto en la dinámica del incendio y/o la transmisión de calor se autocompensa en el tiempo

c. Su efecto en la dinámica del incendio y/o la transmisión de calor queda encubierto con alguna de las otras variables del problema que tampoco se ha estimado convenientemente.

Conocer el motivo real requiere de validaciones que recurran al registro continuado de varias variables a lo largo de todo el evento de fuego.

Respecto a la segunda causa, es indudable que una campaña experimental que incluya puentes a escala real requeriría una inversión económica y de recursos de gran magnitud. Por este motivo, en lugar de ser abordada por parte de un equipo investigador en solitario, convendría crear un grupo de trabajo a escala mundial en el que no solo se discutan cuáles son las necesidades reales a cubrir por esta campaña experimental, sino que se encargue de obtener la financiación necesaria para abordarlas.

Puesto que la situación planteada, aunque deseable, es un proceso que lleva tiempo y dedicación por parte de los distintos expertos en la materia, en el presente trabajo se ha planteado una campaña experimental menos ambiciosa que sirva de punto de partida para próximas campañas experimentales con mayor financiación y recursos.

La campaña experimental que se propone busca cumplir varios objetivos:

1. Obtener registros continuos de variables de tasa de liberación de calor, de temperaturas en el gas, de temperaturas en el acero y de flechas en un puente a escala reducida sometido a fuegos de menor magnitud que las generalmente estimadas para eventos de fuego en puentes (Capítulo 4) 
2. Emplear parte los registros de tasa de liberación de calor y de temperaturas en el gas para realizar una validación del modelo de simulación de incendios que servirá de referencia para realizar los modelos de incendios a mayor escala (Capítulo 5)

3. Emplear parte de los registros de tasa de liberación de calor, temperaturas de los materiales y flechas del tablero para la validación del modelo termo-mecánico que servirá de referencia para realizar el modelado de puentes a mayor escala (Capítulo 6)

4. Comentar las problemáticas afrontadas durante los ensayos y las posteriores validaciones y proponer una serie de recomendaciones de cara a futuros ensayos a mayores escalas (tanto de la estructura de estudio como de la acción del fuego (Capítulo 6)

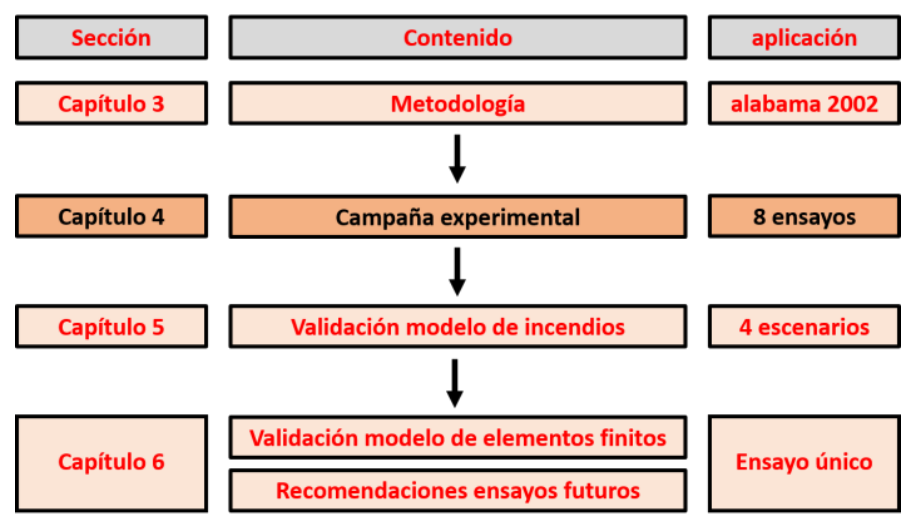

Figura 4-1. Estructura de la tesis. Capítulo 4

\subsection{DESCRIPCIÓN DEL PUENTE EXPERIMENTAL}

El primer objetivo perseguido mediante el diseño del puente experimental es el de estudiar aspectos detectados en estudios numéricos [ref4.03, ref4.05-ref4.09] tales como:

1. El impacto de las llamas en el tablero

2. La dispersión de la llama, del calor y el humo entre las dos vigas del puente

3. La aparición de gradientes térmicos longitudinales significativos

4. La influencia de la carga de fuego sobre las temperaturas de exposición en el entorno de las vigas 
El puente experimental se ha definido multiviga mixto con vigas en doble $\mathrm{T}$ porque, de acuerdo a Peris-Sayol e al. [ref4.05], este es el sistema estructural que mayor número de eventos ha registrado con niveles de daño altos debidos a la acción del fuego.

El puente experimental (ver Figura 4-2) consta de tres partes:

1. Dos estribos construidos sobre una losa de nivelación, cuya cota superior sirve de referencia de cotas, que sitúan la cara inferior de las vigas a una altura $1.9 \mathrm{~m}$.

2. Un tablero mixto de hormigón y acero, de $6.2 \mathrm{~m}$ de longitud y $2.0 \mathrm{~m}$ de ancho, constituido por una losa de hormigón de $0.15 \mathrm{~m}$ de espesor unida por conectores a dos perfiles IPE-160. La distancia entre ejes de las vigas es de $1.0 \mathrm{~m}$, dejando $0.5 \mathrm{~m}$ de vuelo a cada lado. Las vigas se apoyan en los estribos mediante cuatro apoyos elastoméricos cuadrados de $200 \mathrm{~mm}$ de lado y $20 \mathrm{~mm}$ de espesor.

3. Dos pórticos auxiliares empleados para fijar los LVDT empleados para registrar las flechas del tablero durante los ensayos.

(a) Alzado

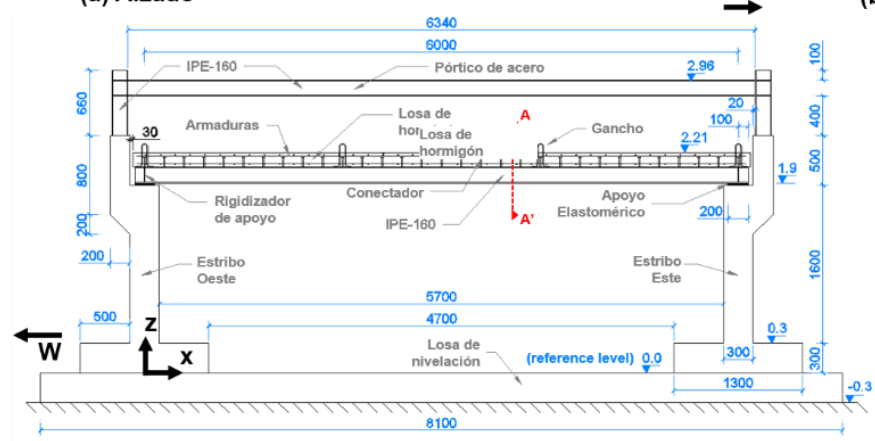

(c) Detalles del tablero (Sección AA')

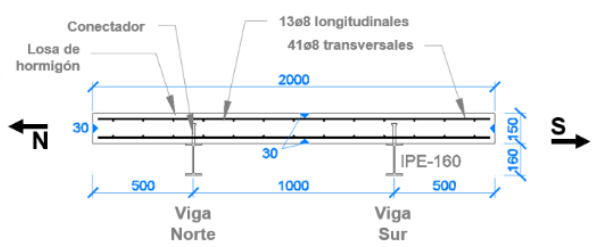

(b) Detalles del estribo

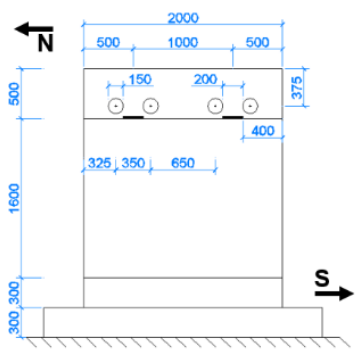

Figura 4-2. Puente experimental: (a) Alzado, (b) Detalles del estribo y (c) Detalles del tablero.

Todas las dimensiones se expresan en mm y todas las cotas se expresan en $\mathrm{m}$.

El acero empleado en las vigas y los pórticos auxiliares es 355JR. La losa y los estribos han sido diseñados con una resistencia a compresión característica a los 28 días con probeta cilíndrica de 25 y $30 \mathrm{MPa}$ respectivamente. Las barras de armado son B500S con $500 \mathrm{MPa}$ de resistencia característica. En la Sección 4.2.5 se puede consultar 
información adicional sobre las propiedades mecánicas de los materiales usados para construir el puente.

En lo que respecta al diseño del puente experimental, cabe destacar que:

1. El sistema estructural empleado se emplea con frecuencia en puentes de luces cortas y medias (Taly [ref4.10] y Llago and García [ref4.11]). Este sistema es diferente del empleado para losas mixtas en edificación (consultar Taranath [ref4.12] para más información) en el que la losa de hormigón se apoya en una chapa nervada anclada o soldada a las vigas en doble $\mathrm{T}$.

2. Los puentes multiviga con vigas en doble $\mathrm{T}$ no tienen generalmente ningún tipo de protección frente al fuego, por lo que los elementos metálicos son susceptibles de sufrir una exposición directa al fuego.

3. El puente no se ha diseñado empleando un criterio de escalado a partir de un puente específico de mayores dimensiones.

4. El puente se ha diseñado sin diafragmas transversales, a pesar de que son habituales en esta tipología, con el fin de simplificar al máximo la estructura. Estos elementos pueden bloquear el flujo de gases calientes entre dos vigas adyacentes durante un incendio según su diseño y por lo tanto influir en las temperaturas del gas en el entorno de la estructura.

\subsubsection{Proceso constructivo}

El puente se ha construido según la siguiente secuencia (ver Figura 4-3):

1. Disposición del encofrado necesario para la losa de nivelación y hormigonado de la misma para obtener una superficie horizontal de referencia

2. Disposición del encofrado de las zapatas de los estribos y hormigonado posterior

3. Disposición del encofrado de los estribos y hormigonado posterior. Los estribos sirven de base tanto para el tablero del puente como para los pórticos auxiliares dispuestos para la medición de flechas del tablero durante los ensayos.

4. Disposición de las vigas sobre los estribos mediante el empleo de 4 neoprenos y de los pórticos auxiliares mediante uniones atornilladas.

5. Disposición del encofrado de la losa soportado por puntales

6. Materialización de agujeros de $4 \mathrm{~mm}$ de diámetro en 6 de los redondos longitudinales empleados en el refuerzo longitudinal de la losa de hormigón y en 3 de los conectadores

7. Preparación del armado de la losa de hormigón con un recubrimiento de $30 \mathrm{~mm}$

8. Colocación de nueve termopares (TCs) para medir las temperaturas en el armado longitudinal (6 TCs) y en las cabezas de los conectadores (3 TCs) y 
protección de las conexiones extremas de los termopares para evitar daños durante el vertido del hormigón de la losa

9. Vertido y curado del hormigón de la losa

10. Retirada del encofrado y de los puntales 50 días después del hormigonado

\subsubsection{ESCENARIOS DE FUEGO}

\subsubsection{ENSAYOS PRELIMINARES}

Antes de realizar los ensayos de fuego con puente se realizaron una serie de ensayos preliminares con el fin de:

1. Verificar que las cargas de fuego corresponden con los valores teóricos definidos para la gasolina

2. Confirmar que es posible realizar una ignición controlada en condiciones de seguridad de la estructura, de la instrumentación y de las personas.

3. Asegurar que la protección de la báscula (ver Sección 4.2.3.1) permite mantener el ordenador y la célula de carga por debajo de $\operatorname{los} 40^{\circ} \mathrm{C}$.

Tras los ensayos preliminares (ver Figura 4-4) se concluye que:

1. Vientos por encima de $2 \mathrm{~m} / \mathrm{s}$ inclinan apreciablemente las llamas distorsionando los resultados que se alcanzarían sin la influencia del viento. Por esta razón, el inicio de cada uno de los ensayos con puente se condicionó a no superar el valor de $2 \mathrm{~m} / \mathrm{s}$. Adicionalmente se dispuso una valla de $2 \mathrm{~m}$ de altura con el fin de reducir el efecto de las rachas de viento durante los ensayos con puente.

2. La ignición de la gasolina en las bandejas de combustible debería realizarse por el personal del Departamento de Bomberos Municipal con el fin de garantizar la seguridad del equipamiento empleado y de las personas. Ya que la gasolina libera gases inflamables a temperatura ambiente los ensayos deben empezar inmediatamente después de verter el combustible

3. Las temperaturas de la báscula de pesaje siempre han sido inferiores a $\operatorname{los} 40^{\circ} \mathrm{C}$, por lo que se considera que la protección ha sido adecuada. 


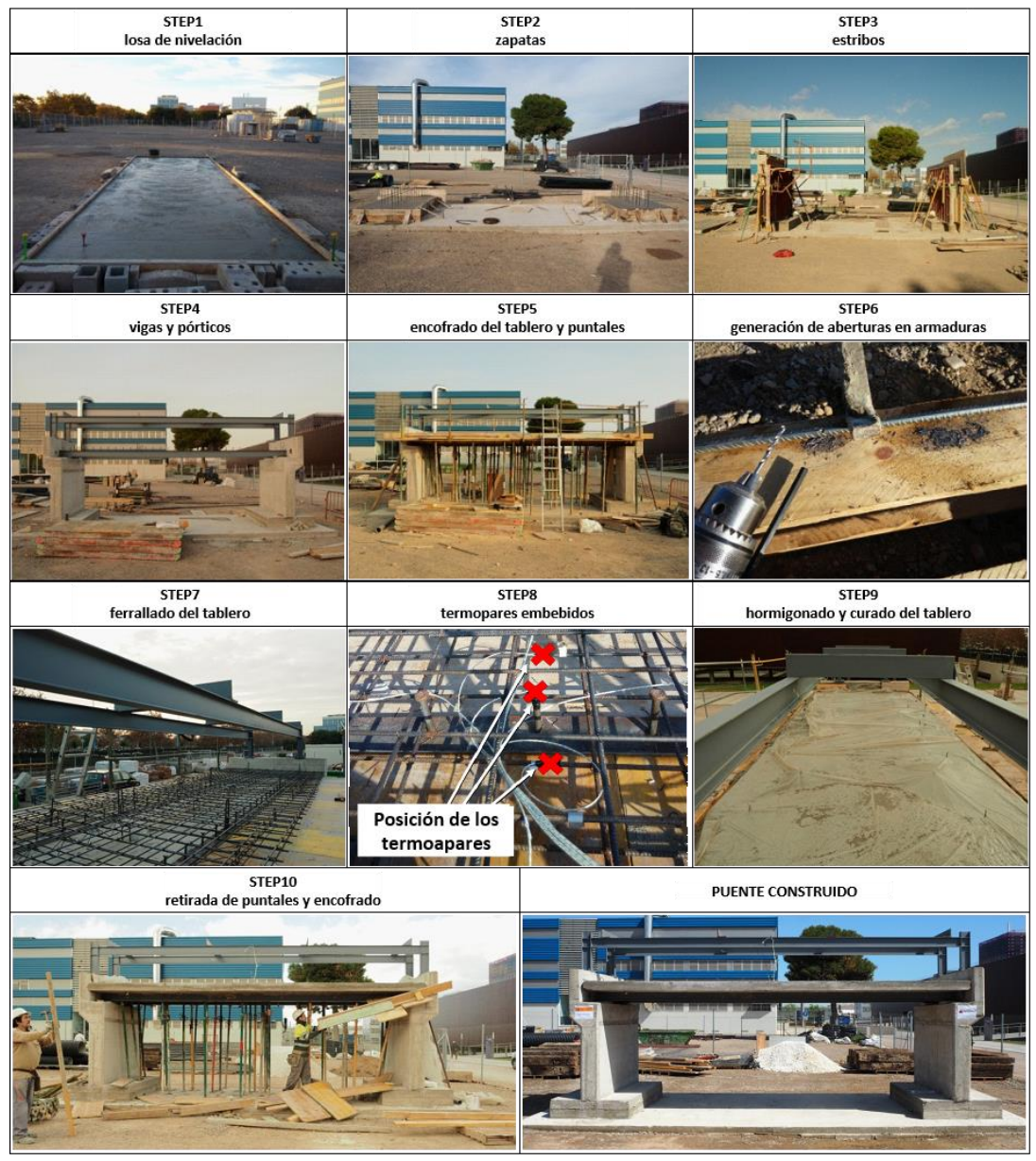

Figura 4-3. Proceso constructivo del puente experimental

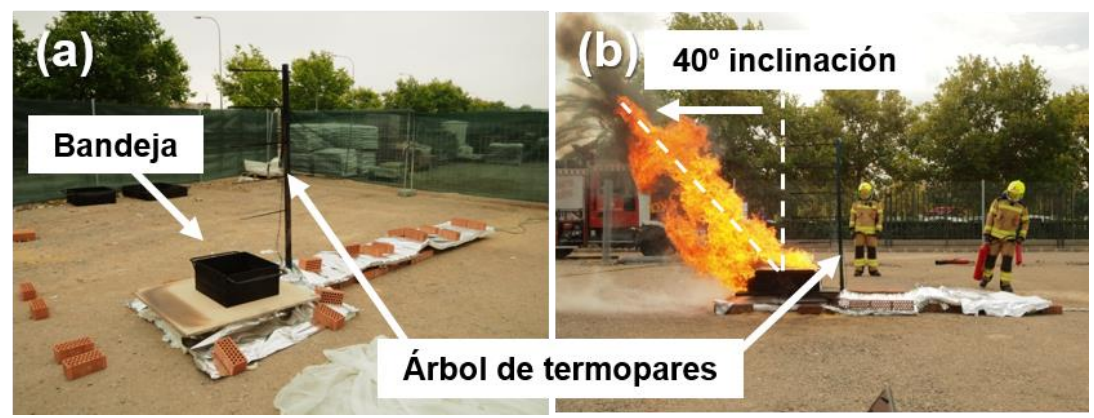

Figura 4-4. Ensayos preliminares: (a) Elementos y (b) vista de uno de los ensayos 


\subsubsection{ENSAYOS CON PUENTE}

El puente experimental ha sido sometido a ocho ensayos agrupados en cuatro escenarios de fuego, involucrando diferentes magnitudes y posiciones de carga de fuego (ver Tabla 4-1 y Figura 4-5). La carga de fuego siempre se ha localizado debajo del puente teniendo en cuenta el estudio realizado por Peris-Sayol et al. [ref4.05] en el que se demuestra que los accidentes más graves son aquellos en los que la carga de fuego está total o parcialmente debajo del puente.

Dadas las diferencias entre los incendios en puentes, edificios y túneles (ver Tabla 4-1), las pruebas de fuego utilizadas para estudiarlos deberían ser diferentes. En este sentido, la presente campaña experimental difiere de trabajos experimentales correspondientes al ámbito de la edificación (ver Nadjai et al. [ref4.13], Li et al. [ref4.14], Baley y Toh [ref4.15]) en los siguientes aspectos:

1. Las características generales del sistema estructural probado

2. El uso de gasolina como carga de fuego

3. Calentamiento del puente no uniforme a lo largo de toda la longitud.

4. Ensayos de fuego al aire libre y no en un horno o compartimento.

La magnitud de la carga de fuego se define por la tasa de liberación de calor (HRR). Los ensayos de fuego con puente involucraron dos bandejas de combustible cuadradas de 0.5 m y $0.75 \mathrm{~m}$. Considerando la corrección de la potencia necesaria para cargas de fuego de pequeña superficie (ver Drysdale [ref4.16]) la potencia teórica es de $415 \mathrm{~kW}$ y $1131 \mathrm{~kW}$ de potencia respectivamente.

\begin{tabular}{|c|c|c|c|c|c|c|c|c|}
\hline \multirow{2}{*}{$\begin{array}{c}\text { Escenario } \\
\text { fuego }\end{array}$} & \multirow{2}{*}{$\begin{array}{c}\text { Ancho bandeja } \\
s(\mathrm{~m})\end{array}$} & \multirow{2}{*}{$\begin{array}{c}\text { Posición } \\
\text { fuego }\end{array}$} & \multirow{2}{*}{$\begin{array}{l}\text { HRR } \\
(\mathbf{k W})\end{array}$} & \multirow{2}{*}{ Ensayo } & \multirow{2}{*}{$\begin{array}{l}\text { Tablón de } \\
\text { protección }\end{array}$} & \multirow{2}{*}{$\begin{array}{c}\text { Distancia al } \\
\text { estribo este (m) }\end{array}$} & \multicolumn{2}{|c|}{ Posición bandeja } \\
\hline & & & & & & & $\mathbf{x}(\mathbf{m})$ & $z(\mathbf{m})$ \\
\hline \multirow{2}{*}{ Fire 1} & \multirow{2}{*}{0.5} & \multirow{2}{*}{ CL } & \multirow{2}{*}{415} & 1 & no & - & \multirow{2}{*}{3.00} & \multirow{2}{*}{0.2} \\
\hline & & & & 2 & no & - & & \\
\hline \multirow{2}{*}{ Fire 2} & \multirow{2}{*}{0.75} & \multirow{2}{*}{ CL } & \multirow{2}{*}{1131} & 3 & no & - & \multirow{2}{*}{3.00} & \multirow{2}{*}{0.2} \\
\hline & & & & 4 & no & - & & \\
\hline \multirow{3}{*}{ Fire 3} & \multirow{3}{*}{0.5} & \multirow{3}{*}{ lateral } & \multirow{3}{*}{415} & 5 & $1.65 \mathrm{~m}$ Este & 0.33 & 5.27 & \multirow{3}{*}{0.5} \\
\hline & & & & 6 & $1.65 \mathrm{~m}$ Este & 0.01 & 5.59 & \\
\hline & & & & 7 & no & 0.01 & 5.59 & \\
\hline Fire 4 & 0.75 & $\mathrm{CL}$ & 1131 & 8 & no & - & 3.00 & 0.8 \\
\hline
\end{tabular}

Tabla 4-1. Escenarios de fuego de la campaña experimental "Valencia bridge fire tests"

La posición de carga de fuego se define por:

1. La cota de la base (coordenada " $z$ ") de la bandeja de combustible a partir de la losa de nivelación varía entre $0.2 \mathrm{~m}, 0.5 \mathrm{~m}$ y $0.8 \mathrm{~m}$ (cara superior de la losa de nivelación). 
2. La coordenada "x" (ver Figura 4-2) del eje que marca el centro de la bandeja de combustible adopta valores de $3.00 \mathrm{~m}$ para fuego en CL y de $5.27 \mathrm{~m}$ y $5.59 \mathrm{~m}$ para los fuegos próximos al estribo este (ver Tabla 4-1).

Adicionalmente, cabe destacar que:

1. Las magnitudes de carga de fuego empleadas en los experimentos son más pequeñas que la carga de fuego correspondiente a un camión cisterna estándar de transporte de gasolina. Suponiendo que la superficie del camión cisterna es de $30 \mathrm{~m}^{2}(12 \times 2.5 \mathrm{~m})$ y considerando una HRRPUA de $2400 \mathrm{~kW} / \mathrm{m}^{2}$ [ref4.17], la HRR resultante es de $72 \mathrm{MW}$. La gran diferencia en valor absoluto entre una HRR observable en un evento real (72 MW) y la potencia máxima empleada en los ensayos (1.1 MW) se debe a los siguientes motivos:

a. La realización de diversos ensayos de fuego empleando un mismo tablero sin que el estado o la geometría del mismo sufra modificaciones significativas entre los distintos ensayos.

b. Las temperaturas en las vigas de acero en el último ensayo (Test 8) han sido del mismo orden de magnitud de las estimadas en incendios reales, como se explica en la Sección 4.3.2.3.

c. Como muestra la Figura 4-5, la carga de fuego empleada ha sido suficiente para que las llamas impacten en el tablero, como suele ocurrir en los incendios de camiones cisterna debajo de puentes

d. Cargas de incendio de mayor magnitud han sido descartadas en la presente campaña experimental por cuestiones económicas, ambientales y de seguridad.

2. Se han realizado dos ensayos para los escenarios de fuego "Fire 1" " "Fire 2".

3. El escenario de fuego "Fire 3" se ha llevado a cabo para estudiar:

a. El efecto de los estribos sobre el fuego, con tres pruebas a diferentes distancias entre el borde de la bandeja y el estribo este $(0.33$ o $0.01 \mathrm{~m})$.

b. La presencia de un tablón aislante que protegía parcialmente el tablero entre ambas vigas en la zona este

4. El escenario de fuego "Fire 4", con una exposición térmica más severa, se ha incluido al final de la campaña experimental con el objetivo de someter al tablero a unas condiciones de incendio similares a las estimadas en accidentes previamente estudiados [ref4.04, ref4.08, ref4.18]. 


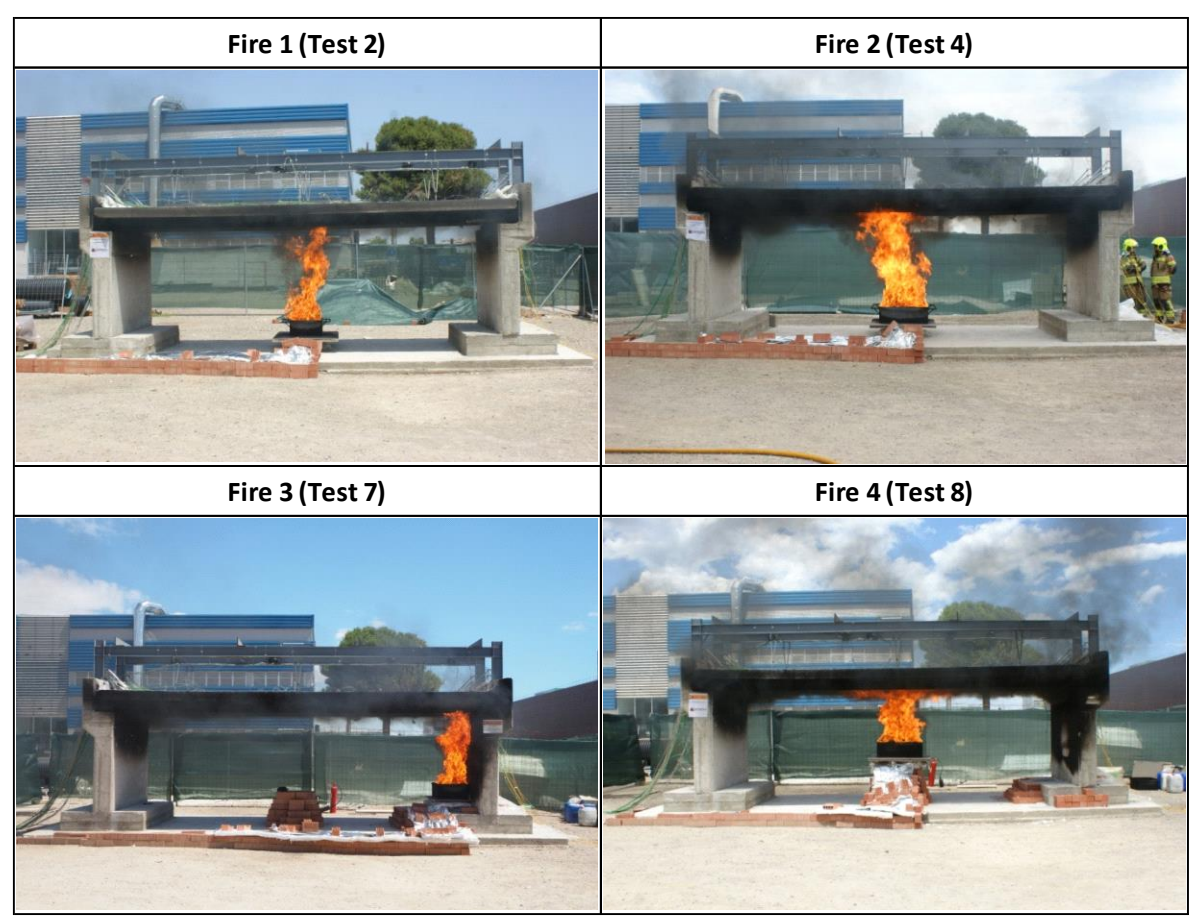

Figura 4-5. Vistas frontales de cada escenario de fuego

\subsubsection{INSTRUMENTACIÓN}

Durante los ensayos se registraron continuamente tres variables:

1. La masa del combustible

2. Le temperatura del entorno de las vigas del tablero y de las propias vigas

3. Las flechas en varios puntos del tablero

Para ello se emplearon respectivamente:

1. Una báscula industrial

2. 72 termopares y 17 sensores de fibra óptica de altas temperaturas

3. 22 LVDT

A continuación, se incluye información sobre la ubicación e instalación de los sistemas de monitoreo, excepto los del nuevo diseño de sensores de fibra óptica, ya que estos se consideraron como instrumentación adicional que se estudiarán por separado en otra línea de investigación 


\subsubsection{BÁSCULA}

Se empleó una báscula industrial PCE-SD 300C, capaz de pesar hasta $300 \mathrm{~kg}$ con una precisión de $100 \mathrm{~g}$, para medir la tasa de pérdida de masa durante las pruebas. Como la báscula no fue diseñada para soportar temperaturas superiores a $\operatorname{los} 40^{\circ} \mathrm{C}$, se ha protegido durante los ensayos mediante manta ignífuga con paneles de silicato alcalinotérreo incombustible (ver Figura 4-6). Esta misma protección se ha empleado para proteger el cable que transmitía la señal desde la báscula a través de la zona de mayor exposición térmica. Se han empleado, además, ladrillos cerámicos para proteger el cable y la propia báscula, así como para elevar la balanza al nivel apropiado en cada ensayo de fuego. La cobertura de aluminio se ha empleado para reflejar el calor recibido por radiación. Durante los ensayos, se han empleado dos termopares para asegurar que las temperaturas en la célula de carga y en el ordenador de la báscula no excedieran los $40^{\circ} \mathrm{C}$ en ningún momento durante los ensayos.

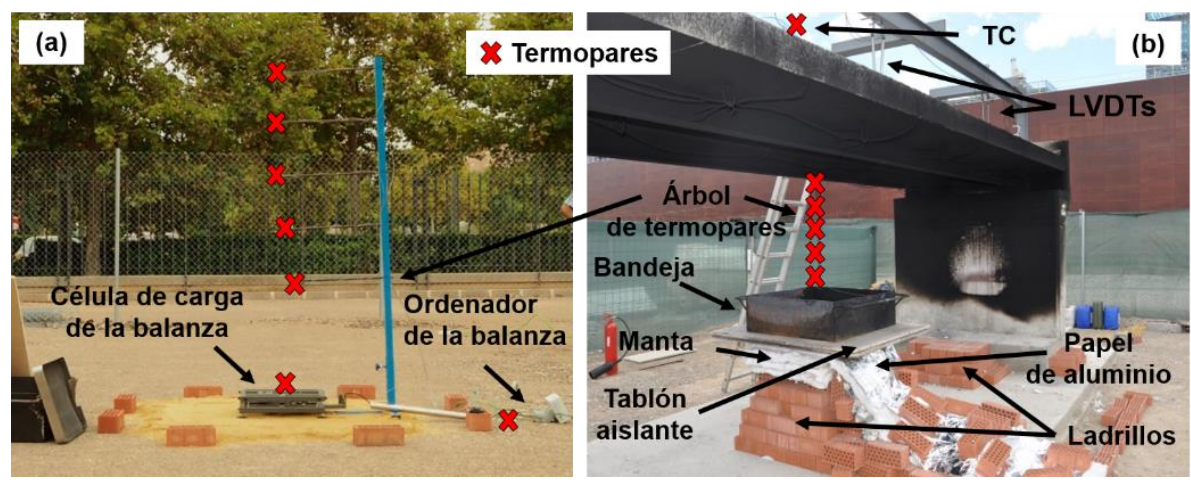

Figura 4-6. (a) Báscula antes de incluir la protección para los Ensayos preliminares. (b) Protección de la báscula con manta aislante, tablones aislantes, ladrillos y papel de aluminio.

\subsubsection{TERMOPARES}

Para medir temperaturas se instalaron un total de 72 termopares tipo K, cuatro de los cuales registraron la temperatura en la báscula y encima de la plataforma, 23 midieron las temperaturas del gas alrededor del puente, 28 en las vigas de cubierta de acero, 3 en los pernos de corte y 6 en las barras de refuerzo. También se utilizó un termopar de referencia para registrar la temperatura ambiente. Siete termopares se usaron para verificar el funcionamiento correcto de los sensores de fibra óptica de alta temperatura. La Tabla 4-2 proporciona las características principales de los termopares utilizados. Para mayor información consultar desde la Sección 4.2.3.2.1 hasta la Sección 4.3.2.4 para más detalles. 


\begin{tabular}{|c|c|c|c|c|}
\hline Medición & Distribución & Posición & Cantidad & Nomenclatura* \\
\hline Báscula & Fig. 3-7a & protegida por material aislante & 2 & SCALE1, SCALE2 \\
\hline LVDT & Fig. 3-7b & sobre el tablero & 2 & LVDT1, LVDT2 \\
\hline \multirow{4}{*}{ Gas } & \multirow{4}{*}{ Fig. 3-8 } & árbol de termopares vertical & 5 & $\mathrm{~V} 1$ to $\mathrm{V} 5$ \\
\hline & & región sur & 6 & GS1 to GS6 \\
\hline & & región central & 6 & GC1 to GC6 \\
\hline & & región norte & 6 & GN1 to GN6 \\
\hline \multirow{6}{*}{ Acero } & \multirow{6}{*}{ Fig. 3-9 } & viga sur - ala inferior & 6 & SG-BF1 to SG-BF6 \\
\hline & & viga sur - alma & 2 & SG-W1 to SG-W6 \\
\hline & & viga sur - ala superior & 6 & SG-TF1 to SG-TF6 \\
\hline & & viga norte - ala inferior & 6 & NG-BF1 to NG-BF6 \\
\hline & & viga norte - alma & 2 & NG-W1 to NG-W6 \\
\hline & & viga norte - ala superior & 6 & NG-TF1 to NG-TF6 \\
\hline \multirow{2}{*}{ Losa } & \multirow{2}{*}{ Fig. 3-10 } & armaduras en $\mathrm{CL}$ & 6 & RB1 to RB6 \\
\hline & & conectores en CL & 3 & $\mathrm{SS} 1$ to SS3 \\
\hline Fibra óptica & - & $\begin{array}{c}\text { próximos a los sensores } \\
\text { de fibra óptica }\end{array}$ & 7 & $\mathrm{TC}-1$ to $\mathrm{TC}-7$ \\
\hline Referencia & Fig. 3-12 & en la mesa de control & 1 & REF \\
\hline
\end{tabular}

Tabla 4-2. Distribución de termopares

\subsection{TERMOPARES DE CONTROL}

Se emplearon cinco termopares de control. Un termopar de referencia fue empleado para medir la temperatura ambiente, dos para verificar que la temperatura de la báscula permaneció por debajo de $40^{\circ} \mathrm{C}$ y otros dos para monitorear las temperaturas alrededor de los LVTD.

\subsubsection{TERMOPARES DE GAS}

Para caracterizar el campo térmico bajo la losa del tablero se emplearon 23 termopares dispuestos en siete árboles de termopares (TCT): seis se colocaron horizontalmente a $2.00 \mathrm{~m}$ sobre el nivel de referencia en las posiciones que se muestran en la Figura 4-7 y se colocó un séptimo verticalmente sobre la bandeja de combustible (ver también en Figura 4-7). La Tabla 4-3 muestra las coordenadas "x" y "z" de los termopares del árbol de termopares vertical, siendo el termopar V1 el más próximo a la bandeja de combustible y el V5 el más alejado.

La nomenclatura de los termopares colocados en el gas tiene tres partes (Figura 4-7):

1. El tipo de registro de la temperatura se indica mediante el primer carácter:

a. G: Gas 
2. La zona del termopar se indica mediante un segundo carácter:
a. N: Norte (North)
b. C: Central (Central)
c. S: Sur (South)

3. La sección se indica al final con un carácter numérico entre 1 y 6

a. 1 indica sección $\mathrm{S} 1$ situada a $\mathrm{x}=0.5 \mathrm{~m}$

b. 6 indica sección $\mathrm{S} 6$ situada a $\mathrm{x}=5.5 \mathrm{~m}$

c. El resto de secciones intermedias se encuentran equiespaciadas $1.0 \mathrm{~m}$

(a) Alzado

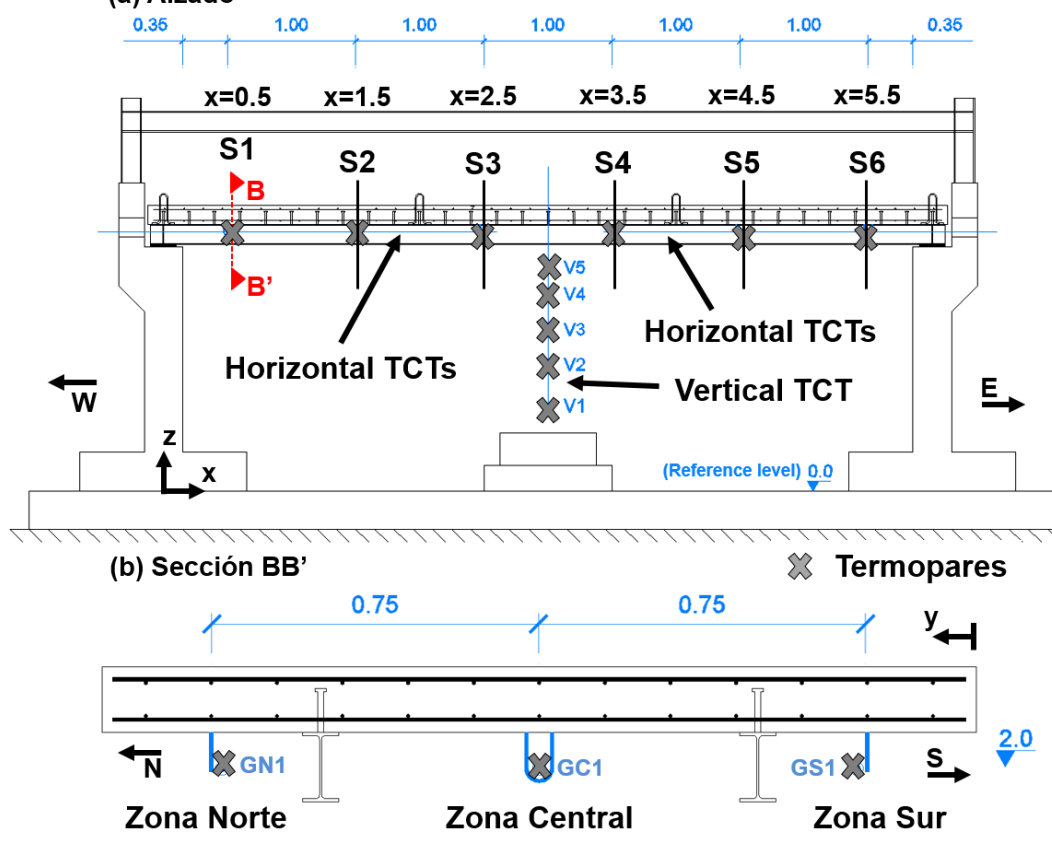

Figura 4-7. Distribución de termopares en el gas. Dimensiones en m.

\begin{tabular}{cccc}
\hline \multirow{2}{*}{ nombre } & \multicolumn{3}{c}{ coordenada z (m) } \\
& Fire 1 \& 2 & Fire 3 & Fire 4 \\
\hline V5 & 1.73 & 1.95 & 1.89 \\
V4 & 1.54 & 1.69 & 1.73 \\
V3 & 1.24 & 1.41 & 1.54 \\
V2 & 0.99 & 1.13 & 1.44 \\
V1 & 0.65 & 0.85 & 1.25 \\
\hline
\end{tabular}

Tabla 4-3. Posición vertical de los termopares del árbol de termopares vertical. 


\subsection{TERMOPARES EN EL ACERO}

Para realizar la medición de las temperaturas del acero se instalaron 28 termopares agrupados en las mismas secciones transversales empleadas para registrar las temperaturas de los gases. Los termopares se distribuyeron simétricamente en ambas vigas según dos distribuciones de termopares en sección (ver Figura 4-8).

1. Sección Tipo A (SA). Esta sección incluye tres termopares situados en las intersecciones del alma con ambas alas y en el centro del alma de cada una de las dos vigas

2. Sección Tipo B (SB). Esta sección incluye dos termopares situados en la intersección entre el alma y el ala inferior y en el centro del alma de cada una de las dos vigas.

La nomenclatura de los termopares colocados en el acero tiene tres partes:

1. Los dos primeros caracteres identifican la viga:

a. SG: viga sur

b. NG: viga del norte

2. La posición está indicada por uno o dos caracteres adicionales:

a. BF: Ala inferior (Bottom Flange)

b. W: Alma (Web)

c. TF: Ala superior (Top Flange)

3. La sección se indica al final con un carácter numérico entre 1 y 6

a. 1 indica sección $\mathrm{S} 1$ situada a $\mathrm{x}=0.5 \mathrm{~m}$

b. 6 indica sección $\mathrm{S} 6$ situada a $\mathrm{x}=5.5 \mathrm{~m}$

c. El resto de secciones intermedias se encuentran equiespaciadas $1.0 \mathrm{~m}$

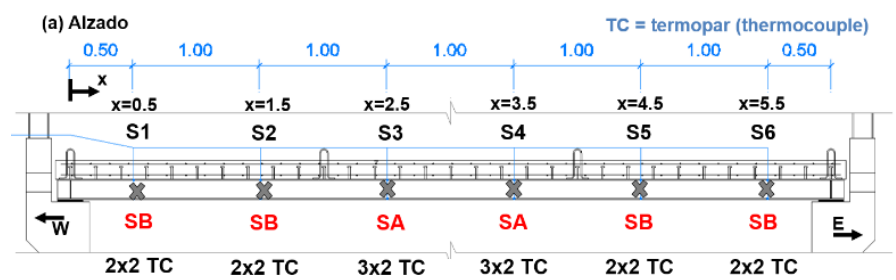

$\begin{array}{ll}\text { (b) Sección tipo } A & \text { (c) Sección tipo } B\end{array}$

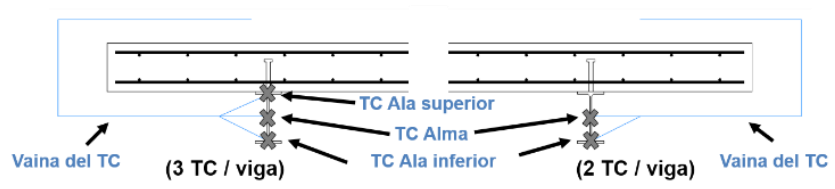

Figura 4-8. Distribución de termopares en el acero. Dimensiones en m. 


\subsection{TERMOPARES EN EL HORMIGÓN}

Los termopares embebidos en el hormigón se han dispuesto bien en las armaduras longitudinales inferiores de la losa (6 termopares) en la sección de CL $(\mathrm{x}=3.0 \mathrm{~m})$ bien en las cabezas de los conectores empleados para unir solidariamente las vigas a la losa (3 termopares). La distribución de todos los termopares se detalla en la Figura 4-9.

La nomenclatura de los termopares en el hormigón es la siguiente:

1. Los dos primeros caracteres identifican donde se encuentra en termopar:

a. RB: En armadura longitudinal (Rebar)

b. SS: En la cabeza del conector (Shear Stud)

2. El tercer carácter es numérico y, junto con la Figura 4-9, permite situar el termopar dentro de la losa de hormigón

a. De 1 a 6 si está en la armadura longitudinal

b. De 1 a 3 si está en la cabeza de algún conector

(a) Vista en planta

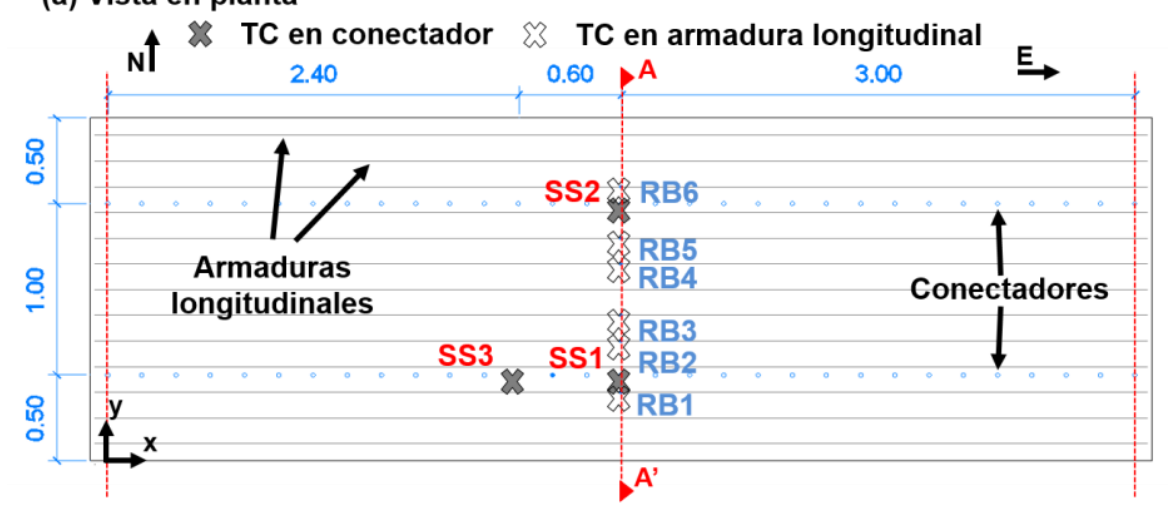

(b) Sección AA'

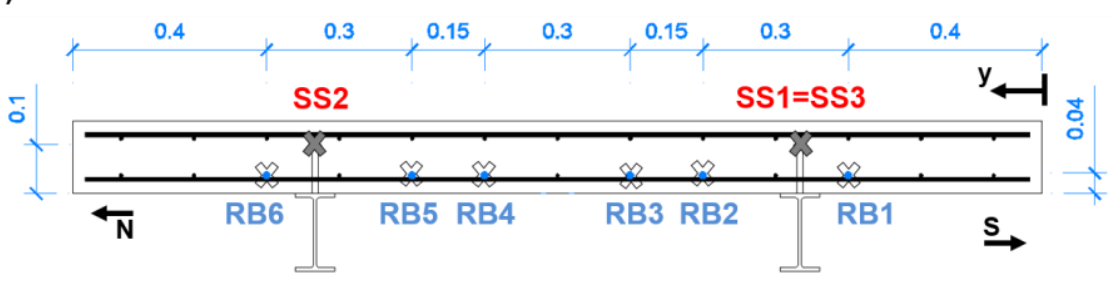

Figura 4-9. Distribución de termopares en la losa de hormigón. Dimensiones en m. 


\subsubsection{LVDT}

Las flechas del tablero se registraron mediante 22 LVDTs de $300 \mathrm{~mm}$ de rango de medición dispuestos de acuerdo a los siguientes criterios (ver Figura 4-10):

1. Dos LVDTs (L21 y L22) sobre los elementos horizontales de los pórticos de acero auxiliares para detectar incrementos de longitud de los propios elementos horizontales derivados de las dilataciones térmicas que podrían producirse durante las pruebas.

2. Ocho LVDTs (L1, L2, L3, L4, L17, L18, L19, L20) midieron los movimientos horizontales del tablero en las juntas de expansión.

3. Doce LVDTs (L5, L6, L7, L8, L9, L10, L11, L12, L13, L14, L15, L16) se organizaron en pares en forma de $\mathrm{V}$ a lo largo de tres secciones en cada viga. De esta forma no solo se duplicaba el número de mediciones sobre cada punto, sino que se podían medir los desplazamientos horizontales.

(a) Alzado del pórtico norte

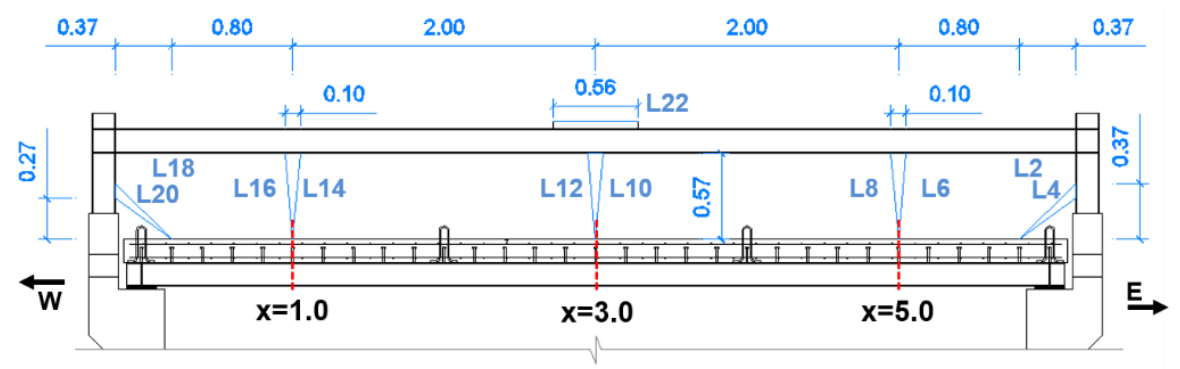

(b) Alzado del pórtico sur

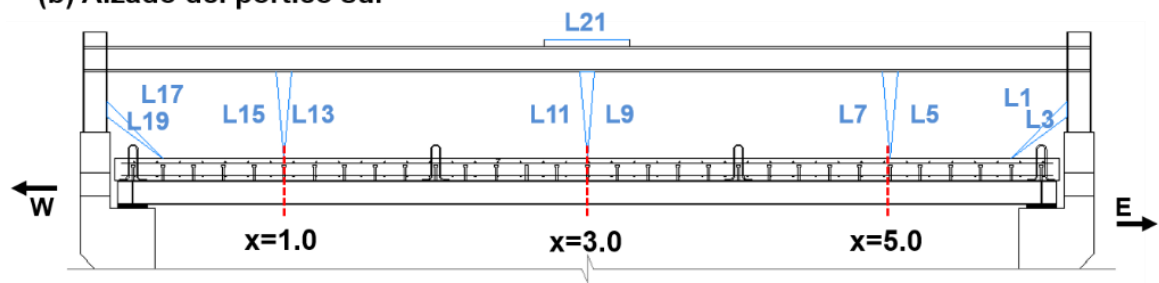

Figura 4-10. Distribución de LVDT. Dimensiones en $m$.

\subsubsection{SENSORES DE FIBRA ÓPTICA DE ALTAS TEMPERATURAS}

Adicionalmente a los sensores previamente detallados, se instalaron una serie de sensores de fibra óptica de alta temperatura para medir las temperaturas del hormigón, 
del gas del acero. Estos sensores son similares a los detallados por Rinaudo et al. [ref4.19-ref4.20] y se colocaron en las siguientes ubicaciones:

1. Dos sensores multiplexados se ubicaron en la sección de medio tramo incrustados en la losa de concreto y midieron las temperaturas del concreto. Cada sensor tenía tres rejillas de Bragg, permitiendo medir en tres ubicaciones diferentes.

2. Un sensor multiplexado estaba ubicado en la Sección S3 (ver Figura 4-7), a 0.5 $\mathrm{m}$ de la sección del puente de media luz. Este sensor tenía dos rejillas de Bragg regeneradas (RFBG en lo sucesivo) y midió la temperatura del gas en dos puntos diferentes, ubicados a 5 y $10 \mathrm{~cm}$ de distancia de la cara inferior de la losa de hormigón.

3. Un sensor multiplexado estaba ubicado en la Sección S2 (ver Figura 4-7), ubicado a $1.5 \mathrm{~m}$ de distancia de la sección de CL. Este sensor tenía tres RFBG y midió la temperatura del gas en tres puntas diferentes, ubicadas a 5,9 y $13 \mathrm{~cm}$ de distancia de la cara inferior de la losa de hormigón.

4. Dos sensores, con una RFBG por sensor, se ubicaron en la unión de la brida inferior y la red de cada viga de acero. Los sensores estaban a $1.5 \mathrm{~m}$ del estribo este y midieron las temperaturas del acero.

5. Dos sensores multiplexados con dos RFBG por sensor se ubicaron en la unión del ala inferior y del alma de cada viga de acero. Cada uno de estos dos sensores midió las temperaturas en puntos ubicados a 1.5 y $2.0 \mathrm{~m}$ del estribo este.

El objetivo de instalar sensores de fibra óptica era probar su funcionamiento en condiciones reales de incendio. Estos sensores se instalaron como un registro redundante, por lo que no fueron necesarios para investigar la respuesta experimental del puente durante las pruebas de fuego. Un análisis detallado de su comportamiento será objeto de estudio en próximas investigaciones.

\subsubsection{REGISTRO DE DATOS}

Para la adquisición de datos se han empleado tres sistemas distintos para termopares, para LVDT y para los sensores de fibra óptica. Las lecturas se almacenaron en distintos equipos separadas debido a la gran cantidad de datos involucrados. Las temperaturas registradas por los termopares fueron registradas por nueve módulos de ocho canales: siete módulos "USB TC-08" y dos "FP-TC-120". Los desplazamientos detectados por los LVDT se registraron mediante un solo módulo cDaq-9205 de 32 canales. Las lecturas de temperatura de los módulos USB TC-08 pudieron monitorearse durante la prueba mediante el software Picolog en los módulos USB TC-08, mientras que el resto de las lecturas pudieron visualizarse con el software CEAD 11.36L desarrollado por personal de ICITECH. 

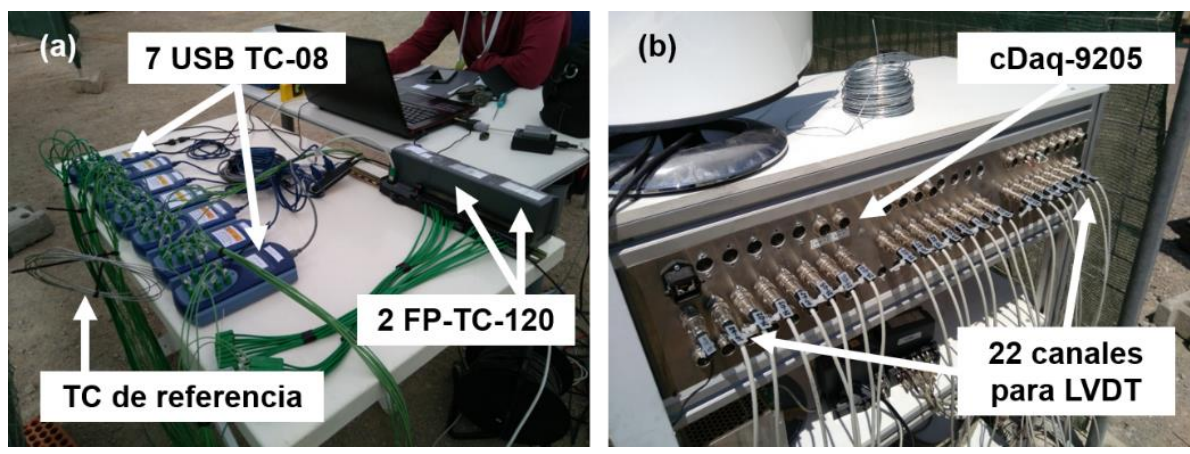

Figura 4-11. (a) Nueve "dataloggers" de termopares de ocho canales y (b) 22 extensiones de LVDT conectadas a un módulo de adquisición de 32 canales.

\subsubsection{ENSAYOS DE LABORATORIO}

Se obtuvieron cuatro probetas cilíndricas de hormigón de $15 \mathrm{~cm}$ de diámetro x $30 \mathrm{~cm}$ de largo que se mantuvieron cerca del tablero con el fin de someterse a las mismas condiciones ambientales. Las probetas proporcionaron una resistencia a la compresión media de $33 \mathrm{MPa}$, así como un módulo de elasticidad promedio de $33.8 \mathrm{GPa}$.

Cuatro muestras del alma y otras cuatro de ala inferior fueron tomadas del perfil IPE160 del lote al que pertenecían las vigas del tablero. A partir de ellas y mediante ensayos de tracción se obtuvieron límites elásticos de 377 y 344 MPa y una resistencia promedio de 512 y $465 \mathrm{MPa}$ en alas y almas, respectivamente.

Se ensayaron a tracción cuatro barras de armado de $8 \mathrm{~mm}$ de diámetro y tres barras de $12 \mathrm{~mm}$ de diámetro del lote de acero B500S utilizado para el refuerzo de la losa del tablero, obteniendo límites elásticos a tracción promedio de 546 y 537 MPa y resistencias últimas a tracción promedio de 644 y $624 \mathrm{MPa}$ para las barras de 8 y 12 mm de diámetro respectivamente

\subsection{RESULTADOS Y DISCUSIÓN}

\subsubsection{TASA DE PÉRDIDA DE MASA}

La Tabla 4-4 compara la pérdida de masa por unidad de superficie y de tiempo obtenida experimentalmente con la pérdida de masa por unidad de superficie y de tiempo teórica de acuerdo con [ref4.17]. En la tabla se incluyen los valores experimentales obtenidos en los ensayos sin puente (ver la Sección 4.2.2.1) para verificar si la presencia del puente influye o no en este valor. Se puede observar que los valores experimentales oscilan entre 
0.030 y $0.043 \mathrm{~kg} / \mathrm{m}^{2} \mathrm{~s}$ para la bandeja de $50 \mathrm{~cm}$ con un valor teórico de $0.038 \mathrm{~kg} / \mathrm{m}^{2} \mathrm{~s}$, mientras que para la bandeja de $75 \mathrm{~cm}$ los valores experimentales están entre $0.046 \mathrm{y}$ $0.055 \mathrm{~kg} / \mathrm{m}^{2} \mathrm{~s}$ con un valor teórico de referencia de $0.046 \mathrm{~kg} / \mathrm{m}^{2} \mathrm{~s}$. La Figura $4-12$ muestra las curvas a partir de las cuales se obtuvieron los valores incluidos en la Tabla 4-4 y las compara con los valores teóricos representados por las líneas de puntos.

\begin{tabular}{cccc}
\hline Ensayo & \multicolumn{2}{c}{ Tasa de pérdida de masa $\left(\mathbf{k g} / \mathbf{m}^{2} \mathbf{s}\right)$} & $\mathbf{( \% )}$ \\
experimental & teórica & diferencia \\
\hline Preliminar 50 & 0.037 & 0.038 & $-2.5 \%$ \\
Test 1 & 0.043 & 0.038 & $13.3 \%$ \\
Test 2 & 0.039 & 0.038 & $1.5 \%$ \\
Test 5 & 0.041 & 0.038 & $8.5 \%$ \\
Test 6 & 0.030 & 0.038 & $-22.3 \%$ \\
Test 7 & 0.033 & 0.038 & $-12.3 \%$ \\
\hline Preliminar 75 & 0.050 & 0.046 & $8.6 \%$ \\
Test 3 & 0.052 & 0.046 & $13.9 \%$ \\
Test 4 & 0.046 & 0.046 & $0.9 \%$ \\
Test 8 & 0.055 & 0.046 & $18.7 \%$ \\
\hline
\end{tabular}

Tabla 4-4. Valores de tasa de pérdida de masa en los ensayos y diferencias expresadas en \% de los valores teóricos.

\begin{tabular}{|c|c|c|c|}
\hline \multirow{2}{*}{ Promedios } & \multicolumn{2}{|c|}{ Tasa de pérdida de masa $\left(\mathrm{kg} / \mathrm{m}^{2} \mathrm{~s}\right)$} & \multirow{2}{*}{$\begin{array}{c}(\%) \\
\text { diferencia }\end{array}$} \\
\hline & experimental & teórica & \\
\hline Bandeja 50cm (seis ensayos) & 0.037 & 0.038 & $-2.3 \%$ \\
\hline Bandeja $75 \mathrm{~cm}$ (cuatro ensayos) & 0.051 & 0.046 & $10.5 \%$ \\
\hline $\begin{array}{l}\text { Preliminar } 50, \\
\text { Test } 1, \text { Test } 2 \text { and Test } 5\end{array}$ & 0.038 & 0.038 & $0.0 \%$ \\
\hline $\begin{array}{l}\text { Preliminar } 75, \\
\text { Test } 3 \text { y Test } 4\end{array}$ & 0.050 & 0.046 & $7.8 \%$ \\
\hline Test 6 y Test 7 & 0.031 & 0.038 & $-17.3 \%$ \\
\hline
\end{tabular}

Tabla 4-5. Valores de tasa de pérdida de masa promedios y diferencias expresadas en \% de los valores teóricos. 
(a) Bandeja de $50 \mathrm{~cm}$

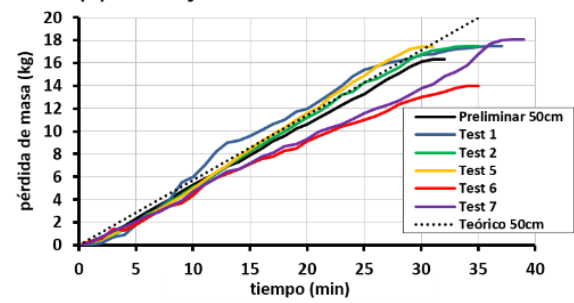

(b) Bandeja de $75 \mathrm{~cm}$

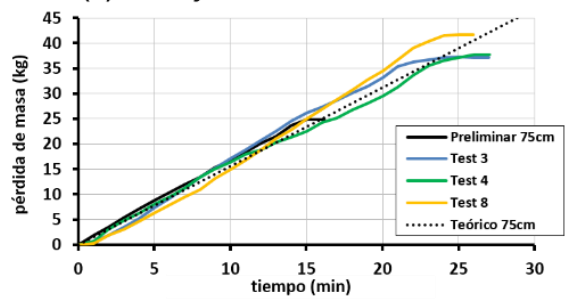

Figura 4-12. Registros de pérdida de masa para (a) ensayos con bandejas de 50cm de lado y (b) ensayos con bandejas de $75 \mathrm{~cm}$ de lado

En vista de los resultados, se puede concluir que:

1. Las tasas de pérdida de masa experimentales y teóricas son similares. Los valores promedios (ver Tabla 4-5) son iguales y un $7.8 \%$ mayores que los teóricos para las bandejas de 50 y $75 \mathrm{~cm}$, respectivamente, si los casos singulares (Test 6, Test 7 y Test 8), que han tenido un efecto considerable en la tasa de pérdida de masa, no se tienen en cuenta.

2. A pesar de haber reducido el efecto del viento respecto a los ensayos preliminares (ver Sección 4.2.2.1), se han registrado variaciones en la tasa de pérdida de masa media del $11.8 \%$ y $13.0 \%$ en los escenarios Fire 1 y Fire 2, respectivamente. En ambos casos, los ensayos con los vientos más fuertes (Test 1 y Test 3) mostraron el valor promedio más alto de pérdida de masa por unidad de área. En la Figura 4-13, se puede observar la pérdida de masa por unidad de área por minuto para los dos ensayos en cada uno de los escenarios (Fire 1 y Fire 2). Se incluye una recta horizontal para representar la pérdida de masa teórica por unidad de superficie en cada caso.

(a) Fire 1 (Test 1 y Test 2)

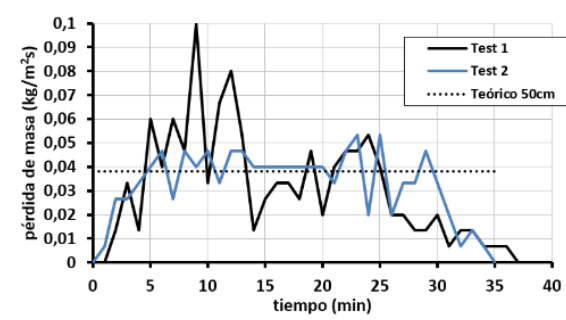

(b) Fire 2 (Test 3 y Test 4)

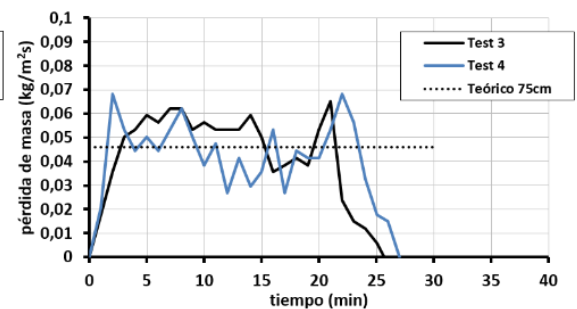

Figura 4-13. Registros de pérdida de masa para (a) escenario "Fire 1" y (b) escenario "Fire 2". 
3. Los ensayos Test 6 y Test 7, en las que la bandeja está cerca del estribo, muestran una tasa de pérdida de masa promedio $17 \%$ menor que el resto de casos con la bandeja de $50 \mathrm{~cm}$, debido a la falta de ventilación cuando la bandeja se encuentra cerca del estribo. Los ensayos Test 6 y Test 7, a la misma altura que el ensayo Test 5, tienen una tasa de pérdida de masa un $25.8 \%$ menor, debido a que el estribo reduce el suministro de oxígeno en aproximadamente un 25\% (uno de cuatro lados no admite la circulación de aire) al actuar como una barrera física que impide la circulación de aire.

4. El ensayo Test 8 tuvo una tasa de pérdida de masa un $10.9 \%$ más alta que la obtenida en los otros tres ensayos con la bandeja de $75 \mathrm{~cm}$, debido a que la carga de fuego se encuentra a menor distancia de las alas inferiores de las vigas (1.1 $\mathrm{m})$ respecto a los ensayos Test 3 y Test $4(1.7 \mathrm{~m})$ donde esta misma distancia es $0.6 \mathrm{~m}$ superior. Al estar las llamas más cerca de la losa de hormigón $(0.16 \mathrm{~m}$ por encima de las alas inferiores de las vigas), se extendieron más a lo largo de la superficie inferior del tablero, aumentando la temperatura y la dimensión de la superficie (correspondiente a la cara inferior de la losa entre ambas vigas) que irradia calor sobre el combustible de la propia bandeja.

\subsubsection{TEMPERATURAS}

\subsubsection{1. ÁRBOL DE TERMOPARES VERTICAL}

La Tabla 4-6 muestra los valores máximos registrados por los cinco termopares (V1 a V5) en el árbol de termopares vertical, mientras que la Figura 4-14 muestra la evolución temporal de estas temperaturas en los ensayos Test 7 y Test 8. La evolución de temperaturas en los ensayos Test 1, Test 2, Test 3, Test 4, Test 5 y Test 6 no se incluye al ser las curvas muy similares a las correspondientes al Test 7 .

\begin{tabular}{lccccc}
\hline \multirow{2}{*}{ Ensayo } & \multicolumn{5}{c}{${\text { Temperaturas }\left({ }^{\circ} \mathbf{C}\right)}$} \\
& V1 & V2 & V3 & V4 & V5 \\
\hline Test 1 & 786 & 597 & 431 & 282 & 280 \\
Test 2 & 765 & 535 & 455 & 315 & 308 \\
Test 3 & 796 & 873 & 813 & 745 & 758 \\
Test 4 & 863 & 886 & 840 & 743 & 702 \\
Test 5 & 813 & 711 & 568 & 596 & - \\
Test 6 & 848 & 774 & 704 & 604 & - \\
Test 7 & 847 & 649 & 675 & 527 & 589 \\
Test 8 & 908 & 885 & 901 & 908 & 926 \\
\hline
\end{tabular}

Tabla 4-6. Máximas temperaturas registradas por el árbol de termopares vertical. 
Las temperaturas máximas en los ensayos Test 7 y Test 8 han sido superiores a $800{ }^{\circ} \mathrm{C}$ y $900^{\circ} \mathrm{C}$, respectivamente. En el ensayo Test 7, las temperaturas de los sensores se reducen conforme se incrementa su distancia a la bandeja de combustible, con una separación entre los termopres de 5-30 cm entre los termopares. En el ensayo Test 8, las lecturas de todos los sensores son similares debido a que están dispuestos muy proximos entre ellos (65 cm entre el primero y el último) y a muy poca distancia de la bandeja de combustible

(a) Test 7

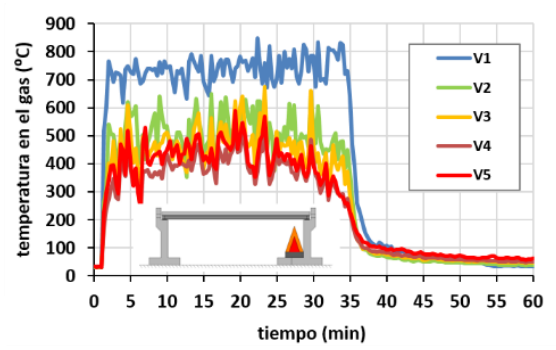

(b) Test 8

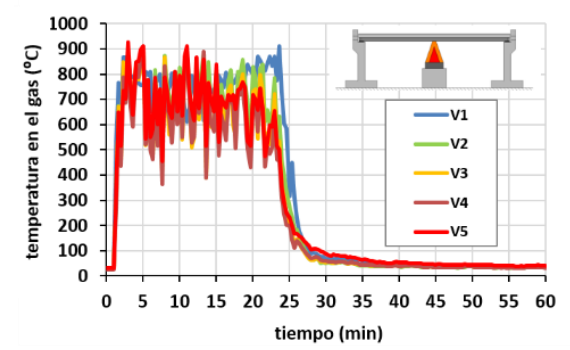

Figura 4-14. Temperaturas registradas mediante el árbol de termopares vertical: (a) Ensayo "Test 7"' y (b) Ensayo Test 8.

\subsubsection{TEMPERATURAS DEL GAS}

La Tabla 4-7 proporciona los valores máximos alcanzados por los seis termopares (GC1 a GC6) en el área central entre las dos vigas, mientras que la evolución de estas temperaturas en los ensayos Test 7 y Test 8 se muestra en la Figura 4-15.

\begin{tabular}{lcccccc}
\hline \multirow{2}{*}{ Ensayo } & GC1 & GC2 & GC3 & GC4 & GC5 & GC6 \\
\hline Test 1 & 141 & 175 & 268 & 288 & 166 & 139 \\
Test 2 & 164 & 205 & 326 & 288 & 172 & 148 \\
Test 3 & 264 & 362 & 607 & 644 & 378 & 279 \\
Test 4 & 279 & 389 & 707 & 737 & 431 & 323 \\
Test 5 & 99 & 105 & 115 & 139 & 200 & 224 \\
Test 6 & 93 & 93 & 102 & 115 & 162 & 153 \\
Test 7 & 133 & 151 & 184 & 234 & 289 & 546 \\
Test 8 & 422 & 639 & 941 & 921 & 594 & 504 \\
\hline
\end{tabular}

Tabla 4-7. Máximas temperaturas registradas en el gas entre las dos vigas. 
En la Figura 4-15, se puede ver como las temperaturas registradas por los termopares GC1 a GC6 disminuyen con la distancia horizontal desde la carga de fuego. Mientras que en el ensayo Test 7 (con la carga cerca del estribo del Este) las temperaturas disminuyen de $500{ }^{\circ} \mathrm{C}$ (GC6) a $280^{\circ} \mathrm{C}$ (GC5) en solo $1 \mathrm{~m}$, en el ensayo Test 8 caen de $900^{\circ} \mathrm{C}(\mathrm{GC} 3)$ a $550^{\circ} \mathrm{C}(\mathrm{GC} 2)$ en la misma distancia. Los gradientes térmicos para los ensayos Test 7 y Test 8 son por lo tanto $220^{\circ} \mathrm{C} / \mathrm{m}$ y $350{ }^{\circ} \mathrm{C} / \mathrm{m}$, respectivamente.
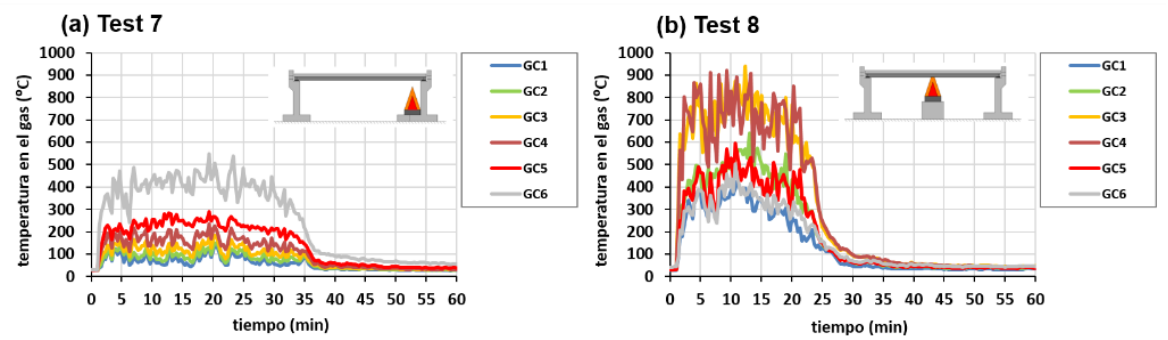

Figura 4-15. Temperaturas registradas en la región central (entre las dos vigas): (a) Ensayo "Test 7" y (b) Ensayo "Test 8".

La Figura 4-16a muestra las temperaturas máximas registradas en el gas en cada una de las tres regiones estudiadas (Norte, Sur, Este y Oeste) en el escenario de fuego Fire 2 (Test 3 y Test 4). Se puede ver que la región central sobre la carga de fuego presenta la temperatura más alta y que el viento ha inclinado las llamas hacia el sur. Las diferencias de temperatura máximas registradas entre los dos ensayos del escenario de fuego Fire 2 alcanzan $120^{\circ} \mathrm{C}$ en las zonas laterales y $60^{\circ} \mathrm{C}$ en la zona central. Estas diferencias de máximas temperaturas representan alrededor del $30 \%$ y del $10 \%$ de los valores máximos registrados en las zonas laterales y la zona central, respectivamente.

(a) Fire 2

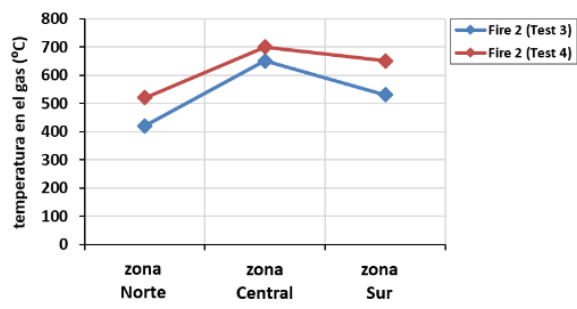

(b) Fire 1, Fire 2, Fire 3 y Fire 4

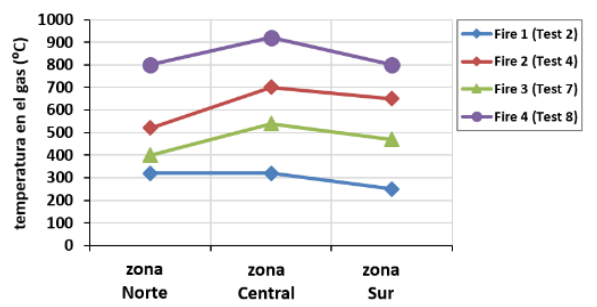

Figura 4-16. Temperaturas máximas registradas por región: (a) Escenario "Fire 2" y (b) cuatro escenarios de fuego.

La Figura 4-16b compara los diferentes escenarios de fuego en los ensayos Test 2, Test 4, Test 7 y Test 8, a partir de los cuales se pueden extraer las siguientes conclusiones: 
1. Las temperaturas máximas registradas por los árboles de termopares horizontales se encuentran en la región central y alcanzan $\operatorname{los} 910^{\circ} \mathrm{C}$ en el ensayo Test $8, \operatorname{los} 700{ }^{\circ} \mathrm{C}$ en el ensayo Test $4, \operatorname{los} 520^{\circ} \mathrm{C}$ en el ensayo Test $7 \mathrm{y}$ los $310^{\circ} \mathrm{C}$ en el ensayo Test 2 .

2. La caída de $210^{\circ} \mathrm{C}$ en la región central entre los ensayos Test 8 y Test 4 (ambos con la bandeja de $75 \mathrm{~cm}$ ) se debe a que la carga de fuego en el ensayo Test 8 se encuentra situada a $1.1 \mathrm{~m}$ por debajo de las alas inferiores de las vigas, mientras que en el ensayo Test 4 esta distancia es de $1.7 \mathrm{~m}$ (0.6 m superior)

3. La caída de $210^{\circ} \mathrm{C}$ en la región central entre los ensayos Test 7 y Test 2 (ambas con bandeja de $50 \mathrm{~cm}$ ) puede atribuirse a la mayor afección de las llamas en el ensayo Test 7 por dos motivos:

a. La bandeja de combustible es $0.3 \mathrm{~m}$ más alta en el ensayo Test 7

b. En el ensayo Test 7, la bandeja que contiene el combustible se encuentra cerca del estribo este, reduciendo la aportación potencial de aire en torno a $25 \%$. El resultado es que la gasolina requiere una mayor altura para combinarse con el oxígeno disponible [ref4.16].

4. La caída de $390{ }^{\circ} \mathrm{C}$ en la región central entre los ensayos Test 4 y Test 2 se atribuye a la menor tasa de liberación de calor (un $63.4 \%$ inferior a la empleada en el Test 2). Esta menor potencia no solo reduce la altura de llama, sino que también provoca que el penacho sea más susceptible al efecto del viento

5. La similitud de las temperaturas en las regiones Norte y Central en el ensayo Test 2 se debe a que las llamas están permanentemente inclinadas hacia el norte.

6. La Figura 4-15 muestra las temperaturas registradas por los sensores de gas en las regiones Sur, Centro y Norte a los 20 minutos del inicio del fuego en los ensayos Test 7 y Test 8 . En ella se aprecia un considerable gradiente de temperatura lateral en estas tres zonas con valores máximos de $212^{\circ} \mathrm{C} / \mathrm{m}$ en el ensayo Test 7 y $377^{\circ} \mathrm{C} / \mathrm{m}$ en el ensayo Test 8 .

(a) Test 7 (20 $\mathrm{min})$

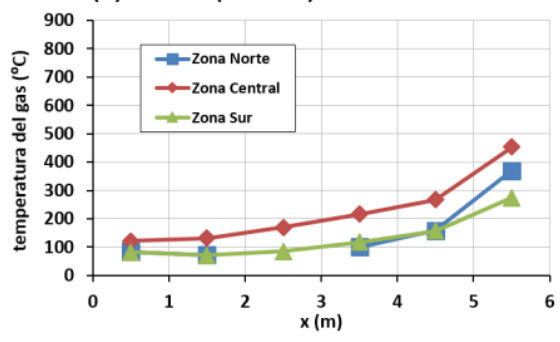

(b) Test 8 (20 min)

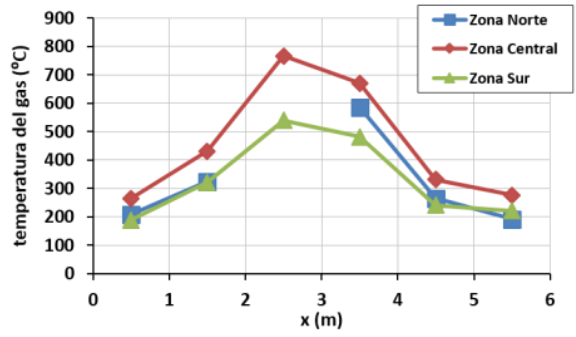

Figura 4-17. Temperaturas del gas por regiones registradas 20 minutos tras la ignición de los ensayos: (a) Test 7 y (b) Test 8. 


\subsubsection{TEMPERATURAS DEL ACERO}

La Tabla 4-8 y la Tabla 4-9 muestran las temperaturas máximas registradas en cada una de los ocho ensayos por los 28 termopares colocados en las vigas de acero. Los resultados se agrupan por vigas (una por tabla), con los sensores del ala inferior primero (BFx), seguidos de los sensores del alma (Wx) y del ala superior (TFx).

\begin{tabular}{ccccccccc}
\hline $\begin{array}{c}\text { viga } \\
\text { norte }\end{array}$ & Test 1 & Test 2 & Test 3 & Test 4 & Test 5 & Test 6 & Test 7 & Test 8 \\
\hline NG-BF1 & 74 & 89 & 131 & 187 & 51 & 46 & 64 & 269 \\
NG-BF2 & 113 & 138 & 206 & 288 & 49 & 48 & 75 & 459 \\
NG-BF3 & 170 & 226 & 294 & 467 & 63 & 60 & 98 & 707 \\
NG-BF4 & 163 & 215 & 279 & 442 & 97 & 88 & 144 & 727 \\
NG-BF5 & 111 & 130 & 212 & 257 & 211 & 160 & 258 & 447 \\
NG-BF6 & 79 & 93 & 135 & 170 & 386 & 283 & 469 & 303 \\
NG-W1 & 83 & 92 & 151 & 190 & 57 & 52 & 78 & 278 \\
NG-W2 & 124 & 147 & 236 & 291 & 61 & 56 & 93 & 479 \\
NG-W3 & 165 & 215 & 337 & 451 & 71 & 66 & 110 & 713 \\
NG-W4 & 175 & 210 & 337 & 454 & 109 & 100 & 167 & 749 \\
NG-W5 & 116 & 128 & 217 & 274 & 157 & 126 & 269 & 466 \\
NG-W6 & 85 & 96 & 149 & 185 & 270 & 201 & 465 & 304 \\
NG-TF3 & 138 & 173 & 278 & 356 & 70 & 64 & 98 & 568 \\
NG-TF4 & 147 & 175 & 286 & 371 & 103 & 94 & 147 & 626 \\
\hline
\end{tabular}

Tabla 4-8. Máximas temperaturas en ${ }^{\circ} \mathrm{C}$ registradas en la viga norte.

En vista de la Tabla 4-8 y la Tabla 4-9 conviene destacar que:

1. Las temperaturas máximas registradas en el acero en los ensayos Test 1, Test 2, Test 5 y Test 6 están por debajo de $400^{\circ} \mathrm{C}$, la temperatura crítica que marca el comienzo de la reducción del límite elástico del acero, según el EC-3 en su parte 1-2 [ref4.21].

2. Las temperaturas máximas registradas en el acero en los ensayos Test 3 y Test 4 son de $459^{\circ} \mathrm{C}$ y $512{ }^{\circ} \mathrm{C}$, respectivamente, y se alcanzaron en el ala inferior de la viga sur (en la sección S3 cerca de CL en la Figura 4-7). La temperatura máxima en el ensayo Test 7 es de $469^{\circ} \mathrm{C}$ en el ala inferior de la viga norte (en la sección S6 cerca del estribo este). 


\begin{tabular}{ccccccccc}
\hline viga sur & Test 1 & Test 2 & Test 3 & Test 4 & Test 5 & Test 6 & Test 7 & Test 8 \\
\hline SG-BF1 & 89 & 101 & 165 & 207 & 58 & 51 & 75 & 287 \\
SG-BF2 & 140 & 141 & 295 & 330 & 52 & 52 & 81 & 465 \\
SG-BF3 & 232 & 214 & 459 & 512 & 62 & 64 & 99 & 725 \\
SG-BF4 & 220 & 203 & 428 & 490 & 97 & 98 & 153 & 733 \\
SG-BF5 & 130 & 132 & 245 & 292 & 200 & 192 & 271 & 475 \\
SG-BF6 & 78 & 89 & 127 & 169 & 365 & 364 & 458 & 297 \\
SG-W1 & 89 & 103 & 179 & 203 & 61 & 53 & 79 & 291 \\
SG-W2 & 134 & 146 & 289 & 325 & 63 & 57 & 90 & 465 \\
SG-W3 & 203 & 211 & 449 & 507 & 81 & 73 & 119 & 747 \\
SG-W4 & 193 & 193 & 398 & 476 & 103 & 97 & 155 & 735 \\
SG-W5 & 127 & 131 & 289 & 310 & 153 & 152 & 262 & 488 \\
SG-W6 & 97 & 107 & 219 & 228 & 247 & 244 & 462 & 353 \\
SG-TF3 & 133 & 149 & 295 & 380 & 54 & 53 & 77 & 543 \\
SG-TF4 & 139 & 148 & 287 & 367 & 84 & 81 & 120 & 569 \\
\hline
\end{tabular}

Tabla 4-9. Máximas temperaturas en ${ }^{\circ} \mathrm{C}$ registradas en la viga sur.

La Figura 4-18 muestra las temperaturas en las secciones más calientes de los ensayos Test 7 (sección S6) y Test 8 (sección S4). Al respecto cabe indicar que:

1. En ambos ensayos, las temperaturas de las alas inferiores y las almas son bastante similares. Estas temperaturas rondan los $430{ }^{\circ} \mathrm{C}$ en el ensayo Test $7 \mathrm{y}$ los $700^{\circ} \mathrm{C}$ en el ensayo Test 8 .

2. En el ensayo Test 8 (Figura 4-18b) las temperaturas máximas de las alas superiores se encuentran en torno a $550{ }^{\circ} \mathrm{C}$ y $600{ }^{\circ} \mathrm{C}$, lo que representa unos 100 ${ }^{\circ} \mathrm{C}$ y $150{ }^{\circ} \mathrm{C}$ por debajo de las temperaturas máximas registradas en las almas y alas inferiores. Esta diferencia de temperatura se debe a que:

a. Las alas inferiores y las almas tienen más superficie de acero expuesta al fuego que las alas superiores

b. Las alas superiores están protegidas en su cara superior por la losa de hormigón, lo que impide que las alas superiores puedan absorber calor a través de esa superficie

Esta diferencia de temperaturas también se observó en estudios previos en los que puentes de acero y mixtos de hormigón y acero con vigas en doble $\mathrm{T}$ de acero se calentaron uniformemente [ref4.02], se sometieron a escenarios de fuego realistas [ref4.03, ref4.08] o se sometieron a curvas de calentamiento estándar empleadas en hornos [ref4.22]). 
3. Las temperaturas máximas registradas en el acero en el ensayo Test 8 varían entre $569^{\circ} \mathrm{C}$ y $749{ }^{\circ} \mathrm{C}$. Estos valores están en el orden de magnitud de aquellos observados en eventos reales de incendios en puentes.

a. El modelo numérico del incendio bajo el paso elevado I-65 en Birmingham, Alabama (EEUU) detallado en el Capítulo 3 estima que las vigas de acero del paso elevado alcanzaron temperaturas máximas entre $500{ }^{\circ} \mathrm{C}$ y $800{ }^{\circ} \mathrm{C}$ aproximadamente

b. Godart et al. [ref4.18] informaron que áreas significativas del puente Mathilde en Rouen (Francia) alcanzaron al menos $600{ }^{\circ} \mathrm{C}$ como consecuencia del incendio ocurrido bajo el puente en 2012.

(a) Test 7 (Sección S6)

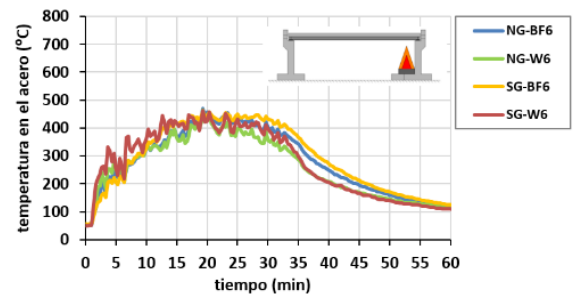

(b) Test 8 (Sección S4)

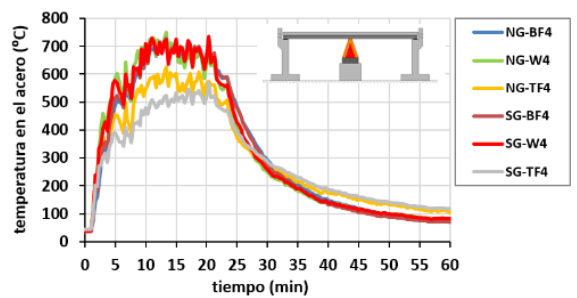

Figura 4-18. Temperaturas del acero en la sección (medida) más caliente: (a) Test 7 (sección S6) y (b) Test 8 (sección S4).

La Figura 4-19 muestra la evolución de la temperatura de los termopares del ala inferior de la viga sur en los ensayos Test 7 y Test 8 . Los gradientes máximos registrados en el acero del ala inferior de la viga sur son de $200^{\circ} \mathrm{C} / \mathrm{m}$ y $250{ }^{\circ} \mathrm{C} / \mathrm{m}$ para los ensayos Test 7 y Test 8 , respectivamente, y son ligeramente inferiores a los registrados en el gas. Los gráficos de los sensores en el alma y la viga norte no se muestran por ser similares a los ya incluidos.

(a) Test 7

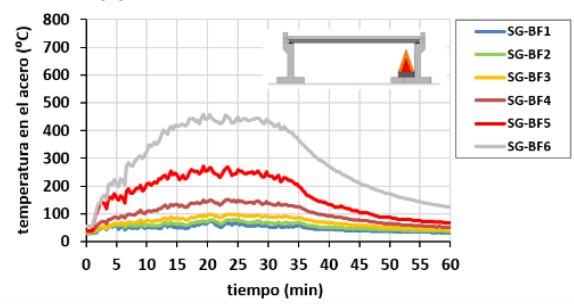

(b) Test 8

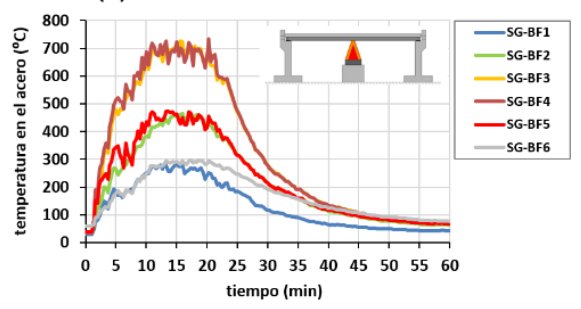

Figura 4-19. Temperaturas del acero en el ala inferior de la viga sur para los ensayos: (a) Test 7 y (b) Test 8 . 
La Figura 4-20 compara las temperaturas máximas en diferentes zonas de las vigas de acero y diferentes secciones de los escenarios de fuego considerados. En base a la Figura 4-20a, se puede afirmar que:

1. No hay diferencias significativas entre las temperaturas registradas en las alas inferiores y las almas de las vigas en ninguno de los cuatro escenarios estudiados.

2. Existen diferencias considerables entre la temperatura de las almas y las alas superiores como resultado de la proximidad de la losa. Las diferencias rondan los $150{ }^{\circ} \mathrm{C}$ para el escenario de fuego Fire 4 , los $120^{\circ} \mathrm{C}$ para el escenario de fuego Fire 2 y los $40^{\circ} \mathrm{C}$ para el escenario de fuego Fire 1.

3. En el escenario de fuego Fire 4, las temperaturas de la viga norte son ligeramente más bajas (en el ala inferior, el alma y el ala superior) como resultado de que las llamas se inclinaran hacia el lado sur.

4. Al no existir información disponible en el ala superior en la sección S6 en el escenario de fuego Fire 3, no se puede evaluar el gradiente entre almas y alas superiores

La Figura 4-20b proporciona las temperaturas máximas en cada sección para cada viga (considerando las dos vigas) para los cuatro escenarios de incendio. Gradientes máximos para los escenarios de fuego Fire 1, Fire 2, Fire 3 y Fire 4 son $60^{\circ} \mathrm{C} / \mathrm{m}, 200{ }^{\circ} \mathrm{C} / \mathrm{m}, 200$ ${ }^{\circ} \mathrm{C} / \mathrm{m}$ y $250{ }^{\circ} \mathrm{C} / \mathrm{m}$, respectivamente. Además, tomando el escenario de fuego Fire 2 como referencia, con una temperatura máxima registrada de $500{ }^{\circ} \mathrm{C}$, se puede ver que:

1. Hay un aumento de $250{ }^{\circ} \mathrm{C}$ sobre esta temperatura cuando la posición de carga de fuego se eleva de 0.2 a $0.8 \mathrm{~m}$ sobre el nivel de referencia.

2. Hay una caída de $290{ }^{\circ} \mathrm{C}$ por debajo de esta temperatura cuando la potencia se reduce en un $63.4 \%$ de los $1135 \mathrm{~kW}$ del escenario de fuego Fire 2.

(a) Fire 1 al Fire 4 (por región)

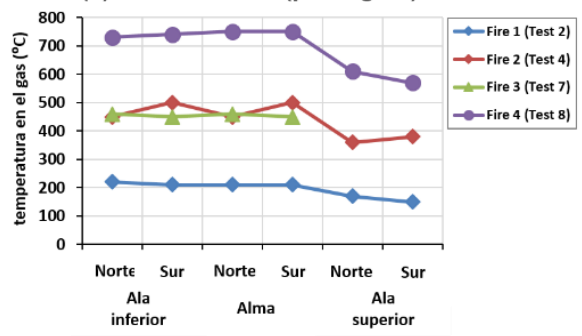

(b) Fire 1 al Fire 4 (por sección)

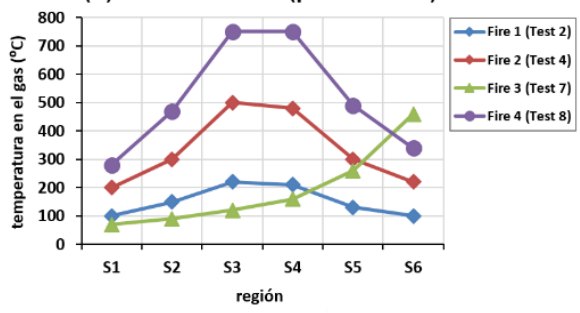

Figura 4-20. Máximas temperaturas del acero en cuatro ensayos representativos: (a) por región y (b) por sección. 
Finalmente, la representación del escenario de fuego Fire 3 en la Figura 4-20b también muestra que el gradiente térmico longitudinal se reduce con la distancia horizontal del fuego.

\subsubsection{TEMPERATURAS EN LA LOSA DE HORMIGÓN ARMADO}

Las temperaturas máximas registradas en las barras de refuerzo y los pernos conectores de la losa de hormigón se encuentran entre $69^{\circ} \mathrm{C}$ y $190{ }^{\circ} \mathrm{C}$ y $48{ }^{\circ} \mathrm{C}$ y $110{ }^{\circ} \mathrm{C}$, respectivamente. Los valores máximos se han alcanzado en el ensayo Test 8 . No se ha observado desprendimiento de hormigón, lo que puede atribuirse tanto al bajo valor de las temperaturas del hormigón como al bajo contenido de humedad de la losa.

\subsubsection{FLECHAS}

La medición de las flechas durante los ensayos sirve para evaluar la evolución de la geometría de la estructura para calibrar los modelos estructurales empleados para reproducir los ensayos de fuego.

Las flechas en los ensayos se han obtenido por trigonometría a partir de los incrementos de desplazamiento registrados por cada par de LVDT. La Tabla 4-10 muestra las flechas máximas registradas por los LVDT en las secciones del tablero con coordenadas $\mathrm{x}=1.0$ $\mathrm{m}, 3.0 \mathrm{~m}$ y $5.0 \mathrm{~m}$. En vista de los resultados se puede concluir que:

\begin{tabular}{lcccccc}
\hline \multirow{2}{*}{ Ensayo } & \multicolumn{2}{c}{$\mathbf{x}=\mathbf{1 . 0} \mathbf{m}$} & \multicolumn{2}{c}{$\mathbf{x = 3 . 0} \mathbf{m}$} & \multicolumn{2}{c}{$\mathbf{x = 5 . 0 ~ m}$} \\
& Norte & Sur & Norte & Sur & Norte & Sur \\
\hline Test 1 & 11 & 12 & 24 & 25 & 11 & 11 \\
Test 2 & 11 & 11 & 24 & 24 & 11 & 10 \\
Test 3 & 25 & 30 & 51 & 55 & 24 & 24 \\
Test 4 & 34 & 38 & 71 & 73 & 33 & 32 \\
Test 5 & 5 & 5 & 15 & 15 & 15 & 13 \\
Test 6 & 4 & 4 & 12 & 12 & 11 & 11 \\
Test 7 & 7 & 7 & 19 & 19 & 17 & 16 \\
Test 8 & 57 & 57 & 121 & 120 & 59 & 56 \\
\hline
\end{tabular}

Tabla 4-10. Máximas flechas (en $\mathrm{mm}$ ) para los ocho ensayos con puente.

1. Aunque los ensayos Test 3 y Test 4 corresponden al mismo escenario de fuego, en el ensayo Test 3, las flechas máximas en el tramo medio fueron un $29 \%$ menores debido a la mayor velocidad del viento durante este ensayo.

2. Las flechas máximas en el ensayo Test 2 (escenario de fuego Fire 1) han sido un $67 \%$ inferiores al ensayo Test 4 (escenario de fuego Fire 2). Esta reducción 
de flechas se debe exclusivamente a la reducción de un $63.4 \%$ de la tasa de liberación de calor (HRR), al haberse realizado ambos ensayos con la bandeja de combustible situada a la misma altura (con su base a cota $0.2 \mathrm{~m}$ ).

3. Tanto el ensayo Test 8 (escenario de fuego Fire 4) como el ensayo Test 4 (Fire 2) involucran una carga de fuego de $1131 \mathrm{~kW}$. Por ello se puede afirmar que las flechas máximas registradas en el ensayo Test 8 aumentaron en torno a un $67 \%$ con respecto al ensayo Test 4 porque la distancia vertical entre la carga de fuego $\mathrm{y}$ las vigas se redujo en $0.6 \mathrm{~m}$.

Respecto a los desplazamientos horizontales cabe indicar:

1. Los valores máximos se han obtenido en el ensayo Test 8 (escenario de fuego Fire 4), siendo su magnitud de $14 \mathrm{~mm}$ en el lado este y $11 \mathrm{~mm}$ en el oeste.

2. En el resto de los ensayos los desplazamientos horizontales no fueron en ningún caso superiores a $5 \mathrm{~mm}$.

3. Los desplazamientos horizontales fueron similares en todas las pruebas.

4. Los LVDT no registraron desplazamientos horizontales en los pórticos auxiliares de acero (L21 y L22), lo que indica que éstos no experimentaron ningún desplazamiento horizontal que pudiera distorsionar las medidas tomadas por los LVDT L1 a L20.

La evolución de las flechas máximas en CL en los ensayos Test 2, Test 4, Test 7 y Test 8 se incluye en la Figura 4-21. De ella se deduce que:

1. Se han alcanzado flechas máximas de $121 \mathrm{~mm}, 71 \mathrm{~mm}, 24 \mathrm{~mm}$ y $19 \mathrm{~mm}$ en los escenarios de fuego Fire 4, Fire 2, Fire 1 y Fire 3 respectivamente. En la Figura 4-22 se muestran además dos imágenes tomadas durante el ensayo Test 8 (escenario de fuego Fire 4) en el período de mayor deformación de la losa.

2. Se han registrado flechas verticales similares en ambas vigas para $x=3.0 \mathrm{~m}$. Esto también aplica para las secciones $\mathrm{x}=1.0 \mathrm{~m} \mathrm{y} \mathrm{x=5.0} \mathrm{m,} \mathrm{no} \mathrm{incluidas} \mathrm{en} \mathrm{la} \mathrm{figura.}$

3. El hecho de que las deflexiones verticales máximas en el escenario de fuego Fire 4 se mantengan durante seis minutos, indica que el tablero alcanzó una situación de equilibrio térmico. Durante este periodo de equilibrio, la distancia entre la carga de fuego y las vigas de acero fue de solo $0.98 \mathrm{~m}$ debido a la flecha existente de $0.12 \mathrm{~m}$.

4. No se registran desviaciones residuales después de las pruebas, lo que lleva a la conclusión de que las deformaciones del puente se deben exclusivamente a la reducción del módulo de Young de las vigas de acero y al efecto de la expansión térmica de las vigas. La falta de deformaciones residuales después de los ensayos también indica que las vigas no han plastificado. 
(a) Viga Norte

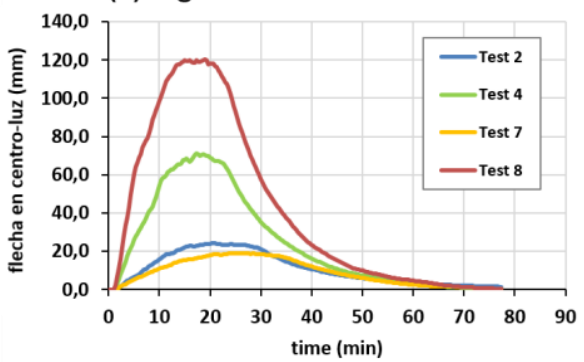

(b) Viga Sur

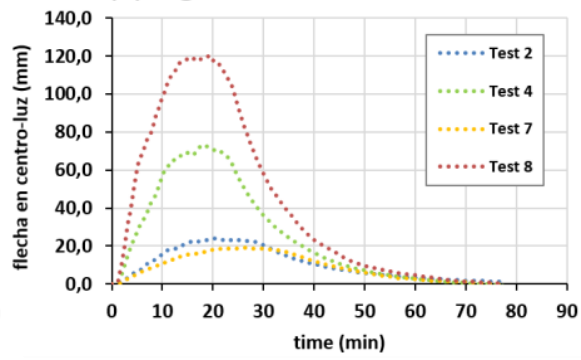

Figura 4-21. Flechas en centro-luz $(C L)(x=3.0 \mathrm{~m})$ para: (a) Viga Norte y (b) Viga Sur.
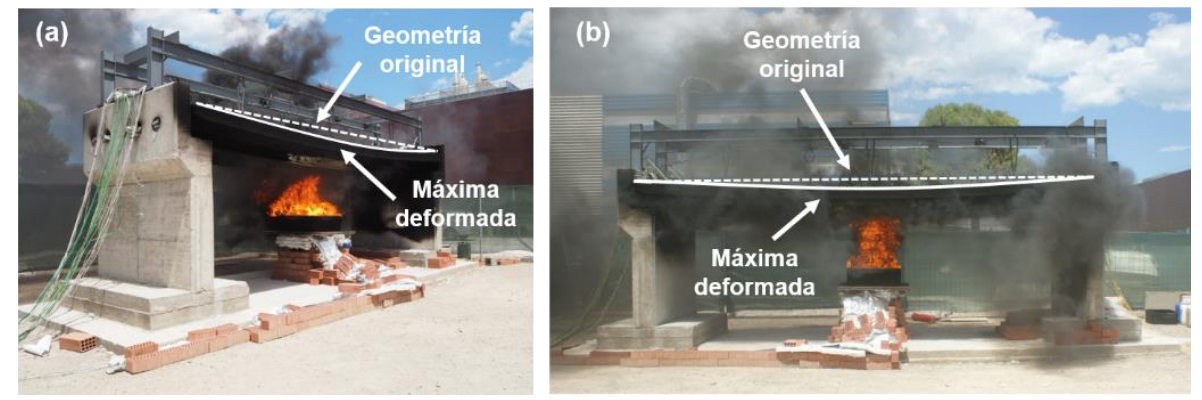

Figura 4-22. Máxima flecha vertical alcanzada por el puente en el ensayo "Test 8": (a) vista en perspectiva y $(b)$ vista frontal.

\subsection{CONCLUSIONES}

Las graves consecuencias de los incendios de puentes y el hecho de que los códigos actuales no proporcionen una guía para estimar la resistencia al fuego de un puente dan lugar a la necesidad de desarrollar un enfoque basado en prestaciones para proteger el puente contra incendios. Este enfoque podría basarse en los resultados de los modelos numéricos, pero también requeriría experimentos para (1) habilitar la calibración de los modelos numéricos y (2) proporcionar información cuantitativa y cualitativa útil sobre incendios de puentes.

A pesar de su importancia, el trabajo experimental en incendios de puentes es bastante escaso y los pocos estudios existentes no reproducen algunas características importantes del fuego del puente, como las curvas de calentamiento de los incendios de hidrocarburos y la existencia de gradientes térmicos longitudinales.

En este contexto, este documento describe dos conjuntos de ensayos de fuego realizados en la Universitat Politècnica de València en Valencia (España) para mejorar el 
conocimiento actual sobre la respuesta de los puentes frente a la acción de fuego. El primer grupo, denominado "pruebas preliminares" no ha involucrado ningún puente y ha tenido como objetivo proporcionar a los autores información relevante sobre cómo realizar pruebas de fuego al aire libre de manera eficiente y segura. El segundo conjunto de pruebas de fuego ha involucrado una serie de ocho ensayos de fuego de diferentes magnitudes y en diferentes posiciones bajo un puente compuesto de vigas en I de $6 \mathrm{~m}$ de vano. Este segundo conjunto de ensayos ha tratado de reproducir escenarios de fuego similares a los que se han producido en puentes reales, aunque a una escala de potencia del fuego de menor magnitud. El hecho de emplear cargas de fuego más pequeñas, motivado inicialmente por razones económicas, de seguridad y ambientales, ha hecho posible emplear una misma estructura para toda la campaña experimental documentada en el presente capítulo.

\subsubsection{APORTACIONES CUANTITATIVAS DE LOS ENSAYOS}

De ambos grupos de ensayos se pueden extraer las siguientes conclusiones:

1. Los valores experimentales de la tasa de pérdida de masa son, en general, similares a los valores propuestos en la literatura. Se observaron diferencias significativas entre los valores experimentales y teóricos en los ensayos Test 6 y Test 7 ( $-17.3 \%$ del valor promedio) y el ensayo Test $8(+18,7 \%)$ debido a la reducción de la ventilación potencial (ensayos Test 6 y Test 7) y la mayor exposición del tablero a la radiación de las llamas (ensayo Test 8).

2. Las temperaturas máximas registradas en el gas se han alcanzado en la región central entre las dos vigas y varían entre $320^{\circ} \mathrm{C}$ (escenario de fuego Fire l) y $920^{\circ} \mathrm{C}$ (escenario de fuego Fire 4).

3. Las temperaturas registradas en el gas varían notablemente a lo largo del eje longitudinal del puente. El gradiente térmico longitudinal promedio es de 350 ${ }^{\circ} \mathrm{C} / \mathrm{m}$ para el escenario de fuego Fire 4 y de $220^{\circ} \mathrm{C} / \mathrm{m}$ para el escenario de fuego Fire 3. Las temperaturas en las vigas de acero también prueban la existencia de un importante gradiente térmico longitudinal $\left(250{ }^{\circ} \mathrm{C} / \mathrm{m}\right.$ para el escenario de fuego Fire $4,200{ }^{\circ} \mathrm{C} / \mathrm{m}$ en los escenarios de fuego Fire 2 y Fire 3 , y $60{ }^{\circ} \mathrm{C} / \mathrm{m}$ en el escenario de fuego Fire 1. Esto significa que una temperatura uniforme del gas o de la viga a lo largo del eje longitudinal del puente no es realista, ni siquiera para puentes con luces cortas. Por este motivo deberían evitarse curvas de exposición que no tuvieran en cuenta los gradientes térmicos longitudinales

4. Las temperaturas máximas registradas en el alma y el ala inferior son muy similares y oscilan entre $220^{\circ} \mathrm{C}$ (ensayo Test 2, escenario de fuego Fire 1) y $720^{\circ} \mathrm{C}$ (ensayo Test 8 , escenario de fuego Fire 4). Las temperaturas registradas 
en el ala superior son significativamente más pequeñas a las anteriores puesto que el ala superior está en contacto directo con la losa de hormigón

5. La potencia del fuego y la distancia vertical desde el fuego hasta el tablero del puente tienen una gran influencia en la respuesta del mismo.

a. Manteniendo la altura de la bandeja de combustible $(1.7 \mathrm{~m})$ y reducir la potencia de la carga de fuego de $1131 \mathrm{~kW}$ (escenario de fuego Fire

2) a $415 \mathrm{~kW}$ (escenario de fuego Fire 1) se deriva en una reducción de la flecha máxima del tablero en CL del $67 \%$

b. Manteniendo la potencia de la carga de fuego constante $(1131 \mathrm{~kW})$ y reduciendo la distancia vertical entre el fuego y el ala inferior de $1.7 \mathrm{~m}$ (escenario de fuego Fire 2) a $1.1 \mathrm{~m}$ (escenario de fuego Fire 4) se deriva en un aumento del $66 \%$ en las flechas máximas registradas en CL.

6. La flecha máxima registrada en ambas vigas ha sido de $120 \mathrm{~mm}$ en el ensayo Test 8 correspondiente al escenario de fuego Fire 4, con una tasa de liberación de calor de $1131 \mathrm{~kW}$ y una distancia entre la carga de fuego y las vigas de 1.1 $\mathrm{m}$. En el ensayo el puente ha recuperado su geometría inicial una vez extinguido el fuego. No se observa deformación residual debida a plastificaciones ni tampoco desprendimiento de la losa de hormigón.

7. El viento puede tener una influencia importante en los ensayos de fuego al aire libre.

a. Los ensayos Test 3 y Test 4 corresponden a un mismo escenario de fuego (Fire 2). Sin embargo, la máxima flecha registrada en CL en el ensayo Test 3 es un $29 \%$ menor que la registrada en el ensayo Test 4. Esta diferencia se atribuye a la mayor presencia de viento en el ensayo Test 3 .

\subsubsection{APORTACIONES CUALITATIVAS DE LA CAMPAÑA EXPERIMENTAL}

Los resultados proporcionados en el presente capítulo son de gran importancia para los investigadores y profesionales interesados en proteger los puentes de los incendios y en aumentar la resiliencia del puente, ya que:

1. Proporcionan una idea cuantitativa y cualitativa de lo que sucede con un puente mixto de vigas en doble $\mathrm{T}$ cuando se produce un incendio bajo el tablero.

2. Sirven de referencia para futuras campañas experimentales en el ámbito del fuego en puentes.

3. Los datos registrados de tasa de pérdida de masa y temperaturas del gas pueden usarse para validar modelos numéricos empleados para la simulación de incendios. 
4. Los datos registrados de temperaturas del gas y del acero, así como las flechas del tablero pueden emplearse para validar modelos numéricos empleados para reproducir la respuesta termo-mecánica de tableros mixtos sometidos a la acción del fuego

5. Estos modelos numéricos validados podrían usarse para:

a. Estimar el daño causado por los incendios a los puentes

b. Estimar la resistencia residual post-incendio de los puentes

c. Reducir los daños asociados a puentes mediante el modelado de diferentes medidas de protección.

\subsection{FUTURAS LÍNEAS}

Realizada la campaña experimental con fuego y puente a pequeña escala se plantean dos líneas de trabajo.

1. La realización de nuevas campañas experimentales:

a. Capaces de causar daños sustanciales a un puente con el fin de estudiar mejor los mecanismos de fallo y cuantificar la resistencia residual del tablero del puente

b. Que reproduzcan eventos de fuego a escala real. Permitiendo el registro de información detallada durante todo el evento, como se ha hecho a pequeña escala.

c. Que permitan analizar la respuesta de otras tipologías en el mismo rango de luces, como los puentes de vigas de hormigón armado o de vigas en cajón.

2. El empleo de los datos obtenidos en los ensayos para realizar validaciones de los modelos empleados para caracterizar numéricamente los eventos de fuego sin necesidad de realizar una gran inversión económica

a. Validación de la simulación de incendios empleada para caracterizar la acción térmica a emplear como input en los modelos de elementos finitos

b. Validación del modelo de elementos finitos empleado para caracterizar la respuesta termo-mecánica del tablero en situación de incendio

\subsection{REFERENCIAS}

[ref4.01] Choi J. Concurrent fire dynamics models and thermomechanical analysis of steel and concrete structures. Georgia Institute of Technology. 2008.

[ref4.02] Paya-Zaforteza I, Garlock ME. A numerical investigation on the fire response of a steel girder bridge. Journal of Constructional Steel Research 75:93-103. 2012. 
[ref4.03] Peris-Sayol G, Paya-Zaforteza I, Alos-Moya J, Hospitaler A. Analysis of the influence of geometric, modeling and environmental parameters on the fire response of steel bridges subjected to realistic fire scenarios. Computers and Structures Journal. 2015. [ref4.04] Gong X, Agraval AK. Numerical simulation of fire damage to a long-span truss bridge. ASCE Journal of Bridge Engineering 20 (10). 2015.

[ref4.05] Peris-Sayol G, Paya-Zaforteza I, Balasch-Parisi S, Alos-Moya J. Detailed analysis of the causes of bridge fires and their associated damaged levels. ASCE Journal of Performance and Constructed Facilities 31 (3). 2017.

[ref4.06] Wright W, Lattimer B, Mahammad N, Sotelino E. Highway bridge fire hazard assessment draft. Guide specification for fire damage evaluation in steel bridges. 2013.

[ref4.07] Peris-Sayol G, Paya-Zaforteza I, Balasch-Parisi S, Alos-Moya J. Analysis of the factors that influence the maximum adiabatic temperatures in I-girder bridges. 9th International Conference on Structures in Fire. Princeton, NY, USA. 2016.

[ref4.08] Alos-Moya J. Análisis del colapso frente al fuego del paso superior de la interestatal I-65 dirección sur sobre la I-65 dirección norte en el ramal sur del intercambiador con la interestatal I-20/59 situado en Birmingham, Alabama, Estados Unidos. Proyecto final de carrera. Universitat Politècnica de València. 2012.

[ref4.09] Peris. Estudio paramétrico de la respuesta termo-estructural de un puente metálico multijácena sometido a incendios reales. Informes de la construcción 66 ( ${ }^{\circ}$ Extra). 2014.

[ref4.10] Taly N. Design of modern highway bridges. McGrawHill. 1998.

[ref4.11] Llago Acero R., García Rodríguez P. Composite twin-girder bridges: a competitive solution for medium span bridges. Revista de Obras Públicas 1695:29-46. 2010 .

[ref4.12] Taranath BS. Steel, concrete and composite design of tall buildings. McGrawHill, USA. 1997.

[ref4.13] Nadjai A, Han S, Ali F, Alam N, Allam A. Fire resistance of axial restraint composite floor steel cellular beams. Journal of Constructional Steel Research 136:22937. 2017. 
[ref4.14] Li GQ, Zhang N, Jiang J. Experimental investigation on thermal and mechanical behaviour of composite floors exposed to standard fire. Fire Safety Journal 89:63-76. 2017.

[ref4.15] Bailey CG, Toh WS. Behaviour of concrete floor slabs at ambient and elevated temperatures. Fire Safety Journal 42 (6-7): 425-36. 2007.

[ref4.16] Drysdale D. An Introduction to Fire Dynamics. John Wiley and Sons, UK. 2011. [ref4.17] Babrauskas V. SFPE Handbook of fire protection engineering. Chapter 26. Heat Release rates. 5th Edition. . 2016.

[ref4.18] Godart B, Berthellemy J, Lucas JP. Diagnosis, assessment and repair of the Mathilde bridge close to collapse during a fire. Structural Engineering International 25(3):331-38. 2015.

[ref4.19] Rinaudo P, Paya-Zaforteza I, Calderón P, Sales S. Experimental and analytical evaluation of the response time of high temperature fiber optic sensors. Sensors and Actuators, A: Physical 243:167-174. 2016.

[ref4.20] Rinaudo P, Torres B, Paya-Zaforteza I, Calderón PA, Sales S. Evaluation of new regenerated fiber Bragg grating high-temperature sensors in an ISO 834 fire test. Fire Safety Journal 71:332-339. 2015.

[ref4.21] European Committee for Standardization (CEN). EN 1993-1-2:2005. Eurocode 3: Design of steel structures - Part 1-2: General rules - Structural fire design. Brussels, Belgium. 2005.

[ref4.22] Aziz, EM, Kodur VK, Glassman, JD, Moreyra Garlock ME. Behaviour of steel bridge under fire conditions. Journal of Constructional Steel Research 106:11-22. 2015. 



\section{VALIDACIÓN DEL MODELO DE INCENDIOS}

Es preferible una solución aproximadamente correcta que exactamente equivocada John Maynard Keynes

El contenido de esta sección ha sido tomado directamente del paper

"Valencia bridge fire tests: Validation of simplified and advanced numerical approaches to model bridge fire scenarios"

aceptado en Noviembre de 2018 en el

Advances in Engineering Software Journal 



\subsection{INTRODUCCIÓN}

En el Capítulo 3 se ha presentado una metodología basada en modelos numéricos para reproducir eventos de fuego con afección directa sobre puentes multiviga mixtos. Puesto que la metodología se ha validado mediante la caracterización aproximada del evento de fuego a partir de imágenes tomadas durante y tras el incendio se ha considerado necesario realizar validaciones específicas adicionales de cada uno de los modelos empleados. Para ello, en el Capítulo 4 se ha realizado una campaña experimental que ha permitido registrar variables como la HRR, las temperaturas en el gas, las temperaturas en el acero y las flechas del tablero durante todos y cada uno de los ocho ensayos que la componen.

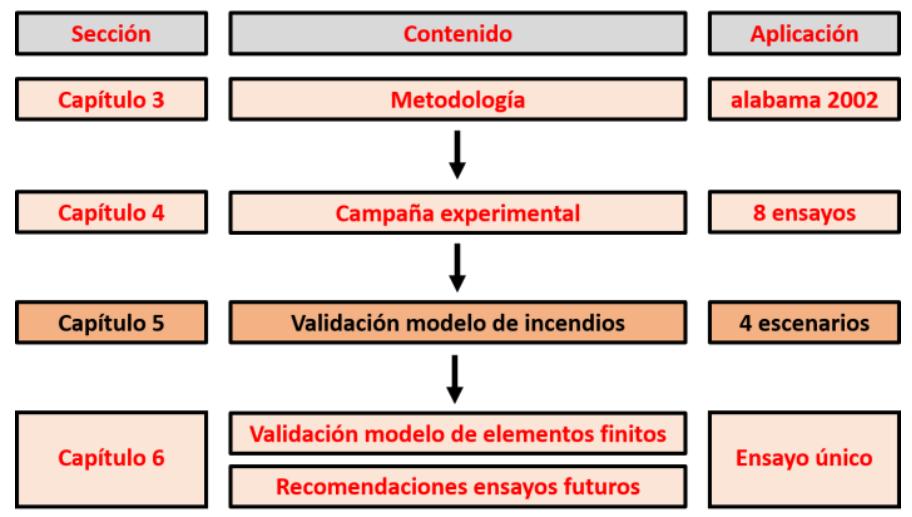

Figura 5-1. Estructura de la tesis: Capítulo 5.

En el presente capítulo se emplearán las variables HRR y temperaturas del gas registradas en el Capítulo 4 de los cuatro ensayos más representativos para validar el modelo de simulación de incendios definido mediante FDS para reproducir la dinámica de los incendios. Previamente a la validación del modelo avanzado de FDS se realizará una validación del modelo simplificado de Heskestad \& Hamada (H\&H en adelante) [ref5.01], puesto que podría servir de punto de partida para emplearlo como referencia orientativa en incendios a mayor escala. Tanto la validación del modelo simplificado de $\mathrm{H} \& \mathrm{H}$ como la validación del modelo avanzado de FDS se han realizado recurriendo a los ensayos realizados con el puente experimental presentado en el Capítulo 4.

\subsection{Caso de estudio}

El puente tiene un vano único simplemente apoyado de $6.0 \mathrm{~m}$ y un gálibo vertical de 1.9 $\mathrm{m}$. La estructura consiste en dos vigas de acero IPE-160 que soportaban una losa de 
hormigón armado de $0.15 \mathrm{~m}$ de espesor conectada a las vigas de acero a través de 62 pernos conectadores. El acero S355-JR empleado para las vigas registró límites elásticos de $360 \mathrm{MPa}$. La resistencia a la compresión de la losa de hormigón fue de $33 \mathrm{MPa}$. El alzado del puente, su sección y detalles sobre la distribución de termopares de gas empleados para la validación del presente capítulo se muestran en la Figura 5-2. Los pórticos de acero apoyados sobre los estribos se incluyeron para sostener los LVDT que monitorizaron las flechas del tablero, pero no tienen ninguna influencia en la validación del modelo de incendios. Para mayor información consultar el Capítulo 4, donde se caracteriza tanto el puente como los ensayos de fuego que sobre él se han realizado.

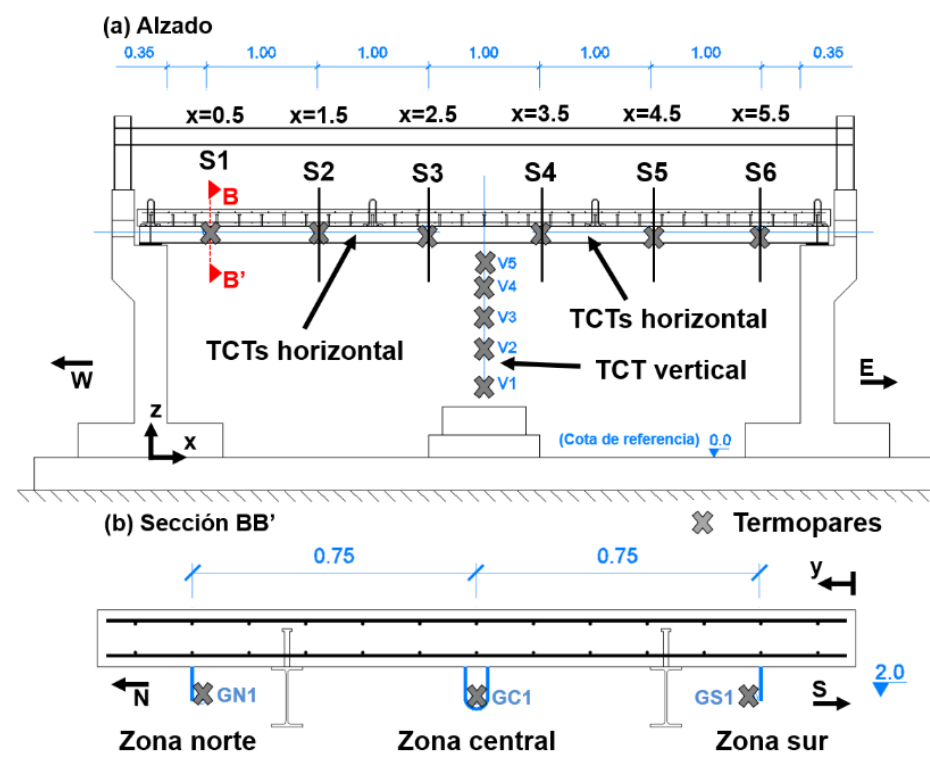

Figura 5-2. Puente experimental: (a) Alzado y (b) Sección BB' con detalles de la distribución de termopares del gas.

\subsection{APROXIMACIÓN EXPERIMENTAL}

\subsubsection{ESCENARIOS DE FUEGO}

Los ensayos "Valencia bridge fire tests" incluyen ocho ensayos de fuego repartidos en cuatro escenarios de fuego diferentes. Las cargas de fuego se han ubicado en todos los casos bajo el puente y consistían en diferentes volúmenes de gasolina vertidos en bandejas de acero de diferentes dimensiones. El presente estudio validará los modelos de fuego simplificado (H\&H) y avanzado (FDS) empleando los resultados de cuatro de 
los ocho ensayos detallados en el Capítulo 4. Concretamente se han seleccionado los ensayos Test 2, Test 4, Test 7 y Test 8 , puesto que son éstos los que mejor caracterizan los cuatro escenarios de fuego (Fire 1, Fire 2, Fire 3 y Fire 4).

1. Los ensayos Test 1 y Test 3 se descartan en favor de los ensayos Test 2 y Test 4 respectivamente debido a la menor influencia del viento en estos últimos.

2. Los ensayos Test 5 y Test 6 se descartan en favor del ensayo Test 7 , ya que este último era el único sin una zona protegida por encima de la carga de fuego.

3. El ensayo Test 8 era el único representante del escenario de fuego Fire 4, por lo que no existe alternativa.

La Tabla 5-1 proporciona detalles de la posición y la magnitud de las cargas de fuego durante los ensayos. El volumen de gasolina utilizado se obtuvo indirectamente a partir de la masa registrada por la báscula y suponiendo una densidad de $740 \mathrm{~kg} / \mathrm{m}^{3}$ [ref5.02]. La HRR promedio de cada ensayo se ha calculado sin tener en cuenta la fase de crecimiento ni la de decrecimiento. Cuatro vistas de los ensayos objeto de la validación se muestran en la Figura 5-3.

\begin{tabular}{|c|c|c|c|c|c|c|c|c|c|}
\hline \multirow{2}{*}{$\begin{array}{c}\text { Escenario } \\
\text { de fuego }\end{array}$} & \multirow{2}{*}{ Ensayo } & \multirow{2}{*}{$\begin{array}{l}\text { Posición } \\
\text { del fuego }\end{array}$} & \multirow{2}{*}{$\begin{array}{l}\text { HRR } \\
(\mathbf{k W})\end{array}$} & \multicolumn{3}{|c|}{ Gasolina } & \multirow{2}{*}{$\begin{array}{l}\text { Lado } \\
s(\mathbf{m})\end{array}$} & \multicolumn{2}{|c|}{ Posición de la bandeja } \\
\hline & & & & $\begin{array}{c}\text { Masa } \\
\text { (kg) }\end{array}$ & $\begin{array}{c}\text { Volumen } \\
\text { (I) }\end{array}$ & $\begin{array}{c}\text { Espesor } \\
(\mathrm{cm})\end{array}$ & & $\mathbf{x}(\mathbf{m})$ & $z(\mathbf{m})$ \\
\hline Fire 1 & Test 2 & $\mathrm{CL}$ & 426 & 17.5 & 23.6 & 9.5 & 0.5 & 3.00 & 0.2 \\
\hline Fire 2 & Test 4 & $\mathrm{CL}$ & 1130 & 37.7 & 50.9 & 9.1 & 0.75 & 3.00 & 0.2 \\
\hline Fire 3 & Test 7 & Estribo & 361 & 18.1 & 24.5 & 9.8 & 0.5 & 5.59 & 0.5 \\
\hline Fire 4 & Test 8 & CL & 1352 & 41.6 & 56.2 & 10.0 & 0.75 & 3.00 & 0.8 \\
\hline
\end{tabular}

Tabla 5-1. Escenarios de fuego empleados en la validación.

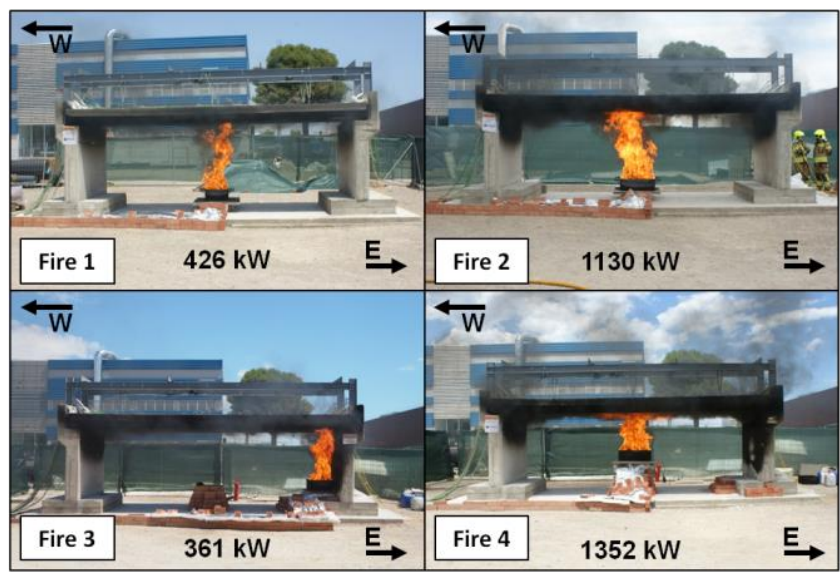

Figura 5-3. Vistas de los escenarios de fuego con HRR promedio de cada escenario. 


\subsubsection{TASA DE PÉRDIDA DE MASA}

En la Figura 5-4 se incluye la tasa de pérdida de masa (por minuto) registrada durante los ensayos de validación. Al multiplicar la tasa de pérdida de masa por el calor de combustión neto $\left(\Delta \mathrm{H}_{\mathrm{c}}\right)$ del combustible (en el caso de la gasolina: $43.7 \mathrm{MJ} / \mathrm{kg}$ ) [ref5.02] se obtiene la tasa de liberación de calor del fuego, variable principal para la caracterización de incendios.

En la Figura 5-4, se puede distinguir para cada ensayo la zona de crecimiento de la potencia del fuego. La zona de meseta solo resulta evidente en los escenarios de fuego Fire 1 y Fire 3, en los que la carga de fuego es menor. En el escenario de fuego Fire2 se observan las mayores oscilaciones (atribuibles a un mayor viento racheado). El crecimiento aproximadamente uniforme del escenario de fuego Fire 4 se asocia con el incremento de radiación incidente sobre la fuente de fuego debido al incremento de la flecha del tablero que lleva asociado una reducción de la distancia entre el tablero y la superficie superior del combustible.

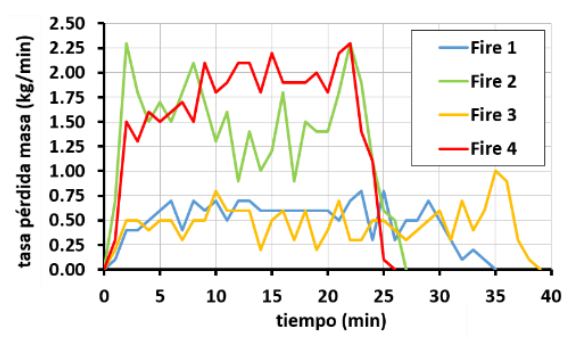

Figura 5-4. Tasa de pérdida de masa registrada durante los ensayos.

\subsubsection{TEMPERATURAS DEL GAS}

Las temperaturas del gas se midieron con 23 termopares de Tipo $\mathrm{K}$ de $1.5 \mathrm{~mm}$ con vainas de acero inoxidable dispuestas en seis árboles de termopares horizontales ("TCT horizontal") para medir las temperaturas a la cota de las vigas y un árbol de termopares vertical ("TCT vertical") para medir las temperaturas en el penacho. La Figura 5-2 muestra la distribución de los termopares dispuestos en los ensayos para medir temperaturas en el gas. Cada árbol de termopares horizontal tenía 3 termopares y el árbol de termopares vertical tenía cinco termopares. Con respecto a la nomenclatura se mantiene la empleada en el Capítulo 4 (consultar la Figura 5-2 para complementar con información visual):

Para los termopares correspondientes a los árboles de termopares horizontales: 
1. El primer carácter indica tipo de registro:

a. G: indica que se registran temperaturas en el GAS

2. El segundo carácter indica zona de medición:
a. S: Sur
b. C: Central
c. $\mathrm{N}$ : Norte

3. El tercer carácter, en este caso numérico, indica la sección:
a. S1: Sección S1
b. S2 a S5: Sección S2 a Sección S5
c. S6: Sección S6

\begin{tabular}{|c|c|c|c|c|c|c|c|c|}
\hline & \multirow{2}{*}{$x(m)$} & \multirow{2}{*}{$\begin{array}{c}\text { Zona Sur } \\
\text { T prom. }\left({ }^{\circ} \mathrm{C}\right) \\
\end{array}$} & \multirow{2}{*}{$\begin{array}{c}\text { Zona Norte } \\
\text { T prom. }\left({ }^{\circ} \mathbf{C}\right)\end{array}$} & \multicolumn{2}{|c|}{ Zona Central } & \multirow{2}{*}{$z(m)$} & \multicolumn{2}{|c|}{ Penacho } \\
\hline & & & & T prom. $\left({ }^{\circ} \mathrm{C}\right)$ & $\mathrm{T} \max .\left({ }^{\circ} \mathrm{C}\right)$ & & T prom. $\left({ }^{\circ} \mathrm{C}\right)$ & $\mathrm{T} \max .\left({ }^{\circ} \mathrm{C}\right)$ \\
\hline \multirow{8}{*}{$\stackrel{-1}{i}$} & 0.5 & 89 & 101 & 112 & 172 & 1.73 & 206 & 402 \\
\hline & 1.5 & 111 & 135 & 141 & 218 & 1.54 & 171 & 387 \\
\hline & 2.5 & 154 & 185 & 221 & 398 & 1.24 & 236 & 549 \\
\hline & 3.5 & 122 & 176 & 200 & 314 & 0.99 & 335 & 688 \\
\hline & 4.5 & 87 & 108 & 122 & 183 & 0.65 & 542 & 827 \\
\hline & 5.5 & 81 & 81 & 103 & 150 & - & - & - \\
\hline & \multirow{2}{*}{$x(m)$} & Zona Sur & Zona Norte & \multicolumn{2}{|c|}{ Zona Central } & \multirow{2}{*}{$z(m)$} & \multicolumn{2}{|c|}{ Penacho } \\
\hline & & T prom. $\left({ }^{\circ} \mathrm{C}\right)$ & T prom. $\left({ }^{\circ} \mathrm{C}\right)$ & T prom. $\left({ }^{\circ} \mathrm{C}\right)$ & $\mathrm{T} \max .\left({ }^{\circ} \mathrm{C}\right)$ & & T prom. $\left({ }^{\circ} \mathrm{C}\right)$ & $\mathrm{T} \max .\left({ }^{\circ} \mathrm{C}\right)$ \\
\hline \multirow{8}{*}{$\begin{array}{l}\text { U } \\
i\end{array}$} & 0.5 & 206 & 176 & 222 & 318 & 1.73 & 450 & 774 \\
\hline & 1.5 & 293 & 230 & 298 & 451 & 1.54 & 381 & 749 \\
\hline & 2.5 & 446 & 310 & 463 & 711 & 1.24 & 405 & 853 \\
\hline & 3.5 & 397 & 274 & 411 & 760 & 0.99 & 501 & 896 \\
\hline & 4.5 & 207 & 187 & 247 & 525 & 0.65 & 685 & 883 \\
\hline & 5.5 & 174 & 141 & 199 & 365 & - & - & - \\
\hline & \multirow{2}{*}{$x(m)$} & Zona Sur & Zona Norte & \multicolumn{2}{|c|}{ Zona Central } & \multirow{2}{*}{$z(m)$} & \multicolumn{2}{|c|}{ Penacho } \\
\hline & & T prom. $\left({ }^{\circ} \mathrm{C}\right)$ & T prom. $\left({ }^{\circ} \mathrm{C}\right)$ & T prom. $\left({ }^{\circ} \mathrm{C}\right)$ & $\mathrm{T}$ max. $\left({ }^{\circ} \mathrm{C}\right)$ & & T prom. $\left({ }^{\circ} \mathrm{C}\right)$ & $\mathrm{T} \max .\left({ }^{\circ} \mathrm{C}\right)$ \\
\hline \multirow{8}{*}{$\begin{array}{l}m \\
\stackrel{0}{i}\end{array}$} & 0.5 & 54 & 63 & 76 & 141 & 1.95 & 422 & 614 \\
\hline & 1.5 & 63 & 67 & 94 & 158 & 1.69 & 387 & 564 \\
\hline & 2.5 & 83 & 31 & 122 & 190 & 1.41 & 462 & 748 \\
\hline & 3.5 & 112 & 109 & 162 & 234 & 1.13 & 515 & 698 \\
\hline & 4.5 & 158 & 153 & 229 & 306 & 0.85 & 739 & 866 \\
\hline & 5.5 & 315 & 276 & 403 & 568 & - & - & - \\
\hline & \multirow{2}{*}{$x(m)$} & Zona Sur & Zona Norte & \multicolumn{2}{|c|}{ Zona Central } & \multirow{2}{*}{$z(m)$} & \multicolumn{2}{|c|}{ Penacho } \\
\hline & & T prom. $\left({ }^{\circ} \mathrm{C}\right)$ & T prom. $\left({ }^{\circ} \mathrm{C}\right)$ & T prom. $\left({ }^{\circ} \mathrm{C}\right)$ & $\mathrm{T} \max .\left({ }^{\circ} \mathrm{C}\right)$ & & T prom. $\left({ }^{\circ} \mathrm{C}\right)$ & $\mathrm{T} \max .\left({ }^{\circ} \mathrm{C}\right)$ \\
\hline \multirow{6}{*}{ 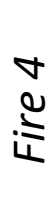 } & 0.5 & 217 & 232 & 295 & 440 & 1.89 & 701 & 949 \\
\hline & 1.5 & 346 & 362 & 465 & 644 & 1.73 & 672 & 905 \\
\hline & 2.5 & 559 & 41 & 713 & 955 & 1.54 & 766 & 938 \\
\hline & 3.5 & 558 & 511 & 712 & 968 & 1.44 & 726 & 896 \\
\hline & 4.5 & 276 & 289 & 427 & 647 & 1.25 & 646 & 909 \\
\hline & 5.5 & 241 & 231 & 332 & 537 & - & - & - \\
\hline
\end{tabular}

Tabla 5-2. Temperatura promedio $\left(\operatorname{Tprom}\left({ }^{\circ} \mathrm{C}\right)\right)$ y máximas $\left(\operatorname{Tmax}\left({ }^{\circ} \mathrm{C}\right)\right)$ registradas durante los ensayos. 
Para los termopares correspondientes al árbol de termopares vertical

1. El primer dígito indica

a. V: Pertenencia al árbol de termopares vertical

2. El segundo dígito, numérico, indica posición vertical relativa con respecto al resto de termopares del árbol de termopares vertical

a. 1 para el termopar situado a menor cota

b. 2, 3, 4 para los termopares intermedios conforme se aumenta cota

c. 5 para el termopar situado a mayor cota

La Tabla 5-2 incluye los valores promedio de las temperaturas del gas en las cuatro zonas (sur, norte, central y penacho) en las que se ha divido el espacio que rodea el puente. También muestra los valores máximos en dos de estas zonas (central y penacho), que se emplearán en la Sección 5.6.3.

La Tabla 5-3 incluye los intervalos de tiempo seleccionados para obtener los valores promedio mostrados en la Tabla 5-2. Como se puede ver en la Figura 5-4, estos valores aseguran que los promedios se obtuvieron en las zonas de meseta. Debe recordarse que la respuesta del termopar a los cambios de temperatura en el gas es casi instantánea.

\begin{tabular}{cccc}
\hline $\begin{array}{c}\text { Escenario } \\
\text { de fuego }\end{array}$ & $\begin{array}{c}\text { Inicio } \\
\text { intervalo (s) }\end{array}$ & $\begin{array}{c}\text { Final } \\
\text { intervalo (s) }\end{array}$ & $\begin{array}{c}\text { Duración } \\
\text { intervalo (s) }\end{array}$ \\
\hline Fire 1 & 400 & 1200 & 800 \\
Fire 2 & 200 & 1300 & 1100 \\
Fire 3 & 200 & 2000 & 1800 \\
Fire 4 & 700 & 1300 & 600 \\
\hline
\end{tabular}

Tabla 5-3. Intervalos considerados para obtener las temperaturas promedio.

\subsection{Modelo Simplificado. CorRelación de HeSKestad \& HAMAda}

\subsubsection{MODELOS EMPLEADOS EN LA INGENIERÍA FRENTE A INCENDIOS}

La ingeniería del fuego utiliza una gran cantidad de modelos, que pueden ordenarse de menor a mayor complejidad, del modo siguiente:

1. Las curvas nominales.

2. El tiempo de exposición equivalente.

3. Los fuegos paramétricos.

4. Los fuegos localizados.

5. Los modelos de zona.

6. Los modelos de campo o modelos de dinámica de fluidos computacional (CFD). 
De la lista cabe indicar que los cinco primeros se consideran modelos simplificados y el último se considera un modelo avanzado

Actualmente no hay, para el caso de fuego en puentes, curvas nominales, tiempos de exposición equivalentes o modelos de fuego paramétrico disponibles o que puedan ser de aplicación para incendios de puentes. Los modelos de zona, por otro lado, son de aplicación en recintos cerrados donde existe una estratificación del aire en dos zonas claramente diferenciadas. Su propia definición los deja fuera de cualquier consideración de su empleo en este tipo de problema.

El hecho de que algunos autores (Peris-Sayol et al. [ref4.03], Quiel et al. [ref4.04]) ya hayan analizado las variables a tener en cuenta en la obtención de las temperaturas máximas alcanzables en la estructura y sus alrededores durante un incendio podría suponer la base para el desarrollo de modelos más sencillos, aunque esto podría tardar algún tiempo dadas las singularidades del campo de estudio.

Hasta que esto ocurra, los primeros modelos simplificados que podrían emplearse para tratar de reproducir los incendios en puentes serían los fuegos localizados, prestando especial atención al modelo de "ceiling jet". A continuación, se estudiará su validez para los cuatro ensayos objeto de estudio en el presente capítulo.

\subsubsection{CEILING JETS}

\subsubsection{ANTECEDENTES TEÓRICOS}

Según Alpert [ref5.05], un ceiling jet es un flujo relativamente rápido de gas en una capa poco profunda debajo de la superficie del techo que es impulsada por la flotabilidad de los productos de combustión calientes del penacho. El flujo del ceiling jet emerge de la región de impacto del penacho en el techo, moviéndose radialmente lejos del fuego. Al hacerlo, la capa se vuelve más gruesa al arrastrar el aire de la habitación, lo que enfría los gases del chorro y reduce su velocidad. De manera similar, el techo también enfría la parte del chorro adyacente a él. La Figura 5-5 muestra un croquis del concepto de ceiling jet y una fotografía de una de los ensayos realizados con el puente experimental en la Universitat Politècnica de València. 
(a) Esquema conceptual

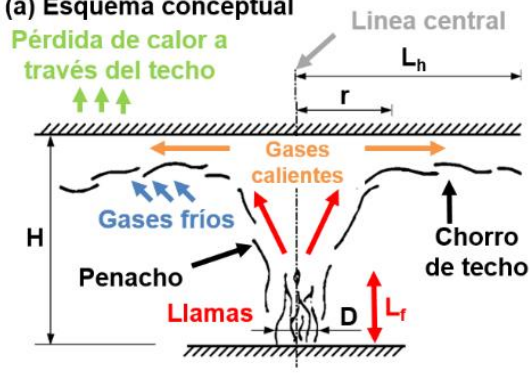

(b) Caso experimental

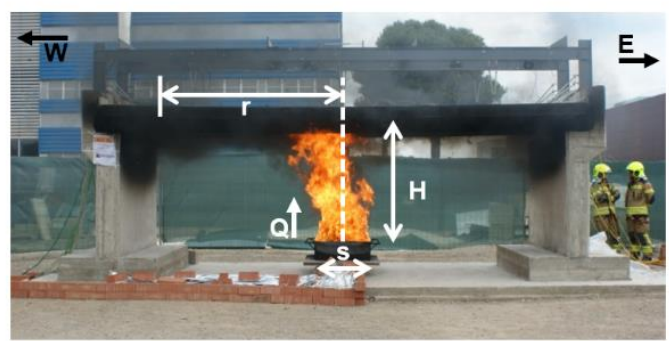

Figura 5-5. Ceiling jet con impacto de la llama: (a) Esquema conceptual y (b) Caso experimental.

Dependiendo de la relación $\mathrm{L}_{\mathrm{f}} / \mathrm{H}$ (ver Figura 5-5b), donde $\mathrm{L}_{\mathrm{f}}$ es la longitud de la llama y $\mathrm{H}$ la distancia vertical entre el combustible en llamas y el techo, se hace una distinción entre penachos débiles (donde la convección es el modo dominante de calor transferencia) y penachos fuertes (donde la radiación térmica será igual o más importante que la convección) [ref5.06]. No existe un límite claro entre ambos tipos de penacho, pero la teoría general de Alpert para penachos débiles [ref5.05, ref5.07] se obtuvo explícitamente para casos en los que la altura de la llama es mucho menor que la distancia entre el combustible encendido y el techo, mientras que la teoría de Heskestad \& Hamada [ref5.01] para penachos fuertes se validó para proporciones $\mathrm{L}_{\mathrm{f}} / \mathrm{H}$ que van de 0.2 a 2.0. En el presente estudio, la longitud de la llama $\mathrm{L}_{\mathrm{f}}$ se obtuvo utilizando la ecuación (ver Ec. 5-1) de Heskestad [ref5.08].

$L_{f}=-1.02 \cdot D+0.235 \cdot \mathrm{Q}^{2 / 5}$

Donde:

$\mathrm{Q}=$ Tasa de liberación de calor $(\mathrm{kW})$

$\mathrm{D}=$ Diámetro equivalente $(\mathrm{m})$ obtenido asumiendo que la Fuente de fuego es un círculo de la misma área que la de la fuente de fuego real. Para bandejas cuadradas el D se obtiene mediante la Ec. 5-2:

$D=2 \cdot s / \sqrt{\pi}$

donde s es el lado de la bandeja cuadrada.

La Tabla 5-4 muestra la aplicación de la Ec. 5-1 y la Ec. 5-2 a los ensayos de fuego del puente experimental analizados en este capítulo para obtener la longitud de la llama y la relación $L_{f} / H$ resultante. Los valores $L_{f} / H>1$ muestran que el fuego está incidiendo claramente en la losa de hormigón en los cuatro escenarios, por lo que los cuatro ensayos se consideran penachos fuertes. Este hecho indica que la correlación de Hamada y 
Heskestad [ref5.01] es el mejor enfoque simplificado para estimar las temperaturas del gas. Cabe señalar, además, que la correlación de Kowslowski y Motevalli [ref5.09], obtenida específicamente para configuraciones de canales (es decir, incendios confinados entre dos elementos longitudinales) para incendios de $5,2 \mathrm{~kW}$, no puede aplicarse a las pruebas del puente de Valencia porque solo es aplicable a penachos débiles con potencias de fuego muy inferiores.

\begin{tabular}{|c|c|c|c|c|c|c|}
\hline \multirow{2}{*}{$\begin{array}{c}\text { Escenario } \\
\text { de fuego }\end{array}$} & \multicolumn{2}{|c|}{ Bandeja } & \multirow{2}{*}{$\begin{array}{l}\text { HRR } \\
(\mathrm{kW})\end{array}$} & \multicolumn{2}{|c|}{ Altura } & \multirow{2}{*}{$\begin{array}{c}\mathbf{L f} / \mathbf{H} \\
(.)\end{array}$} \\
\hline & $\begin{array}{l}\text { Lado } \\
\text { s (m) }\end{array}$ & $\begin{array}{l}\text { Diámetro } \\
\text { (m) }\end{array}$ & & $\begin{array}{c}\text { Llama } \\
\text { (m) }\end{array}$ & $\begin{array}{c}\text { Losa } \\
(\mathbf{m})\end{array}$ & \\
\hline Fire1 & 0.50 & 0.56 & 426 & 2.07 & 1.85 & 1.12 \\
\hline Fire2 & 0.75 & 0.85 & 1130 & 3.05 & 1.85 & 1.65 \\
\hline Fire3 & 0.50 & 0.56 & 361 & 1.90 & 1.55 & 1.23 \\
\hline Fire4 & 0.75 & 0.85 & 1352 & 3.34 & 1.25 & 2.67 \\
\hline
\end{tabular}

Tabla 5-4. Resumen de la obtención de las ratios Lf/H.

\subsubsection{CORRELACión de HeSKestad \& HAMAda}

Heskestad \& Hamada [ref5.01] midieron temperaturas de ceiling jet para relaciones $\mathrm{L}_{\mathrm{f}} / \mathrm{H}$ que iban de 0.3 a 3.0 para fuegos de quemador de propano desde 12 a $764 \mathrm{~kW}$ situados bajo techos no confinados con $\mathrm{H}$ (distancia vertical entre quemador y techo) hasta $2.5 \mathrm{~m}$. Sus resultados se emplearon para obtener el incremento de la temperatura del gas bajo el techo a partir de los incrementos de temperatura del penacho para proporciones $\mathrm{L}_{\mathrm{f}} / \mathrm{H}$ menores o iguales a 2. Para valores $\mathrm{L}_{\mathrm{f}} / \mathrm{H}$ mayores de 2 , el calor liberado a través del techo resulta el causante de la falta de correlación con la correlación propuesta por los autores [ref5.05]. De acuerdo con los valores de $\mathrm{L}_{\mathrm{f}} / \mathrm{H}$ que se muestran en la Tabla 5-4, el escenario de fuego Fire 4 excede en gran medida el rango de aplicación de la correlación de Heskestad \& Hamada impuesto por los propios autores

\subsubsection{PARÁMETRos Y LiMitaciones}

La Eq. 5-3 propuesta por Heskestad \& Hamada [ref4-001] correlaciona el exceso de temperatura del gas $(\Delta \mathrm{T})$ a una distancia radial particular $r$ del eje vertical central del penacho y el incremento de temperatura en el gas del penacho $\left(\Delta T_{p}\right)$ donde alcanza el techo. La ecuación se aplica con r/b entre 1 y 40, donde b es el radio de la pluma efectiva en la intersección con el techo, es decir, el radio donde la velocidad del penacho de impacto es la mitad del valor de la línea central. La expresión para b viene dada por la Eq. 5-4. 
$\frac{\Delta \mathrm{T}}{\Delta T_{p}}=1.92 \cdot\left(\frac{b}{r}\right)-\exp \left[1.61 \cdot\left(1-\frac{\mathrm{r}}{b}\right)\right]$

$b=0.42 \cdot\left[\left(c_{\mathrm{p}} \cdot \rho_{\infty}\right)^{4 / 5} \cdot T_{\infty}^{3 / 5} \cdot g^{2 / 5}\right]^{-1 / 2} \cdot T_{\mathrm{p}}^{1 / 2} \cdot Q_{c}^{2 / 5} / \Delta \mathrm{T}_{p}^{3 / 5}$

Donde $c_{\mathrm{p}}=1.005 \mathrm{~kJ} \cdot \mathrm{kg}^{-1} \cdot \mathrm{K}^{-1}, \rho_{\infty}=1.204 \mathrm{~kg} / \mathrm{m}^{3}, \mathrm{~T}_{\infty}=20^{\circ} \mathrm{C}, \mathrm{g}=9.81 \mathrm{~m} / \mathrm{s}, \mathrm{Q}_{\mathrm{c}}$ (componente convectiva de la tasa de liberación de calor en $\mathrm{kW}$ ) y $T_{p}$ (temperatura en el centro del eje vertical del penacho en el punto de impacto con el techo expresado en ${ }^{\circ} \mathrm{C}$ ) se obtienen mediante la Ec. 5-5 y la Ec. 5-6, respectivamente.

$Q_{c}=\left(1-\chi_{r}\right) \cdot Q$

$T_{p}=\Delta T_{p}-T_{\infty}$

donde $\mathrm{Q}$ es la tasa de liberación de calor en $\mathrm{kW}, \Delta \mathrm{Tp}$ es el incremento de temperatura en el eje vertical central del penacho a la cota del techo y se obtiene mediante la Ec. 5-7 [ref5.05, ref5.10] y $\chi_{r}$ es la fracción radiactiva que se asume igual a 0.35 , de acuerdo con [ref5.11].

$\Delta T_{p}=16.9 \cdot \frac{\mathrm{Q}^{2 / 3}}{H^{5 / 3}} \quad($ Válida para $r / H \leq 0.18)$

(Ec. 5-7)

\subsubsection{APLICACIÓN A LOS ENSAYOS "VALENCIA BRIDGE FIRE TESTS".}

La Figura 5-5a muestra cómo la distancia radial desde la línea central ( $\mathrm{r}$ en la Ec. 4-3) ha sido sustituida por la distancia longitudinal desde el eje vertical central del penacho de fuego (ver Figura 5-5b), obteniendo una buena correlación (ver la Figura 5-6b) con los resultados presentados en la Sección 5.3. Cabe señalar que, aunque la correlación de Heskestad \& Hamada [ref5.01], se definió para techos no confinados (con la obstrucción al fuego más cercana al fuego situada al menos a $3 \mathrm{H}$ [ref5.12]), encaja perfectamente con los resultados experimentales obtenidos para los ensayos empleados para representar los escenarios de fuego Fire 1 y Fire 3 (donde apenas hay $1 \mathrm{~m}$ entre los ejes de las vigas). Los valores $\mathrm{H}$ se han obtenido restando el nivel del combustible al comienzo de la prueba (0.2 m para los escenarios de fuego Fire 1 y Fire 2, 0.5 para el escenario de fuego Fire 3 y $0.8 \mathrm{~m}$ para el escenario de fuego Fire 4 ) a la cota (de $2.05 \mathrm{~m}$ ) de la superficie inferior de la losa de hormigón. El resultado es una $\mathrm{H}$ de $1.85 \mathrm{~m}$ para los escenarios de fuego Fire 1 y Fire 2, una $\mathrm{H}$ de $1.55 \mathrm{~m}$ para el escenario de fuego Fire $3 \mathrm{y}$ una $\mathrm{H}$ de $1.25 \mathrm{~m}$ para el escenario de fuego Fire 4.

La Figura 5-6 muestra las temperaturas del gas en toda la región central obtenidas del modelo de Heskestad \& Hamada [ref5.01], es decir, de acuerdo con la Ec. 4-3 a la Ec. 4-7. La Figura 5-6a compara los cuatro escenarios de incendio considerados, mientras que la Figura 5-6b solo incluye los tres escenarios de incendios (Fire 1, Fire 2 y Fire 3) 
dentro del rango de aplicación del modelo $\left(\mathrm{L}_{\mathrm{f}} / \mathrm{H} \leq 2\right)$. A partir de los resultados mostrados en la Figura 5-6, se puede afirmar que:

1. El modelo de Heskestad \& Hamada da una buena predicción de la forma general de las temperaturas a lo largo del eje longitudinal del puente, así como de las temperaturas pico del gas.

2. Las temperaturas máximas predichas por la correlación de Heskestad \& Hamada en la zona central (considerando únicamente los termopares correspondientes a los árboles de termopares horizontales) en los experimentos son:

a. $333^{\circ} \mathrm{C}$ en las secciones $\mathrm{S} 3(\mathrm{x}=2.5 \mathrm{~m})$ y S4 $(\mathrm{x}=3.5 \mathrm{~m})$ en el Fire 1

b. $\quad 620^{\circ} \mathrm{C}$ en las secciones $\mathrm{S} 3(\mathrm{x}=2.5 \mathrm{~m})$ y S4 $(\mathrm{x}=3.5 \mathrm{~m})$ en el Fire 2

c. $396^{\circ} \mathrm{C}$ en la sección $\mathrm{S} 6(\mathrm{x}=5.5 \mathrm{~m})$ en el Fire 3

3. Estos valores son un:

a. $16.3 \%$ más bajo que el medido en el escenario de fuego Fire 1

b. $18.5 \%$ más bajo que el medido en el escenario de fuego Fire 2

c. $30.4 \%$ más bajo que el medido en el escenario de fuego Fire 3

4. Las diferencias observadas pueden atribuirse a:

a. la existencia de las vigas que confinan los gases más calientes

b. la influencia de las variables no incluidas en el modelo simplificado de Heskestad \& Hamada, como el tipo de combustible

c. el hecho asumir algunos de los valores empleados en el modelo, como es el caso de la fracción radiativa $\left(\chi_{r}\right)$.

Dados los resultados obtenidos se puede decir que:

1. La correlación de Heskestad \& Hamada se puede utilizar para el diseño preliminar de futuros ensayos de incendios en puentes con HRR entre 361 y $1130 \mathrm{~kW}$. Aunque este modelo podría subestimar las temperaturas del gas hasta en un $30.4 \%$, se acercará bastante a la forma general de las temperaturas de gas esperadas en todo el puente, así como también a las temperaturas máximas.

2. La correlación Heskestad \& Hamada no se puede utilizar para estudiar incendios de puentes reales, ya que estos eventos involucran tasas de liberación de calor superiores al límite de aplicación de la correlación (la HRR para un automóvil es de 5 MW y la de un camión cisterna es de aproximadamente 100-200 MW [ref5.13, ref5.14]). 

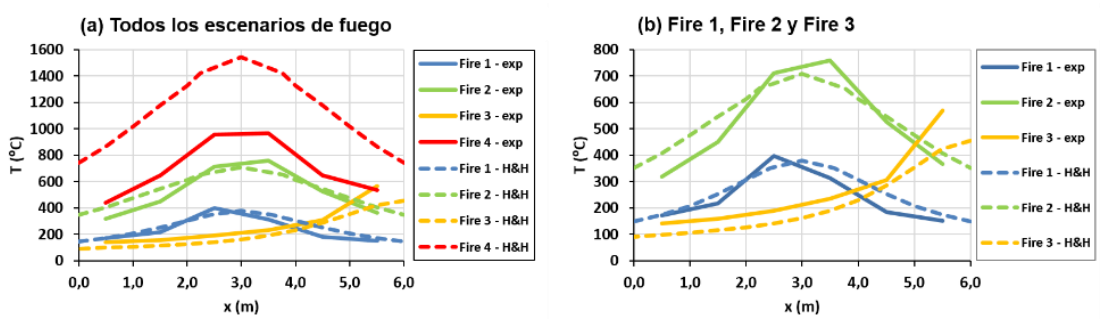

Figura 5-6. Temperaturas en la zona central para (a) todos los escenarios de fuego y (b) escenarios de fuego Fire 1, Fire 2 y Fire 3. Valores experimentales máximos en línea continua y procedentes de la correlación de $H \& H$ en línea a trazos.

La Figura 5-7 muestra la dispersión entre las temperaturas estimadas por el modelo de Heskestad \& Hamada y las temperaturas medidas experimentalmente a lo largo del eje longitudinal del puente para los ensayos Test 2 (Fire 1), Test 4 (Fire 2) y Test 7 (Fire 3). La dispersión en las secciones S3 $(\mathrm{x}=2.5 \mathrm{~m})$ y $\mathrm{S} 4(\mathrm{x}=3.5 \mathrm{~m})$ varía entre $-16 \%$ y $+6 \%$ para el escenario de fuego Fire 1 y entre $-12 \%$ y $-18 \%$ para el escenario de fuego Fire 2. La dispersión en las secciones S5 $(\mathrm{x}=4.5 \mathrm{~m})$ y S6 $(\mathrm{x}=5.5 \mathrm{~m})$ varía entre $-11 \%$ y $-30 \%$ para el escenario de fuego Fire 3. Estos valores son aceptables si se tiene en cuenta que una dispersión de hasta el 20\% [ref5.11, ref5.15] se considera aceptable en modelos de fuego avanzados (CFDs) que se supone deberían dar una mejor aproximación a la realidad.

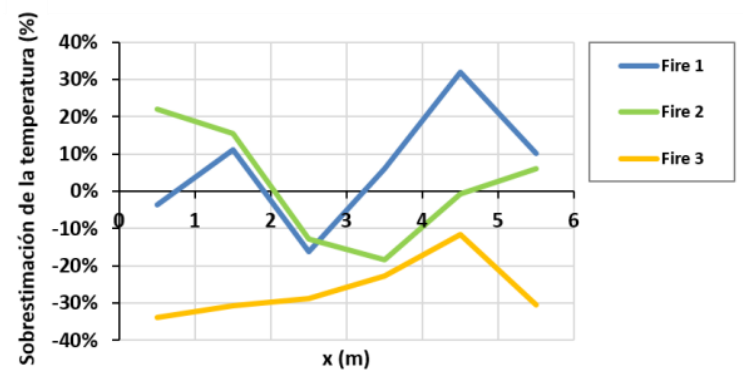

Figura 5-7. Dispersión en la región central entre las temperaturas obtenidas mediante la correlación de Heskestad y Hamada y las temperaturas máximas registradas experimentalmente.

\subsection{MOdelo AVANZADo. Fire DYNAMICS SIMUlator (FDS)}

En esta sección, se estudia la capacidad de los métodos de cálculo avanzados (modelos de CFD) implementados en el software Fire Dynamics Simulator (FDS en adelante) para predecir los resultados obtenidos en los ensayos realizados en el Capítulo 4. El modelo hidrodinámico de FDS resuelve numéricamente una forma de las ecuaciones de Navier- 
Stokes apropiadas para baja velocidad (Ma <0.3), correspondiente a flujos impulsados térmicamente, con énfasis en el transporte de humo y calor en los incendios. El algoritmo central es un esquema explícito predictor-corrector, de segundo orden preciso en espacio y tiempo. La turbulencia se considera por medio de un modelo de simulación de grandes remolinos (LES). El FDS utiliza una reacción química controlada por mezcla en un solo paso para el modelo de combustión, que utiliza tres especies agrupadas (aire, combustible y productos), las dos últimas se calculan explícitamente. La transferencia de calor radiativa se incluye en el modelo a través de la solución de la ecuación de transporte de radiación para un gas gris. La ecuación se resuelve usando el Método de los volúmenes finitos (FVM). Los coeficientes de absorción de las mezclas de gas y hollín se calculan utilizando el modelo de banda estrecha RadCal [ref5.11].

Aunque el FDS se ha utilizado previamente en el ámbito del fuego en puentes [ref5.015, ref5.16, ref5.17], no ha sido validado para este tipo de aplicación específica más que mediante el empleo de datos, habitualmente escasos y poco precisos, recopilados una vez extinguido el incendio empleado para la validación

La construcción de un modelo FDS [ref5.11] requiere definir:

1. El volumen de control donde se realizará el análisis y sus condiciones de contorno para representar el efecto del entorno que no queda incluido en el volumen de control

2. El mallado o discretización del volumen de control que dividirá el volumen de control en celdas sobre las que se resolverán las ecuaciones del problema. A priori una menor dimensión de las celdas implicará soluciones más precisas a cambio de mayores costes computacionales.

3. La geometría incluida en el volumen de control y adaptada a las dimensiones de las celdas de la malla empleada. La geometría sirve tanto definir recintos que condicionen el movimiento de los gases y otros productos como para representar elementos estructurales sometidos a cierta exposición térmica.

4. Las propiedades de los materiales, sean combustibles o no. En el caso de materiales estructurales en los que se quiera estudiar su calentamiento son de interés propiedades como la conductividad, la densidad, el calor específico y la emisividad.

5. Las fuentes de fuego que pueden definirse mediante reacciones químicas o imponiendo una tasa de liberación de calor específica, si es conocida.

6. El modelo de combustión que permite caracterizar como se produce la misma.

7. Los sensores puntuales o superficiales donde se registran los resultados del análisis, como temperaturas, velocidades y flujos de calor entre otros 
En los siguientes apartados se detallan los componentes del modelo definidos para la validación mediante FDS.

\subsubsection{VOLUMEN DE CONTROL Y MALLADO}

El volumen de control utilizado en este estudio (ver Figura 5-8) se ha dimensionado para incluir el puente, así como un volumen adicional a su alrededor con el fin de garantizar que las condiciones de contorno no afecten la dinámica del problema. Mide $12.0 \mathrm{~m} \mathrm{x}$ $12.0 \mathrm{~m} \mathrm{x} 12.0 \mathrm{~m}$ en las direcciones $x, y \mathrm{y} z$, respectivamente. El volumen tiene un total de 691000 celdas paralelepipédicas distribuidas en 8 mallas no uniformes. La mayoría de las celdas tienen dimensiones de $0.125 \mathrm{~m}$ x $0.125 \mathrm{~m}$ x $0.100 \mathrm{~m}$ en las direcciones $x, y$ y $z$, respectivamente. En la región donde se encuentran las vigas y la losa de hormigón las dimensiones de las celdas se redujeron a $0.0625 \mathrm{~m}$ y $0.075 \mathrm{~m}$ en las direcciones $y \mathrm{y}$ $z$, respectivamente.

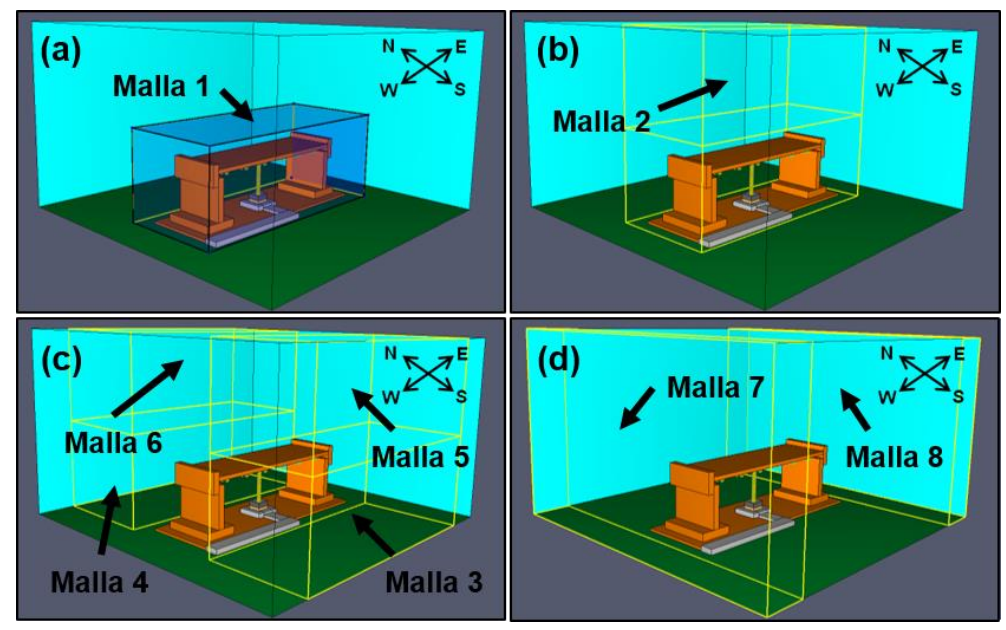

Figura 5-8. Ocho mallas no uniformes empleadas en el modelo FDS.

El volumen de control y las dimensiones de las ocho mallas son el resultado de un análisis de sensibilidad que ha buscado un equilibrio entre precisión y tiempo de cálculo. Como se sugiere en la guía de usuario FDS6 [ref5.11], la relación de aspecto de la celda se ha mantenido igual o inferior a 2 para no penalizar la eficiencia del cálculo. En la Figura 5-8 se muestra la distribución de mallas en el volumen de control para reducir las imprecisiones asociadas con la transferencia de llama y hollín entre mallas. La malla 1 (ver Figura 5-8a) se ha definido así para contener la totalidad de las llamas en su interior. De manera similar, el transporte de hollín se ha limitado principalmente a las Mallas 1 y 2 (ver Figura 5-8b). El resto de mallas (desde la 3 hasta la 8) se han empleado (ver Figura 
5-8c y Figura 5-8d) para incorporar suficiente distancia desde la fuente de fuego hasta los contornos del volumen de control, asegurando así que las condiciones de contorno abierto empleadas no afectaran a los resultados.

\subsubsection{GEOMETRÍA Y MATERIALES}

La geometría del puente incluida en el modelo FDS se muestra en la Figura 5-9. Las diferencias entre la geometría mostrada en esta figura y las correspondientes a la Figura 5-2 se deben al necesario ajuste de la geometría al tamaño de las celdas definido previamente. Por este motivo para la definición del mallado descrito previamente se tuvo en cuenta la reproducción fiel de los parámetros geométricos básicos del problema:

1. Gálibo de $1.9 \mathrm{~m}$

2. Canto de las vigas de $0.15 \mathrm{~m}$

3. Canto de la losa de $0.15 \mathrm{~m}$

4. Separación entre ejes de las vigas de $1.0 \mathrm{~m}$

5. Ancho de la losa de hormigón de $2.0 \mathrm{~m}$

Además de la geometría del puente, en cada escenario de fuego se ha incluido la zona inerte (ver Figura 5-10) que materializaba la base sobre la que se dispone la bandeja de combustible y la protección del cableado hasta la báscula.

(a) Alzado

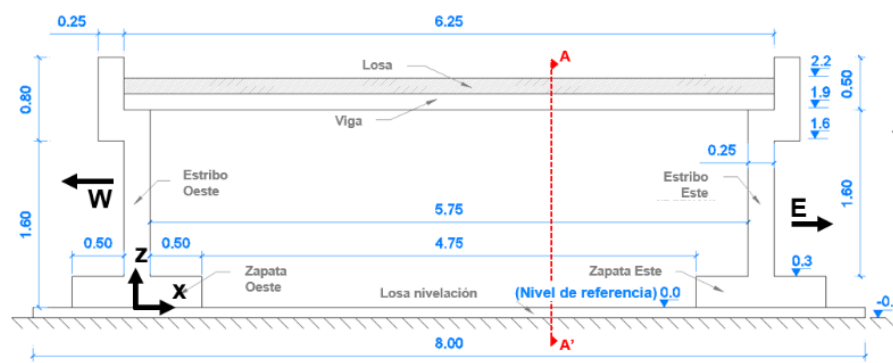

(b) Estribo y detalles tablero

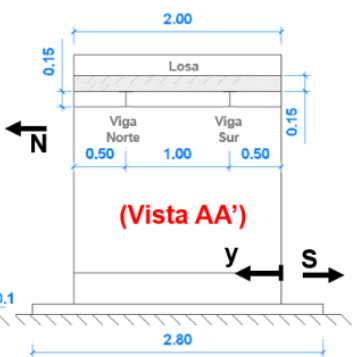

Figura 5-9. Geometría del puente en FDS: (a) Alzado y (b) Estribo y detalles del tablero. Dimensiones expresadas en $m$.

El modelo FDS calcula la transferencia de calor unidimensional requerida por la definición de los espesores y las propiedades de los materiales utilizados. Los espesores del material se especifican en la Figura 5-10 y sus propiedades térmicas se han incluido en la Tabla 5-5. El parámetro de "superficie trasera" ("backing parameter") utilizado para indicar condiciones de contorno térmico en sólidos se ha fijado como "Expuesto" para las superficies planas de acero y "Hueco de aire " ("air gap") para los sólidos de 
hormigón en los que se presupone que estarán a temperatura ambiente en su cara no expuesta.

(a) Materiales y superficies

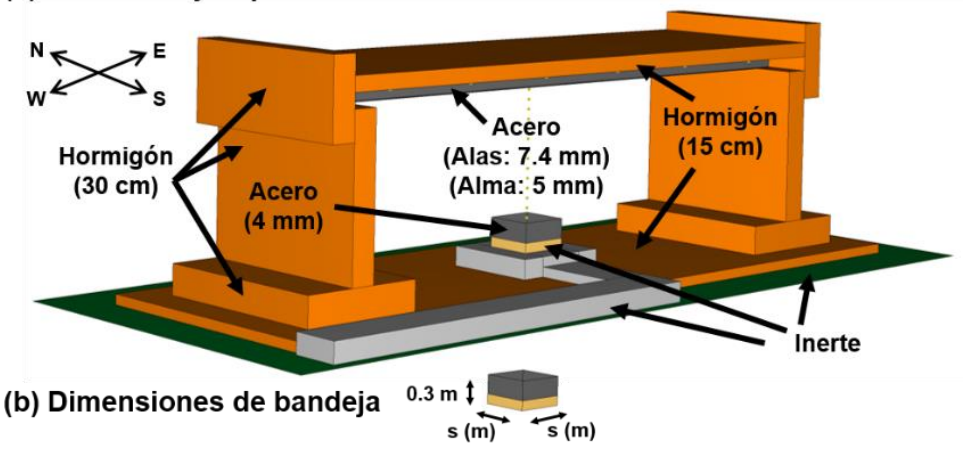

(c) Área inerte

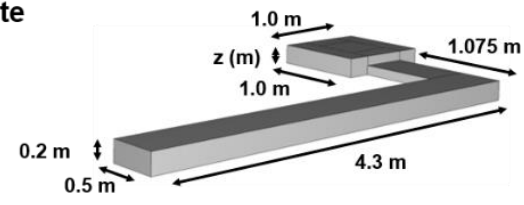

Figura 5-10. Definición del modelo FDS: (a) Materiales y superficies, (b) Dimensiones de las bandejas y (c) Área inerte.

\begin{tabular}{cccccc}
\hline Material & $\begin{array}{c}\text { Densidad } \\
\left(\mathbf{k g} / \mathbf{m}^{3}\right)\end{array}$ & $\begin{array}{c}\text { Calor } \\
\text { específico } \\
\left(\mathbf{k J} / \mathbf{k g}^{\circ} \mathbf{C}\right)\end{array}$ & $\begin{array}{c}\text { Conductividad } \\
\left(\mathbf{W} / \mathbf{m}^{\circ} \mathbf{C}\right)\end{array}$ & $\begin{array}{c}\text { Emisividad } \\
(.)\end{array}$ & $\begin{array}{c}\text { Coeficiente } \\
\text { absorción }\end{array}$ \\
\hline Acero & 7850 & 0.46 & 45.8 & 0.95 & $5 \cdot 10^{4}$ \\
Hormigón & 2280 & 1.04 & 1.8 & 0.9 & $5 \cdot 10^{4}$ \\
\hline
\end{tabular}

Tabla 5-5. Propiedades térmicas del material. Base de datos de Pyrosim [ref5.018]. 


\subsubsection{CARGA DE FUEGO Y MODELO DE COMBUSTIÓN}

La carga de fuego se ha definido en función de los pesos registrados por la báscula durante los cuatro ensayos objeto de estudio (ver Figura 5-2 y Tabla 5-4). En la Figura 5-11 cabe diferenciar entre:

1. La HRR obtenida indirectamente a partir del registro de la báscula durante los ensayos mediante la Ec. 5-8 y empleada como input en los modelos de fuego.

2. La HRR finalmente registrada por el software FDS durante las simulaciones.

$\mathrm{Q}=A_{\text {fire }} \cdot \dot{m}^{\prime \prime} \cdot \Delta H_{c}$

Donde:

$Q$ es la tasa de liberación de calor del fuego en MW

$A_{\text {fire }}$ es la huella del fuego en $\mathrm{m}^{2}$.

$\dot{m}$ " es la tasa de pérdida de masa en $\mathrm{kg} / \mathrm{m}^{2} / \mathrm{s}$.

$\Delta H_{c}$ es el calor de combustión en MJ/kg. $43.7 \mathrm{MJ} / \mathrm{kg}$ si es gasolina [Ref4-002]

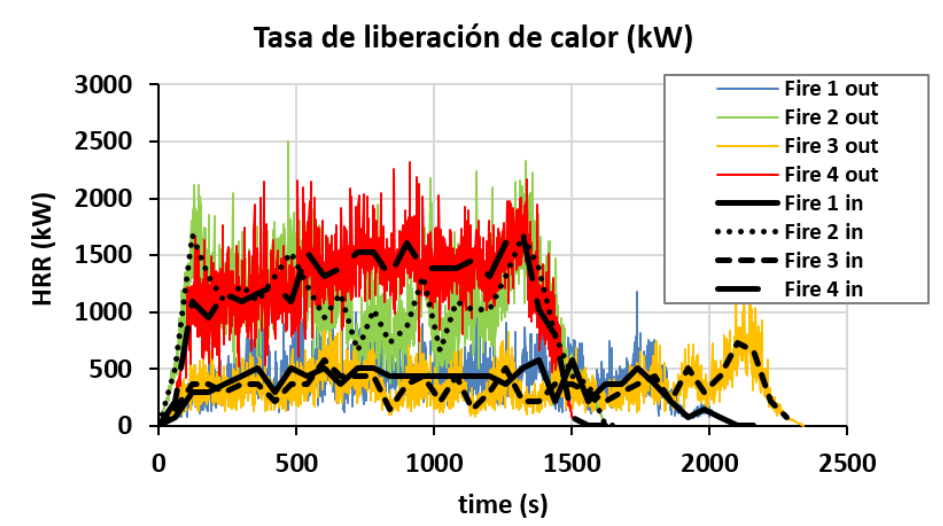

Figura 5-11. Curva tiempo-HRR para los cuatro escenarios de fuego: (negro) definido como el input $y$ (coloreado) el registrado durante las simulaciones de FDS.

FDS permite la definición de las fuentes de fuego a través de superficies específicas identificadas como quemadores. En las simulaciones FDS realizadas para reproducir los ensayos realizados en el puente experimental, el quemador se ha representado mediante una superficie cuadrada horizontal: 
1. De $0.25 \mathrm{~m}^{2}$ para los escenarios de fuego Fire 1 y Fire 3

2. De $0.5625 \mathrm{~m}^{2}$ para los escenarios de fuego Fire 2 y Fire 4

La curva tiempo-tasa de liberación de calor por unidad de superficie (t-HRRPUA) se ha obtenido dividiendo la curva tiempo-tasa de liberación de calor (t-HRR), que corresponde a la curva negra en la Figura 5-11, por la superficie correspondiente del quemador para cada ensayo concreto.

Los valores promedio registrados en FDS durante la simulación de HRR y HRRPUA para cada escenario se incluyen en la Tabla 5-1 y la Figura 5-12, respectivamente. La coordenada vertical del quemador $\left(\mathrm{z}_{\mathrm{b}}\right)$ para cada escenario se define en la Figura 5-12 y representa el nivel de la base de las llamas.

La carga de fuego emplea la reacción de heptano proporcionada por la librería de combustibles Pyrosim 2016.1.0425 [ref5.018] y el modelo de combustión de fracción de mezcla propuesto por McGrattan et al [ref5.11, ref5.19], con un factor de radiación de 0.35. El rendimiento de hollín (soot yield) se ha fijado en 0.037, de acuerdo con [ref5.20].

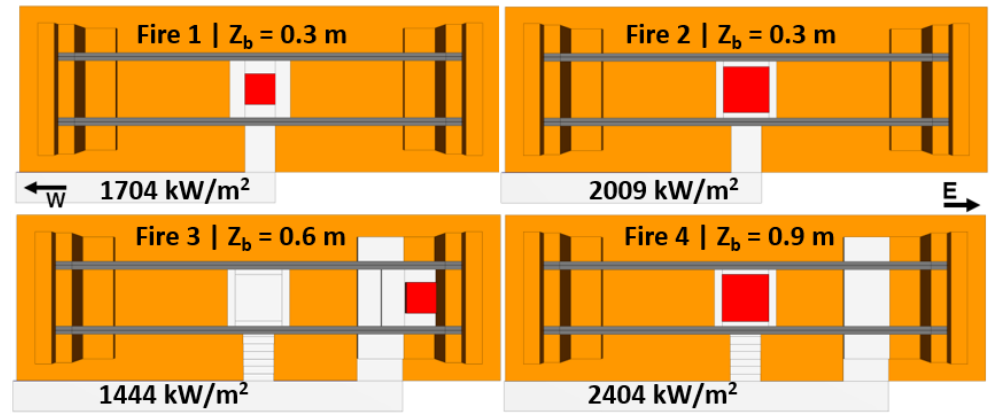

Figura 5-12. Modelo FDS. Vista en planta de los distintos escenarios. La superficie del quemador se representa en rojo y las vigas de acero en gris (losa de hormigón no se ha incluido en la figura).

\subsubsection{DISTRIBUCIÓN Y TIPO DE SENSORES}

Los sensores del modelo FDS son elementos puntuales que almacenan una o más de las variables empleadas y calculadas durante la simulación. Su existencia permite reducir las dimensiones de los archivos de salida, al permitir el almacenamiento de las variables seleccionadas en las posiciones definidas, lo que permite omitir el almacenamiento de información que no se vaya a emplear posteriormente.

Para registrar las temperaturas durante las simulaciones a comparar con las registradas experimentalmente durante los ensayos, se han incluido dieciocho termopares con vaina de acero inoxidable de $1.5 \mathrm{~mm}$ de diámetro. Los sensores se han colocado $5 \mathrm{~cm}$ debajo 
de la losa de hormigón en las mismas seis secciones definidas en los ensayos experimentales (ver Figura 5-2).

También se han incluido cinco termopares directamente encima del quemador en la posición de los termopares en el árbol de termopares vertical (ver Figura 5-2).

\subsubsection{RESUltadOS}

La Figura 5-13a y la Figura 5-13b comparan las temperaturas obtenidas mediante las simulaciones de incendios mediante FDS y los resultados obtenidos experimentalmente. En la Figura 5-13a, la comparación emplea temperaturas promedio durante la etapa de meseta del incendio. En estos casos, los modelos numéricos sobreestiman las temperaturas experimentales entre un 30 y un 120\% (ver Figura 5-13c). Esta diferencia se puede atribuir al viento presente durante los ensayos, pero no modelado en las simulaciones numéricas. El viento, que en ocasiones inclinó las llamas lejos de la vertical (ver Figura 5-14a), enfrió en parte los gases bajo el tablero.
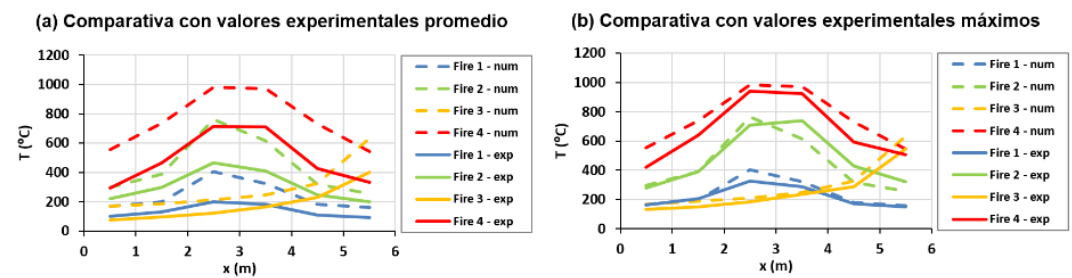

(c) \% diferencias con valores experimentales promedio
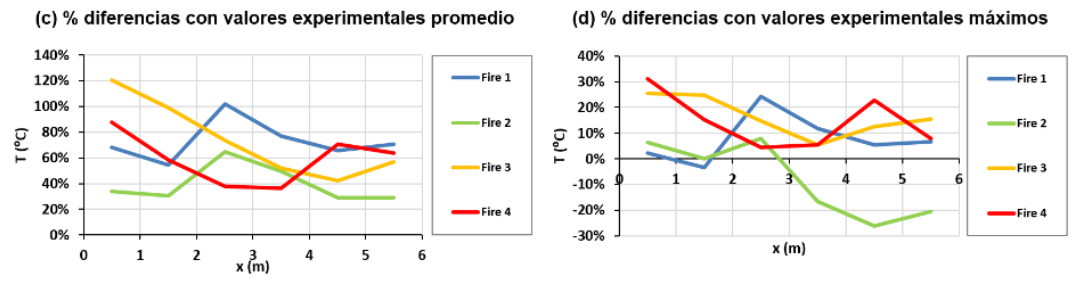

Figura 5-13. Comparativa entre resultados experimentales (exp) y numéricos (num). Todos los valores numéricos son promedios mientras que los valores experimentales son promedios (gráficas a yc) y máximos (gráficas b y d).

En la Figura 5-13b se comparan las temperaturas máximas del gas registradas experimentalmente (entendiendo que éstas temperaturas deberían aproximarse más a las que se habrían registrado durante los mismos ensayos sin la existencia de viento) con las obtenidas mediante las simulaciones de incendios (donde no se ha considerado el efecto del viento). Se puede observar que los modelos numéricos proporcionan una predicción muy precisa de los valores máximos y de la distribución de las temperaturas del gas en 
la zona central del tablero. En este caso, la diferencia entre las temperaturas medidas y las pronosticadas por la simulación de incendios (ver Figura 5-13d) oscila entre:

1. Un -25\% para el escenario de fuego Fire 2

2. Un $+30 \%$ para el escenario de fuego Fire 4

Estas diferencias son aceptables en la validación experimental de los modelos FDS, como se explicará más adelante en la Sección 5.6.3.2.

La comparativa entre la Figura 5-14b y la Figura 5-14c permite apreciar visualmente la similitud entre el fuego simulado mediante FDS y el fuego obtenido en el ensayo experimental para el caso concreto del escenario de fuego Fire 4.
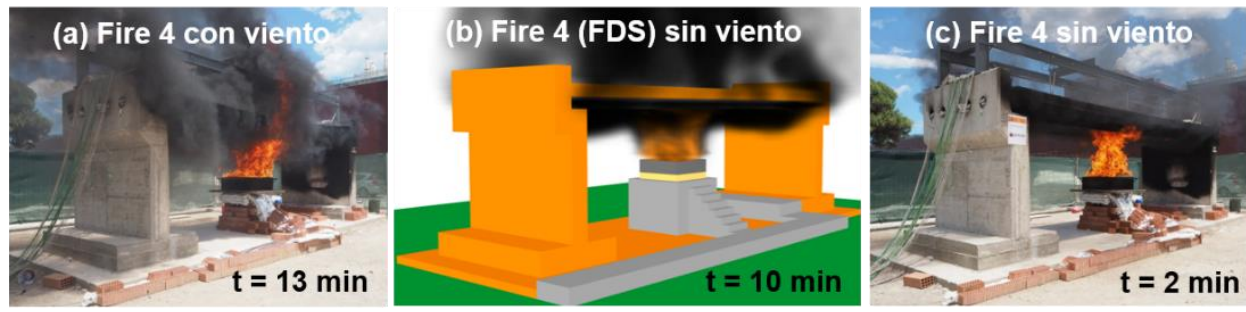

Figura 5-14. Efecto del viento en el escenario de fuego Fire 4: (a) Ensayo Test 8 con viento, (b) Simulación numérica sin viento y (c) Ensayo Test 8 sin viento.
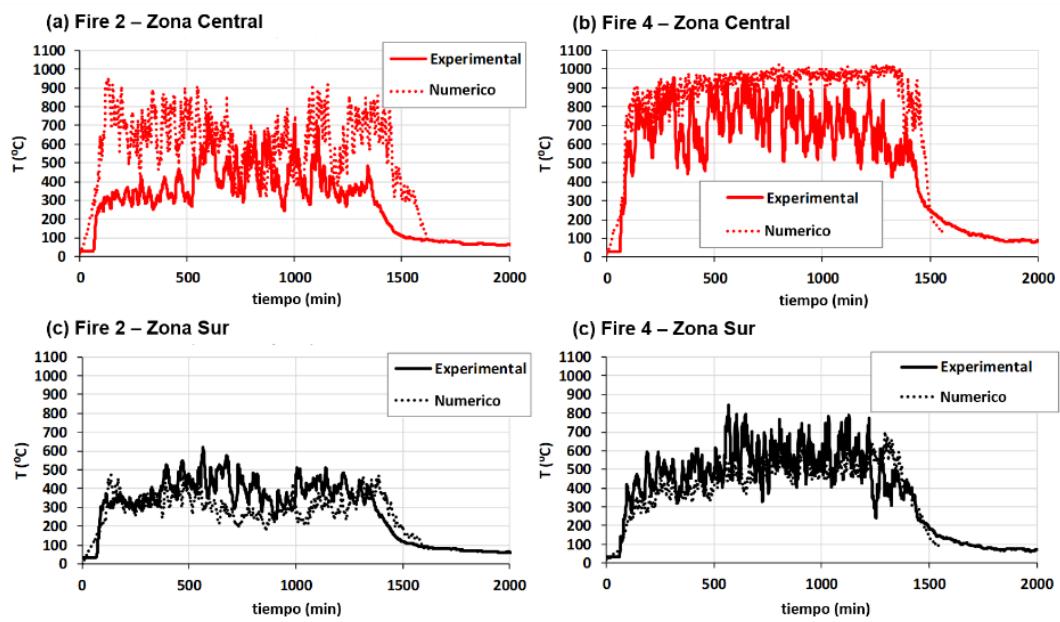

Figura 5-15. Curvas tiempo-temperatura en la sección S4: (a) Fire 2 en la Zona Central, (b) Fire 4 en la Zona Central, (c) Fire 2 en la Zona Sur y (d) Fire 4 en la Zona Sur. 
La Figura 5-15 muestra las temperaturas del gas registradas en el tiempo en la sección S4 (ver Figura 5-2) en las zonas central y sur para los escenarios de fuego Fire 2 y Fire 4. Estos escenarios han sido seleccionados porque han mostrado una clara influencia del viento sobre las temperaturas de los gases. No se proporcionan figuras similares para el resto de ensayos puesto que los valores han sido similares.

\begin{tabular}{|c|c|c|c|c|c|c|}
\hline T prom. $\left({ }^{\circ} \mathrm{C}\right)$ & $x(m)$ & Zona Sur & Zona Norte & Zona Central & $z(m)$ & Penacho \\
\hline \multirow{6}{*}{ 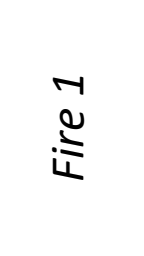 } & 0.5 & 125 & 125 & 168 & 1.73 & 470 \\
\hline & 1.5 & 125 & 125 & 198 & 1.54 & 520 \\
\hline & 2.5 & 161 & 154 & 405 & 1.24 & 609 \\
\hline & 3.5 & 150 & 148 & 322 & 0.99 & 663 \\
\hline & 4.5 & 116 & 117 & 182 & 0.65 & 799 \\
\hline & 5.5 & 124 & 123 & 158 & - & - \\
\hline \multirow{6}{*}{$\begin{array}{l}\text { U } \\
\stackrel{Ð}{*}\end{array}$} & 0.5 & 212 & 210 & 297 & 1.73 & 768 \\
\hline & 1.5 & 233 & 239 & 389 & 1.54 & 722 \\
\hline & 2.5 & 342 & 318 & 762 & 1.24 & 728 \\
\hline & 3.5 & 303 & 287 & 615 & 0.99 & 737 \\
\hline & 4.5 & 206 & 203 & 319 & 0.65 & 746 \\
\hline & 5.5 & 200 & 197 & 257 & - & - \\
\hline \multirow{6}{*}{$\begin{array}{l}m \\
\stackrel{0}{*} \\
\stackrel{1}{*}\end{array}$} & 0.5 & 104 & 103 & 169 & 1.95 & 462 \\
\hline & 1.5 & 82 & 81 & 191 & 1.69 & 366 \\
\hline & 2.5 & 93 & 92 & 216 & 1.41 & 386 \\
\hline & 3.5 & 123 & 121 & 253 & 1.13 & 487 \\
\hline & 4.5 & 168 & 165 & 334 & 0.85 & 755 \\
\hline & 5.5 & 241 & 240 & 643 & - & - \\
\hline \multirow{6}{*}{$\begin{array}{l}\forall \\
\stackrel{\Theta}{*} \\
\stackrel{*}{*}\end{array}$} & 0.5 & 361 & 336 & 554 & 1.89 & 661 \\
\hline & 1.5 & 355 & 338 & 736 & 1.73 & 979 \\
\hline & 2.5 & 514 & 443 & 982 & 1.54 & 983 \\
\hline & 3.5 & 522 & 454 & 970 & 1.44 & 975 \\
\hline & 4.5 & 367 & 370 & 729 & 1.25 & 791 \\
\hline & 5.5 & 396 & 372 & 544 & - & - \\
\hline
\end{tabular}

Tabla 5-6. Temperaturas promedio (T prom. $\left.\left({ }^{\circ} \mathrm{C}\right)\right)$ obtenidas a partir de las simulaciones de incendios realizadas con FDS

La Figura 5-15a y la Figura 5-15b muestran cómo las temperaturas experimentales registradas por el termopar GC4 (ver Figura 5-2) en la zona central (para los escenarios de fuego Fire 2 y Fire 4, respectivamente) son iguales o menores que calculadas mediante las simulaciones de incendios. La Figura 5-15b muestra claramente que los valores máximos registrados durante el ensayo correspondiente al escenario de fuego Fire 4 son muy similares a los valores obtenidos mediante la simulación de incendios, 
lo que puede atribuirse al menor efecto del viento durante ese ensayo. Por otro lado, la Figura 5-15c y la Figura 5-15d muestran las temperaturas registradas por el termopar GS4 (en la región sur), donde las temperaturas obtenidas experimentalmente son superiores a las temperaturas obtenidas a partir de las simulaciones de incendios. Esto podría atribuirse a que, en el registro experimental con viento, el viento inclina las llamas hacia el sur provocando un aumento de la temperatura del gas en esa zona.

Los resultados de la Figura 5-15 quedarían explicados si se toma como base la simulación de incendios (sin consideración de viento) y se introduce un caso alternativo con viento norte-sur, como corresponde a los ensayos experimentales). La presencia de viento norte-sur inclinaría las llamas hacia la zona sur, produciendo un descenso de las temperaturas de la zona central y un incremento de las mismas en la zona sur.

En la Tabla 5-6 se incluyen las temperaturas promedio registradas durante las simulaciones numéricas realizadas en FDS mediante los intervalos definidos en la Tabla 5-3 para los cuatro escenarios de incendio. Estas temperaturas se emplearán, junto con las registradas durante los ensayos (ver Tabla 5-2) en el análisis de incertidumbre de la Sección 5.6.

\subsection{ANÁLISIS DE INCERTIDUMBRE DE LOS RESULTADOS OBTENIDOS CON FDS.}

Una vez obtenidas las temperaturas mediante el modelo de avanzado de simulación de incendios y comparadas con las temperaturas registradas durante los ensayos se detectan diferencias entre ambos registros. Estas diferencias pueden ser debidas tanto a errores de medición durante los ensayos (errores experimentales, $u_{E}$ ) como a inexactitudes en el modelo numérico (errores de modelo, $u_{M}$ ). Los errores de medición se pueden clasificar en aquellos correspondientes a la medición experimental de variables prescritas, $\mathrm{u}_{\mathrm{E} 1}$, (empleadas como input en el modelo, como la pérdida de masa o la tasa de liberación de calor) y aquellos correspondientes a la medición experimental de variables calculadas, $\mathrm{u}_{\mathrm{E} 2}$, (output de las simulaciones de incendios). Los errores del modelo se pueden atribuir a distintas casusas, cómo:

1. Las diferencias entre la geometría real y modelada

2. Las diferencias entre la HRR experimental y la HRR finalmente empleada en las simulaciones (ver Figura 5-13)

3. Las hipótesis y suposiciones físicas del modelo ( $\mathrm{p}$. Ej. factor de radiación y parámetro de soot yield). 
En la Figura 5-16 se incluye un esquema que resume las fuentes de error mencionadas e incluye las variables concretas del caso de estudio.

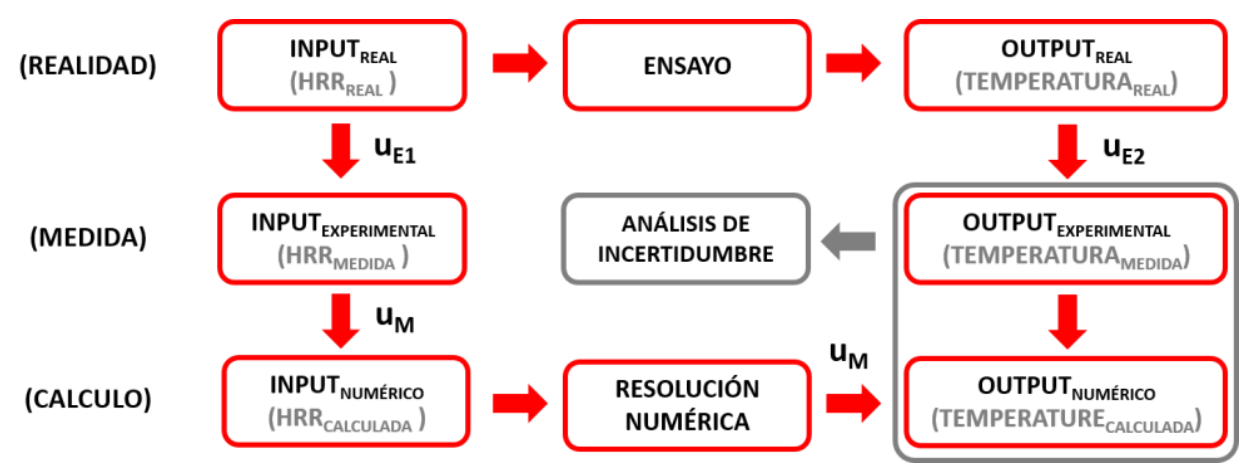

Figura 5-16. Fuentes de error e incertidumbre.

En el campo de la validación de ensayos de fuego, el concepto de incertidumbre es más comúnmente utilizado que el concepto de error. El error y la incertidumbre expresan diferentes conceptos [ref5.21]:

1. El término "error" se utiliza para:

a. Cuantificar la diferencia entre el resultado de una medición y el valor real

b. Cuantificar la imperfección del método y/o el dispositivo utilizado

2. La incertidumbre de la medición es un parámetro no negativo que caracteriza la dispersión de los valores atribuidos a una variable medida.

Las siguientes secciones detallan cómo se definen las incertidumbres experimentales y del modelo, para posteriormente trabajar con las distintas incertidumbres en relación a los ensayos de fuegos realizados en el puente experimental (ver Capítulo 4).

\subsubsection{INCERTIDUMBRE EXPERIMENTAL}

Según McGrattan [ref5.15, ref5.22], la incertidumbre experimental de una variable que un modelo intenta predecir es igual a $\mathrm{k}$ veces la desviación estándar relativa experimental $\left(\omega_{E}\right)$ de la variable analizada (en este caso la temperatura en el gas). Para un intervalo de confianza del 95\%, $\mathrm{k}$ se asume igual a 2 [ref5.15, ref5.022, ref5.023].

La desviación estándar relativa experimental $\omega_{E}$ se obtiene usando la Ec. 5-9:

$\omega_{E}^{2}=\omega_{0}^{2}+\sum_{\mathrm{i}}^{\mathrm{n}} \mathrm{p}_{\mathrm{i}}^{2} \cdot \omega_{\mathrm{i}}^{2}$

(Ec. 5-9) 
Donde:

$\omega_{\mathrm{o}}$ es la desviación típica estándar relativa de las medidas de salida y representa la incertidumbre del dispositivo que registra la variable (temperatura del gas en este caso) que el modelo intenta predecir.

La expresión $\sum_{\mathrm{i}}^{\mathrm{n}} \mathrm{p}_{\mathrm{i}}^{2} \cdot \omega_{\mathrm{i}}^{2}$ representa el término $\mathrm{u}_{\mathrm{E} 2}$ de la Figura 5-16 donde:

$p_{i}$ son los factores que representan las dependencias de peso de los parámetros de entrada individuales

$\omega_{\mathrm{i}}$ es la desviación estándar relativa de las medidas de entrada y representa la incertidumbre de los dispositivos que registran los parámetros de entrada requerido por el modelo numérico (corresponde a la $\mathrm{u}_{\mathrm{E} 1}$ definida en la Figura 5-16).

$\mathrm{n}$ representa el número de términos relevantes que afectan a la incertidumbre experimental de la variable de salida objeto de estudio (la temperatura del gas). En el presente estudio $n=1$, ya que la HRR es el único parámetro físico del modelo numérico de los ensayos de fuego considerado en el estudio de incertidumbre.

Los parámetros físicos más importantes asociados con las diversas cantidades medidas en los experimentos de fuego, junto con su dependencia de potencia $\left(\mathrm{p}_{\mathrm{i}}\right)$ se detallan en [ref5.22, ref5.023].

\subsubsection{INCERTIDUMBRE DEL MODELO}

Para obtener la incertidumbre del modelo, se deben considerar los siguientes supuestos [ref5.22, ref5.023]:

1. Las mediciones experimentales no están sesgadas, por lo que se supone que su incertidumbre se distribuye normalmente con una desviación estándar relativa experimental constante $\left(\omega_{E}\right)$.

2. La incertidumbre del modelo se distribuye normalmente sobre el valor predicho multiplicado por un factor de sesgo, $\delta$. Este factor de sesgo $\delta$ indica cómo, en promedio, el modelo infradimensiona o sobredimensiona las mediciones experimentales. La desviación estándar relativa del modelo de la distribución de temperatura se denota como $\omega_{M}$ y se usa para medir la dispersión de los output numéricos.

Una vez definida la incertidumbre experimental (calculando la desviación estándar relativa experimental $\left.\omega_{E}\right)$.), y dado un conjunto de medidas experimentales $\left(\mathrm{E}_{\mathrm{i}}\right)$, así como un conjunto correspondiente de predicciones del modelo $\left(\mathrm{M}_{\mathrm{i}}\right)$, los parámetros $\omega_{M}$ 
y $\delta$, que caracterizan el incertidumbre del modelo, se obtendrán a partir de la Ec. 5-10 y la Ec. 5-11, respectivamente [ref5.15, ref5.022]

$$
\begin{aligned}
& \omega_{M}^{2}+\omega_{E}^{2}=\frac{1}{n-1} \cdot \sum_{\mathrm{i}=1}^{\mathrm{n}}\left[\ln \left(M_{i} / E_{i}\right)-\overline{\ln (M / E)}\right]^{2} \\
& \delta=\exp \left[\overline{\ln \left(\frac{M}{E}\right)}+\frac{\omega_{M}^{2}}{2}-\frac{\omega_{E}^{2}}{2}\right]
\end{aligned}
$$

Donde $\overline{\ln (M / E)}$ se obtiene de acuerdo a la Ec. 5-12:

$\overline{\ln (M / E)}=\frac{1}{n} \cdot \sum_{i=1}^{n} \ln \left(M_{i} / E_{i}\right)$

\subsubsection{APLICACIÓN A LOS ENSAYOS "VALENCIA BRIDGE FIRE TESTS"}

\subsubsection{INCERTIDUMBRE EXPERIMENTAL}

En el caso particular de los ensayos detallados en el Capítulo 4, la Ec. 4-9 se convierte en la Ec. 5-13.

$\omega_{\mathrm{E}}^{2}=\omega_{\text {TEMPERATURAS }}^{2}+\mathrm{p}_{\text {TEMPERATURAS } / \mathrm{HRR}}^{2} \cdot \omega_{\mathrm{HRR}}^{2}$

Donde:

$\omega_{E}$ es la desviación estándar relativa experimental $\left(\sigma_{\mathrm{E}} / \delta\right)$

$\omega_{\text {TEMPERATURAS }}$ se obtiene como la combinación de las incertidumbres de los termopares y del datalogger, de acuerdo con la Ec. 5-14 [ref5.24],

$\omega_{\text {TEMPERATURAS }}^{2}=\omega_{\text {TERMOPARES }}^{2}+\omega_{\text {DATALOGGER }}^{2}($ Ec. 5-14)

$\mathrm{p}_{\text {TEMPERATURA/HRR }}^{2}$ es igual a 2/3 según [ref5.23, ref5.25]. Este factor proporciona la incertidumbre de la temperatura directamente atribuible a la incertidumbre de las medidas de HRR.

$\omega_{H R R}$ es la incertidumbre asociada con la medición de HRR

Empleando los valores $\omega_{\text {TERMOPARES }}=0.75 \%, \omega_{\text {DATALOGGER }}=0.25 \% \mathrm{y} \omega_{H R R}=$ $15.00 \%$ proporcionados por los proveedores de los dispositivos y por [ref5.025], la desviación típica relativa experimental, $\omega_{E}$, es del $10.03 \%$. Por lo tanto, adoptando un factor $\mathrm{k}=2$, como se ha explicado en la Sección 5.6.1, para un intervalo de confianza del $95 \%$, la incertidumbre experimental relativa es del $20.06 \%$.

\subsubsection{INCERTIDUMBRE DEL MODELO}


Como se explica en la Sección 5.6.2, la incertidumbre del modelo requiere el cálculo de $\omega_{M}$ y $\delta$ a partir de los valores de temperatura experimentales $\left(\mathrm{E}_{\mathrm{i}}\right)$ y de las temperaturas obtenidas por los modelos numéricos $\left(\mathrm{M}_{\mathrm{i}}\right)$.

La Figura 5-17 muestra la dispersión entre las temperaturas experimentales máximas y las temperaturas promedio obtenidas de los modelos numéricos para los cuatro escenarios de incendios. La Figura 5-17a incluye los valores registrados por los termopares en la zona de ceiling jet en las zonas sur, central y norte bajo la losa de hormigón. Se puede ver que los valores del modelo numérico muestran un factor de sesgo

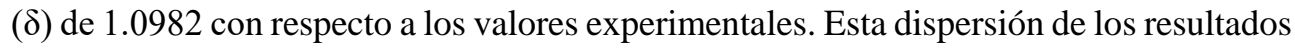
se debe a los supuestos del modelo de FDS, las incertidumbres en los parámetros de entrada del modelo de FDS (por ejemplo, soot yield y fracción de radiación) y el efecto del viento. La última variable, aunque en teoría perteneciente a la incertidumbre experimental, no podía separarse de la incertidumbre numérica, simplemente porque tanto su magnitud como su dirección han cambiado en el tiempo. Este fenómeno se repetirá en cualquier ensayo futuro llevado a cabo en condiciones de viento. La Figura 5-17b proporciona datos similares para el árbol de termopar vertical en el penacho del fuego. En este caso, se utilizan menos datos que para el ceiling jet (20 en lugar de 70).

(a) Temperaturas del chorro de techo

(b) Temperaturas del penacho de fuego
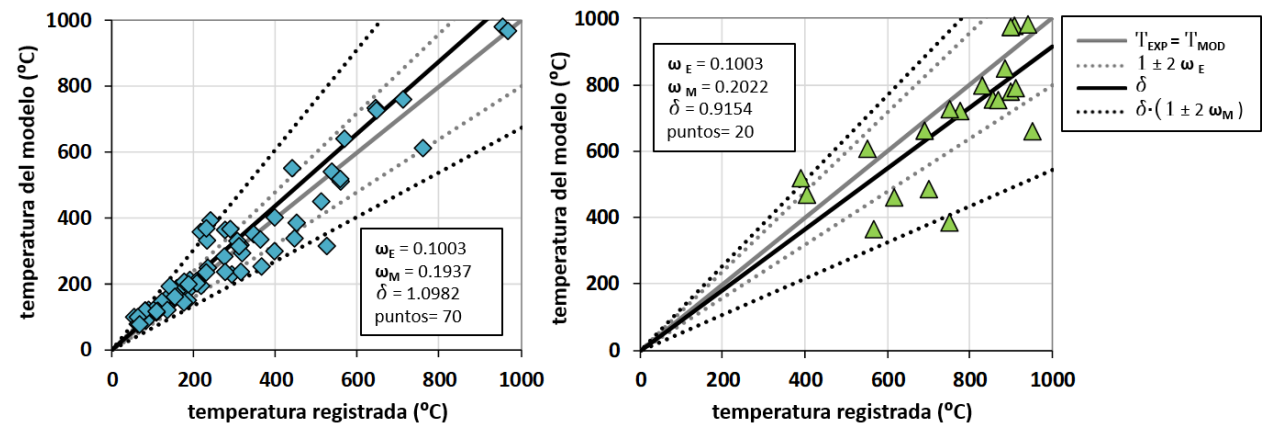

Figura 5-17. Dispersión entre las temperaturas registradas experimentalmente y las obtenidas en el modelo para (a) el chorro de techo y (b) penacho de fuego.

La Tabla 5-7 y la Tabla 5-8 comparan los parámetros utilizados para medir la incertidumbre (sin y con la corrección del viento indicada en la Sección 5.5.5) con los obtenidos por McGrattan et al. [ref5.15] en los ensayos de validación de FDS. Cabe señalar que tanto el factor de sesgo como la desviación típica relativa de los modelos se aproximan más a los parámetros de McGrattan et al. [ref5.15] al emplear temperaturas 
experimentales máximas (en lugar de promedio). Las mayores incertidumbres obtenidas en el presente estudio se pueden explicar por la influencia del viento, una variable ausente en el trabajo de validación de FDS presentado en [ref5.15]. Dadas estas consideraciones, los autores consideran que la validación realizada del modelo FDS es correcta.

\begin{tabular}{ccccc}
\hline Ceiling jet & $\boldsymbol{\omega}_{\mathrm{E}}$ & $\boldsymbol{\omega}_{\mathrm{M}}$ & $\delta$ & $\mathbf{n}$ \\
\hline Valencia bridge fire tests (T prom.) & 0.1 & 0.237 & 1.291 & 70 \\
Valencia bridge fire tests (T max.) & 0.1 & 0.194 & 1.098 & 70 \\
McGrattan [ref5.15] & 0.07 & 0.14 & 1.05 & 898 \\
\hline
\end{tabular}

Tabla 5-7. Parámetros de incertidumbre para ceiling jets. 70 medidas consideradas

\begin{tabular}{ccccc}
\hline Penacho de fuego & $\boldsymbol{\omega}_{\mathrm{E}}$ & $\boldsymbol{\omega}_{\mathrm{M}}$ & $\delta$ & $\mathbf{n}$ \\
\hline Valencia bridge fire tests (T prom.) & 0.1 & 0.346 & 1.518 & 20 \\
Valencia bridge fire tests (T max.) & 0.1 & 0.202 & 0.915 & 20 \\
McGrattan [ref5.15] & 0.07 & 0.16 & 1.18 & 107 \\
\hline
\end{tabular}

Tabla 5-8. Parámetros de incertidumbre para penachos de fuego. 20 medidas consideradas

\subsection{CONCLUSIONES}

El presente capítulo compara las temperaturas de gases experimentales registradas en los ensayos Test 2, Test 4, Test 7 y Test 8 descritos en el Capítulo 4 con las temperaturas calculadas tanto mediante un modelo de fuego localizado como por un modelo de dinámica de fluidos computacional. La comparación entre los datos experimentales y la simulación de incendios (modelo avanzado) se ha realizado en dos pasos. En primer lugar, se ha incluido una comparativa directa entre temperaturas registradas experimentalmente y temperaturas calculadas numéricamente. De esta forma se ha podido determinar dónde se producían las mayores diferencias. A continuación, se ha realizado un análisis de incertidumbre para comparar las incertidumbres del modelo con otros ensayos similares validados en la guía de validación de FDS [ref5.15]. A partir de estos análisis, se pueden extraer las siguientes conclusiones:

1. Dado que los ensayos se llevaron a cabo al aire libre, a diferencia de los ensayos realizados en hornos o espacios cerrados, se vieron afectados significativamente por el viento. El viento inclinó las llamas lateralmente, afectando también a la columna ascendente de gases con base en la bandeja de combustible.

2. Aunque el modelo de Heskestad \& Hamada se definió originalmente para incendios no confinados, se ha podido comprobar cómo ofrece buenas 
predicciones de ensayos de fuegos en puentes con HRR entre 361 y $1130 \mathrm{~kW}$ siempre que $L_{f} / H<2$. El modelo de fuego localizado ha proporcionado una buena aproximación de la forma general de las temperaturas máximas y las temperaturas de gas esperadas alrededor del puente, aunque las temperaturas del gas se han subestimado hasta en un $30.4 \%$.

3. La correlación de Heskestad \& Hamada no se puede utilizar para estudiar incendios de puentes reales directamente, ya que se desarrolló para incendios con una HRR máxima de $764 \mathrm{~kW}$ (valor muy inferior a los 100-300 MW correspondientes al incendio de un camión cisterna [ref5.13, ref5.14, ref5.26])

4. Los cuatro escenarios de incendio se validaron con una incertidumbre ligeramente superior a la obtenida por McGrattan [ref5.15]. La mayor dispersión numérica puede atribuirse principalmente al efecto del viento durante los ensayos. Para reducir la incertidumbre relativa al viento se recomienda utilizar una protección contra el viento. Los estudios de viento, si se realizan deberán hacerse con vientos controlados en recintos habilitados a tal efecto, con el fin de poder estudiar su influencia real (difícil de caracterizar si el viento varía en el tiempo y en el espacio en magnitud y dirección).

5. Tanto el enfoque simplificado como el avanzado proporcionan buenos resultados en lo que respecta a la predicción de las temperaturas del gas para los escenarios de fuego Fire 1, Fire 2 y Fire 3, siempre que se aplique la corrección de velocidad del viento cero explicada en la Sección 5.5.5. Las temperaturas en el escenario de fuego Fire 4 pueden predecirse con precisión por el modelo de FDS, pero no por la correlación de Heskestad y Hamada, ya que la HRR en este escenario es más alta que los límites de aplicación de la correlación.

El trabajo expuesto en el presente capítulo, por tanto:

1. Ha validado la aplicación de modelos de CFD para el estudio de incendios de puentes y ha corroborado los límites de aplicación de un enfoque simplificado común para chorros de techo.

2. Es un importante paso adelante en el estudio de los efectos de los incendios en puentes y la mejora de la resiliencia de las redes de infraestructura frente a los riesgos de incendio.

3. Ha permitido resaltar la dificultad de la consideración del viento, dada su variabilidad en dirección y magnitud, tanto espacial como temporal. En ensayos futuros se recomienda tan solo la consideración del viento si éste es controlado mediante las disposiciones que sean necesarias. La consideración de viento de origen ambiental introduce incertidumbre innecesaria en lo que respecta a la caracterización del problema. 


\subsection{REFERENCIAS}

[ref5.01] Heskestad G, Hamada T. Ceiling Jets of Strong Fire Plumes. Fire Safety Journal 21:69-82. 1993.

[ref5.02] Babrauskas V. Chapter 26. Heat Release rates. SFPE Handbook of fire protection engineering. 5th Edition. 2016.

[ref5.03] Peris-Sayol G, Paya-Zaforteza I, Balasch-Parisi S, Alos-Moya J. Analysis of the factors that influence the maximum adiabatic temperatures in I-girder bridges. 9th International Conference on Structures in Fire. Princeton, NY, USA. 2016.

[ref5.04] Quiel S, Zhu Z, Mueller K, Carlton A, Marjanishvili S. Performance-based prioritization of fire mitigation for highway bridges. 9th International Conference on Structures in Fire. Princeton, NY, USA. 2016.

[ref5.05] Alpert RL. Chapter 14. Ceiling jet flows. SFPE Handbook of fire protection engineering. 5th Edition. 2016.

[ref5.06] Hasemi Y, Yokobayashi S, Wakamatsu T, Ptchelintsev A. Fire Safety of building vomponents rxposed to a localized fire: Scope and experiments on ceiling/beam system exposed to a localized fire. AsiaFlam 95. 1995.

[ref5.07] Alpert RL. Turbulent ceiling jet induced by large scale fires. Combustion Science and Technology 11:197-213. 1975.

[ref5.08] Heskestad G. Chapter 13. Fire plumes, flame height, and air entrainment. SFPE Handbook of fire protection engineering. 5th Edition. 2016.

[ref5.09] Koslowski CC, Motevalli V. Behavior of a 2-dimensional ceiling jet Flow: A beamed ceiling configuration. Fire Safety Science - 4th International Symposium. 1994.

[ref5.10] Alpert RL. Calculation of Response Time of Ceiling-Mounted Fire Detectors. Fire Technology 8:181. 1972.

[ref5.11] McGrattan K, Hostikka S, McDermott R, Floyd J, Weinschenk C, Overholt K. Fire Dynamics Simulator User Guide (version 6). NIST Special Publication 1019, Gaithersburg, MD, USA. 2013.

[ref5.12] Drysdale D. An Introduction to Fire Dynamics. John Wiley and Sons, UK. 2011.

[ref5.13] Cheong MK, Spearpoint M J, Fleischmann CM. Design fires for vehicles in road tunnels. 7th International Conference on Performance-Based Codes and Fire Safety Design Methods. 2008. 
[ref5.14] Ingason H. Design fires in tunnels. 2nd International Symposium. Safe \& Reliable Tunnels Innovative European Achievements, Lausanne. 2006.

[ref5.15] Alós-Moya J, Paya-Zaforteza I, Garlock MEM, Loma-Ossorio E, Schiffner D, Hospitaler A. Analysis of a bridge failure due to fire using computational fluid dynamics and finite element models. Engineering Structures 68: 96-110. 2014.

[ref5.15] McGrattan K, Hostikka S, McDermott R, Floyd J, Weinschenk C, Overholt K. Fire Dynamics Simulator Technical Reference Guide. Volume 3: Validation (version 6). NIST Special Publication 1018-3, Gaithersburg, MD, USA. 2013.

[ref5.16] Gong X, Agraval AK. Numerical simulation of fire damage to a long-span truss bridge. ASCE Journal of Bridge Engineering 20 (10). 2015.

[ref5.17] Peris-Sayol G, Paya-Zaforteza I, Alos-Moya J, Hospitaler A. Analysis of the influence of geometric, modeling and environmental parameters on the fire response of steel bridges subjected to realistic fire scenarios. Computers and Structures Journal. 2015.

[ref5.18] Thunderhead Engineering. Pyrosim User Manual. Included in Pyrosim version 2016.1.0425. 2016.

[ref5.19] McGrattan K, Hostikka S, McDermott R, Floyd J, Weinschenk C, Overholt K. Fire Dynamics Simulator Technical Reference Guide. Volume 1: Mathematical model (version 6). NIST Special Publication 1018, Gaithersburg, MD, USA. 2013.

[ref5.20] Hurley MJ. Appendix 3: Fuel Properties and Combustion Data. SFPE Handbook of fire protection engineering. 5th Edition. 2016.

[ref5.21] Centro español de la metrología. Evaluación de datos de medición. Guía para la expresión de la incertidumbre de medida. 2008.

[ref5.22] McGrattan K, Steward Miles S. Chapter 32. Modeling Fires Using Computational Fluid Dynamics (CFD). SFPE Handbook of Fire Protection Engineering. 5th edition. 2016.

[ref5.23] McGrattan K, Toman B. Quantifying the predictive uncertainty of complex numerical models. Metrologia 48:173-80. 2011.

[ref5.24] Gutierrez-Montes C, Sanmiguel-Rojas E, Kaiser AS, Viedma A. Numerical model and validation of atrium enclosure fire in a new fire test facility. Building and Environment. 2008. 
[ref5.26] Rivkin CH. Section 21. Transportation Fire Safety. Fire Protection Handbook. NFPA 502, Standard for Road Tunnels, Bridges and Other Limited Access Highways. 2008. 


\section{VALIDACIÓN DEL MODELO TERMO-MECÁNICO}

La raza humana necesita un desafío intelectual. Debe ser aburrido ser Dios y no tener nada que descubrir

Stephen Hawking

El contenido de esta sección ha sido tomado directamente del paper

"Valencia bridge fire tests: Validation of thermo-mechanical finite element model of a concrete-steel composite bridge"

con envío previsto en Diciembre de 2018 al

Journal of Constructional Steel Research 



\subsection{INTRODUCCIÓN}

En el Capítulo 3 se ha presentado la metodología general de simulación numérica del fenómeno mediante su aplicación en un puente sometido a un incendio real. A continuación, en el Capítulo 4 se ha realizado una campaña experimental que ha permitido registrar, a lo largo de cada uno de los ocho ensayos realizados sobre un puente experimental de $6 \mathrm{~m}$ de vano, variables como la HRR, las temperaturas en el gas, las temperaturas en el acero y las flechas del tablero. Seguidamente, en el Capítulo 5, se han empleado las HRR y las temperaturas del gas registradas en el Capítulo 4 de cuatro de los ocho ensayos para validar el modelo de simulación de incendios definido mediante FDS6. Para concluir con la presente investigación, en el presente capítulo, se van a emplean los registros realizados durante el ensayo Test 8 para realizar una validación del modelo termo-mecánico definido en ABAQUS.

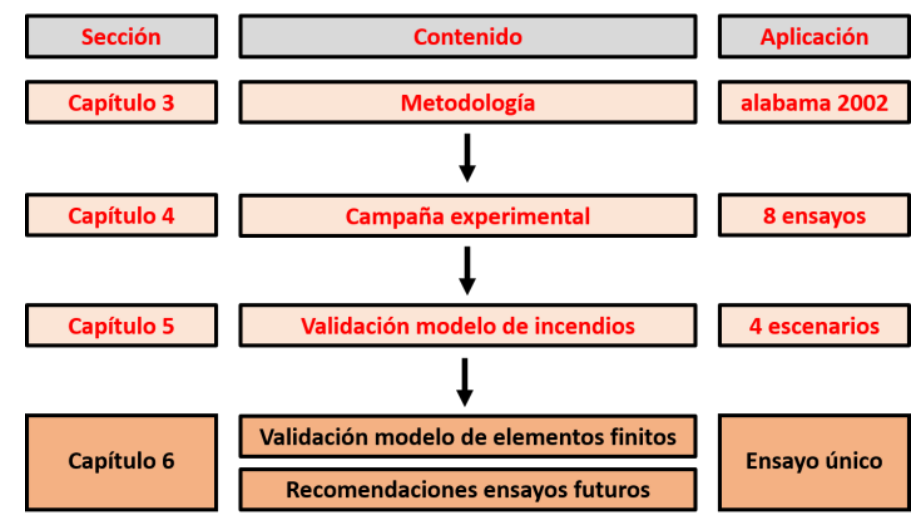

Figura 6-1. Estructura de la tesis: Capítulo 6.

Para entender el porqué y el para qué del presente capítulo resulta conveniente recordar el camino recorrido hasta ahora (ver Figura 6-1). Tras plantear la metodología numérica expuesta y validada en el Capítulo 3 se detectaron dos debilidades en la validación. En primer lugar, la caracterización del fuego se realizó basándose tan solo en unas pocas imágenes y en segundo lugar la validación se limitaba a la comparación de la deformada post-incendio con la máxima deformada alcanzada mediante los modelos de simulación de incendios y termo-mecánico.

Por ello se planteó realizar una validación más rigurosa que permitiese una mejor caracterización de la carga de fuego en el tiempo, así como un registro continuo durante los eventos de fuego de tasas de liberación de calor, temperaturas y flechas durante los ensayos. La campaña experimental detallada en el Capítulo 4 se planteó con el fin de 
realizar una validación más robusta de los modelos numéricos empleados en la metodología presentada previamente.

En este contexto la variable económica no solo resultó limitante en lo referente a la magnitud del puente, sino también a la magnitud de la carga de fuego. Esto fue así puesto que, queriendo aprovechar la misma estructura para la realización de la campaña experimental completa, la potencia de los ensayos tuvo que limitarse a valores en los que no implicase un calentamiento excesivo del tablero.

Como se puede comprobar en el propio Capítulo 4, las flechas registradas en siete de los ocho ensayos no superaron los $70 \mathrm{~mm}$ de flecha dada una luz entre apoyos de $6000 \mathrm{~mm}$. Este nivel de severidad permitió emplear el mismo tablero sin modificar la geometría original tras cada una de las pruebas de fuego. Con ello, los ocho ensayos partieron de las mismas condiciones geométricas iniciales. De esta forma no solo se pudieron replicar algunos de los escenarios de fuego, sino que se pudo realizar una validación del modelo de simulación de incendios empleando cuatro escenarios de fuego distintos (Capítulo 5).

En el último ensayo (Test 8) se quiso someter a la estructura a una carga de fuego que permitiera realizar una calibración del modelo termo-mecánico (imposible mediante los primeros siete ensayos) sin llevar el puente al colapso. El resultado fue una flecha máxima en centro luz (CL) de $120 \mathrm{~mm}$ en ambas vigas que se recuperó por completo tras el ensayo. Aunque la no existencia de deformada residual indica que no se produjo plastificación del acero, el ensayo Test 8 se empleará en el presenta capítulo para validar el modelo termo-mecánico en el rango de temperaturas alcanzadas durante el mismo. Una vez validado el modelo termo-mecánico en este rango de temperaturas será empleado en otro trabajo para plantear el ensayo de fuego en el que se llevará el tablero al colapso.

Adicionalmente, a lo largo de la validación del modelo termo-mecánico se ha analizado y comentado la utilidad y limitaciones de cada una de las mediciones realizadas durante el ensayo Test 8.

Una vez validado el modelo termo-mecánico se ha comparado la respuesta mecánica que se habría estimado mediante la metodología y los modelos validados en el presente documento con la registrada experimentalmente. Se concluye el capítulo analizando las limitaciones del modelo de Hasemi planteado en el Eurocódigo 1 [ref6.01] para fuegos localizados para su aplicación a fuegos en puentes 


\subsection{METODOLOGía}

En el presente capítulo cabe diferenciar entre la metodología general empleada para reproducir un evento de fuego (resolución en tres etapas) y la metodología de validación iterativa del modelo termo-mecánico planteada de acuerdo a los datos disponibles.

\subsubsection{METOdología GenERAL}

La metodología general es la que permite desacoplar el problema específico de "incendio en puente" en tres etapas caracterizadas de forma independiente (modelo de simulación de incendios, modelo térmico de transmisión de calor en la estructura y modelo mecánico de caracterización del equilibrio de la estructura mediante actualización de las temperaturas de los materiales). Esta metodología se ha definido y validado en el Capítulo 3 del presente documento.

En la Figura 6-2 se incluye un esquema de la metodología general en el que se distingue entre el modelo de simulación de incendios y los modelos térmico y mecánico. En el esquema se indican los dominios y los softwares empleados para cada uno de los modelos, así como las variables de entrada y salida en cada caso.

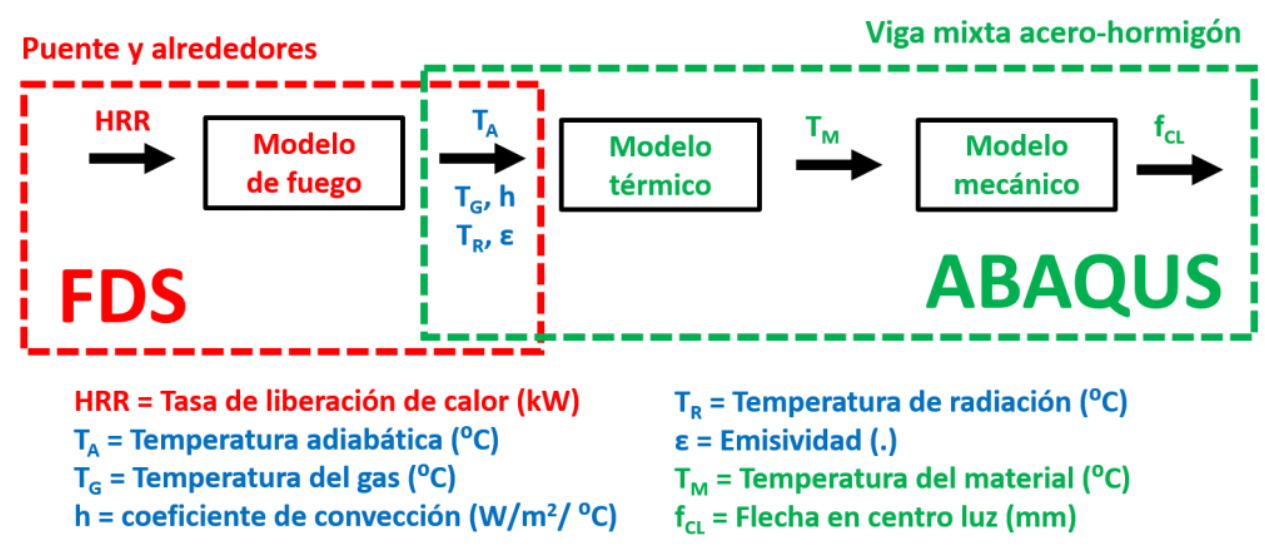

Figura 6-2. Metodología general en tres etapas.

\subsubsection{VALIDACIÓN DEL MODELO TERMO-MECÁNICO}

El modelo termo-mecánico, caracterizado por las ecuaciones que gobiernan el problema, se considerará validado cuando dadas unas variables de entrada registradas experimentalmente (conocidas) el modelo calcule unas variables de salida similares a las registradas experimentalmente (conocidas también). 
Esto es así puesto que el modelo termo-mecánico no es más que el conjunto de relaciones entre las variables de entrada y de salida expresadas en forma de ecuaciones para poder calcular las segundas a partir de las primeras. Las ecuaciones se determinan teniendo en cuenta la naturaleza de los fenómenos, considerando una serie de simplificaciones, incluyendo las relaciones existentes entre las variables e implicando las constantes universales correspondientes.

Retomando la Figura 6-2 y considerando el modelo termo-mecánico de forma conjunta se deduce que la variable de entrada al modelo es el flujo neto de calor sobre la estructura y la variable de salida es la deformación del tablero medida en forma de flecha en centroluz (CL). En conclusión, se puede decir que, dada una evolución de flujo neto y una evolución de flecha asociada (ambas conocidas) la validación del modelo termomecánico se limita a realizar el cálculo con el modelo a validar y comparar los resultados numéricos obtenidos con la respuesta registrada experimentalmente.

\subsubsection{DEFINICIÓN DEL FLUJO TÉRMICO NETO SOBRE LA ESTRUCTURA}

En la Figura 6-2 se indican como variables de entrada para definir el flujo térmico neto hacia la estructura:

1. La temperatura del gas $\left(T_{g}\right)$

2. El coeficiente de convección $(h)$

3. La temperatura equivalente de radiación $\left(T_{r}\right)$

4. La emisividad $(\varepsilon)$

Donde la temperatura del gas y el coeficiente de convección permiten definir el flujo de convección mientras que la temperatura equivalente de radiación y la emisividad son necesarias para definir el flujo de radiación. La temperatura del material en el contacto con el entorno, aunque no se ha incluido en el esquema por ser una temperatura que tan solo se define en el instante inicial, interviene en la obtención tanto del flujo de convección como en el flujo de radiación.

Adicionalmente a las cuatro variables previamente definidas se ha incluido se ha querido incluir la temperatura adiabática $\left(T_{a}\right)$. Esta temperatura no complementa a las anteriores, sino que se plantea como una alternativa al empleo de las temperaturas del gas $\left(T_{g}\right)$ y equivalente de radiación $\left(T_{r}\right)$, obteniendo resultados muy similares [ref6.02].

Se puede afirmar, por tanto, que la definición del flujo térmico neto sobre la estructura es completa si, además de disponer de la temperatura inicial de la estructura, se definen 
en el tiempo $T_{g}, T_{r}, h, \varepsilon$ en el caso general o $T_{a}, h, \varepsilon$ en caso de emplear la temperatura adiabática.

De acuerdo a los resultados expuestos en el Capítulo 3, el único valor experimental registrado a lo largo de los ensayos es el de la $T_{g}$, y ni siquiera se ha registrado en las zonas inferiores a las vigas de acero. Aun considerando un valor de la emisividad del acero de 0.7 y un coeficiente de convección de $35 \mathrm{~W} \cdot \mathrm{m}^{-2} \cdot{ }^{\circ} \mathrm{C}-1$ propuesto por el Eurocódigo 1 en su parte 1-2, la temperatura equivalente de radiación $\left(T_{r}\right)$ no ha sido registrada. La alternativa de definición del flujo térmico neto sobre la estructura mediante la temperatura adiabática $\left(T_{a}\right)$ queda descartada también puesto que tampoco se ha registrado.

\subsubsection{VALIDACIÓN MIXTA DEL MODELO TERMO-MECÁNICO}

Puesto que no se puede realizar una validación termo-mecánica estricta, se recurrirá al empleo de la simulación de incendios, ya validada en el Capítulo 5, para hacer posible una validación mixta del modelo termo-mecánico.

La validación mixta se define como tal puesto que, en lugar de emplear variables de entrada y salida experimentales, empleará variables de entrada obtenidas a partir de otro modelo, de simulación de incendios, previamente validado.

Para realizar la validación mixta del modelo termo-mecánico se recurrirá al ensayo Test 8 definido en el Capítulo 4 y a la simulación de incendios Fire 4 validada con ese mismo ensayo en el Capítulo 5.

Al emplear como datos de entrada los datos obtenidos a partir de una simulación de incendios, en lugar de a partir de un ensayo real, se asume un error de entrada debido al propio empleo del modelo de simulación de incendios. Por este motivo, este tipo de validación tan solo resulta conveniente cuando no se dispone de registros experimentales suficientes para realizar una validación estricta del modelo termo-mecánico.

\subsubsection{VALIDACIÓN MIXTA ITERATIVA DEL MODELO TERMO-MECÁNICO}

La validación mixta propuesta sería suficiente si el modelo se hubiera validado sin la presencia de viento. Sin embargo, se recuerda que en el Capítulo 5 se ha podido comprobar como las temperaturas del gas obtenidas para cada uno de los cuatro escenarios estudiados han sobredimensionado las registradas durante los ensayos en la zona central (entre vigas). Por este motivo se plantea una validación mixta iterativa.

En la Figura 6-3 se incluye el esquema completo del procedimiento empleado para la validación iterativa mixta. Mediante este tipo de validación se intentará reproducir una 
exposición térmica similar a la ocurrida en el ensayo Test 8 considerando el efecto del viento de forma indirecta mediante una reducción de la tasa de liberación de calor registrada. Cabe destacar con ello que el modelo de incendios no va a incluir directamente el efecto del viento ocurrido durante el ensayo, sino que lo incluirá de forma indirecta mediante la reducción del calor liberado. Para comprobar que se ha conseguido obtener una exposición térmica similar a la ocurrida durante los ensayos se empleará el registro de temperaturas del acero en las seis secciones representativas. Es por ello que, además de la curva tiempo-tasa de liberación de calor y de la curva tiempo-flecha en CL, se emplearán las curvas tiempo-temperatura en el acero de los distintos termopares empleados en el ensayo Test 8 .

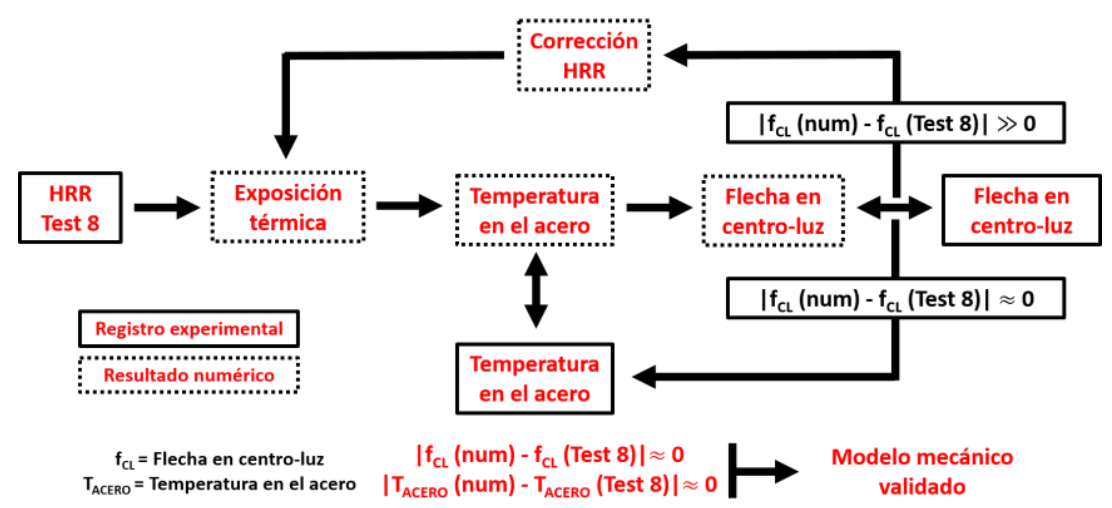

Figura 6-3. Esquema de la validación mixta iterativa del modelo termo-mecánico

En la Figura 6-3 se ha incluido de forma compacta toda la información que se va a explicar a continuación paso por paso:

\section{Paso 1. Primera iteración a partir de la tasa de liberación de calor con hipótesis de viento nulo}

Paso1.1. Se emplea el modelo de simulación de incendios detallado en el Capítulo 5 para, a partir de la HRR registrada en el Test 8 , obtener una exposición térmica de partida de la estructura. Esta exposición se obtiene asumiendo que durante el experimento no hubo viento. Como se detalla en el Capítulo 5, la consideración de esta hipótesis implica un sobredimensionamiento de la exposición térmica real.

Paso1.2. A partir dela exposición térmica obtenida en el paso1.1, se emplea el modelo térmico para obtener las temperaturas de los materiales a lo largo del ensayo. 
Paso1.3. A partir de las temperaturas de los materiales a lo largo del tiempo, se emplea el modelo mecánico para obtener la respuesta mecánica en el tiempo a partir del deterioro de las características mecánicas de los materiales con el incremento de su temperatura.

\section{Paso2. Aproximación iterativa para reproducción de la flecha en $\mathrm{CL}$}

Partiendo de la hipótesis de que el modelo mecánico ha sido adecuadamente definido (la hipótesis de comprobará en el paso2) la diferencia entre flechas en el modelo termomecánico y las flechas registradas en el ensayo Test 8 se deberá en gran parte al efecto del viento. Puesto que el efecto del viento se va a considerar de forma indirecta mediante la corrección de la tasa de liberación de calor en un escenario de viento cero en cada iteración se realizará una corrección de la curva tiempo-tasa de liberación de calor (tHRR) que permitirá ir ajustando la respuesta tiempo-flecha en CL numérica a la del registro experimental en el ensayo Test 8 . Para ello se seguirán los siguientes pasos:

Paso2.1. Comparando la evolución en el tiempo de la flecha en CL del paso1.3 con la evolución en el tiempo de la flecha del Test 8 se puede decidir hasta qué momento la exposición térmica es realista (como se verá en la Sección 6.4.5 el efecto del viento se acentúa conforme avanza el ensayo). En el intervalo donde la respuesta mecánica modelada difiere de la real se reduce la HRR si se está sobredimensionando la flecha real y se incrementa si se está infradimensionando.

Paso2.2. Se repiten los pasos paso1.2 y paso1.3 con la nueva exposición térmica y se vuelve a comparar la flecha en CL obtenida numéricamente con la obtenida en el Test 8 .

Paso2.3. Se repiten los pasos paso2.1 y paso 2.2 se repiten hasta que la evolución de flechas obtenida es similar a la registrada en el Test 8

\section{Paso3. Validación del modelo mecánico}

Hasta el momento, se ha obtenido una curva tiempo-tasa de liberación de calor que dado el modelo termo-mecánico disponible calcula una evolución de flechas en CL similar a la registrada durante el ensayo Test 8. Llegado a este punto, para validar el modelo mecánico es necesario verificar que las temperaturas calculadas en el acero en la última iteración son similares a las registradas en el ensayo de referencia. Este paso es necesario porque si las temperaturas del acero experimentales y calculadas no fueran similares el escenario de incendio planteado habría permitido obtener una respuesta mecánica similar a partir de un campo térmico distinto, lo que no serviría para validar el modelo mecánico.

Step3.1. Se comparan cualitativamente las temperaturas de la viga del modelo mecánico de la última iteración con las registradas en el ensayo Test 8 . Como se indica en la Figura 6-3, si tanto la flecha máxima del puente como las temperaturas en el acero son similares en el modelo termo-mecánico respecto al registro experimental, el modelo mecánico 
estaría validado para reproducir el comportamiento del puente sometido a una carga de fuego de 1.3MW.

\section{Paso4. Validación del modelo térmico}

Para realizar una validación estricta del modelo térmico se requeriría de la comparación de las temperaturas del gas $\left(\mathrm{T}_{\mathrm{g}}\right)$ y de las temperaturas equivalentes de radiación $\left(\mathrm{T}_{\mathrm{r}}\right)$ calculadas con respecto a las registradas. Puesto que esto no es posible al no haber registrado las temperaturas equivalentes de radiación, se compararán únicamente las temperaturas del gas registradas experimentalmente. Esto no supone un problema puesto que el modelo térmico es mucho menos complejo que el modelo mecánico empleado.

Paso4.1. Se comparan cualitativamente las temperaturas del gas en las zonas central y sur en las secciones S1, S2 y S3 (Figura 6-4). En las secciones S4, S5 y S6 se comprueba que los resultados son similares.

Step4.2. Se explica a que pueden deberse las diferencias de temperaturas del gas calculadas en la última iteración con respecto a las registradas experimentalmente en el ensayo Test 8 .

\subsection{Caso de estudio}

El puente tiene un vano único simplemente apoyado de $6.0 \mathrm{~m}$ y un gálibo vertical de 1.9 m. La estructura consiste en dos vigas de acero IPE-160 que soportaban una losa de hormigón armado de $0.15 \mathrm{~m}$ de espesor conectada a las vigas de acero a través de 62 pernos conectadores. El acero S355-JR empleado para las vigas registró límites elásticos de 344 y 377 MPa. La resistencia a la compresión de la losa de hormigón fue de $33 \mathrm{MPa}$. El alzado del puente, su sección, la nomenclatura de los sensores empleados y una imagen del ensayo Test 8 empleado para la validación se muestran en la Figura 6-4. La carga de fuego se ha caracterizado por una bandeja cuadrada rellena de gasolina de 0.75 $\mathrm{m}$ de lado situada a $0.8 \mathrm{~m}$ de altura sobre el nivel de referencia, siendo la potencia promedio del ensayo de $1.35 \mathrm{MW}$ de potencia. Los pórticos de acero apoyados sobre los estribos se incluyeron para sostener los LVDT que monitorizaron las flechas del tablero, pero no tienen ninguna influencia en la validación del modelo termo-mecánico. Para mayor información consultar el Capítulo 4, donde se caracteriza tanto el puente como los ensayos de fuego que sobre él se han realizado. 


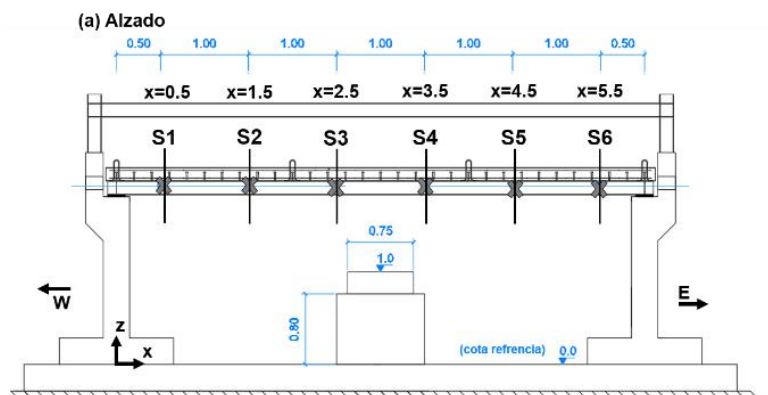

(c) Nomenclatura de los termopares

\begin{tabular}{|c|c|c|c|c|}
\hline nombre & temperatura & zona & posición & secciones \\
\hline GNX & gas & norte & - & S1 a S6 \\
\hline GCX & gas & central & - & S1 a S6 \\
\hline GSX & gas & sur & - & S1 a S6 \\
\hline SG-BF & acero & viga sur & ala inferior & S1 a S6 \\
\hline NG-BF & acero & viga norte & ala inferior & S1 a S6 \\
\hline SG-W & acero & viga sur & alma & S1 a S6 \\
\hline NG-W & acero & viga norte & alma & S1 a S6 \\
\hline SG-TF & acero & viga sur & ala superior & S3 a S4 \\
\hline NG-TF & acero & viga norte & ala superior & S3 a S4 \\
\hline
\end{tabular}

(d) Imagen del ensayo Test 8
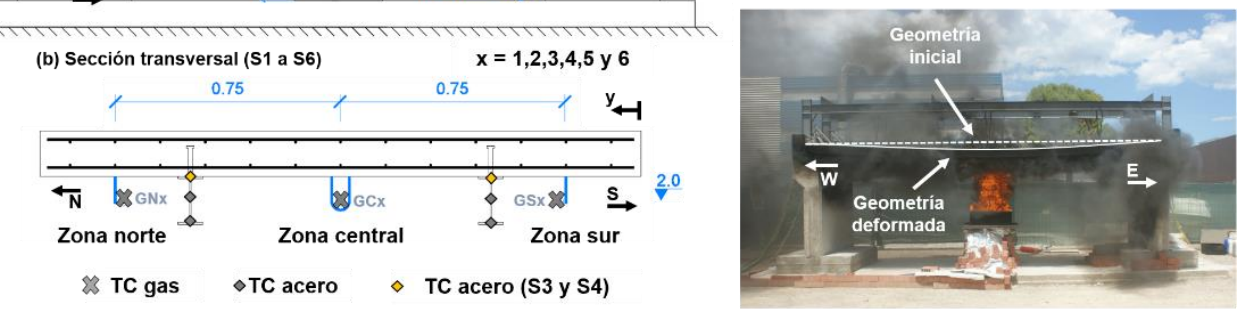

Figura 6-4. Puente experimental: (a) Alzado, (b) Sección transversal, (c) Nomenclatura de los termopares e $(d)$ imagen del ensayo Test 8.

\subsection{REGISTROS EXPERIMENTALES}

En la Figura 6-5 se incluye un esquema resumen sobre la información recopilada durante el ensayo Test 8 , organizada de acuerdo con la etapa a la que pertenece de acuerdo con el procedimiento explicado en la Figura 6-2. En la Figura 6-5 se indica también qué información se ha empleado para cada una de las validaciones:

1. Validación FDS. Corresponde a la validación de la simulación del incendio realizada en el Capítulo 5.

2. Validación Abaqus. Corresponde a la validación del modelo termo-mecánico realizada en el Capítulo 6. 


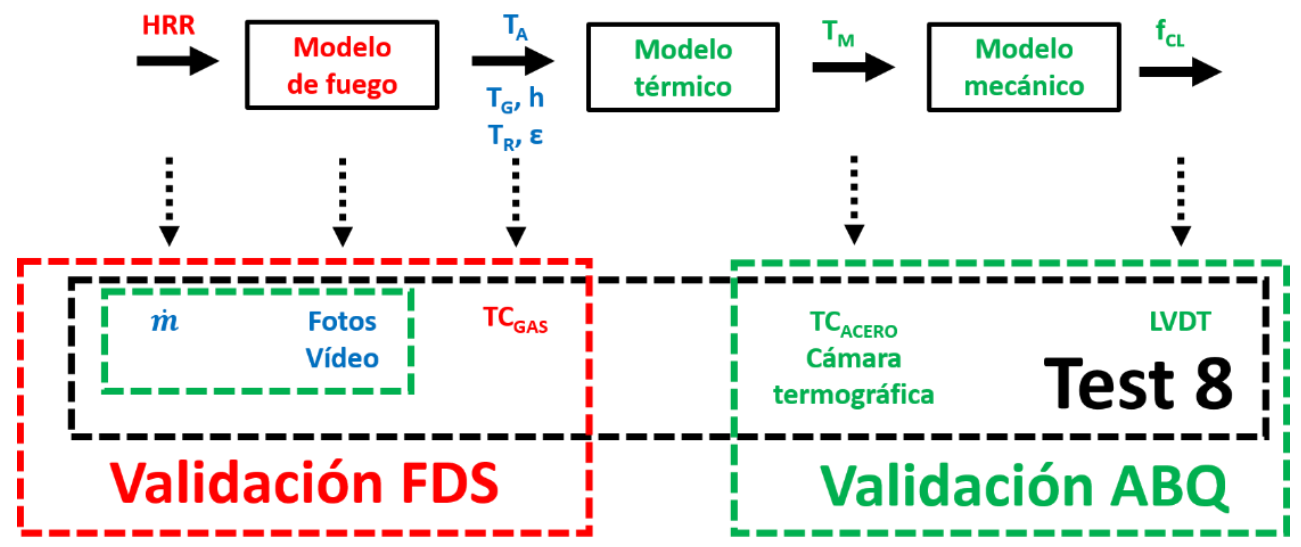

Figura 6-5. Registros experimentales del ensayo Test 8.

\subsubsection{TASA DE PÉRDIDA DE MASA}

La tasa de liberación de calor teórica suele estimarse asumiendo la hipótesis de combustión completa. De acuerdo a la Ec. 6-1, la tasa de liberación de calor teórica in $\mathrm{kW}$ puede ser obtenida como la tasa de pérdida de masa del material ( $\dot{m}=A_{\text {fire }} \cdot \dot{m}$ ") en $\mathrm{kg} / \mathrm{s}$ multiplicada por el calor de combustión $\left(\Delta H_{c}\right)$ en $(\mathrm{kJ} / \mathrm{kg})$ [ref6.03].

$\mathrm{Q}=A_{\text {fire }} \cdot \dot{m}^{\prime \prime} \cdot \Delta H_{c}$

$\mathrm{Q}=\chi \cdot A_{\text {fire }} \cdot \dot{m}^{\prime \prime} \cdot \Delta H_{c}$

Donde:

$Q$ es la tasa de liberación de calor del fuego en kW

$A_{\text {fire }}$ es la huella del fuego in $\mathrm{m}^{2}$.

$\dot{m}$ " es la tasa de pérdida de masa en $\mathrm{g} / \mathrm{m}^{2} \mathrm{~s}$.

$\Delta H_{c}$ es el calor de combustión en $\mathrm{MJ} / \mathrm{kg}$. $43.7 \mathrm{MJ} / \mathrm{kg}$ para la gasolina [ref6.04].

Para considerar el caso de combustión incompleta (ver Ec. 6-2) se incluye además el parámetro de eficiencia de la combustión $(\chi)$, que es el ratio entre la tasa de liberación de calor en la hipótesis de combustión completa y la tasa de liberación de calor en la hipótesis de combustión incompleta. 
En la Figura 6-6 se muestran la tasa de liberación de calor (HRR) y la tasa de liberación de calor por unidad de superficie (HRRPUA) obtenidas considerando la pérdida de masa registrada durante el ensayo Test 8 y asumiendo la hipótesis de combustión completa (con una eficiencia de combustión igual a 1).

(a) HRRPUA (kW/m²)

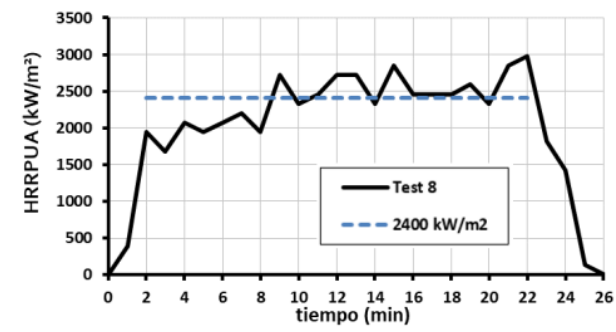

(b) HRR (kW)

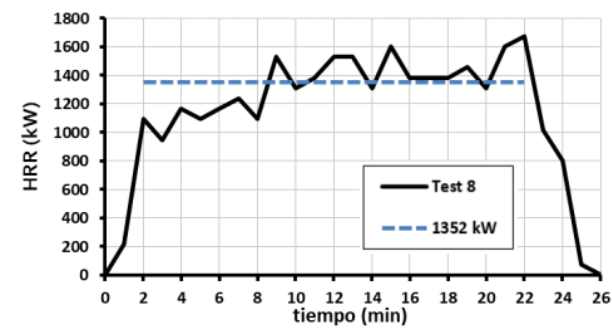

Figura 6-6. Comparativa de valor experimental con valor teórico de: (a) Tasa de liberación de calor por unidad de área y (b) Tasa de liberación de calor.

\subsubsection{EXPOSICIÓN TÉRMICA}

Durante el ensayo Test 8 se registraron las temperaturas en el gas mediante 18 termopares de acero inoxidable de $1.5 \mathrm{~mm}$ de espesor situados en las seis secciones y las tres posiciones indicadas en la Figura 6-4. Como se ha indicado previamente, para definir adecuadamente el flujo neto de calor sobre la estructura, se requiere de la caracterización de cuatro variables:

1. La temperatura del gas $\left(T_{g}\right)$

2. El coeficiente de convección $(h)$

3. La temperatura equivalente de radiación $\left(T_{r}\right)$

4. La emisividad $(\varepsilon)$

Asumiendo conocidos los coeficientes de radiación $(\varepsilon)$ y convección $(h)$, se explican los motivos por los que los registros realizados no son suficientes para caracterizar la exposición térmica a la que se encuentra sometida la estructura:

1. Aunque se puede asumir que con los termopares se registra la temperatura del gas $\left(T_{g}\right)$, faltarían por incluir termopares que registraran las temperaturas bajo las alas inferiores de las vigas metálicas. En la Figura 6-7a se incluyen los valores registrados en una simulación de incendios en la que sí se han incluido termopares en esta zona bajo las alas inferiores

2. Los termopares existentes en el gas (ver Figura 6-7b) se encuentran a $0.5 \mathrm{~m}$ de las caras interiores de las almas de las vigas (termopar central) y a $0.25 \mathrm{~m}$ de las 
caras exteriores de las almas de las vigas (termopares en los laterales). Estas distancias deberían reducirse a valores en torno a $\operatorname{los} 5 \mathrm{~cm}$ para que caractericen temperaturas realmente representativas de la exposición del alma. (Figura 6-7b)

3. La temperatura equivalente de radiación $\left(T_{r}\right)$ no se ha registrado en ningún punto ni tampoco se puede obtener indirectamente a partir de otras mediciones relacionadas. Por este motivo el flujo neto por radiación resulta imposible de obtener.

(a) Efecto de zona

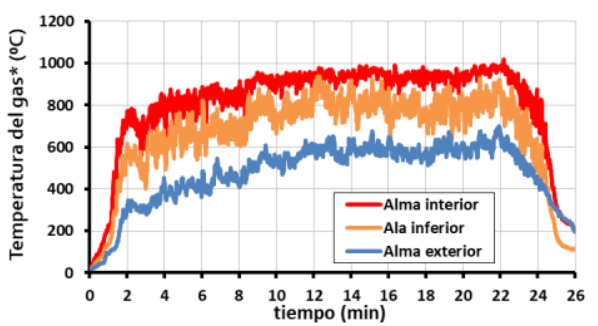

(b) Efecto de distancia al alma

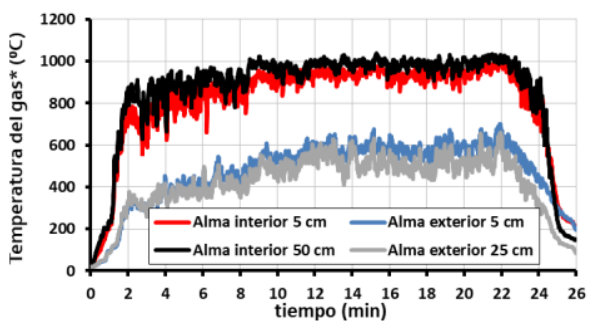

Figura 6-7. Registros de temperaturas realizados mediante termopares de acero inoxidable de 1.5 mm situados en el gas en la sección S3 en torno a la viga sur en el modelo de FDS empleado para reproducir el ensayo Test 8 en la validación del modelo de incendios.

Puesto que tampoco se ha registrado la temperatura adiabática $\left(T_{a}\right)$ planteada como alternativa en la Figura 6-5 durante el ensayo Test 8 queda descartada la validación directa propuesta en la Figura 6-8, tanto mediante temperaturas adiabáticas $\left(T_{a}, \varepsilon\right.$ y $\left.h\right)$ como mediante temperaturas del gas y temperaturas equivalentes de radiación $\left(T_{r}, \varepsilon, T_{g}\right.$ $\mathrm{y} h)$.

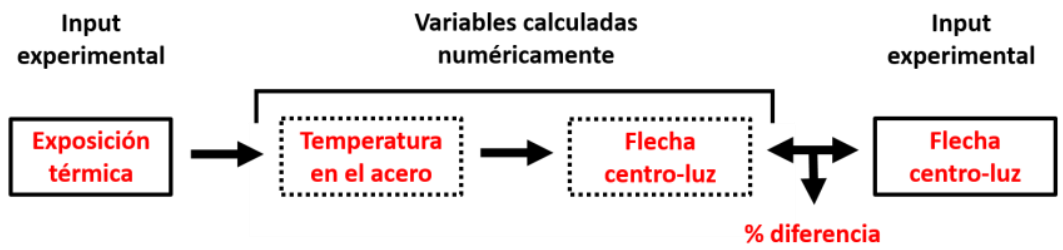

Figura 6-8. Validación directa del modelo termo-mecánico a partir de registros experimentales de la exposición térmica y de la flecha en centro-luz del tablero. Procedimiento descartado por la ausencia de registros necesarios. 


\subsubsection{TEMPERATURAS EN EL ACERO}

Durante el ensayo Test 8, como se puede consultar en la Figura 6-4, se registraron mediciones puntuales de temperaturas en el acero en las seis secciones (S1 a S6). Mientras que las temperaturas en el centro del ala inferior y en el centro del alma se registraron para todas las secciones ( $\mathrm{S} 1$ a $\mathrm{S} 6$ ), las temperaturas en el centro del ala superior tan solo se registraron en las secciones centrales (S3 y S4). Para poder medir realizar este tipo de medición puntual de las temperaturas en el acero, se practicaron agujeros de $4 \mathrm{~mm}$ de espesor, donde se introdujeron los extremos de los termopares.

Adicionalmente a los termopares, se empleó una cámara termográfica para registrar las temperaturas de la cara exterior del alma de la viga sur desde la sección $\mathrm{S} 3(\mathrm{x}=2.5 \mathrm{~m})$ a la sección $\mathrm{S6}(\mathrm{x}=5.5 \mathrm{~m})$. Obtenidas las imágenes a partir de la cámara se puede obtener un registro en el tiempo de las temperaturas en uno o más puntos de las imágenes. Aunque este tipo de medición permite, una vez realizado el ensayo, seleccionar entre cualquier punto de los contenidos en la imagen, presenta el inconveniente de que, si se quiere obtener una medición en el tiempo, las grandes deformaciones del tablero provocarán que un punto fijo en la imagen esté registrando la temperatura de distintos puntos de la viga dado el movimiento de los mismos durante el ensayo.

(a) $10 \mathrm{~s}$ tras ignición

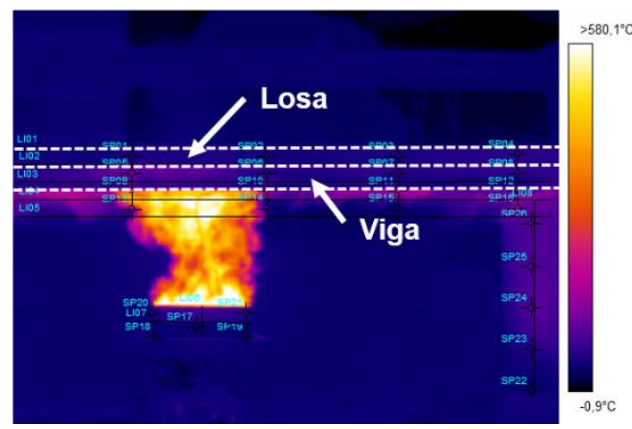

(b) 13 min tras ignición

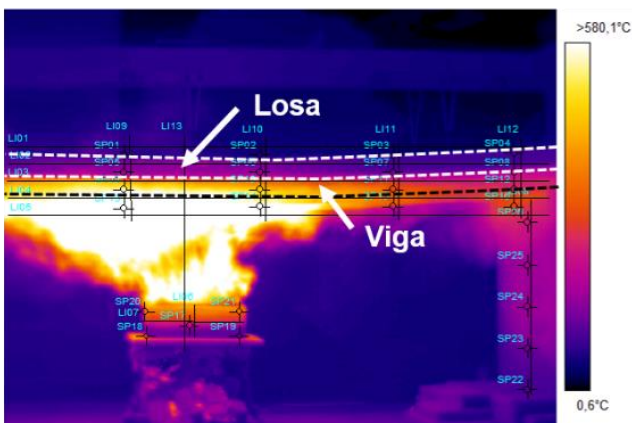

Figura 6-9. Imágenes tomadas mediante la cámara termográfica durante el ensayo Test 8.

En la Figura 6-9 se puede ver se presentan dos capturas obtenidas mediante la cámara termográfica. En la Figura 6-9a se puede ver como la viga aún se encuentra a una temperatura muy próxima a la temperatura ambiente y la llama es la que muestra las mayores temperaturas. Además, en la leyenda de la derecha de cada una de las dos capturas se puede ver como la máxima temperatura admitida por la cámara termográfica es de $580^{\circ} \mathrm{C}$ (limitación del empleo de esta tecnología frente al uso de termopares tipos $\mathrm{K}$ que permiten registrar temperaturas hasta más de $1000^{\circ} \mathrm{C}$ sin necesidad de acotar un 
intervalo menor). La limitación del rango de temperaturas se hace visible en las Figura 6-10a y Figura 6-10b, donde las temperaturas claramente han superado este valor, pero las imágenes no permiten cuantificar temperaturas por encima de ese rango.

Otro aspecto interesante a destacar en la Figura 6-9b es que la llama, como consecuencia de una racha de viento, se ha interpuesto en la visual entre la cámara y la cara sur del alma. Cuando esto ocurre, la temperatura no corresponde con los valores reales de la superficie del alma, sino con la propia temperatura de la llama. Es por esto que en la Figura 6-10 las curvas correspondientes a los registros obtenidos a partir de la cámara termográfica presentan una variabilidad muy superior a la presentada por los termopares.

Finalmente cabe destacar como a partir del minuto 30 a partir de la ignición, cuando la llama deja de interponerse en la visual entre el alma y la cámara termográfica, las temperaturas entre la cámara termográfica y los termopares ajustan casi perfectamente. Anteriormente a este momento, cabe destacar que la cámara termográfica ofrece resultados con mucha mayor dispersión que los propios termopares.

(a) Sección 3 ( $x=2.5 \mathrm{~m})$

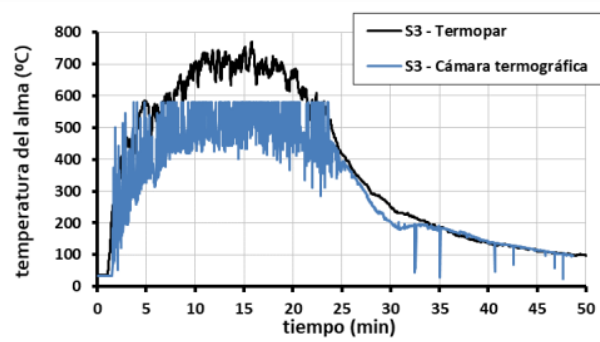

(a) Sección 5 ( $x=4.5 \mathrm{~m})$

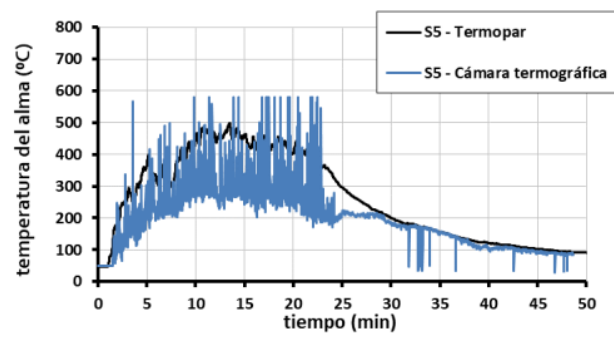

(b) Sección 4 ( $x=3.5 \mathrm{~m})$

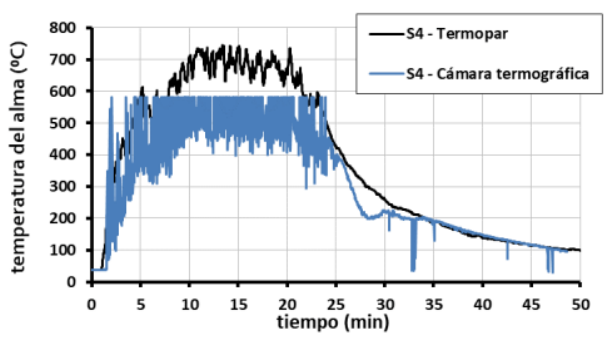

(b) Sección 6 ( $x=5.5 \mathrm{~m})$

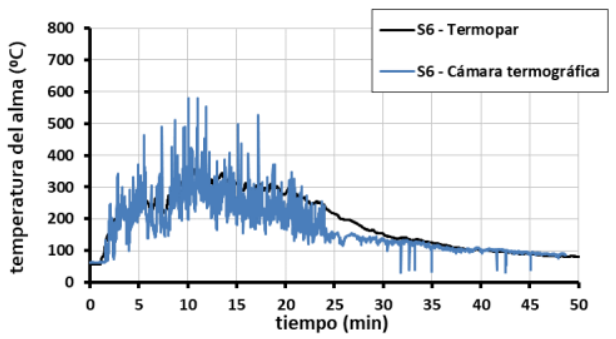

Figura 6-10. Comparativa de temperaturas registradas en el ensayo Test 8 mediante termopares situados en el acero e imágenes procedentes de la cámara termográfica.

Partiendo de los resultados obtenidos mediante los termopares podría plantearse una validación que prescindiría tanto del modelo de simulación de incendios como el de transmisión de calor (ver Figura 6-11). En esta validación se debería definir un campo 
predefinido de temperaturas en los materiales variable en el tiempo como input del modelo mecánico y a partir de él obtener las deformaciones de la estructura en el tiempo. Estas deformaciones se compararían con las registradas en el Test 8 mediante la variable flecha en CL.

Este tipo de validación se ha descartado porque las mediciones disponibles son puntuales y deberían hacerse un gran número de suposiciones para definir un campo térmico en el tiempo. Entre las suposiciones se encontrarían asumir o no una temperatura del ala inferior o del alma constante en sección, asumir qué temperatura correspondería al ala superior de las secciones 1,2,3 y 4 (ver Figura 6-4) y a la losa de hormigón en toda su longitud. Puesto que las exposiciones al calor de las zonas son distintas, los distintos gradientes (longitudinales y seccionales en el alma o las propias alas) deberían considerarse más allá de saltos térmicos bruscos entre tramos longitudinales o en las uniones ala-alma.

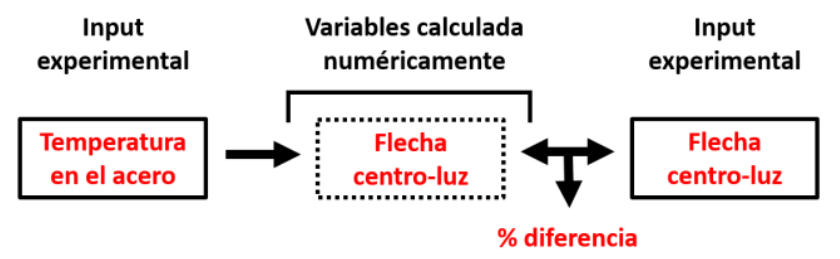

Figura 6-11. Validación directa del modelo termo-mecánico a partir de registros experimentales de la temperatura en el acero y de la flecha en centro-luz del tablero. Procedimiento descartado por la ausencia de registros necesarios.

\subsubsection{FLECHAS}

Las flechas del puente se midieron en tres secciones $(\mathrm{x}=1.0 \mathrm{~m}, \mathrm{x}=3.0 \mathrm{~m}$ y $\mathrm{x}=5.0 \mathrm{~m})$ con LVDT situados en cada una de las dos vigas. En la Figura 6-12 se representa la evolución en el tiempo de la flecha cada uno de los seis registros. En la figura se aprecia una simetría casi perfecta de las flechas registradas tanto en el plano longitudinal como en el plano transversal respecto al eje del puente y a la sección de CL respectivamente.

La simetría respecto al eje longitudinal del puente en cada una de las tres secciones de control de flechas $(\mathrm{x}=1.0 \mathrm{~m}, \mathrm{x}=3.0 \mathrm{~m} \mathrm{y} \mathrm{x}=5.0 \mathrm{~m})$ permite que en el modelo termomecánico tan solo sea necesario modelar medio tablero (viga sur y losa asociada) si se incorpora la condición de simetría correspondiente. Mediante esta condición de simetría se reduce tanto el tiempo de modelado como el tiempo de computación sin reducir la precisión de los resultados. 
$\mathrm{El}$ hecho de que las deformaciones verticales de las secciones $\mathrm{x}=1.0 \mathrm{~m} \mathrm{y} \mathrm{x}=5.0 \mathrm{~m}$ sean muy similares permite comprobar que las rachas de viento no han tenido un efecto notable sobre la exposición térmica del puente, puesto que si la llama se hubiera desplazado hacia el este u oeste durante gran parte del ensayo las flechas no serían simétricas longitudinalmente. Que las deformaciones de la viga sur y de la viga norte sean similares también permite dar una idea de que las rachas de viento en dirección norte-sur tampoco han repercutido notablemente en la respuesta termo-mecánica del tablero mixto.

La mayor flecha correspondiente a la viga norte $(3.5 \mathrm{~mm}$ superior a la viga sur) en la sección $\mathrm{x}=5.0 \mathrm{~m}$ probablemente se debe a la presencia de material aislante en la parte inferior del alma y sobre el ala inferior situadas en la zona central de exposición (entre $\mathrm{x}$ $=4.0 \mathrm{~m} \mathrm{y} \mathrm{x}=6.0 \mathrm{~m}$ ) de la viga sur. Este material aislante, cuya función es proteger parte de la monitorización de fibra óptica, no se ha dispuesto en la viga norte.

(a) Flechas (Test 8)

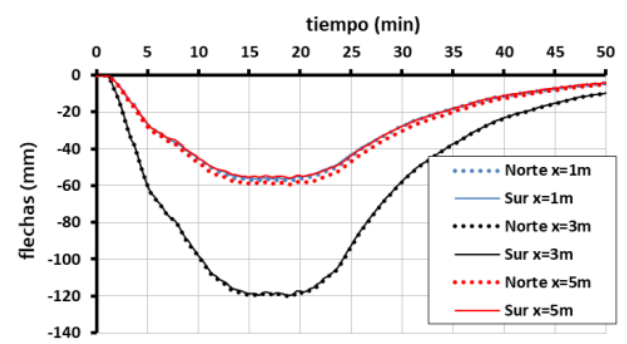

(b) Diferencia de flechas (norte-sur)

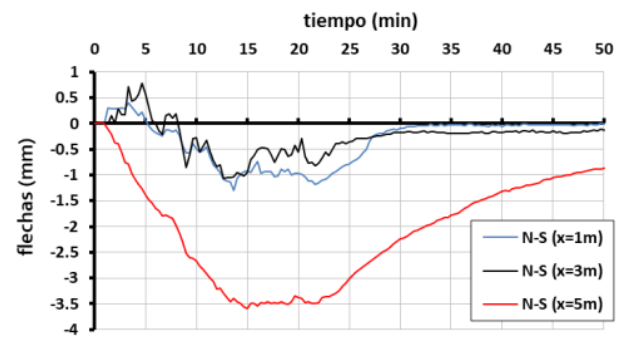

Figura 6-12. Evolución en el tiempo de (a) la flecha en CL en las vigas norte y sur y (b) la diferencia de flechas entre la viga norte y la viga sur para las secciones $x=1 \mathrm{~m}, x=3 \mathrm{~m}$ y $x=5 \mathrm{~m}$

\subsubsection{VIENTO}

A diferencia de lo que ocurre con otras acciones, existe una fuerte dependencia del fuego con respecto al viento. Esto es así puesto que el viento no solo puede desplazar los humos, sino que también puede inclinar el penacho del fuego. La complejidad de la consideración de esta variable en los modelos de simulación de incendios se debe a tres factores:

1. Es una variable vectorial, por lo que para su completa definición requiere de la caracterización tanto su magnitud como su dirección en cada punto.

2. Tanto su magnitud como su dirección pueden variar en el tiempo y en el espacio 
3. Según a la distancia que se encuentre el punto de medición de la fuente de fuego, de la potencia del fuego y de la magnitud del viento el registro de viento se puede ver alterado por la propia dinámica del incendio

En lo que respecta al ensayo Test 8 , se ha empleado un anemómetro manual que ha permitido, en base a un umbral de velocidad del viento máximo de $2 \mathrm{~m} / \mathrm{s}$, dar inicio al ensayo.

Aunque no se han realizado registros en el tiempo de la velocidad del viento durante el ensayo, si se ha podido valorar cualitativamente el incremento en magnitud de las rachas de viento a partir del minuto 10 en base al estudio de imágenes y el video grabado durante el ensayo. Como se puede ver en la Figura 6-13, aunque durante los primeros minutos apenas se registran inclinaciones de las llamas, a partir del minuto diez la frecuencia a la que se inclinan las llamas y la propia inclinación se incrementa notablemente. Esto provoca una alteración en el movimiento de los humos y una variación en la exposición térmica de las vigas de acero.
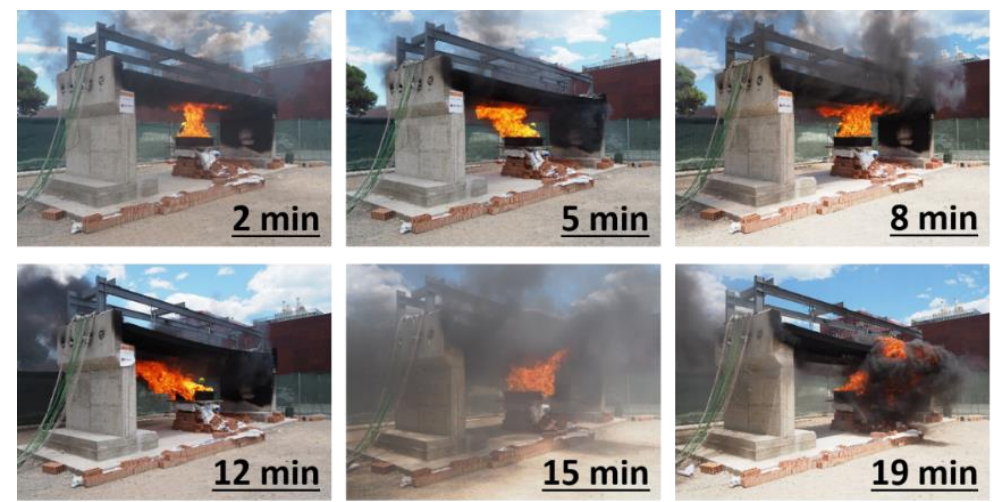

Figura 6-13. Evolución del efecto del viento durante el ensayo Test 8.

\subsection{MODELO DE SIMULACIÓN DE INCENDIOS}

\subsubsection{DEFINICIÓN DEL MODELO}

El volumen de control, de 691000 celdas paralepipédicas de en torno a $10 \mathrm{~cm}$ de lado, es un cubo de $12.0 \mathrm{~m}$ de lado para asegurar que las condiciones de contorno no afectan a la dinámica del problema. En la Figura 6-14 se muestra la geometría modelada (que no el volumen de control completo) que incluye el tablero, los estribos, la losa de referencia, la bandeja de combustible (de $0.75 \mathrm{~m}$ de lado y $0.3 \mathrm{~m}$ de alto) y la base sobre la que está 
dispuesta. Todos los elementos se han ajustado al mallado empleado. Se han empleado tres tipos de materiales: hormigón, acero y material inerte [ref6.05].Se ha habilitado la transmisión de calor a través de las chapas de acero.

(a) Materiales y superficies

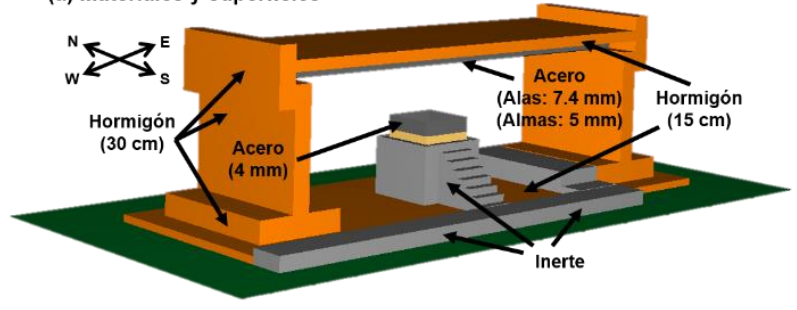

(b) Vista en planta

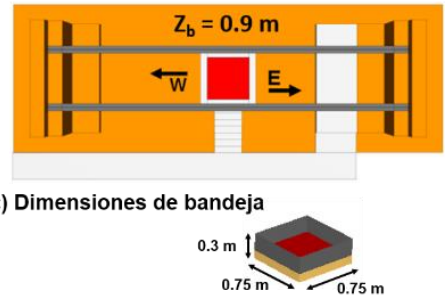

Figura 6-14. Modelo de incendios del ensayo Test 8: (a) Materiales y superficies, (b) Vista en planta $y$ (c) Dimensiones de la bandeja.

Respecto a la tasa de liberación de calor (HRR), se ha modificado a lo largo del proceso iterativo. La tasa de liberación de calor (HRR) de la iteración inicial, obtenida a partir de la pérdida de masa registrada en el ensayo Test 8, se incluye en la Figura 6-6,. La altura del burner se encuentra a $0.9 \mathrm{~m}$ sobre la losa. Se emplea la reacción del heptano proporcionada por la librería de combustibles 2016.1.0425 de Pyrosim [ref6.05], un modelo de fracción de mezcla propuesto por McGrattan et al. [ref6.06, ref6.07], un factor de radiación $\left(\chi_{\mathrm{r}}\right)$ de $0.35 \mathrm{y}$ un soot yield de $0.037 \mathrm{~g} / \mathrm{g}$ [ref6.08].

\subsubsection{DISTRIBUCIÓN Y TIPO DE SENSORES}

La distribución y el tipo de sensores empleados en el presente capítulo difieren de los definidos en el capítulo 5 (Sección 5.5.4) para la validación del modelo de simulación de incendios. Esto es así puesto que cada capítulo cubre un tipo de validación, lo que exige un tipo de información diferente en cada caso.

En la validación del modelo termo-mecánico se han empleado tres tipos de sensores (termopares en el gas, temperaturas adiabáticas y coeficientes de convección), todos ellos dispuestos en cada una de las seis secciones (S1, S2, S3, S4, S5 y S6) dispuestas en las coordenadas $\mathrm{x}=0.5,1.5,2.5,3.5,4.5,5.5 \mathrm{~m}$ respectivamente.

Mientras que los coeficientes de convección y las temperaturas adiabáticas se han empleado para caracterizar adecuadamente los flujos de convección y radiación empleados en el modelo termo-mecánico, los termopares en el gas se han empleado para la comprobación final de la exposición térmica mediante su comparación con las temperaturas registradas experimentalmente. 
En la Figura 6-15a se muestra la distribución espacial de los 90 sensores mientras que en la Figura 6-15b se incluye la posición en sección de cada sensor. La nomenclatura de los sensores se detalla a continuación:

1. Termopares en el gas
a. $\mathrm{GN}=$ Termopar en el gas en la zona norte
b. $\mathrm{GC}=$ Termopar en el gas en la zona central
c. $\mathrm{GS}=$ Termopar en el gas en la zona sur

2. Temperaturas adiabáticas
a. TA-SG-WS = Temperatura adiabática en la cara sur de la viga sur
b. TA-SG-WN = Temperatura adiabática en la cara norte de la viga sur
c. TA-SG-BF = Temperatura adiabática en el ala inferior de la viga sur
d. TA-NG-WS = Temperatura adiabática en la cara sur de la viga norte
e. TA-NG-WN = Temperatura adiabática en la cara norte de la viga norte
f. TA-NG-BF = Temperatura adiabática en el ala inferior de la viga norte

3. Coeficientes de convección

a. h-SG-WS = Coeficiente de convección en la cara sur de la viga sur

b. h-SG-WN = Coeficiente de convección en la cara norte de la viga sur

c. h-SG-BF = Coeficiente de convección en el ala inferior de la viga sur

d. h-NG-WS = Coeficiente de convección en la cara sur de la viga norte

e. h-NG-WN = Coeficiente de convección en la cara norte de la viga norte

f. h-NG-BF $=$ Coeficiente de convección en el ala inferior de la viga norte

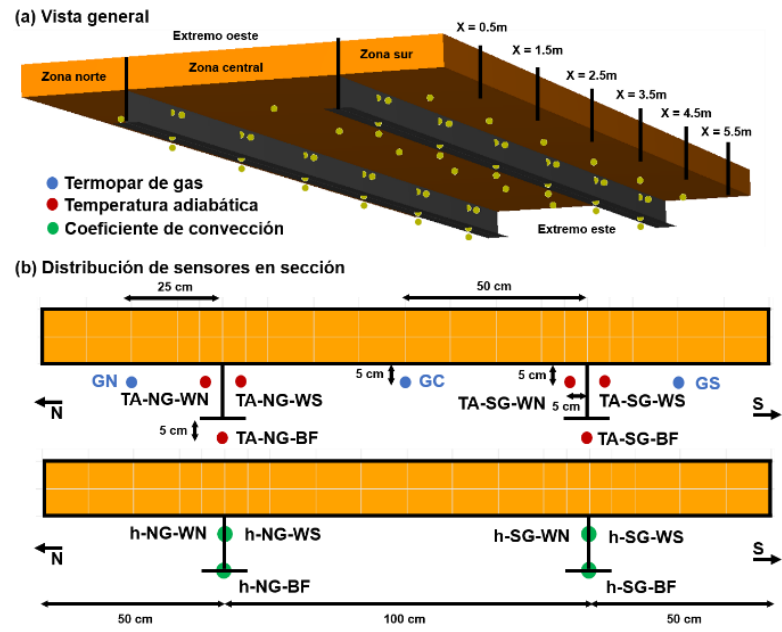

Figura 6-15. Simulación de incendios del ensayo Test 8: (a) Vista general y (b) Distribución de sensores en sección. 
Donde:

TA $=$ Temperatura adiabática

$\mathrm{h}=$ Coeficiente de convección

$\mathrm{SG}=$ Viga sur (South Girder)

$\mathrm{NG}=$ Viga norte (North Girder)

WS = Cara sur del alma (Web South face)

$\mathrm{WN}=$ Cara norte del alma (Web North face)

$\mathrm{BF}=$ Ala inferior (Bottom flange)

\subsection{MODELO DE ELEMENTOS FINITOS TERMO-MECÁNICO}

En esta sección, la viga sur y su losa tributaria (ver Figura 6-16) se analizan usando un análisis termo-mecánico no acoplado.

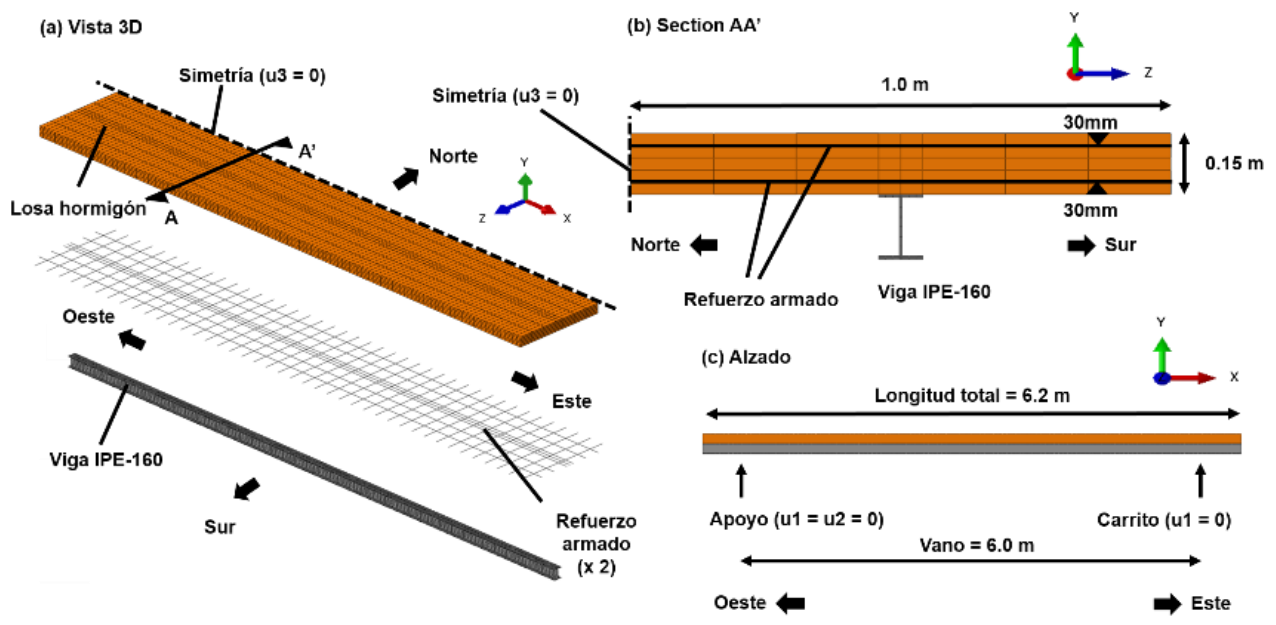

Figura 6-16. Modelo de elementos finitos de la viga sur en Abaqus: (a) Vista 3D, (b) Sección AA' y (c) Alzado.

En la primera etapa (el análisis térmico), la estructura se calienta empleando las temperaturas adiabáticas obtenidas mediante el modelo de simulación de incendios en FDS. Durante esta etapa el modelo de transferencia de calor proporciona la evolución de temperaturas en el tiempo de cada nodo. En la segunda etapa (el análisis mecánico), se 
calcula el equilibrio de la estructura partiendo de la actualización de las propiedades mecánicas derivada de los cambios de temperatura a los que se somete a cada nodo del modelo. Todos los análisis se han realizado mediante el software de elementos finitos ABAQUS [ref6.09]. Todos los modelos de ABAQUS se han ejecutado en un ordenador con procesador i7-3770 de 3.4-3.9 GHz y 32 GB de RAM, siendo el tiempo de ejecución de cada simulación de una hora aproximadamente.

\subsubsection{ELEMENTOS Y MALLA}

Para el análisis térmico, se ha empleado el elemento finito DC3D8 para el modelado de la losa y de la viga y el elemento finito DC1D2 para el modelado de las armaduras de la losa. Mientras que el elemento DC3D8 es un elemento volumétrico de transferencia de calor lineal tridimensional de ocho nodos con un grado de libertad por nodo, el DC1D2 es un elemento unidimensional de transferencia de calor de dos nodos con un grado de libertad por nodo.

Para el análisis mecánico, se ha empleado el elemento finito C3D8 para el modelado de la losa y la viga y el elemento finito B31 para el modelado de las armaduras de la losa. Mientras que el elemento C3D8 es un elemento continuo tridimensional de ocho nodos con tres grados de libertad por nodo, el B31 es un elemento lineal de dos nodos con tres grados de libertad por nodo.

\begin{tabular}{ccccc}
\hline \multirow{2}{*}{ Partes del modelo } & $\mathbf{n}$ & \multicolumn{3}{c}{ Elementos finitos } \\
\cline { 3 - 5 } & & térmico & mecánico & EF \\
\hline Viga & 1 & DC3D8 & C3D8 & 5456 \\
Losa & 1 & DC3D8 & C3D8 & 4960 \\
Armadura longitudinal & 14 & DC1D2 & B31 & 124 \\
Armadura transversal & 82 & DC1D2 & B31 & 8 \\
\hline Total elementos 3D & - & DC3D8 & C3D8 & 10416 \\
Total elementos 1D & - & DC1D2 & B31 & 2392 \\
\hline Total & - & - & - & 12808 \\
\hline
\end{tabular}

Tabla 6-1. Número de elementos finitos organizados por partes del modelo

Los análisis realizados mediante elementos finitos han incluido no linealidades geométricas (fuerzas actuantes en geometría deformada) y del material (ecuaciones constitutivas de los materiales con tramos plásticos, definición independiente de región de tracción y compresión y dependientes de las temperaturas del material). El modelo de elementos finitos ha incluido elementos sólidos y lineales para capturar fenómenos locales como el pandeo del alma, que podría controlar la respuesta global y el modo de 
fallo de la viga estudiada. La malla empleada es homogénea a lo largo de toda la longitud del vano. Los modelos térmicos y mecánicos de elementos finitos comparten distribución de malla y tienen 17863 nodos y 61620 elementos finitos. La Tabla 6-1 no solo detalla cómo se distribuyen los elementos finitos en el modelo, sino que también incluye el número total de barras empleadas en el modelo.

\subsubsection{Propiedades de los MATERIaleS}

Las propiedades térmicas (densidad, calor específico y conductividad) del hormigón y del acero se han definido dependientes de la temperatura, de acuerdo como indica el Eurocódigo 4 de estructuras mixtas [ref6.10]. Las características mecánicas de ambos materiales se detallan a continuación.

La densidad del acero $\left(\rho_{\mathrm{a}}\right)$ se ha asumido de $7850 \mathrm{~kg} / \mathrm{m}^{3}$ e independiente de la temperatura. Las curvas tensión-deformación se han definido de acuerdo a la propuesta del Eurocódigo 4 [ref6.10] con un límite elástico a temperatura ambiente de $355 \mathrm{MPa}$ para el perfil IPE-160 y de 500 MPa para la armadura empleada en la losa. El módulo de elasticidad a temperatura ambiente se ha asumido igual a $210 \mathrm{GPa}$ en ambos casos. Los valores nominales de tensiones $(\sigma)$ y deformaciones $(\varepsilon)$ han sido convertido en tensiones y deformaciones reales $\left(\sigma_{\mathrm{n}}, \varepsilon_{\mathrm{n}}\right)$ de acuerdo con la Ec. 6-3 y la Ec. 6-4.

$\sigma_{\mathrm{n}}=\sigma(1+\varepsilon)$

$\varepsilon_{\mathrm{n}}=\ln (1+\varepsilon)$

El hormigón se ha caracterizado mediante el modelo "Concrete Damage Plasticity" (CDP) que asume que los dos principales mecanismos de fallo son la fisuración en tracción y el aplastamiento del hormigón en compresión y que tiene en cuenta que la evolución de esfuerzos de tracción y compresión pueden ser diferentes.

Como ángulo de dilatancia ("dilatation angle") del hormigón se adoptó un valor de 30 grados sexagesimales. Para el resto de parámetros del modelo, excentricidad ("eccentricity"), ratio de resistencia del hormigón biaxial/uniaxial ("ratio of the biaxial compression strength to uniaxial compression strength of concrete") y ratio entre el segundo invariante de tensiones en tracción y compresión ("ratio of the second stress invariant on the tensile meridian to that on the compressive meridian"), se han adoptado los valores por defecto $(0.1,1.16$ y 0.67 respectivamente) propuestos por ABAQUS [ref6.09].

La densidad del hormigón $\left(\rho_{\mathrm{h}}\right)$ se ha asumido de $2300 \mathrm{~kg} / \mathrm{m}^{3}$ y dependiente de la temperatura. Los áridos empleados han sido calcáreos. La curva constitutiva en su zona de compresión se ha caracterizado de acuerdo con el modelo propuesto por el Eurocódigo 
4 [ref6.10] partiendo de una resistencia característica $\left(\mathrm{f}_{\mathrm{c}}\right)$ de $30 \mathrm{MPa}$ a temperatura ambiente. El comportamiento en tracción a partir de la tensión de fisuración de $2.9 \mathrm{MPa}$ se ha definido mediante una recta decreciente lineal que se reduce al $10 \%$ del de la tensión de fisuración con $0.3 \mathrm{~mm}$ de abertura de fisura. La curva constitutiva en tracción se ha definido en función de pares de valores tensión-abertura de fisura.

\subsubsection{DISCRETIZACIÓN DE LA EXPOSICIÓN TÉRMICA}

Las temperaturas adiabáticas obtenidas a partir del modelo de simulación de incendios se emplean para calcular los flujos de calor por convección y radiación. En el análisis térmico se ha introducido la evolución de las temperaturas adiabáticas a lo largo del tiempo en función de las secciones (S1, S2, S3, S4, S5 y S6) y de las zonas de exposición de la viga sur (sur, inferior y norte).

Los coeficientes de convección se han definido constantes en el tiempo e independientes de las secciones consideradas. Se ha considerado un valor de $10 \mathrm{~W} \cdot \mathrm{m}^{-2} \cdot{ }^{\circ} \mathrm{C}^{-1}$ para las zonas norte e inferior (zonas con exposición a la llama directa) y un valor de $4 \mathrm{~W} \cdot \mathrm{m}^{-2} \cdot{ }^{\circ} \mathrm{C}$ ${ }^{-1}$ para la zona sur (sin exposición a la llama directa). Los valores se han aproximado a partir de los registros numéricos obtenidos a partir de los sensores dispuestos de acuerdo a la Figura 6-15 con el fin de obtener valores de coeficientes de convección acordes con el escenario de fuego considerado.

(a) Sección de la viga sur (zonas de exposición)

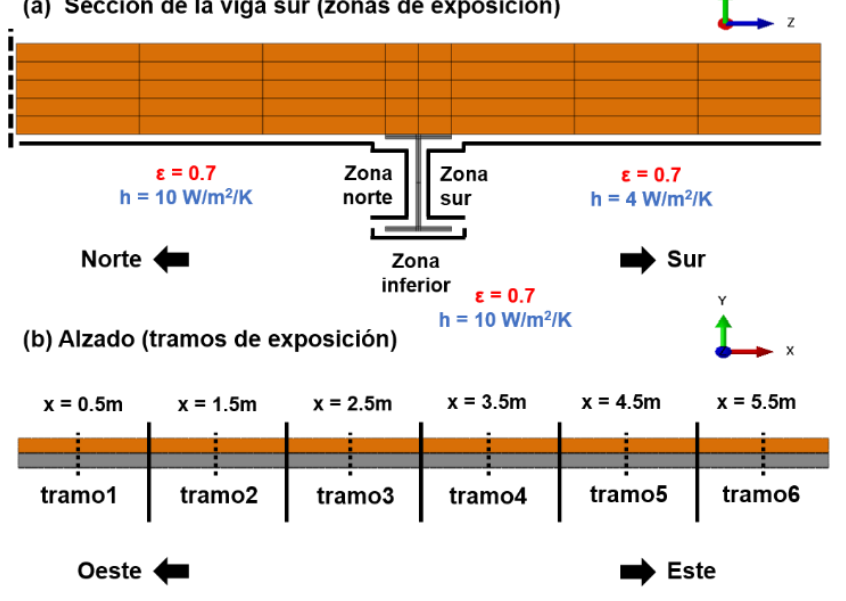

Figura 6-17. Discretización de las temperaturas de exposición en el modelo termo-mecánico: (a) Sección de la viga sur (zonas de exposición) y (b) Alzado (tramos longitudinales de exposición). 
Para la emisividad $(\varepsilon)$ se ha adoptado un valor de 0.7 [ref6.10] único para todas las secciones y zonas. En la Figura 6-17a se incluye una sección de la viga sur donde se indican los coeficientes empleados en cada una de las zonas (los coeficientes no dependen de la sección, tan solo de la zona de exposición definida en el modelo de elementos finitos).

Además de la discretización en tres zonas (sur, inferior y norte), las curvas "tiempotemperatura adiabática de exposición" se han caracterizado en el modelo térmico en seis tramos longitudinales (ver Figura 6-17b), de forma que cada curva tiempo-temperatura se ha definido a partir de un sensor de temperatura adiabática situado en el centro de cada tramo. En la Figura 6-18 se comparan los registros de temperaturas adiabáticas obtenidos en la sección S3 del modelo FDS (1 dato/s) con los mismos registros introducidos en el modelo térmico de ABAQUS tras realizar un promediado de los valores (1 dato/minuto).

(a) Output del modelo de incendios

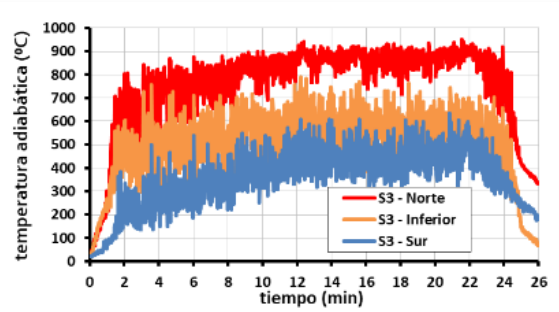

(b) Input del modelo termíco

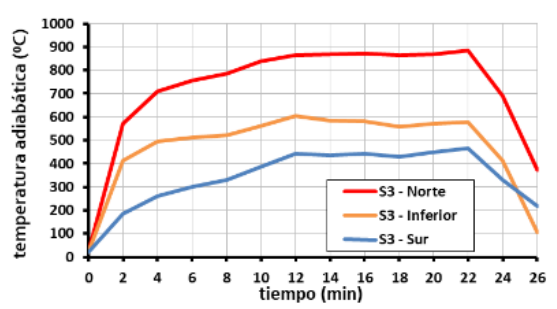

Figura 6-18. Temperaturas adiabáticas: (a) registradas en la sección S3 en el modelo de incendios de FDS e (b) introducidas en el tramo 3 en el modelo térmico de ABAQUS.

\subsubsection{RESTRICCIONES Y CONDICIONES DE CONTORNO Y SIMETRÍA}

El puente experimental es mixto, por lo que las vigas de acero y la losa de hormigón están conectadas mediante pernos conectadores para garantizar su trabajo solidario a temperatura ambiente. Esta adherencia perfecta (materializada mediante la vinculación "TIE" de ABAQUS) a temperatura ambiente podría verse comprometida conforme se incremente la temperatura de los pernos conectadores. Sin embargo, la hipótesis de adherencia perfecta se ha considerado buena por dos motivos:

1. Las temperaturas máximas registradas en la intersección entre alas superiores y almas en las secciones centrales $\mathrm{S} 3(\mathrm{x}=2.5 \mathrm{~m})$ y $\mathrm{S} 4(\mathrm{x}=3.5 \mathrm{~m})$ apenas han superado los $550{ }^{\circ} \mathrm{C}$ (ver Figura 6-19a).

2. El número de pernos conectadores dispuestos en cada viga se sobredimensionó notablemente durante el diseño de los ensayos con el fin de garantizar esta adherencia perfecta incluso en condiciones de incendio. 
También se ha considerado adherencia perfecta entre la armadura de refuerzo (situada como en el peor de los casos a $5 \mathrm{~cm}$ de la cara inferior de la losa expuesta al fuego) y el hormigón de la losa.

Las vigas metálicas apoyan en los estribos mediante neoprenos como los que se pueden ver en la Figura 6-19b. Los neoprenos restringen el desplazamiento vertical $(\mathrm{u} 2=0)$ pero no restringen ni el desplazamiento transversal $(u 3 \neq 0)$ al eje del tablero ni el desplazamiento en sentido longitudinal $(\mathrm{u} 1 \neq 0)$. En la Figura 6-20, donde se muestran las condiciones de contorno y de simetría del modelo, se puede ver como en el apoyo oeste se ha añadido la condición de $(\mathrm{u} 1=0)$ para asegurar que el modelo numérico se encuentre en equilibrio estático con cualquier sistema de cargas. Esta última condición no representa una condición de contorno real, sino que es una condición de contorno puramente numérica.

(a) Temperaturas experimentales en la viga sur

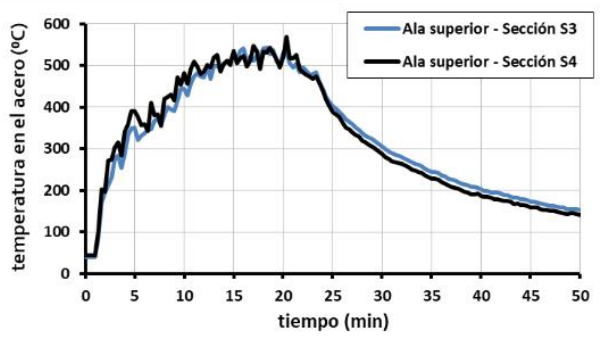

(b) Apoyos elastoméricos del estribo este
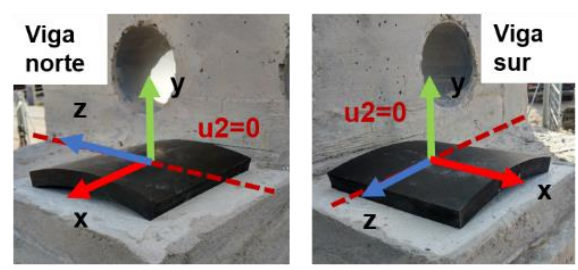

Figura 6-19. (a) Temperaturas en el centro de las alas superiores de las vigas y (b) Apoyos elastoméricos empleados en el estibo este.

Al definir en el modelo numérico termo-mecánico se ha modelado tan solo la mitad del tablero. Para ello se ha requerido de la imposición de una condición de simetría (u3=0) en la cara norte del tramo de losa tributario a la viga sur. 


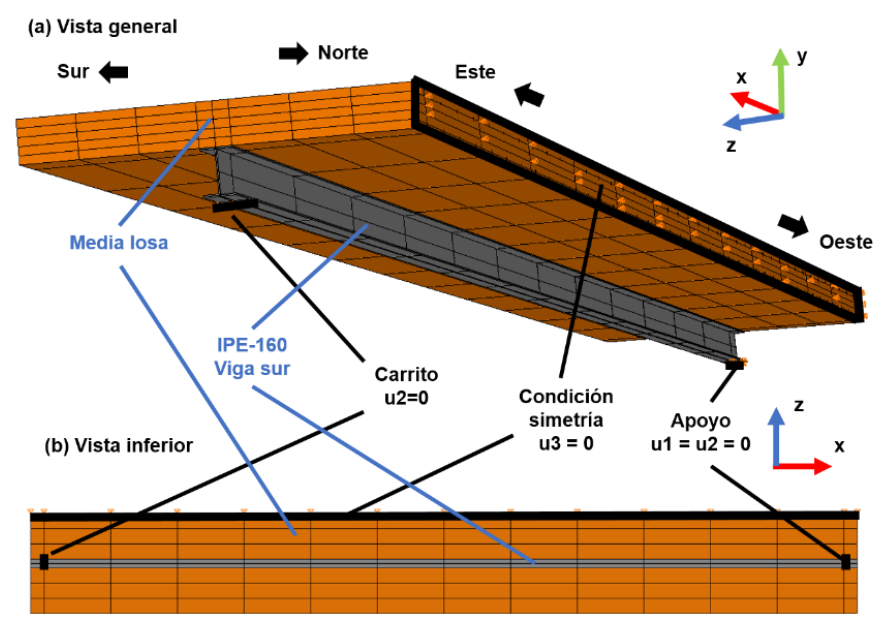

Figura 6-20. Condiciones de contorno (apoyo: $u 1=u 2=0$, carito: $u 2=0$ ) y condición de simetría $(u 3=0)$ : (a) Vista general y (b) Vista inferior.

\subsubsection{Cargas gravitatorias}

Se han considerado las cargas gravitatorias correspondientes al peso propio de:

1. La viga de acero $(0.926 \mathrm{kN})$

2. La zona tributaria de la losa de hormigón $(20.984 \mathrm{kN})$

3. Las barras de refuerzo longitudinales $(0.336 \mathrm{kN})$

4. Las barras de refuerzo transversales $(0.317 \mathrm{kN})$

No se han considerado cargas muertas ni variables en el modelo.

\subsection{VALIDACIÓN TERMO-MECÁNICA}

De acuerdo al procedimiento de validación del modelo termo-mecánico expuesto en la Figura 6-3 los pasos a seguir son los siguientes:

1. Se realizará una primera iteración en la que se emplearán las temperaturas adiabáticas obtenidas a partir de un modelo de simulación de incendios con una tasa de liberación de calor (HRR) igual a la registrada experimentalmente y con una hipótesis de viento nulo.

2. Se modificará iterativamente la curva de la tasa de liberación de calor en el tiempo (t-HRR) dentro del modelo de incendio hasta que el modelo termomecánico reproduce la evolución en el tiempo de las flechas en CL. En este paso se busca considerar indirectamente el efecto del viento sobre la exposición 
térmica mediante la modificación de la curva de la tasa de liberación e calor en el tiempo

3. Una vez se haya conseguido reproducir la evolución de la flecha en CL registrada experimentalmente se compararán las temperaturas en el acero calculadas mediante el modelo térmico de forma que si son similares a las registradas experimentalmente se daría por valido el modelo mecánico.

4. Finalmente se compararán las temperaturas en el gas calculadas mediante el modelo de simulación de incendios de forma que si son similares a las registradas experimentalmente se daría por válido el modelo el modelo térmico y se consideraría aceptable la consideración indirecta del viento mediante la reducción de la tasa de liberación de calor (HRR) en el modelo de incendios.

\subsubsection{PASO 1. ITERACIÓN INICIAL CON HIPÓTESIS DE VIENTO NULO}

En la primera iteración, el modelo de incendios incluye la tasa de liberación de calor por unidad de área (HRRPUA) directamente registrada en el ensayo Test 8 (ver Figura 6-21a). Recurriendo al modelo termo-mecánico al que se le introducen las temperaturas adiabáticas obtenidas en el modelo de incendios se obtiene una evolución de flechas en CL que se compara con el registro experimental equivalente (Figura 6-21b). Como ocurre con todos los modelos de incendios del presente capítulo, se ha asumido la hipótesis de viento nulo.

En la Figura 6-21b se puede ver como la flecha en CL calculada a partir de los modelos de incendios, térmico y mecánico numérica, a partir del minuto 8 , sobredimensiona notablemente la flecha en CL registrada experimentalmente. Si se consulta la Figura 6-21a, se comprueba cómo en torno a los 8 minutos de la ignición se produce un incremento de la tasa de liberación de calor por unidad de área (HRRPUA) que en el video del ensayo (ver Figura 6-13) se corresponde con un incremento en la intensidad de las rachas de viento presentes durante el desarrollo del ensayo Test 8 .

(a) HRRPUA - Test 8

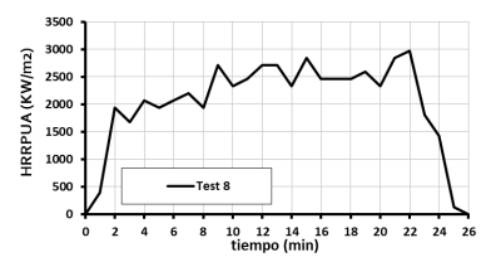

(b) Flecha en centro-luz

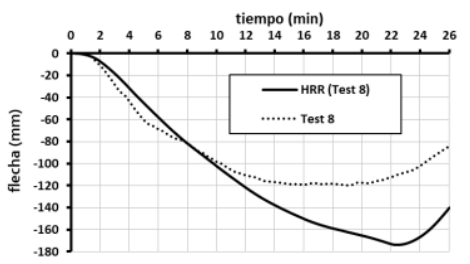

Figura 6-21. (a) Tasa de liberación de calor por unidad de área (HRRPUA) calculada a partir de la pérdida de masa registrada experimentalmente y (b) flecha en CL obtenida mediante el modelo termo-mecánico a partir de la HRRPUA mostrada en (a). 
Se entiende que el incremento de potencia del fuego se debe al incremento de las rachas de viento que sobrealimentan el fuego al aportar más oxígeno del que recibían previamente en condiciones de viento casi nulo. Puesto que en el modelo de incendios no se ha incluido el viento, pero si se ha considerado la tasa de liberación de calor (HRR) registrada experimentalmente no se ha podido desviar parte del calor ascendente desde la fuente de fuego hacia ambos laterales. Esta situación es la que justifica que la flecha registrada en esta iteración inicial sea muy superior a la registrada experimentalmente.

Puesto que la afección del viento no se puede modelar en FDS dada su complejidad (Sección 6.4.5) se ha decido incluir el efecto del viento de forma indirecta Figura 6-13 mediante una reducción de la HRRPUA en el modelo de simulación de incendios. Se busca obtener una exposición térmica equivalente a la que se produjo en el ensayo Test 8 mediante un escenario de fuego "equivalente".

\subsubsection{PASO2. REPRODUCCIÓN DE LA RESPUESTA MECÁNICA}

\section{Iteración 2: Definición de curva trilineal de tasa de liberación de calor}

Escenario de incendio:

"plateau2000"

La primera corrección de la tasa de liberación de calor por unidad de área (HRRPUA) surge de suponer que, si no se hubiese producido un incremento en la magnitud de las rachas de viento, la potencia por unidad de superficie se habría mantenido en torno a los $2000 \mathrm{~kW} / \mathrm{m}^{2}$, como ocurre durante los primeros ocho minutos.

Es por ello que la primera corrección consiste en proponer una curva tiempo-HRRPUA trilineal en la que se alcanza el máximo a los dos minutos y el decay comienza en el minuto 22, como ocurre en el registro experimental del ensayo Test 8 (ver Figura 6-22a).

(a) HRRPUA - corrección de meseta

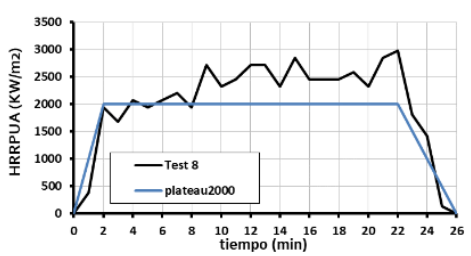

(b) Flecha en centro-luz

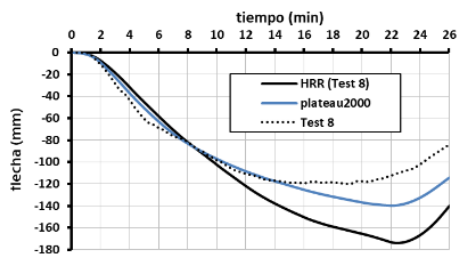

Figura 6-22. (a) Tasa de liberación de calor por unidad de área (HRRPUA) con meseta hasta minuto 22 y (b) flecha en CL obtenida mediante el modelo termo-mecánico a partir de la HRRPUA mostrada en $(a)$.

$\mathrm{Al}$ aplicar la nueva tasa de liberación de calor por unidad de área (HRRPUA) se puede ver como la nueva respuesta mecánica del modelo "plateau2000" (ver Figura 6-22b) se 
ajusta bastante bien al registro experimental durante los primeros trece minutos (cinco minutos más que la HRRPUA experimental). El hecho de que a partir del minuto trece la flecha experimental comience a reducirse más rápidamente que la numérica indica que la exposición térmica real es menos severa que la obtenida mediante el modelo de simulación de incendios. Probablemente la causa sea que el modelo numérico no ha llegado a compensar el efecto del viento mediante un descenso suficiente de la tasa de liberación de calor (HRR) en ese intervalo temporal.

Es por este motivo que en la siguiente iteración se propone reducir la tasa de liberación de calor por unidad de área (HRRPUA) linealmente a varios ritmos distintos a partir del minuto trece para ver qué respuesta mecánica se ajusta mejor a la flecha registrada experimentalmente.

\section{Iteración 2: Decrecimiento lineal de potencia a partir del minuto 13}

Escenarios de incendios:

$$
\begin{aligned}
& \text { "plateau2000-decay1" } \\
& \text { "plateau2000-decay2" } \\
& \text { "plateau2000-decay3" }
\end{aligned}
$$

(a) HRRPUA - corrección de decay

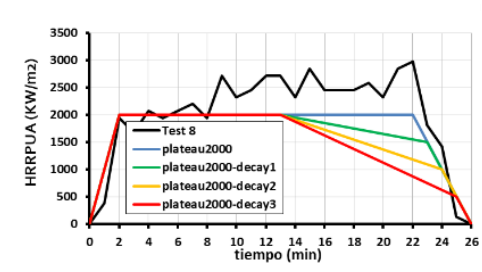

(b) Flecha en centro-luz

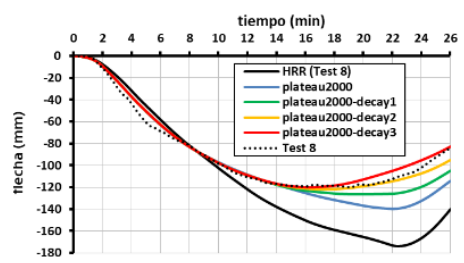

Figura 6-23. (a) Tasas de liberación de calor por unidad de área (HRRPUA) con meseta hasta minuto 13 y (b) flechas en CL obtenidas mediante el modelo termo-mecánico a partir de las HRRPUA mostradas en (a).

En la Figura 6-23 se presentan las distintas curvas de tasas de liberación de calor por unidad de área (HRRPUA) empleadas y las distintas respuestas mecánicas representadas por la evolución de flechas en CL asociadas a cada uno de los escenarios de fuego.

En ella se puede ver como el escenario de fuego que mejor ajusta es el "plateau2000decay2". 


\title{
Iteración 3: Corrección del tramo final de la curva tiempo-HRRPUA
}

\author{
Escenario de incendio: "plateau2000-decay4"
}

Finalmente se ha decidido acelerar la reducción de la tasa de liberación de calor por unidad de área (HRRPUA) a partir del minuto 21 y considerar el fuego extinguido en el minuto 25. Con ello se estaría incluyendo el mayor efecto que tiene el viento sobre la reducción de la temperatura de exposición cuando la potencia del fuego es menor.

En la Figura 6-24 se puede ver cómo la última caracterización de la curva que define la tasa de liberación de calor por unidad de área (HRRPUA) permite obtener una respuesta mecánica bastante ajustada a la registrada experimentalmente.

Si se presta atención a la Figura 6-24b se puede ver como se ha podido obtener una respuesta mecánica casi idéntica a la registrada experimentalmente. Para dar por validado el modelo mecánico quedaría comprobar si efectivamente esa respuesta mecánica se debe a una exposición térmica similar (el modelo termo-mecánico quedaría validado) o si la exposición térmica difiere notablemente (en cuyo caso lo único que habríamos conseguido es reproducir la flecha en CL).

(a) HRRPUA - corrección final

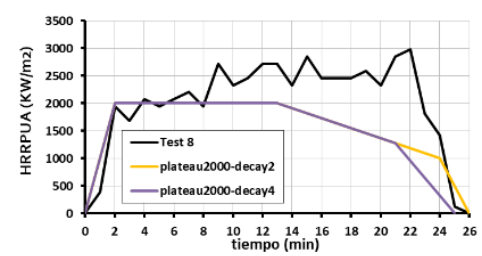

(b) Flecha en centro-luz

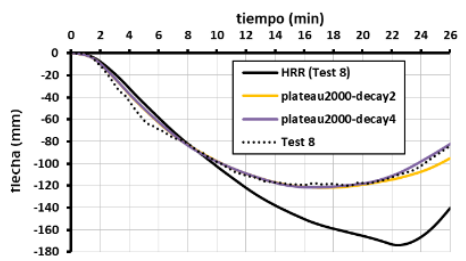

Figura 6-24. (a) Tasas de liberación de calor por unidad de área (HRRPUA) con meseta hasta minuto 13 y doble pendiente en decay y (b) flechas en CL obtenidas mediante el modelo termomecánico a partir de las HRRPUA mostradas en (a).

\subsubsection{PASO3. VALIDACión del MODElo MECÁNICO}

Una vez obtenida una evolución temporal de la flecha en centro-luz numérica similar a la registrada durante el ensayo "Test 8 " se puede afirmar que las respuestas mecánicas son similares, pero no que el modelo mecánico está validado. Atendiendo a la Figura 6-25 resulta sencillo entender como la condición de respuesta mecánica similar no es suficiente para validar el modelo. En la figura se presentan dos situaciones en las que se cumple (o no) que las temperaturas en el acero (en los materiales en general) imputadas en el modelo mecánico sean similares a las registradas experimentalmente. Si lo son a lo 
largo de todo el ensayo se estará verificando que la realidad se está reproduciendo adecuadamente.

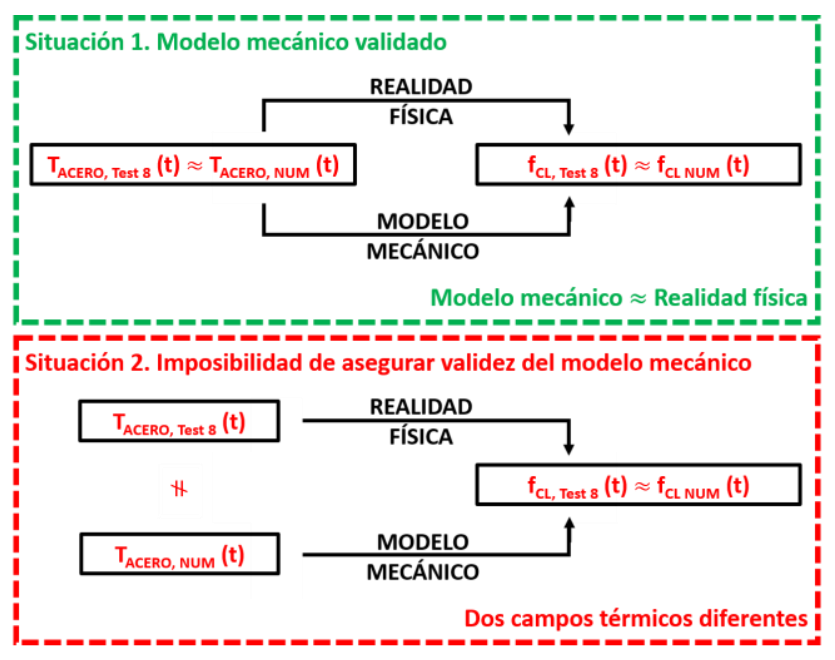

Figura 6-25. Esquema resumen sobre la segunda condición a cumplir para la validación del modelo mecánico.

Si por el contrario las temperaturas en los materiales no se parecen en absoluto, no habremos conseguido el objetivo (planteado al finalizar el paso1 del presente apartado) de generar una exposición térmica equivalente a la generada durante el ensayo "Test 8 " a partir de un modelo numérico con una tasa de liberación de calor inferior, pero incluyendo la hipótesis de viento nulo (ver Figura 6-26). Si esto es así, no se podrá proceder a la validación del modelo mecánico por este camino. 

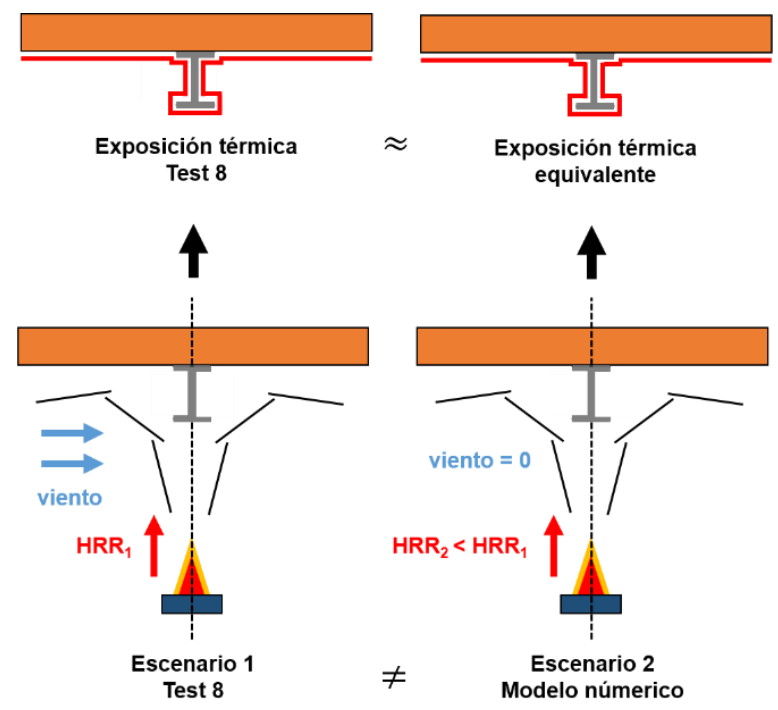

Figura 6-26. Esquema ilustrativo de la generación de una exposición térmica equivalente a la correspondiente al ensayo "Test 8 " a partir de un modelo sin viento y una tasa de liberación de calor reducida respecto a la registrada experimentalmente.

En la Figura 6-27 se comparan las temperaturas registradas en el escenario de incendio "plateau2000-decay4" (línea continua) con las temperaturas registradas experimentalmente en el ensayo Test 8 (línea discontinua) por los termopares colocados en el acero para medir su temperatura en tres posiciones distintas (ala inferior, alma y ala superior) para tres secciones distintas (S1, S2 y S3). En ella se puede ver como las temperaturas en el acero del modelo numérico son inferiores a las medidas experimentalmente mediante termopares.

La nomenclatura empleada en la Figura 6-27 incluye la siguiente codificación:

1. TS-num = temperatura del acero registrada en el modelo "plateau2000-decay4"

2. TCsteel-exp $=$ temperatura del acero registrada mediante termopar de $1.5 \mathrm{~mm}$ de diámetro de vaina durante el ensayo "Test 8 "

3. $\mathrm{BF}=$ ala inferior (Bottom Flange)

4. $\mathrm{W}=$ alma (Web)

5. $\mathrm{TF}=$ ala superior $($ Top Flange $)$ 
(a) Sección $\mathrm{S1}$

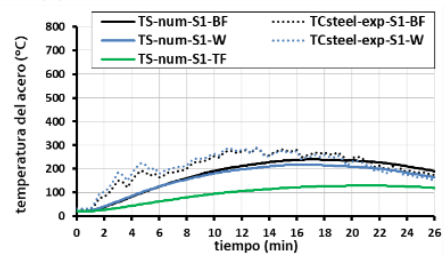

(b) Sección $\mathrm{S2}$

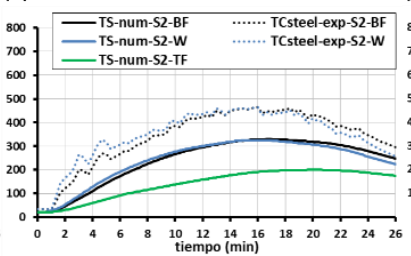

(c) Sección S3

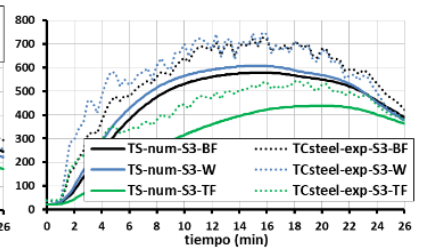

Figura 6-27. Comparativa entre temperaturas experimentales (ensayo Test 8) y temperaturas numéricas (modelo "plateau2000-decay4") en las secciones $S 1(x=0.5 \mathrm{~m}), S 2(x=1.5 \mathrm{~m})$ y $S 3(x=$ $2.5 m)$.

Aunque la diferencia entre ambas mediciones puede parecer excesiva, cabe recordar que los termopares de $1.5 \mathrm{~mm}$ de espesor se dispusieron en el acero en agujeros de $4 \mathrm{~mm}$, tal como se indica en la Sección 6.4.3. A pesar de que los termopares fueron fijados contra el acero, la turbulencia asociada al fuego fácilmente pudo provocar que los termopares registraran una temperatura intermedia entre el acero y el entorno del propio termopar (en lugar de registrar la temperatura del acero, como se tenía previsto).

Con el fin de obtener un rango orientativo dentro del cual debería situarse la temperatura registrada experimentalmente basta con, mediante el escenario de incendio "plateau2000-decay4" comparar las temperaturas en el acero y las temperaturas en el gas de sensores situados en las nueve posiciones representadas en la Figura 6-27. Es esperable que las temperaturas registradas experimentalmente se encuentren en un valor intermedio entre ambos valores.

En la Figura 6-28 se han representado las diferencias entre las temperaturas registradas en el gas en la zona norte de la viga sur (en el modelo FDS) y las temperaturas registradas en el acero en el alma de la viga sur (en el modelo Abaqus) para la secciones S1, S2 y S3 (los resultados para las secciones S4, S5 y S6 son aproximadamente simétricos). Para su obtención se ha empleado el escenario de incendio "plateau2000-decay4".

En la Figura 6-28 se puede ver como las temperaturas del gas han sido siempre mayores a las temperaturas del acero (hecho razonable si se tiene en cuenta que el acero presenta mayor inercia térmica que el aire). La diferencia se acentúa:

1. Al comienzo de la simulación (ensayo numérico)

2. Con la proximidad de la sección a centro luz (CL)

Aunque las diferencias de temperaturas (temperatura del gas - temperatura del acero) llegan a alcanzar los 400, los 500 y $\operatorname{los} 600{ }^{\circ} \mathrm{C}$ para las secciones S1, S2 y S3 respectivamente, $200{ }^{\circ} \mathrm{C}$ podría considerarse un valor promedio aceptable. 
(a) Sección $\mathrm{S1}$

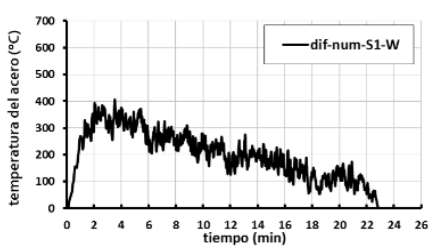

(b) Sección S2

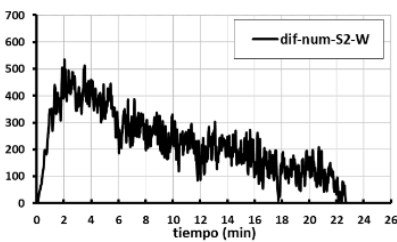

(c) Sección S3

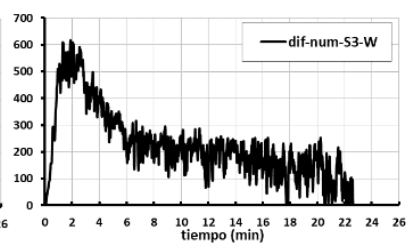

Figura 6-28. Diferencia entre las temperaturas registradas por termopares en el gas (FDS) y las temperaturas registradas en el acero (FDS) en el escenario de fuego "plateau2000-decay4" a la altura del alma: (a) Sección S1 $(x=0.5 m)$, (b) Sección $S 2(x=1.5 m)$ y (c) Sección $S 3(x=2.5 m)$.

Hasta aquí se puede concluir que la diferencia de temperaturas promedio (entre las temperaturas en el acero y las temperaturas registradas por un termopar situado en el gas) en la simulación de incendios para el escenario de fuego "plateau2000-decay" ronda los $200{ }^{\circ} \mathrm{C}$. Al haber validado en el Capítulo 5 el modelo de simulación de incendios empleado, se puede afirmar que esa misma diferencia de temperaturas para el ensayo Test 8 rondará ese mismo valor $\left(200^{\circ} \mathrm{C}\right)$.

\section{Hipótesis:}

Estimación de temperaturas experimentales en el acero a partir de los registros mediante termopares en el acero

Aunque se estima que las temperaturas registradas experimentalmente se pueden haber sobreestimado hasta unos $200{ }^{\circ} \mathrm{C}$, no es posible cuantificar con exactitud la magnitud del incremento sufrido como consecuencia a la exposición parcial a las mayores temperaturas del gas y de las llamas en el entorno de los termopares.

(a) Sección $\mathrm{S1}$

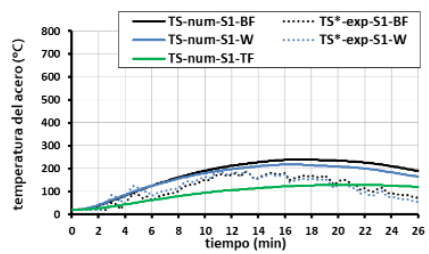

(b) Sección S2

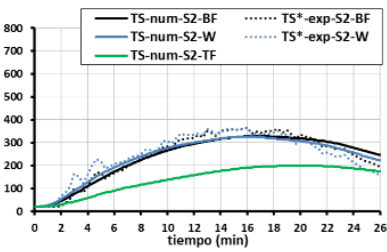

(c) Sección S3

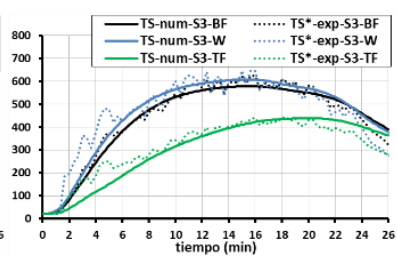

Figura 6-29. Comparativa entre las temperaturas del acero registradas experimentalmente (ensayo Test 8) corregidas por el efecto de la temperatura del gas de las proximidades y las temperaturas del acero en el modelo "plateau2000-decay4" en (a) la sección S1 $(x=0.5 m)$, (b) la sección S2 $(x=$ $1.5 m)$ y $(c)$ la sección $S 3(x=2.5 m)$.

$\mathrm{Al}$ no haber indicios que permitan justificar una mayor proximidad de las temperaturas registradas a las temperaturas del acero o a las temperaturas en el gas se ha asumido una 
diferencia de temperaturas de $100{ }^{\circ} \mathrm{C}$. Lo que situaría las temperaturas registradas experimentalmente (registro real) $100{ }^{\circ} \mathrm{C}$ por encima de las temperaturas en el acero o $100{ }^{\circ} \mathrm{C}$ por debajo de las temperaturas en el gas próximo a los puntos de medición.

En la Figura 6-29 se presentan los mismos resultados expuestos en la Figura 6-27 reduciendo en $100^{\circ} \mathrm{C}$ las temperaturas registradas experimentalmente en el ensayo Test 8. En ella se puede ver que los registros obtenidos en el escenario de incendio son bastante similares a los registrados experimentalmente corregidos por el valor estimado a partir del escenario de incendio "plateau2000-decay4" (* indica que la temperatura del acero $\left(\mathrm{T}_{\mathrm{s}}\right)$ no es un valor real sino estimado).

El hecho de que las temperaturas del acero a lo largo de la viga sean similares entre el modelo numérico "pleateau2000-decay4" y los registros experimentales corregidos permite afirmar que nos encontramos en la situación 1 expuesta en la Figura 6-25, en la cual el modelo mecánico está representando la realidad física y por tanto se considera validado.

\subsubsection{PASO4. VALIDACión DEL MODElo TÉRMico}

Para realizar una validación estricta del modelo térmico, bastaría con poder comparar las temperaturas en el acero obtenidas mediante el modelo numérico (output-numérico) con las registradas experimentalmente (output-experimental) a partir de las temperaturas de exposición registradas también experimentalmente (input-experimental).

Como se ha hecho en la validación del modelo mecánico, la validación térmica se realizará partiendo de la similitud de variables de salida (en este caso temperaturas en el acero) entre el registro experimental (ensayo Test 8 ) y el correspondiente al escenario de incendio "plateau2000-decay4" y comparando los valores de las variables de entrada (en este caso temperaturas registradas por termopares en el gas).

Aunque la situación ideal sería realizar la comparación de temperaturas adiabáticas a pocos centímetros de los perfiles de acero expuestos, puesto este registro no se llevó a cabo en el ensayo Test 8, se compararán las temperaturas del gas registradas mediante termopares de $1.5 \mathrm{~mm}$ de espesor $5 \mathrm{~cm}$ bajo la losa y a $50 \mathrm{~cm}$ de las almas en la zona central y a $25 \mathrm{~cm}$ de las almas en las zonas laterales (de acuerdo como se indica en la Figura 6-4). Con ello, aunque no se puede decir que se valida completamente el modelo térmico, al menos se puede afirmar que las temperaturas en el gas son similares (y el flujo de convección también lo será).

En la Figura 6-30 se puede ver que: 
1. En la zona central, las temperaturas registradas experimentalmente (ensayo Test8) son inferiores a las calculadas numéricamente (escenario de incendio "plateau2000-decay4").

2. En la zona sur, las temperaturas registradas experimentalmente (ensayo Test8) son superiores a las calculadas numéricamente (escenario de incendio "plateau2000-decay4").

Esta aparente contradicción se debe a la influencia del viento. Se recuerda que los escenarios de fuego considerados:
1. "plateau2000-decayl"
2. "plateau2000-decay2"
3. "plateau2000-decay3"
4. "plateau2000-decay4"

Han tratado de reproducir la exposición térmica ocurrida durante el ensayo Test8 con presencia de viento, mediante una reducción de la magnitud de la potencia de fuego a lo largo del ensayo. Aunque tanto la presencia de viento como la reducción de potencia tienen un efecto similar en cuanto a que reducen la severidad del incendio, no hay que olvidar que mientras la primera lo hace mediante una mayor ventilación, la segunda lo hace reduciendo directamente el calor emitido. Se concluye, por tanto, que la obtención de una exposición equivalente de un escenario con viento mediante otro escenario sin viento, pero con una potencia minorada (mediante la metodología propuesta) tenderá a sobredimensionar las temperaturas en el gas en la zona central y e infradimensionar las temperaturas en el gas en la zona lateral hacia la que se inclinen las llamas.

Dados los resultados presentados en la Figura 6-30, se puede considerar que la magnitud de las diferencias entre temperaturas en el gas en las diferentes secciones no es notable y las diferencias parecen compensarse entre caras del alma (zona central con zona sur para la viga sur de estudio). Es por ello que, considerando la hipótesis de obtención de una exposición equivalente mediante un escenario de fuego sin viento, pero con potencia reducida, se podría dar por buena la validación del modelo térmico.

No se muestran en la Figura 6-30 las secciones S4, S5 y S6 por presentar valores casi simétricos a los de las secciones $\mathrm{S} 1, \mathrm{~S} 2$ y S3). 
(a) Sección S1
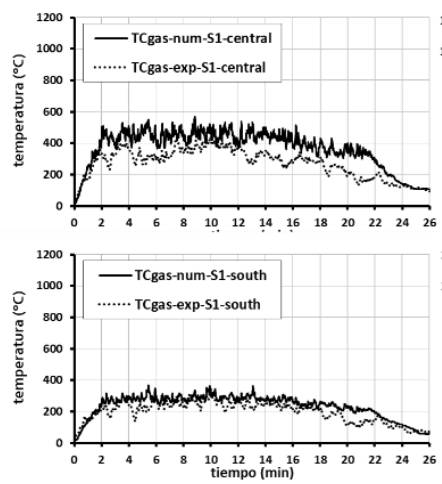

(b) Sección S2
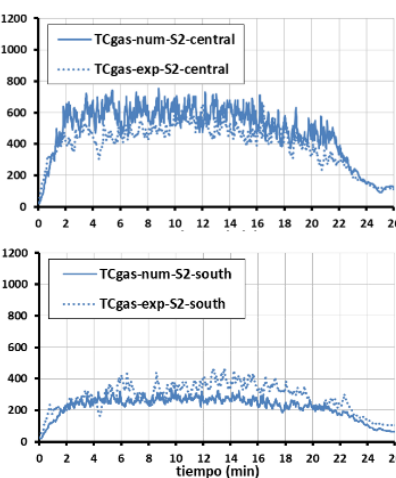

(c) Sección S3
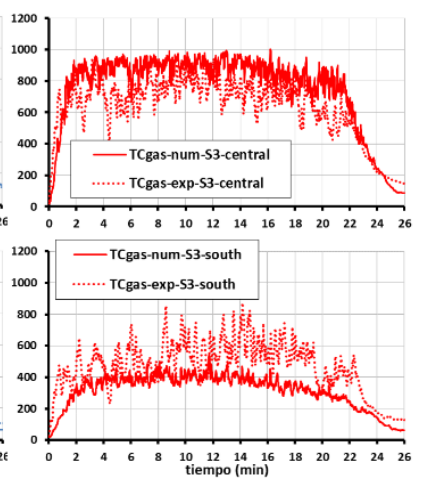

Figura 6-30. Comparativa entre las temperaturas del gas registradas experimentalmente (ensayo Test 8) y numéricamente (modelo "plateau2000-decay4") por termopares de 1.5mm de espesor en las zonas central (fila superior) y sur (fila inferior) en torno a la viga sur.

\subsection{Metodologías PREDiCTIVAS}

Validados los modelos térmico y mecánico resulta interesante cuantificar el nivel de aproximación que se habría obtenido partiendo del valor teórico de la tasa de liberación de calor por unidad de área (HRRPUA). En el presente apartado se van cuantificar los niveles de aproximación para cada una de las opciones propuestas por el Eurocódigo1 [ref6.01]:

1. Mediante un modelo avanzado de incendios (realizado con FDS)

2. Mediante un modelo de fuego localizado (modelo de HASEMI)

Especial atención merece la consideración Finalmente, se estudiará el efecto de considerar el coeficiente de convección propuesto por el Eurocódigo1 $\left(\mathrm{h}=35 \mathrm{~W} \cdot \mathrm{m}^{-2} \cdot{ }^{\circ} \mathrm{C}-\right.$ $\left.{ }^{1}\right)$ para definir el flujo de calor de convección en el modelo térmico.

\subsubsection{PREdicCión MEdiANTE MOdelo de CAMPO}

El objetivo del presente apartado es resaltar algunas de las aportaciones más relevantes de la validación del modelo termo-mecánico realizada en el presente capítulo. Para ello se presentará la evolución de la tasa de liberación de calor empleada para la predicción de la respuesta mecánica del ensayo Test 8 y se compararán los resultados obtenidos numéricamente con los registrados experimentalmente. Por su interés de cara a futuros estudios se comentará también el efecto del coeficiente de convección sobre la predicción de la respuesta mecánica. 


\subsubsection{DEFINICIÓN DE LOS MODELOS NUMÉRICOS}

Los modelos numéricos empleados en la metodología presentada en el Capítulo 3 son dos. Por un lado se tiene el modelo de simulación de incendios definido en la Sección 6.5 y por otro el modelo termo-mecánico definido en la Sección 6.6.

Si se presta atención a la definición de ambos modelos se verá que ambos pueden ser definidos casi por completo previamente a la realización del ensayo simplemente conociendo la geometría y las características de los materiales. Tan solo quedarían por definir la tasa de liberación de calor y el viento existente durante el ensayo a realizar en el caso del modelo de incendios y las condiciones de contorno térmicas en el modelo termo-mecánico (derivadas directamente del propio modelo de simulación de incendios).

En conclusión, se puede afirmar que, validados los modelos de simulación de incendios y de elementos finitos, la correcta predicción de la evolución de la flecha en centro-luz (CL) dependerá fundamentalmente de una correcta definición de la tasa de liberación de calor (en magnitud y posición) y de una correcta caracterización del viento.

\subsection{VIENTO}

La hipótesis de viento nulo a priori se considera la más desfavorable. A menor presencia de viento más se calentará la zona central entre ambas vigas metálicas. Puesto que es una situación que se puede producir durante la ejecución de los ensayos la predicción debe considerar como mínimo un escenario de fuego sin viento.

\subsection{TASA DE LIBERACIÓN DE CALOR (HRR)}

La definición más sencilla de la evolución de la tasa de liberación de calor por unidad de área (HRRPUA), así como de la tasa de liberación de calor (HRR), consiste en caracterizar cada una de las tres fases del fuego (crecimiento, meseta y decay) mediante tramos lineales.

Para definir la forma de la curva se han considerado las siguientes restricciones:

1. La energía total liberada $(1817 \mathrm{MJ})$ debe ser igual a la registrada mediante la pérdida de masa durante el Test 8 (41.6 kg), considerando de $43.7 \mathrm{MJ} / \mathrm{kg}$ para el calor de combustión de la gasolina [ref6.04].

2. El inicio de la fase de meseta se sitúa un minuto después de la ignición. Sin otros datos que permitan mayor precisión este habría sido el valor adoptado, teniendo en cuenta que se requiere de un tiempo mínimo para alcanzar la HRRPUA máxima teórica. 
3. El inicio de la fase de decay se inicia cuando el $70 \%$ del combustible ha sido consumido (hipótesis tomada del Anexo E del Eurocódigo 1 [ref6.01])

Aplicando las tres restricciones anteriores y asumiendo un valor de la HRRPUA $=2000$ $\mathrm{kW} / \mathrm{m}^{2}$ [ref6.04] se caracteriza la curva tiempo-HRRPUA del escenario de fuego "prediction". La HRRPUA de este escenario de fuego se puede consultar en la Figura 6-31a y sus fases se definen a continuación:

1. Fase de crecimiento: Crecimiento lineal el primer minuto hasta alcanzar la HRRPUA máxima, fijada en $2000 \mathrm{~kW} / \mathrm{m}^{2}$.

2. Fase de meseta: Desde el primer minuto hasta el minuto 19, donde la HRRPUA se mantiene en su valor máximo de $2000 \mathrm{~kW} / \mathrm{m}^{2}$.

3. Fase de decay: Reducción lineal desde el minuto 19 al minuto 35, donde la HRRPUA cae desde su valor máximo de $2000 \mathrm{~kW} / \mathrm{m}^{2}$ hasta la extinción.

\subsubsection{PREDiCCIONES DE LOS MODELOS NUMÉRICOS}

(a) HRRPUA - predicción

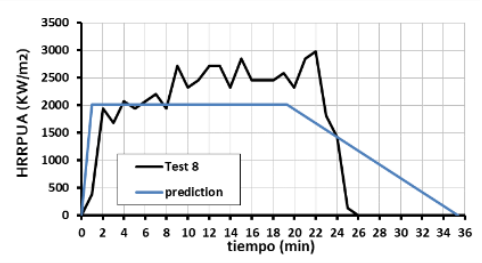

(b) Flecha

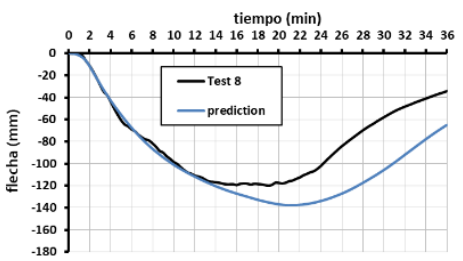

Figura 6-31. (a) Tasa de liberación de calor por unidad de área (HRRPUA) asumiendo crecimiento lineal hasta valor máximo en 1 minuto y decay a partir del 70\% del combustible consumido y $(b)$ flecha en CL obtenida mediante el modelo termo-mecánico a partir de la HRRPUA mostrada en (a).

En la Figura 6-31a se compara la tasa de liberación de calor por unidad de área definida en el Sección 6.8.1.1 con la registrada experimentalmente en el ensayo Test 8, mientras que en la Figura 6-31b se compara la predicción de flechas en CL con la registrada durante el ensayo Test 8 . Las conclusiones que se derivan de las gráficas se incluyen a continuación:

\section{Escenario de fuego "prediction" vs ensayo "Test 8"}

1. El hecho de considerar una fase de crecimiento de uno o dos minutos no es significativo en la respuesta termo-mecánica del tablero.

2. El escenario de fuego "prediction" ha permitido realizar un ajuste casi exacto de la flecha en centro luz durante los primeros 12 minutos del ensayo "Test8". Se recuerda que fue durante ese intervalo cuando se registró una menor afección del viento sobre las llamas. 
3. A pesar de que la energía liberada en ambos casos es la misma (ver áreas bajo las curvas en la Figura 6-31b), dadas las distintas curvas de tasa de liberación de calor, se aprecian diferencias apreciables en lo que respecta a las evoluciones de flecha en centro luz.

4. En el minuto 19 la tasa de liberación de calor por unidad de área del ensayo "Test 8" se sitúa unos $500 \mathrm{~kW} / \mathrm{m}^{2}$ por encima del valor definido para el escenario "prediction", siendo la flecha en centro luz es $20 \mathrm{~mm}$ inferior (hecho destacable teniendo en cuenta que en el minuto 8 tanto la HRR como la flecha en CL son muy similares en ambos casos). Esta aparente incoherencia se explica al tener en cuenta que un mayor efecto del viento (tan solo presente en el ensayo "Test 8") no solo influye en la ventilación de gases calientes bajo el tablero y la inclinación de la llama, sino que también puede repercutir en el incremento de la potencia del fuego.

\subsubsection{SOBRE EL COEFICIENTE DE CONVECCIÓN}

En la definición de los flujos térmicos sobre la estructura se han empleado para el modelo avanzado de FDS:

$$
\begin{aligned}
& h=10 \mathrm{~W} \cdot \mathrm{m}^{-2} \cdot{ }^{\circ} \mathrm{C}^{-1} \text { para las zonas expuestas (central e inferior) } \\
& h=4 \mathrm{~W} \cdot \mathrm{m}^{-2} \cdot{ }^{\circ} \mathrm{C}^{-1} \text { para la zona no expuesta (sur) }
\end{aligned}
$$

Mientras que el valor recomendado por el Eurocódigo 1 es de:

$$
h=35 \mathrm{~W} \cdot \mathrm{m}^{-2} \cdot{ }^{\circ} \mathrm{C}^{-1}
$$

"En caso de que la exposición térmica se calcule mediante un modelo de simulación de incendios o no se tenga información adicional."

En la Figura 6-32a se han representado las flechas en CL registradas para distintos coeficientes de convección considerados a partir del escenario de fuego de referencia "prediction". En la Figura 6-32b se indica que coeficiente se ha empleado para cada zona de exposición de la viga sur.

Del análisis de los resultados presentados en la Figura 6-32 se puede concluir que:

1. Empleando los coeficientes de convección obtenidos directamente del modelo FDS (caso "h10-h10-h04") el valor de flecha en CL obtenido es muy similar al registrado durante el ensayo "Test 8 ".

2. Si se considera el coeficiente de convección de $35 \mathrm{~W} \cdot \mathrm{m}^{-2} \cdot{ }^{\circ} \mathrm{C}{ }^{-1}$ propuesto por el Eurocódigo 1 para las zonas expuestas (caso " $h 35-h 35-h 04$ ") o para las tres zonas (caso " $h 35-h 35-h 35$ ") se puede ver como la flecha en centro-luz (CL) se sobreestima entre 10 y $15 \mathrm{~mm}$ entre el minuto 2 y el minuto 13 . Esta mayoración 
supone un sobredimensionamiento de en torno al $50 \%$ a los 2 minutos y de aproximadamente un $10 \%$ a los 13 minutos.

3. El valor del coeficiente de convección propuesto por el Eurocódigo 1 para modelos avanzados, de $35 \mathrm{~W} \cdot \mathrm{m}^{-2 .}{ }^{\circ} \mathrm{C}^{-1}$, puede quedarse del lado de la inseguridad en la fase de enfriamiento, al perder calor a un ritmo mayor del real. Este hecho se aprecia levemente a partir del minuto 16 , donde el caso " $h 35-h 35$ $h 35^{\prime \prime}$, con un coeficiente de convección en la zona sur de $35 \mathrm{~W} \cdot \mathrm{m}^{-2} \cdot{ }^{\circ} \mathrm{C}^{-1}$ (en lugar de los $4 \mathrm{~W} \cdot \mathrm{m}^{-2} \cdot{ }^{\circ} \mathrm{C}^{-1}$ considerados en el caso "h35-h35-h04") favorece un enfriamiento más rápido dadas las mismas temperaturas de exposición.

(a) Respuesta mecánica

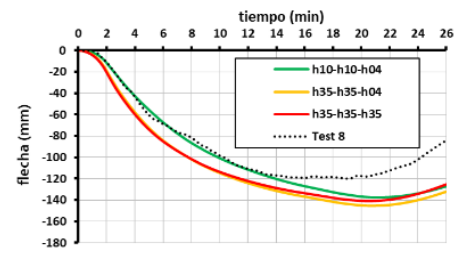

(b) Valores del coeficiente de convección

\begin{tabular}{cccc}
\hline W $/ \mathrm{m}^{2} /{ }^{\circ} \mathrm{C}$ & \multicolumn{3}{c}{ coeficiente de convección } \\
zona & central & inferior & sur \\
\hline h10-h10-h04 & 10 & 10 & 4 \\
h35-h35-h04 & 35 & 35 & 4 \\
h35-h35-h35 & 35 & 35 & 35 \\
Test 8 & - & - & - \\
\hline
\end{tabular}

Figura 6-32. (a) Sensibilidad de la respuesta mecánica a los parámetros de convección empleados y (b) Valores de coeficientes de convección empleados para cada escenario.

En vista de los resultados, se recomienda que, en caso de realizar un modelo de simulación de incendios para obtener las temperaturas de exposición, se registre también el coeficiente de convección con el fin de caracterizar adecuadamente la exposición térmica.

\subsubsection{PREdicción MEdiante MOdelo de FUEgo localizado}

Una vez analizada la predicción mediante el modelo de campo, es conveniente evaluar si resultaría suficiente emplear el modelo simplificado propuesto por el Eurocódigo 1 [ref6.01] con el fin de obtener una primera estimación de la respuesta mecánica del tablero sin necesidad de recurrir al modelado del incendio. Para ello se planteará el método de Hasemi y se estudiarán algunas limitaciones que se han detectado en su aplicación para la predicción de las temperaturas adiabáticas de exposición.

\subsubsection{Planteamiento del MÉtodo de HaSemi}

El Eurocódigo 1 en su parte 1-2 [ref6.01] propone el empleo del método de Hasemi para la evaluación de flujos térmicos sobre elementos estructurales sometidos a llamas directas y acota su ámbito de aplicación a fuegos con un diámetro equivalente de $10 \mathrm{~m}$ 
y con una potencia máxima de $50 \mathrm{MW}$, de acuerdo a los ensayos que dieron lugar a las expresiones [ref6.11, ref6.12].

En la Figura 6-33, donde se incluye un esquema sobre cómo obtener los flujos de calor recibidos por los materiales estructurales, se puede ver como el método de Hasemi propuesto por el Eurocódigo 1 en su anexo C [ref6.01] permite caracterizar el flujo incidente sobre superficies expuestas directamente a las llamas. Para obtener el flujo incidente total sobre un punto concreto (considerando los mecanismos de calentamiento de radiación y convección) se obtiene la altura de llama $\left(\mathrm{L}_{\mathrm{f}}\right)$ y se comprueba si es inferior a la distancia entre la base del fuego y el techo sobre el que puede o no impactar (el tablero de un paso superior en el caso de un puente). $\mathrm{Si} \mathrm{L}_{\mathrm{f}}>\mathrm{H}$ se considera que la llama estará en contacto con la superficie del tablero a lo largo de una longitud horizontal $\left(\mathrm{L}_{\mathrm{h}}\right)$ de proyección de la llama. Obtenida esta longitud, se puede obtener, en función de la distancia radial (r) al eje del penacho del fuego, el flujo incidente.

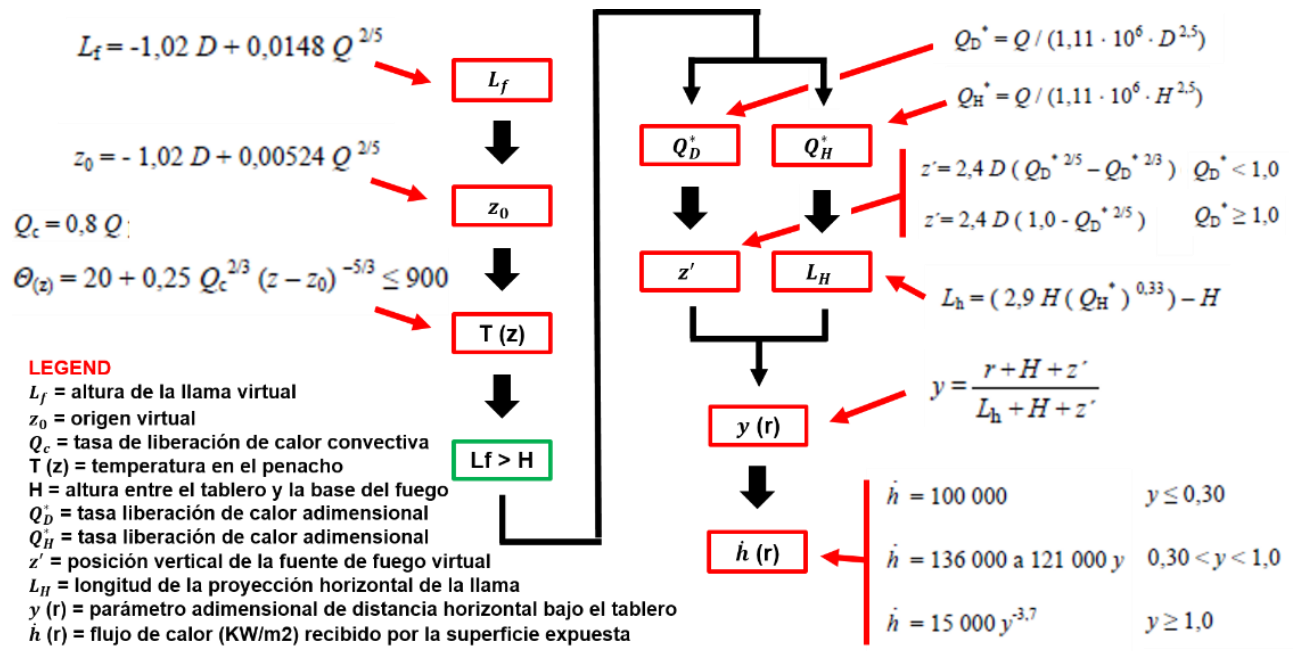

Figura 6-33. Esquema de la obtención del flujo total recibido por cada superficie expuesta al fuego de acuerdo con el Eurocódigo 1.

Aunque no se especifica en el Eurocódigo 1 [ref6.01], cabe remarcar que el método de Hasemi puede infradimensionar los flujos recibidos en la zona en la que $r>L_{h}$, puesto que este método está calibrado únicamente para las zonas en que la llama está en contacto con la estructura. Para distancias mayores Franssen [ref6.11, ref6.12] propone, pensando en fuegos en parkings o grandes recintos, obtener los flujos incidentes mediante un modelo de dos zonas. 
El método de Hasemi propuesto en el Eurocódigo 1 [ref6.01], además de las limitaciones indicadas explícitamente en el propio Eurocódigo 1 (diámetro equivalente máximo de $10 \mathrm{~m}$ y potencia máxima de $50 \mathrm{MW}$ ), presenta otras limitaciones que se explicarán a continuación.

\subsubsection{LIMITACIÓN RELATIVA A LA POSICIÓN RELATIVA ENTRE EL FUEGO Y ELEMENTO ESTRUCTURAL}

En la Figura 6-34, dónde se incluyen diversas posiciones relativas entre elementos estructurales y fuegos.

El método se puede emplear para calcular los flujos totales recibidos por la estructura:

1. En la superficie inferior de la losa si ésta se encuentra justo encima del fuego

a. Considerando como distancia entre fuego y techo la distancia hasta la cara inferior de la losa

2. En la superficie inferior de la viga si ésta se encuentra justo encima del fuego.

a. Considerando como distancia entre fuego y techo la distancia hasta la cara inferior de la viga

Aunque en la Figura 6-34 se han representado fuegos con $\mathrm{L}_{\mathrm{f}}<\mathrm{H}$ por claridad gráfica, se recuerda que el método de Hasemi ofrece resultados más próximos a los registros experimentales para ratios $\mathrm{L}_{\mathrm{f}} / \mathrm{H}>1$.

\section{Limitación para caso de fuego bajo viga}

Para el caso de fuego bajo viga (Figura 6-34b) el Eurocódigo 1 no indica que flujo recibido debería considerarse para el caso de:

1. La cara superior del ala inferior

2. Las dos caras del alma

3. La cara inferior del ala superior de la viga

Aunque se podrían asumir valores intermedios entre el flujo recibido por la losa y la viga que deberían corregirse con un factor de sombra debido a la existencia de la cara inferior de la viga.

\section{Limitación para caso de fuego situado a una distancia $\mathrm{x}$ del eje de la viga}

Cuando el fuego no se encuentra directamente debajo de la viga de estudio (ver Figura 6-34c), como ocurre en el puente bijácena considerado en la validación del modelo termo-mecánico del presente estudio, el método de Hasemi resulta insuficiente para obtener el flujo recibido por cada una de las tres zonas (Central, Inferior y Sur) representadas en la figura. En este caso: 
1. Siempre que $\mathrm{L}_{\mathrm{f}} / \mathrm{H}>1$ y la distancia de separación entre el eje vertical del penacho del fuego y el eje del alma sea reducida $(0.5 \mathrm{~m}$ para el ensayo Test 8$)$ se puede obtener el valor del flujo recibido en la zona central expuesta mediante el método de Hasemi.

2. El método de Hasemi dejaría de ser de aplicación para las zonas inferior y sur, por lo que deberían buscarse alternativas de cálculo:

a. Para el flujo recibido por la zona inferior podría emplearse el "Anexo G. Factores de sombra".

b. Para el flujo recibido por la zona sur (totalmente oculta a la exposición directa por radiación) no se podría realizar una estimación mediante modelos simplificados.
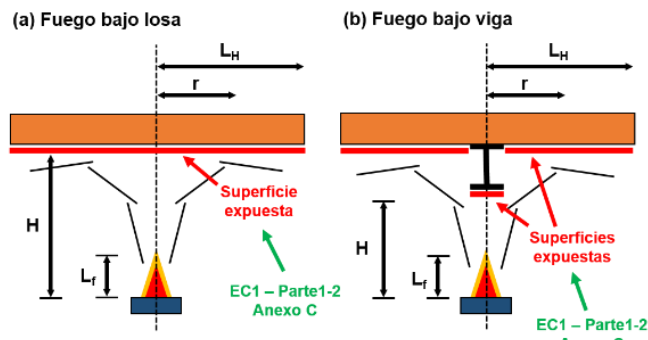

(c) Configuración ensayo Test8

Anexo C

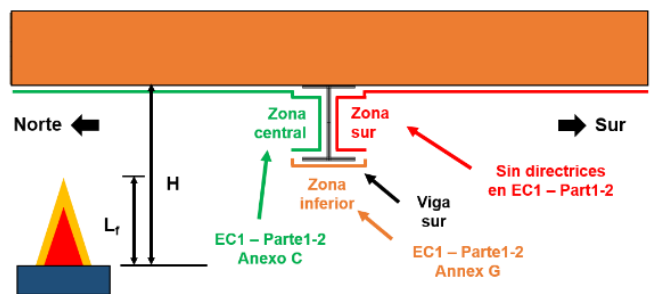

Figura 6-34. Posición relativa de elementos estructurales respecto al fuego: (a) Fuego bajo losa, (b) Fuego bajo viga y (c) Configuración del ensayo Test 8.

\subsubsection{LIMITACIÓN RELATIVA AL FALLO GLOBAL DE LA ESTRUCTURA}

En la Figura 6-35 se muestra un esquema sobre cómo se han obtenido las distancias radiales $r$ indicadas en la Figura 6-33 desde el punto donde se encuentra el eje vertical del penacho del fuego hasta donde se calcula el flujo incidente en el alma en cada una de las seis secciones de referencia. 


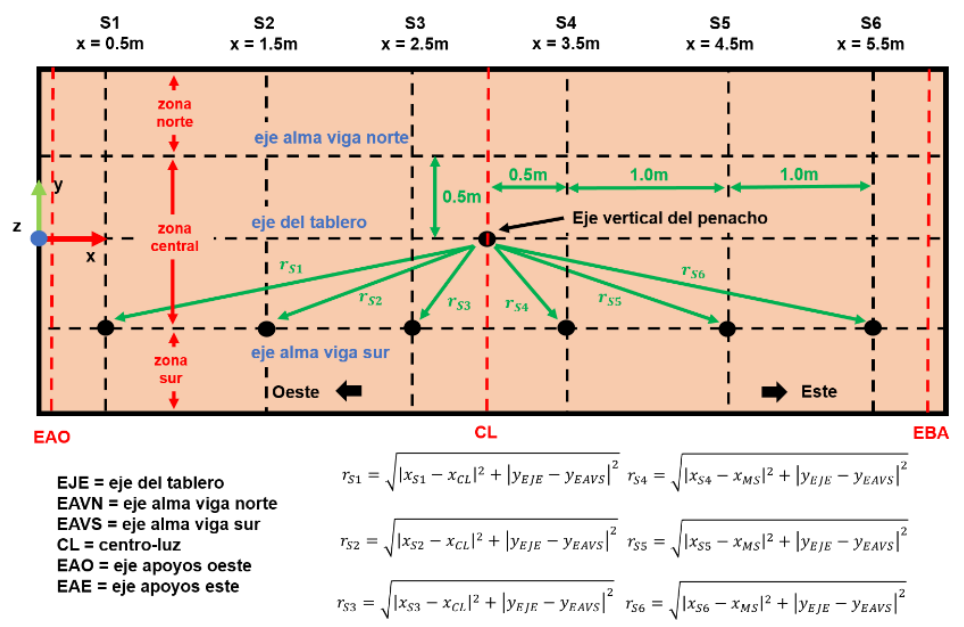

Figura 6-35. Vista en planta del tablero mostrando esquema de la obtención de la distancia radial r desde cada una de las seis secciones de la viga sur al eje vertical del penacho de fuego.

A partir del flujo recibido por el alma en cada una de las secciones se ha obtenido una temperatura adiabática considerando unos coeficientes de emisividad de 0.7 y de convección de $35 \mathrm{~W} \cdot \mathrm{m}^{-2} \cdot{ }^{\circ} \mathrm{C}^{-1}$ tal como indica el Eurocódigo 1 para estructuras de acero y para el caso de modelos de fuego localizados.

La nomenclatura de la Figura 6-35 se detalla a continuación:

1. EJE representa en el eje longitudinal central de la losa de hormigón

2. CL representa la sección de centro-luz del tablero

3. EAE representa el eje de apoyos Este

4. EAO representa el eje de apoyos Oeste

5. EAVS representa el eje del alma de la viga Sur

6. EAVN representa el eje del alma de la viga Norte

En la Figura 6-36a se muestran:

1. En línea continua las temperaturas adiabáticas obtenidas de acuerdo a las distancias diagonales indicadas en la Figura 6-35 entre el eje vertical del penacho del fuego y cada una de las secciones de la viga sur a la altura del eje de la propia viga.

2. En línea discontinua las temperaturas adiabáticas a las que estaría sometida la cara inferior de losa de hormigón a la altura del eje del tablero.

En la Figura 6-36b se comparan las temperaturas obtenidas mediante el modelo avanzado presentado en el Sección 6.8.1 en las tres zonas con la temperatura adiabática obtenida a 
partir del flujo recibido calculado mediante el método de Hasemi. En ella se puede comprobar como el ajuste con la zona central es muy bueno en las secciones S2, S3, S4 y S5, infravalorando las temperaturas en las secciones S1 y S6, más alejadas del fuego. Este resultado respalda la recomendación del Eurocódigo1 (para el ámbito de la edificación) de combinar el empleo de fuegos localizados con el uso de modelos de zonas [ref6.01, ref6.11], permitiendo una mejor cuantificación de la temperatura en las zonas donde la exposición depende más de la temperatura del gas que de la radiación de las llamas.

(a) Sensibilidad a la coordenada transversal

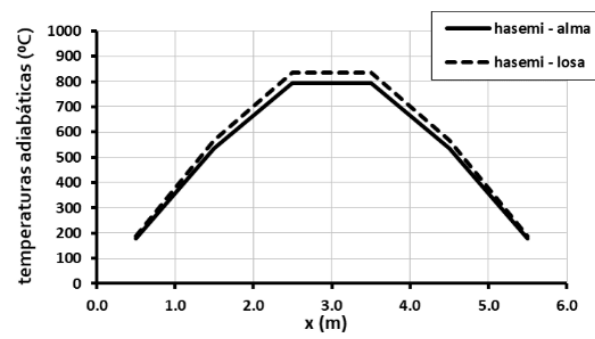

(b) Hasemi vs predicción con FDS

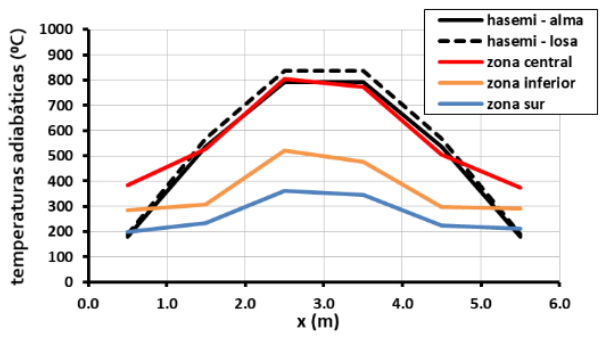

Figura 6-36. Temperaturas adiabáticas (a) calculadas a partir del modelo de Hasemi considerando la exposición a lo largo del eje de la losa y considerando la exposición a la altura del alma (b) comparadas con las temperaturas adiabáticas registradas por zonas en la simulación de incendios "prediction" realizada mediante FDS.

Si el caso de estudio es un puente multijácena, el modelo de zonas queda totalmente descartado (por su naturaleza está vinculado a fuegos confinados) para complementar el modelo de fuego localizado, siendo el modelo de campo el único capaz de proporcionar información suficiente para caracterizar completamente la exposición térmica de la estructura afectada (y que por otro lado no requiere de ningún modelo de fuego localizado para complementarlo).

En conclusión, se puede afirmar que:

1. Como ocurre en el ámbito de la edificación, el modelo de fuego localizado de Hasemi puede emplearse para predecir un fallo local en la zona de impacto de las llamas en el ámbito de los puentes.

2. A diferencia del ámbito de la edificación, un fallo global de la estructura a flexión tan solo podrá evaluarse mediante un modelo de campo (y no mediante la combinación de un modelo de fuego localizado con un modelo de zonas). 


\subsection{CONCLuSiOnes}

\subsubsection{SOBRE LA METODOLOGÍA GENERAL}

Aunque la metodología general se ha validado en el Capítulo 3 mediante el empleo de un evento de incendios con un incendio de en torno a $230 \mathrm{MW}$ de potencia máxima, el empleo de esta misma metodología Spara la validación del modelo termo-mecánico del ensayo Test 8 (con una carga de fuego de $1.3 \mathrm{MW}$ de potencia y un puente de $6.2 \mathrm{~m}$ ) supone una segunda validación de esta metodología. En este caso la metodología se ha validado para un puente de menor escala, un incendio de menor escala, pero con una cantidad de información recopilada durante el evento de fuego muy superior

\subsubsection{SOBRE EL MODELO TERMO-MECÁNICO}

El presente estudio se centra en la validación del modelo termo-mecánico de una viga mixta de acero y hormigón. En él se ha visto como, a partir de:

1. La geometría del puente experimental

2. La caracterización de los materiales a partir de su resistencia característica (hormigón) y su límite elástico (acero) y la adaptación de las expresiones propuestas por el Eurocódigo 4, asumiendo para el hormigón un modelo constitutivo "Concrete Damage Plasticity" (CDP) sin consideración del daño

Se ha podido reproducir adecuadamente la respuesta de la viga mixta de estudio con temperaturas en el acero hasta $600^{\circ} \mathrm{C}$.

Quedaría por validar este mismo modelo para un fuego más severo en el que se sometiera a la estructura a deformaciones no recuperables.

\subsubsection{SOBRE EL MODELO DE HASEMI}

Además de las limitaciones expresadas en el Eurocódigo 1 en relación al diámetro máximo $(10 \mathrm{~m})$ y la potencia máxima $(50 \mathrm{MW})$ a considerar mediante el modelo simplificado de Hasemi cabe destacar otras limitaciones en lo que respecta a la consideración de fuegos bajo puentes mixtos de hormigón y acero multiviga.

1. El coeficiente de convección propuesto de $35 \mathrm{~W} \cdot \mathrm{m}^{-2} \cdot{ }^{\circ} \mathrm{C}^{-1}$ puede quedar del lado de la inseguridad, especialmente en la fase de enfriamiento de los fuegos. En caso del empleo de modelos de campo se recomienda registrar los valores de coeficientes de convección para una definición de la exposición térmica más precisa. 
2. El modelo de Hasemi puede infradimensionar los flujos recibidos por la etsructura en la zona en la que $r>L h$, puesto que este método está calibrado únicamente para las zonas en que la llama está en contacto con la estructura.

3. La obtención de flujos incidentes sobre vigas metálicas no situadas directamente sobre la fuente de fuego se encuentra por definir mediante el modelo simplificado de Hasemi, debiendo recurrir por ello a un modelo de campo para su adecuada caracterización.

4. Aunque permite predecir la aparición de un fallo local en la zona directamente expuesta a las llamas, la prediccón de aparición de fallos globales queda comprometida parcialmente por las tres limitaciones anteriores.

\subsubsection{SOBRE LOS REGISTROS EXPERIMENTALES}

Durante el proceso de validación del modelo termo-mecánico se han estudiado los distintos registros realizados durante el ensayo Test 8 . Mediante su estudio se puede concluir que:

1. El registro de imágenes y video ha sido de gran utilidad para repasar la evolución del fuego durante el ensayo. Esto se debe a que durante el mismo se centró la atención en:

a. El buen funcionamiento de los equipos de medición

b. Detectar desviaciones del comportamiento real respecto al teórico previsto que pueden requerir de la toma de decisiones durante los ensayos. Un ejemplo sería el de realizar la extinción del fuego para salvaguardar la integrar de los equipos de medición.

2. La pérdida de masa resultó:

a. Esencial en la correcta definición de las fases de crecimiento, meseta y decrecimiento de la HRR.

b. De utilidad para entender que el viento sobrealimentó de oxígeno el fuego, reduciendo con ello la duración teórica esperada.

3. La exposición térmica:

a. Comprende la caracterización de los flujos de radiación y convección incidentes en la estructura. Estos flujos dependen de la definición de una temperatura del gas y una temperatura equivalente de radiación (o una temperatura adiabática en lugar de las dos anteriores), además del empleo de los coeficientes de convección y radiación.

b. No se definió por completo en el ensayo Test 8 , donde tan solo se registró la temperatura del gas, pero no la de radiación. Para una completa caracterización de la exposición térmica sería necesario el empleo de plate thermometers (que permiten registrar temperaturas 
adiabáticas, pudiendo definir así tanto el flujo de radiación, como el de convección).

4. Las temperaturas en el acero:

a. Se han registrado mediante cámara termográfica y termopares

b. Registradas mediante cámara termográfica se han interpuesto en la visual entre la cámara y la viga de estudio. Para que estas mediciones sean de utilidad convendrá garantizar en futuros ensayos que las llamas no se interpondrán en dicha visual

c. Registradas mediante termopares de $1.5 \mathrm{~mm}$ de diámetro en agujeros de $4 \mathrm{~mm}$ de diámetro se han visto afectadas por las temperaturas del gas y de las propias llamas. Para evitar este efecto se recomiendan orificios de diámetro muy similar al de los propios termopares (orificios de 2 $\mathrm{mm}$ para termopares de $1.5 \mathrm{~mm}$ )

5. La medición de flechas

a. Se ha realizado aprovechando la propia estructura a ensayar para proteger la instrumentación. Al tratarse de un ensayo no destructivo la medición ha sido un éxito sin necesidad de recurrir a protecciones adicionales.

b. En caso de ensayos futuros donde se busque el colapso de la estructura requerirá:

i. Considerar las consecuencias del colapso de la estructura sobre la instrumentación empleada, puesto que la integridad de la instrumentación puede quedar comprometida tanto por acción mecánica como por acción térmica. Valorar el coste económico que supondría destruir la instrumentación empleada durante el ensayo o adoptar medidas que permitan garantizar su integridad post-falo de la estructura son dos soluciones a tener en cuenta.

\subsubsection{EL VIENTO}

1. Ha podido considerarse de forma indirecta mediante una reducción de la tasa de liberación de calor (HRR). Con ello no se ha replicado el comportamiento real del fuego, pero si se ha conseguido obtener una exposición térmica que se puede asumir como equivalente.

2. No solo influye en la ventilación de los humos y en la inclinación de la llama, sino que también incrementa la tasa de liberación de calor sin que ello implique necesariamente un incremento de las temperaturas de exposición, pero reduciendo en cualquier caso el tiempo que dura el fuego. 
3. Ha reducido la flecha máxima alcanzada con respecto al escenario de fuego teórico (empleado en la predicción), lo que deja a la predicción mediante modelo de campo del lado de la seguridad.

4. Es una variable cuya incorporación es compleja dada su variabilidad espacial de su magnitud y su dirección. Es por ello que, para futuras validaciones, en lugar de registrar su efecto, se recomienda eliminar la variable de los ensayos (imposibilitando su existencia). Una vez validados los modelos de simulación de incendios para incendios de 200 MW de potencia, se podrán emplear esos mismos modelos numéricos para hacer análisis de sensibilidad de la variable viento.

\subsection{REFERENCIAS}

[ref6.01] European Committee for Standardization (CEN). EN 1991-1-2:2002. Eurocode 1: Actions on structures - Part 1-2: General Actions - Actions on structures exposed to fire. Brussels, Belgium. 2002.

[ref6.02] Sandström J. Thermal boundary conditions based on field modelling of fires. Heat transfer calculations in CFD and FE models with special regards to fire exposure represented with adiabatic surface temperatures. Licentiate thesis. Lulea University of Technology. 2013.

[ref6.03] Heskestad G. Chapter 13. Fire plumes, flame height, and air entrainment. SFPE Handbook of fire protection engineering. 5th Edition. 2016.

[ref6.04] Babrauskas V. Chapter 26. Heat Release rates. SFPE Handbook of fire protection engineering. 5th Edition. 2016.

[ref6.05] Thunderhead Engineering. Pyrosim User Manual. Included in Pyrosim version 2016.1.0425. 2016.

[ref6.06] McGrattan K, Hostikka S, McDermott R, Floyd J, Weinschenk C, Overholt K. Fire Dynamics Simulator User Guide (version 6). NIST Special Publication 1019, Gaithersburg, MD, USA. 2013.

[ref6.07] McGrattan K, Hostikka S, McDermott R, Floyd J, Weinschenk C, Overholt K. Fire Dynamics Simulator Technical Reference Guide. Volume 1: Mathematical model (version 6). NIST Special Publication 1018, Gaithersburg, MD, USA. 2013.

[ref6.08] Hurley MJ. Appendix 3: Fuel Properties and Combustion Data. SFPE Handbook of fire protection engineering. 5th Edition. 2016.

[ref6.09] Simulia. Abaqus/standard version 6.11. User manual. 2011. 
[ref6.10] European Committee for Standardization (CEN). EN 1994-1-2:2005. Eurocode 4: Design of composite steel and concrete structures - Part 1-2: General rules - Actions on structures exposed to fire. Brussels, Belgium. 2005.

[ref6.11] Franssen JM, Kodur V, Zaharia R. Designing steel structures for fire safety. Taylor \& Francis Group, London, UK. 2009.

[ref6.12] Franssen JM, Cajot LG, Schleich JB. Natural fires in large compartments. Effects caused on the structure by localised fires in large compartments. Proceedings of the Eurofre'98 Conference. 11-13th March. Brussels, Belgium. 1998. 



\section{CONCLUSIONS}

Brevity is the soul of wit

William Shakespeare, Hamlet 



\subsection{INTRODUCTION}

Although detailed conclusions have been included at the end of the prvious chapters, it has been found interesting to include an additional chapter in order to show the reader the most interesting findings of the current work.

Figura 7-1 includes a summary of the content of the Thesis in a way that offers a general overview useful to contextualize the conclusions that are presented below. In the figure, two information sources are shown: (1) Alabama incident happened on 2002 and (2) the usefulValencia Bridge Fire Test conducted in 2016.

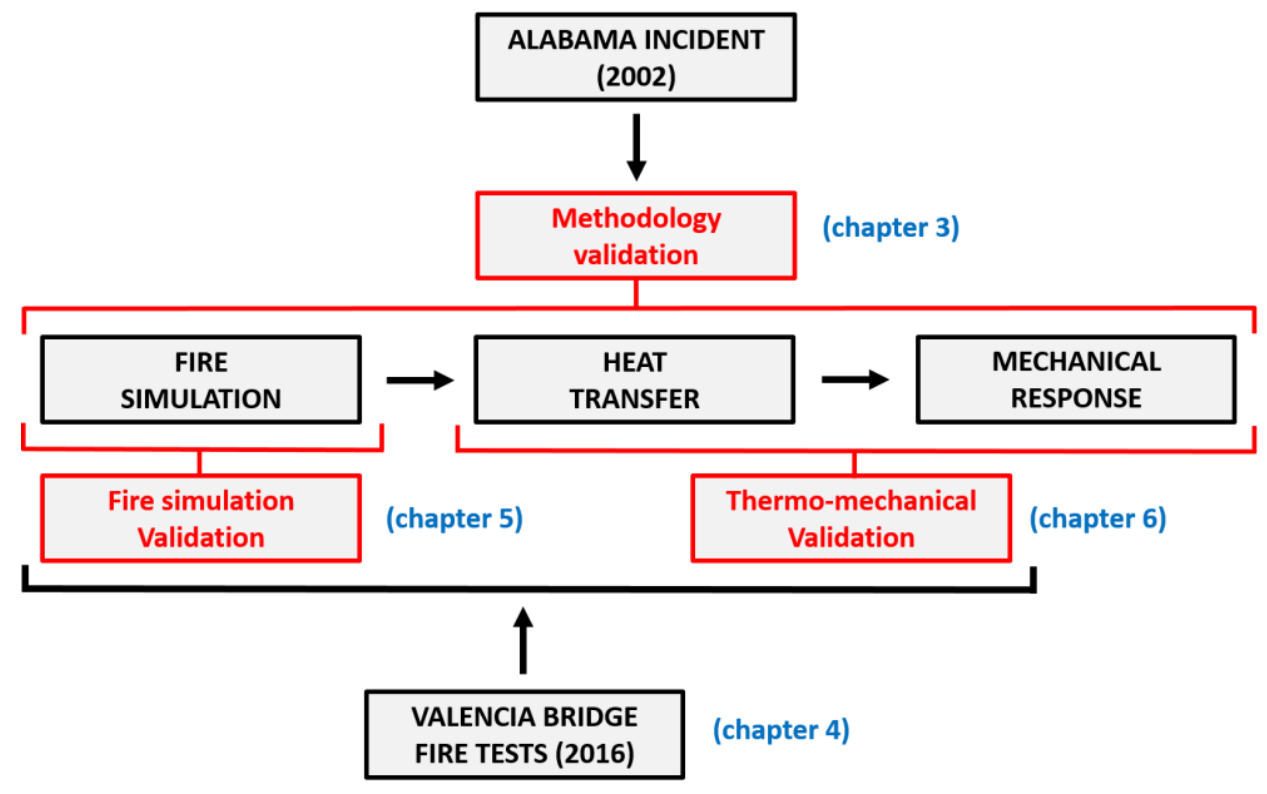

Figura 7-1. Summary scheme of the thesis.

Tabla 7-1 shows the most relevant data employed throught in each of the three validations detailed in this document. Although the general validation of the methodology was carried out with information with a high level of approximation, the two following validations (fire and thermo-mechanical model validations) required a more precise definition of the variables involved in both models. This was one of the reasons that justified the realization of the experimental campaign presented as "Valencia bridge fire tests". 


\begin{tabular}{ccc}
\hline Date & Alabama incident & $\begin{array}{c}\text { Valencia bridge } \\
\text { fire tests }\end{array}$ \\
\hline Fire definition & Pictures & 2016 \\
\hline Bridge definition & Design drawings & HRR $(\mathrm{t})$ curve \\
\hline $\begin{array}{c}\text { Dire event } \\
\text { information }\end{array}$ & No info & $\begin{array}{c}\text { Tgas }(\mathrm{t}) \text { curves } \\
\text { Tsteel }(\mathrm{t}) \text { curves } \\
\text { Deflection }(\mathrm{t}) \text { curves }\end{array}$ \\
\hline $\begin{array}{c}\text { Post-fire event } \\
\text { information }\end{array}$ & Residual deflection & \begin{tabular}{c} 
No residual deflection \\
\hline
\end{tabular}
\end{tabular}

Tabla 7-1. Comparison between data sources

\subsection{Chapter 3. Methodology}

In this chapter, the general methodology employed to predict the thermo-mechanical response of a bridge submitted to a particular fire was introduced. The methodology (see Figura 7-2) was validated with a real event by estimating the location and size of the fire load from pictures taken during and after the fire, since there was no type of continuous recording during the event.

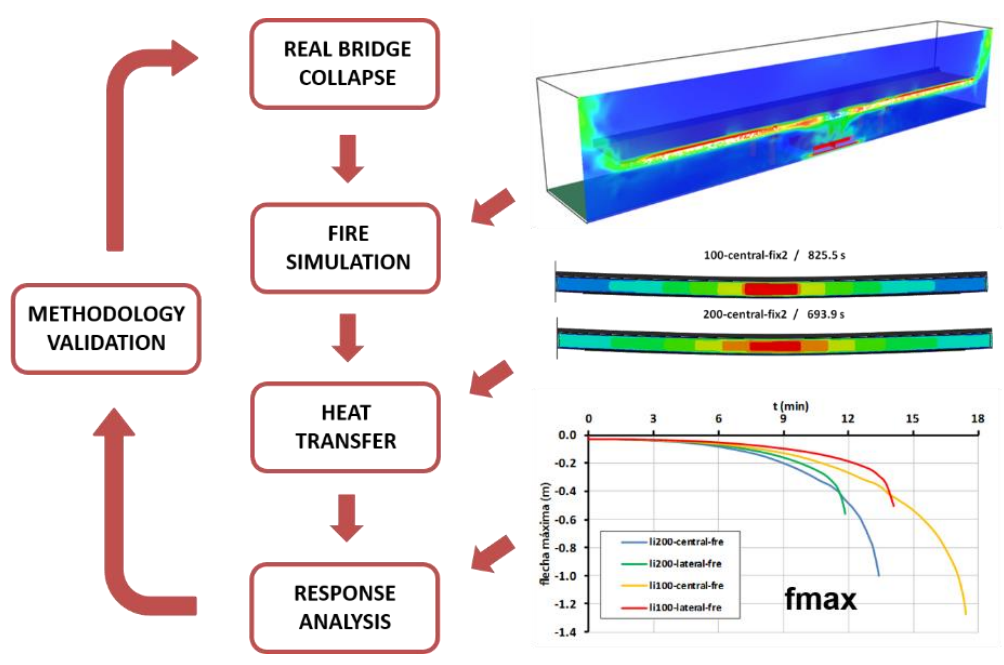

Figura 7-2. General methodology scheme 
The main conclusions in this chapter are listed below:

1. About thermal gradients:

a. Fires under bridges cause strong gradients both longitudinal and between exposure zones.

b. In multigirder bridges, it is recommended, to characterize the thermal exposure by sections (longitudinally) and by zones (transversely) rather than use a unique thermal exposure for all the exposed surfaces.

2. It is discouraged to employ a single heating curve:

a. For bridges longer than $30 \mathrm{~m}$.

b. For bridges of less than $30 \mathrm{~m}$ length, unless a field model is used to determine that its use is reasonable.

3. About sensor distribution in multigirder bridges, it is aceptable to employ:

a. $\quad 0.6 \mathrm{~m}$ distance between consecutive measurement sections

b. One sensor per section and exposure region

4. About the mechanical response of steel and concrete and steel composite multigirder bridges:

a. The longitudinal restriction to the movement is a significant variable with regard to the time of failure. This is due to the magnitude of the thermal strains when steel girders reach $700^{\circ} \mathrm{C}$.

5. About the general methodology

a. Although similar vertical deflections have been obtained through it, the validation of fire and finite element models require additional information not provided in a real fire accident

\subsection{CHAPTER 4. VALENCIA BRIDGE FIRE TESTS}

Once the general validation of the methodology was carried out, it was considered necessary to have a better definition of the fire load in order to validate the fire and thermo-mechanical models. Given the large deployment of economic means, instrumentation and personnel that would have required a campaign on a larger scale, it was decided to define a small-scale experimental campaign,

The experimental campaign consisted of eight trials conducted on the same structure. All of them served to characterize four fire scenarios (see Figura 7-3) that subsequently served to validate the fire model and the thermo-mechanical model. 


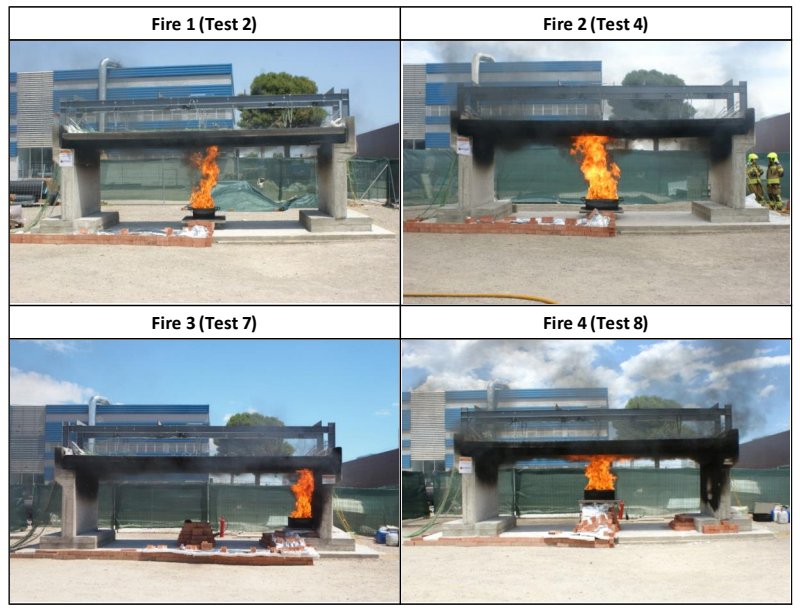

Figura 7-3. Views of fire tests corresponding to each fire scenario

The main conclusions in this chapter are listed below:

1. About the heat release rate (HRR):

a. Experimental values are, in general, similar to the values proposed in the literature. Significant differences were observed between the experimental and theoretical values in Test 6 and Test 7 (-17.3\% of the average value) and Test $8(18.7 \%)$ due to the reduction of potential ventilation (Test 6 and Test 7) and the greatest exposure of the panel to the radiation of the flames (Test 8 ).

2. About longitudinal thermal gradients:

a. Recorded gas temperatures vary considerably along the longitudinal axis of the bridge. The average longitudinal thermal gradient is $350{ }^{\circ} \mathrm{C}$ / $\mathrm{m}$ for Fire 4 and $220^{\circ} \mathrm{C} / \mathrm{m}$ for Fire 3.

b. Recorded steel temperatures also prove the existence of a significant longitudinal thermal gradient $\left(250^{\circ} \mathrm{C} / \mathrm{m}\right.$ for Fire $4,200{ }^{\circ} \mathrm{C} / \mathrm{m}$ for Fire 2 and Fire 3, and $60^{\circ} \mathrm{C} / \mathrm{m}$ in Fire 1.

c. A uniform exposure temperature is not realistic in the field of multigirder bridges, regardless of their length.

3. About steel temperatures:

a. Maximum temperatures recorded in the web and bottom flange are very similar and range between $220^{\circ} \mathrm{C}$ (Test 2, Fire 1) and $720^{\circ} \mathrm{C}$ (Test 8 , Fire 4). 
b. Top flange temperatures are significantly smaller than bottom flange and web temperaturas since top flange is in direct contact with the concrete slab

4. About wind influence:

a. Maximum vertical deflection recorded in Test 3 was $29 \%$ lower tan the one recorded in Test 4, due solely to the effect of the wind (both tests define Fire 2 fire scenario.

5. About thermal dilatation:

a. In Test 8, the máximum vertical deflection (mvd) reached around 120 $\mathrm{mm}$ in a span (L) of $6000 \mathrm{~mm}$, which supposes a ratio mvd/ $\mathrm{L}$ of approximately $1 / 50$, which has been completely recovered once the thermal action has been extinguished.

\subsection{Chapter 5. Fire MOdel VALIDATION}

By using the fire scenarios defined in the experimental campaign:

1. FDS models has been validated in the field of bridges on fire

2. The application range of Heskestad and Hamada model [ref7.01] has been checked for confined ceilings

3. The effect of the wind on the deck heating has been highlighted (see Figura 7-4).
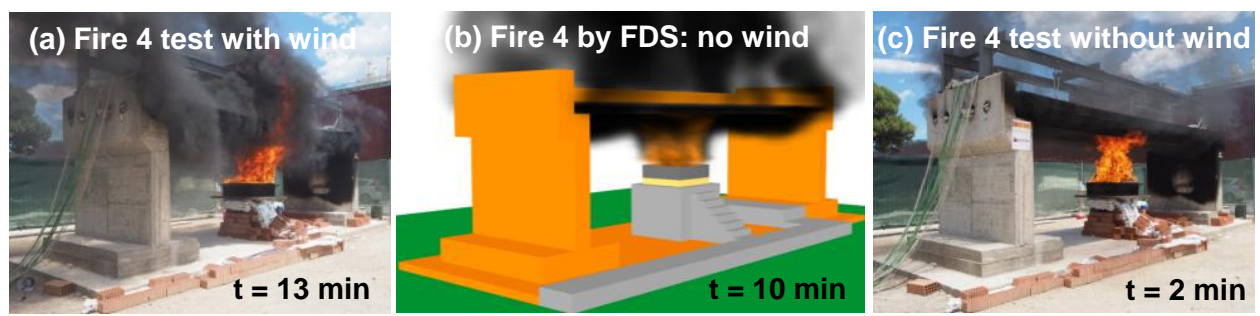

Figura 7-4. Wind effect in Fire 4: (a) Test 8 with wind, (b) Fire simulation without wind and (c) Test 8 without wind.

The main conclusions in this chapter are listed below:

1. About Heskestad y Hamada model [ref7.01]:

a. Although it was originally defined for unconfined fires, it has been proven that it offers good predictions of fire test on bridges with HRR between 361 and $1130 \mathrm{~kW}$ provided that $L_{f} / H<2$.

b. It cannot be used to study real bridge fires directly, since it was developed for fires with a maximum HRR of $764 \mathrm{~kW}$ (value much 
lower than the 100-300 MW corresponding to the fire of a tanker [ref7.02, ref7.03, ref7.04])

2. About fire simulation validation with FDS:

a. Four fire scenarios were validated with an uncertainty slightly higher than the one obtained by McGrattan [ref7.05]. The higher uncertainty was attributed to the wind effect during the tests.

b. To reduce the uncertainty related to wind it is recommended to omit the variable in future experimental campaigns carried out in enclosures where, without limiting the contribution of oxygen to fire, the effect of external wind is limited

3. About predictions using simplified and field fire models:

a. Both approaches adequately predict gas temperatures for Fire 1, Fire 2 and Fire 3 fire scenarios once the effect of wind on them has been corrected.

b. Temperatures in Fire 4 can be predicted accurately by the FDS model, but not by the Heskestad and Hamada correlation, which is consistent with the fact that such a scenario is outside the application limits of the correlation $\left(L_{f} / H>2\right)$.

\subsection{CHAPTER 6. THERMO-MECHANICAL MODEL}

Once the fire model was validated, the thermo-mechanical model validation was carried out (see Figura 7-5) by using the information recorded during Test 8 . Since the tests proposed in the experimental campaign were mainly focused on the validation of the fire simulation model, the registered thermal variables were not enough to carry out a direct validation from the experimental records.

For this reason, the previously validated fire model was used to generate an equivalent thermal exposure. To this end, the fire power was reduced iteratively so that the thermal exposure of the study beam produced a máximum vertical deflection similar to the one registered during Test 8 and it was subsequently proved that both steel and gas temperatures were similar to those recorded in the benchmark Test 8 .

During the whole process that covered the validation of the thermo-mechanical model, it was possible to study the usefulness of each one of the records carried out in the experimental campaign with a view to its use in the validation itself and to the adequacy of the records for future tests. Finally, a series of recommendations of practical utility for future experimental campaigns and future rules which will eventually consider the fire action in the field of bridge design. 


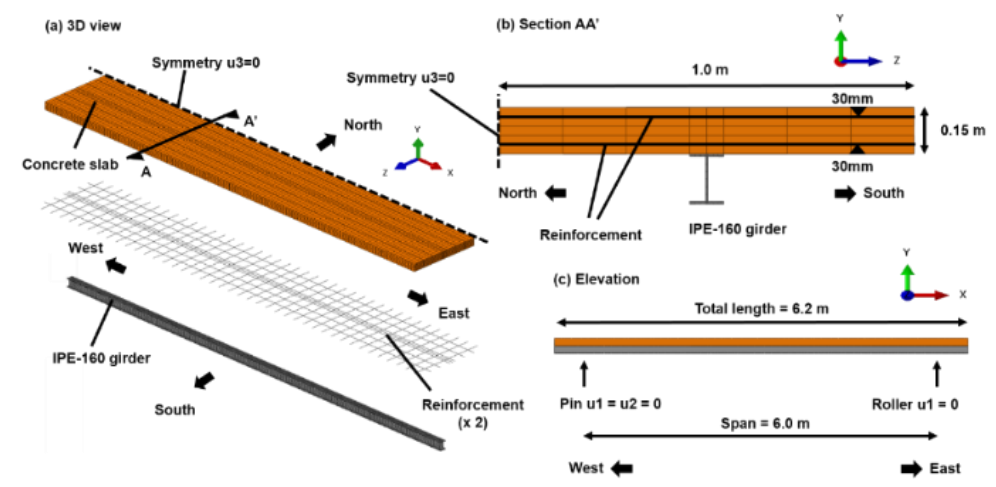

Figura 7-5. South girder finite element model in Abaqus: (a) 3D view, (b) Section AA'y (c) Elevation.

The main conclusions in this chapter are listed below:

1. About the thermo-mechanical model

a. The thermo-mechanical response of the concrete and steel composite girder has been properly reproduced with steel temperatures up to 600 ${ }^{\circ} \mathrm{C}$.

b. Since no residual vertical deflections have been recorded, it is recommended to validate the model for a more severe fire in which the structure does not recover its initial geometry

2. About the experimental records:

a. Pictures and videos:

i. Have allowed to review the evolution of fire during the tests.

b. Mass loss rate:

i. Has been essential for the definition of growth, plateau and decay phases of the heat release rate (HRR).

ii. Useful to understand that wind supercharged oxygen to the fire, reducing fire duration regarding to theoretical HRR values

c. Thermal exposure:

i. Was not completely defined in Test 8 , since radiation flux could not be obtained from gas temperatures.

ii. In case thermal exposure must be accurately defined, adiabatic temperature, as it happens in when it is defined from the output obtained from a fire model, is a useful variable to take into account.

d. Steel temperatures: 
i. Recorded by a thermal camera, they have presented the drawback of oversizing when the flames were interposed between the camera and the girder under study.

ii. Recorded by 1.5 milimeter thermocouples in 4 milimeter diameter holes they have been affected both by gas temperatures and by the flames themselves. Steel girder holes must be just slightly thicker than the thermocouples in order to reduce the magniude of the affection.

e. Vertical deflections

i. The elaboration of the structure employed in the experimental campaign has been designed to protect the instrumentation. Since all of carried out tests were non-destructive, the records cover teh entire duration of each and every test without the need for additional protections.

ii. For future tests where the structure will be submitted to fires until failure, collapse consequences over the instrumentation and records must be considered.

3. About wind effect

a. Its consideration in field models is complex given its spatial magnitude and direction variability.

b. It not only influences the ventilation of the smoke and the inclination of the flame, but also increases the rate of heat release without necessarily involving an increase in exposure temperatures.

c. Its existance has lead to reduce the maximum vertical deflection reached by the strutcure with respect to the prediction made by the fire model. That result highlight the fact that not considering the variable keep the design on the side of safety.

d. It has been considered indirectly by an equivalent model without wind and with a reduced heat release rate (HRR). Although the actual behavior of the fire has not been reproduced, the equivalent themal exposure obtained by the equivalent model has been enough to validate the thermo-mechanical model

e. It is recommended to prevent its appearance rather than trying to record its variations in future experimental campaigns.

\subsection{GENERAL CONCLUSIONS}

From this work, a series of conclusions and general comments are derived that will serve as a starting point for future studies in the field of fire bridges. 
In Chapter 2, where the fire on bridges state of art of fire is exposed, it has become evident the need to acquire a greater understanding of the problem that allows the development of optimal solutions having in mind all the stages of the structure (design, construction and maintenance).

In Chapter 3, the reproduction of the thermo-mechanical response of a $37 \mathrm{~m}$ span bridge submitted to fire has been successfully addressed. However, the little information available for the adequate characterization of a real fire has also been made evident, being the most useful information the images taken during the fire event. It has been detected, therefore, the need to validate the models used before (1) carrying out parametric studies and (2) proposing guidelines and design rules applicable in regulations.

In Chapter 4, a series of experimental records have been obtained to serve as a reference for (1) validating numerical models to be used for the reproduction of open-air fire tests (in the absence of larger scale tests), (2) future tests of higher entity (talking both about fire load and size of the bridge submitted to the fire.

In Chapter 5, (1) the loss mass rate and (2) the temperatures in the gas in the vicinity of the bridge have been employed for the validation of a fire model characterized by: 1) the calculation region definition (control volume and meshing), (2) the geometric definition of the bridge, (3) the thermal properties of the bridge materials, (4) the definition of the combustion reaction and (5) the definition of the fire as a flat horizontal surface with a specific rate of heat release per unit area. Remarkable is the fact that null wind assumption has been assumed. From the validation of the models it was possible to conclude that (1) the effect of the wind on the dynamics of the fire should be studied independently (once the problem has been studied without its consideration and simplified models of application to bridge design have been proposed) and that (2) the simplified models of existing localized fires must be redefined (or alternative models proposed) to take into account higher power fires, such as those that result from fires in tanker trucks.

In Chapter 6 the usefulness of the records collected during the Test 8 evaluated during the thermo-mechanical validation of a bridge model subjected to a $1.3 \mathrm{MW}$ fire. This chapter has allowed: (1) validate the thermo-mechanical model and (2) propose alternative validation procedures and (3) analyze one by one the different measurements done during Test 8 to propose recommendations for the definition of future experimental campaigns. Chapter 6 provides a reference model to (1) reproduce fire events on a larger scale and (2) define future experimental campaigns in the field of fire on bridges.

In general terms, this work has allowed to better understand the "fire on bridges" problem and the necessary data for properly defining the numerical models employed to 
reproduce fire events already happened and to anticipate future ones to come. The results presented in this document will help future researchers to focus their efforts on developing guidelines and design recommendations.

\subsection{REFERENCES}

[ref7.01] Heskestad G, Hamada T. Ceiling Jets of Strong Fire Plumes. Fire Safety Journal 21:69-82. 1993.

[ref7.02] Cheong MK, Spearpoint M J, Fleischmann CM. Design fires for vehicles in road tunnels. 7th International Conference on Performance-Based Codes and Fire Safety Design Methods. 2008.

[ref7.03] Ingason H. Design fires in tunnels. 2nd International Symposium. Safe \& Reliable Tunnels Innovative European Achievements, Lausanne. 2006.

[ref7.04] Rivkin CH. Section 21. Transportation Fire Safety. Fire Protection Handbook. NFPA 502, Standard for Road Tunnels, Bridges and Other Limited Access Highways. 2008.

[ref7.05] McGrattan K, Hostikka S, McDermott R, Floyd J, Weinschenk C, Overholt K. Fire Dynamics Simulator Technical Reference Guide. Volume 3: Validation (version 6). NIST Special Publication 1018-3, Gaithersburg, MD, USA. 2013. 



\section{FUTURAS LÍNEAS}

Lo importante es no dejar de hacerse preguntas

Albert Einstein 



\subsection{Futuras Líneas}

De cara a plantear futuras líneas de investigación, es conveniente recordar los distintos bloques temáticos propuestos en el Capítulo 1 (ver Figura 8-1).

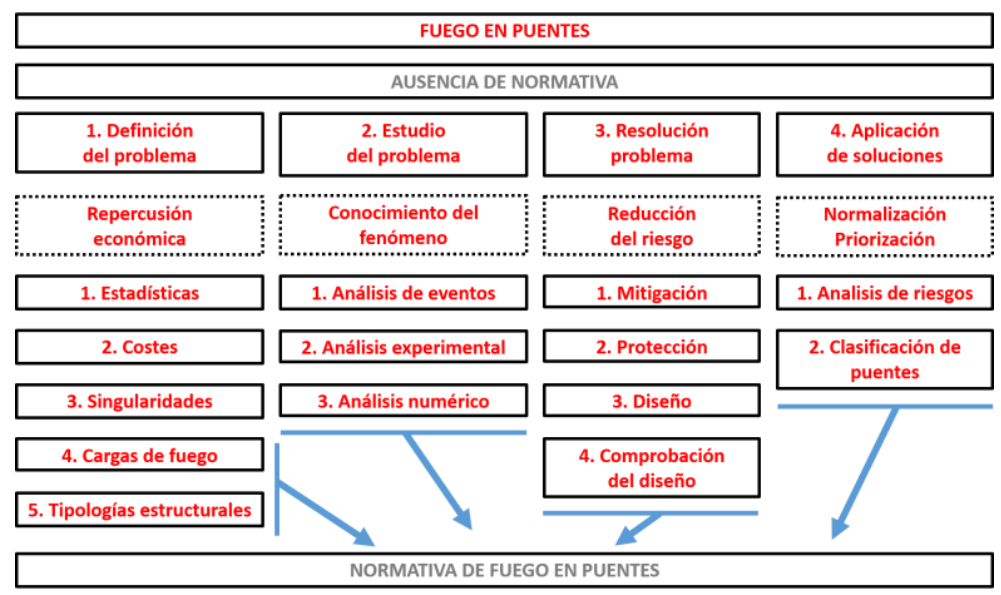

Figura 8-1. Bloques temáticos y líneas de investigación en el ámbito del fuego en puentes. Situación en 2018

Realizada la campaña experimental presentada en el Capítulo 4 y una vez concluidas las validaciones del modelo de simulación de incendios (Capítulo 5) y del modelo termomecánico (Capítulo 6) se plantean las siguientes líneas de investigación:

1. Realización de un último ensayo en el puente experimental en el que se llevara al colapso la estructura mediante el incremento de la carga de fuego. De esta forma podría realizarse una validación del modelo termo-mecánico en el rango de las deformaciones plásticas del acero y teniendo en cuenta el comportamiento del hormigón a mayores temperaturas. Para el nuevo ensayo se propone:

a. Medir las temperaturas adiabáticas para definir la exposición térmica del modelo termo-mecánico adecuadamente

b. Registrar las temperaturas en el acero mediante el empleo de orificios de menor dimensión, con el fin de reducir el error introducido por la interferencia de llamas o de la temperatura del gas.

c. Reducir la presencia de viento a cero mediante la incorporación de un muro perimetral.

2. Realización de una nueva campaña experimental con puentes a escala real y cargas de fuego de al menos $100 \mathrm{MW}$, prescindiendo de la variable viento. 
3. Validados los modelos numéricos de incendios y termo-mecánico a escala real sería el momento de realizar un análisis de sensibilidad a viento de la exposición térmica.

A un nivel más general, cabe esperar que el presente trabajo suponga una referencia a seguir para otros estudios experimentales todavía por desarrollar, como es el caso de:

1. El estudio de la dinámica del incendio, de la transmisión de calor y de la respuesta termo-mecánica de un puente cajón sometido a escenarios de fuego predefinidos

2. El estudio de la resistencia al fuego de distintas protecciones de tirantes y cables empleados en puentes de mayor envergadura. 


\section{GLOSARIO Y NOTACIÓN}

El mayor enemigo del conocimiento no es la ignorancia, sino la ilusión del conocimiento

Stephen Hawking 



\subsection{NOTACIÓN}

$A_{\text {fire }}=$ Huella del fuego $\left(\mathrm{m}^{2}\right)$

$b=$ Radio efectivo del penacho en la intersección a cota del techo (m)

$c_{p}=$ Calor específico del aire $=1.005\left(\mathrm{~kJ} \cdot \mathrm{kg}^{-1} \cdot{ }^{\circ} \mathrm{C}^{-1}\right)$

$D=$ Diámetro equivalente del fuego (m)

$E_{i}=$ Temperatura registrada por un termopar en un ensayo experimental $\left({ }^{\circ} \mathrm{C}\right)$

$f_{a}=$ Límite elástico del acero (MPa)

$f_{h}=$ Resistencia característica del hormigón (MPa)

$g=$ Aceleración gravitacional $=9.81\left(\mathrm{~m} / \mathrm{s}^{2}\right)$

$h=$ Coeficiente de convección $\left(\mathrm{W} \cdot \mathrm{m}^{-2} \cdot{ }^{\circ} \mathrm{C}^{-1}\right)$

$\dot{h}(r)=$ flujo de calor recibido por unidad de superficie $\left(\mathrm{kW} / \mathrm{m}^{2}\right)$

$H=$ Altura del techo respecto de la superficie del combustible (m)

$L_{f}=$ Altura de la llama $(\mathrm{m})$

$L_{f} / H=$ Ratio empleado para diferenciar entre el penacho fuerte y el penacho débil (.)

$L_{h}=$ Longitud horizontal de proyección de la llama (m)

$\dot{m}=$ Tasa de pérdida de masa $(\mathrm{kg} / \mathrm{min})$

$\dot{m} "$ = Tasa de pérdida de masa por unidad de área $\left(\mathrm{kg} / \mathrm{m}^{2} / \mathrm{s}\right)$

$M_{i}=$ Temperatura registrada por un termopar en un modelo numérico $\left({ }^{\circ} \mathrm{C}\right)$

$M a=$ Número de Mach

$Q=$ Tasa de liberación de calor $(\mathrm{kW})$

$Q_{c}=$ Tasa de liberación de calor convectiva $(\mathrm{kW})$

$Q_{D}^{*}=$ Tasa de liberación de calor adimensional $(\mathrm{kW})$

$Q_{H}^{*}=$ Tasa de liberación de calor adimensional $(\mathrm{kW})$

$r=$ Distancia radial desde el eje del penacho de fuego (m) 
$s=$ Lado de la bandeja de planta cuadrada (m)

$T=$ Temperatura $\left({ }^{\circ} \mathrm{C}\right)$

$T_{a}=$ Temperatura adiabática $\left({ }^{\circ} \mathrm{C}\right)$

$T_{g}=$ Temperatura en el gas $\left({ }^{\circ} \mathrm{C}\right)$

$T_{p}(z)=$ Temperatura a una altura particular $\mathrm{z}$ en el eje vertical del penacho $\left({ }^{\circ} \mathrm{C}\right)$

$T_{r}=$ Temperatura equivalente de radiación $\left({ }^{\circ} \mathrm{C}\right)$

$T_{\infty}=$ Temperatura ambiente $=20\left({ }^{\circ} \mathrm{C}\right)$

$y(r)=$ Distancia horizontal adimensional bajo el tablero techo $($.

$z_{0}=$ Origen virtual $(\mathrm{m})$

$z_{b}=$ Coordenada vertical de la superficie superior del combustible (m)

$\delta=$ Factor de sesgo del modelo

$\Delta H_{c}=$ Calor de combustión neto $(\mathrm{MJ} / \mathrm{kg})$

$\Delta T=$ Exceso de temperatura del gas en un punto específico a una distancia particular del eje central del penacho. Es igual a $T-T_{\infty}\left({ }^{\circ} \mathrm{C}\right)$, siendo $T$ la temperatura en el punto considerado y $T_{\infty}$ la temperatura ambiente.

$\Delta T_{p}=$ Exceso de temperatura del gas en el penacho al nivel del techo. Es igual a $T_{p}-T_{\infty}$ $\left({ }^{\circ} \mathrm{C}\right)$, siendo $T_{\mathrm{p}}$ la temperatura en el punto de impacto con el techo.

$\varepsilon=$ Emisividad

$\varepsilon=$ Deformación nominal (.)

$\varepsilon_{\mathrm{n}}=$ Deformación real (.)

$\varepsilon_{m}=$ Emisividad del material

$\theta=$ Valor real de la temperatura $\left({ }^{\circ} \mathrm{C}\right)$

$\lambda=$ Conductividad $\left(\mathrm{W} / \mathrm{m}^{\circ} \mathrm{C}\right)$

$\rho=\operatorname{Densidad}\left(\mathrm{kg} / \mathrm{m}^{3}\right)$

$\rho_{a}=$ Densidad del acero $\left(\mathrm{kg} / \mathrm{m}^{3}\right)$

$\rho_{h}=$ Densidad del hormigón $\left(\mathrm{kg} / \mathrm{m}^{3}\right)$ 
$\rho_{\infty}=$ Densidad del gas a temperatura ambiente $=1.204\left(\mathrm{~kg} / \mathrm{m}^{3}\right)$

$\sigma=$ Tensión nominal (MPa)

$\sigma_{n}=$ Tensión real $(\mathrm{MPa})$

$\sigma_{E}=$ Desviación estándar experimental (debida a las medidas)

$\sigma_{M}=$ Desviación estándar del modelo (debida al modelo)

$\chi=$ Eficiencia de la combustión

$\chi_{r}=$ Fracción radiativa

$\omega_{0}=$ Incertidumbre relativa de la variable output medida

$\omega_{E}=$ Desviación estándar relativa experimental, $\sigma_{\mathrm{E}} / \theta$

$\omega_{M}=$ Desviación estándar relativa del modelo, $\sigma_{\mathrm{M}} /[\theta \cdot(1+\delta)]$

$\omega_{i}=$ Incertidumbre relativa de los dispositivos que miden las diversas variables de entrada que requiere el modelo. 



\subsection{Abreviaturas}

ALDOT: Alabama Department of Transportation (Departamento de transporte de Alabama)

CFD: Computacional Fluid Dynamics (Dinámica de Fluidos Computacional)

LVDT: Linear Variable Differential Transformer. Transformador diferencial de variación lineal. Es un tipo de transformador eléctrico utilizado para medir desplazamientos lineales, con una precisión habitualmente de $1 \mu \mathrm{m}$

H\&H: Heskestad and Hamada. Dado el gran número de veces que se referencia a la correlación en el Capítulo 4 se decidió emplear la citada abreviatura.

HRR: Heat release rate (Tasa de liberación de calor). Constituye el parámetro más representativo de un incendio indicando la magnitud del mismo. Se habla indistintamente de HRR o de potencia del incendio

HRRPUA: Heat release rate per unit area (Tasa de liberación de calor por unidad de superficie). Parámetro dependiente del combustible o material. Si la HRR indica la potencia global del incendio el HRRPUA indica la intensidad de potencia dado un metro cuadrado. Es una magnitud que permite comparar combustibles y su valor multiplicado por la superficie en la que se extienda la carga de fuego permitirá obtener el valor de la HRR.

TCs: Thermocouple (Termopar)

TCTs: Thermocouple trees (Árbol de termopares). Consiste en la disposición de varios termopares siguiendo una misma dirección de forma que la señal de todos ellos se transmite forma paralela. La disposición de termopares en "árbol" se emplea porque resulta más sencilla de instalar.

Horizontal TCT: Árbol de termopares dispuesto en posición horizontal y con los termopares situados aproximadamente a la misma cota.

Vertical TCT: Árbol de termopares dispuesto en posición vertical con los termopares compartiendo coordenadas en planta aproximadamente

CL: Centro-luz. Empleado para referirse a la posición longitudinal equidistante de los dos apoyos del tablero de los puentes. También se usa en el ámbito de la edificación con un significado similar 


\subsection{TÉRMINOS ANGLOSAJONES}

Burner: Elemento empleado en el modelo de simulación de incendios de FDS para representar una fuente de fuego en el modelo.

Datalogger: Registrador de datos. Es un dispositivo electrónico que registra datos en el tiempo o en relación a la ubicación por medio de instrumentos y sensores propios o conectados externamente.

Decay: Fase del fuego en el que la tasa de liberación de calor (HRR) comienza a reducirse como consecuencia de que el combustible disponible para mantener el fuego ya no es suficiente para mantener la máxima potencia. Esta fase concluye con la extinción del fuego.

Fire plume vertical axis: Eje vertical del penacho del fuego.

Plate thermometer: Termómetro de placa. Permite registrar la temperatura adiabática de exposición de un elemento estructural

Spalling: Desprendimiento del hormigón al someterlo a altas temperaturas.

Ceiling Jet: Proyección de techo. Se considera al flujo relativamente rápido en una capa de poco espesor bajo la superficie del techo que es conducida por la flotación de los productos de combustión calientes del penacho.

Plume centerline: Eje vertical central del penacho.

Soot yield: Ratio de generación de hollín dada una reacción de combustión. A mayor magnitud mayor será el residuo a partir del combustible. Se mide en g/g. 



\section{ACLARACIONES}

Suponer está bien, averiguar es mejor

Mark Twain 



\subsection{INTRODUCCIÓN}

A lo largo del presente documento se han hecho una serie de consideraciones que, según casos, han variado de un capítulo a otro. El presente capítulo se plantea como una oportunidad de aclarar estas diferencias entre capítulos. Al final del mismo se ha incluido también una descripción sobre los tipos de validaciones numéricas planteadas en el Capítulo 6.

\subsection{LIMITACIÓN DEL SISTEMA ESTRUCTURAL CONSIDERADO}

Aunque el estudio se circunscribe a vigas de perfiles abiertos tipo doble $\mathrm{T}$ de débil rigidez torsional, el sistema estructural objeto de estudio se limita a vigas de un tramo simplemente apoyadas. El ala libre inferior del perfil está traccionada y se supone la correcta inmovilización del ala superior a la losa mediante los conectadores. Por esta razón, las vigas no son susceptibles al fenómeno del vuelco lateral del cordón comprimido (lateral torsional buckling). Así, en la simulación numérica estructural durante el incendio no ha sido precisa la introducción de las convenientes imperfecciones globales y/o locales iniciales o un sistema de fuerzas equivalentes.

\subsection{FORMULACIÓN DE LA CONDICIÓN DE CONTORNO TÉRMICA}

A continuación, se incluye una breve explicación de la definición de la condición de contorno definida para el calentamiento de los sólidos expuestos a altas temperaturas omitida en el texto principal con el fin de no entretener al lector familiarizado con los conceptos básicos de transmisión de calor.

Un sólido se encuentra continuamente intercambiando calor con su entorno a través de los mecanismos de transmisión de calor de radiación y convección.

La transmisión de calor mediante radiación se produce mediante la transferencia de energía en forma de ondas electromagnéticas. No requiere un medio determinado para propagarse por lo que puede producirse en vacío y es independiente de la temperatura del gas del medio (salvo que éste emita radiación). En la ecuación 10-1 se presentan las variables de las que depende el flujo de radiación neto sobre el sólido.

$q_{R A D}=\varepsilon_{m} \cdot \sigma \cdot\left(T_{r}^{4}-T_{\text {solido }}^{4}\right)$

Siendo:

$\mathrm{q}_{\mathrm{RAD}}=$ Flujo de calor neto absorbido por el sólido por radiación $\left(\mathrm{W} / \mathrm{m}^{2}\right)$

$\varepsilon_{\mathrm{m}}=$ Emisividad del material 
$\sigma=$ Constante de Stefan Boltzmann $=5.67 \cdot 10^{-8}\left(\mathrm{~W} / \mathrm{m}^{2} \mathrm{~K}^{4}\right)$

$\mathrm{T}_{\mathrm{r}}=$ Temperatura equivalente de radiación $\left({ }^{\circ} \mathrm{K}\right)$

$\mathrm{T}_{\text {solido }}=$ Temperatura de la superficie expuesta del sólido $\left({ }^{\circ} \mathrm{K}\right)$

La transmisión de calor mediante convección se produce cuando existe una diferencia de temperatura entre el sólido y el fluido en contacto con el mismo. La convección puede ser natural, si el movimiento se debe exclusivamente a la no uniformidad de la temperatura, o forzada, si el movimiento se logra sometiendo el fluido a un gradiente de presiones al forzar el movimiento según las leyes de la mecánica de fluidos. En la ecuación 10-2 se presentan las variables de las que depende el flujo de convección neto sobre el sólido.

$q_{\text {CONV }}=h \cdot\left(T_{\text {gas }}-T_{\text {solido }}\right)$

Siendo:

qCONV $=$ Flujo de calor neto absorbido por el sólido por convección $\left(\mathrm{W} / \mathrm{m}^{2}\right)$

$\mathrm{h}=$ Coeficiente de convección (no es una propiedad del material) $\left(\mathrm{W} / \mathrm{m}^{2}{ }^{\circ} \mathrm{K}\right.$ )

$\mathrm{T}_{\text {gas }}=$ Temperatura del gas en contacto con el sólido $\left({ }^{\circ} \mathrm{K}\right.$ o $\left.{ }^{\circ} \mathrm{C}\right)$

$\mathrm{T}_{\text {solido }}=$ Temperatura de la superficie expuesta del sólido $\left({ }^{\circ} \mathrm{K}\right.$ o $\left.{ }^{\circ} \mathrm{C}\right)$

El flujo de calor neto absorbido por el sólido total es la suma de los flujos de calor debidos a cada uno de los mecanismos mencionados previamente. En la ecuación 10-3 se presenta La transmisión de calor total

$q_{\text {TOT }}=q_{R A D}+q_{C O N}=\varepsilon_{m} \cdot \sigma \cdot\left(T_{r}^{4}-T_{\text {solido }}^{4}\right)+h \cdot\left(T_{\text {gas }}-T_{\text {solido }}\right)$

Siendo:

qтот $=$ Flujo de calor neto absorbido por el sólido total $\left(\mathrm{W} / \mathrm{m}^{2}\right)$

Mientras que en un fluido la mayor parte del calor es transportado mediante convección, en incendios la radiación cobra gran importancia, llegando a dominar el proceso en las zonas en que las llamas están próximas y/o la dimensión del fuego no es despreciable respecto al elemento expuesto. 


\subsection{EMPLEO DE LA SUPERFICIE ADIABÁTICA}

A lo largo de la presente tesis se ha empleado el recurso de la superficie adiabática en los Capítulos 3 y 6 sin entrar a explicar en qué consiste. Aunque en la Sección 3.3 se explica a nivel práctico la utilidad del empleo de esta herramienta no se entra a explicar a nivel teórico en que consiste.

Para entender que es la superficie adiabática es necesario conocer previamente que es una condición de contorno térmica. Si bien es cierto que para los profesionales relacionados con la ingeniería del fuego es un concepto básico, es posible que para los profesionales especializados en la ingeniería estructural puede ser útil la explicación proporcionada en la Sección 10.3.

Una definición complementaria de la condición de contorno térmica sería el flujo neto (positivo si se dirige hacia el sólido y negativo si parte de él) definido en el extremo de la zona a modelar y que sirve para reproducir la relación a nivel térmico con la zona en contacto que ya no entra a formar parte del modelo. El equivalente en el campo de las estructuras serían todas las fuerzas y momentos que se aplicarían como condiciones de contorno mecánicas.

Una superficie adiabática no transfiere flujo térmico a su través. Si se recupera la Ec. 103 , cuyos conceptos se explican en la Sección 10.3 y se supone que no existe flujo térmico hacia o desde la estructura sometida a una carga de fuego se está imponiendo una condición adiabática definida según la Ec. 10-4.

$$
\begin{aligned}
& q_{T O T}=q_{R A D}+q_{C O N}=\varepsilon_{m} \cdot \sigma \cdot\left(T_{r}^{4}-T_{\text {solido }}^{4}\right)+h \cdot\left(T_{\text {gas }}-T_{\text {solido }}\right) \\
& 0=q_{R A D}+q_{C O N}=\varepsilon_{m} \cdot \sigma \cdot\left(T_{r}^{4}-T_{a}^{4}\right)+h \cdot\left(T_{\text {gas }}-T_{a}\right)
\end{aligned}
$$

Si se observa en detalle la Ec. 10-4 rápidamente se deduce que existen dos posibles soluciones:

Solución 1 (trivial):

$$
\begin{aligned}
& 0=q_{R A D}=\varepsilon_{m} \cdot \sigma \cdot\left(T_{r}^{4}-T_{a}^{4}\right) \rightarrow T_{r}^{4}=T_{a}^{4} \\
& 0=q_{C O N}=h \cdot\left(T_{\text {gas }}-T_{a}\right) \rightarrow T_{\text {gas }}=T_{a}
\end{aligned}
$$

En cuyo caso se puede ver rápidamente como la ausencia de flujo neto se debe a que la temperatura del sólido en su superficie coincide con la temperatura del gas en contacto y con la temperatura equivalente de radiación. 
$\underline{\text { Solución } 2 \text { (superficie adiabática) }}$

$q_{R A D}=-q_{C O N}$

(Ec. 10-7)

$\varepsilon_{m} \cdot \sigma \cdot\left(T_{r}^{4}-T_{a}^{4}\right)=-h \cdot\left(T_{g a s}-T_{a}\right)$

(Ec. 10-8)

En este segundo caso la imposición de la condición adiabática exige que el flujo neto de calor de radiación y el flujo neto de calor de convección presenten magnitudes iguales y signos opuestos (ver ecuaciones Ec. 10-7 y Ec. 10-8). Si se atiende a la Ec. 10-8, considerando que $\varepsilon_{m}, \sigma$ y h son siempre positivos, se deduce que $\left(T_{r}^{4}-T_{a}^{4}\right)$ y $\left(T_{g a s}-\right.$ $T_{a}$ ) necesariamente presenta signos opuestos, lo que implica que:

Si $T_{\text {gas }}>T_{a} \rightarrow T_{r}<T_{a}$

Si $T_{\text {gas }}<T_{a} \rightarrow T_{r}>T_{a}$

Se recuerda que el caso de $T_{g a s}=T_{a} \rightarrow T_{r}=T_{a}$ no se considera al formar parte de la solución trivial.

Si se presta atención a las ecuaciones Ec. 10-9 y Ec. 10-10 se puede entender como la herramienta de la superficie adiabática permite obtener una temperatura, que se llamará adiabática $\left(T_{a}\right)$ dado su origen, que tendrá un valor intermedio entre la temperatura de radiación $\left(T_{r}\right)$ y la temperatura de convección $\left(T_{\text {gas }}\right)$.

$$
\begin{aligned}
& q_{T O T}=q_{R A D}+q_{C O N}=\varepsilon_{m} \cdot \sigma \cdot\left(T_{r}^{4}-T_{\text {solido }}^{4}\right)+h \cdot\left(T_{\text {gas }}-T_{\text {solido }}\right) \\
& 0=q_{R A D}+q_{C O N}=\varepsilon_{m} \cdot \sigma \cdot\left(T_{r}^{4}-T_{a}^{4}\right)+h \cdot\left(T_{\text {gas }}-T_{a}\right)
\end{aligned}
$$

Recuperando las ecuaciones Ec. 10-3 y Ec. 10-4 se puede entender como al fijar un flujo neto igual a cero, la temperatura adiabática $\left(T_{a}\right)$ obtenida correspondería con la temperatura a la que se debería encontrar el sólido en la superficie de estudio para que el flujo neto hacia o desde el mimo fuera cero a través de ella.

$$
\begin{aligned}
& q_{\text {TOT }}=\varepsilon_{m} \cdot \sigma \cdot\left(T_{r}^{4}-T_{\text {solido }}^{4}\right)+h \cdot\left(T_{\text {gas }}-T_{\text {solido }}\right) \\
& 0=\varepsilon_{m} \cdot \sigma \cdot\left(T_{r}^{4}-T_{a}^{4}\right)+h \cdot\left(T_{\text {gas }}-T_{a}\right)
\end{aligned}
$$

Si de las ecuaciones Ec. 10-3 y 10-4 nos quedamos con la última parte de la igualdad obtenemos las ecuaciones Ec. 10-3b y Ec. 10-4b. Si restamos a la Ec. 10-3b la Ec. 10-4b se obtiene la Ec. 10-11.

$q_{\text {TOT }}=\varepsilon_{m} \cdot \sigma \cdot\left(T_{a}^{4}-T_{\text {solido }}^{4}\right)+h \cdot\left(T_{a}-T_{\text {solido }}\right)$ 
Si se presta atención, se puede ver como la Ec. 10-11 es idéntica a la Ec. 10-3b con la única diferencia de que se han sustituido la temperatura del gas $\left(T_{\text {gas }}\right)$ y la temperatura equivalente de radiación $\left(T_{r}\right)$ por la temperatura adiabática $\left(T_{a}\right)$ previamente calculada.

$\mathrm{Al}$ emplear la temperatura adiabática $\left(T_{a}\right)$ se está aplicando sobre la superficie del sólido el mismo flujo neto total que se habría aplicado mediante el uso de las temperatura del gas $\left(T_{\text {gas }}\right)$ y la temperatura equivalente de radiación $\left(T_{r}\right)$ con la diferencia de que en este caso se está recurriendo a una única variable $\left(T_{a}\right)$ en lugar de a dos $\left(T_{g a s}\right.$ y $\left.T_{r}\right)$.

Para concluir con la explicación, en la Figura 10-1 se representa de forma visual lo explicado previamente mediante ecuaciones. En ella se puede ver como el recurso de la superficie adiabática permite definir la condición de contorno a partir de los coeficientes de radiación y convección originales y la temperatura adiabática en lugar de recurrir a la definición de esa misma condición de la forma tradicional (mediante los coeficientes de radiación de convección y las temperaturas del gas y equivalente de radiación) sin que esto suponga una variación en el valor del flujo neto sobre la estructura.

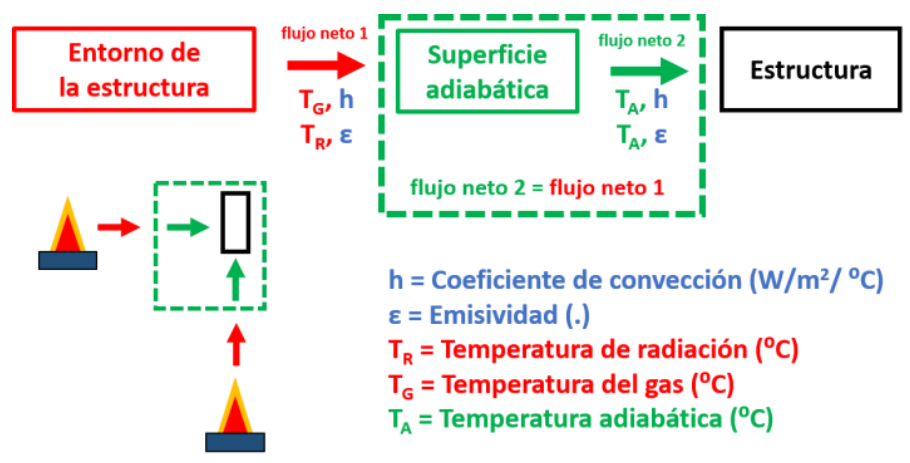

Figura 10-1. Esquema explicativo de la superficie adiabática.

\subsection{CONSIDERACIÓN DE APLICACIÓN DE LA SUPERFICIE ADIABÁTICA}

Hasta el momento se ha explicado el recurso de la superficie adiabática de forma genérica. A continuación, se va a detallar como aplicarla adecuadamente en una aplicación númerica que considera un tablero mixto compuesto de dos o más vigas de acero que soportan una losa de hormigón.

En la Figura 10-1 se puede apreciar como la superficie adiabática se aplica en todo el contorno de la estructura expuesta, permitiendo transformar las temperaturas del gas y de radiación en temperaturas adiabáticas equivalentes. 
Imaginemos que la superficie adiabática se compone de pequeñas superficies de dimensión finita (ver Figura 10-2) que juntas envuelven el tablero sometido a la acción de fuego. Para cada superficie y para cada intercalo temporal se obtendrá la temperatura adiabática equivalente a partir de las temperaturas del gas y equivalente de radiación asociadas. Esto es así porque la exposición térmica no es uniforme ni en el tiempo ni en el espacio.

Como se puede suponer, el registro de temperaturas adiabáticas puntuales en el gas no supone ninguna modificación de la dinámica del incendio (recordemos que estamos trabajando con un modelo numérico). Por ello los registros permiten obtener flujos netos sobre y desde la estructura equivalentes a los que se obtendrían mediante el empleo de las temperaturas del gas y equivalentes de radiación.

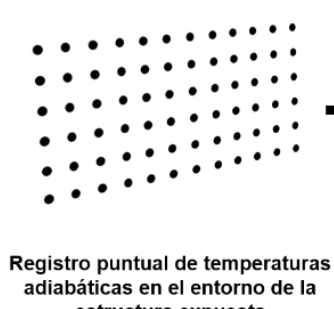
estructura expuesta

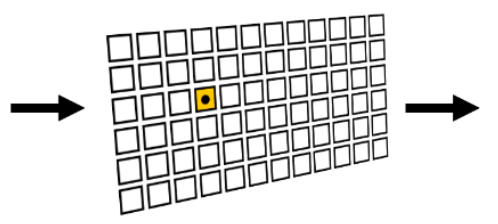

Cada uno de los registros servirá para definir una parte de la condición de contorno térmica.

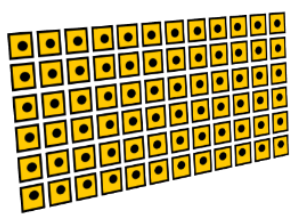

La superficie adiabática sería la que se genera al repetir el proceso para todos los registros.

Figura 10-2. Esquema explicativo de la definición de la superficie adiabática en FDS.

Si en lugar de definir la superficie adiabática tal y como se ha explicado previamente se recurre a la incorporación de superficies adiabáticas disponibles en el software FDS se estarían sobreestimando tanto las temperaturas adiabáticas como de las temperaturas del gas y equivalentes de radiación, especialmente en la zona más expuesta al fuego. EL motivo no sería otro que el de transformar las vigas de acero, por naturaleza muy buen conductor de calor, en viga totalmente adiabáticas.

\subsection{VERSIONES DE FDS EMPLEADAS}

Dado el gran periodo temporal que ha abarcado la publicación de los distintos artículos se han empleado dos versiones del software FDS. Mientras que en el capítulo 2 se ha empleado la versión FDS5, en los capítulos 4 y 5 se ha empleado la versión FDS6.

\subsection{DENSIDAD DEL HORMIGÓN}

En el Capítulo 3 de validación de la metodología general mediante el empleo de un evento real (incendio en Alabama en 2002) se ha empleado una densidad del hormigón $\left(\rho_{\mathrm{h}}\right)$ a temperatura ambiente de $2500 \mathrm{~kg} / \mathrm{m}^{3}$, mientras que en el Capítulo 6 esta misma 
densidad se ha considerado igual a $2300 \mathrm{~kg} / \mathrm{m}^{3}$. La diferencia entre ambos modelos se debe a que mientras que en el Capítulo 3 el peso de las armaduras se incorpora en la definición del hormigón de la losa, en el Capítulo 6 el peso de las armaduras se considera explícitamente en las propias armaduras.

\subsection{TASA DE LIBERACIÓN DE CALOR POR UNIDAD DE SUPERFICIE}

El combustible de referencia en el presente trabajo ha sido la gasolina con una tasa de liberación por unidad de superficie (con sus siglas en inglés: HRRPUA) de $2500 \mathrm{~kW} / \mathrm{m}^{2}$ en el Capítulo 2 y de $2400 \mathrm{~kW} / \mathrm{m}^{2}$ en el resto de capítulos. Esto es así porque en el primer estudio se adoptó un valor orientativo que terminó afinándose con el tiempo. El valor teórico promedio adoptado para la gasolina es de $2400 \mathrm{~kW} / \mathrm{m}^{2}$, como puede deducirse de multiplicar el calor de combustión por la tasa de pérdida de masa por unidad de área de la misma.

$\Delta \mathrm{H}_{\mathrm{c}, \text { gasolina }}=$ Calor de combustión neto de la gasolina $=43.7 \mathrm{MJ} / \mathrm{kg}$

$\dot{m}_{\text {gasolina }}^{\prime \prime}=$ Tasa de pérdida de masa por unidad de área de la gasolina $=0.055 \mathrm{~kg} / \mathrm{m}^{2} / \mathrm{s}$

\subsection{JUSTIFICACIÓN DE CURVAS DE HRRPUA SIN FASE DE ENFRIAMIENTO}

En la Sección 3.4.2.2 se indica:

"El hecho de que las curvas de HRRPUA no presenten fase de enfriamiento se debe a que, como se comprobó al finalizar el estudio, el colapso se producía antes de que el fuego consumiese el 15\% de la energía disponible".

La afirmación previa se justifica a continuación:

1. Una energía disponible de 1,212,675 MJ correspondiente al volumen total de gasolina transportado por la cisterna $(37.5 \mathrm{~m} 3)$ multiplicado por la densidad de la misma (740 $\mathrm{kg} / \mathrm{m}^{3}$ ) y por el calor de combustión neto de la gasolina $(43.7 \mathrm{MJ} / \mathrm{kg})$

2. Tiempo de colapso de 13.1 minutos (786 s).

3. Una potencia liberada máxima de 230.13 MW correspondiente a la suma de potencias relativa al camión ardiendo (75 MW) y el combustible derramado sobre el pavimento (155,13 MW) obteniéndose los valores a partir de:

$2.5 \mathrm{MW} / \mathrm{m}^{2} \cdot 30 \mathrm{~m}^{2}=75 \mathrm{MW}$

$1.0 \mathrm{MW} / \mathrm{m}^{2} \cdot 155,13 \mathrm{~m}^{2}=155,13 \mathrm{MW}$ 
para el caso que mejor reproduce la respuesta termo-mecánica de la viga más expuesta la potencia liberada por unidad de superficie en el derrame es de $1.0 \mathrm{MW} / \mathrm{m}^{2}$.

Conocido el tiempo de colapso y suponiendo que se la potencia del fuego es máxima desde que se inicia se tiene que en el momento del colapso se han consumido:

786 segundos $\cdot 230.13 \mathrm{MW}=180,882.18 \mathrm{MJ}$

Lo que supone un $14.91 \%$ de la energía total disponible

$14.9180,882.18 / 1,212,675=14.9 \%$

\subsection{DETALLES SOBRE LOS TERMOPARES EMPLEADOS EN LA CAMPAÑA EXPERIMENTAL}

En el Capítulo 4 se han empleado, para el registro de temperaturas, dos tipos de termopares:

1. Para el registro de temperaturas en el gas y en el acero de las vigas se han empleado termopares tipo $\mathrm{K}$, de $3 \mathrm{~m}$ de aislamiento de acero inoxidable AISI 310 mediante vaina de $1.5 \mathrm{~mm}$ de diámetro con temperatura de exposición máxima de $1100{ }^{\circ} \mathrm{C}$. Se decidió emplear este tipo de vaina puesto que estos termopares podían estar expuestos en menor o mayor medida a llama directa y podían ser empleados en futuras campañas experimentales.

2. Para el registro de temperaturas en las barras de acero y en las cabezas de los conectadores se han empleado termopares fabricados a partir de cable C76-KX (cable para termopar tipo $\mathrm{K}$, par paralelo de hilo sólido $2 \times 0.5 \mathrm{~mm}$, aislado individualmente y en conjunto con doble aislamiento con fibra de vidrio con temperatura de exposición máxima de $800{ }^{\circ} \mathrm{C}$ ). Se decidió emplear este tipo de cable porque dentro del hormigón las temperaturas no alcanzarían los valores que se alcanzan en el acero y en el gas y puesto que los termopares quedarían embebidos en el hormigón no podrían ser utilizados en futuros ensayos.

No se ha dispuesto de termómetros de placa (plate thermometers) aunque se recomienda su uso en futuros ensayos centrados más en la respuesta termo-mecánica de la estructura que en la simulación de incendios (como ha sido el caso de la campaña experimental presentada en el Capítulo 4). 

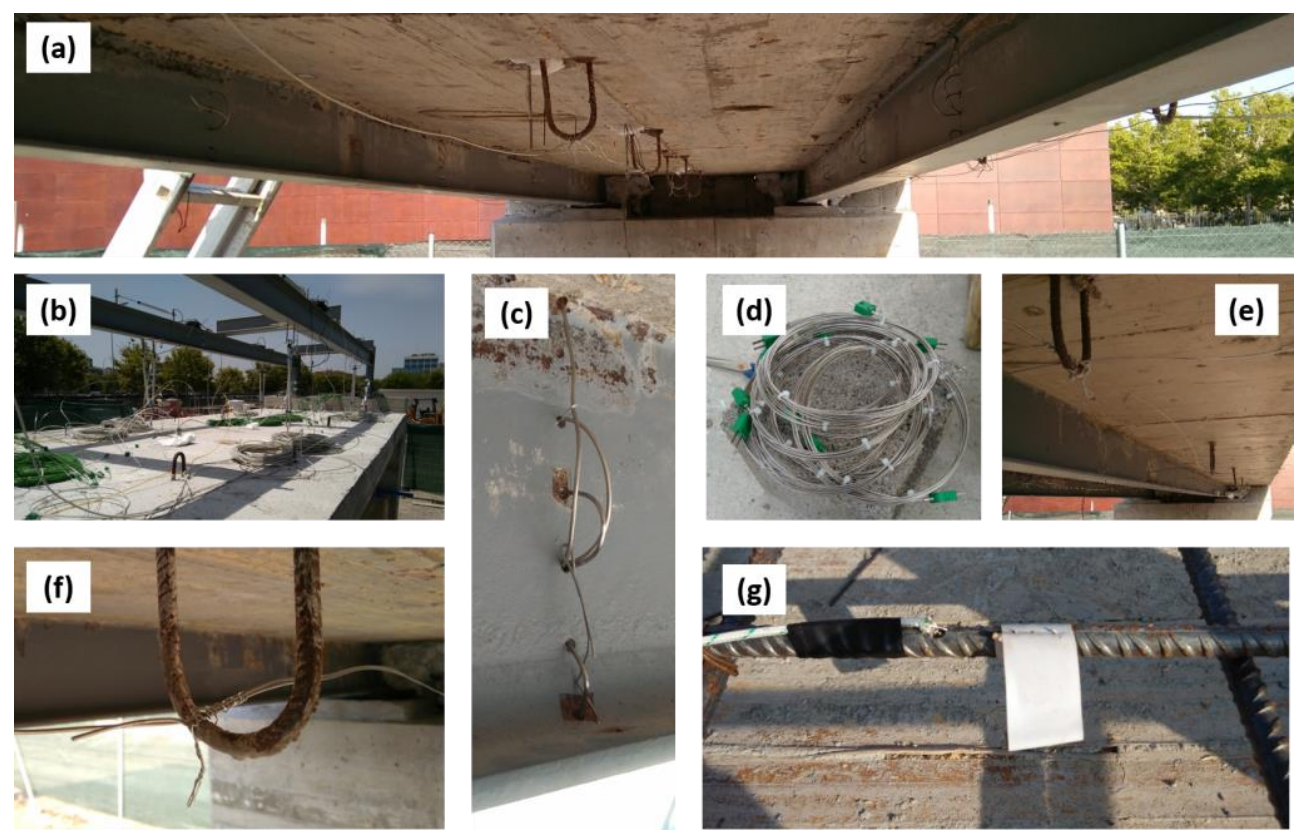

Figura 10-3. Imágenes de la instrumentación empleada en la campaña experimental.

Con el fin de servir de utilidad para futuras campañas experimentales similares, en la Figura 10-3 se presentan algunas imágenes tomadas relativas a la instrumentación de termopares. Mientras que en la imagen (a) se aprecia una captura general de los sensores del gas y del acero en la zona entre vigas bajo el puente, en la imagen (b) se presenta una captura general del cableado dispuesto sobre el puente durante la disposición del mismo. En la imagen (c) se presenta un detalle de gran interés en lo referente a la disposición de los termopares en el alma y el ala inferior de la losa. En la imagen (d) se presentan varios termopares tipo $\mathrm{K}$ de vaina de acero inoxidable de $1.5 \mathrm{~mm}$ de diámetro y $3 \mathrm{~m}$ de largo. En la imagen (e) se presenta un detalle de uno de los laterales del puente en el que se puede ver como los termopares en el gas se han dispuesto empleando ganchos de acero no estructurales embebidos en el hormigón. En la imagen (f) se presenta un detalle del atado de dos termopares pasando por uno de los ganchos. Finalmente, en la imagen (g) se presenta un termopar encargado de registrar temperaturas en una de las barras de armado de la losa antes de realizar el vertido de hormigón y dejarlo embebido. 


\subsection{DESCARTE DE LA HIPÓTESIS DE TEMPERATURA DE RADIACIÓN ASIMILABLE A LA TEMPERATURA DEL GAS}

En el capítulo 3 (Acciones para el análisis térmico) del Eurocódigo 1 en su parte 1-2 se indica que, para elementos totalmente rodeados por el fuego, la temperatura de radiación puede asimilarse a la temperatura del gas alrededor del elemento.

Si bien es cierto que para situaciones en las que los elementos estén totalmente rodeados por el fuego, el hecho de asimilar la temperatura de radiación a la temperatura del gas alrededor del elemento estructural es perfectamente asumible, en el problema tratado en la presente tesis doctoral las llamas tan solo contactan con algunas regiones de la viga y ni siquiera lo hacen de forma continua durante ninguno de los ensayos. Por este motivo, si se asumiese que las temperaturas de radiación fueran iguales a las del gas registradas por los termopares se estaría introduciendo un error de tal magnitud que imposibilitaría cualquier tipo de validación.

\subsection{DistribuCIONES Y TIPOS DE SENSORES EMPLEADOS EN LAS DISTINTAS VALIDACIONES DE LOS MODELOS NUMÉRICOS}

La distribución y el tipo de sensores empleados en los Capítulos 5 y 6 , aunque se han dispuesto en un modelo de simulación incendios idéntico para el caso del ensayo Test 8 (con excepción de la definición de la tasa de liberación de calor) son completamente diferentes. Esto es así porque cada validación (del modelo de simulación de incendios en el Capítulo 4 y del modelo termo-mecánico en el Capítulo 5) requieren unas variables específicas relativas al problema a modelar en cada caso.

Para la validación de la simulación de incendios (ver Figura 10-4) se han empleado:

1. Termopares en el gas en las seis secciones representativas (comunes)

2. Termopares en el gas en el penacho de fuego (solo validación incendios)

con el fin de comparar estos valores con los registrados experimentalmente.

Para la validación de la simulación de incendios (ver Figura 10-5) se han empleado:

1. Temperaturas adiabáticas de las tres zonas de exposición para cada una de las seis secciones obtenidas a $5 \mathrm{~cm}$ de las superficies expuestas del acero (solo validación del modelo termo-mecánico)

a. Para definir adecuadamente los flujos de convección y de radiación empleados en el modelo térmico.

2. Coeficientes de convección de las tres zonas de exposición para cada una de las seis secciones obtenidas (solo validación del modelo termo-mecánico) 
a. Para definir adecuadamente los flujos de convección empleados en el modelo térmico

3. Termopares en el gas en las seis secciones representativas (comunes)

a. Para la comparación final de temperaturas en el gas del modelo definitivo con las temperaturas registradas experimentalmente

\subsection{TIPOS DE VALIDACIONES NUMÉRICAS}

En el Capítulo 6 se han empleado los conceptos de validación numérica estricta, validación numérica mixta y validación numérica iterativa mixta. A continuación, se incluye una explicación en detalle sobre cada una de ellas.

Validación numérica: Dado un ensayo se registra la evolución en el tiempo de dos o más variables representativas. El número mínimo de variables es de dos, siendo una de entrada y otra de salida. Las variables deben ser representativas del fenómeno objeto de estudio. En el caso del Capítulo 6, donde se quiere validar el modelo termo-mecánico, las variables serían el flujo neto de calor sobre la viga (variable de entrada) y la flecha de la viga de estudio (variable de salida).

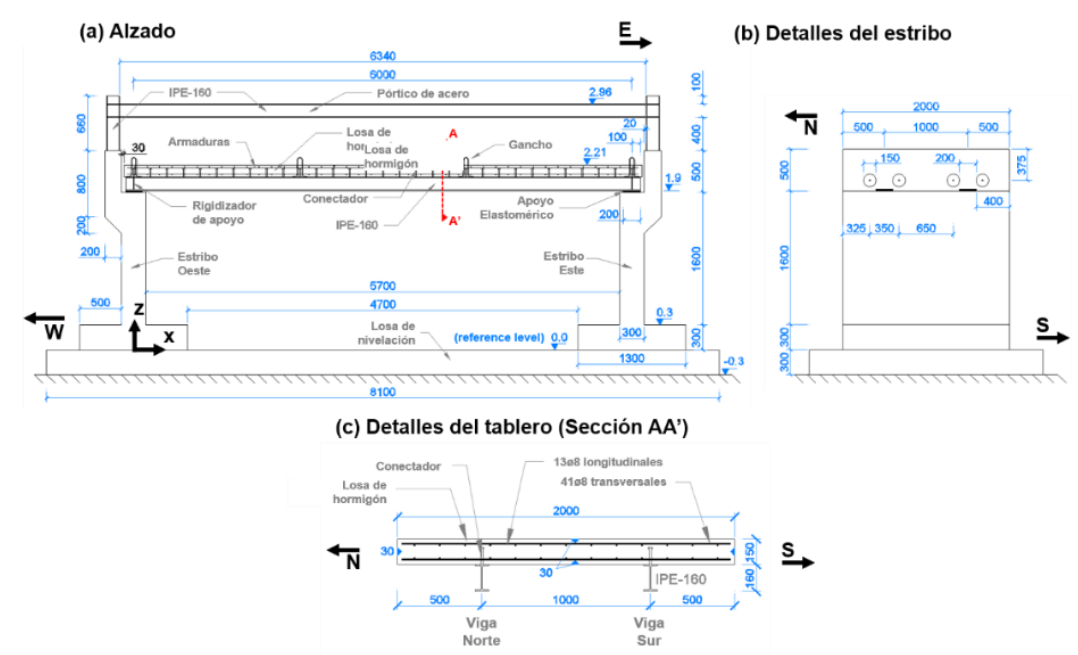

Figura 10-4. Puente experimental: (a) Alzado, (b) Detalles del estribo y (c) Detalles del tablero. Todas las dimensiones se expresan en mm y todas las cotas se expresan en m. 


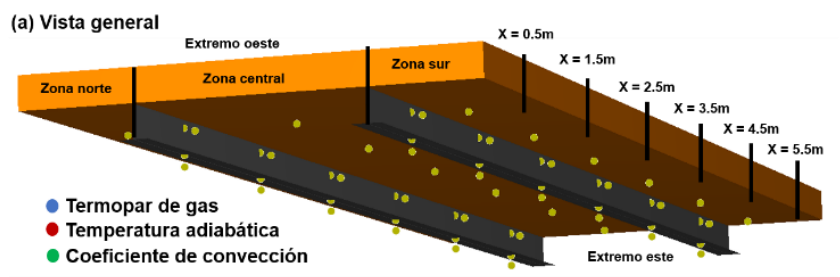

(b) Distribución de sensores en sección

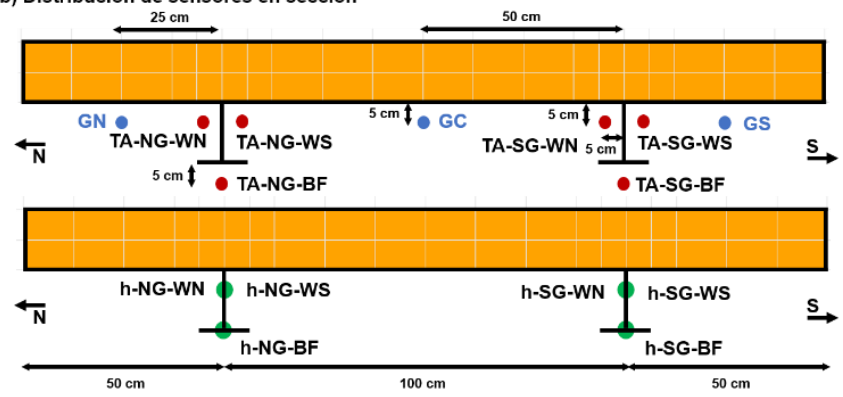

Figura 10-5. Simulación de incendios del ensayo Test 8: (a) Vista general y (b) Distribución de sensores en sección.

Validación numérica estricta: Se considera que una validación numérica es estricta cuando emplea únicamente registros experimentales para verificar que el modelo está bien definido. En el caso del Capítulo 6, una validación numérica estricta requeriría de la medición en el ensayo experimental del flujo neto de calor en la estructura en las secciones representativas, además de las flechas del puente.

Validación numérica mixta: Se habla de validación numérica mixta cuando se emplea como variable de entrada un registro obtenido en una etapa anterior mediante otro modelo numérico ya validado y como variable de salida un registro experimental. Su aplicación es de utilidad para casos donde no se puede aplicar una validación numérica estricta. En el caso del Capítulo 6, la variable de entrada es el flujo neto de calor obtenido a partir de (1) la temperatura del gas ( $\mathrm{T}_{\mathrm{g}}$ ), (2) el coeficiente de convección (h), (3) la temperatura equivalente de radiación $\left(\mathrm{T}_{\mathrm{r}}\right)$ y (4) la emisividad y la variable de salida es la flecha de la viga de estudio.

Validación numérica mixta iterativa: La connotación "iterativa" surge en contraposición o una validación directa. Mientras que en una validación directa se introduce en el modelo la variable de entrada que permite calcular la variable de salida cuyo valor se comparará con el registro experimental correspondiente, en una validación iterativa el valor de la variable de entrada se va corrigiendo a lo largo de las distintas iteraciones o ciclos hasta que se obtiene una variable de salida similar a la registrada experimentalmente. Su aplicación es de utilidad para casos en los que el valor disponible 
de la variable de entrada es cuestionable por el motivo que sea. En el caso del Capítulo 6, la variable de entrada es el flujo neto de calor obtenida a partir de una simulación de incendios que considera la influencia del viento de forma indirecta mediante una reducción de la tasa de liberación de calor del fuego. Para que este tipo de consideración se pueda dar por buena se recurre a una variable intermedia (entre el modelo térmico y el modelo mecánico) que permite asegurar que, aunque el modelo de incendio no represente exactamente el fuego experimental, se está obteniendo una exposición térmica equivalente. 



\section{ANEXO 1. CONCLUSIONES}

Conocer lo que conoces y lo que no conoces, eso es el verdadero conocimiento

Confucio 



\subsection{INTRODUCCIÓN}

Aunque cada uno de los capítulos previos ha incluido una serie de conclusiones específicas del apartado, se ha decidido incluir un capítulo adicional en el que se recopilen las conclusiones más generales de la presente investigación. Si se quieren conocer conclusiones a nivel más específico, se recomienda consultar el apartado correspondiente en cada uno de los capítulos.

En la se incluye un esquema resumen del contenido de la Tesis de forma que se ofrece una visión general de gran ayuda para contextualizar las conclusiones que a continuación se exponen. En ella se pueden apreciar como existen dos fuentes de información: (1) la correspondiente al incidente ocurrido en Alabama en 2002 y (2) los ensayos realizados durante el presente trabajo durante el 2016.

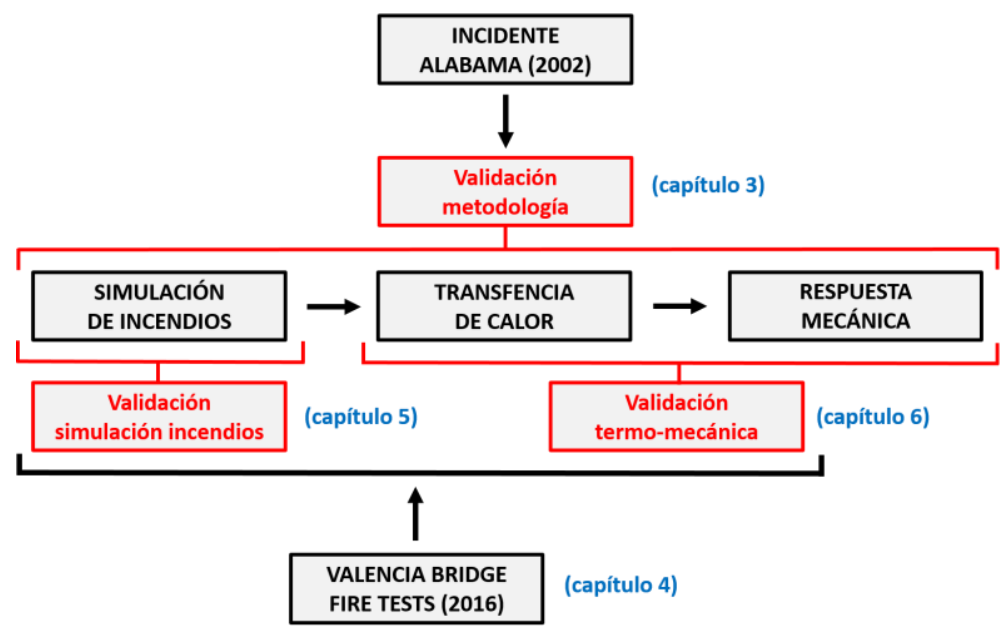

Figura 11-1. Esquema resumen del contenido de la tesis.

En la Tabla 11-1 se presentan algunos datos relevantes sobre la naturaleza de la información empleada en cada una de las tres validaciones realizadas en el presente documento. Si bien es cierto que la validación general de la metodología se realizó con información con un alto nivel de aproximación, las dos validaciones de los modelos de simulación de incendios y de modelo mediante elementos finitos requirieron una definición más precisa de parte de las variables implicadas en cada uno de los modelos. Este fue uno de los motivos que contribuyó a la realización de la campaña experimental presentada como "Valencia bridge fire tests", donde se registraron una serie de variables de gran interés para la validación de los modelos numéricos empleados en la metodología. 


\begin{tabular}{ccc}
\hline & Incidente alabama & Valencia bridge fire tests \\
\hline $\begin{array}{c}\text { Fecha } \\
\text { adquisición }\end{array}$ & 2002 & 2016 \\
\hline $\begin{array}{c}\text { Definición } \\
\text { del fuego }\end{array}$ & Imágenes & curva t-HRR \\
\hline $\begin{array}{c}\text { Definición } \\
\text { del puente }\end{array}$ & Planos de diseño & Planos de diseño \\
\hline $\begin{array}{c}\text { Adquisición de datos } \\
\text { durante el incendio }\end{array}$ & No hay & $\begin{array}{c}\text { curvas t-Tgas } \\
\text { cuvas t-Tacero } \\
\text { curvas t-flecha }\end{array}$ \\
\hline $\begin{array}{c}\text { Adquisición de datos } \\
\text { post-incendio }\end{array}$ & Deformación residual & Sin deformación residual \\
\hline
\end{tabular}

Tabla 11-1. Diferencias entre las dos fuentes de información empleadas en las validaciones

\subsection{Capítulo 3. Metodología}

En este capítulo se presenta la metodología general que permite predecir la respuesta estructural de un puente concreto dado un escenario de fuego. La metodología (cuyas etapas pueden verse en la Figura 7-2) se validó con un evento real en el que la carga de fuego tuvo que estimarse mediante imágenes, puesto que no hubo ningún tipo de registro continuo durante el evento.

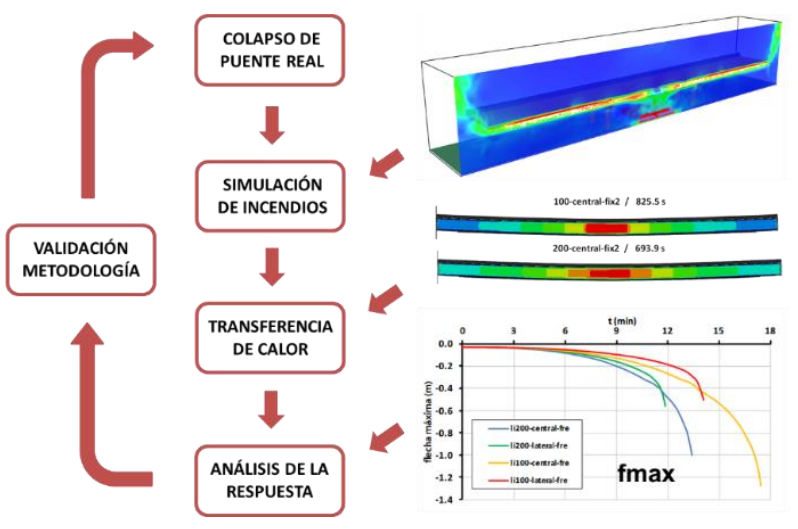

Figura 11-2. Esquema de la metodología empleada

Las principales conclusiones del capítulo son las siguientes:

1. Sobre gradientes térmicos:

a. Los incendios en puentes provocan fuertes gradientes térmicos longitudinales y entre zonas de exposición. Por ello, se recomienda 
caracterizar la exposición térmica por tramos (longitudinalmente) y por zonas (transversalmente) para el caso de puentes multiviga

2. Sobre el empleo de una curva de calentamiento única:

a. Queda descartado para puentes de longitud superior a los $30 \mathrm{~m}$

b. Se desaconsejará para puentes de longitud inferior a los $30 \mathrm{~m}$, salvo que se realice un modelo de campo que permita determinar que su empleo es razonable

3. Sobre la distribución de sensores en el modelo de incendios de puentes con tableros multiviga. Se considera razonables el empleo de:

a. Separaciones longitudinales de $0.6 \mathrm{~m}$

b. Un único sensor por zona de exposición de las vigas metálicas, siendo las zonas:

i. Cara inferior del ala inferior

ii. Zona lateral $\mathrm{A}$

iii. Zona lateral $\mathrm{B}$

4. Sobre la respuesta mecánica de vigas metálicas y mixtas:

a. La restricción longitudinal al movimiento resulta una variable significativa en lo que respecta al tiempo de fallo. Esto es debido a la magnitud de la deformación térmica que se produce en las vigas metálicas de puente al estar sometidas a temperaturas del orden de los $700^{\circ} \mathrm{C}$.

5. Sobre la metodología propuesta

a. Se ha validado a nivel general mediante un incendio real

b. La validación de los modelos numéricos empleados requiere información adicional de la que no se ha dispuesto en el caso del incendio real.

\subsection{Capítulo 4. Campaña EXPerimental}

Realizada la validación general de la metodología se consideró necesario disponer de una mejor definición de la carga de fuego para poder validar los modelos de incendios y termo-mecánico. Para ello se decidió plantear una campaña experimental a pequeña escala, dado el gran despliegue de medios económicos, de instrumentación y de personal que hubiera requerido una campaña a mayor escala.

La campaña experimental constó de ocho ensayos realizados sobre la misma estructura. Todos ellos sirvieron para caracterizar cuatro escenarios de fuego (ver Figura 7-3) que sirvieron posteriormente para validar el modelo de incendios y el modelo termomecánico. 


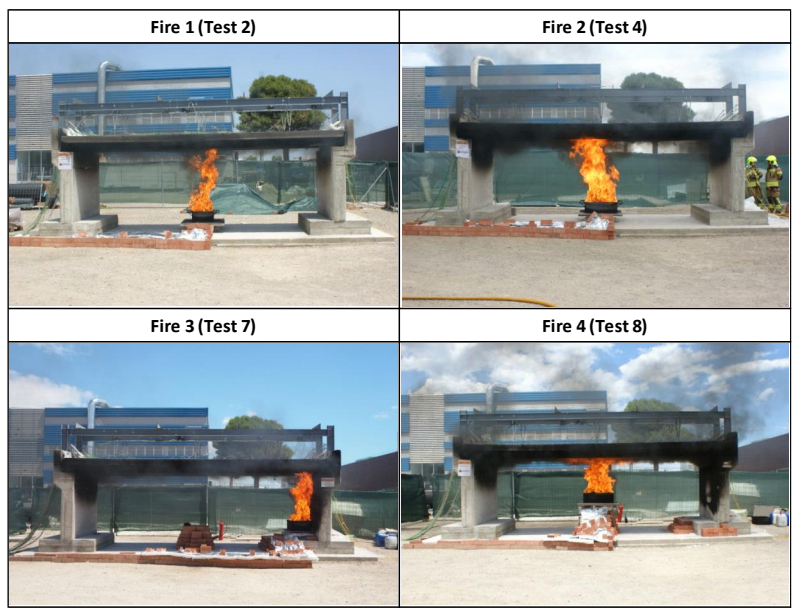

Figura 11-3. Vistas frontales de cada escenario de fuego

Las principales conclusiones del capítulo son las siguientes:

1. Sobre la tasa de liberación de calor:

a. Los valores experimentales son, en general, similares a los valores propuestos en la literatura. Se observaron diferencias significativas entre los valores experimentales y teóricos en los ensayos Test 6 y Test 7 (-17.3\% del valor promedio) y el ensayo Test $8(+18,7 \%)$ debido a la reducción de la ventilación potencial (ensayos Test 6 y Test 7) y la mayor exposición del tablero a la radiación de las llamas (ensayo Test 8).

2. Sobre los gradientes longitudinales:

a. Las temperaturas registradas en el gas varían notablemente a lo largo del eje longitudinal del puente. El gradiente térmico longitudinal promedio es de $350{ }^{\circ} \mathrm{C} / \mathrm{m}$ para el escenario de fuego Fire 4 y de 220 ${ }^{\circ} \mathrm{C} / \mathrm{m}$ para el escenario de fuego Fire 3.

b. Las temperaturas en las vigas de acero también prueban la existencia de un importante gradiente térmico longitudinal $\left(250{ }^{\circ} \mathrm{C} / \mathrm{m}\right.$ para el escenario de fuego Fire 4, $200^{\circ} \mathrm{C} / \mathrm{m}$ en los escenarios de fuego Fire 2 y Fire 3, y $60^{\circ} \mathrm{C} / \mathrm{m}$ en el escenario de fuego Fire 1.

c. Una temperatura uniforme de exposición no es realista en el ámbito de los puentes multiviga, sea cual sea su longitud.

3. Sobre las temperaturas en el acero: 
a. Las temperaturas máximas registradas en el alma y el ala inferior son muy similares y oscilan entre $220^{\circ} \mathrm{C}$ (ensayo Test 2 , escenario de fuego Fire 1) y $720^{\circ} \mathrm{C}$ (ensayo Test 8 , escenario de fuego Fire 4).

b. Las temperaturas registradas en el ala superior son significativamente más pequeñas a las anteriores al estar en contacto directo con la losa de hormigón

4. Sobre la influencia del viento:

a. Se ha registrado una flecha máxima un $29 \%$ menor en el ensayo Test 3 respecto al ensayo Test 4, debido únicamente al efecto del viento.

5. Sobre la dilatación del puente:

a. En el ensayo Test 8 se ha alcanzado una flecha en torno a los $120 \mathrm{~mm}$ en un vano de $6000 \mathrm{~mm}$, lo que supone una ratio f/L de aproximadamente $1 / 50$, que se ha recuperado por completo una vez extinguida la acción térmica.

\subsection{CAPÍTUlo 5. VALIDACión DEL MODELO DE INCENDIOS}

Mediante el empleo de los cuatro escenarios de fuego definidos en la campaña experimental, se ha validado la aplicación de modelos de CFD para el estudio de incendios de puentes y se han comprobado los límites de aplicación del modelo de Heskestad y Hamada [ref7.01]. La validación del modelo de incendios también ha permitido resaltar el efecto del viento sobre el calentamiento de la estructura (ver Figura $7-4)$.
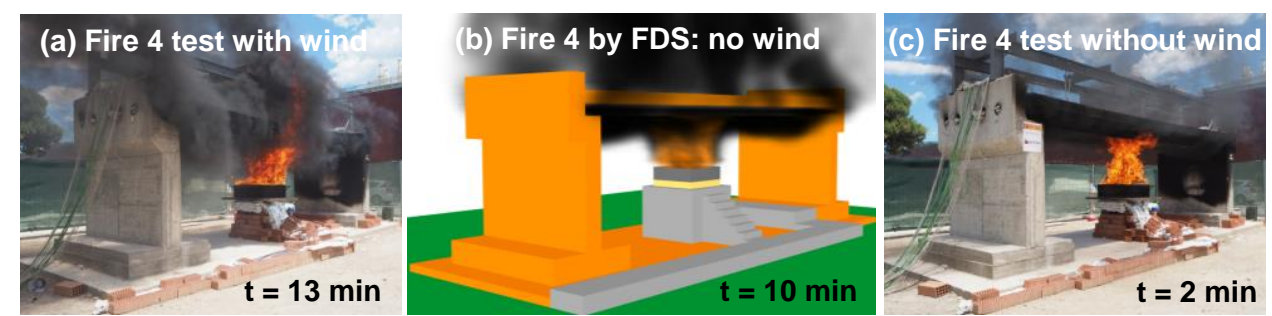

Figura 11-4. Efecto del viento en el escenario de fuego Fire 4: (a) Ensayo Test 8 con viento, (b) Simulación numérica sin viento y (c) Ensayo Test 8 sin viento.

Las principales conclusiones del capítulo son las siguientes:

1. Sobre el modelo de Heskestad y Hamada [ref7.01]:

a. Aunque fue definido originalmente para incendios no confinados, se ha comprobado cómo ofrece buenas predicciones de ensayos de fuegos en puentes con HRR entre 361 y $1130 \mathrm{~kW}$ siempre que $L_{f} / H<2$. 
b. No se puede utilizar para estudiar incendios de puentes reales directamente, ya que se desarrolló para incendios con una HRR máxima de $764 \mathrm{~kW}$ (valor muy inferior a los 100-300 MW correspondientes al incendio de un camión cisterna [ref7.02, ref7.03, ref7.04])

2. Sobre la validación del modelo de simulación de incendios con FDS:

a. Los cuatro escenarios de incendio se validaron con una incertidumbre ligeramente superior a la obtenida por McGrattan [ref7.05] atribuida al efecto del viento durante los ensayos.

b. Para reducir la incertidumbre relativa al viento se recomienda omitirlo del problema en futuras campañas experimentales realizadas en recintos donde, sin limitar la aportación de oxígeno al fuego, se limite el efecto de viento externo

3. Sobre las predicciones mediante modelos simplificado y de campo:

a. Ambos enfoques predicen adecuadamente las temperaturas del gas para los escenarios de fuego Fire 1, Fire 2 y Fire 3 una vez corregido el efecto del viento sobre las mismas.

b. Las temperaturas en el escenario de fuego Fire 4 pueden predecirse con precisión por el modelo de FDS, pero no por la correlación de Heskestad y Hamada, lo que es coherente con el hecho de que dicho escenario se encuentra fuera de los límites de aplicación de la correlación $\left(L_{f} / H>2\right)$.

\subsection{CAPítulo 6. VALIDACión del MOdelo TERMO-MECÁNICO}

Validado el modelo de simulación de incendios se realizó la validación del modelo termo-mecánico (ver Figura 7-5) mediante el ensayo Test 8 de la campaña experimental. Puesto que los ensayos planteados en la campaña experimental estuvieron centrados principalmente en la validación del modelo de simulación de incendios, las variables térmicas registradas no fueron suficientes para realizar una validación directa a partir de los registros experimentales.

Por este motivo se recurrió al modelo de incendios previamente validado para generar una exposición térmica equivalente. Para ello se redujo iterativamente la potencia del incendio durante el ensayo de forma que la exposición térmica de la viga de estudio produjese una flecha en centro-luz (CL) similar a la registrada durante los ensayos y posteriormente se comprobó que tanto las temperaturas en el acero como las temperaturas en el gas eran similares a las registradas en el ensayo Test 8 de referencia.

Durante todo el proceso que abarcó la validación del modelo termo-mecánico se pudo estudiar la utilidad de cada uno de los registros llevados a cabo en la campaña experimental de cara a su empleo en la propia validación y a la adecuación de los 
registros para futuros ensayos. Finalmente se propusieron una serie de recomendaciones de utilidad práctica para futuras campañas experimentales y de utilidad teórica para el planteamiento de guías de diseño de puentes frente al fuego.

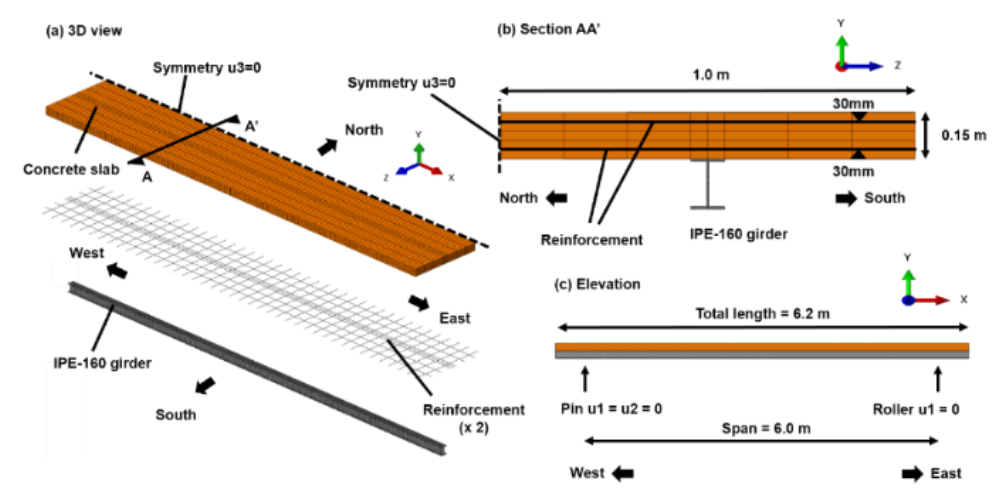

Figura 11-5. Modelo de elementos finitos de la viga sur en Abaqus: (a) Vista 3D, (b) Sección AA' y (c) Alzado.

Las principales conclusiones del presente capítulo son las siguientes:

1. Sobre el modelo termo-mecánico

a. Se ha podido reproducir adecuadamente la respuesta de la viga mixta de estudio con temperaturas en el acero hasta $600^{\circ} \mathrm{C}$.

b. Quedaría por validar este mismo modelo para un fuego más severo en el que se sometiera a la estructura a deformaciones no recuperables.

2. Sobre los registros experimentales

a. El registro de imágenes y video ha sido de gran utilidad para repasar la evolución del fuego durante el ensayo.

b. La pérdida de masa resultó:

i. Esencial en la correcta definición de las fases de crecimiento, meseta y decrecimiento de la HRR.

ii. De utilidad para entender que el viento sobrealimentó de oxígeno el fuego, reduciendo con ello la duración teórica esperada.

c. La exposición térmica:

i. No se definió por completo en el ensayo Test 8 , al registrar la temperatura del gas, pero no la de radiación.

ii. Para una completa caracterización de la exposición térmica en futuras campañas se propone el empleo de sensores que permitan registrar temperaturas adiabáticas directamente 
d. Las temperaturas en el acero:

i. Registradas mediante cámara termográfica han presentado el inconveniente de sobredimensionarse cuando las llamas se interponían en la visual entre la cámara y la viga de estudio.

ii. Registradas mediante termopares de $1.5 \mathrm{~mm}$ de diámetro en agujeros de $4 \mathrm{~mm}$ de diámetro se han visto afectadas por las temperaturas del gas y de las propias llamas. Se recomienda para futuros ensayos el empleo de orificios de diámetro muy similar al de los propios termopares.

e. La medición de flechas

i. Se ha realizado aprovechando la propia estructura a ensayar para proteger la instrumentación. Al tratarse de un ensayo no destructivo la medición ha sido un éxito sin necesidad de recurrir a protecciones adicionales.

ii. En caso de ensayos futuros donde se busque el colapso de la estructura requerirá considerar las consecuencias del colapso de la estructura sobre la instrumentación empleada.

3. Sobre el viento

a. Ha podido considerarse de forma indirecta mediante un modelo equivalente sin viento y con una tasa de liberación de calor (HRR) reducida. Con ello no se ha reproducido el comportamiento real del fuego, pero si se ha conseguido obtener una exposición térmica equivalente.

b. No solo influye en la ventilación de los humos y en la inclinación de la llama, sino que también incrementa la tasa de liberación de calor sin que ello implique necesariamente un incremento de las temperaturas de exposición.

c. Ha reducido la flecha máxima alcanzada con respecto a la predicción realizada mediante el modelo de incendios, lo que supone que la no consideración de viento queda del lado de la seguridad.

d. Es una variable cuya incorporación es compleja dada su variabilidad espacial de su magnitud y su dirección. Por ello, para futuras validaciones del modelo de incendios, antes que registrar su efecto, se recomienda imposibilitar su aparición.

\subsection{CONCLUSIONES GENERALES}

Del presente trabajo se derivan una serie de conclusiones y comentarios generales que servirán de punto de partida para próximos estudios en el ámbito del fuego en puentes. 
En el Capítulo 2, donde se expone el estado del arte actual del fuego en puentes, se ha puesto en evidencia la necesidad de adquirir un mayor entendimiento del problema que permita el desarrollo de soluciones óptimas teniendo en cuenta todas las etapas de la estructura (diseño, construcción y mantenimiento).

En el Capítulo 3 se ha abordado con éxito la reproducción de la respuesta termomecánica de un puente de $37 \mathrm{~m}$ de vano principal sometido a la acción del fuego. Sin embargo, también se ha puesto en evidencia la poca información disponible para la adecuada caracterización de un incendio real, siendo la información más útil las imágenes tomadas durante el evento del fuego. Se ha detectado, por tanto, la necesidad de validar los modelos empleados antes de (1) realizar estudios paramétricos y (2) proponer directrices y reglas de diseño aplicables en normativas.

En el Capítulo 4 se han obtenido una serie de registros experimentales que servirán de referencia para (1) validar modelos numéricos a emplear para reproducción de ensayos de fuego al aire libre (a falta de ensayos de mayor entidad), (2) futuros ensayos de mayor entidad tanto en lo que respecta a la carga de fuego como a la dimensión del puente objeto de estudio.

En el Capítulo 5 se han empleado (1) la tasa de pérdida de masa para la caracterización de la potencia de fuego y (2) las temperaturas en el gas en el entorno del puente para la validación de un modelo de incendios caracterizado a partir de: (1) la definición de la región de cálculo (volumen de control y mallado), (2) la definición geométrica del puente, (3) la definición de las propiedades térmica de los materiales del puente, (4) la definición de la reacción de combustión y (5) la definición del fuego a partir de una superficie plana horizontal y una tasa de liberación de calor por unidad de área. Destacable es el hecho de que en el modelo se ha asumido hipótesis de viento nulo. A partir de la validación de los modelos se ha podido concluir que (1) el efecto del viento en la dinámica del incendio debería estudiarse de forma independiente (una vez se haya estudiado el problema sin su consideración y propuesto modelos simplificados de aplicación al diseño de puentes) y que (2) los modelos simplificados de fuegos localizados existentes deben redefinirse (o plantear modelos alternativos) para tener en cuenta fuegos de mayores potencias, como los que se derivan de incendios en camiones cisterna cargados de combustible.

En el Capítulo 6 se ha realizado una validación del modelo termo-mecánico de puente sometido a un fuego de en torno a 1.3 MW de potencia pudiendo analizar en el proceso la utilidad de los registros recopilados durante el ensayo Test 8. Esto ha permitido: (1) dar por bueno el modelo termo-mecánico definido y (2) plantear procedimientos de resolución del problema alternativos a la validación tradicional y (3) analizar uno por uno los registros realizados en el Capítulo 4, proponiendo recomendaciones para la 
definición de futuras campañas experimentales. El Capítulo 6 pone a disposición de la comunidad científica un modelo de referencia para reproducir eventos de fuego a mayor escala, así como para definir futuras campañas experimentales en el ámbito del fuego en puentes.

El trabajo en su conjunto ha permitido entender mejor el problema y los datos necesarios para la caracterización de los modelos numéricos empleados para reproducirlo. Los resultados aquí presentados servirán para que en futuros trabajos los investigadores puedan centrar sus esfuerzos en el desarrollo de directrices y recomendaciones de diseño, teniendo en cuenta para ello las problemáticas ya abordadas en el presente documento.

\subsection{REFERENCIAS}

[ref7.01] Heskestad G, Hamada T. Ceiling Jets of Strong Fire Plumes. Fire Safety Journal 21:69-82. 1993.

[ref7.02] Cheong MK, Spearpoint M J, Fleischmann CM. Design fires for vehicles in road tunnels. 7th International Conference on Performance-Based Codes and Fire Safety Design Methods. 2008.

[ref7.03] Ingason H. Design fires in tunnels. 2nd International Symposium. Safe \& Reliable Tunnels Innovative European Achievements, Lausanne. 2006.

[ref7.04] Rivkin CH. Section 21. Transportation Fire Safety. Fire Protection Handbook. NFPA 502, Standard for Road Tunnels, Bridges and Other Limited Access Highways. 2008.

[ref7.05] McGrattan K, Hostikka S, McDermott R, Floyd J, Weinschenk C, Overholt K. Fire Dynamics Simulator Technical Reference Guide. Volume 3: Validation (version 6). NIST Special Publication 1018-3, Gaithersburg, MD, USA. 2013. 


\section{ANEXO 2. JUSTIFICACIÓN DE IMPACTO}

A continuación, se muestra la justificación del índice de impacto de las publicaciones publicadas en esta tesis a partir del "Journal of Citation Reports" 

De los tres artículos publicados, los dos primeros son Q1 de acuerdo a las revistas y los años de publicación y el tercero se espera que sea también Q1 teniendo en cuenta que ha sido aceptado en 2018 y el factor de impacto del 2017 para esta revista se encuentra en 87.791 para el campo de ingeniería al que pertenece de acuerdo con esta tesis.

\section{Revista Engineering Structures (Q1):}

(2014) Alós-Moya J., Payá-Zaforteza I., Garlock M.E.M., Loma de Osorio E., Schiffner E., Hospitaler A. "Analysis of a bridge failure due to fire using computational fluid dynamics and finite element models", Engineering Structures (68) pp96-110

En el año 2014, año en el que se publicó el artículo el percentil medio del Journal Impact Factor de la revista era de $\mathbf{8 3 . 6 0 0}$ en el campo de la ingeniería civil, lo que supone que la revista se encuentra en el primer cuartil (Q1).

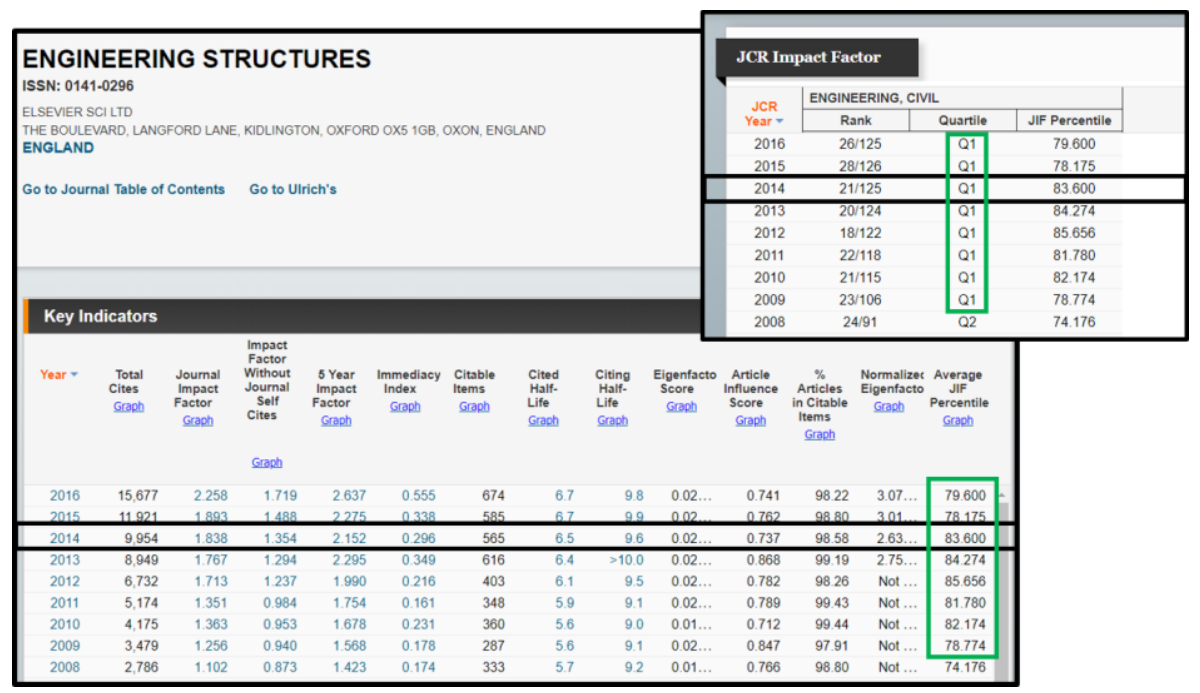

Figura 12-1. Factor de impacto de Engineering Structures.

El artículo ha recibido en el periodo comprendido entre 2014 en que fue publicado y el 11 de Noviembre de 2018 en que se realiza esta consulta 27 citas de otros documentos, lo que hace que se encuentre en el percentil $91 \%$ de ingeniería (solo un 9\% de los artículos han recibido más citas) teniendo en cuenta artículos de la misma fecha y del mismo tipo. 
Analysis of a bridge failure due to fire using computational fluid dynamics and finite element models Back to article (2014) Engineering Structures, 68 pp. 96-110

\section{Scopus Metrics 2}

\begin{tabular}{|l|l|l|l|}
\hline $\begin{array}{l}\text { Citation Count } \\
27\end{array}$ & $\begin{array}{l}\text { Field-Weighted Citation Impact } \\
3.12\end{array}$ & $\begin{array}{l}\text { Citation Benchmarking } \\
91 \text { th percentile } \\
\text { Compared to Engineering articles of same age } \\
\text { and document type }\end{array}$ \\
\hline
\end{tabular}

Cited by

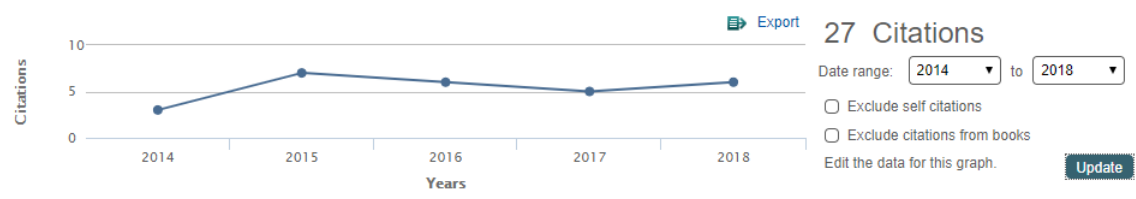

Figura 12-2. Métricas de Scopus para el primer artículo de la tesis. 


\section{Journal of Constructional Steel Research (Q1)}

(2017) Alós-Moya J., Payá-Zaforteza I., Hospitaler A., Rinaudo P. "Valencia bridge fire tests: Experimental study of a composite bridge under fire", Journal of Constructional Steel Research (138) pp538-554

En el año 2017, año en el que se publicó el artículo el percentil medio del Journal Impact Factor de la revista era de $\mathbf{8 0 . 8 5 9}$ en el campo de la ingeniería civil, lo que supone que la revista se encuentra en el primer cuartil (Q1).

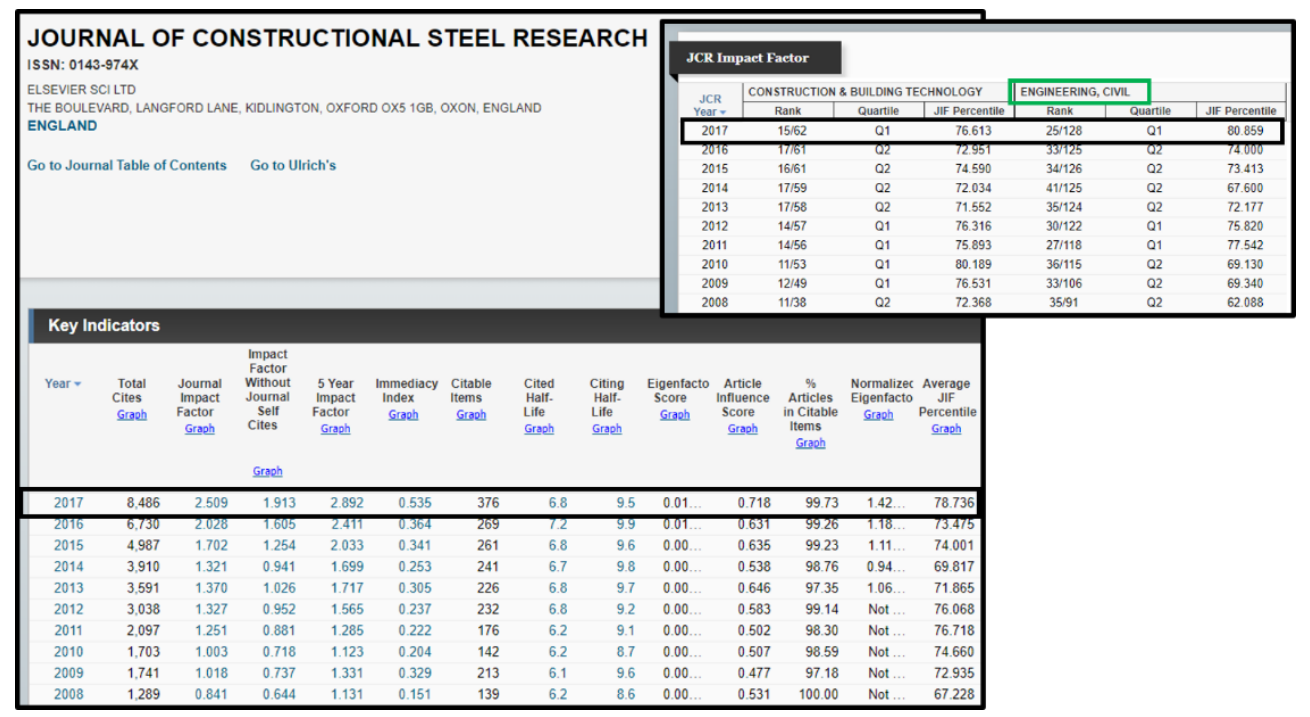

Figura 12-3. Factor de impacto del Journal of Constructional Steel Research. 


\section{Journal of Advances in Engineering Software (Q1)}

(2018) Alós-Moya J, Payá-Zaforteza I, Hospitaler A, Loma de Osorio E. "Valencia bridge fire tests: Validation of simplified and advanced numerical approaches to model bridge fire scenarios", Advances in Engineering Software (Accepted in November 2018)

En el año 2018, año en el que se aceptó el artículo todavía no se ha obtenido el percentil medio del Journal Impact Factor de la revista. Sin embargo, el año anterior este percentil era de 87.791 en el campo de ingeniería, lo que supuso que la revista se encontraba en el primer cuartil (Q1) en el ámbito en el que se enmarca esta publicación.

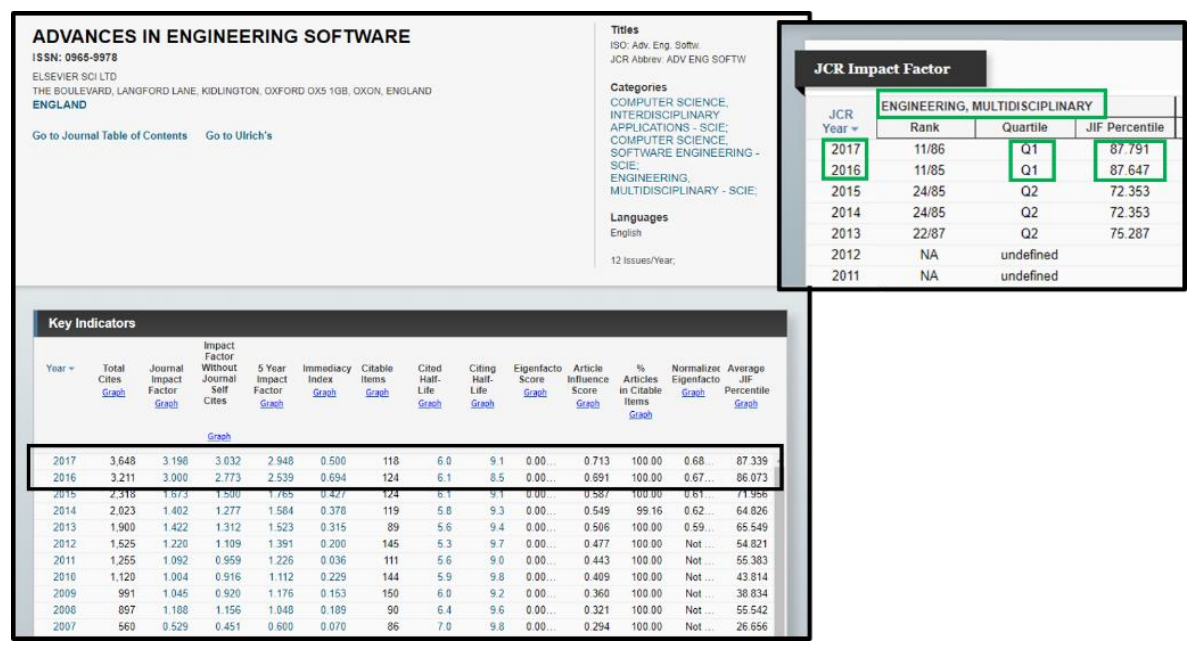

Figura 12-4. Factor de impacto del Journal of Advances in Engineering Software. 



\section{AneXo 3. CARTAS DE ACEPTACIÓN Y ARTÍCULOS PUBLICADOS}

En el presente anexo se incluye documentación relativa a la aceptación y publicación de artículos. 



\title{
Engineering Structures (2014)
}

(2014) Alós-Moya J., Payá-Zaforteza I., Garlock M.E.M., Loma de Osorio E., Schiffner E., Hospitaler A. "Analysis of a bridge failure due to fire using computational fluid dynamics and finite element models", Engineering Structures (68) pp96-110

\section{Carta de aceptación}

$6 / 18 / 2018$

Gmail - News about our bridge fire paper

\author{
News about our bridge fire paper \\ 1 message \\ Ignacio Paya Zaforteza <igpaza@upvnet.upv.es> \\ Mon, Feb 24, 2014 at 6:48 PM \\ To: Maria Garlock<mgarlock@princeton.edu>,Jose Alos <joalmo11@gmail.com>, Antoni o Hospitaler \\ <ahospitaler@cst.upv.es>, dschiffner@thorntontomasetti.com, Eduardo Fuego <edlobla@gmail.com>
}

Dear co-authors,

We have very good news! The paper about the Alabama bridge has been accepted! (see the mail below).

I will keep you posted on the paper proofs and the rest of the publishing process

Best,

Nacho

Ignacio Paya-Zaforteza, Ph.D., P.E.

Associate Professor

Universitat Politecnica de Valencia

Department of Construction Engineering - ICITECH Camino de Vera S/N

Phone: +34 +3496387 7000 - Ext.: 75623

46022 Valencia, Spain

Forwarded message

From: "Herbert Mang" < Herbert.Mang@tuwien.ac.at>

To: igpaza@cst.upv.es

Cc:

$\mathrm{BCC}$

Date: 24 Feb 2014 14:34:04 +0000

Subject: Your Submission

Ms. Ref. No: ENGSTRUCT-D-13-01132R1

Title: Analysis of a bridge failure due to fire using computational fluid dynamics and finite element models

Engineering Structures

Dear Dr. Paya-Zaforteza,

The paper "Analysis of a bridge failure due to fire using computational fluid dynamics and finite element models" has been accepted for publication in Engineering Structures.

Proofs and a copyright form will be send directly to you by Elsevier prior to publication.

When your paper is published on ScienceDirect, you want to make sure it gets the attention it deserves. To help you get your message across, Elsevier has developed a new, free service called AudioSlides: brief, webcast-style presentations that are shown (publicly available) next to your published article. This format gives you the opportunity to explain your research in your own words and attract interest. You will receive an invitation email to create an AudioSlides presentation shortly. For more information and examples, please visit http $/ /$ www.elsevier.com audioslides. 


\section{Portada del artículo publicado}

Engineering Structures 68 (2014) 96-110

Contents lists available at ScienceDirect

Engineering Structures

ELSEVIER

journal homepage: www.elsevier.com/locate/engstruct

\section{Analysis of a bridge failure due to fire using computational fluid dynamics and finite element models}

J. Alos-Moya ${ }^{\text {a }}$, I. Paya-Zaforteza ${ }^{\text {a,* }}$, M.E.M. Garlock ${ }^{\text {b }}$, E. Loma-Ossorio ${ }^{\text {c }}$, D. Schiffner ${ }^{\text {d }}$, A. Hospitaler ${ }^{\text {a }}$

a ICTECH, Departamento de Ingeniería de la Construcción, Universitat Politècnica de València, Camino de Vera s/n, 46071 Valencia, Spain

${ }^{b}$ Department of Civil and Environmental Engineering, Princeton University, 59 Olden Street, Princeton, NJ 08544, USA

${ }^{c}$ Fire Department of Valencia, Parque Central de Bomberos, Av de la Plata 20, 46013 Valencia, Spain

${ }^{\circledR}$ Thomton Tomasetti, Market St 1750, Philadelphia, PA 19103, USA

\section{A R T I C L E I N F O}

\section{Article history:}

Received 24 September 2013

Revised 21 January 2014

Accepted 24 February 2014

\section{Keywords:}

Fire

Bridge

Steel girder bridge

I-65 overpass

Performance-based design

\section{A B S T R A C T}

Bridge fires are a major concern because of the consequences that these kind of events have and because they are a real threat. However, bridge fire response is under researched and not covered in the codes. This paper studies the capabilities of numerical models to predict the fire response of a bridge and provides modeling guidelines useful for improving bridge design. To reach this goal, a numerical analysis of the fire of the I-65 overpass in Birmingham, Alabama, USA in 2002 is carried out. The analyses are based on computational fluid dynamics (CFD) for creating the fire model, and finite element (FE) software for obtaining the thermo-mechanical response of the bridge. The models are validated with parametric studies that consider heat release rate of the spilled fuel, discretization of the fire temperature in the transition from CFD to FE modeling, and boundary conditions. The validated model is used in a study to evaluate the influence of fire scenario (CFD versus standard fires), and live load. Results show that numerical models are able to simulate the response of the bridge and can be used as a basis for a performancebased approach for the design of bridges under fire. Additionally, it is found that applying the Eurocode standard and hydrocarbon fires along the full length of the bridge does not adequately represent a real bridge fire response for medium-long span bridges such as this case study. The study also shows that live loads essentially do not influence the response of the bridge.

2014 Elsevier Ltd. All rights reserved. 


\title{
Journal of Constructional Steel Research (2017)
}

(2017) Alós-Moya J., Payá-Zaforteza I., Hospitaler A., Rinaudo P. "Valencia bridge fire tests: Experimental study of a composite bridge under fire", Journal of Constructional Steel Research (138) pp538-554

\section{Carta de aceptación}

\section{Fwd: Your manuscript JCSR_2017_367_R1 has been accepted}

\author{
1 message
}

Ignacio Paya Zaforteza <igpaza@upvnet.upv.es>

Mon, Apr 23, 2018 at 10:18 PM To: joalmo11@gmail.com

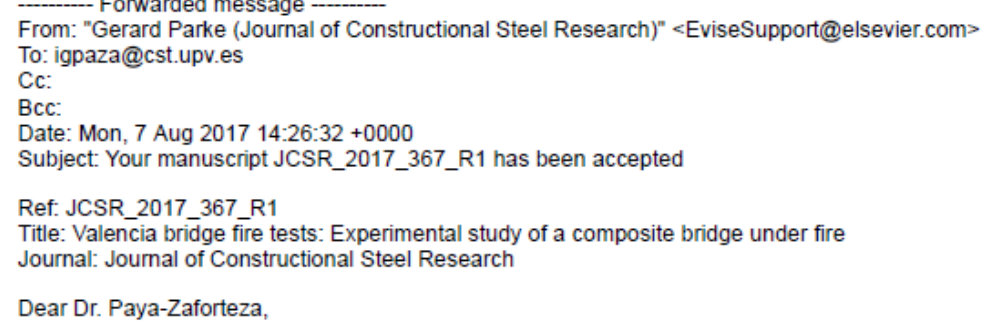

Thank you for submitting your work to Journal of Constructional Steel Research. We hope you consider us again for future submissions.

Kind regards,

Gerard Parke

Editor

Journal of Constructional Steel Research

Comments from the editors and reviewers:

Have questions or need assistance?

For further assistance, please visit our Customer Support site. Here you can search for solutions on a range of topics, find answers to frequently asked questions, and learn more about EVISE® via interactive tutorials. You can also talk $24 / 5$ to our customer support team by phone and $24 / 7$ by live chat and email.

Copyright () 2017 Elsevier B.V. | Privacy Policy

Elsevier B.V., Radarweg 29, 1043 NX Amsterdam, The Netherlands, Reg. No. 33156677. 


\section{Portada del artículo publicado}

Journal of Constructional Steel Research 138 (2017) 538-554

Contents lists available at ScienceDirect

Journal of Constructional Steel Research

Valencia bridge fire tests: Experimental study of a composite bridge under fire

Jose Alos-Moya, Ignacio Paya-Zaforteza *, Antonio Hospitaler, Paula Rinaudo

ICITECH, Departamento de Ingeniería de la Construcción, Universitat Politècnica de València, Camino de Vera s/n, 46022 Valencia, Spain

A R T I C LE I N F O

\section{Article history:}

Received 12 May 2017

Received in revised form 31 July 2017

Accepted 7 August 2017

Available online xxxx

\section{Keywords:}

Valencia bridge fire tests

Steel-concrete composite bridge

Mass loss rate

Bridge fire

Bridge resilience

\section{A B S T R A C}

The consequences of bridge fires and the lack of guidelines on the evaluation of the fire resistance of bridges have triggered a lot of recent research. Most of these studies are based on numerical models and thus need validation by experimental studies.

This paper aims to bridge this gap by describing a battery of open air fire tests carried out under an experimental bridge at the Universitat Politècnica de València in Valencia, Spain. The bridge, with a $6 \mathrm{~m}$ span and a composite deck with two steel I-girders supporting an RC slab, was submitted to four different fire scenarios similar to those of real bridge fires, although smaller in magnitude. Results show that: (a) maximum gas temperatures are reached in the region between the I-girders, (b) as gas and steel temperatures vary significantly along the longitudinal axis of the bridge, it is unrealistic to assume a longitudinally uniform gas or girder temperature (c) temperatures in the bottom flange and the web of the l-girders are very similar and significantly higher than top web temperatures, and (d) the magnitude of the fire load and its position are key factors in the bridge response. This study is of major importance as it enables the validation of the numerical models used in bridge fire engineering and is a crucial step towards the development of a performance-based approach for the design of bridges against fires. The information given will also be useful to those interested in carrying out open air experimental bridge fire tests. 


\section{Journal of Advances in Engineering Software (Q1)}

(2018) Alós-Moya J, Payá-Zaforteza I, Hospitaler A, Loma de Osorio E. "Valencia bridge fire tests: Validation of simplified and advanced numerical approaches to model bridge fire scenarios", Advances in Engineering Software (Accepted in November 2018)

\section{Carta de aceptación}

$11 / 11 / 2018$

MGmail
Gmail - Fwd: Your manuscript ADES_2018_639_R1 has been acoepted

\section{Fwd: Your manuscript ADES_2018_639_R1 has been accepted}

1 message

Ignacio Paya Zaforteza <igpaza@upvnet.upv.es>

Tue, Nov 6, 2018 at 9:42 AM To: joalmo11@gmail.com

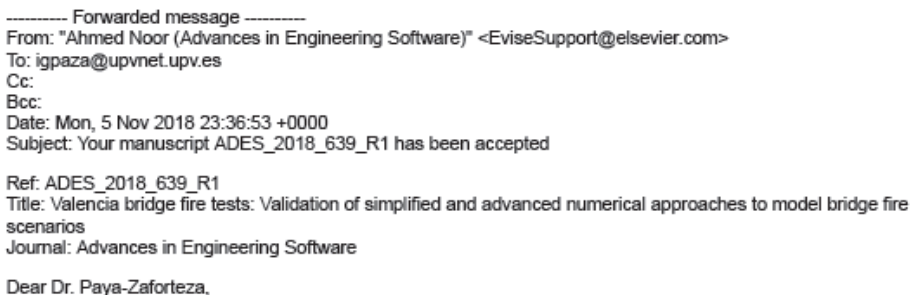

I am pleased to inform you that your paper has been accepted for publication. My own comments as well as any reviewer comments are appended to the end of this letter. Now that your manuscript has been accepted for publication it will proceed to copy-editing and production.

Thank you for submitting your work to Advances in Engineering Software. We hope you consider us again for future submissions.

Kind regards,

Professor Ahmed Noor

Editor

Advances in Engineering Software

Comments from the editors and reviewers:

- Reviewer 1

$$
\text { - }
$$

The remarks did it previously by this reviewer were correctly fixed. Therefore, I consider now that this paper is perfectly good for publication

- Reviewer 2

- The reviewer thanks the authors for their thorough responses. All comments have been adequately addressed and the reviewer recommends publication of the paper.

- Reviewer 3

- Thank you for your thorough response - I have no further comments.

Have questions or need assistance?

For further assistance, please visit our Customer Support site. Here you can search for solutions on a range of topics, find answers to frequently asked questions, and learn more about EVISEs via interactive tutorials. You can also talk $24 / 5$ to our customer support team by phone and $24 / 7$ by live chat and email. 


\section{Portada del artículo aceptado}

Advances in Engineering Software xxx (2018) xxx-xxx

Contents lists available at ScienceDirect

Advances in Engineering Software

journal homepage: www.elsevier.com

Research paper

Valencia bridge fire tests: Validation of simplified and advanced numerical approaches to model bridge fire scenarios

J. Alos-Moya, I. Paya-Zaforteza*, A. Hospitaler, E. Loma-Ossorio

ICITECH, Departamento de Ingeniería de la Construcción, Universitat Politècnica de València, Camino de Vera s/n, 46071 Valencia, Spain

\section{ARTICLE INFO}

\section{Keywords:}

Numerical modeling

Valencia bridge fire test

Composite (steel-concrete) bridge

Mass loss rate

Bridge fire

Bridge resilience
A B S T R A C T

Bridge fires are a major concern and the subject of many studies that use numerical models. However, experimental studies are still required to test the validity of these numerical models and improve their accuracy. This paper uses temperature results of the Valencia bridge fire tests carried out at the Universitat Politècnica de València, in Valencia (Spain) to calibrate the fire models that constitute the first step in modeling any bridge fire event. The calibration is carried out by both a simplified approach (Heskestad and Hamada's correlation) and advanced numerical models (Computational Fluid Dynamics models built with the Fire Dynamics Simulator -FDS- software).

The Valencia bridge fire tests involved four fire scenarios under a composite bridge with Heat Release Rate (HRR) values between 361 and $1352 \mathrm{~kW}$. The results show that applying Heskestad and Hamada's correlation gave good results when used within its limits ( HRR $<0.764 \mathrm{MW}$ ) but did not work well beyond them, which means it would be suitable for planning reduced scale bridge fire tests but not in the analysis of real bridge fires. On the other hand, FDS provides good predictions of the temperatures and can be used to study bridge fire responses. This work is therefore an important step forward in the study of bridge fires and towards the improvement of the resilience of infrastructure networks vis-à-vis fire hazards. It also highlights the problems that can arise in fire tests in the open air, the influence of the wind being of critical importance. 



\section{AnEXo 4. ARtículos}

A continuación, se presentan los tres artículos publicados de los que forma parte esta tesis en su versión de autor 
Alos-Moya J, Payá-Zaforteza I, Garlock MEM,

Loma de Osorio E, Schiffner D, Hospitaler A (2014)

"Analysis of a bridge failure due to fire using computational fluid dynamics and finite element models"

Engineering Structures. Volume 68. Pages 91-110 



\section{Analysis of a bridge failure due to fire using computational fluid dynamics and finite element models}

J. Alos-Moya ${ }^{1}$, I. Paya-Zaforteza ${ }^{1}$, M.E.M. Garlock ${ }^{2}$, E. Loma de Osorio ${ }^{3}$, D. Schiffner ${ }^{4}$, A. Hospitaler ${ }^{1}$

${ }^{1}$ ICITECH, Departamento de Ingeniería de la Construcción, Universitat Politècnica de València. Camino de Vera s/n, 46071 Valencia, Spain

${ }^{4}$ Department of Civil and Environmental Engineering, Princeton University, 59 Olden Street, Princeton, NJ, 08544, USA

${ }^{3}$ Fire Department of Valencia, Parque Central de Bomberos, Av de la Plata 20, 46013, Valencia, Spain

${ }^{4}$ Thornton Tomasetti, Market St 1750 Philadelphia, PA, 19103, USA

Authors e-mail addresses:

José Alos-Moya: $\quad$ joalmo11@upv.es

Ignacio Paya-Zaforteza: igpaza@ upv.es

Maria Garlock: $\quad$ mgarlock@ princeton.edu

Daniel Schiffner: $\quad$ dschiffner@thorntontomasetti.com

Eduardo Loma de Osorio eloma-ossorio@ valencia.es

Antonio Hospitaler ahospitaler@ upv.es 


\begin{abstract}
Bridge fires are a major concern because of the consequences that these kind of events have and because they are a real threat. However, bridge fire response is an under researched topic not covered in the codes. This paper studies the capabilities of numerical models to predict the fire response of a bridge and provides modeling guidelines useful for improving bridge design. To reach this goal, a numerical analysis of the fire of the I-65 overpass in Birmingham, Alabama, USA in 2002 is carried out. The analyses are based on computational fluid dynamics (CDF) for creating the fire model, and finite element (FE) software for obtaining the thermo-mechanical response of the bridge. The models are validated with parametric studies that consider heat release rate of the spilled fuel, discretization of the fire temperature in the transition from CFD to FE modeling, and boundary conditions. The validated model is used in a study to evaluate the influence of fire scenario (CFD versus standard fires), and live load. Results show that numerical models are able to simulate the response of the bridge and can be used as a basis for a performance-based approach for the design of bridges under fire conditions. Additionally, it is found that applying the Eurocode standard and hydrocarbon fires along the full length of the bridge does not adequately represent a real bridge fire response for medium-long span bridges such as this case study. The study also shows that live loads essentially do not influence the response of the bridge.
\end{abstract}

Keywords: fire, bridge, CFD, steel girder bridge, I-65 overpass, performance-based design.

* Corresponding author. Tel: +34 963877562; fax: +34 963877568 


\section{Introduction}

Bridges are a critical component of the transportation system whose loss can result in important social and economical consequences (e.g. Chang and Nojima [1], Zhu et al. [2]). Therefore, a lot of effort has been paid to understand and predict the effects on bridges of accidental extreme load events such as earthquakes, winds, scour, and ship collisions (e.g. Ghosn et al. [3], Cheng [4]). Fire is an additional major hazard in bridges for two reasons. First, traffic on bridges damaged by fire is usually hard to detour and affects the traffic quality in the region. For example, the collapse of two spans of the MacArthur Maze in Oakland, USA on April 29th 2007 due to a fire resulted in repairs and rebuilding operations costing more than US $\$ 9$ million [5,6]. Another example is provided by a bridge fire caused by a dump truck in Robbinsville (NJ, USA) on October 3rd 2012. This fire forced to close the Interstate 95 Highway as well as $79 \mathrm{~km}$ of the New Jersey Turnpike, one of the major highways in the US East Coast, and affected the traffic in areas located hundreds of kilometers away of the accident in the states of Delaware and Conneticut. Secondly, bridge fires are a real threat as shown by data of a voluntary bridge failure survey, which was responded by the departments of transportation of 18 US states [8]. This survey was conducted in 2011 and collected data related to 1746 bridge failures and showed that fire had caused more bridge collapses than earthquakes (seismic states like California participated in the survey).

Despite its importance, bridge fires have got very little attention in the past as proved by Garlock et al. [9]. In fact, fire safety engineering and structural fire engineering have mainly been concerned with building and tunnel fires (e.g. Buchanan [10], Couto et al. [11], Quiel et al. [12], Gunalan and Mahendran [13], López-Colina et al. [14], Moliner et al.[15] and Seif and McAllister [16]), but bridge fires are different to those and deserve a particular approach. This is due to several reasons such as the cause of fire, the fire loads, the fire ventilation conditions, the use of fire protection, and the type of connections among structural members used (see Paya-Zaforteza and Garlock [17] for more details).

Within this general context, and using a case study, this paper (a) delves into the fire response of steel girder composite bridges as this type of bridge is widely used [18] and is especially vulnerable to fire events [9], and (b) illustrates modeling techniques that can be used to predict the fire response of steel bridges. To reach this goal, the authors have performed a numerical investigation of the behavior of the I-65 overpass in Birmingham (AL, USA) during the fire event happened on January $5^{\text {th }} 2002$. The event resulted in the demolition of the overpass and the rebuilding of a new structure and affected highways carrying 240,000 vehicles per day. The numerical investigation is based on data provided by the Alabama Department of Transportation (ALDOT) and comprises a fire model of the event using computer fluid dynamics (CFD) techniques 
with the software FDS [19], and a thermo-mechanical model of the response of the bridge using Abaqus [20]. Numerical results were validated by comparison with the information provided by ALDOT which (a) enables a better understanding of the advantages and the limitations of numerical models to explain the fire response of bridges and (b) paves the way for the use of these models to study the improvement of the fire response of bridges in high fire risk situation. This kind of knowledge is of major importance for two reasons. First, previous research (see e.g. Payá-Zaforteza and Garlock [17], Aziz and Kodur [21]) is scarce and based more on standard fires or predefined fire events, than on the analysis of real cases and therefore has limitations. And second, it is difficult to conduct full scale experimental studies on bridges because of the dimensions of their structural members and the fire loads required.

\section{Case study}

The I-65 overpass is a three spans bridge located in Birmingham (Alabama, USA) which enables the Interstate I-65 North highway to cross over the I-65 Interstate South highway. The original design of the bridge had a total length of $88.53 \mathrm{~m}$. distributed in a central span of $37.32 \mathrm{~m}$. and two lateral spans of 25.91 and $25.30 \mathrm{~m}$. (see Fig. 1). Each span was a simply supported deck with a composite cross section defined by a reinforced concrete slab structurally connected with shear studs to built-up I-sections made of A36 steel.

Fig. 1c shows the cross section of the central span which was the span that experienced the most damage during the fire. It had seven built up I-girders with a variable depth between $1.442 \mathrm{~m}$ (mid-span section) and $1.432 \mathrm{~m}$ (supports section). The girders supported a reinforced concrete slab $15.40 \mathrm{~m}$. wide having an average depth of $0.16 \mathrm{~m}$. Fig. 2 provides the geometric definition of Girder 1 which experienced the largest deflections during the fire event. Girder 1 had a total of 34 stiffeners. Four of them were located on the girder supports and had a thickness of $25.4 \mathrm{~mm}(1 \mathrm{inch})$ and the rest were located on the side of Girder 1 facing Girder 2 and had a thickness of $11 \mathrm{~mm}$. Cross braces were placed every $6.2 \mathrm{~m}$. and at the supports to provide lateral stability to the bridge deck. There were two expansion joints between the central span and the lateral spans each one having a width of $38 \mathrm{~mm}$.

About 10:15 in the morning on January 5th 2002 a tanker truck traveling North on the I65 carrying $37.5 \mathrm{~m}^{3}$ of gasoline, swerved and crashed into the piers supporting the North East end of the central span. The columns survived the impact because they were protected by a $0.50 \mathrm{~m}$ height wall but when the truck and the spilled fuel caught fire under the overpass, the composite bridge suffered serious damage after some minutes (see Fig. 3). When the fire department quelled the fire, the girder of the central span named Girder 7 in Fig. 1c had small deflections (see Fig. 3b) but Girder 1 was very damaged and had deflections of almost $2.5 \mathrm{~m}$ in a section located around $15 \mathrm{~m}$. from its 
North end (Fig. 3a) [22]. The bridge deck could not be rehabilitated and was demolished and replaced by a new precast prestressed concrete deck. The new structure was opened to traffic 54 days after the accident. The cost resulting from closure of the overpass was estimated at 100,000 US \$ per day $(5,400,000$ US $\$$ in total) and the cost of the new bridge was $3,396,421$ US $\$[22,23]$. Therefore, the final cost of the accident can be estimated to be around 8.8 US \$ millions.

In the next few sections a numerical analysis of the Alabama case study is carried out in three steps. First, a model of the fire event is built with the computer fluid dynamics software FDS [19] (Section 3). Then, temperatures in the most fire-exposed girder of the overpass are obtained through a thermal analysis with the software Abaqus [20] (Section 4.1). Finally, the structural response of the most exposed girder is obtained using Abaqus [20] and considering non-linearities (geometrical and mechanical) as well as temperature dependent material properties (Section 4.2).

\section{Computer fluid dynamics (CFD) Model}

A fire model of the event was developed with the software Fire Dynamics Simulator (FDS) [19]. FDS is a software designed to predict the values of fire engineering related variables such as temperatures, heat fluxes or gas pressures in fire events. It is based on CFDs techniques and contains large eddy simulation (LES) turbulence models. The software has been developed at the National Institute of Standards and Techonolgy (NIST) of the USA and has been extensively validated experimentally [25].

Building a FDS model requires defining: (1) a control volume with its boundary conditions which represents the volume where all the analysis will be carried out, (2) a geometry included in the control volume which is submitted to fire load, (3) a mesh or a discretization of the control volume, (4) material properties (conductivity, density, specific heat and emissivity), (5) fire sources, (6) a combustion model, and (7) sensors or elements of the model where outputs of the analysis (e.g. temperatures) are recorded. All the FDS models were run as a MPI parallel job on a cluster made of HP Proliant DL 580 servers (4 six-core AMD Opteron Model 8439 SE), under a Torque resource manager and scheduler. The resources asigned were 16 cores and 8 GB RAM per core. A typical simulation took three days and four hours.

\subsection{Control volume}

The control volume must be wide enough to adequately represent the volume affected by the fire but small enough to enable the model to be run in a reasonable computing time. Fig. 4 shows the control volume used in this research as well as its boundary conditions. It contains the I- 65 overpass as well as its approaches and surroundings, and 
has plan dimensions of $115.2 \mathrm{~m}$ per $39.6 \mathrm{~m}$ and a height of $16.2 \mathrm{~m}$. The volume has a total of $6,998,400$ parallelepiped cells, having all the cells dimensions of $0.24 \mathrm{~m}$ per 0.22 $\mathrm{m}$ per $0.20 \mathrm{~m}$. The overpass geometry was obtained from the original construction drawings of the bridge provided by ALDOT and was simplified as detailed in [26].

(a)

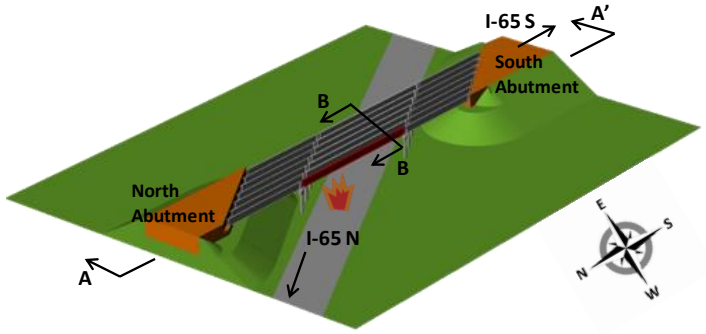

(b)

Section A-A

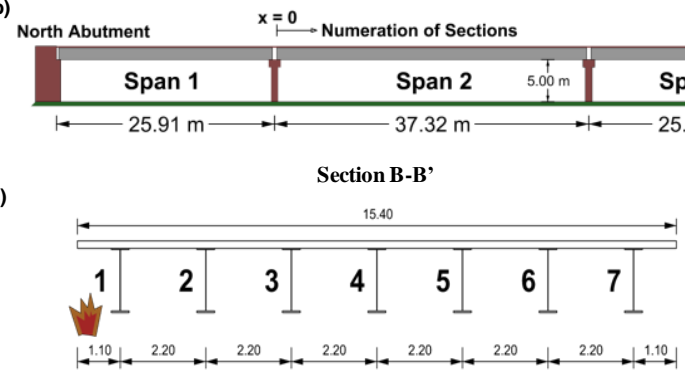

Figure 1. I-65 overpass: (a) general view, (b) elevation, (c) cross section
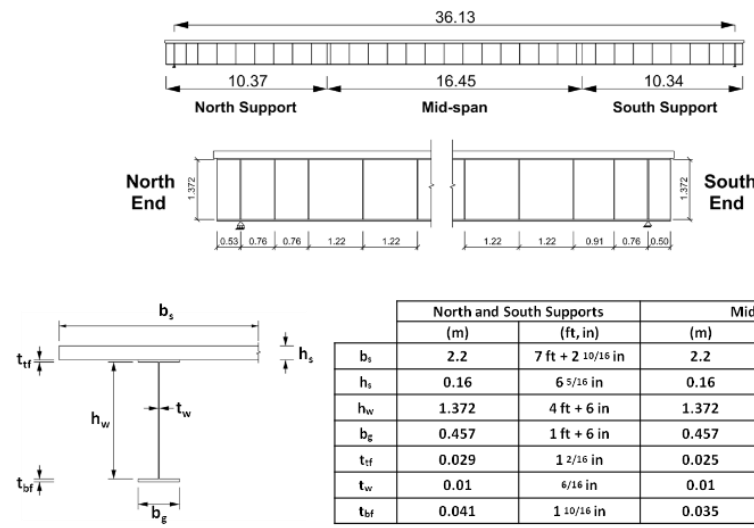

\begin{tabular}{|c|c|c|c|c|}
\cline { 2 - 5 } \multicolumn{1}{c|}{} & \multicolumn{2}{c|}{ North and South Supports } & \multicolumn{2}{c|}{ Mid-Span } \\
\cline { 2 - 5 } \multicolumn{1}{c|}{} & $(\mathrm{m})$ & $(\mathrm{ft}$, in) & $(\mathrm{m})$ & $(\mathrm{ft}$, in) \\
\hline $\mathrm{b}_{\mathrm{s}}$ & 2.2 & $7 \mathrm{ft}+210 / 16 \mathrm{in}$ & 2.2 & $7 \mathrm{ft}+210 / 16 \mathrm{in}$ \\
\hline $\mathrm{h}_{\mathrm{s}}$ & 0.16 & $65 / 16 \mathrm{in}$ & 0.16 & $65 / 16 \mathrm{in}$ \\
\hline $\mathrm{h}_{\mathrm{w}}$ & 1.372 & $4 \mathrm{ft}+6 \mathrm{in}$ & 1.372 & $4 \mathrm{ft}+6 \mathrm{in}$ \\
\hline $\mathrm{b}_{\mathrm{g}}$ & 0.457 & $1 \mathrm{ft}+6 \mathrm{in}$ & 0.457 & $1 \mathrm{ft}+6 \mathrm{in}$ \\
\hline $\mathrm{t}_{\mathrm{tf}}$ & 0.029 & $12 / 16 \mathrm{in}$ & 0.025 & $1 \mathrm{in}$ \\
\hline $\mathrm{t}_{\mathrm{w}}$ & 0.01 & $6 / 16 \mathrm{in}$ & 0.01 & $6 / 16 \mathrm{in}$ \\
\hline $\mathrm{t}_{\mathrm{bf}}$ & 0.041 & $110 / 16 \mathrm{in}$ & 0.035 & $16 / 16 \mathrm{in}$ \\
\hline
\end{tabular}

Figure 2. I-65 overpass. Elevation and geometric definition of Girder 1. Except on supports, stiffeners were located only in the side of Girder 1 facing Girder 2. 
The size of the control volume and the size of the FDS mesh were obtained through a three steps sensitivity study. Firstly, the FDS mesh was fixed and the size of the control volume was obtained (step 1). Secondly, the size of the control volume was fixed and the FDS mesh was refined (step 2). Thirdly, it was necessary to check that the control volume did not have to be modified due to changes in the FDS mesh between step 1 and step 2 (step 3). These steps are described next.

- $\quad$ Step 1 .

The initial dimensions of the control volume were $115.2 \mathrm{~m} \mathrm{x} 32 \mathrm{~m}$ x $12 \mathrm{~m}$ along the $\mathrm{x}, \mathrm{y}$ and $\mathrm{z}$-directions respectively. A value of $115.2 \mathrm{~m}$ was chosen for the control volume length to include the full bridge as well as part of its approaches. By selecting a $32 \mathrm{~m}$ control volume width, the east border of the control volume was $3 \mathrm{~m}$ away from the east side of the bridge and the west border was $3 \mathrm{~m}$ away from the further west point of the fire footprint, what the authors considered a reasonable starting point. Finally, the maximum level ( $\mathrm{z}$ coordinate) of the control volume was initially chosen to be four meters above the top face of the bridge concrete slab what gave the control volume an initial height of $12.0 \mathrm{~m}$. These dimensions of the control volume were increased until the temperatures in four control points did not change in two successive iterations. The resulting dimensions of the control volume were $115.2 \mathrm{~m}$ (length) x $38.4 \mathrm{~m}$ (width) $\mathrm{x}$ $16.0 \mathrm{~m}$ (height). In all the analyses, the control volume was meshed using cubic cells of size $0.40 \mathrm{~m}$.

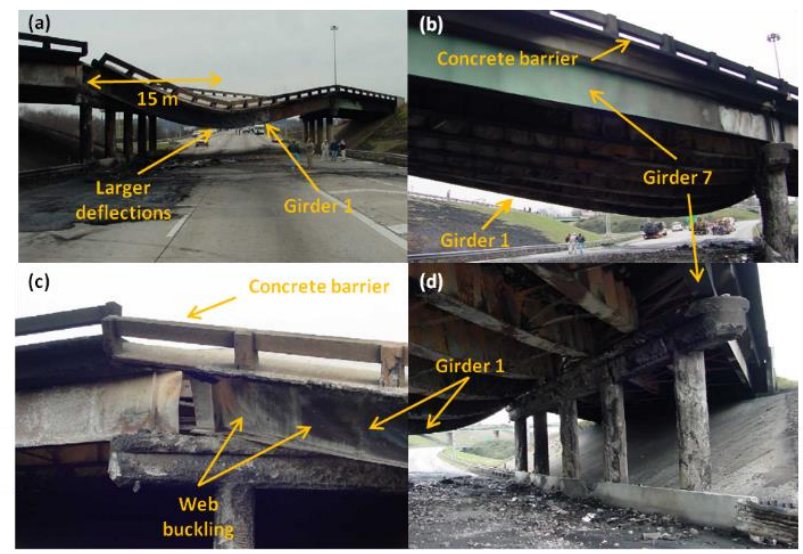

Figure 3. Damage caused by the fire to the steel girders of the I-65 overpass. Source of the images: Alabama Department of Transportation. 
- $\quad$ Step 2.

Once obtained the control volume size, the mesh had to be refined. The authors tried three different meshes with cubic cells of size $0.40 \mathrm{~m}, 0.30 \mathrm{~m}$, and $0.20 \mathrm{~m}$. They verified that the temperatures in the control points were the same for the meshes with cells of size $0.30 \mathrm{~m}$ and $0.20 \mathrm{~m}$ and that both cell sizes could then be used. Finally cells of size 0.24 $\mathrm{m}$ (along x-direction), $0.22 \mathrm{~m}$ (along y-direction), and $0.20 \mathrm{~m}$ (along $\mathrm{z}$-direction) were selected to get a mesh that provided a good approximation to the geometry of the overpass. Note that the FDS mesh does not coincide with the mesh used in the software used in the thermo-mechanical models (Abaqus). Note also that the dimensions of the control volume had to be slightly modified so it could accommodate the new cell sizes, which resulted in the control volume dimensions shown in Fig. 4: $115.2 \mathrm{~m}$ (length) $\mathrm{x}$ $39.6 \mathrm{~m}$ (width) x $16.2 \mathrm{~m}$ (height).

- $\quad$ Step 3.

In the step 3 it was checked that changes in the FDS mesh size from step 1 to step $2 \mathrm{did}$ not affect the size of the control volume.

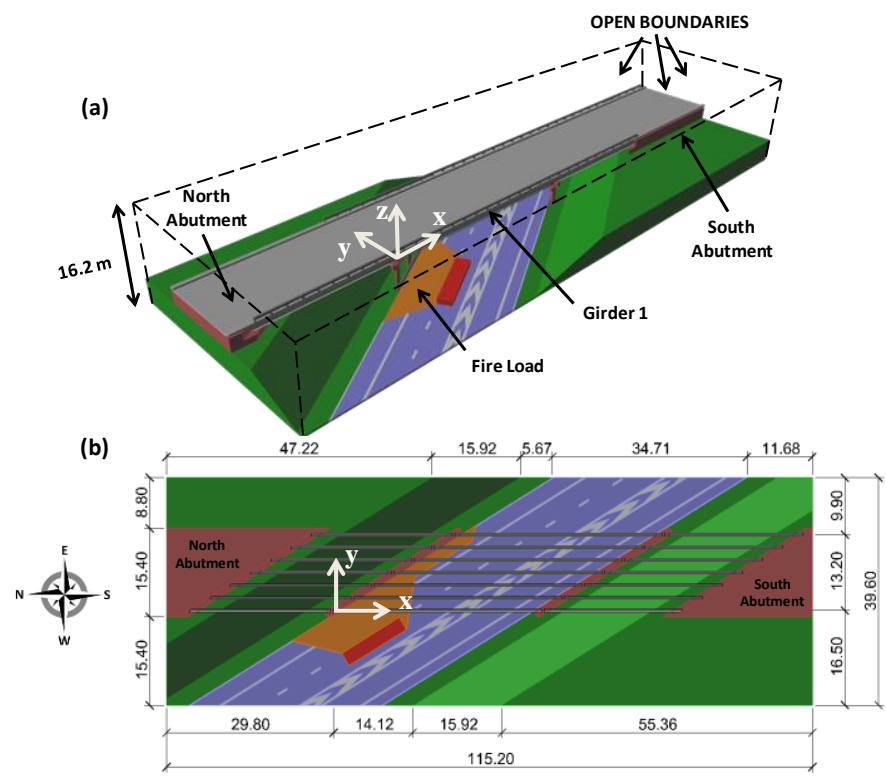

Figure 4. FDS model: general view (top) and plan view (bottom) of the control volume. 


\subsection{Fire Load}

The fire load, located in the area of $185.13 \mathrm{~m}^{2}$ shown in Fig. 5, is modeled using the mixture fraction combustion model proposed by FDS [27] with a soot yield of 0.018 according to [28]. This area has two components. The first one, red-filled in Fig. 5, measures $30 \mathrm{~m}^{2}$ and corresponds to the fuel burning in the tanker after the accident. The second one, brown-filled in Fig. 5, measures $155.13 \mathrm{~m}^{2}$ and corresponds to the fuel spilled on the road by the accident. The authors could not find any official report detailing the extension of the areas detailed in Fig. 5. Therefore, these areas were estimated on the basis of the analysis of the pictures of the fire event and of the damage observed in the overpass girders. Note that the footprint of the fire affects the severity of the fire by directly influencing the rate of fuel consumption, the flame height, and the total heat release of the fire. A parametric study on the influence of this footprint is not included in this paper but the interested reader can find in Peris-Sayol et al. [29] a study of this kind performed for a steel girder bridge of $12.2 \mathrm{~m}$ of span length.

The heat release rate per unit area (HRRPUA) curves increase linearly from 0 to their maximum values (HRRPUA $A_{\mathrm{MAX}}$ ) in 20 seconds and remain constant until the failure. The HRRPUA $A_{M A X}$ is $2500 \mathrm{~kW} / \mathrm{m}^{2}$ [30] in the area corresponding to the fuel burning in the tanker. A parametric study is developed in Section 5.1 to determine HRRPUA MAX for the area corresponding to the spilled fuel. A minimum value of $500 \mathrm{~kW} / \mathrm{m}^{2}$ is considered in the parametric study because according to [31] the HRRPUAMAX of the spill fire can be estimated to be one-fifth of the HRRPUA $A_{\mathrm{MAX}}$ of the fuel burning in the tanker. However, fuel accumulations due to the slope of the I-65N and the presence of a concrete barrier (see Fig. 3d) could result in values of the HRRPUAMAX in the spilled fuel area higher than $500 \mathrm{~kW} / \mathrm{m}^{2}$. The maximum possible value HRRPUA $A_{M A X}$ for the spill fire is $2500 \mathrm{~kW} / \mathrm{m}^{2}$ because it cannot be higher than the HRRPUA $A_{M A X}$ of the fuel burning in the tanker. To complete the parametric study, three intermediate values between 500 and $2500 \mathrm{~kW} / \mathrm{m}^{2}$ are considered: 1000,1500 and $2000 \mathrm{~kW} / \mathrm{m}^{2}$. Note also that the HRRPUA curves do not have any decay phase because the numerical model results show that the overpass failed when only $15 \%$ of the available fire load was consumed.
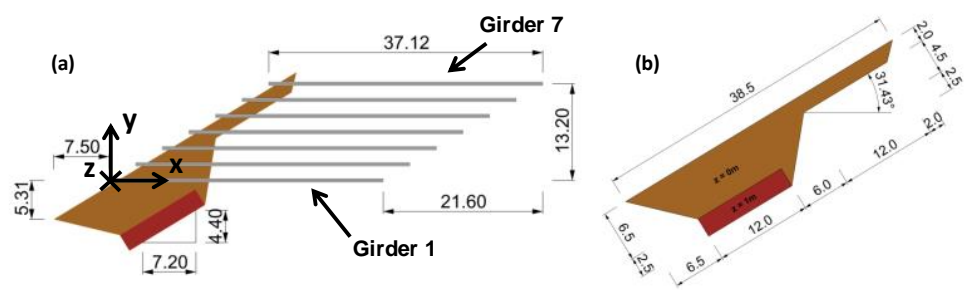

Figure 5. FDS model fire load location (a) and geometric definition (b) of the fire load. 


\subsection{Adiabatic temperatures}

The adiabatic surface temperature developed by Wickström et al. [24] is used to transfer the information obtained by the fire model to the thermal model. This adiabatic surface temperature is a fictitious temperature obtained by FDS assuming that the structural element is a perfect insulator and it is an effective temperature depending on the incident heat flux by radiation and convection to a surface and the gas temperature adjacent to that surface. This temperature can then be considered as a uniform fire temperature when calculating the heat flux to an exposed structure.

The model includes 5754 sensors to measure the adiabatic temperatures in 417 crosssections of the overpass. Cross sections located on the supports were monitored with 12 sensors whereas the rest of sections were monitored with 14 sensors (see Fig. 6).

Fig. 7a shows the fire scenario 3 minutes after the beginning of the fire event. Fig. $7 \mathrm{~b}$ shows the evolution of the adiabatic surface temperatures $\left(T_{a}\right)$ in the cross section of Girder 1 located at $7.5 \mathrm{~m}$ from its North end. Note that for clarity, Fig. $7 \mathrm{~b}$ does not contain results measured by all the sensors. It is seen that sensors 2 through 7 , representing the west (open to air) face of Girder 1 have essentially the same temperature. Although not shown, sensors 2' through 7', representing the east face (adjacent to Girder 2), also measure essentially the same temperature. These temperatures are similar to those measured by sensors 4 and 4' respectively (differences are lower than 5\%). Similarly, the temperatures measured by sensors 1 and 1 ' are almost the same.

Therefore, to simplify the transition from the CFD to finite element model, each girder cross section was divided in three parts, each having a shared adiabatic temperature: The West Face, Bottom Face and East Face have adiabatic temperatures measured by sensors 4,1 , and 4 ' respectively.

Fig. 8a and $8 \mathrm{~b}$ plot average adiabatic surface temperature values at the girder mid-depth (sensors labeled as 4 and 4' in Fig. 6) in the steady state (between 50 and 400 seconds after the beginning of the fire). This temperature is plotted along each girder's longitudinal axis, $\mathrm{x}$, where $x=0$ represents the north end. Fig. $8 \mathrm{a}$ and $8 \mathrm{~b}$ show that particularly in girders 1 and 2 there is a large variation of the adiabatic temperatures along the longitudinal axis. For example, adiabatic temperatures vary between $841^{\circ} \mathrm{C}$ and $185^{\circ} \mathrm{C}$ in the West Face and between $867^{\circ} \mathrm{C}$ and $495^{\circ} \mathrm{C}$ in the East face of Girder 1; between $381^{\circ} \mathrm{C}$ and $238^{\circ} \mathrm{C}$ in the West Face Girder 7 , and between $166^{\circ} \mathrm{C}$ and $73^{\circ} \mathrm{C}$ in the East Face Girder 7. Also, results show peak temperatures in the regions of girders 1 and 2 directly affected by the fire flames. 


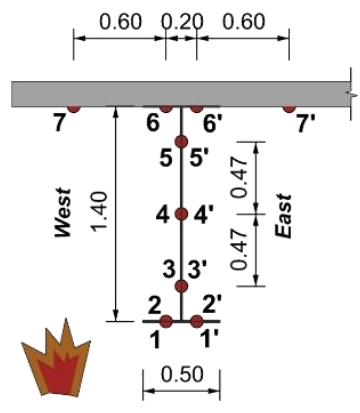

Figure 6. FDS model. Adiabatic surface temperature sensors in a typical monitored cross section.

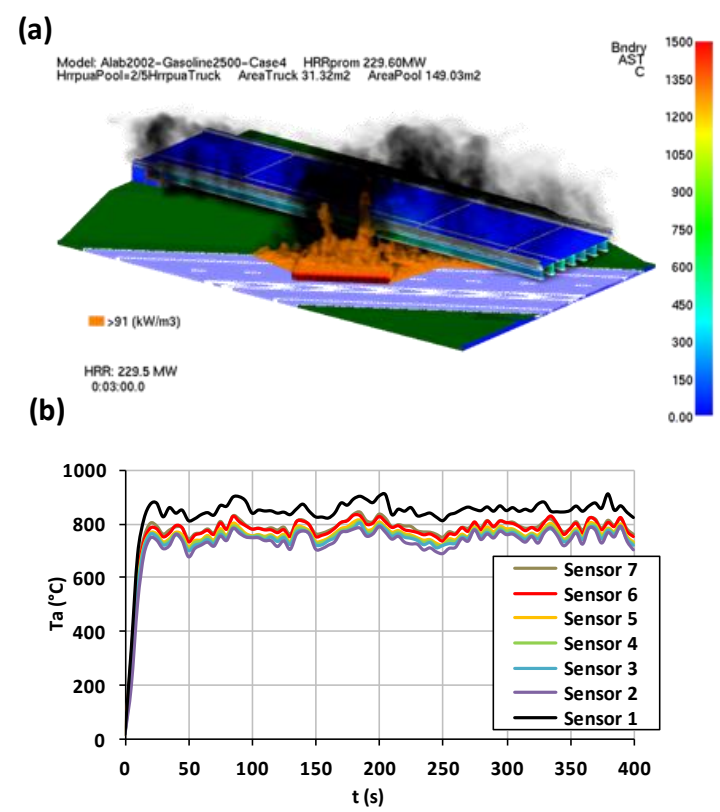

Figure 7. FDS results: (a) general view of the l-65 overpass 3 minutes after the beginning of the fire event, (b) evolution of the adiabatic temperatures $\left(T_{a}\right)$ in the cross section of Girder 1 located at $7.5 \mathrm{~m}$ of its north end. Assumed HRRPUAMAX,SPILL= $1000 \mathrm{~kW} / \mathrm{m}^{2}$.

Fig. 8c plots the temperature difference between the West and East faces of the girders (sensor 4 minus sensor 4'). A negative value therefore implies that the East Face is hotter than the West Face. It is seen that for the exterior girders (Girders 1 and 7) temperatures 
in the East and West faces can be very different. The maximum temperature difference ranges from $-311^{\circ} \mathrm{C}$ in Girder 1 to $+284^{\circ} \mathrm{C}$ in Girder 7. These values represent $36 \%$ and $19 \%$ of the maximum adiabatic temperatures of each girder. The fire occurred on the west side of the span, near Girder 1. Therefore, temperatures in the West face of the girders are generally higher than in the East face with the exception of Girder 1, whose West face does not have any important obstacle to avoid the free rising of hot gases.

It is noted that although the analyses presented in Figure 7 and 8 were done assuming

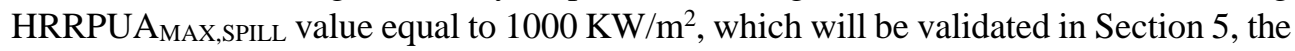
trends and discussion do not change with other values of HRRPUAMAX,SPILL.

(a)

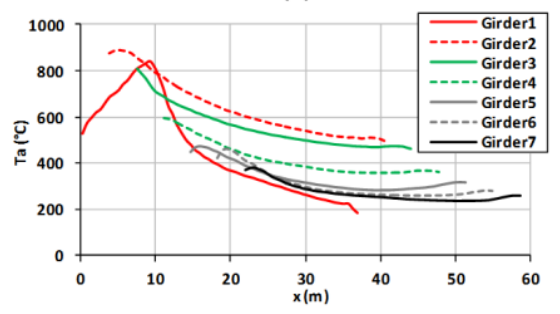

(b)

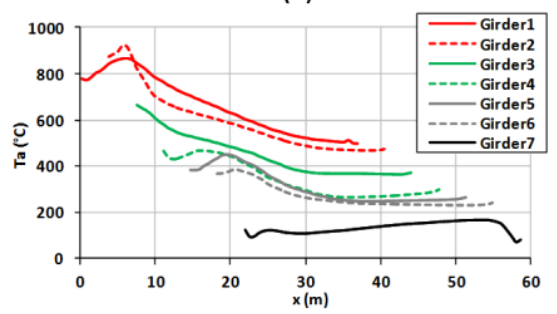

(c)

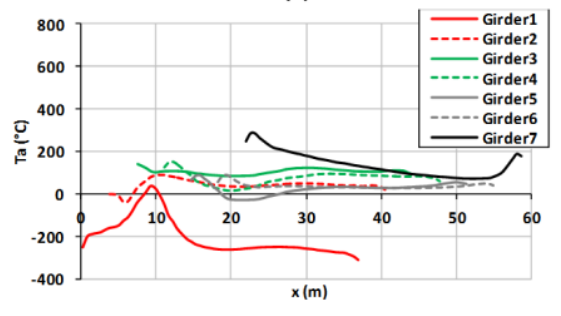

Figure 8. Average values of the adiabatic temperatures $\left(T_{a}\right)$ along the mid-depth of the girders web: (a) West Face (Sensor 4 in Fig. 6), (b) East Face (Sensor 4' in Fig. 6), (c) difference between the values measured by sensors 4 and 4'. Assumed HRRPUAMAX,SPILL= $1000 \mathrm{~kW} / \mathrm{m}^{2}$.

\section{Finite element (FE) model for thermo-mechanical analysis}

In this section, the girder which suffered more damage during the fire event, i.e. Girder 1 , and its corresponding concrete slab are analyzed using an uncoupled thermomechanical analysis. The width of the slab in the FE model is $2.2 \mathrm{~m}$ according to the dimmensions ploted in Fig. 1c. In the first step (the thermal analysis) the structure is heated using the adiabatic surface temperatures given by FDS, and the heat transfer 
method provides the transient nodal temperatures with respect to time. In the second step (the structural analysis), the nodal temperatures are read from the thermal analysis and corresponding temperature dependent mechanical material properties are used to find the equilibrium of the structure. All the analyses are carried out using the FE software Abaqus [20]. All the Abaqus models were run in a computer with an i7-3770 processor of 3.4-3.9 GHz and $32 \mathrm{~GB}$ of RAM, being three hours the running time of a typical simulation.

To validate both the CFD and FE models, parametric studies are performed in Section 5 where the results are compared to the case study fire event. The following CFD and FE model characteristics are used as part of that parametric study: (1) the fire load as affected by HRRPUA $A_{\text {MAX }}$ of the fuel spill (as described in Section 3.2); (2) the discretization of temperature along the length of the girder; and (3) the boundary conditions through constraints on the roller support motion. This section introduces these parameters, and Section 5 discusses the results.

\subsection{Elements and mesh}

For the thermal analysis, Abaqus element DC3D8 is employed. This is a three dimensional eight-noded linear heat transfer brick element with one degree of freedom per node. For the structural analysis, Abaqus element C3D8 is used, which is a three dimensional eight-noded solid continuum element with three degrees of freedom per node.

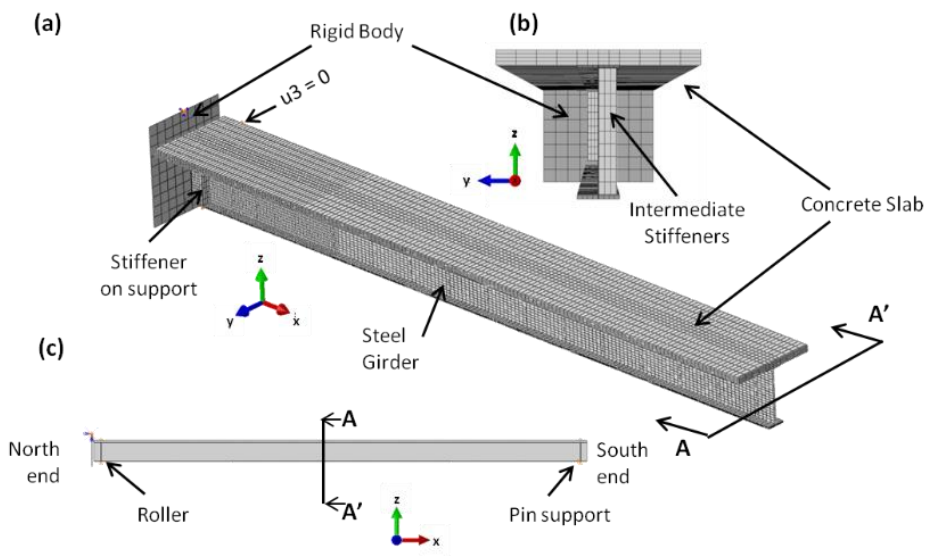

Figure 9. Finite Element Model of Girder 1 built with Abaqus: (a) 3D view of half girder, (b) Section A-A', (c) elevation. 
FE analyses include geometric and material non-linearity. A complex FE model with solid elements is used instead of a simpler model with beam elements to capture local phenomena such as web buckling that might control the global response and the failure mode of the bridge. Fig. 9 shows a 3D view of the model. Note that the mesh is finer in the vicinity of the supports because these are areas of high stress more susceptible to local buckling. The FE model has 87791 nodes and 61620 solid elements.

\subsection{Material properties}

Thermal properties suggested by EC-4 [32] were used for concrete and steel elements respectively. It was assumed that concrete aggregates were calcareous and that concrete unit mass, $\rho_{c}$, was $2500 \mathrm{~kg} / \mathrm{m}^{3}$. According to the drawings of the overpass project, a value of the concrete compressive strength of $27.58 \mathrm{MPa}(4000 \mathrm{psi})$ at ambient temperature was assumed and used to build concrete stress-strain curves according to EC-4 [32]. A value for the unit mass of steel, $\rho_{s}$, of $7850 \mathrm{~kg} / \mathrm{m}^{3}$ was used along with the stress-strain curves with strain hardening proposed by EC-4 [32] for steel with a yield stress at ambient temperature, $f_{y}$, of $248.21 \mathrm{MPa}(36 \mathrm{ksi})$. Finally, engineering values of stresses $(\sigma)$ and strains $(\varepsilon)$ were converted into true stress strain laws $\left(\sigma_{n}-\varepsilon_{n}\right)$ and introduced in Abaqus as detailed in Eq. 1 and 2.

$\begin{array}{ll}\sigma_{\mathrm{n}}=\sigma(1+\varepsilon) & \text { (Eq. 1) } \\ \varepsilon_{\mathrm{n}}=\ln (1+\varepsilon) & \text { (Eq. 2) }\end{array}$

\subsection{Discretization of temperature along girder length}

Adiabatic surface temperatures obtained with FDS are considered as uniform temperatures in the gas surrounding the structure and, therefore, are used to heat the deck. In the thermal analysis a convective heat transfer coefficient, $h_{c}$, of $50 \mathrm{~W} / \mathrm{m}^{2} \mathrm{~K}$ and an emissivity coefficient, $\varepsilon$, of 0.7 corresponding to a petrol fire was used according to EC$1[31]$ and EC-4 [30].

Curves giving FDS adiabatic surface temperatures such as those of Fig. 8a and $8 \mathrm{~b}$ have been discretized (modeled as stepped curves) to facilitate merging with Abaqus. The coarseness or fineness of the discretization is a parameter to be studied in Section 5.2. The study divided the length of the girder into 1, 2, 4, 8, and 16 equal segments. Using a value of one implies uniform temperature along the full length of the girder. Fig. 10 shows an example using a 16 step discretization and compares, for this case, the adiabatic temperature curves obtained with FDS to the stepped curves introduced in Abaqus (assuming HRRPUA $\mathrm{MAX}_{\mathrm{SPILL}}=1000 \mathrm{KW} / \mathrm{m}^{2}$ ). As explained in Section 3.3, temperatures measured by sensors 4, 4' and 1 have been taken as representative of the temperatures in the West, East and Bottom faces of Girder 1 respectively. 

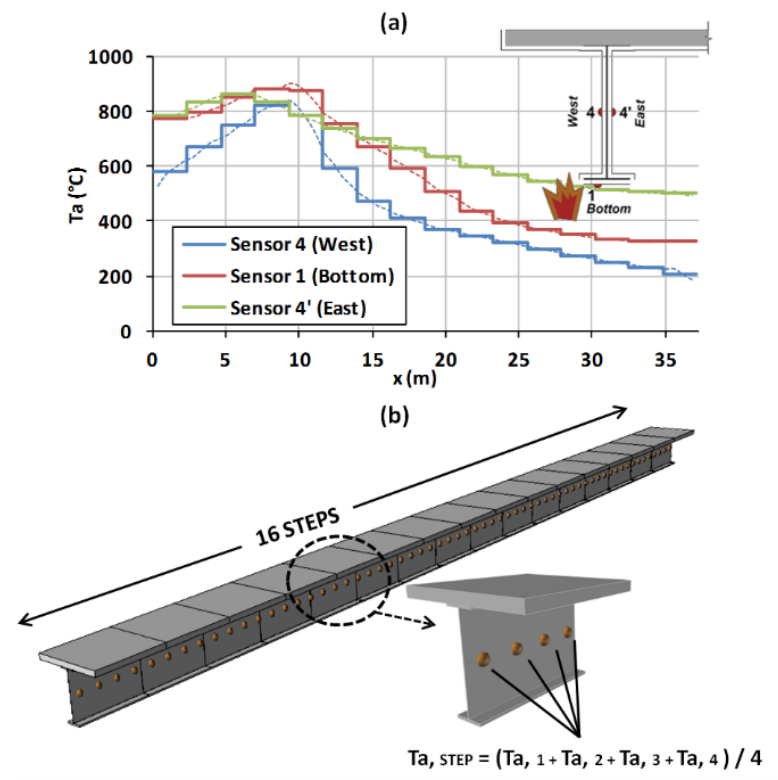

Figure 10. Girder 1. Example of a 16 step discretization of the adiabatic temperature curves for merging CFD with Abaqus. Assumed HRRPUAMAX,SPILL= $1000 \mathrm{~kW} / \mathrm{m}^{2}$. (a) Adiabatic temperatures along the girder span. Dashed lines represent the smooth continuous CFD results. Solid lines represent the discretization. (b) Model showing the 16 steps and the calculation of the average temperature at each step.

\subsection{Boundary conditions}

The bridge studied in this paper was a composite bridge, i.e., the steel girders and the concrete slab where connected with shear connectors to ensure that both elements worked together to sustain the loads acting on the bridge. However, temperatures caused by the fire can deteriorate the connectors and reduce the load bearing capacity of the deck.

All the analyses carried out in the present work consider full composite action through the full fire event. This assumption is based on two facts: (a) there was no evidence showing a steel-concrete connection failure due to the fire event, and (b) numerical models showed that temperatures in the interface between the steel girder and the slab during the fire event were smaller than $500^{\circ} \mathrm{C}$ (see Section 6.1). Other boundary conditions considered are: 
- Lateral "y" displacements (named $u 3$ in Fig. 9) at the supports ( $x=0.53 \mathrm{~m}$ and $\mathrm{x}=35.66 \mathrm{~m}$ ) are fixed at the level of the concrete slab to take into account the influence of parts of slab not included in the FE model. Note that fixing these lateral displacements along the full length of Girder 1 would result in null lateral displacements of the top part of the composite girder which is not possible due to the transverse rotations and large deflections experienced by Girder 1 during the fire event

- The south support of the girder was considered as pinned and the north support was considered to be a roller. The extent of roller motion is a parameter in the study. As explained by Paya-Zaforteza and Garlock [17], it is important to consider when studying the fire response of a bridge that temperature variations in the deck caused by a fire are significantly larger than those due to weather changes. These temperatures can provoke deck expansion movements which might be eventually restrained by the abutments or an adjacent span. To consider this possibility, two types of numerical analyses were carried out. The first one corresponds to a situation where the bridge is allowed to freely expand without any restraint. The second one corresponds to a more realistic situation where the bridge is allowed to expand only up to the width of the expansion joint. Therefore, and only for the latter case, a rigid body was created at a distance from the North outer cross section of the bridge equal to the expansion joint width $(0.152 \mathrm{~m}$.). In doing so, the axial expansion of the nodes of the outer cross section of the bridge was restrained once their horizontal displacement equaled the width of the expansion joint. Section 5.3 discusses the effects of including or excluding this axial expansion restraint.

\subsection{Gravity Loads}

Gravity loads corresponding to the self weight of the of steel girder (130.6 kN in total) and the concrete slab (327.98 $\mathrm{kN}$ in total) are computed automatically by the software. Furthermore, a total dead load of $121.2 \mathrm{kN}$ corresponding to the weight of the wearing surface of the deck and of $83.6 \mathrm{kN}$ along the $0.2 \mathrm{~m}$ west end of the girder corresponding to the safety barrier weight have been also considered.

The authors did not find any evidence of vehicles (live load) crossing the I-65 overpass while it was on fire so only the above mentioned dead loads are considered in the model validation of the case study. However, an analysis of the effects of live load is done in Section 6.3 


\section{Parametric Study for Model Validation}

As mentioned previously, parametric studies are performed to validate the CFD and FE models. The results are compared to the case study fire event. The following model parameters are studied: (1) the fire load as affected by HRRPUAMAX of the fuel spill; (2) the discretization of temperature along the length of the girder; and (3) the boundary conditions through restrained thermal expansion.

Table 1 presents the model parameters studied (as introduced in Section 4) and the analysis names where the nomenclature is as follows: the first number represents the

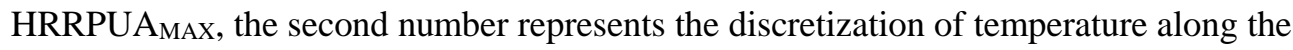
length, and 'fre' or 'fix' represents a boundary condition with unlimited free thermal expansion or a limited thermal expansion, respectively.

\begin{tabular}{|c|c|c|c|c|c|c|c|}
\hline \multirow{2}{*}{$\begin{array}{c}\text { Parametric } \\
\text { Study }\end{array}$} & \multirow{2}{*}{$\begin{array}{c}\text { Analysis } \\
\text { name }\end{array}$} & \multirow{2}{*}{$\begin{array}{c}\text { HRRPUA }_{\text {MAX }} \\
\text { spill fire } \\
\left(\mathrm{kW} / \mathbf{m}^{2}\right)\end{array}$} & \multirow{2}{*}{$\begin{array}{c}\text { Number of } \\
\text { Temperature } \\
\text { Steps }\end{array}$} & \multirow{2}{*}{$\begin{array}{l}\text { Axial } \\
\text { restraint } \\
\text { at the } \\
\text { North } \\
\text { support }\end{array}$} & \multicolumn{3}{|c|}{ Failure } \\
\hline & & & & & $\begin{array}{l}\text { Time } \\
(\min )\end{array}$ & Mode & $\begin{array}{c}\text { Maximum } \\
\text { deflection } \\
\text { (m) }\end{array}$ \\
\hline \multirow{5}{*}{$\begin{array}{c}\text { Fire Load } \\
\text { (HRRPUA) }\end{array}$} & $2500-16$-fix & 2500 & 16 & Fixed & 1.6 & $\begin{array}{c}\text { LB, } R, S, \\
\text { WB }\end{array}$ & 0.54 \\
\hline & $2000-16$-fix & 2000 & 16 & Fixed & 2 & LB, R, WB & 0.57 \\
\hline & $1500-16$-fix & 1500 & 16 & Fixed & 3.8 & LB, $R, W B$ & 0.86 \\
\hline & $1000-16$-fix & 1000 & 16 & Fixed & 13.1 & LB, S, WB & 1.91 \\
\hline & $500-16$-fix & 500 & 16 & Fixed & $>30$ & $\mathrm{LB}, \mathrm{S}$ & 0.67 \\
\hline \multirow{4}{*}{$\begin{array}{l}\text { Discretization } \\
\text { of the } \\
\text { temperature }\end{array}$} & $1000-8$-fix & 1000 & 8 & Fixed & 14.4 & $\begin{array}{c}\text { LB, R, S, } \\
\text { WB }\end{array}$ & 1.87 \\
\hline & $1000-4$-fix & 1000 & 4 & Fixed & 14.8 & $\begin{array}{c}\text { LB, R, } S \\
\text { WB }\end{array}$ & 1.26 \\
\hline & $1000-2$-fix & 1000 & 2 & Fixed & 11.4 & LB, S, WB & 0.76 \\
\hline & $1000-1$-fix & 1000 & 1 & Fixed & 16.8 & LB, $\mathrm{S}$ & 0.83 \\
\hline $\begin{array}{l}\text { Boundary } \\
\text { condition }\end{array}$ & $1000-16$-fre & 1000 & 16 & Free & 12.3 & LB, $\mathrm{S}$ & 1.36 \\
\hline
\end{tabular}

Table 1. Parameters and results of the analyses carried out for model validation.

The times to failure and the structural response at this time are discussed in each of the subsections to follow. In the structural analysis, the transient nodal temperatures with respect to time obtained with the thermal analysis are used to find the equilibrium of the structure considering temperature dependent mechanical material properties, second order effects, and gravity loads. As proposed by Payá-Zaforteza and Garlock [17], the structure is assumed to fail when any of the following conditions is fulfilled: 
(1) Fracture occurs, which is assumed to happen when the ultimate strain $\varepsilon_{u}$ of the material is attained. This mode of failure is checked by comparing the maximum principal strain of the structure with $\varepsilon_{u}$ based on true values (Eq. 2).

(2) The structure becomes unstable based on a drastic increase in the rate of vertical deflections or an inward movement of the roller support towards the center of the span.

\subsection{Fire Load (HRRPUA)}

As shown in Table 1, five values of maximum heat release rate per unit area in the spilled

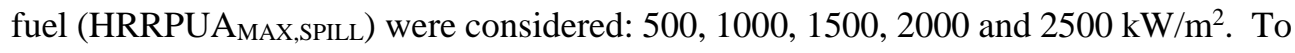
validate the value, a comparison with the structural response of the case study is done. Table 1 shows the assumptions made regarding the FE model in these analyses: discretizing the temperature along the length of Girder 1 into 16 steps (validated in Section 5.2), and a limited axial expansion ('fixed' support conditions as will be validated in Section 5.3).

Fig. 11 examines the effects of HRRPUA $A_{M A X, S P I L L}$ on the steady state adiabatic temperatures for Girder 1 West face. It is seen that the amount of the HRRPUAMAX,SPILL has a strong influence on the adiabatic surface temperatures along Girder 1. For example, moving from a value of $500 \mathrm{~kW} / \mathrm{m}^{2}$ to a value of $2500 \mathrm{~kW} / \mathrm{m}^{2}$ multiplies the maximum adiabatic temperatures by 1.73 (from 724 to $1251^{\circ} \mathrm{C}$ ). Although not shown, in the East face and Bottom face the multiplicative difference is 2.67 (from 549 to $1469^{\circ} \mathrm{C}$ ) and 1.54 (from 811 to $1251^{\circ} \mathrm{C}$ ), respectively.

These differences in adiabatic temperature have an effect on the structural response of Girder 1. For example, Table 1 shows that increasing HRRPUAMAX,SPILL results in reducing the times to failure, which vary between $13.1 \mathrm{~min}$. (HRRPUA $\mathrm{A}_{\mathrm{MAX}, \mathrm{SPILL}}=1000$ $\left.\mathrm{kW} / \mathrm{m}^{2}\right)$ and $1.6 \mathrm{~min}\left(\right.$ HRRPUA $\left._{\mathrm{MAX}, \mathrm{SPILL}}=2500 \mathrm{~kW} / \mathrm{m}^{2}\right)$.

Figure 12 examines the effect of HRRPUAMAX, sPILL on the vertical displacement of the girder. Figure 12a plots, as a function of time, the maximum vertical displacement. It is observed that HRRPUA $A_{M A X, S P I L L}$ equal to $1000 \mathrm{~kW} / \mathrm{m}^{2}$ reaches a final maximum deflection equal to $1.91 \mathrm{~m}$ (also seen in Table 1), which is the closest to the case study value of $2.5 \mathrm{~m}$. reported by ALDOT. 


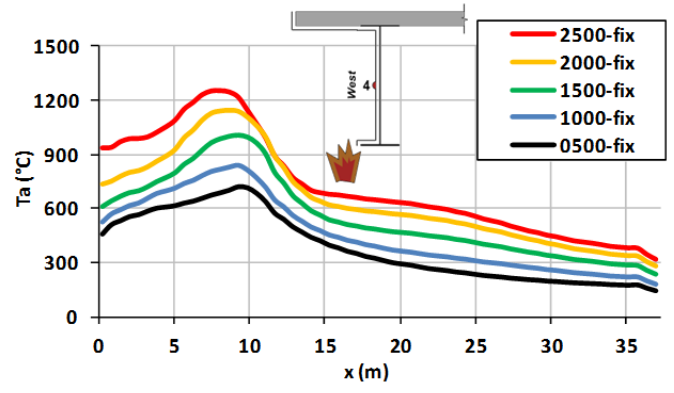

Figure 11. Effect of HRRPUAMAX,SPILL on the steady state adiabatic temperatures for Girder 1 West face (sensor 4).

(a)

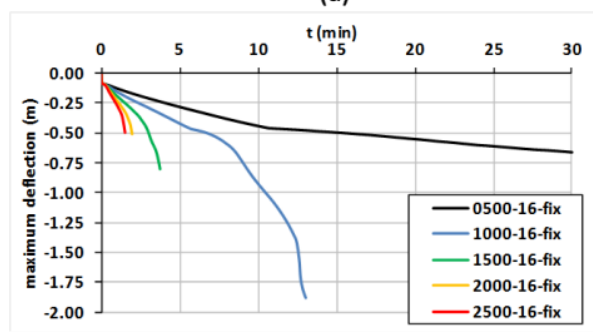

(b)

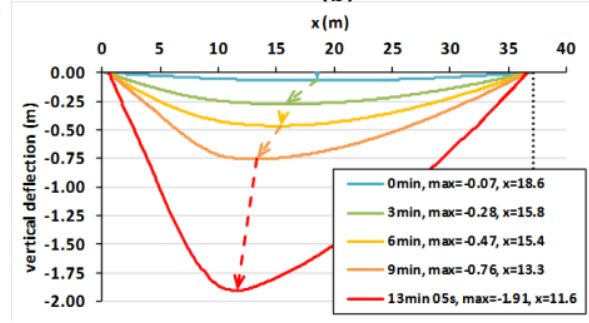

Figure 12. Effect of HRRPUAMAX, SPILL on the vertical displacement of the girder: (a) maximum displacement over time, and (b) displacement along the length of the girder for some discrete points in time for analysis 1000-16-fix.

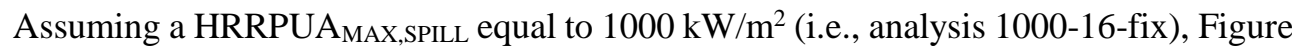
$12 \mathrm{~b}$ plots the displacement along the length of the girder for some discrete points in time. The arrows indicate the point of maximum deflection. It is seen that the maximum vertical deflection of the girder displaces with time towards the North end of Girder 1. This happens because the fire load is non-symmetric, which results in a non-symmetric structural response. Additionally, the point of maximum deflection given by the case 1000-16-fix is located $11.6 \mathrm{~m}$ away from the north support, only $3.4 \mathrm{~m}$ (9\% of the span length) away from the point of maximum deflection estimated using ALDOT pictures (Fig. 3) which is located $15 \mathrm{~m}$ away from the north support.

Figure 13 plots (a) the horizontal displacement of the roller, and (b) the out-of-plane displacement of the web. For the analyses that did not fail too soon (HRRPUAMAX,SPILL equal to 500 and $1000 \mathrm{~kW} / \mathrm{m}^{2}$ ), it is seen that the horizontal displacement of the roller becomes a constant value once the displacement reaches the expansion joint width $(0.152$ $\mathrm{m})$. This response indicates that these two analyses had the girder bear against the rigid 
body (see Fig. 9) and axially restrained expansion once the horizontal expansion reached $0.152 \mathrm{~m}$. Figure $13 \mathrm{~b}$ and Table 1 show that values of HRRPUA $A_{M A X}$,SPLL equal to 1000 $\mathrm{kW} / \mathrm{m}^{2}$ or higher produce web buckling noticed by high transverse web displacements. Buckling is accompanied by an inward movement of the roller support towards the center of the span (see Fig. 13a cases with HRRPUAMAX,SPILL equal to 1500, 2000 and 2500 $\mathrm{kW} / \mathrm{m}^{2}$ ) or a drastic increase in the rate of vertical deflections (see case with

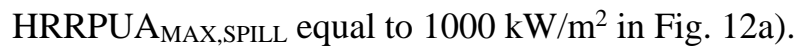

(a)

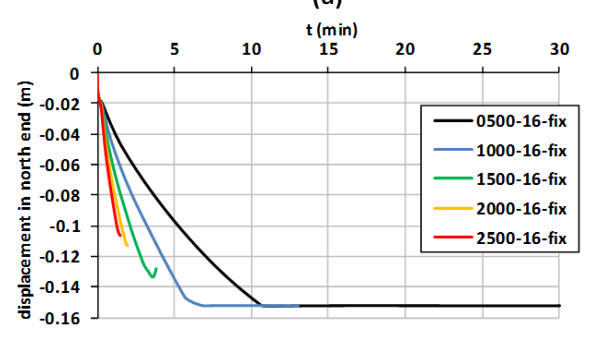

(b)

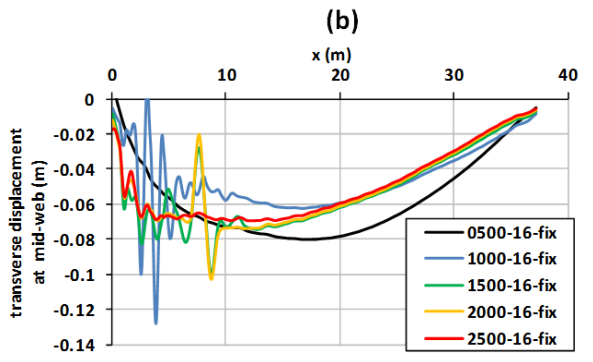

Figure 13. Effect of HRRPUAMAX,SPLL on the evolution of (a) horizontal displacement of the roller and (b) transverse (out-of-plane) displacements at mid-web.

\subsection{Discretization of the temperature along the length}

As explained in Section 4.3 each FDS adiabatic surface temperature curve must be discretized into a stepped curve for merging CFD results into Abaqus. The higher the number of steps, the higher the precision of the analysis but also a higher computational effort. In this section, the influence of the discretization (number of steps) in the results is analyzed. The study is done for five number of steps $(1,2,4,8$ and 16) using a value of HRRPUA $A_{M A X, S P I L L}$ equal to $1000 \mathrm{~kW} / \mathrm{m}^{2}$ since this value is shown to correlate the best with the events of the case study as discussed in the previous section. All the analyses assume a limited axial expansion ('fixed' support conditions as will be validated in Section 5.3).

Table 1 and Fig. 14 show the main results of these analyses, where Fig. 14 plots the (a) maximum vertical displacement and (b) transverse (out-of-plane) displacements of the web as a function of time for the number of discretized steps studied. Fig 14a shows that the maximum vertical displacement is affected by the discretization where the larger the number of discretized steps the larger the displacement. Fig. 14b shows that the out-ofplane displacement is also affected by the discretization. This displacement converges to a solution at a 16 step discretization since those results are close to the 8 step discretization results. In addition, the modes of failure are the same for 8 step and 16 step discretization. 
(a)

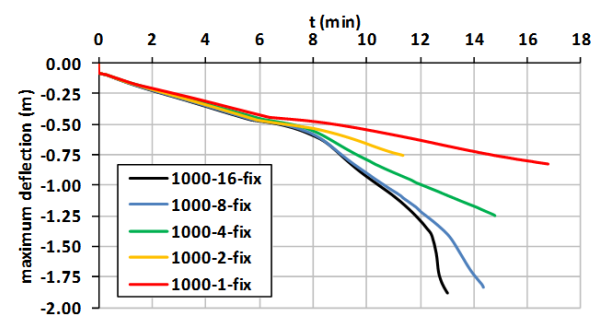

(b)

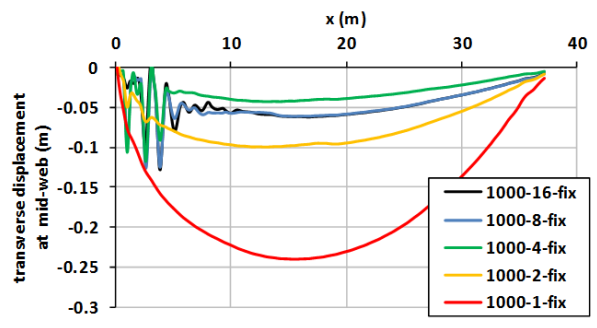

Figure 14. Effect of temperature discretization on the evolution of (a) maximum vertical displacement; and (b) transverse (out-of-plane) displacements of the mid-web.

Using less than 8 steps leads to results that are not consistent with the case study response. For example, maximum deflections are largely underestimated as shown in Table 1 (2.5 m maximum deflection was reported by ALDOT). Further, models with 1 and 2 step discretizations do not produce transverse web displacements produced by web buckling as seen in the case study (see Fig. 3c).

\subsection{Axial restraint boundary conditions}

Two types of boundary conditions were considered at the roller support end. The first one allows the bridge to freely expand without any restraint (called 'fre' in Table 1). The second one corresponds to a more realistic situation where deck is allowed to expand only up to the width of the expansion joint (called 'fix' in Table 1). Therefore, and only for the 'fix' case, a rigid body was created at a distance from the North outer cross section of the bridge equal to the expansion joint width $(0.152 \mathrm{~m}$.) (see Fig. 9).

The analyses presented to this point have assumed a 'fix' condition, which the authors believe more closely represents the case study condition. To validate this assumption, another analysis was done, similar to analysis 1000-16-fix, but where the roller is permitted to freely move without restriction (analysis 1000-16-fre).

Table 1 and Figure 15 present the results of this study. Fig. 15a plots the maximum vertical displacement (VD) and the horizontal displacement (HD) of the roller as a function of time for analyses 1000-16-fix and 1000-16-fre. Fig. 15b plots the transverse (out-of-plane) displacements of the web for the same two analyses. Figure 15 shows that the trend in vertical displacement is the same for both boundary conditions, but Table 1 shows that the 'fre' analysis fails sooner than the 'fix' analysis and therefore results in smaller maximum vertical deflection. Fig. 15a also shows that the 'fix' analysis reaches the maximum horizontal displacement value of $0.152 \mathrm{~m}$ representing the extent of the expansion joint, while the 'fre' analysis continues to have its roller support move 
horizontally. Finally, Fig 15b shows that analysis 1000-16-fre has essentially no out-ofplane displacement oscillations of the web, indicating no web shear buckling. This is contrary to the case study response as seen in Fig. 3.

(a)

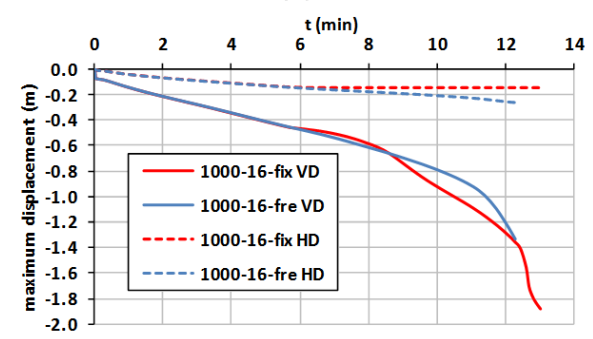

(b)

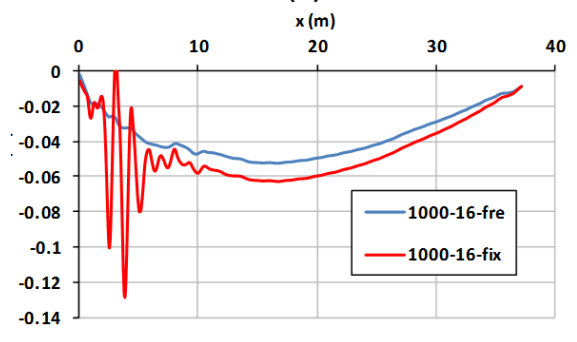

Figure 15. Effects of boundary conditions through a comparison of analyses 1000-16-fix and 1000-16-fre: (a) maximum vertical displacement (VD) and horizontal displacement (HD) of the roller and (b) transverse (out-of-plane) displacements of the web.

\subsection{Conclusions of Parametric Study for Model Validation}

From the three parameters studied and presented in Sections 5.1 through 5.3, the following parameters are recommended to obtain a model that represents as closely as possible the case study results:

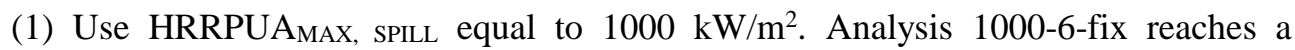
displacement closest to that observed in the case study. The final maximum deflection in this case is $1.91 \mathrm{~m}$, which is the closest to the value of $2.5 \mathrm{~m}$. reported by ALDOT. Note that ALDOT's values were an estimation and not the result of a measurement with surveying instruments. Note also that FDS solves the CFD problem without considering the deformation of the structure. In the real event, the deformation of the structure caused by the fire brings the structure in closer proximity to the fire load resulting in higher temperatures and higher deflections.

(2) Use a 16 step discretization to model the temperature of the girder along its length. While an 8 step discretization may be acceptable, 16 steps results in maximum vertical displacements that are slightly larger and closer to the case study event. If 16 steps are used, each step has a length of $2.33 \mathrm{~m}$. Using 4 steps (step length equal to $9.29 \mathrm{~m}$ ) provides some valuable insight in the expected mode of failure but can lead to important errors in the estimation of times to failure and deflections. Using smaller number of steps for a bridge with a span length close to $37 \mathrm{~m}$ is inadvisable because of the low quality of the results obtained. 
(a)
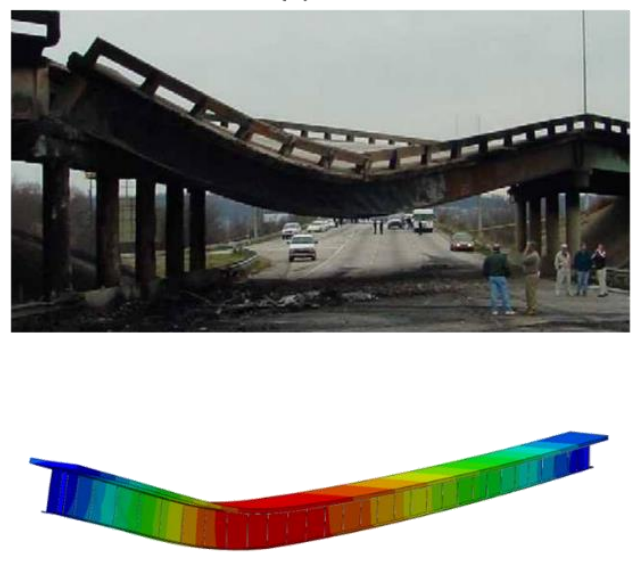

(b)
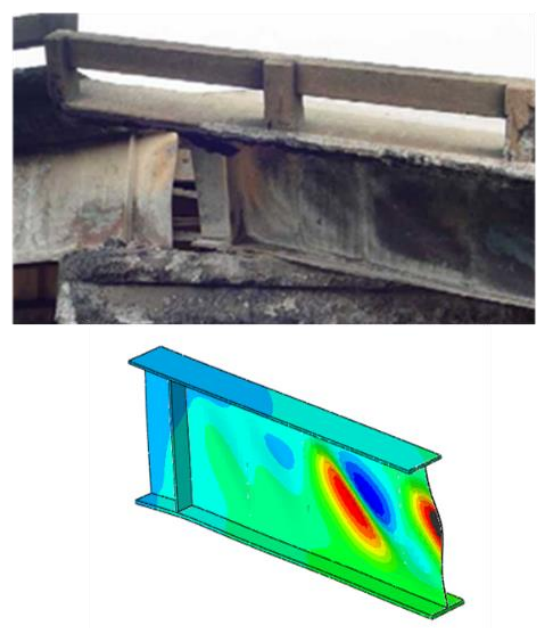

Figure 16. Comparison of validated model 1000-16-fix with images of the case study fire event: (a) Deformed shape of Girder 1 (West face). Red colors represent maximum values of vertical displacements; (b) close up of west face of Girder 1 at north support where web buckling is observed. Red colors represent maximum values of out of plane displacements.

(3) Use 'fix' boundary conditions that consider the width of the expansion joint and restrain axial displacement once the movement exceeds the width. Analysis model 100016-fre deflections are much smaller than those of 1000-16-fix (1.36 m versus $1.96 \mathrm{~m})$, and this model does not predict the web buckling as seen in the case study. Additionally, 'fre' boundary conditions seem less realistic as they do not include the influence of the adjacent span.

From this study it can be concluded that the model that better fits the observed response of the bridge is analysis case 1000-16-fix. Fig. 16 compares deformed shapes and failure modes obtained with validated analysis model 1000-16-fix to those observed in the real bridge. Excellent correlation is observed in the deformed shape both at the global level as represented by Fig. 16a and at the local level as represented by Fig 16b.The former shows overall vertical deflection and the latter shows web buckling in Girder 1 which also was the failure mode observed in the model 1000-16-fix.

\section{Additional Thermal and Structural Studies}

Using validated model 1000-16-fix, the following additional parameters that are not related to the model validation are examined: (1) a comparison of fire scenarios as 
represented by time-temperature curves obtained by CFD versus some standard curves and (2) the presence of live load. In addition, an examination of the thermal response of the case study Girder 1 is examined.

\subsection{Thermal Response of Case Study}

Fig. 17a shows the evolution along time of the temperature profiles of the cross section with " $\mathrm{x}$ " coordinate equal to $7.5 \mathrm{~m}$ (section where temperatures were maximal). A non linear thermal gradient is seen which causes mechanical strains (and therefore stresses) even if the structure is statically determinate and no gravity load is applied. Fig. 17b plots the evolution of temperatures at representative points of the same cross section. Temperatures in the steel-concrete interface are never higher than $500^{\circ} \mathrm{C}$ which justifies considering the bridge as composite as discussed in Section 4.4.

(a)

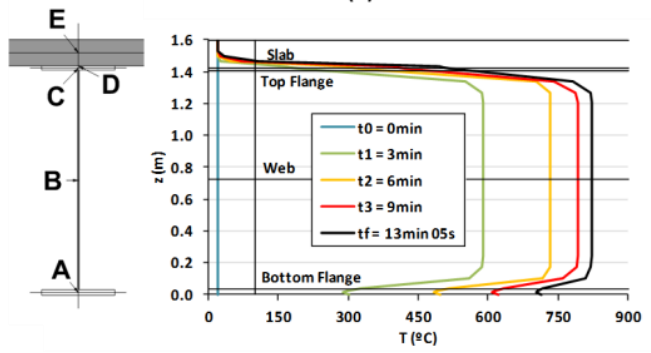

(b)

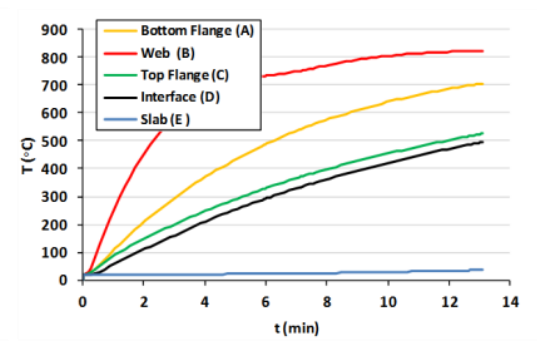

Figure 17. Section of Girder 1 located $7.5 \mathrm{~m}$ from the north end, analysis 1000-16-fix: (a) temperature distribution in the cross section at discrete points in time and, (b) temperature evolution at five points of the cross section of the bridge. All the points are in the vertical axis of the girder.

Fig. 18 displays the temperatures along the length of Girder 1 at the time of failure. There is a large variation of the temperatures along the bridge length. This variation is important to model as observed by the temperature discretization study of Section 5.2. Assuming a constant fire load along the bridge for mid-span or long-span bridges is therefore unrealistic. However, these temperatures do not experience big changes in the region directly affected by flames (region with " $x$ " coordinates between $4.65 \mathrm{~m}$ and $11.61 \mathrm{~m}$ ). This suggests that assuming a uniform fire load in short span bridges can be reasonable. 


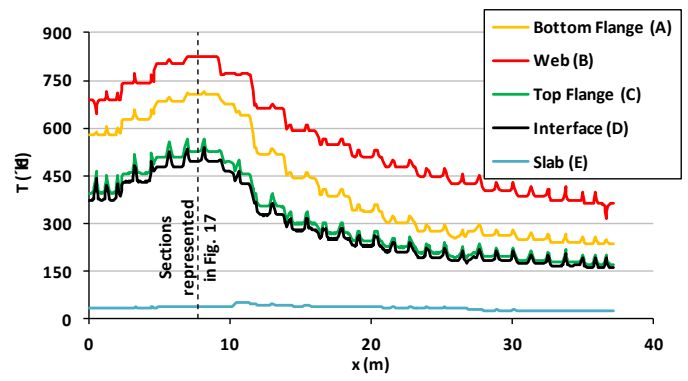

Figure 18. Girder 1 temperatures at the time of failure along the length at representative points of its cross section.

The temperature in the cross section also varies. In Figs. 17 and 18 it can be seen that temperatures range from 362 to $823^{\circ} \mathrm{C}$ in the mid-web, from 237 to $702^{\circ} \mathrm{C}$ in the bottom flange and from 166 to $530^{\circ} \mathrm{C}$ in the top flange.

The peaks and valleys in the curves of Fig. 18 are due to conductive heat transfer phenomena between the stiffeners and the bottom and top flanges of the girder. This phenomenon appears when the thickness of the stiffeners is different from the thickness of the web. The element with smaller thickness is heated up more quickly and transfers part of its heat to the elements at lower temperatures which are in contact with it.

\subsection{Influence of Fire Scenario}

It is a common approach in fire engineering to test building elements with the standard fire curve proposed by the Part 1-2 of the Eurocode 1 [33]. On the other hand, PayaZaforteza and Garlock [17] have proposed the application of the hydrocarbon fire curve of Eurocode 1 [31] to short span bridges (up to $12.20 \mathrm{~m}$ ). This section compares the response of the case study girder when subjected to the following three fire scenarios: (1) the "CFD" modeled fire presented in this paper simulating the real fire event, (2) the "standard" fire curve for building elements by the Eurocode 1; and (3) the "hydrocarbon" fire curve by the Eurocode 1. The FE model is based on validated model 1000-16-fix as discussed in Section 5.4. The results of this study are presented in Table 2 and Fig. 19 and are discussed next.

Fig. 19a plots the temperature in the middle of the web of Girder 1 in the moment of failure for the fire scenarios analyzed. It is seen that along the length of the girder, the thermal response is very different: whereas the Eurocode fire curves heated the web uniformly along the length until temperatures of $716^{\circ} \mathrm{C}$ (standard) and $762^{\circ} \mathrm{C}$ (hydrocarbon) were reached, the CFD simulated fire resulted in very variable 
temperatures along Girder 1 , with peak values of $824{ }^{\circ} \mathrm{C}$ and valley values of $313{ }^{\circ} \mathrm{C}$. Similar results are obtained when top and bottom flanges temperatures are analyzed.

(a)

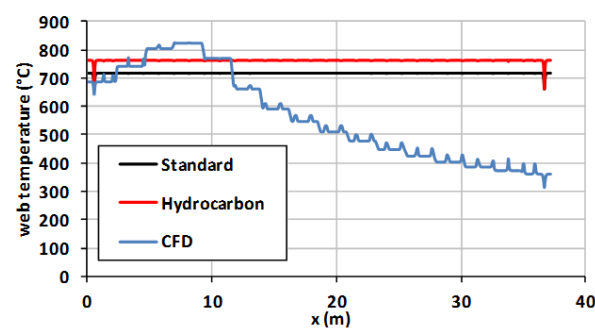

(b)

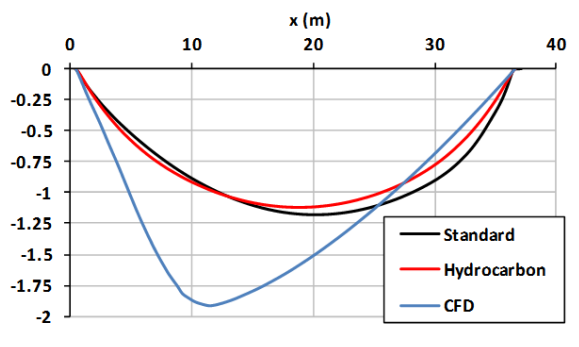

Figure 19. Influence of the fire scenario used to heat Girder 1: (a) temperatures in the web at the time of failure, (b) vertical deflections at the time of failure.

As a result of the variation in temperatures, the structural response of the girder is also very different depending on the fire scenario. Fig. 19b shows the vertical deflections of the girder at the time of failure. The final shape of the girder when heated with the Eurocode fires (building and hydrocarbon) is similar and the maximum deflections are around $1.15 \mathrm{~m}$ in both cases, thus $40 \%$ smaller than the maximum deflections obtained when the bridge is heated with the CFD simulation.

Table 2 shows that the times to failure are very different: $17.4 \mathrm{~min}$ for the Eurocode building fire, $5.3 \mathrm{~min}$ for the Eurocode hydrocarbon fire and $13.1 \mathrm{~min}$ for the CFD simulation. Therefore, the Eurocode building fire curve overestimates the time to failure by $33 \%$ and the Eurocode hydrocarbon fire curve underestimates the time to failure by 59\% compared to the CFD fire simulation. The smaller times to failure of the hydrocarbon curve can be explained by the fact that temperatures in the girder when the hydrocarbon fire is used are generally much higher than when the CFD model is used what results in (a) more loss of stiffness and resistance as the mechanical properties of the materials are temperature dependent and (b) more internal forces caused by the contact of Girder 1 with the the adjacent span because the thermal expansion of Girder 1 is bigger. 


\begin{tabular}{|c|c|c|c|c|}
\hline \multirow{2}{*}{$\begin{array}{c}\text { Fire Scenario } \\
\text { Name }\end{array}$} & \multirow{2}{*}{ Description } & \multicolumn{3}{|c|}{ Failure } \\
\hline & & $\begin{array}{l}\text { Time } \\
\text { (min) }\end{array}$ & Mode $^{a}$ & $\begin{array}{c}\text { Maximum } \\
\text { deflection }(\mathrm{m})\end{array}$ \\
\hline CFD & $\begin{array}{l}\text { Validated model of case } \\
\text { study }(1000-16-\text {-fix })\end{array}$ & 13.1 & LB, R, S, WB & 1.91 \\
\hline Standard & Eurocode (EC-1 Part 1-2) & 17.4 & LB, WB, S & 1.19 \\
\hline Hydrocarbon & Eurocode (EC-1 Part 1-2) & 4.3 & LB, WB, S & 1.14 \\
\hline
\end{tabular}

Table 2. Fire scenario study description and results.

All the analyses predict the failure of the girder by web buckling but the location of the failure is different: north end in the CFD simulation and south end in the both Eurocode fires. Note that temperatures in the south end of the girder are much higher in models using Eurocode fire curves than in the model using the CFD simulation, which explains the change in the location of the failure.

From this study, it seems that any fire whose footprint is less than the length of the bridge may not be conducive to the use of the standard or hydrocarbon fire curves over the entire length of the bridge deck. It may be more appropriate in those cases to apply the standard or hydrocarbon fire over a partial length of the bridge at the fire location and taper the fire temperatures according to the distance from the fire. Additional research is required to define how to scale standard curves up and down along the longitudinal axis of the bridge to make them represent real bridge fire scenarios.

\subsection{Influence of Live Load}

Finally, the influence of the live loads in the fire response of the bridge is analyzed. This study is motivated by the absence in the fire codes such as the Eurocode 1 Part 1-2 [33] or in the bridge standards such as the Eurocode 1 Part 2 [34] of any recommendation related to the live load to be considered when studying the fire response of a bridge. Previous work carried out by Paya-Zaforteza and Garlock [17] has found that live loads have very little influence, but this conclusion was obtained for a short span bridge with a span length of $12.2 \mathrm{~m}$. No studies have been done for medium-long span bridges as our case study.

Table 3 presents the four live load cases studied. The first one is the baseline case, which has no live load (only dead load) and represents the validated model 1000-16-fix described in Section 5. The next three cases modify the baseline case by adding three different values of live load: $1.2 \mathrm{kN} / \mathrm{m}, 2 \mathrm{kN} / \mathrm{m}$ and $4 \mathrm{kN} / \mathrm{m}$ representing $30 \%, 50 \%$ and $100 \%$ of the live load acting on Girder 1 according to the AASHTO LRFD Bridge Design 
Specifications [35]. This live load does not include any truck as the authors have not found any evidence of a truck crossing a bridge while it was on fire.

Table 3 and Fig. 20 summarize the main results, where Fig. 20 plots the evolution of maximum deflections over time. One notices that if live load is added, the times to failure decrease up to $13.7 \%$ when the full live load is acting. Maximum deflections do not appreciably change and the modes of failure and failure location remain the same: in every case, the girder experiences web buckling in the section located at $4.5 \mathrm{~m}$ of its north end accompanied by lateral buckling. The small influence of the live load can be explained by the fact that the dead load acting on Girder 1 is $17.8 \mathrm{kN} / \mathrm{m}, 4.4$ times more than the maximum live load acting on the same girder.

\begin{tabular}{cccc}
\hline \multirow{2}{*}{$\begin{array}{c}\text { Live Load } \\
\text { Combination }\end{array}$} & \multicolumn{3}{c}{ Failure } \\
\cline { 2 - 4 } & $\begin{array}{c}\text { Time } \\
(\mathbf{m i n})\end{array}$ & Mode $^{\mathrm{b}}$ & $\begin{array}{c}\text { Maximum } \\
\text { deflection }(\mathbf{m})\end{array}$ \\
\hline $\mathrm{G}^{\mathrm{c}}$ & 13.1 & LB, WB, S & 1.91 \\
$\mathrm{G}+0.3 \mathrm{Q}$ & 12.6 & LB, WB, S & 1.92 \\
$\mathrm{G}+0.5 \mathrm{Q}$ & 12 & LB, WB, S & 1.82 \\
$\mathrm{G}+\mathrm{Q}$ & 11.3 & LB, WB, S & 1.76 \\
\hline
\end{tabular}

a G: dead load; Q: live load

${ }^{\mathrm{b}} \mathrm{B}$ : Instability due to lateral buckling, R: Instability noticed by the movement of north (roller) end towards the center of span, S: Ultimate strain reached, WB: Instability due to web buckling on north side

${ }^{c}$ This baseline case with no live load is equal to analysis 1000-16-fix of Table 1

Table 3. Live load study description and results.

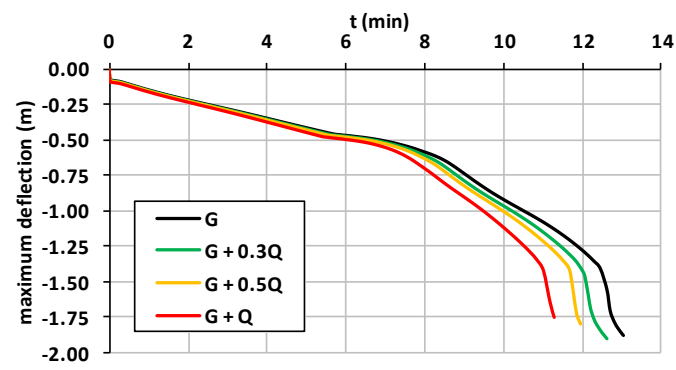

Figure 20. Influence of live load on the maximum deflection of Girder 1 over time. 
These results indicate that the amount of live load does not seem to have any representative influence from the engineering point of view in the fire response of steel girder bridges with span lengths up to $37 \mathrm{~m}$.

\section{Conclusions and future work}

Bridge fires are currently a major concern due to the number of fire events and corresponding social and economic consequences. However, there are very few studies on this topic and, in addition, experimental studies are difficult to conduct due to the large dimensions that bridge elements typically have and the fire loads required. Therefore, it is of major importance to develop numerical models to characterize bridges fire response. The validity of these models must be checked with data coming from real fire events.

In this paper, the authors have first developed numerical models to analyze the behavior of the I-65 overpass in Birmingham, Alabama, USA during the fire event that happened on January 5th 2002. These models have two components, a CFD model built with the software FDS and a thermo-structural model built with the software Abaqus. Numerical models proved to be able to accurately predict the behavior of the bridge. These models were then used to perform a parametric study related to the discretization of the fire load, the use of fire curves included in the codes, and the influence of the live loads acting on the bridge. Results of the study show that:

(1) Real fires produce a strong variation of the temperatures along the bridge. Therefore, assuming a constant fire load along the bridge for medium-span or long-span bridges is unrealistic.

(2) Temperatures do not experience big changes in the region directly affected by flames, (areas with " $\mathrm{x}$ " coordinate between 5 and $12 \mathrm{~m}$ in the case study analyzed in this paper), which suggests that assuming a uniform fire load in short span bridges is reasonable.

(3) Adiabatic temperatures obtained with the CFD model do not appreciably change within a given face of a girder cross section. Therefore, only one CFD model temperature sensor is necessary in each face of the girder where the temperatures are measured.

(4) When approximating adiabatic temperature curves with stepped curves, a step length of $2.33 \mathrm{~m}$ corresponding to $\mathrm{L} / 16$ ( $\mathrm{L}$ being the span length of the bridge) is recommended to obtain good results in bridges with span length around $37 \mathrm{~m}$. Note that span lengths or fire footprints different than those studied in this paper need additional study and might require a different step length. 
(5) Fire induces longitudinal movements in the bridge which are higher than the width of the expansion joint. Therefore, numerical models must be capable to take into account the influence of an adjacent span or abutment.

(6) The direct use in medium-span or long-span bridges of curves included in the codes such as the standard or the hydrocarbon fire is not advisable. Additional research is required to see how these curves can be scaled to represent real fire scenarios.

(7) The amount of live load acting on the bridge has little effect on its fire response.

(8) The numerical models proposed and validated in this paper are complex but can be used to perform a forensic engineering analysis of a bridge damaged by a fire and to study how bridge performance in fire events can be improved. Additionally, and if complementary experimental research and extensive parametric studies are carried out, these numerical models can be used to develop simpler design methodologies to assess the effects of fire on bridges.

Future work in this area might include the analysis of the entire bridge deck. By doing so, the numerical model could capture effects such as the load redistribution that happens when a bridge girder fails and reproduce the restraint imposed by the concrete slab to the displacements of the girders.

\section{Acknowledgements}

Funding for this research has been provided by the Spanish Ministry of Science and Innovation (research project BIA 2011-27104) and the Universitat Politècnica de València (Research and Development Support Program PAID-06-11). Funding has also been provided to Dr. Maria Garlock by the National Science Foundation (NSF) under award number CMMI-1068252. The authors are grateful to R. King from the Federal Highway Administration of the USA, J. Black and T. Colquett from the Alabama Department of Transportation, J. Glassman from Princeton University, J.V. Aguado from Ecole Centrale de Nantes and to J. Hidalgo from the University of Edinburgh for all the information and support provided. All opinions expressed in this paper are the authors' and do not necessarily reflect the policies and views of the sponsors.

\section{References}

[1] Chang S and Nojima N. Measuring post-disaster transportation system performance: the 1995 Kobe earthquake in comparative perspective. Transportation Research Part A 2001; 35: 475-484. 
[2] Zhu S., Levinson D, Liu HX, Harder K. The traffic and behavioral effects of the I35W Mississippi River bridge collapse. Transportation Research Part A: Policy and Practice 201044 (10): 771-784.

[3] Ghosn M, Moses F, Wang J. NCHRP Report 489. Design of Highway Bridges for Extreme Events. Transportation Research Board of the National Academies. Washington D.C., USA. 2003.

[4] Cheng J. Reliability analysis of the Sutong Bridge Tower under ship impact loading, Structure and Infraestructure, doi: 10.1080/15732479.2012.757792

[5] San Francisco Gate. The Maze Meltdown. www.sfgate.com. Accessed August 17, 2011.

[6] Chung P., Wolfe R.W., Ostrom T., Hida S. Editors. Accelerated Bridge Construction Applications in California- A "Lessons Learned. Report issued by the California Department of Transportation, 55 pages. 2008.

[7] 6 abc action news. Driver killed in fiery truck crash on NJ Turnpike. www.abclocal.go.com/wpvi/index. Accessed November 28, 2012.

[8] New York State Department of Transportation. Bridge Fire Incidents in New York State (Private Correspondence with Prof. M. Garlock), New York State Department of Transportation, USA, 2011.

[9] Garlock ME, Paya-Zaforteza I, Gu L, Kodur V. Fire Hazard in Bridges: Review, Assesment and Repair Strategies. Engineering Structures 2012;35:89-98.

[10] Buchanan AH. Structural Design for Fire Safety. John Wiley \& Sons, Chichester, United Kingdom, 2002.

[11] Couto C, Vila Real P, Lopes N, Rodrigues JP. Buckling analysis of braced and unbraced steel frames exposed to fire. Engineering Structures 2013; 49: 541-59.

[12] Quiel SE, Garlock MEM, Paya-Zaforteza I. Closed Form Procedure for Predicting the Capacity and Demand of Steel Beam-Columns under Fire. ASCE Journal of Structural Engineering 2011; 137: 967-76.

[13] Gunalan S, Mahen Mahendran M. Development of improved fire design rules for cold-formed steel wall systems. Journal of Constructional Steel Research 2013; 88:33962 .

[14] López-Colina C, Serrano-López MA, Gayarre FL, del Coz-Díaz JJ. Stiffness of the component 'lateral faces of RHS' at high temperature. Journal of Constructional Steel Research. 2011; 67(12): 1953-65. 
[15] Moliner V, Espinos A, Romero ML, Hospitaler A. Fire behavior of eccentrically loaded slender high strength concrete-filled tubular columns. Journal of Constructional Steel Research 2013; 83:137-146.

[16] Seif M, McAllister T. Stability of wide flange structural steel columns at elevated temperatures. Journal of Constructional Steel Research, 2013; 84:17-26

[17] Payá-Zaforteza I, Garlock M. A numerical investigation on the fire response of a steel girder bridge. Journal of Constructional Steel Research 2012; 75: 93-103.

[18] Chen W, Duan L. Bridge Engineering Handbook. New York, 2000

[19] Mc Grattan K, McDermott R, Hostikka S, Floyd J. Fire Dynamics Simulator (version 5). User's Guide. NIST Special Publication 1019-5, Gaithersburg, MD, USA, 2010.

[20] Simulia. Abaqus/standard version 6.9 user's manual; 2009.

[21] Aziz E, Kodur V. An approach for evaluating the residual strength of fire exposed bridge girders. Journal of Constructional Steel Research 2013; 88: 34-42.

[22] Powerpoint presentation emailed to Prof. Maria Garlock by Robert King of the Alabama Department of Transportation on July 8, 2010.

[23] Barkley T, Strasburg G. Bridge Rebuilt on the Fast Track. Public Roads 2002; 66(2).

[24] Wickstrom U, Dat Duthinh D, McGrattan K. Adiabatic Surface Temperature for Calculating Heat Transfer to Fire Exposed Structures. Interflam 2007. September 2007, Vol. 2: 943-953.

[25] Mc Grattan K, McDermott R, Hostikka S, Floyd J. Fire Dynamics Simulator (Version 5). Technical Reference Guide. Volume 3: Validation. NIST Special Publication 1018-5, Gaithersburg, MD, USA, 2010.

[26] Alós-Moya J. Análisis del colapso frente al fuego del paso superior de la interestatal I-65 dirección Sur sobre la I-65 dirección Norte en el ramal Sur del intercambiador con la interestatal I-20/59 situado en Birmingham, Alabama, Estados Unidos. Analysis of the failure due to fire of the I-65 flyover in Birmingham, Alabama, United States. Master Thesis, In Spanish, Valencia, 2012.

[27] Mc Grattan K, Hostikka S, Floyd J, Baum H,Rehm R, Mell W, McDermott. Fire Dynamics Simulator (Version 5). Technical Reference Guide. Volume 1: Mathematical model. NIST Special Publication 1018-5, Gaithersburg, MD, USA, 2010. 
[28] Tewarson, A. Generation of Heat and Chemical Compounds in Fires, In: Walton, W.D. editor. SFPE Handbook of Fire Protection Engineering, 4th edition, Quincy, MA. 2008, Section 3, Chapter 4, p. 3/82-161.

[29] Peris-Sayol G, Alós-Moya J, Payá-Zaforteza I, Hospitaler-Pérez A. A parametric study on the thermo-mechanical response of a multi-girder steel bridge submitted to real fires. Informes de la Construcción 2014, Accepted for publication

[30] Karlsson, B, Quintiere, J. G. Enclosure Fire Dynamics. Washington, D.C.: CRC Press, 1999.

[31] Quintiere, J.G. Surface Flame Spread, In: Beyler, C.L. editor. SFPE Handbook of Fire Protection Engineering, 4th edition, Quincy, MA. 2008, Section 2, Chapter 12, p. 2/246-257.

[32] European Committee for Standardization (CEN). EN 1994-1-2:2005 Eurocode 4 Design of composite steel and concrete structures, Part 1-2: General rules - Structural fire design, European Committee for Standardization. Brussels, Belgium. 2005.

[33] European Committee for Standardization (CEN). EN 1991-1-2:2002 Eurocode 1: Actions on structures - Part 1-2: General Actions - Actions on structures exposed to fire. Brussels, Belgium. 2002.

[34] European Committee for Standardization (CEN). Eurocode 1 Actions on Structures, Part 2: Traffic loads on bridges, European Committee for Standardization. Brussels, Belgium. 2003.

[35] American Association of State Highway and Transportation Officials (AASHTO). LRFD Bridge design specifications. Washington D.C, USA, 2009. 

Jose Alos-Moya, Ignacio Paya-Zaforteza, Antonio Hospitaler, Paula Rinaudo (2017)

"Valencia bridge fire tests: Experimental study of a composite bridge under fire"

Journal of Constructional Steel Research. Volume 138. pages 538-554 



\title{
Valencia bridge fire tests: Experimental study of a composite bridge under fire
}

\author{
Jose Alos-Moya $^{1}$, Ignacio Paya-Zaforteza ${ }^{*}$, Antonio Hospitaler ${ }^{1}$, Paula \\ Rinaudo $^{1}$
}

${ }^{1}$ ICITECH, Departamento de Ingeniería de la Construcción, Universitat Politècnica de València. Camino de Vera s/n, 46022 Valencia, Spain
Authors' e-mail addresses:
José Alos-Moya:
joalmo11@cst.upv.es
Ignacio Paya-Zaforteza: igpaza@cst.upv.es
Antonio Hospitaler: $\quad$ ahospitaler@cst.upv.es
Paula Rinaudo
pauri@alumni.upv.es

\begin{abstract}
The consequences of bridge fires and the lack of guidelines on the evaluation of the fire resistance of bridges have triggered a lot of recent research. Most of these studies are based on numerical models and thus need validation by experimental studies.
\end{abstract}

This paper aims to bridge this gap by describing a battery of open air fire tests carried out under an experimental bridge at the Universitat Politècnica de València in Valencia, Spain. The bridge, with a $6 \mathrm{~m}$ span and a composite deck with two steel I-girders supporting an RC slab, was submitted to four different fire scenarios similar to those of real bridge fires, although smaller in magnitude. Results show that: (a) maximum gas temperatures are reached in the region between the I-girders, (b) as gas and steel temperatures vary significantly along the longitudinal axis of the bridge, 
it is unrealistic to assume a longitudinally uniform gas or girder temperature (c) temperatures in the bottom flange and the web of the I-girders are very similar and significantly higher than top web temperatures, and (d) the magnitude of the fire load and its position are key factors in the bridge response. This study is of major importance as it enables the validation of the numerical models used in bridge fire engineering and is a crucial step towards the development of a performance-based approach for the design of bridges against fires. The information given will also be useful to those interested in carrying out open air experimental bridge fire tests.

Keywords: Valencia bridge fire tests; steel-concrete composite bridge; mass loss rate; bridge fire; bridge resilience.

* Corresponding author. Tel: +34 963875623; fax: +34 963877568

\section{Introduction}

As bridges are a critical component of the road transport infrastructure, a lot of effort has been put into designing them to withstand accidental extreme load events, such as earthquakes, winds, scour, and ship collisions (e.g. Ghosn et al. [1]). Recent studies (Peris-Sayol et al. [2], Wright et al. [3] and Garlock et al. [4]) have shown that fire is also a major hazard for bridges and highlight the lack of guidelines in current codes on how to estimate a bridge fire resistance.

The serious consequences that can arise from a bridge fire can be illustrated by two fire events: an overturned tanker truck in the MacArthur Maze in Oakland, USA on April 29th 2007 caused the collapse of two spans of the Maze. This collapse resulted in repairs and rebuilding operations costing more than US $\$ 9$ million [5] and indirect costs due to traffic detours of US $\$ 6$ million per day [6]. The second example is the fire caused by a tanker truck that overturned when crossing the Mathilde Bridge in Rouen (France) on October 29th 2012, caught fire and spilled fuel that set fire to some trucks parked under the bridge. The bridge suffered severe damage and had to be closed until August 26th 2014, almost two years afterwards. The total cost associated with this event has been estimated at $€ 18$ million [7].

Traditionally, fire engineering has paid a lot of attention to mitigating the effects of fires in buildings and tunnels (see e.g. Fischer and Varma [8], Gernay et al. [9], Rodrigues 
and Laím [10], Rinaudo et al. [11]). However, as can be seen in Table 1, bridge fires have specific features that distinguish them from building and tunnel fires, which together with the gap in the current codes, have generated a lot of research on this topic in recent years. Garlock et al. [4] carried out a detailed review of incidents, case studies and assessed repair strategies related to bridge fires. This study was complemented by Peris-Sayol et al. [2], who used statistical tools to collect and analyze data from 154 bridge fires and proposed a classification of bridge fire damage levels. The study showed that the bridge vertical clearance and deck material, the type of vehicle involved in the fire, the fuel carried by the vehicle and its position, were the main factors involved in the extent of bridge damage. Other researchers (Naser and Kodur [20], Gil et al. [21]) have proposed specific risk analysis methodologies, while others have used different approaches to study bridges fire response, including the use of fire curves (see e.g. the study on a steel girder bridge by Payá-Zaforteza and Garlock [12]), simplified methodologies based on the calculation of radiation heat fluxes applied to fires below steel and composite girder bridges (Quiel et al. [22]) or Computational Fluid Dynamics models of: (a) fire events below steel and composite bridges (Alós-Moya et al. [23], Peris-Sayol et al. [24, 25], Wright et al. [3]), (b) a fire event in a long-span truss bridge (Gong and Agraval [26]) and (c) fires below and on the deck of cable supported bridges (Gong and Agraval [27]).

Experimental work on bridge fires is quite scarce due to the dimensions of bridge elements and the fire loads required, being noteworthy the work by Aziz et al. [28], who experimentally and numerically analyzed the fire performance of steel girders similar to those used in bridges. The girders spanned $3.658 \mathrm{~m}$ and were uniformly heated along their length in a furnace with the standard fire curve. The work by Aziz et al [28] is an important contribution but it also has limitations that justify additional experimental research on bridge fires, including: (1) the standard fire curve is a cellulosic fire curve developed for building fires and is not representative of bridge fires, (2) bridge fires do not uniformly heat girders along their length and cross section, (3) bridge fires happen in the open air in conditions different to those in a furnace and (4) the bridge expansion joints should be considered in the experiments, since they can play a major role in the structural response, as has been shown by [12, 23-25].

Within this general context, this paper details the procedures and results of a battery of fire tests conducted on an experimental bridge with a composite deck at the campus of the Universitat Politècnica de València in Valencia, Spain. The tests described here are of major importance, because, as far as the authors know, this is the first time that an entire bridge has been submitted to a number of different realistic fire scenarios, although of smaller fire load magnitude, and a complete set of thermal and structural results is provided. These results could subsequently be used to calibrate the numerical models used in bridge fire engineering. The experimental validation of these models is crucial 
to adequately predict the damage fires can cause on bridges and therefore to increase bridge resilience through the development of a performance-based approach to protect bridges from fires. The paper also provides interesting qualitative and quantitative information on bridge fire response, as well as detailed information that will be useful to those interested in carrying out open air experimental tests involving bridge fires.

\begin{tabular}{|c|c|c|c|}
\hline & Bridge fires & Building fires & Tunnel fires \\
\hline Cause of the fire & $\begin{array}{l}\text { Collisions (e.g. tanker truck accident). } \\
\text { Ignition of construction materials (e.g. } \\
\text { wooden formwork) during construction. } \\
\text { Ignition of materials stored under the bridge. } \\
\text { For further information, see Garlock at al. [4] } \\
\text { and Peris-Sayol et al. [2]. }\end{array}$ & $\begin{array}{l}\text { Ignition of the materials stored in the } \\
\text { building }\end{array}$ & Collisions (e.g. tanker truck accident) \\
\hline $\begin{array}{l}\text { Type of fire and } \\
\text { fire development }\end{array}$ & $\begin{array}{l}\text { Hydrocarbon fire (in the most harmful case) } \\
\text { with fast heating rates and high fire } \\
\text { intensities (see Paya-Zaforteza and Garlock } \\
\text { [12]) } \\
\text { The fire is fuel controlled, there is no oxygen } \\
\text { limitation. } \\
\text { The heat feedback to the fuel surface in } \\
\text { girder bridges depends mainly on the flame } \\
\text { volume, the position of the fuel surface and } \\
\text { the bridge geometry (see Peris-Sayol et al. } \\
\text { [13]). }\end{array}$ & $\begin{array}{l}\text { The typical building fire is cellulosic. This } \\
\text { fire is less intense and results in lower } \\
\text { temperatures than a hydrocarbon fire. } \\
\text { The fire can be fuel or ventilation controlled. } \\
\text { Flashover can happen. } \\
\text { For further information see Buchanan and } \\
\text { Abu [15]. }\end{array}$ & $\begin{array}{l}\text { Hydrocarbon fire (in the most harmful case). } \\
\text { Tunnel fires can be fuel-controlled (then } \\
\text { unreacted air by-passes the burning vehicles), } \\
\text { or ventilation-controlled (with large amounts } \\
\text { of toxic combustion products or toxic } \\
\text { chemical species and incomplete combustion } \\
\text { products). } \\
\text { There is a heat feedback to the fuel surface } \\
\text { from the surrounding environment which } \\
\text { depends on parameters such as flame volume, } \\
\text { tunnel lining, tunnel cross sectional area and } \\
\text { tunnel ventilation. } \\
\text { For further information, see Ingason et al. } \\
\text { [17] }\end{array}$ \\
\hline Fire curves & No specific fire curves available & $\begin{array}{l}\text { Nominal fire curves such as the ISO- } 834 \text { and } \\
\text { the ASTM E1 } 19 \text { available. } \\
\text { Parametric fire curves available. See e.g. EC- } \\
1 \text { Part } 1-2[16]\end{array}$ & $\begin{array}{l}\text { Fire curves available, such as the modified } \\
\text { hydrocarbon HCM, RWS, RABT ZTV. See } \\
\text { ITA [18]. }\end{array}$ \\
\hline $\begin{array}{l}\text { Structural } \\
\text { engineering }\end{array}$ & $\begin{array}{l}\text { As design codes do not specify any fire } \\
\text { resistance for bridges, bridges are not } \\
\text { designed against fires and do not typically } \\
\text { have any type of fire protection. } \\
\text { Bridge span lengths and design loads are } \\
\text { usually much higher than in buildings. } \\
\text { Therefore, bridge steel members are usually } \\
\text { more slender and prone to failure modes not } \\
\text { so critical in buildings, such as web buckling. } \\
\text { (see Paya-Zaforteza and Garlock [12], } \\
\text { Glassman and Garlock [14]) }\end{array}$ & $\begin{array}{l}\text { Design codes specify the fire resistance } \\
\text { required in buildings. Therefore, buildings } \\
\text { are designed against fire hazards and can have } \\
\text { passive and/or active fire protection. }\end{array}$ & $\begin{array}{l}\text { Some guidelines (ITA [18], NFPA [19]) have } \\
\text { proposed design criteria for the fire } \\
\text { resistance of road tunnels. } \\
\text { As fire hazards are commonly considered in } \\
\text { tunnels, they can have passive and/or active } \\
\text { fire protection. }\end{array}$ \\
\hline Design objectives & $\begin{array}{l}\text { Loss of life is not a major issue as fatalities } \\
\text { are usually caused by the collision that } \\
\text { started the fire, not by the bridge collapse or } \\
\text { bridge damage. } \\
\text { The major issue is to ensure the bridge can } \\
\text { continue in operation and so avoid traffic } \\
\text { problems }\end{array}$ & Avoiding life loss is the major objective & Avoiding life loss is the major objective \\
\hline
\end{tabular}

Table 1. Differences among bridge, building and tunnel fires.

\section{Description of the experimental bridge}

The experimental bridge (see Fig. 1) was divided into three parts:

1) Two abutments built on a leveling slab that placed the lower surface of the deck girders at a height of $1.9 \mathrm{~m}$ above the top face of the leveling slab. This top face was taken as the reference level (level 0 in Fig. 1a) in the project. 
2) A composite steel-concrete deck formed by a $0.15 \mathrm{~m}$ thick concrete slab joined by shear studs to two IPE-160 steel girders. The deck was $6 \mathrm{~m}$ long and $2 \mathrm{~m}$ wide. The separation between the axes of the two IPE- 160 girders was $1 \mathrm{~m}$, with a $0.5 \mathrm{~m}$ overhang on each side. The girders were supported on the abutments by two unreinforced elastomeric bearings measuring 200x200x20 mm. A composite deck with I-girders was chosen because the analysis of bridge fire events by Peris-Sayol et al. [2] found this to be the most common structural system in bridges that had collapsed or suffered severe damage in fire events.

3) Two auxiliary steel frames used to fix the LVDT sensors used to record the vertical deflections of the deck during the tests.

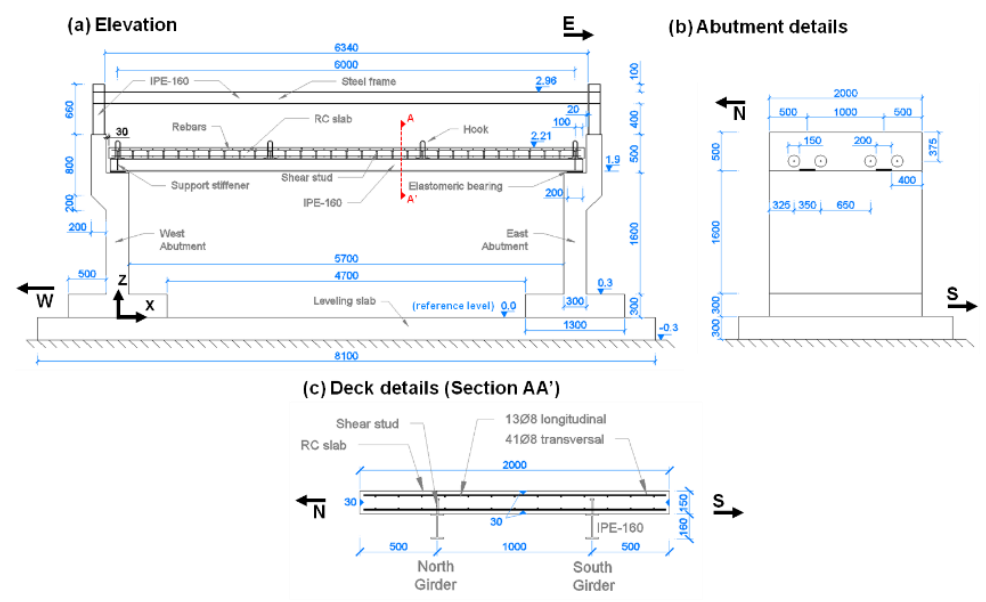

Figure 1. Experimental bridge: (a) Elevation, (b) Abutment details and (c) Deck details. All the dimensions are expressed in $\mathrm{mm}$. All the levels ( $\mathrm{z}$ coordinates) are expressed in $\mathrm{m}$.

Both the deck girders and the auxiliary frames were of S355JR steel. The deck slab and abutments were designed with a characteristic compressive strength obtained from cylindrical specimens at 28 days of 25 and $30 \mathrm{MPa}$, respectively. The reinforcing steel was B500S with $500 \mathrm{MPa}$ as characteristic yield strength. Section 2.5 contains further details on the mechanical properties of the materials used to build the bridge.

Regarding the design of the experimental bridge, it is important to note that:

1) The structural system tested is commonly used in short and medium span highway structures (Taly [29] and Llago and García [30]). This system is different to the typical composite floors used in buildings (see e.g. Taranath [31]), in which the concrete slab is supported by a steel deck anchored or welded to the I-girders. 
2) The bridge I-girders do not have any fire protection because bridges are not usually designed against fire hazards and therefore their steel elements are unprotected.

3) The bridge was not designed as a replica or reduced scale model of a specific bridge. The guiding principle of the bridge design and the experiments was to enable the study of some important aspects that previous studies [2,3,13,23-25] on bridge fires had highlighted, such as: (1) the impingement of the flames on the bridge deck, (2) the spread of flames, heat and smoke between two adjacent bridge girders, (3) the creation of significant longitudinal thermal gradients along the bridge girders and (4) the influence of the fire load position on gas and bridge temperatures.

4) The experimental bridge was designed without transverse diaphragms between the two girders, despite the fact that they are often found in real bridges. These elements could block the longitudinal flow of hot gases between two adjacent girders during a fire event and thus influence the temperatures of the gases around the structure. However, the authors considered that this influence would be small because: (a) the diaphragm depth is typically much smaller than the main girder depth (see e.g. the bridge analyzed in [12]) and (b) sometimes (see e.g. the bridge analyzed in [23]), the diaphragm is a truss structure and therefore is almost transparent to the flow of hot gases.

\subsection{Construction process}

The bridge was constructed in the following steps (see Fig. 2):

Step 1: Placing the formwork and pouring the concrete of the leveling slab to create a horizontal surface upon which to build the foundations of the bridge abutments.

Step 2: Erection of formwork and pouring of concrete for the abutments footings.

Step 3: Erection of formwork and pouring of concrete for the abutments walls. The abutments support both the deck under study and the steel frames used to measure the deflections.

Step 4: Placing girders and auxiliary frames.

Step 5: Placing the deck slab formwork supported by shores.

Step 6: Drilling small holes in six rebars of the lower longitudinal deck reinforcement and in three connecting bolts for the thermocouples.

Step 7: Placement of deck reinforcement with a concrete cover of $30 \mathrm{~mm}$. 
Step 8: Placing of nine thermocouples (TCs) to measure temperatures in rebars (6 TCs) and shear studs ( $3 \mathrm{TCs}$ ), and protecting the thermocouple connections to avoid damage while pouring the deck concrete. Placing conduits and auxiliary hooks for the thermocouples used to measure gas temperatures around the bridge and steel girders.

Step 9: Pouring and curing deck concrete.

Step 10: Removal of formwork and shores from the deck 50 days after concrete pouring.

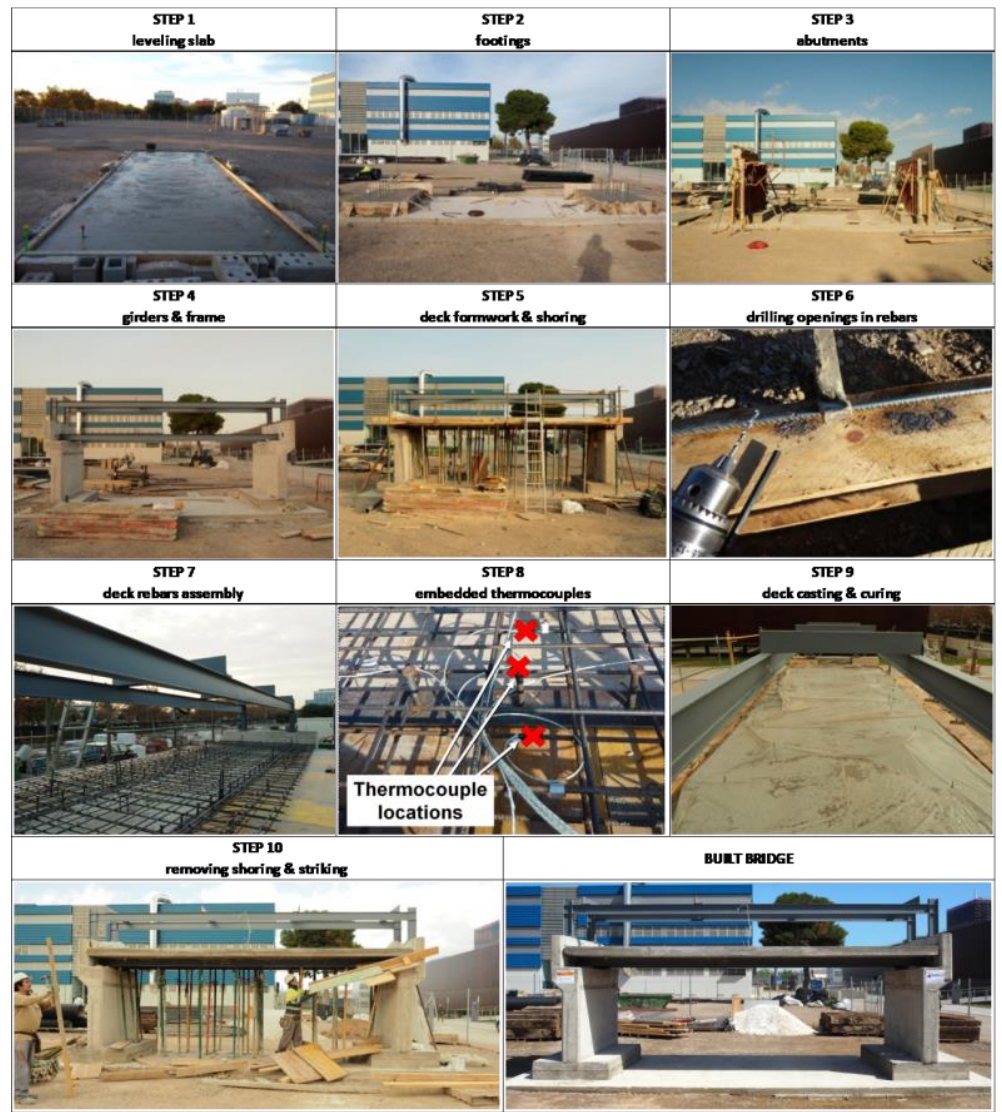

Figure 2. Construction process of the experimental bridge.

\subsection{Fire Scenarios}

\subsubsection{Preliminary tests}

Before carrying out the tests on the bridge itself, a series of preliminary tests were performed with the following aims: 
1) To characterize the fire loads under the bridge before the actual tests.

2) To confirm whether or not the gasoline could be ignited with safety.

3) To ensure that the protection of the weighing scale used to measure mass loss rate (see Section 2.3.1) would keep the scale temperature below $40^{\circ} \mathrm{C}$.

After these tests (Fig. 3) the following conclusions were drawn:

1) Winds above $2 \mathrm{~m} / \mathrm{s}$ strongly deflect flames (see Fig. 3b) and considerably distort the results achieved with no wind. For this reason, all the tests on the bridge were carried out with winds below this figure and a $2 \mathrm{~m}$ high fence was built around the site to reduce the effects of gusts during the tests.

2) The pans of fuel should only be ignited by the local Fire Department to guarantee the safety of personnel and equipment. Since gasoline gives off inflammable gases at ambient temperatures, the tests should begin immediately after pouring the gasoline into the pans.

3) The scale was adequately protected since the recorded temperatures were always lower than $40^{\circ} \mathrm{C}$.

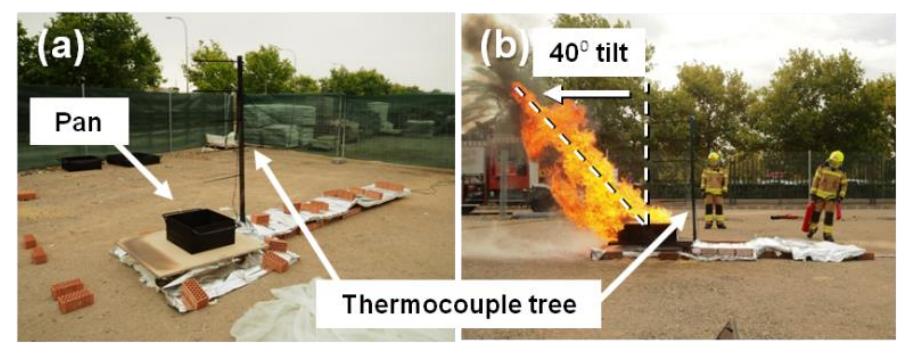

Figure 3. Preliminary tests: (a) Elements. (b) View of one of the tests.

\subsubsection{Bridge fire scenarios}

The experimental bridge was subjected to eight fire tests in four different scenarios involving different magnitudes and fire load positions (see Table 2 and Fig. 4). The fire load was always located under the bridge because the statistical analysis of bridge fires by Peris-Sayol et al. [2] shows that fires caused by tanker trucks cause the most damage and the most serious accidents are those in which the tanker is either immediately under the bridge or actually on the bridge but with significant oil spillage under the bridge.

Given the differences between bridge, building and tunnel fires (see Table 1) the fire tests used to study them should be different. In this sense, the present study differs from previous experimental work with composite floor slabs typically used in buildings (see e.g. Nadjai et al. [32], Li et al. [33], Baley and Toh [34]) as follows: (a) the general features of the structural system tested, (b) the use of gasoline as fire load, (c) the bridge 
tested was submitted to considerable longitudinal thermal gradients and was not uniformly heated along its length, (d) the Valencia bridge fire tests were carried out in the open air and not in a furnace or compartment.

Fire load magnitude is defined by the Heat Release Rate (HRR). As the Valencia bridge fire tests involved gasoline in two square pans, one with a side of $0.5 \mathrm{~m}$ and the other one with a side of $0.75 \mathrm{~m}$, according to Drysdale [35] the expected power corrected for the size effect was 415 and $1131 \mathrm{~kW}$, respectively.

The fire load position is defined by:

1) The level (" $z$ " coordinate) of the base of the pan containing gasoline, which varied between $0.2,0.5$ and $0.8 \mathrm{~m}$.

2) The " $x$ " coordinate (see Fig. 1) at the center of the fuel pan, which could have values of $3.00,5.27$ and $5.59 \mathrm{~m}$, according to whether the pan was placed at the center or near to the East abutment (see Table 2).

\begin{tabular}{|c|c|c|c|c|c|c|c|c|}
\hline \multirow{2}{*}{$\begin{array}{c}\text { Fire } \\
\text { scenario }\end{array}$} & \multirow{2}{*}{$\begin{array}{c}\text { Pan side } \\
s(\mathrm{~m})\end{array}$} & \multirow{2}{*}{$\begin{array}{c}\text { Fire } \\
\text { location }\end{array}$} & \multirow{2}{*}{ HRR $(\mathbf{k W})$} & \multirow{2}{*}{ Test } & \multirow{2}{*}{$\begin{array}{c}\text { Protection } \\
\text { board }\end{array}$} & \multirow{2}{*}{$\begin{array}{c}\text { Distance to } \\
\text { East Abutment (m) }\end{array}$} & \multicolumn{2}{|c|}{ Pan location } \\
\hline & & & & & & & $\mathbf{x}(\mathbf{m})$ & $z(\mathbf{m})$ \\
\hline \multirow{2}{*}{ Fire 1} & \multirow{2}{*}{0.5} & \multirow{2}{*}{ mid-span } & \multirow{2}{*}{415} & 1 & no & - & \multirow{2}{*}{3.00} & \multirow{2}{*}{0.2} \\
\hline & & & & 2 & no & - & & \\
\hline \multirow{2}{*}{ Fire 2} & \multirow{2}{*}{0.75} & \multirow{2}{*}{ mid-span } & \multirow{2}{*}{1131} & 3 & no & - & \multirow{2}{*}{3.00} & \multirow{2}{*}{0.2} \\
\hline & & & & 4 & no & - & & \\
\hline \multirow{3}{*}{ Fire 3} & \multirow{3}{*}{0.5} & \multirow{3}{*}{ lateral } & \multirow{3}{*}{415} & 5 & $1.65 \mathrm{~m}$ East & 0.33 & 5.27 & \multirow{3}{*}{0.5} \\
\hline & & & & 6 & $1.65 \mathrm{~m}$ East & 0.01 & 5.59 & \\
\hline & & & & 7 & no & 0.01 & 5.59 & \\
\hline Fire 4 & 0.75 & mid-span & 1131 & 8 & no & - & 3.00 & 0.8 \\
\hline
\end{tabular}

Table 2. Valencia bridge fire tests. Fire scenarios.

The following circumstances should be noted:

1) The fire load magnitudes in the experiments are smaller than the fire load of a typical tanker truck carrying gasoline. If the tanker surface is assumed to be 30 $\mathrm{m} 2(12 \times 2.5 \mathrm{~m})$ and a HRR per Unit of Area of $2400 \mathrm{~kW} / \mathrm{m} 2$ is considered according to Babrauskas [36], then the resulting HRR is $72 \mathrm{MW}$. Although there is a big difference in the HRR absolute value, it is not so relevant when the following circumstances are considered: (1) the research goals of the experimental campaign required several tests with the fire under the bridge but without the bridge suffering any major damage, (2) the temperatures in the steel girders in Test 8 were similar to those of real fire events, as explained in Section 3.2.3, (3) As Fig. 4 shows, the fire load in the tests was high enough to make the flames impinge on the deck, as usually happens in tanker truck fires under bridges, (4) economic, environmental and safety concerns ruled out the fire loads involved in a typical tanker truck accident. 
2) Due to the influence of the wind on the fire, two tests were performed for each of the Fire 1 and Fire 2 scenarios.

3) Fire 3 scenario was carried out to check the influence of (a) the abutments on the effects of the fire, with three tests at different distances between the edge of the pan and the abutment $(0.33$ or $0.01 \mathrm{~m})$ and $(\mathrm{b})$ the presence of an insulating board that partially protected the deck.

4) Test 8 involved the $0.75 \mathrm{~m}$ pan at $0.5 \mathrm{~m}$ higher than in Tests 3 and 4 , with the aims of subjecting the bridge to more intense thermal exposure, and obtaining a thermo-mechanical response closer to that found in previously studied accidents $[23,26,37]$.

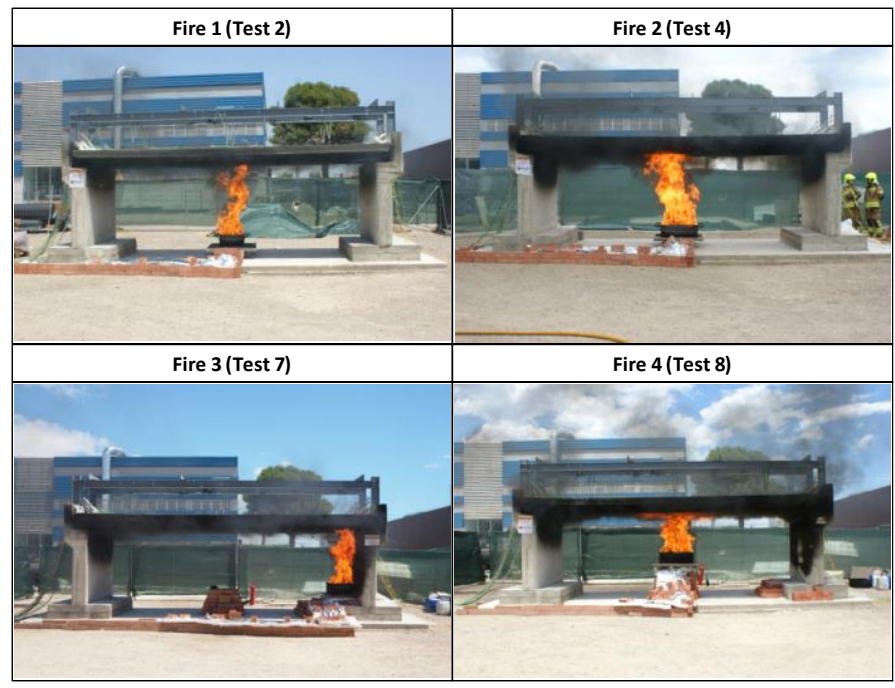

Figure 4. Views of fire tests corresponding to each fire scenario.

\subsection{Instrumentation}

During the tests three variables were continuously recorded: weight of fuel, gas surrounding the deck and deck temperatures, and vertical deflections at various points of the deck, by means of a weight scale, 72 thermocouples (TCs) and 22 LVDTs, as well as 17 high temperature fiber optic sensors. Additional information is given below on the location and installation of the monitoring systems, except for those of the new design of fiber optic sensors, since these were regarded as extra instrumentation and were installed to test their operation under actual fire conditions and will be the subject of a separate study. 


\subsubsection{Scale}

An industrial PCE-SD 300C scale able to weigh up to $300 \mathrm{~kg}$ to an accuracy of within $100 \mathrm{~g}$ was used to measure mass loss rate during the tests. Since it could only resist up to $40^{\circ} \mathrm{C}$ it had to be protected by a fire blanket with incombustible alkaline earth silicate panels (see Fig. 5), which also protected the cable that transmitted the signal from the scale through the zone of highest thermal exposure. Bricks were also used to protect the cable and scales and raise the scale to the appropriate level in each fire test. Radiant heat was mitigated by aluminum foil. During the tests two thermocouples were used to ensure that temperatures in the load cell and scale computer did not exceed $40^{\circ} \mathrm{C}$.

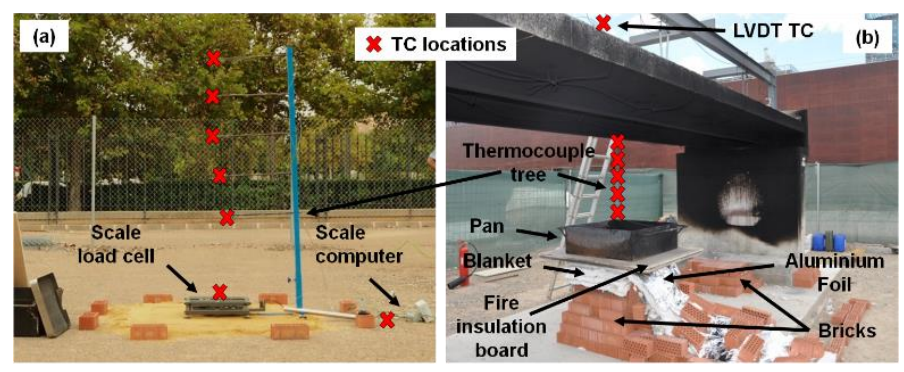

Figure 5. (a) Scale before placing protection for a preliminary test. (b) Scale protection with insulation blanket, insulation boards, bricks and aluminum foil.

\subsubsection{Thermocouples}

A total of 72 Type-K thermocouples were installed to measure temperatures, four of which recorded the temperature in the scale and over the deck, 23 measured gas temperatures around the bridge, 28 in the steel deck girders, 3 in the shear studs, and 6 in the rebars. A reference thermocouple was also used to record ambient temperatures. Seven thermocouples were used to check the correct operation of the high-temperature fiber optic sensors. Table 3 gives the main characteristics of the thermocouples used (see Sections 2.3.2.1 to 2.3.2.4 for further details).

\subsubsection{Control thermocouples}

A reference TC was used to measure ambient temperatures, two to check that the scale temperature remained below $40^{\circ} \mathrm{C}$ and two others to monitor temperatures around the LVTDs.

\subsubsection{Gas thermocouples}

Twenty-three TCs arranged on 7 thermocouple trees (TCTs) were used to characterize the thermal field around the lower deck face: six were placed horizontally at $2.00 \mathrm{~m}$ above the reference level in the positions shown in Fig. 6, and a seventh was placed vertically over the fuel pan (also shown in Fig.6). Table 4 gives the " $x$ " and " $z$ " 
coordinates of the TCs of the vertical tree, identified as V1 to V5, with V1 nearest to the pan and V5 furthest away. The nomenclature of a thermocouple belonging to a horizontal TCT was in three characters: the first being " $G$ " as it measured gas temperatures, and the second could be "N", "C" or "S", according to whether it was in the North, Central or South region of the gas surrounding the deck (Fig. 6c). The third character varied between 1 and 6, according to the TC's longitudinal position (Sections S1 to S6 in Fig. 6a)

\begin{tabular}{|c|c|c|c|c|}
\hline Measurement & Distribution & Thermocouple location & Number of TCs & Name of TC \\
\hline Scale control & see Fig. 5a & under the isolation materials & 2 & SCALE1, SCALE2 \\
\hline LVDT control & see Fig. 5b & over the deck & 2 & LVDT1, LVDT2 \\
\hline \multirow{4}{*}{ Gas } & \multirow{4}{*}{ see Fig. 6} & vertical thermocouple tree & 5 & V1 to V5 \\
\hline & & South region & 6 & GS1 to GS6 \\
\hline & & Central region & 6 & $\mathrm{GC} 1$ to $\mathrm{GC} 6$ \\
\hline & & North region & 6 & GN1 to GN6 \\
\hline \multirow{6}{*}{ Steel } & \multirow{6}{*}{ see Fig. 7} & South girder - bottom flange & 6 & SG-BF1 to SG-BF6 \\
\hline & & South girder - web & 2 & SG-W1 to SG-W6 \\
\hline & & South girder - top flange & 6 & SG-TF1 to SG-TF6 \\
\hline & & North girder - bottom flange & 6 & NG-BF1 to NG-BF6 \\
\hline & & North girder - web & 2 & NG-W1 to NG-W6 \\
\hline & & North girder - top flange & 6 & NG-TF1 to NG-TF6 \\
\hline \multirow{2}{*}{ Slab } & \multirow{2}{*}{ see Fig. 8} & rebars at mid-span & 6 & RB1 to RB6 \\
\hline & & shear studs at mid-span & 3 & SS1 to SS3 \\
\hline $\begin{array}{c}\text { Fiber optic } \\
\text { sensor control }\end{array}$ & - & near the fiber optic sensors & 7 & TC-1 to TC-7 \\
\hline Reference & see Fig. 10 & on the monitoring table & 1 & REF \\
\hline
\end{tabular}

Table 3. Thermocouple distribution.

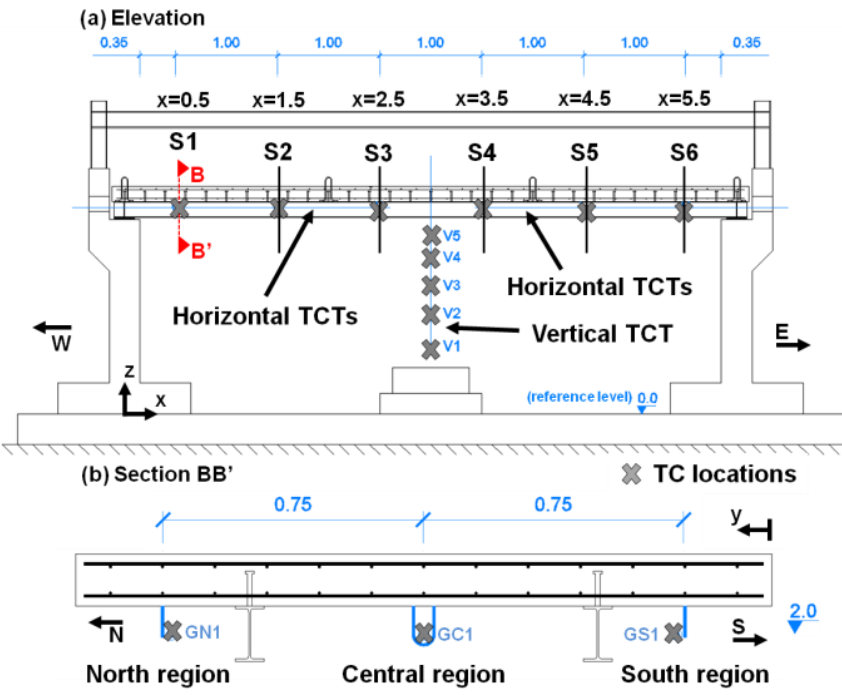

Figure 6. Gas thermocouple distribution. All dimensions are given in $\mathrm{m}$. 


\begin{tabular}{cccc}
\hline \multirow{2}{*}{ TC name } & \multicolumn{3}{c}{ zcoordinate $(\mathbf{m})$} \\
& Fire 1 \& 2 & Fire 3 & Fire 4 \\
\hline V5 & 1.73 & 1.95 & 1.89 \\
V4 & 1.54 & 1.69 & 1.73 \\
V3 & 1.24 & 1.41 & 1.54 \\
V2 & 0.99 & 1.13 & 1.44 \\
V1 & 0.65 & 0.85 & 1.25 \\
\hline
\end{tabular}

Table 4. Location of thermocouples in the vertical TCT.

\subsubsection{Steel thermocouples}

The 28 TCs installed in the girders were attached at the same transversal sections as those used to measure gas temperatures in order to acquire gas exposure temperatures and steel temperatures on both sides of the girders. The TCs were symmetrically distributed on both girders in two types of section (see Fig. 7).

1) Type A Section (SA in Fig. 7a). This section had three TCs in each monitored girder section. The sensors were placed on the web mid-point at the intersection of the top and bottom flanges with the web (see Fig. 7b).

2) Type B Sections (SB in Fig. 7a) with two TCs in each section placed on the web mid-point at the intersection of the bottom flange with the web of each girder (see Fig. 7c).

The nomenclature of the TCs placed on the steel has three parts: the first two characters identify the girder (SG: South Girder, NG: North Girder) while the position is indicated by one or two additional characters (BF: Bottom Flange, W: Web, TF: Top Flange) plus the section number (1 to 6 ).
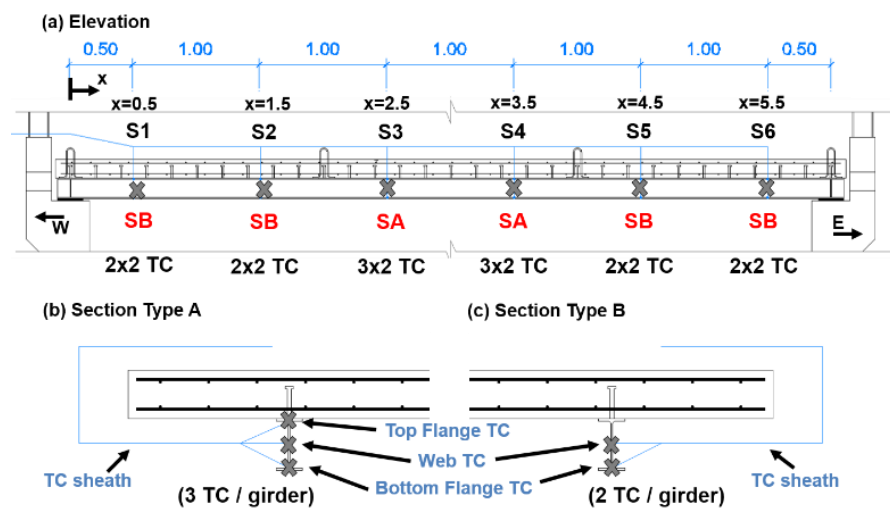

Figure 7. Steel thermocouple distribution. All dimensions are given in $\mathrm{m}$. 


\subsubsection{Concrete thermocouples}

Six of the nine TCs embedded in the concrete monitored temperatures in the longitudinal reinforcement rebars (TCs RB1 to RB6 in Fig. 8) and were placed in the section with $x$ $=3.00 \mathrm{~m}$. Transversal separation varied (see Fig. $8 \mathrm{~b}$ ), with four TCs between the two girders (RB2, RB3, RB4, RB5) and two (RB1 and RB6) located in the slab overhangs.

TCs SS1, SS2 and SS3 were in contact with the heads of three shear studs at $10 \mathrm{~cm}$ above the top flanges of the IPE-160 girders (see Fig. 8).

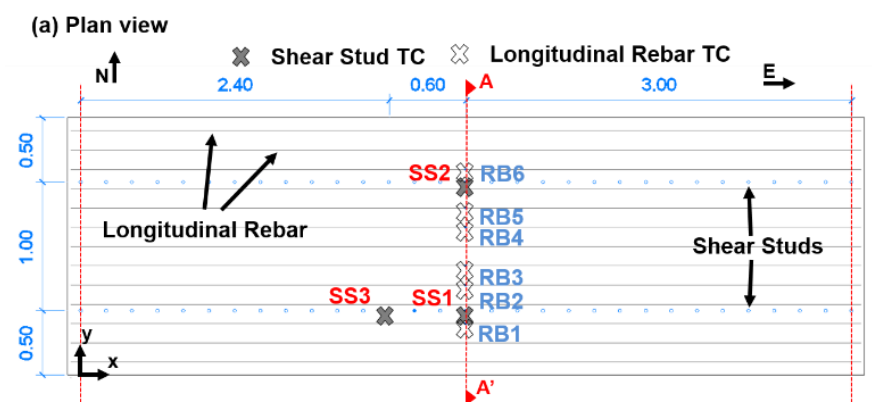

(b) Section AA'

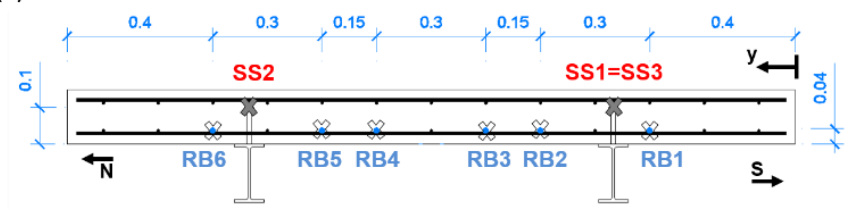

Figure 8. RC slab thermocouple locations. All dimensions are given in $\mathrm{m}$.

\subsubsection{LVDT}

Deck deflections were monitored by twenty-two $300 \mathrm{~mm}$ range LVDTs arranged as follows (Fig. 9):

1) Two LVDTs (L21 and L22) were placed on the auxiliary steel frames to detect length increments in the frames due to thermal expansions due to the temperature reached during the tests.

2) Eight LVDTs (L1, L2, L3, L4, L17, L18, L19, L20) measured horizontal deck movements at the expansion joints.

3) Twelve LVDTs (L5, L6, L7, L8, L9, L10, L11, L12, L13, L14, L15, L16) were arranged in pairs in V-formation along three sections on each girder to record deflection evolution in order to obtain duplicate readings at all six points during the tests and to measure horizontal displacements. 

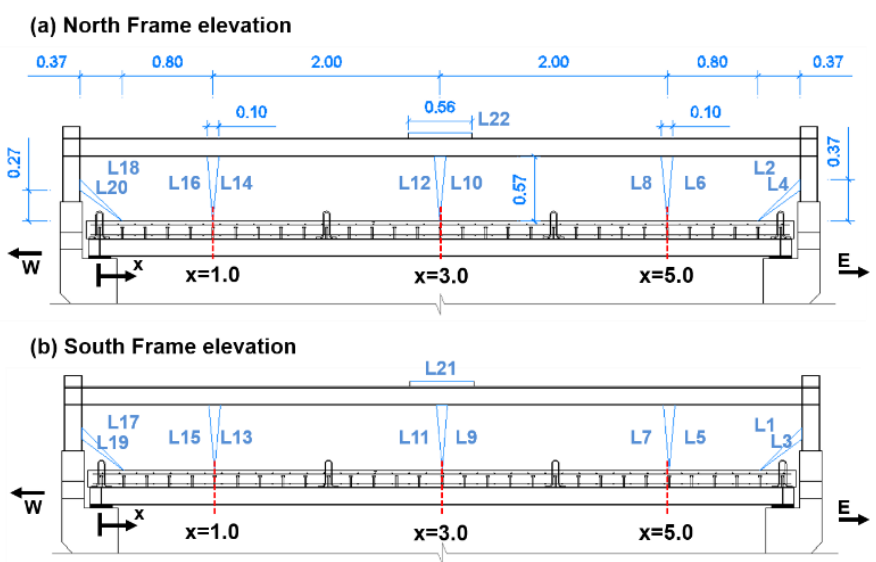

Figure 9. LVDT distribution. All dimensions are given in $\mathrm{m}$.

\subsubsection{High temperature fiber optic sensors.}

A series of high temperature sensors were installed to measure concrete, gas, and steel temperatures. These sensors were similar to those developed by Rinaudo et al. [38, 39] and were placed in the following locations:

1) Two multiplexed sensors were located at the mid-span section embedded in the concrete slab and measured concrete temperatures. Each sensor had three Fiber Bragg Gratings (FBGs) and measured temperatures at three different locations.

2) One multiplexed sensor was located at Section S3 (see Fig. 6), $0.5 \mathrm{~m}$ away from the mid-span bridge section. This sensor had two Regenerated Fiber Bragg Gratings (RFBGs henceforth) and measured gas temperatures at two different points, located 5 and $10 \mathrm{~cm}$ away from the RC slab bottom face.

3) One multiplexed sensor was located at Section S2 (see Fig. 6), located $1.5 \mathrm{~m}$ away from the mid-span bridge section. This sensor had three RFBGs and measured gas temperatures at three different pointes, located 5, 9 and $13 \mathrm{~cm}$ away from the RC slab bottom face.

4) Two sensors each one having a single RFBG were located at the junction of the bottom flange and the web of each steel girder. The sensors were $1.5 \mathrm{~m}$ away from the East abutment and measured steel temperatures.

5) Two multiplexed sensors with two RFBGs per sensor were located at the junction of the bottom flange and the web of each steel girder. Each one of these two sensors measured temperatures at points located 1.5 and $2 \mathrm{~m}$ away from the East abutment. 
The goal of installing fiber optic sensors was to test their operation under actual fire conditions. These sensors were installed as a redundant monitoring, since they were not necessary to investigate the experimental response of the bridge during the fire tests. A detailed analysis of their behavior is the object of future research.

\subsection{Data recording}

Three different data acquisition systems were used for TCs, LVDTs and fiber optic temperature sensors. These readings were stored in separate computers due to the large quantities of data involved. Temperatures recorded by the TCs were registered by nine modules of eight channels: seven "USB TC-08" modules and two "FP-TC-120". The displacements detected by the LVDTs were recorded by a single 32-channel cDaq-9205 module. The temperature readings from the USB TC- 08 modules could be monitored during the test by means of the Picolog software in the USB TC-08 modules, while the rest of the readings could be visualized by the CEAD 11.36L software developed by ICITECH personnel.
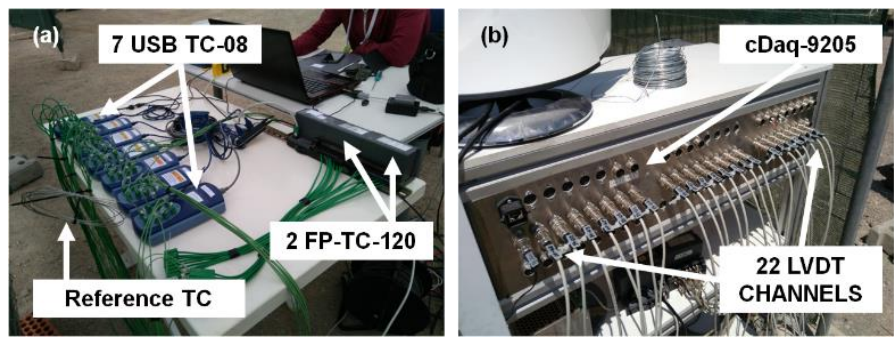

Figure 10. (a) Nine 8-channel thermocouple dataloggers and (b) 22 LVDTs extensions connected to the 32-channel data acquisition module

\subsection{Laboratory tests}

Four cylindrical $15 \mathrm{~cm}$ diameter x $30 \mathrm{~cm}$ long deck concrete specimens were obtained. These were kept close to the deck so as to undergo the same ambient conditions. The tests on the specimens provided a mean compressive strength of $33 \mathrm{MPa}$ as well as a mean modulus of elasticity of $33.8 \mathrm{GPa}$.

Four specimens from the web and four from the IPE-160 flanges from the batch to which the deck girders belonged were subjected to tensile tests, obtaining elastic limits of 377 and $344 \mathrm{MPa}$ and yield strengths of 512 and $465 \mathrm{MPa}$ in flange and webs, respectively.

Four $8 \mathrm{~mm}$ diameter rebars and three $12 \mathrm{~mm}$ diameter rebars from the B500S steel batch used for the deck slab reinforcement were traction tested, obtaining a mean elastic limit 
of 546 and $537 \mathrm{MPa}$ and a mean yield strength of 644 and $624 \mathrm{MPa}$ for $8 \mathrm{~mm}$ diameter rebars and $12 \mathrm{~mm}$ diameter rebars, respectively.

\section{Results and discussion}

\subsection{Mass loss rate}

Table 5 compares the mass loss per surface unit obtained experimentally with the theoretical mass loss per unit according to [36]. The table includes the mass loss rate obtained experimentally without the existence of the bridge (see Section 2.2.1) in order to verify whether the bridge had an influence on this value. It can be seen that the experimental values oscillate between 0.030 and $0.043 \mathrm{~kg} / \mathrm{m} 2 \mathrm{~s}$ for the $50 \mathrm{~cm}$ pan with a theoretical value of $0.038 \mathrm{~kg} / \mathrm{m} 2 \mathrm{~s}$, while for the $75 \mathrm{~cm}$ pan the experimental values are between 0.046 and $0.055 \mathrm{~kg} / \mathrm{m} 2 \mathrm{~s}$ with a reference theoretical value of $0.046 \mathrm{~kg} / \mathrm{m} 2 \mathrm{~s}$. Figure 11 shows the curves from which Table 5 was obtained and compares them with the theoretical values represented by the dotted lines.

\begin{tabular}{cccc}
\hline Test & $\begin{array}{c}\text { Mass loss rate }\left(\mathbf{k g} / \mathbf{m}^{\mathbf{2}} \mathbf{s}\right) \\
\text { theoretical }\end{array}$ & $\begin{array}{c}(\boldsymbol{\%}) \\
\text { difference }\end{array}$ \\
\hline Preliminary 50 & 0.037 & 0.038 & $-2.5 \%$ \\
Test 1 & 0.043 & 0.038 & $13.3 \%$ \\
Test 2 & 0.039 & 0.038 & $1.5 \%$ \\
Test 5 & 0.041 & 0.038 & $8.5 \%$ \\
Test 6 & 0.030 & 0.038 & $-22.3 \%$ \\
Test 7 & 0.033 & 0.038 & $-12.3 \%$ \\
\hline Preliminary 75 & 0.050 & 0.046 & $8.6 \%$ \\
Test 3 & 0.052 & 0.046 & $13.9 \%$ \\
Test 4 & 0.046 & 0.046 & $0.9 \%$ \\
Test 8 & 0.055 & 0.046 & $18.7 \%$ \\
\hline Average 50 (six tests) & 0.037 & 0.038 & $-2.3 \%$ \\
Average 75 (four tests) & 0.051 & 0.046 & $10.5 \%$ \\
Average of Preliminary 50, Test 1, Test 2 and Test 5 & 0.038 & 0.038 & $0.0 \%$ \\
Average of Preliminary 75, Test 3 and Test 4 & 0.050 & 0.046 & $7.8 \%$ \\
Average of Test 6 and Test 7 & 0.031 & 0.038 & $-17.3 \%$ \\
\hline
\end{tabular}

Table 5. Experimental mass loss rate values. Differences (\%) expressed in \% of the theoretical values

(a) $50 \mathrm{~cm}$ pan tests

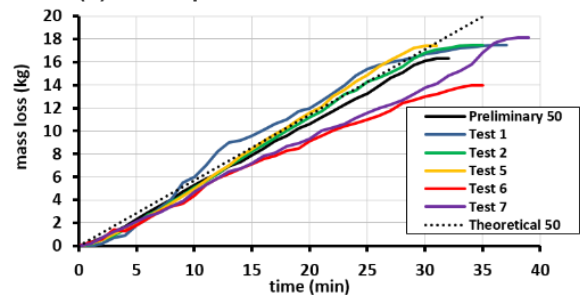

(b) $75 \mathrm{~cm}$ pan tests

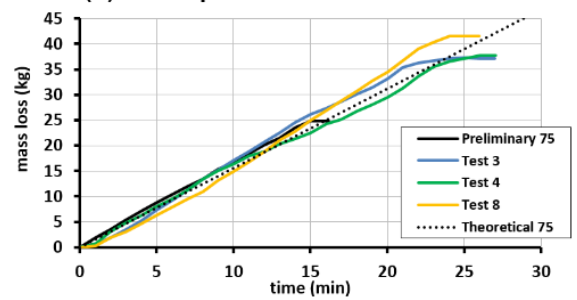

Figure 11. Mass loss evolution for (a) $50 \mathrm{~cm}$ side pan cases and (b) $75 \mathrm{~cm}$ side pan cases. 
In view of the results, it can be concluded that:

1) The experimental and theoretical mass loss rates are similar. The mean values are equal and $7.8 \%$ higher than theoretical for the 50 and $75 \mathrm{~cm}$ pans, respectively, if the singular cases (Tests 6,7 and 8 ), which had a considerable effect on mass loss rate, are not taken into account.

2) In spite of having reduced the wind effect (see Section 2.2.1), there were variations in mean mass loss rate of 11.8 and $13.0 \%$ in scenarios 1 and 2, respectively. In both cases, the tests with the strongest winds (1 and 3) showed the highest average value of mass loss per unit of area. In Fig. 12, the mass loss per unit of area per minute can be seen for the two tests in each of the scenarios 1 and 2. A curve is included to represent theoretical mass loss per surface unit in each case.
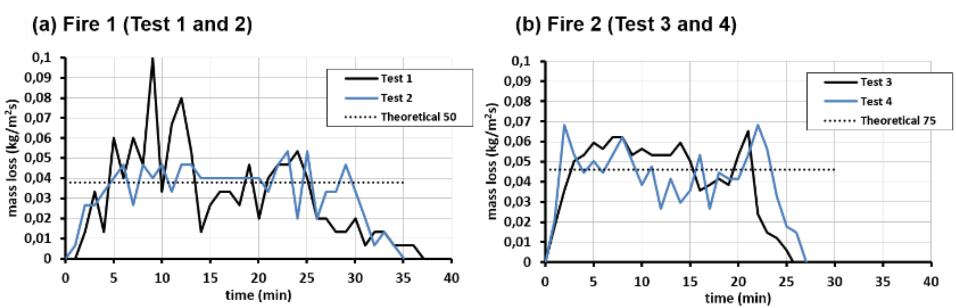

Figure 12. Mass loss rate evolution in time for (a) Fire 1 and (b) Fire 2.

3) Tests 6 and 7, in which the pan is close to the abutment, show a mean mass loss rate $17 \%$ lower than the other cases with the $50 \mathrm{~cm}$ pan, due to the lack of adequate ventilation on the pan side close to the abutment. Tests 6 and 7 , at the same height as Test 5 , have a $25.8 \%$ lower mass loss rate, due to the abutment reducing the supply of oxygen by approximately $25 \%$ ( 1 of 4 sides) by acting as a physical barrier preventing the circulation of air.

4) Test 8 had a mass loss rate $10.9 \%$ higher than that obtained in the three other tests with the $75 \mathrm{~cm}$ pan, due to the fire load being very close to the lower girder flanges $(1.1 \mathrm{~m})$, unlike Tests 3 and 4 , in which this distance was $60 \mathrm{~cm}$ greater $(1.7 \mathrm{~m})$. As the flames were closer, they spread further along the deck and increased the heat radiating surface over the pan itself. 


\subsection{Temperatures}

\subsubsection{Vertical thermocouple tree}

Table 6 shows the maximum values recorded by the five TCs (V1 to V5) on the vertical TC tree, while Figure 13 gives the time evolution of these temperatures in Tests 7 and 8. The temperature evolution in Tests 1 to 6 was not included, since these curves were quite similar to those of Test 7.

\begin{tabular}{ccccccc}
\hline $\begin{array}{c}\text { Test } \\
\text { name }\end{array}$ & GC1 & GC2 & GC3 & GC4 & GC5 & GC6 \\
\hline Test 1 & 141 & 175 & 268 & 288 & 166 & 139 \\
Test 2 & 164 & 205 & 326 & 288 & 172 & 148 \\
Test 3 & 264 & 362 & 607 & 644 & 378 & 279 \\
Test 4 & 279 & 389 & 707 & 737 & 431 & 323 \\
Test 5 & 99 & 105 & 115 & 139 & 200 & 224 \\
Test 6 & 93 & 93 & 102 & 115 & 162 & 153 \\
Test 7 & 133 & 151 & 184 & 234 & 289 & 546 \\
Test 8 & 422 & 639 & 941 & 921 & 594 & 504 \\
\hline
\end{tabular}

Table 6. Maximum temperatures recorded in the vertical thermocouple tree

The maximum temperatures in Tests 7 and 8 were in excess of 800 and $900^{\circ} \mathrm{C}$, respectively. In Test 7 the sensor temperatures were seen to be in proportion to their distance from the fire, due to a vertical separation of $25-30 \mathrm{~cm}$ between the TCs. In Test 8 the readings of all the sensors are similar due to their being arranged in a length of 65 $\mathrm{cm}$ because of the short distance between the pan and the deck.

(a) Test 7

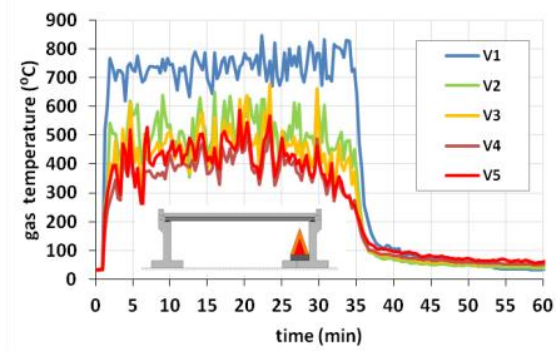

(b) Test 8

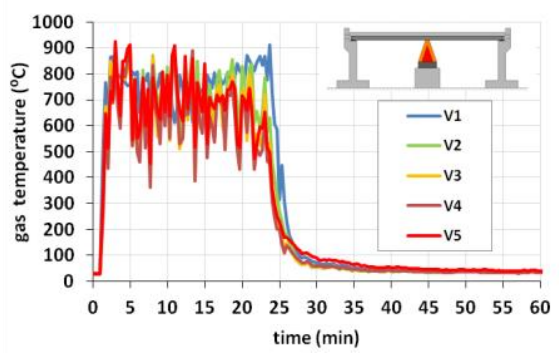

Figure 13. Temperatures recorded by vertical TCT: (a) Test 7 and (b) Test 8

\subsubsection{Gas temperatures}

Table 7 gives the maximum values reached by the six TCs (GC1 to GC6) in the central area between the two girders, while the evolution of these temperature in Tests 7 and 8 is shown in Figure 14. 


\begin{tabular}{cccccc}
\hline $\begin{array}{c}\text { Test } \\
\text { name }\end{array}$ & V1 & V2 & V3 & V4 & V5 \\
\hline Test 1 & 786 & 597 & 431 & 282 & 280 \\
Test 2 & 765 & 535 & 455 & 315 & 308 \\
Test 3 & 796 & 873 & 813 & 745 & 758 \\
Test 4 & 863 & 886 & 840 & 743 & 702 \\
Test 5 & 813 & 711 & 568 & 596 & - \\
Test 6 & 848 & 774 & 704 & 604 & - \\
Test 7 & 847 & 649 & 675 & 527 & 589 \\
Test 8 & 908 & 885 & 901 & 908 & 926 \\
\hline
\end{tabular}

Table 7. Maximum temperatures recorded in the gas between both girders.

In Figure 14 the temperatures recorded by TCs GC1 to GC6 can be seen to drop with the horizontal distance from the fire load. While in Test 7 (load close to the East abutment) the temperatures decrease from $500^{\circ} \mathrm{C}$ (GC6) to $280^{\circ} \mathrm{C}$ (GC5) in only $1 \mathrm{~m}$, in Test 8 they drop from $900^{\circ} \mathrm{C}(\mathrm{GC} 3)$ to $550^{\circ} \mathrm{C}(\mathrm{GC} 2)$ in the same distance. The thermal gradients for Tests 7 and 8 are therefore $220^{\circ} \mathrm{C} / \mathrm{m}$ and $350^{\circ} \mathrm{C} / \mathrm{m}$, respectively.
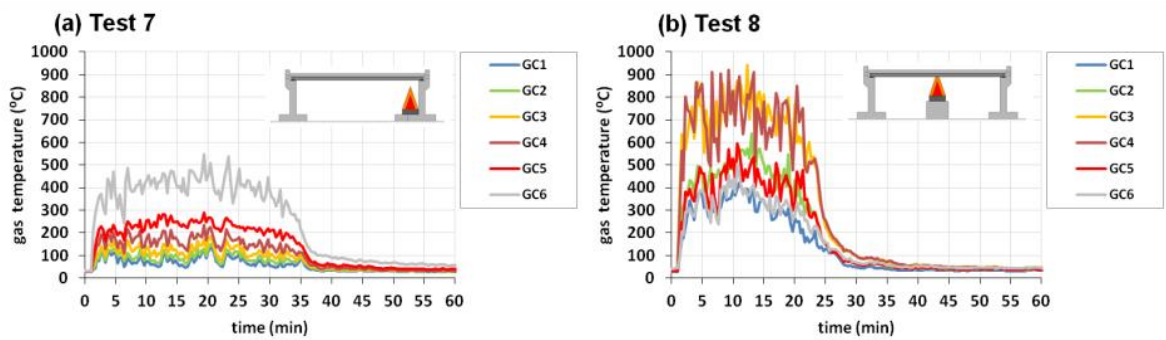

Figure 14. Temperatures recorded in the central region between the two bridge girders: (a) Test 7 and (b) Test 8.
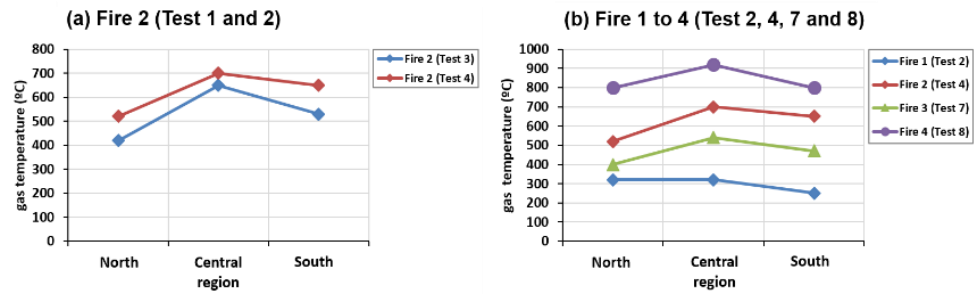

Figure 15. Maximum gas temperatures recorded per region: (a) Fire 2 and (b) four fire scenarios. 
Figure 15a gives the maximum gas temperatures registered in each of the regions studied (North, South, East and West) in the scenario Fire 2 (Tests 3 and 4). It can be seen that the central region over the fire load presents the highest temperature and that the wind has blown the flames towards the South. The maximum registered temperature differences between both tests in scenario Fire 2 reach $120^{\circ} \mathrm{C}$ at the sides and $60^{\circ} \mathrm{C}$ in the central zone, or around 30 and $10 \%$ of the maximum values registered at the sides and central zone, respectively.

Fig. 15b compares the different fire scenarios in Tests 2, 4, 7 and 8, from which the following conclusions can be drawn:

1) The maximum temperatures recorded by the horizontal TCTs were in the central region and reached $910^{\circ} \mathrm{C}$ in Test $8,700^{\circ} \mathrm{C}$ in Test $4,520^{\circ} \mathrm{C}$ in Test 7 and $310^{\circ} \mathrm{C}$ in Test 2.

2) The drop of $210^{\circ} \mathrm{C}$ in the central region between Tests 8 and 4 (both with the 75 $\mathrm{cm}$ pan) was due to the fire load in Test 8 being $1.1 \mathrm{~m}$ below the girder flanges, while in Test 4 this distance was $1.7 \mathrm{~m}$, or $60 \mathrm{~cm}$ greater.

3) The drop of $210^{\circ} \mathrm{C}$ in the central region between Tests 7 and 2 (both with the 50 $\mathrm{cm}$ pan) can be attributed to the flames reaching higher in Test 7 for two reasons: a) the fuel pan was $0.3 \mathrm{~m}$ higher in Test 7 , and b) in Test 7 , the pan containing the fuel was close to the East abutment, which reduced air entrainment by around 25\% and meant that the gasoline required a greater height to combine with the available oxygen [35].

4) The drop of $390^{\circ} \mathrm{C}$ in the central region between Tests 4 and 2 is due exclusively to the $63.4 \%$ lower heat release rate employed in Test 2 . This lower power not only reduced the height of the flames but also made the flames more susceptible to the effect of the wind.

5) The similarity of the temperatures in the North and Central regions in Test 2 is due to the flames being permanently inclined over these zones.
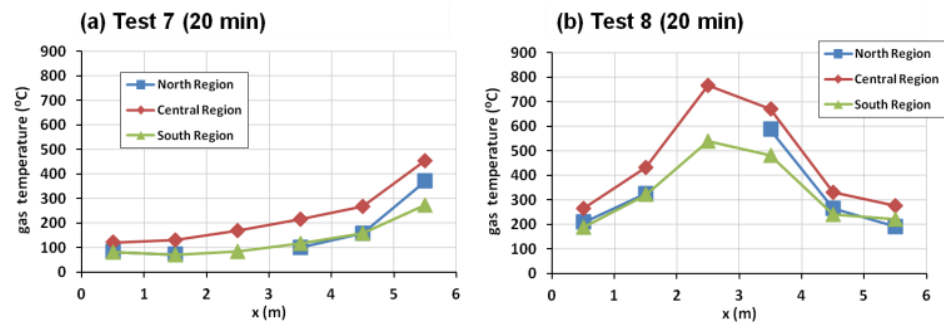

Figure 16. Gas temperatures recorded 20 minutes after the beginning of (a) Test 7 and (b) Test 8 
Fig. 16 gives the temperatures recorded by the gas sensors in the South, Central and North regions at 20 minutes after the start of the fire in Tests 7 and 8 . They show a considerable lateral temperature gradient in these three zones with maximum values of $212^{\circ} \mathrm{C} / \mathrm{m}$ in Test 7 and $377{ }^{\circ} \mathrm{C} / \mathrm{m}$ in Test 8 .

\subsubsection{Steel temperatures}

Table 8 gives the maximum temperatures recorded in each of the eight tests by the 28 TCs placed on the steel girders. The results are grouped by girders, with the bottom flange sensors first, followed by web and top flange sensors.

\begin{tabular}{|c|c|c|c|c|c|c|c|c|}
\hline North Girder & test 1 & test 2 & test 3 & test 4 & test 5 & test 6 & test 7 & test 8 \\
\hline NG-BF1 & 74 & 89 & 131 & 187 & 51 & 46 & 64 & 269 \\
\hline NG-BF2 & 113 & 138 & 206 & 288 & 49 & 48 & 75 & 459 \\
\hline NG-BF3 & 170 & 226 & 294 & 467 & 63 & 60 & 98 & 707 \\
\hline NG-BF4 & 163 & 215 & 279 & 442 & 97 & 88 & 144 & 727 \\
\hline NG-BF5 & 111 & 130 & 212 & 257 & 211 & 160 & 258 & 447 \\
\hline NG-BF6 & 79 & 93 & 135 & 170 & 386 & 283 & 469 & 303 \\
\hline NG-W1 & 83 & 92 & 151 & 190 & 57 & 52 & 78 & 278 \\
\hline NG-W2 & 124 & 147 & 236 & 291 & 61 & 56 & 93 & 479 \\
\hline NG-W3 & 165 & 215 & 337 & 451 & 71 & 66 & 110 & 713 \\
\hline NG-W4 & 175 & 210 & 337 & 454 & 109 & 100 & 167 & 749 \\
\hline NG-W5 & 116 & 128 & 217 & 274 & 157 & 126 & 269 & 466 \\
\hline NG-W6 & 85 & 96 & 149 & 185 & 270 & 201 & 465 & 304 \\
\hline NG-TF3 & 138 & 173 & 278 & 356 & 70 & 64 & 98 & 568 \\
\hline NG-TF4 & 147 & 175 & 286 & 371 & 103 & 94 & 147 & 626 \\
\hline South Girder & test 1 & test 2 & test 3 & test 4 & test 5 & test 6 & test 7 & test 8 \\
\hline SG-BF1 & 89 & 101 & 165 & 207 & 58 & 51 & 75 & 287 \\
\hline SG-BF2 & 140 & 141 & 295 & 330 & 52 & 52 & 81 & 465 \\
\hline SG-BF3 & 232 & 214 & 459 & 512 & 62 & 64 & 99 & 725 \\
\hline SG-BF4 & 220 & 203 & 428 & 490 & 97 & 98 & 153 & 733 \\
\hline SG-BF5 & 130 & 132 & 245 & 292 & 200 & 192 & 271 & 475 \\
\hline SG-BF6 & 78 & 89 & 127 & 169 & 365 & 364 & 458 & 297 \\
\hline SG-W1 & 89 & 103 & 179 & 203 & 61 & 53 & 79 & 291 \\
\hline SG-W2 & 134 & 146 & 289 & 325 & 63 & 57 & 90 & 465 \\
\hline SG-W3 & 203 & 211 & 449 & 507 & 81 & 73 & 119 & 747 \\
\hline SG-W4 & 193 & 193 & 398 & 476 & 103 & 97 & 155 & 735 \\
\hline SG-W5 & 127 & 131 & 289 & 310 & 153 & 152 & 262 & 488 \\
\hline SG-W6 & 97 & 107 & 219 & 228 & 247 & 244 & 462 & 353 \\
\hline SG-TF3 & 133 & 149 & 295 & 380 & 54 & 53 & 77 & 543 \\
\hline SG-TF4 & 139 & 148 & 287 & 367 & 84 & 81 & 120 & 569 \\
\hline
\end{tabular}

Table 8. Maximum steel temperatures in ${ }^{\circ} \mathrm{C}$ recorded in the North and South Girder. 
Table 8 shows that:

1) Maximum steel temperatures in Tests $1,2,5$ and 6 were below $400{ }^{\circ} \mathrm{C}$, the critical temperature that marks the beginning of the reduction of the steel yield strength, according to EC-3 part 1-2 [40].

2) Maximum steel temperatures in Tests 3 and 4 were 459 and $512{ }^{\circ} \mathrm{C}$ respectively and were reached at the bottom flange of the South Girder (section S3 near midspan in Fig. 6). The maximum temperature in Test 7 was $469^{\circ} \mathrm{C}$ at the bottom flange of the North Girder (Section S6 close to the East abutment).
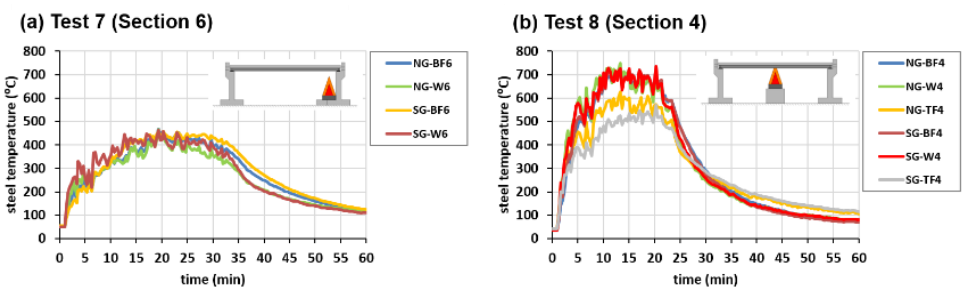

Figure 17. Steel temperatures in the hottest section: (a) Test 7 (Section 6) and (b) Test 8

(Section 4).

Fig. 17 gives the temperatures in the hottest sections in Test 7 (Section S6) and Test 8 (Section S4). The following comments can be made:

1) In both tests the bottom flange temperatures and web temperatures were quite similar. These temperatures were around $430^{\circ} \mathrm{C}$ in Test 7 and $700^{\circ} \mathrm{C}$ in Test 8 .

2) In Test 8 (see Fig.17b) maximum top flange temperatures were around 550 and $600^{\circ} \mathrm{C}$ and were between 100 and $150^{\circ} \mathrm{C}$ below the maximum temperatures recorded in the webs and bottom flanges. This temperature difference was due to (a) the bottom flange and the web having more steel surface exposed to the fire than the top flange; and (b) the top flange being protected by the RC slab. This difference in temperatures was also observed in previous studies in which steel and composite I-girders used in bridges were uniformly heated (see e.g. Paya-Zaforteza and Garlock [12]) or submitted to realistic fire scenarios (see e.g. Alos-Moya et al. [23], Peris-Sayol et al. [24, 25],) or submitted to a standard fire in a furnace (Aziz et al. [28]).

3) Maximum steel temperatures in Test 8 varied between $569^{\circ} \mathrm{C}$ and $749^{\circ} \mathrm{C}$. These values are in the order of magnitude of those observed in real bridge fire events. The numerical model of the fire under the I-65 overpass in Birmingham, Alabama (USA) carried out by Alos-Moya et al. [23], estimated that the steel girders of the overpass reached peak temperatures between approximately $500^{\circ} \mathrm{C}$ and $800^{\circ} \mathrm{C}$. Similarly, Godart et al. [37] reported that significant areas of 
the Mathilde Bridge in Rouen (France) reached at least $600^{\circ} \mathrm{C}$ as a consequence of the fire under the bridge in 2012.

Figure 18 gives the temperature evolution of the TCs on the lower flange of the South Girder in Tests 7 and 8. The maximum gradients in the steel of the lower flange of the South Girder are $200^{\circ} \mathrm{C} / \mathrm{m}$ and $250^{\circ} \mathrm{C} / \mathrm{m}$ for Tests 7 and 8 , respectively, and are slightly lower than those recorded in the gas. The graphs of the sensors in the web and the North Girder are not shown for being similar to those given here.

(a) Test 7

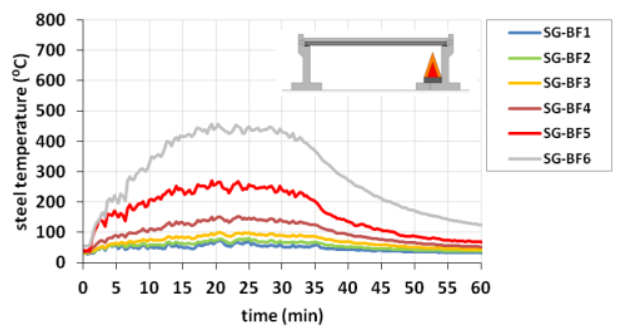

(b) Test 8

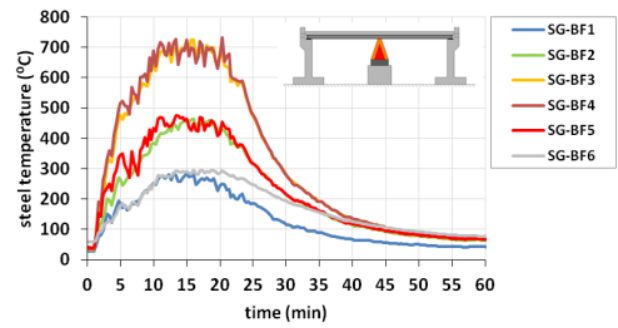

Figure 18. Steel temperatures on the bottom flange of the South Girder for (a) Test 7 and

(b) Test 8.

Figure 19 compares the maximum temperatures in different zones of the steel girders and different sections of the fire scenarios considered. Based on Figure 19a, it can be stated that:

1) There are no significant differences between the temperatures recorded in the web and bottom flange in any of the four scenarios studied.

2) There are considerable differences between the web and top flange temperatures as a result of the proximity of the slab: around $150^{\circ} \mathrm{C}$ for the scenario Fire 4 , $120^{\circ} \mathrm{C}$ for scenario Fire 2 and $40^{\circ} \mathrm{C}$ for scenario Fire 1.

3) In scenario Fire 4 the North girder temperatures are slightly lower (in lower flange, web and upper flange) as a result of the flames being blown towards the South.

4) As no information is available on the temperature of the top flange in Section 6 in scenario Fire 3, no assessment can be made of the gradient between the web and top flange.

Fig. 19b gives the maximum temperatures in each section (including both girders) for the four fire scenarios. Maximum gradients for scenarios Fire 1, Fire 2, Fire 3 and Fire 4 are $60,200,200$ and $250^{\circ} \mathrm{C} / \mathrm{m}$, respectively. In addition, taking Fire 2 as reference with a recorded maximum temperature of $500^{\circ} \mathrm{C}$, it can be seen that: 
1) There is a rise of $250^{\circ} \mathrm{C}$ beyond this temperature when the fire load position is raised from 0.2 to $0.8 \mathrm{~m}$ over the reference level.

2) There is a drop of $290^{\circ} \mathrm{C}$ below this temperature when the power is reduced by $63.4 \%$ of the $1135 \mathrm{~kW}$ of scenario Fire 2.

Finally, the representation of the scenario Fire 3 in Figure $19 \mathrm{~b}$ also shows that the longitudinal thermal gradient is reduced with horizontal distance from the fire.

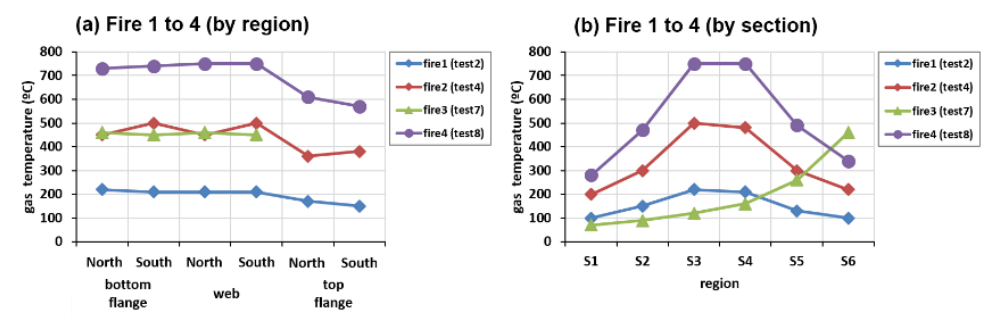

Figure 19. Maximum steel temperatures in four representative tests: (a) by region and (b) by section.

\subsubsection{Reinforced concrete slab temperatures}

The temperatures recorded in the reinforcing bars and shear studs of the RC slab were found to be between 69 and $190^{\circ} \mathrm{C}$ and 48 and $110^{\circ} \mathrm{C}$, respectively. The maximum values were reached in Test 8 . No concrete spalling was observed, which can be attributed to the low value of the concrete temperatures and the low moisture content of the slab.

\subsection{Deflections}

Measuring vertical deflections during a fire test is important to evaluate the damage caused by the fire to the structure and to obtain a set of data to calibrate the structural models of the fire tests.

Vertical deflections in the Valencia bridge fire tests were obtained by trigonometry from the displacement increments recorded by each pair of LVDTs. Table 9 gives the maximum deflections recorded by the LVDTs in the deck sections with coordinates $\mathrm{x}=$ 1,3 and $5 \mathrm{~m}$. It can be concluded that:

1) Even though Tests 3 and 4 belonged to the same fire scenario, in Test 3 the midspan maximum deflections were $29 \%$ lower due to the higher wind speed during this test.

2) Maximum deflections in Test 2 (Fire 1) were 67\% lower than Test 4 (Fire 2) as the fire load was reduced by $63.4 \%$ and the pan level was kept the same ( $\mathrm{z}$ coordinate equal to $0.20 \mathrm{~m}$ ). 
3) Both Test 8 (Fire 4) and Test 4 (Fire 2) involved a $1131 \mathrm{~kW}$ fire load. However, maximum deflections recorded in Test 8 increased by about $67 \%$ over Test 4 because the vertical distance between the fire load and girders was reduced by $0.6 \mathrm{~m}$.

\begin{tabular}{ccccccc}
\hline \multirow{2}{*}{$\begin{array}{c}\text { Test } \\
\text { name }\end{array}$} & \multicolumn{2}{c}{$\mathrm{x}=1.0 \mathrm{~m}$} & \multicolumn{2}{c}{ Vertical deflections $(\mathrm{mm})$} & \multicolumn{2}{c}{$\mathrm{x}=5.0 \mathrm{~m}$} \\
& North & South & North & South & North & South \\
\hline test 1 & 11 & 12 & 24 & 25 & 11 & 11 \\
test 2 & 11 & 11 & 24 & 24 & 11 & 10 \\
test 3 & 25 & 30 & 51 & 55 & 24 & 24 \\
test 4 & 34 & 38 & 71 & 73 & 33 & 32 \\
test 5 & 5 & 5 & 15 & 15 & 15 & 13 \\
test 6 & 4 & 4 & 12 & 12 & 11 & 11 \\
test 7 & 7 & 7 & 19 & 19 & 17 & 16 \\
test 8 & 57 & 57 & 121 & 120 & 59 & 56 \\
\hline
\end{tabular}

Table 9. Maximum vertical deflections ( $\mathrm{mm})$ for all the tests.

The following comments should be noted in regard to the horizontal displacements:

1) The maximum values were obtained in Test 8 (Fire 4 scenario) and were $14 \mathrm{~mm}$ on the East side and $11 \mathrm{~mm}$ on the West.

2) In the remaining tests horizontal displacements were in no case greater than $5 \mathrm{~mm}$.

3) Horizontal displacements were similar in all the tests.

4) No horizontal displacements were recorded by the LVDTs on the steel frames (L21 and L22), which indicates that the auxiliary frames did not experience any horizontal displacement that could have an influence on the measurements taken by L1 to L20.

The evolution of the maximum mid-span deflections in Tests 2, 4, 7 and 8 can be seen in Fig. 20. The following comments can be made:

1) Maximum vertical deflections of $121,71,24$ and $19 \mathrm{~mm}$ were reached in fire scenarios 4, 2, 1 and 3, respectively. Fig. 21 shows two views taken during Test 8 (Fire 4) in the period of the greatest slab deformation.

2) Similar vertical deflections were recorded in both girders, as also occurred in the sections at $x=1 \mathrm{~m}$ and $\mathrm{x}=5 \mathrm{~m}$, as can be seen in Table 7 .

3) The fact that maximum vertical deflections in the Fire 4 scenario were experienced for six minutes indicates that the composite deck reached an equilibrium state. During this period, the distance between the fire load and the steel girders was only $0.98 \mathrm{~m}$ due to the deck deflection of $0.12 \mathrm{~m}$.

4) No residual deflections were recorded after the tests had been carried out, which leads to the conclusion that the bridge deformations were caused by the reduction of the Young's modulus of the steel girders and by the thermal 
expansion of the girders. The lack of residual deformations after the tests also indicates that the girders did not suffer any plastic damage.
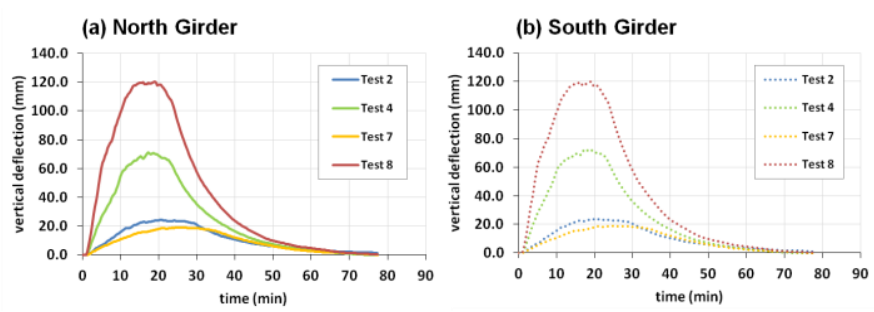

Figure 20. Vertical deflection at mid-span for (a) North Girder and (b) South Girder
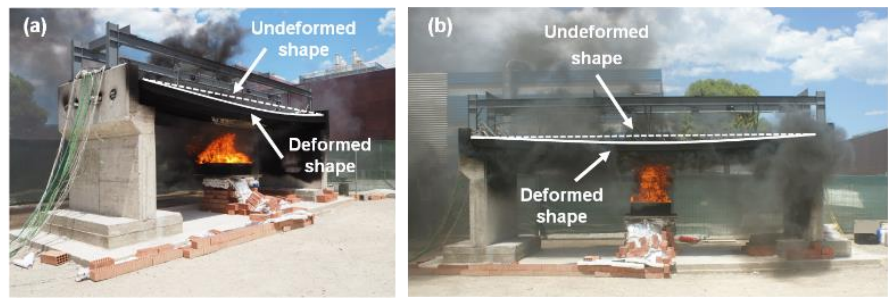

Figure 21. Test 8: (a) perspective view and (b) front view of bridge showing the maximum vertical deflection reached.

\section{Conclusions and future work.}

The serious consequences of bridge fires and the failure of current codes to give guidance on estimating a bridge fire resistance give rise to the need to develop a performancebased approach to bridge fire protection. This approach could be based on the results of numerical models, but would also require experiments to (1) enable the calibration of the numerical models and (2) provide useful quantitative and qualitative information on bridge fires.

Despite its importance, experimental work on bridge fires is quite scarce and the few existing studies do not reproduce some important bridge fire characteristics, such as the heating curves of hydrocarbon fires and the existence of longitudinal thermal gradients. In addition, previous experimental works do not analyze the influence of the expansion joints on the bridge response, the position of the fire load, or the vertical clearance.

Within this context, this paper describes two sets of fire tests conducted at the Universitat Politècnica de València in Valencia, Spain to improve current knowledge on the response of bridges to fires. The first set (called "preliminary tests") did not involve any bridge 
and were aimed at providing the authors with important information on how to perform open air fire tests efficiently and safely. The second set of fire tests involved a series of eight fires of different magnitudes and at different positions under a $6 \mathrm{~m}$ long I-girder composite bridge. This second set reproduced fire scenarios similar to those of real bridge fires, although smaller in magnitude. This decision to use smaller fire loads made it possible to use the experimental bridge in several tests and was also due to economic, safety and environmental reasons.

From both series of tests, the following conclusions can be drawn:

1) The experimental values of the mass loss rate are, in general, similar to the values proposed in the literature. Significant differences between the experimental and theoretical values were observed in Tests 6 and 7 (-17.3\% of average value) and Test $8(+18.7 \%)$ due to reduced air entrainment (Tests 6 and 7) and the increased deck exposure to radiation from the flames (Test 8).

2) Maximum gas temperatures are reached in the central region between the two girders and vary between $320^{\circ} \mathrm{C}$ (Fire 1 scenario) and $920^{\circ} \mathrm{C}$ (Fire 4 scenario).

3) Gas temperatures vary widely along the longitudinal axis of the bridge. For example, the average longitudinal thermal gradient is $350^{\circ} \mathrm{C} / \mathrm{m}$ for the Fire 4 scenario and $220^{\circ} \mathrm{C} / \mathrm{m}$ for Fire 3 . The temperatures in the steel girders also prove the existence of an important longitudinal thermal gradient $\left(250^{\circ} \mathrm{C} / \mathrm{m}\right.$ for Fire 4 scenario, $200^{\circ} \mathrm{C} / \mathrm{m}$ in Fire scenarios 2 and 3 , and $60^{\circ} \mathrm{C} / \mathrm{m}$ in the Fire 1 scenario. This means assuming a uniform gas or girder temperature along the longitudinal axis of the bridge is unrealistic, even for small span bridges, and should be avoided.

4) Maximum web and bottom flange girder temperatures are very similar and range between $220^{\circ} \mathrm{C}$ (Test 2, Fire 1) and $720^{\circ} \mathrm{C}$ (Test 8, Fire 4). Top flange temperatures are significantly smaller because the top flange is partially protected by the top RC slab.

5) The power of the fire and the vertical distance from the fire to the bridge deck have a strong influence on the response of the bridge. For example: (a) keeping the fire-deck distance constant $(1.7 \mathrm{~m})$ but reducing the power of the fire load from $1131 \mathrm{~kW}$ (Fire 2) to $415 \mathrm{~kW}$ (Fire 1) reduced the maximum vertical deflection of the deck by 67\%; (b) keeping the power constant $(1131 \mathrm{~kW})$ but reducing the vertical distance between the fire and the bottom flange from 1.7 (Fire 2) to $1.1 \mathrm{~m}$ (Fire 4) resulted in a $66 \%$ increase in the maximum deflections. The existence of this influence had already been foreseen in the analysis of a typical steel I-girder bridge carried out by Peris-Sayol et al. [18], but the experiments described here have verified it experimentally for the first time.

6) The maximum deflection registered in both girders was $120 \mathrm{~mm}$ in Fire 4, which had a power of $1131 \mathrm{~kW}$ and a distance between fire load and girders of $1.1 \mathrm{~m}$. 
The bridge recovered its initial geometry after the test and no plastic deformation in the steel girders or spalling in the concrete slab was observed.

7) Wind can have a very strong influence on open air fire tests. For example, Tests 3 and 4 were in the same fire scenario. However, the maximum mid-span vertical deflection in Test 3 was $29 \%$ smaller than in Test 4 . This effect was due to the higher wind speed in Test 3 , which deflected the flames. Wind speed should therefore be under a predefined threshold before conducting any open air fire test.

The results provided in this paper are of major importance for researchers and practitioners interested in protecting bridges from fires and in increasing bridge resilience since:

1) They provide a quantitative and qualitative idea of what happens to a bridge when a fire breaks out under its deck.

2) The data measured in relation to mass loss rate and gas temperatures can be used to validate the numerical models that analyze the fire event.

3) The data measured in relation to deck temperatures and deflections enables the validation of the thermo-structural models that give the response of the bridge through time.

4) These validated numerical models could then be used to predict: (a) the damage caused by fires to bridges and the bridges residual strength, (b) the damage reduction associated with different potential protection measures.

5) Furthermore, the information provided in this paper will be useful to anyone interested in carrying out open air experimental tests to study bridge fires.

Future work in this area should involve higher fire loads capable of causing substantial damage to a bridge in order to better study bridge residual strength and failure mechanisms. It would also be of great interest to carry out experimental tests with other deck structural systems and construction materials (e.g. prestressed concrete or boxgirders) as well as other bridge configurations (for example, fires under multi-span bridges).

\section{Acknowledgements.}

Funding for this research was provided by the Spanish Ministry of Science and Innovation (Research Project BIA 2011-27104). The authors are grateful to the Infrastructure and Safety departments of the Universitat Politècnica de València and the City of Valencia Fire Department (Cuerpo de Bomberos de Valencia), which provided crucial support in conducting the tests. Finally, the authors would like to thank Dr. Luke Bisby from the University of Edinburgh, and Dr. Juan Hidalgo and Dr. Cristian Maluk 
from the University of Queensland for their advice and support during the early stages of planning the fire tests.

\section{References}

[1] Ghosn M, Moses F, Wang J. NCHRP Report 489. Design of Highway Bridges for Extreme Events. Transportation Research Board of the National Academies. Washington D.C., USA. 2003.

[2] Peris-Sayol G, Paya-Zaforteza I, Balasch-Parisi S, Alos-Moya J. Detailed Analysis of the Causes of Bridge Fires and Their Associated Damage Levels. Journal of Performance of Constructed Facilities 2017; 31(3). doi: 10.1061/(ASCE)CF.1943-5509.

[3] Wright W., Lattimer B., Woodworth M., Nahid M., and Sotelino E. Highway bridge fire assessment draft final report. NCHRP Program Transportation Research Board of the National Academies. Virginia Polytechnic Institute and State University. Blacksburg, VA; 2013.

[4] Garlock ME, Paya-Zaforteza I, Gu L, Kodur V. Fire hazard in bridges: review, assesment and repair strategies. Engineering Structures 2012;35:89-98.

[5] San Francisco Gate. The Maze Meltdown. www.sfgate.com. Accessed Dec. 12, 2016.

[6] Chung P, Wolfe RW, Ostrom T, Hida S, editors. Accelerated bridge construction applications in California - a lessons learned. Report issued by the California Department of, Transportation; 2008.

[7] Le Figaro. "Pont de Rouen: le routier ne paiera pas les dégâts." "Rouen Bridge: the truck driver will not pay the damage." http://www.lefigaro.fr . Accessed Oct. 24, 2015. In French.

[8] Fischer EC, Varma AH. Fire resilience of composite beams with simple connections: Parametric studies and design. Journal of Constructional Steel Research 2017; 128: 119135. doi: 10.1016/j.jcsr.2016.08.004

[9] Gernay T, Elhami Khorasani N, Garlock M. Fire fragility curves for steel buildings in a community context: A methodology. Engineering Structures. 2016;113:259-276. http://dx.doi.org/10.1016/j.engstruct.2016.01.043

[10] Rodrigues JPC, Laím, L. Fire resistance of restrained composite columns made of concrete filled hollow sections. Journal of Constructional Steel Research 2017;133:6576.

doi: 10.1016/j.jcsr.2017.02.011 
[11] Rinaudo P, Paya-Zaforteza I, Calderón PA. Improving tunnel resilience against fires: A new methodology based on temperature monitoring. Tunnelling and Underground Space Technology 2016;52:71-84. DOI: 10.1016/j.tust.2015.11.021

[12] Payá-Zaforteza I, Garlock M. A numerical investigation on the fire response of a steel girder bridge. Journal of Construction Steel Research 2012;75:93-103.

[13] Peris-Sayol G, Paya-Zaforteza I, Balasch-Parisi S, Alos-Moya J. Analysis of the Factors that Influence the Maximum Adiabatic Temperatures in I-girder Bridges. 9th International Conference on Structures in Fire (SiF), Princeton, NJ, 2016, pages 743-750

[14] Glassman, JD, Moreyra Garlock ME. Compression model for ultimate postbuckling shear strength at elevated temperatures. Journal of Structural Engineering, 2017, 143(6): 04017023

[15] Buchanan A.H., Abu A.K. Structural design for fire safety. John Wiley \& Sons; 2017.

[16] CEN (European Committee for Standardization). Actions on structures, part 1-2: general actions - actions on structures exposed to fire. Brussels (Belgium), 2002.

[17] Ingason H., Li Y.Z., Lönnermark A. Tunnel fire dynamics. Springer; 2015. DOI 10.1007/978-1-4939-2199-7

[18] ITA (International Tunneling and Underground Space Association). Structural fire protection for road tunnels. ITA Report 18, 2017.

[19] NFPA (National Fire Protection Association). NFPA 502: Standard for road tunnels, bridges, and other limited highways. Quincy, MA, USA, 2017.

[20] Naser, MZ., Kodur VKR. A probabilistic assessment for classification of bridges against fire hazard. Fire Safety Journal 2015;76: 65-73.

[21] Gil H, Seo S, Park C. Fire Risk Management for Highway Bridges in Korea. IABSE Conference Geneva (Switzerland). Structural Engineering: Providing Solutions to Global Challenges. Report p. 890-896.

[22] Quiel S.E, Yokoyama T, Bregman L.S, Mueller K.A, Marjanishvili S.M. A streamlined framework for calculating the response of steel-supported bridges to openair tanker truck fires. Fire Safety Journal 2015;73:63-65.

[23] Alos-Moya J, Paya-Zaforteza I, Garlock MEM, Loma-Ossorio E, Schiffner D, Hospitaler A. Analysis of a bridge failure due to fire using computational fluid dynamics and finite element models. Engineering Structures 2014;68:96-110. 
[24] Peris-Sayol G, Alós-Moya J, Payá-Zaforteza I, Hospitaler-Pérez A. A parametric study on the thermo-mechanical response of a multi-girder steel bridge submitted to real fires (Estudio paramétrico de la respuesta termo-estructural de un puente metálico multijácena sometido a incendios reales). Informes de la Construcción 2014;66 ( $\mathrm{N}^{\circ}$ Extra-1):1-11 http://dx.doi.org/10.3989/ic.13.077 . In Spanish.

[25] Peris-Sayol G, Paya-Zaforteza I, Alos-Moya J, Hospitaler A. Analysis of the influence of geometric, modeling and environmental parameters on the fire response of steel bridges subjected to realistic fire scenarios. Computers and Structures 2015;158:333-345.

[26] Gong X, Agrawal AK. Numerical Simulation of Fire Damage to a Long-Span Truss Bridge. Journal Bridge Engineering 2015;20(10). doi: 10.1061/(ASCE)BE.19435592.0000707\#sthash.nhj5KqVo.dpuf

[27] Gong X, Agrawal AK. Safety of Cable-Supported Bridges during Fire Hazards. Journal of Bridge Engineering 21(4). doi: 10.1061/(ASCE)BE.1943-5592.0000870

[28] Aziz, EM, Kodur VK, Glassman, JD, Moreyra Garlock ME. Behavior of steel bridge girders under fire conditions. Journal of Constructional Steel Research 2016; 106:11-22. doi: 10.1016/j.jcsr.2014.12.001.

[29] Taly N. Design of modern highway bridges. McGrawHill, 1998.

[30] Llago Acero R., García Rodríguez P. Composite twin-girder bridges: a competitive solution for medium span bridges. Revista de Obras Públicas 2010:1695;29-46. In Spanish.

[31] Taranath BS. Steel, concrete and composite design of tall buildings. McGrawHill, USA, 1997.

[32] Nadjai A, Han S, Ali F, Alam N, Allam A. Fire resistance of axial restraint composite floor steel cellular beams. Journal of Constructional Steel Research 2017:136;229-37. DOI: 10.1016/j.jcsr.2017.05.016.

[33] Li GQ, Zhang N, Jiang J. Experimental investigation on thermal and mechanical behaviour of composite floors exposed to standard fire. Fire Safety Journal 2017;89:6376. DOI:10.1016/j.firesaf.2017.02.009.

[34] Bailey CG, Toh WS. Behaviour of concrete floor slabs at ambient and elevated temperatures. Fire Safety Journal 2007;42 (6-7):425-36. DOI:10.1016/j.firesaf.2006.11.009. 
[35] Drysdale D. An Introduction to Fire Dynamics. John Wiley and Sons. United Kingdom; 2011.

[36] Babrauskas V. Chapter 26. Heat Release rates. In: SFPE handbook of fire protection engineering, 5th ed. 2016. p. 799-904.

[37] Godart B, Berthellemy J, Lucas JP. Diagnosis, assessment and repair of the Mathilde bridge close to collapse during a fire. Structural Engineering International 2015;25(3):331-38

[38] Rinaudo P, Paya-Zaforteza I, Calderón P, Sales S. Experimental and analytical evaluation of the response time of high temperature fiber optic sensors. Sensors and Actuators, A: Physical 2016;243:167-174

[39] Rinaudo P, Torres B, Paya-Zaforteza I, Calderón PA, Sales S. Evaluation of new regenerated fiber Bragg grating high-temperature sensors in an ISO 834 fire test. Fire Safety Journal 2015:71:332-339

[40] CEN (European Committee for Standardization). Eurocode 3: Design of steel structures - Part 1-2: General rules - Structural fire design. Brussels (Belgium), 2005. 

Jose Alos-Moya, Ignacio Paya-Zaforteza, Antonio Hospitaler, Eduardo Loma (2018)

"Valencia bridge fire tests: Validation of simplified and advanced numerical approaches to model bridge fire scenarios"

Journal of Advances in Engineering Software. Accepted in November 2018 



\title{
Valencia bridge fire tests: Validation of simplified and advanced numerical approaches to model bridge fire scenarios
}

\author{
J. Alos-Moya ${ }^{1}$, I. Paya-Zaforteza ${ }^{1 *}$, A. Hospitaler ${ }^{1}$, E. Loma-Ossorio ${ }^{2}$ \\ ${ }^{1}$ ICITECH, Departamento de Ingeniería de la Construcción, Universitat Politècnica de \\ València. Camino de Vera s/n, 46022 Valencia, Spain \\ Authors e-mail addresses: José Alos-Moya: Joalmo11@upv.es \\ Ignacio Paya-Zaforteza: igpaza@upv.es \\ Antonio Hospitaler: $\quad$ ahospitaler@upv.es \\ Eduardo Loma-Ossorio: eloma-ossorio@valencia.es
}

\begin{abstract}
Bridge fires are a major concern and the subject of many studies that use numerical models. However, experimental studies are still required to test the validity of these numerical models and improve their accuracy. This paper uses temperature results of the Valencia bridge fire tests carried out at the Universitat Politècnica de València, in Valencia (Spain) to calibrate the fire models that constitute the first step in modeling any bridge fire event. The calibration is carried out by both a simplified approach (Heskestad \& Hamada's correlation) and advanced numerical models (Computational Fluid Dynamics models built with the Fire Dynamics Simulator FDS- software).
\end{abstract}

The Valencia bridge fire tests involved four fire scenarios under a composite bridge with Heat Release Rate (HRR) values between 361 and $1352 \mathrm{~kW}$. The results show that applying Heskestad \& Hamada's correlation gave good results when used 
within its limits ( $\mathrm{HRR}<0.764 \mathrm{MW}$ ) but did not work well beyond them, which means it would be suitable for planning reduced scale bridge fire tests but not in the analysis of real bridge fires. On the other hand, FDS provides good predictions of the temperatures and can be used to study bridge fire responses. This work is therefore an important step forward in the study of bridge fires and towards the improvement of the resilience of infrastructure networks vis-à-vis fire hazards. It also highlights the problems that can arise in fire tests in the open air, the influence of the wind being of critical importance.

Keywords: numerical modelling, Valencia bridge fire test, composite (steel-concrete) bridge, mass loss rate, bridge fire, bridge resilience.

* Corresponding author. Tel: +34 963875623; fax: +34 963877568

\section{Notation}

$A_{\text {fire }}=$ Footprint of the fire $\left(\mathrm{m}^{2}\right)$

$\mathrm{b}=$ Effective plume radius at the intersection with the ceiling elevation (m)

$\mathrm{c}_{\mathrm{p}}=$ specific heat of the air $=1.005\left(\mathrm{~kJ} \cdot \mathrm{kg}^{-1} \cdot \mathrm{K}^{-1}\right)$

$\mathrm{D}=$ Fire equivalent diameter $(\mathrm{m})$

$\mathrm{E}_{\mathrm{i}}=$ Temperature in a particular thermocouple in an experimental test $\left({ }^{\circ} \mathrm{C}\right)$

$\mathrm{g}=$ Gravitational acceleration $=9.81\left(\mathrm{~m} / \mathrm{s}^{2}\right)$

$\mathrm{H}=$ Ceiling height above the burning fuel (m)

$\mathrm{L}_{\mathrm{f}} \quad=$ Flame length $(\mathrm{m})$

$\mathrm{L}_{\mathrm{f}} / \mathrm{H}=$ ratio used to difference between strong and weak plume.

$\dot{m}=$ Mass loss rate $(\mathrm{kg} / \mathrm{min})$

$\dot{m} "=$ Mass loss rate per unit area $\left(\mathrm{kg} / \mathrm{m}^{2} / \mathrm{s}\right)$

$\mathrm{M}_{\mathrm{i}}=$ Temperature in a particular thermocouple in the model $\left({ }^{\circ} \mathrm{C}\right)$ 
$\mathrm{Ma}=$ Mach number

$\mathrm{Q}=$ Heat Release Rate $(\mathrm{kW})$

$\mathrm{Q}_{\mathrm{c}}=$ Convective Heat Release Rate $(\mathrm{kW})$

$\mathrm{r}=$ Radial distance from axis of the fire plume $(\mathrm{m})$

$\mathrm{s}=$ side of the square pan $(\mathrm{m})$

$\mathrm{T}=$ Temperature at a particular point $\left({ }^{\circ} \mathrm{C}\right)$

$\mathrm{T}_{\mathrm{p}}=$ Temperature at a particular height in the centerline of the plume $\left({ }^{\circ} \mathrm{C}\right)$

$\mathrm{T}_{\infty}=$ Ambient temperature $=20\left({ }^{\circ} \mathrm{C}\right)$

$\mathrm{Z}_{\mathrm{b}}=$ Vertical coordinate of the fuel top surface inside the pan (m)

$\Delta \mathrm{H}_{\mathrm{c}}=$ Net heat of combustion $(\mathrm{MJ} / \mathrm{kg})$

$\Delta \mathrm{T}=$ Excess gas temperature at a point at a particular distance from the centerline of the plume. It is equal to $T-T_{\infty}\left({ }^{\circ} \mathrm{C}\right), T$ being the temperature at the point considered and $T_{\infty}$ the ambient temperature.

$\Delta \mathrm{T}_{\mathrm{p}}=$ Excess gas temperature in plume at the ceiling level. It is equal to $T_{p}-T_{\infty}\left({ }^{\circ} \mathrm{C}\right), T_{\mathrm{p}}$ being the temperature on the centerline at the impingement point on the ceiling.

$\delta \quad=$ bias factor of the model.

$\varepsilon_{m}=$ material emissivity

$\theta=$ True value of the temperature $\left({ }^{\circ} \mathrm{C}\right)$

$\lambda=$ conductivity $\left(\mathrm{W} / \mathrm{m}^{\circ} \mathrm{C}\right)$

$\rho=$ density $\left(\mathrm{kg} / \mathrm{m}^{3}\right)$

$\rho_{\infty}=$ Gas density at ambient temperature $=1.204\left(\mathrm{~kg} / \mathrm{m}^{3}\right)$

$\sigma_{\mathrm{E}}=$ Experimental standard deviation (due to measurements)

$\sigma_{M}=$ Model standard deviation (due solely to the model)

$\chi_{\mathrm{r}}=$ radiative fraction

$\omega_{0}=$ Relative uncertainty of the measured output quantity

$\omega_{\mathrm{E}}=$ Experimental relative standard deviation, $\sigma_{\mathrm{E}} / \theta$ 
$\omega_{M}=$ Model relative standard deviation, $\sigma_{M} /[\theta \cdot(1+\delta)]$

$\omega_{\mathrm{i}}=$ Relative uncertainty of the devices that measure the various input parameters that the model requires.

\section{Introduction}

The harmful consequences of bridge fires (see e.g. Peris-Sayol et al.[1]) have given rise to significant research in recent years (see a summary e.g. in Garlock et al. [2] and Quiel et al.[3]). This research is based on the use of numerical models to analyze previous fire incidents (see e.g. Alos-Moya et al. [4], Gong \& Agrawal [5], Godart et al. [6]) as well as the study of bridge responses to hypothetical fire scenarios (e.g. Peris-Sayol et al. [7] and Nahid et al. [8]).

The numerical analysis of bridge fires involves: (1) fire models to obtain the gas temperatures surrounding the structure, (2) heat transfer models to obtain the temperatures on the surface and within the bridge elements and (3) structural models to obtain the bridge's mechanical response. The first step is therefore to model the fire itself, and this has been done by different approaches; some researchers have built complex fire models using Computational Fluid Dynamics (CFD henceforth) (see e.g. Alos-Moya et al. [4], Peris-Sayol et al. [9], Gong and Agrawal [5]), while others have proposed simplified approaches based on the use of fire curves (see e.g. Payá-Zaforteza \& Garlock [10]) or radiation heat fluxes (Quiel et al. [3]). Modeling a fire event is always challenging, since numerical models and simplified curves have been widely applied and validated by fires in buildings and tunnels (see e.g. Buchanan [11], Albero et al [12], Quiel et al. [13], Rackauskaite et al. [14], Maraveas and Vrakas [15], Ji et al. [16]), but, as pointed out by Payá-Zaforteza \& Garlock [10], bridge fires have specific features and deserve a particular approach. To obtain an accurate bridges fire response, the numerical and simplified approaches need to be validated by experiments. However, the dimensions of bridge structural elements, the magnitude of the fire loads in bridge fires and the difficulties of carrying out open-air fire tests make experimental work on bridge fires rather complex and expensive. As a result, this type of work, e.g. the Valencia bridge fire tests carried out by Alos-Moya et al. [17], is not often undertaken. These tests consisted of reproducing different fire scenarios under a composite I-girder bridge built at the Universitat Politècnica de València, in Valencia, Spain. These conditions (fire positions and bridge deck structural system) were chosen because a previous statistical analysis of bridge fire incidents carried out by Peris-Sayol et al. [1] showed that (a) composite I-girder bridges are especially vulnerable to bridge fires and (b) the worst possible position for the fire is under the bridge deck. 
Within this general context, the objective of the present study is to calibrate the numerical and simplified approaches available to model this type of fire. The Valencia bridge fire tests (Alos-Moya et al. [17]) are used to analyze the accuracy of two approaches (jet ceilings and Computational Fluid Dynamics) in reproducing the temperatures in the gases around the bridge during the experiments. This analysis enables both the calibration of the models used and establishes their application limits. The authors consider that the results obtained are a crucial step towards the development of a performance-based approach that can be used to improve the resilience of bridge systems against fire hazards.

The paper is structured as follows: Sections 2 and 3 describe the experimental bridge and summarize the features of the fire tests used to validate fire models. The validity is studied of both the simplified (jet ceilings, Section 4) and advanced calculation methods (CFDs, Section 5) used to predict the results of the fire tests. Section 6 describes an uncertainty analysis of the results obtained by advanced calculation methods, and Section 7 summarizes the main conclusions of the research carried out and points to areas in which future work is required.

\section{Case study and methodology}

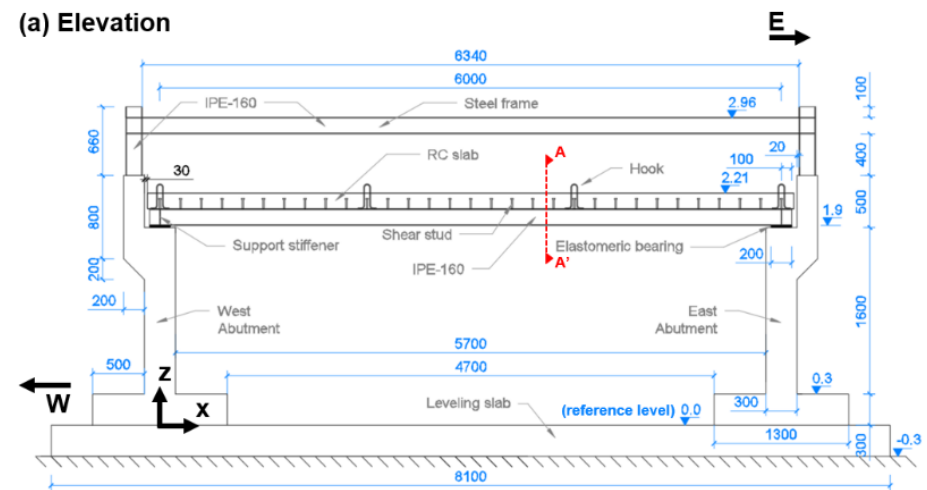

(b) Deck details (Section AA')

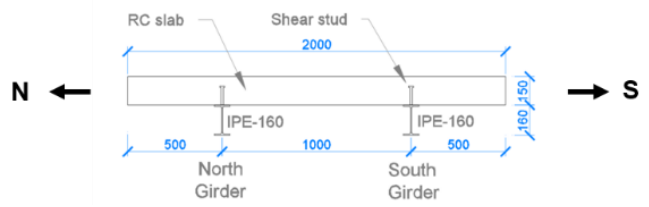

Figure 1. Experimental bridge: (a) elevation, (b) deck details. All the dimensions are expressed in $\mathrm{mm}$. All the levels ( $\mathrm{z}$ coordinates) are expressed in $\mathrm{m}$. 
The reduced-scale bridge used in the present study was a simply-supported bridge specifically designed by the authors in order to carry out the tests detailed in Alos et al. [17]. The bridge had a span of $6.0 \mathrm{~m}$ and a vertical clearance of $1.9 \mathrm{~m}$. The structure consisted of two IPE-160 steel girders which supported a $0.15 \mathrm{~m}$ thick reinforced concrete slab connected to the steel girders through 62 shear studs. The S355-JR steel employed for the girders showed yield stresses of between 344 and $377 \mathrm{MPa}$. The concrete slab compressive strength was $33 \mathrm{MPa}$. Bridge elevation, abutment details and deck details are shown in Fig. 1. Further information on the geometry and the materials used can be found in Alos et al. [17]. Two auxiliary steel frames were placed over the deck to sustain the LVDT's that monitored the deck deflections during the fire tests.

\section{Experimental approach}

\subsection{Fire scenarios}

The Valencia fire tests involved eight fire tests with four different fire scenarios. The fire loads were located under the bridge and consisted of different quantities of gasoline poured into steel pans of different dimensions. The present study calibrates the fire models using results from four tests (tests 2, 4,7 and 8) out of the eight tests carried out. These four tests were chosen because they best characterized the scenarios studied. Tests 1 and 3 were discarded for 2 and 4 due to the smaller influence of the wind in the latter. Tests 5 and 6 were discarded for 7, since the latter was the only one without a protected zone over the fire load. Table 1 gives details of the position and magnitude of the fire loads during the tests. The volume of gasoline used was obtained by weight and assuming a density of $740 \mathrm{~kg} / \mathrm{m}^{3}$ [18]. Four views of the tests are shown in Fig. 2.

\begin{tabular}{|c|c|c|c|c|c|c|c|c|c|}
\hline \multirow{2}{*}{$\begin{array}{c}\text { Fire } \\
\text { Scenario }\end{array}$} & \multirow{2}{*}{ Test } & \multirow{2}{*}{$\begin{array}{c}\text { Fire } \\
\text { location }\end{array}$} & \multirow{2}{*}{$\begin{array}{l}\text { HRR } \\
(\mathrm{kW})\end{array}$} & \multicolumn{3}{|c|}{ Gasoline } & \multirow{2}{*}{$\begin{array}{l}\text { Side } \\
\mathrm{s}(\mathrm{m})\end{array}$} & \multicolumn{2}{|c|}{ Pan Location } \\
\hline & & & & Weight $(\mathrm{kg})$ & Volume (l) & Thickness (cm) & & $\mathrm{x}(\mathrm{m})$ & $\mathrm{z}(\mathrm{m})$ \\
\hline Fire 1 & Test 2 & mid-span & 426 & 17.5 & 23.6 & 9.5 & 0.5 & 3.00 & 0.2 \\
\hline Fire 2 & Test 4 & mid-span & 1130 & 0.7 & 50.9 & 9.1 & 0.75 & 3.00 & 0.2 \\
\hline Fire 3 & Test 7 & abutment & 361 & 18.1 & 24.5 & 9.8 & 0.5 & 5.59 & 0.5 \\
\hline Fire 4 & Test 8 & mid-span & 1352 & 41.6 & 56.2 & 10.0 & 0.75 & 3.00 & 0.8 \\
\hline
\end{tabular}

Table 1. Fire scenarios employed in the validation

It must be noted that the experimental bridge was not a replica or a reduced scale model of a specific bridge. The experimental bridge was designed to reproduce a structural system very common in highway bridges and the fire scenarios were defined to enable the study of some important aspects that previous studies $[1,4,7,9,19]$ on bridge fires had highlighted, such as: (1) the impingement of the flames on the bridge deck, (2) the spread of flames, heat and smoke between two adjacent bridge girders, (3) the creation 
of significant longitudinal thermal gradients along the bridge girders and (4) the influence of the fire load position on gas and bridge temperatures.

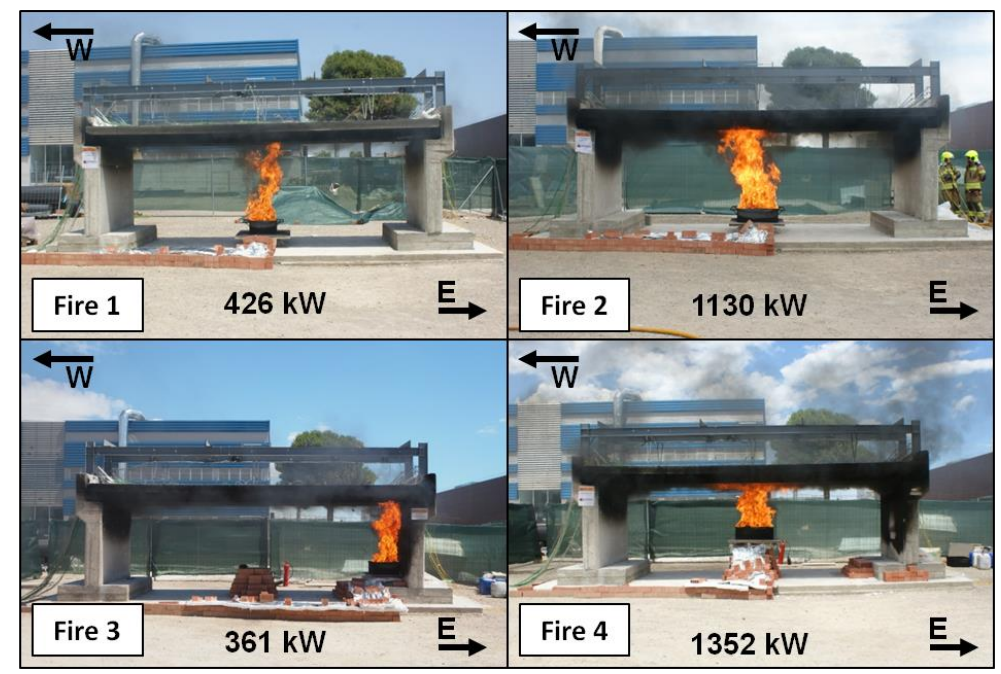

Figure 2. Views of the fire scenarios considered. Images include the power (Heat Release Rate) of the fire in each test.

\subsection{Mass loss rate}

Fig. 3 gives the mass loss rate recorded during the four validation tests. This value is important as when it is value is multiplied by the gasoline net heat of combustion $\left(\Delta h_{c}\right)$ (43.7 MJ/kg) [18] the Heat Release Rate (HRR) of the fire is obtained. The HRR is a key variable in characterizing fires in the models used in fire engineering.

In Fig. 3 the growth zones in each of the tests can be distinguished. The plateau is only clearly defined in Fires 1 and 3, in which the fire load is lower. In the stronger fires the higher dispersion of the average values shown in Table 1 can be seen, which was calculated excluding the growth and decay phases. While in Fire 2 the higher mass loss values can be attributed to gusts of wind, the steady growth during Fire 4 is associated with the higher radiation from the bridge deck due to the lower distance between deck and pan filled with gasoline. This radiation is progressively increased during Fire 4 due higher deflections recorded during the test [17]. 


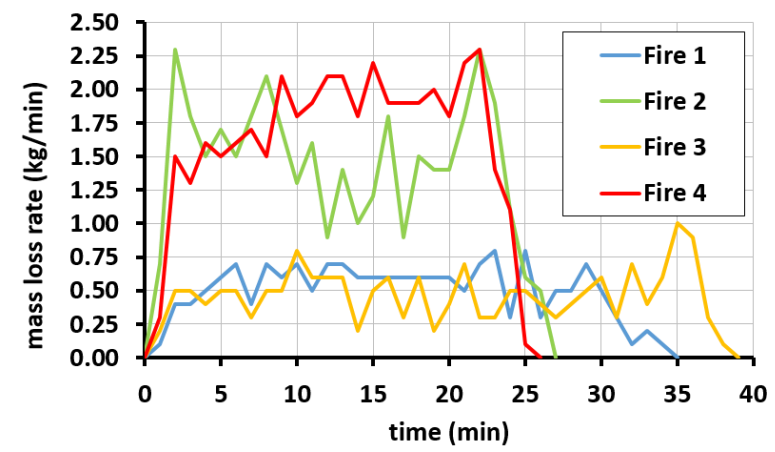

Figure 3. Mass loss rate evolution during the tests

\subsection{Gas temperatures}

Gas temperatures were measured by $231.5 \mathrm{~mm}$ Type K thermocouples (TCs) with stainless steel sheaths arranged in six horizontal thermocouple trees (TCTs) and one vertical TCTs. Fig. 4 shows the thermocouple layout. Every horizontal TCT had 3 TCs and the vertical TCT had five TCs. Regarding the nomenclature of the TCs in the horizontal TCTs: "G" indicates GAS, "S", "C" and "N" mean South Region, Central Region and North Region, respectively (see Fig. 4), and the number at the end indicates the section in which the TC is placed.

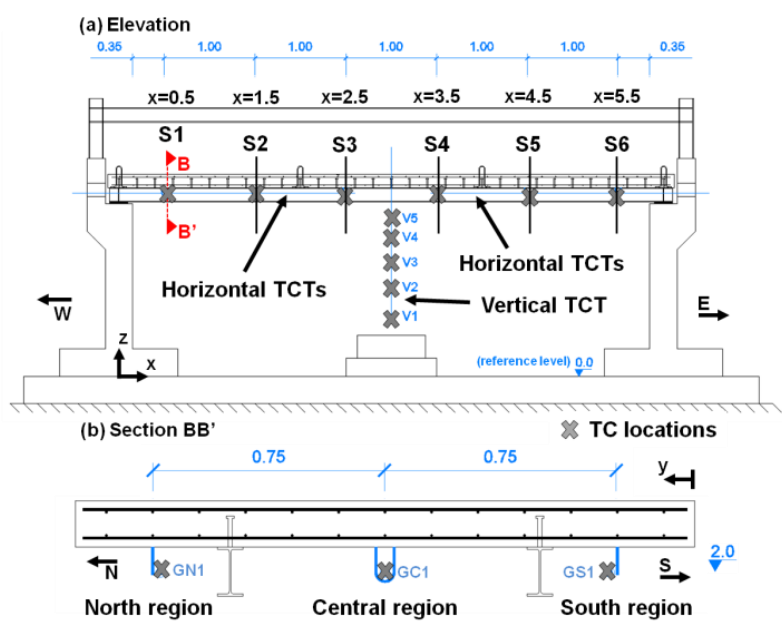

Figure 4. Gas thermocouple distribution. All dimensions are given in $\mathrm{m}$. 
The vertical TCT was used to measure temperatures in the plume. Regarding the nomenclature of the TCs in the vertical TCT: "V" indicates that the TC belongs to the vertical thermocouple tree and the number at the end indicates the order, starting from the TC closest to the pan.

\begin{tabular}{|c|c|c|c|c|c|c|c|c|}
\hline & \multirow{2}{*}{$x(m)$} & \multirow{2}{*}{$\begin{array}{l}\text { South region } \\
\text { Aver. } \mathrm{T}\left({ }^{\circ} \mathrm{C}\right)\end{array}$} & \multirow{2}{*}{$\begin{array}{l}\text { North region } \\
\text { Aver. } \mathrm{T}\left({ }^{\circ} \mathrm{C}\right)\end{array}$} & \multicolumn{2}{|c|}{ Central region } & \multirow{2}{*}{$z(m)$} & \multicolumn{2}{|c|}{ Fire plume } \\
\hline & & & & Aver. $\mathrm{T}\left({ }^{\circ} \mathrm{C}\right)$ & $\operatorname{Max} . \mathrm{T}\left({ }^{\circ} \mathrm{C}\right)$ & & Aver. $\mathrm{T}\left({ }^{\circ} \mathrm{C}\right)$ & $\operatorname{Max} . \mathrm{T}\left({ }^{\circ} \mathrm{C}\right)$ \\
\hline \multirow{8}{*}{ 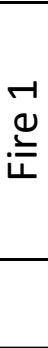 } & 0.5 & 89 & 101 & 112 & 172 & 1.73 & 206 & 402 \\
\hline & 1.5 & 111 & 135 & 141 & 218 & 1.54 & 171 & 387 \\
\hline & 2.5 & 154 & 185 & 221 & 398 & 1.24 & 236 & 549 \\
\hline & 3.5 & 122 & 176 & 200 & 314 & 0.99 & 335 & 688 \\
\hline & 4.5 & 87 & 108 & 122 & 183 & 0.65 & 542 & 827 \\
\hline & 5.5 & 81 & 81 & 103 & 150 & - & - & - \\
\hline & \multirow{2}{*}{$x(m)$} & South region & North region & \multicolumn{2}{|c|}{ Central region } & \multirow{2}{*}{$z(m)$} & \multicolumn{2}{|c|}{ Fire plume } \\
\hline & & Aver. T $\left({ }^{\circ} \mathrm{C}\right)$ & Aver. $\mathrm{T}\left({ }^{\circ} \mathrm{C}\right)$ & Aver. T $\left({ }^{\circ} \mathrm{C}\right)$ & $\operatorname{Max} . \mathrm{T}\left({ }^{\circ} \mathrm{C}\right)$ & & Aver. T $\left({ }^{\circ} \mathrm{C}\right)$ & $\operatorname{Max} . \mathrm{T}\left({ }^{\circ} \mathrm{C}\right)$ \\
\hline \multirow{8}{*}{$\begin{array}{c}\text { 는 } \\
\text { 는 }\end{array}$} & 0.5 & 206 & 176 & 222 & 318 & 1.73 & 450 & 774 \\
\hline & 1.5 & 293 & 230 & 298 & 451 & 1.54 & 381 & 749 \\
\hline & 2.5 & 446 & 310 & 463 & 711 & 1.24 & 405 & 853 \\
\hline & 3.5 & 397 & 274 & 411 & 760 & 0.99 & 501 & 896 \\
\hline & 4.5 & 207 & 187 & 247 & 525 & 0.65 & 685 & 883 \\
\hline & 5.5 & 174 & 141 & 199 & 365 & - & - & - \\
\hline & \multirow{2}{*}{$x(m)$} & South region & North region & \multicolumn{2}{|c|}{ Central region } & \multirow{2}{*}{$z(m)$} & \multicolumn{2}{|c|}{ Fire plume } \\
\hline & & Aver. T $\left({ }^{\circ} \mathrm{C}\right)$ & Aver. T $\left({ }^{\circ} \mathrm{C}\right)$ & Aver. T $\left({ }^{\circ} \mathrm{C}\right)$ & $\operatorname{Max} . \mathrm{T}\left({ }^{\circ} \mathrm{C}\right)$ & & Aver. T $\left({ }^{\circ} \mathrm{C}\right)$ & $\operatorname{Max} . T\left({ }^{\circ} \mathrm{C}\right)$ \\
\hline \multirow{8}{*}{ 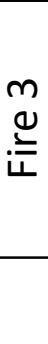 } & 0.5 & 54 & 63 & 76 & 141 & 1.95 & 422 & 614 \\
\hline & 1.5 & 63 & 67 & 94 & 158 & 1.69 & 387 & 564 \\
\hline & 2.5 & 83 & 31 & 122 & 190 & 1.41 & 462 & 748 \\
\hline & 3.5 & 112 & 109 & 162 & 234 & 1.13 & 515 & 698 \\
\hline & 4.5 & 158 & 153 & 229 & 306 & 0.85 & 739 & 866 \\
\hline & 5.5 & 315 & 276 & 403 & 568 & - & - & - \\
\hline & \multirow{2}{*}{$x(m)$} & South region & North region & \multicolumn{2}{|c|}{ Central region } & $7 \mathrm{ml}$ & \multicolumn{2}{|c|}{ Fire plume } \\
\hline & & Aver. $\mathrm{T}\left({ }^{\circ} \mathrm{C}\right)$ & Aver. $\mathrm{T}\left({ }^{\circ} \mathrm{C}\right)$ & Aver. T $\left({ }^{\circ} \mathrm{C}\right)$ & $\operatorname{Max} . \mathrm{T}\left({ }^{\circ} \mathrm{C}\right)$ & (III) & Aver. T $\left({ }^{\circ} \mathrm{C}\right)$ & $\operatorname{Max} . \mathrm{T}\left({ }^{\circ} \mathrm{C}\right)$ \\
\hline \multirow{6}{*}{ 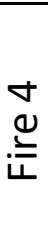 } & 0.5 & 217 & 232 & 295 & 440 & 1.89 & 701 & 949 \\
\hline & 1.5 & 346 & 362 & 465 & 644 & 1.73 & 672 & 905 \\
\hline & 2.5 & 559 & 41 & 713 & 955 & 1.54 & 766 & 938 \\
\hline & 3.5 & 558 & 511 & 712 & 968 & 1.44 & 726 & 896 \\
\hline & 4.5 & 276 & 289 & 427 & 647 & 1.25 & 646 & 909 \\
\hline & 5.5 & 241 & 231 & 332 & 537 & - & - & - \\
\hline
\end{tabular}

Table 2. Average temperatures (Ave. $\mathrm{T}\left({ }^{\circ} \mathrm{C}\right)$ ) and maximum temperatures (Max. $\mathrm{T}\left({ }^{\circ} \mathrm{C}\right)$ ) recorded during the tests. Average values were calculating during the intervals defined in Table 3. 
Table 2 includes the average values of the gas temperatures in the four zones (North, South and Central regions and Fire plume) into which the space surrounding the bridge was divided. It also shows the maximum values in two of these regions (Central and Fire Plume), which are used in Section 6.3.

\begin{tabular}{cccc}
\hline Fire Scenario & Initial time (s) & Last time (s) & Total time (s) \\
\hline Fire 1 & 400 & 1200 & 800 \\
Fire 2 & 200 & 1300 & 1100 \\
Fire 3 & 200 & 2000 & 1800 \\
Fire 4 & 700 & 1300 & 600 \\
\hline
\end{tabular}

Table 3. Intervals considered to obtain average temperatures

Table 3 includes the time intervals selected to obtain the average values. As can be seen in Fig. 3, these values ensure that the averages were obtained in the plateau zones. It should be remembered that the thermocouple response to temperature changes in gas is almost instantaneous.

Further information on the gas temperatures recorded can be found in [17].

\section{Simplified approach to modeling the Valencia bridge fire tests. Heskestad \& Hamada's correlation.}

A large number of models are used in the field of fire engineering, including (from low to high complexity): 1) nominal curves, 2) equivalent exposure time, 3) parametric fires, 4) localized fires, 5) zone models, and 6) CFD models. At the present time there are no nominal curves, equivalent exposure time or parametric fire models available specifically for bridge fires, although certain authors (Peris-Sayol et al. [19], Quiel et al. [20]) have analyzed the factors that play a role in the maximum temperatures reached in the bridge and its surroundings during a blaze. The first simplified models that could be used to study bridge fires were thus the localized fire and the more specialized ceiling jet models. Their potential for application to bridge fires is analyzed below.

\subsection{Ceiling jets}

\subsubsection{Theoretical background}

According to Alpert [21], a ceiling jet refers to "the relatively rapid gas flow in a shallow layer beneath the ceiling surface that is driven by the buoyancy of the hot combustion products from the plume". The ceiling jet flow emerges from the region of plume impingement on the ceiling, moving radially away from the fire. As it does so, the layer grows thicker by entraining room air, which cools the gases in the jet and reduces its 
velocity. Similarly, the ceiling also cools down the portion of the jet adjacent to it. Fig. 5 shows a sketch of the ceiling jet concept and a photograph of one of the tests on the experimental bridge carried out at the Universitat Politècnica de València.

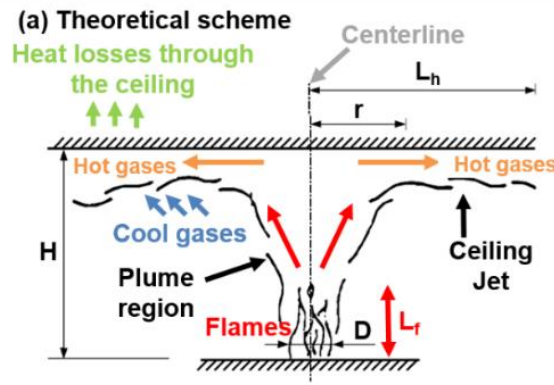

(b) Experimental case

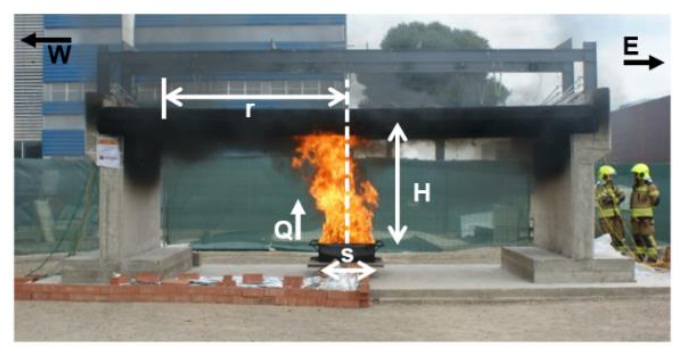

Figure 5. Ceiling jets with flame impingement: (a) Theoretical scheme, (b) Experimental case. Fig. 7a adapted from Eurocode 1 Part 1-2.

Depending on the $L_{f} / H$ ratio (see Fig. $5 b$ ), where $L_{f}$ is the flame length and $H$ is the vertical distance between the burning fuel and the ceiling, a distinction is made between weak plumes (where convection is the dominant mode of heat transfer) and strong plumes (where thermal radiation will be equally or more important than convection) [22]. There is no clear boundary between both types of plume, but Alpert's general theory for weak plumes [21,23] was explicitly obtained for cases in which the flame height is much smaller than the distance between the burning fuel and the ceiling, while Heskestad \& Hamada's theory [24] for strong plumes was validated for $L_{f} / H$ ratios ranging from 0.2 to 2.0. In the present study, the flame length $L_{f}$ was obtained using Heskestad's equation Eq. 1 [25].

$$
L_{f}=-1.02 \cdot D+0.235 \cdot Q^{2 / 5}
$$

Where:

$Q=$ Heat Release Rate $(\mathrm{kW})$

$D=$ Equivalent diameter $(\mathrm{m})$ obtained assuming that the fire source is a circle with the same area as that of the real fire source. For square pans, $D$ is given by Eq. 2:

$$
D=2 \cdot s / \sqrt{\pi}
$$

where $s$ is the side of the square pan. 
Table 4 shows the application of Eqs. 1 and 2 to the Valencia bridge fire tests analyzed in this paper to obtain the flame length and resulting $L_{f} / H$ ratio. They show that the fire is clearly impinging on the concrete slab $\left(L_{f} / H>1\right)$ in the four scenarios, so that the four tests are therefore in the strong plume field. This shows that Hamada and Heskestad's correlation [24] is the best simplified approach to estimating gas temperatures. It should be noted that Kowslowski \& Motevalli's correlation [26], obtained specifically for channel configurations (i.e. fires confined between two longitudinal elements) for 5.2 $\mathrm{kW}$ fires, cannot be applied to the Valencia bridge tests because it is only applicable to weak plumes with much lower HRRs.

\begin{tabular}{ccccccc}
\hline $\begin{array}{c}\text { Fire } \\
\text { scenario }\end{array}$ & $\begin{array}{c}\text { Pan side } \\
(\mathrm{m})\end{array}$ & $\begin{array}{c}\text { Diameter } \\
(\mathrm{m})\end{array}$ & $\begin{array}{c}\text { HRR } \\
(\mathrm{kW})\end{array}$ & $\begin{array}{c}\text { Flame lenght } \\
(\mathrm{m})\end{array}$ & $\begin{array}{c}\text { Height } \\
(\mathrm{m})\end{array}$ & $\begin{array}{c}\mathrm{L}_{\mathrm{f}} / \mathrm{H} \\
(\mathrm{m})\end{array}$ \\
\hline Fire1 & 0.50 & 0.56 & 426 & 2.07 & 1.85 & 1.12 \\
Fire2 & 0.75 & 0.85 & 1130 & 3.05 & 1.85 & 1.65 \\
Fire3 & 0.50 & 0.56 & 361 & 1.90 & 1.55 & 1.23 \\
Fire4 & 0.75 & 0.85 & 1352 & 3.34 & 1.25 & 2.67 \\
\hline
\end{tabular}

Table 4. $L_{f} / H$ ratios from Eq. 1 for the fire scenarios analyzed.

\subsection{Heskestad \& Hamada's correlation}

Heskestad \& Hamada [24] measured ceiling jet temperatures for $L_{f} / \mathrm{H}$ ratios ranging from 0.3 to 3.0 for propane burner fires ranging from 12 to $764 \mathrm{~kW}$ beneath unconfined ceilings with $H$ up to $2.5 \mathrm{~m}$. Their results were employed to obtain the increment of the gas temperature below the ceiling from the increments of temperatures in the plume for $L_{f} / H$ ratios less than or equal to about 2 . At greater flame-height ratios, significant heat released through the ceiling itself appears to be the cause of a lack of agreement [21]. According to the $L_{f} / H$ values shown in Table 4 , the Fire 4 scenario would greatly exceed the application range of Heskestad \& Hamada's correlation.

\subsubsection{Parameters and limitations}

Eq. 3 proposed by Heskestad \& Hamada [24] gives the ratio between the excess gas temperature $(\Delta T)$ at a particular radial distance $r$ from the plume centerline and the excess gas temperature in the plume $\left(\Delta T_{p}\right)$ where it meets the ceiling. The equation is applied with $r / b$ ranging from 1 to 40 , where $b$ is the effective plume radius at the intersection with the ceiling, i.e. the radius where the velocity of the impingement plume is one-half the centerline value. The expression for $b$ is given by equation Eq. 4 . 


$$
\frac{\Delta \mathrm{T}}{\Delta T_{p}}=1.92 \cdot\left(\frac{b}{r}\right)-\exp \left[1.61 \cdot\left(1-\frac{\mathrm{r}}{b}\right)\right]
$$

$$
b=0.42 \cdot\left[\left(c_{\mathrm{p}} \cdot \rho_{\infty}\right)^{4 / 5} \cdot T_{\infty}^{3 / 5} \cdot g^{2 / 5}\right]^{-1 / 2} \cdot T_{\mathrm{p}}^{1 / 2} \cdot Q_{c}^{2 / 5} / \Delta \mathrm{T}_{p}^{3 / 5}
$$

Where $c_{\mathrm{p}}=1.005 \mathrm{~kJ} \cdot \mathrm{kg}^{-1} \cdot \mathrm{K}^{-1}, \rho_{\infty}=1.204 \mathrm{~kg} / \mathrm{m}^{3}, \mathrm{~T}_{\infty}=20{ }^{\circ} \mathrm{C}, \mathrm{g}=9.81 \mathrm{~m} / \mathrm{s}$ and $\mathrm{Q}_{\mathrm{c}}$ (Convective Heat Release Rate in $\mathrm{kW}$ ) and $T_{p}$ (temperature at the centerline at the impingement point on the ceiling expressed in ${ }^{\circ} \mathrm{C}$ ) are given by Eqs. 5 and 6 , respectively.

$$
\begin{aligned}
& Q_{c}=\left(1-\chi_{r}\right) \cdot Q \\
& T_{p}=\Delta T_{p}-T_{\infty}
\end{aligned}
$$

where $Q$ is the Heat Release Rate in $\mathrm{kW}, \Delta T_{p}$ is the excess temperature at the plume centerline at the level of the ceiling and is given by Eq. 7 [21,27] and $\chi_{r}$ is assumed to be equal to 0.35 , according to [28].

$$
\Delta T_{p}=16.9 \cdot \frac{\mathrm{Q}^{2 / 3}}{H^{5 / 3}} \quad(\text { valid for } r / H \leq 0.18)
$$

It must be noted that $\chi_{r}$ can also be calculated using Eq. 8 proposed by McGrattan et al. [29], where $\chi_{r, \max }=0.35, k=0.05 \mathrm{~m}^{-1}$ and $D$ is the fire equivalent diameter. The application of Eq. 8 to the fire scenarios studied in this paper gives a value of $\chi \mathrm{r}=0.34$, which differs from the value proposed in [28] by less than $3 \%$.

$$
\chi_{r}=\chi_{r, \max } \cdot e^{-k D}
$$

\subsubsection{Application to the Valencia bridge fire tests.}

Fig. $5 \mathrm{~b}$ shows how the radial position from the centerline ( $r$ in Eq. 3 ) has been substituted by the longitudinal distance from the fire centerline. It should be noted that although Heskestad \& Hamada's correlation [24] was defined for unconfined ceilings (i.e. where the fire is at least $3 H$ distant from the nearest vertical obstruction [30]), it perfectly fits the experimental results for Fires 1 to 3 (where there is barely $1 \mathrm{~m}$ between both girders). The $H$ values were obtained by subtracting the level of the fuel at the beginning of the test $(0.2 \mathrm{~m}$ for Fires 1,2 and 3 and $0.8 \mathrm{~m}$ for Fire 4$)$ from the level of the bottom surface of the concrete slab, which is $2.06 \mathrm{~m}$. By doing so, $H$ is $1.85 \mathrm{~m}$ for Fires 1 and 2, 1.55 for Fire 3 and $1.25 \mathrm{~m}$ for Fire 4.

Fig. 6 shows the gas temperatures throughout the Central region obtained from the Heskestad \& Hamada model [24], i.e. according to Eqs. 3 to 7. Fig. 6a compares the four fire scenarios considered, whereas Fig. $6 \mathrm{~b}$ only includes the three fire scenarios (Fires 1, 2 and 3) within the model's application range $\left(L_{f} / H \leq 2\right)$. From these figures, it can be stated that: 
- Heskestad \& Hamada's model gives a good prediction of the overall shape of the temperatures along the longitudinal axis of the bridge as well as that of the peak gas temperatures. The maximum peak temperatures predicted by the model in the central region in the six sections where thermocouples where located in the experiments are $333{ }^{\circ} \mathrm{C}$ (section $\mathrm{S} 3$ and $\mathrm{S} 4, x=2.5$ and $3.5 \mathrm{~m}$ ) for Fire 1,620 ${ }^{\circ} \mathrm{C}$ (section S3 and S4, $x=2.5$ and $3.5 \mathrm{~m}$ ) for Fire 2 and $396^{\circ} \mathrm{C}$ (section S6, $x=5.5$ $\mathrm{m})$ for Fire 3. These values are 16.3, 18.5 and $30.4 \%$ lower than those measured in the experiment for Fires 1, 2 and 3, respectively. The differences observed can be attributed to: the existence of the girders and the abutments that confine the hotter gases, the influence of variables not included in the model (e.g. type of fuel) and to the fact that the values of some variables were taken from previous references (e.g. value of $\chi_{r}$ ). In the particular case of Fire 3, another factor explains the temperature difference: previous research (Peris-Sayol et al. [7]) has shown that when the fire is close to the bridge abutment, the Coandă effect makes the flames adhere to the abutment walls and reach higher levels, which results in higher gas temperatures near the deck and further deck heating. This effect can be captured by advanced fire models (CFDs) but not by simplified methods such as Heskestad \& Hamada's.

- The Heskestad \& Hamada correlation can be used for the preliminary design of future bridge fire tests with HRR between 361 and $1130 \mathrm{~kW}$. Although this model might underestimate gas temperatures up to $30.4 \%$, it will come fairly close to the overall shape of the expected gas temperatures throughout the bridge, as well as that of the peak temperatures.

- The Heskestad \& Hamada correlation cannot be used to study real bridge fires, since these events involve HRRs higher than the limit of application of the correlation (the HRR for a car is about $5 \mathrm{MW}$ and for a tanker truck is about 100-200 MW according to [31, 32]). However, and since the correlation provides a good estimation of the overall shape of the temperatures along the bridge, it has the potential to be used in future, together with additional numerical and experimental work, to develop a simplified approach to study bridge fires. 
(a) All fires

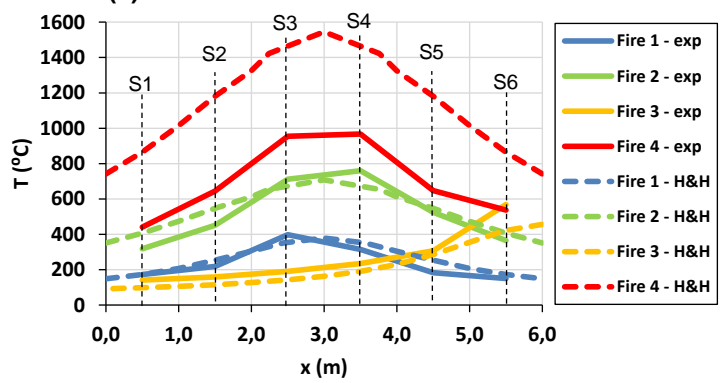

(b) Fire 1, 2 and 3

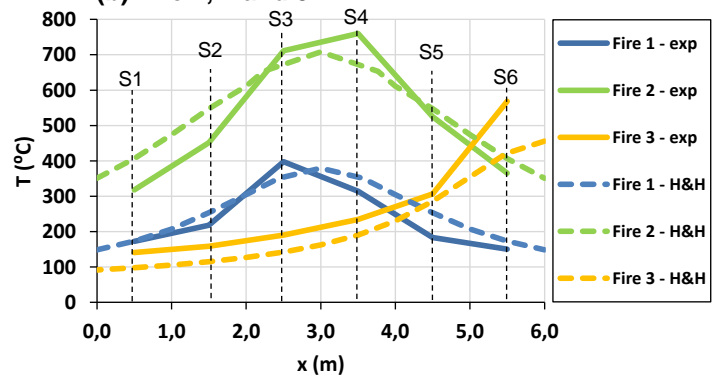

Figure 6. Central region temperatures for (a) all fire scenarios and (b) Fires 1, 2 and 3.

Continuous lines are experimental values and dashed lines are those of Heskestad \& Hamada's model. Experimental temperatures are the maximum recorded temperatures, not average temperatures.

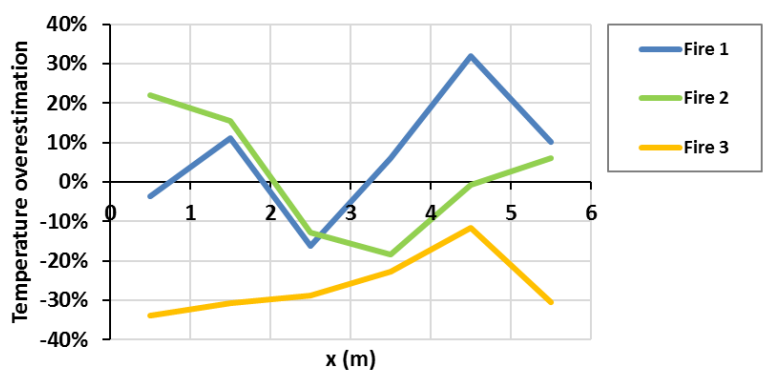

Figure 7. Scatter between the temperatures predicted in the Central region by the Heskestad \& Hamada model [24] and the maximum recorded temperatures. 
Fig. 7 shows the scatter between the predicted and measured temperatures along the longitudinal axis of the bridge. The scatter in sections $x=2.5 \mathrm{~m}$ and $\mathrm{x}=3.5 \mathrm{~m}$ ranges between -16 to $+6 \%$ for Fire 1 and from -12 to $-18 \%$ for Fire 2 . The scatter in sections $\mathrm{x}=4.5$ and $\mathrm{x}=5.5 \mathrm{~m}$ ranges from -11 to $-30 \%$ for Fire 3. These values are acceptable, considering that a scatter of $20 \%$ is considered as acceptable in much more complex models that use CFDs to solve fire engineering problems [28, 33].

\section{Advanced approach. Computational fluid dynamics model.}

In this section, the capability of advanced calculation methods (CFD models implemented in the software Fire Dynamics Simulator) to predict the results of the Valencia bridge fire tests is studied. The Fire Dynamics Simulator (FDS) is a computational fluid dynamics (CFD) fire-driven fluid flow model [28]. The FDS hydrodynamic model solves numerically a form of the Navier-Stokes equations appropriate for low-speed (Mach number $M a<0.3$ ), thermally-driven flow, with an emphasis on smoke and heat transport in fires. The core algorithm is an explicit predictor-corrector scheme, second order accurate in space and time. Turbulence is considered by means of a Large Eddy Simulation (LES) model. The FDS uses a single step, mixing-controlled chemical reaction for the combustion model, which uses three lumped species (air, fuel and products), the last two being explicitly computed. Radiation Transport Radiative heat transfer is included in the model via the solution of the radiation transport equation for a gray gas. The equation is solved using the Finite Volume Method (FVM). The absorption coefficients of the gas-soot mixtures are computed using the RadCal narrow-band model. Although the FDS has previously been used for bridge fires (see e.g. FDS models in [4, 5, 9]), as far as the authors are aware, it has been validated for the first time in the present study for use in bridge fires by the results of a battery of bridge fire experiments. Note also that the FDS validation is valid even if the bridge dimensions and the HRR of the fire tests are smaller than those of real bridge fires because the experimental bridge and the tests were designed to reproduce the specific aspects of bridge fires.

Building an FDS model $[4,9]$ requires defining: (1) a control volume with its boundary conditions which represents the volume in which the entire analysis will be carried out, (2) a mesh or discretization of the control volume, (3) a geometry included in the control volume which is submitted to fire load, (4) material properties (conductivity, density, specific heat and emissivity), (5) fire sources, (6) a combustion model, and (7) sensors or elements of the model where outputs of the analysis (e.g. temperatures) are recorded. The components of the FDS model are described below. 


\subsection{Control volume and mesh}

The control volume used in this study is shown in Fig. 8 and includes the bridge as well as an additional volume required to properly represent the physics of the problem. It measures $12.0 \mathrm{~m} \mathrm{x} 12.0 \mathrm{~m} \mathrm{x} 12.0 \mathrm{~m}$ along the $\mathrm{x}, \mathrm{y}$ and $\mathrm{z}$-directions, respectively. The volume has a total of 691,000 parallelepiped cells distributed in 8 non-uniform meshes. Most of the cells have dimensions of $0.125 \mathrm{~m} \mathrm{x} 0.125 \mathrm{~m} \mathrm{x} 0.100 \mathrm{~m}$ along the $x, y$ and $z$ directions, respectively. However, $y$ and $z$ dimensions were reduced in some areas to $0.0625 \mathrm{~m}$ and $0.075 \mathrm{~m}$, respectively, to obtain a finer mesh in the elements representing the deck girders and the RC slab.

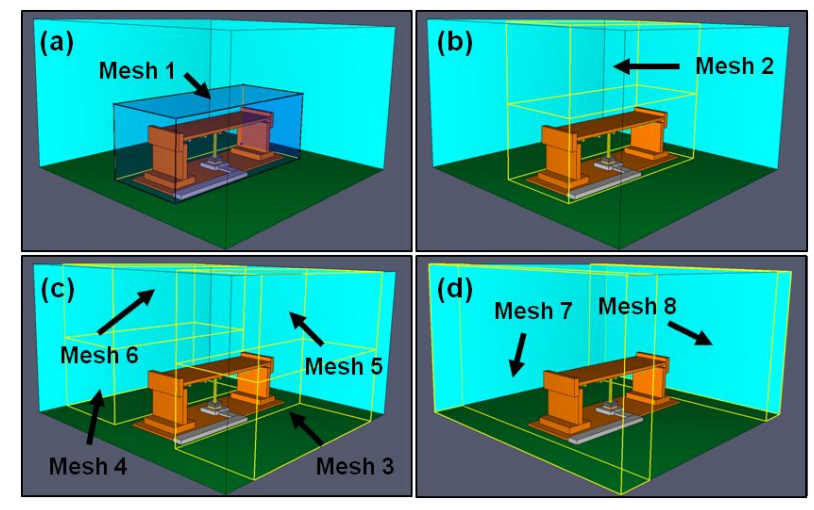

Figure 8. Eight non-uniform meshes employed for FDS model

The control volume and mesh sizes were the result of a sensitivity analysis and are a trade-off between precision and calculation times. As suggested in the FDS6 user guide [28], cell aspect ratio has been kept equal or lower than 2 in order not to penalize the efficiency of the calculation. Fig. 8 shows how the meshes were distributed along the control volume to reduce inaccuracies associated with flame and soot transfer between different meshes. Mesh 1 (see Fig. 8a) was defined to include internal flames. Similarly, soot transport was mostly limited to Meshes 1 and 2 (see Fig. 8b). Meshes 3 to 8 (see Fig. $8 \mathrm{c}$ and Fig. 8d) were added to provide enough distance from the fire source to ensure that the open boundary conditions (e.g. room temperature and pressure) did not affect the results.

\subsection{Geometry and materials}

The bridge geometry included in the FDS model is shown in Fig. 9. It can be seen to be slightly different from the actual geometry in Fig. 1, due to the cell sizes finally employed. However, the FDS model faithfully reproduces the basic geometric 
parameters (vertical height $1.9 \mathrm{~m}$, beam edge $0.15 \mathrm{~m}$, beam centerline separation $1.0 \mathrm{~m}$, and bridge width $2.0 \mathrm{~m}$ ). Besides the geometry, each fire scenario also included an inert zone (see Fig. 10) that represented the base that supported the fuel pan and the protection of the cable to the weighing scale.

(a) Elevation

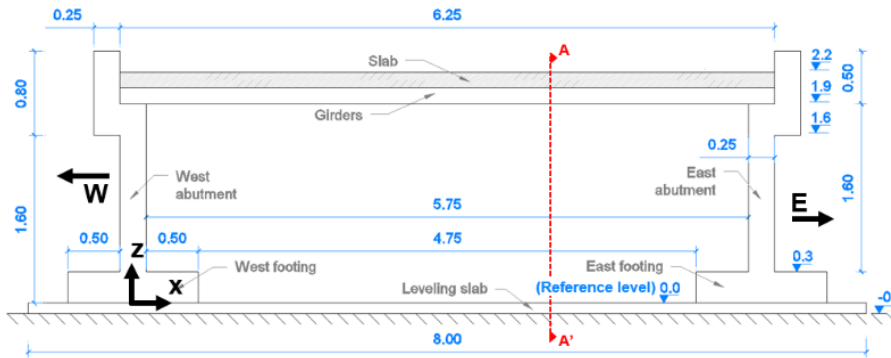

(b) Abutment \& deck details

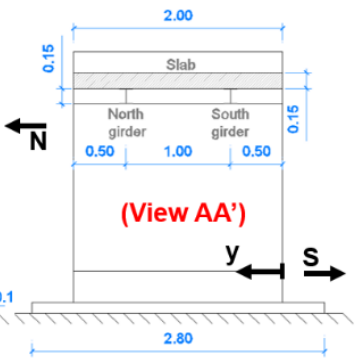

Figure 9. Bridge geometry in FDS6: (a) Elevation and (b) Abutment and deck details. All the dimensions expressed in $\mathrm{m}$.

The FDS model calculates the one-dimensional heat transfer required by the definition of the thicknesses and properties of the materials used. Material thicknesses are specified in Fig. 10 and their thermal properties are given in Table 5. The FDS backing parameter (used to indicate thermal boundary conditions) was set as "Exposed" for the steel planar surfaces and "Air Gap" at room temperature for concrete obstructions.

(a) Materials \& surfaces

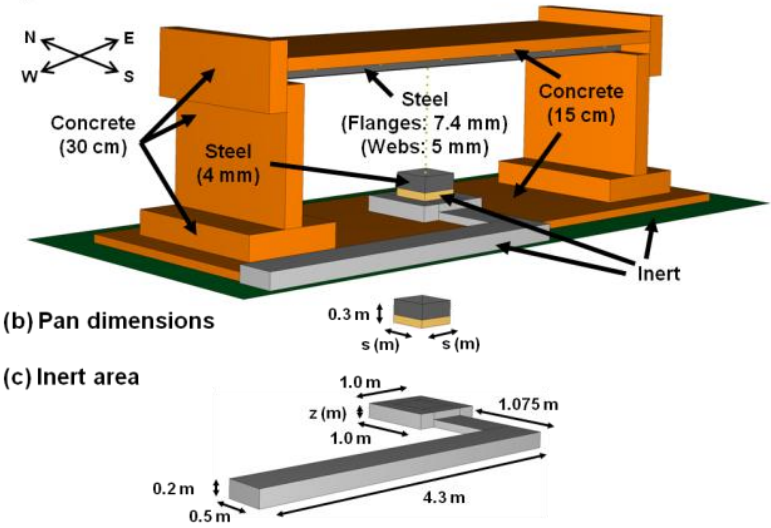

Figure 10. FDS model details: (a) Materials and surfaces, (b) Pan dimensions and (c) Inert area. 


\begin{tabular}{cccccc}
\hline Material & $\begin{array}{c}\mathrm{kg} / \mathrm{m}^{3} \\
\text { Density }\end{array}$ & $\begin{array}{c}\mathrm{kJ} / \mathrm{kg}^{\circ} \mathrm{C} \\
\text { Specific heat }\end{array}$ & $\begin{array}{c}\mathrm{W} / \mathrm{m}^{0} \mathrm{C} \\
\text { Conductivity }\end{array}$ & $\begin{array}{c}(.) \\
\text { Emissivity }\end{array}$ & $\begin{array}{c}\text { Absortion } \\
\text { coefficient }\end{array}$ \\
\hline Steel & 7850 & 0.46 & 45.8 & 0.95 & $5 \cdot 10^{4}$ \\
Concrete & 2280 & 1.04 & 1.8 & 0.9 & $5 \cdot 10^{4}$ \\
\hline
\end{tabular}

Table 5. Material thermal properties. Source: Pyrosim database [34].

\subsection{Fire Load and combustion model}

The fire load used was defined according the weights recorded by the scale underneath the pan filled with gasoline. The FDS model was built for the four fire scenarios studied and shown in Fig. 2 and Table 4. Fig. 11 shows: (a) the HRR used as an input in the fire models, which was obtained from the mass loss rate per unit area measurements according to Eq. 9, and (b) the HRR given by the FDS software during the simulations.

$$
\mathrm{Q}=A_{\text {fire }} \cdot \dot{m}^{\prime \prime} \cdot \Delta H_{c}
$$

Where:

$Q$ is the heat release rate of the fire in $\mathrm{kW}$

$A_{\text {fire }}$ is the footprint of the fire in $\mathrm{m}^{2}$. Tables 1 and 4 give side values to obtain these areas $\dot{m}$ ' is the mass loss rate per unit area in $\mathrm{kg} / \mathrm{m}^{2} / \mathrm{s}$.

$\Delta H_{c}$ is the heat of combustion in $\mathrm{MJ} / \mathrm{kg}$. Gasoline has a $43.7 \mathrm{MJ} / \mathrm{kg}$ value [18]

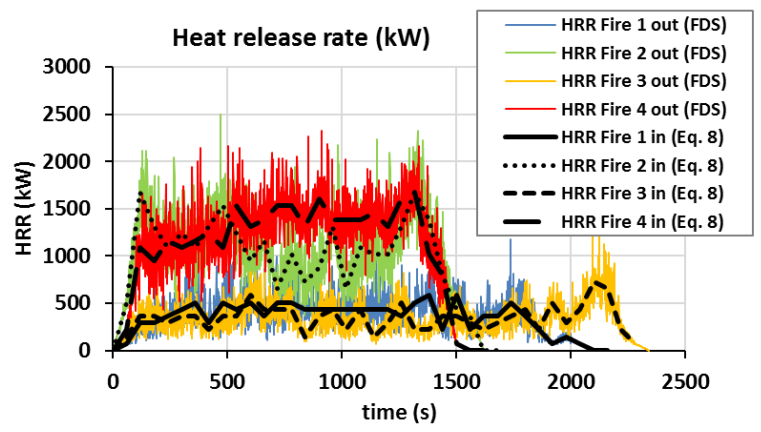

Figure 11. HRR through time for different fire scenarios: (black) defined as an FDS input and (colored) employed by FDS during the simulations. 
FDS defines the fire sources through specific surfaces identified as burners. In the FDS simulations of the Valencia bridge fire tests, the burner that represents the fire source is a horizontal square surface of either $0.25 \mathrm{~m}^{2}$ (Fires 1 and 3) or $0.5625 \mathrm{~m}^{2}$ (Fires 2 and 4). The input heat curve of the release rate per unit area (HRRPUA) was defined by dividing the HRR (black curves in Fig. 11) by the corresponding burner surface. The HRR eventually used for the FDS is represented in Fig. 11 by colored lines. The average HRR and HRRPUA values for each scenario are included in Table 1 and Fig. 14, respectively. The vertical burner coordinate $(z b)$ for each scenario is defined in Fig. 12 and represents the level of the flames basis.

The fire load uses the heptane reaction provided by the Pyrosim 2016.1.0425 fuel library [34] because it is the closest to the gasoline reaction among those available. The fire load also uses the mixture fraction combustion model proposed by McGrattan et al [28, 35], with a radiation factor of 0.35 . Soot yield was set to 0.037 , in accordance with [36].

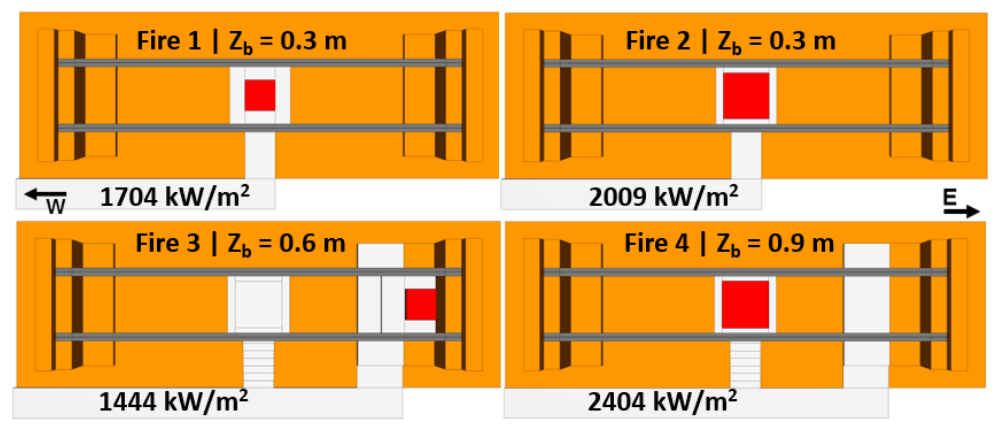

Figure 12. FDS modeling. Plan view showing the fire scenarios considered. The surface of the burner is represented in red and the steel deck beams in grey.

\subsection{Sensors}

The FDS model sensors are elements (usually points) that store one or more of the simulation variables and enable the output dimensions to be reduced, as they avoid the storage of variables that will not be used subsequently. Eighteen $1.5 \mathrm{~mm}$ diameter stainless steel sheath thermocouples were defined in the models to record temperatures that could be compared to the temperatures recorded by the real thermocouples. The FDS model includes sensors placed $5 \mathrm{~cm}$ below the concrete slab in six sections at $x=0.5,1.5$, 2.5, 3.5, 4.5 y $5.5 \mathrm{~m}$, respectively (see Fig. 4), coinciding with the thermocouples in the horizontal TCTs (see Fig. 4). Five FDS thermocouples were also placed directly above the burner at the position of the thermocouples in the vertical TCT (see Fig. 4). 


\subsection{Results}

Fig. 13a and Fig. 13b compare the temperatures obtained from the numerical models with those obtained experimentally. In Fig. 13a the comparison uses average temperatures during the plateau stage of the fire. In these cases, numerical models overestimate the experimental temperatures by between 30 and $120 \%$ of the experimental values (see Fig. 13c). This difference can be attributed to the wind present during the experiments, which was not allowed for in the numerical models. The wind at times blew the flames away from the vertical (see Fig. 14a), thus cooling the gases under and around the deck.

Fig. 13b compares the maximum experimental gas temperatures (which are obtained with no wind) with those predicted by the numerical models. It can be observed that the numerical models give a highly accurate prediction of both the peak values and the distribution of gas temperatures in the deck's central region. In this case, the difference between the measured and predicted temperatures (plotted in Fig. 13d) varies between $25 \%$ (Fire 2) and $+30 \%$ (Fire 4). These differences are acceptable in the experimental validation of FDS models, as will be explained below (see Section 6.3.2). Figs. 14b and $14 \mathrm{c}$ compare Fire 4 in the experiment with the FDS's no-wind predictions and both can be seen to be remarkably similar.

(a) Comparison with averaged experimental values

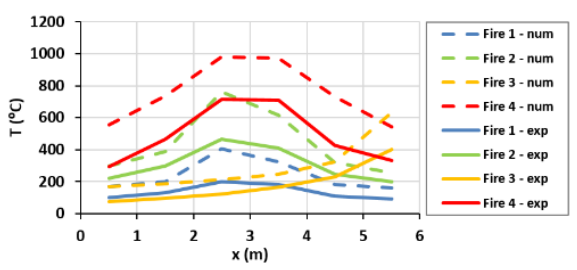

(c) \% differences with averaged experimental values

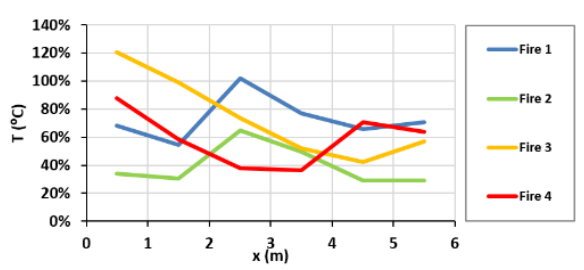

(b) Comparison with maximum experimental values

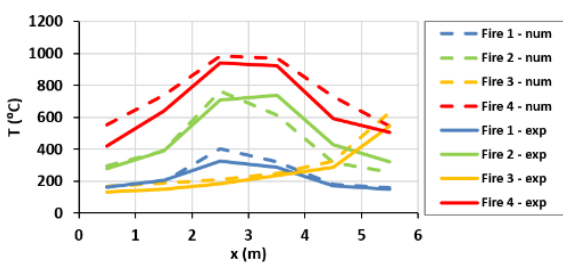

(d) \% differences with maximum experimental values

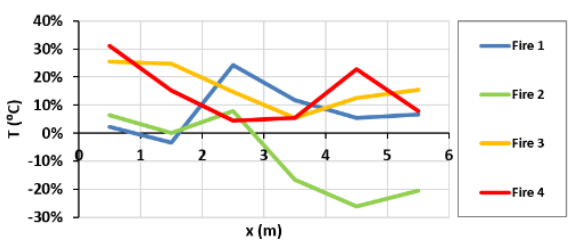

Figure 13. Comparison between experimental vs. numerical results, considering: average experimental values (a) and (c) and maximum experimental values (b) and (d). All numerical values are averages. 

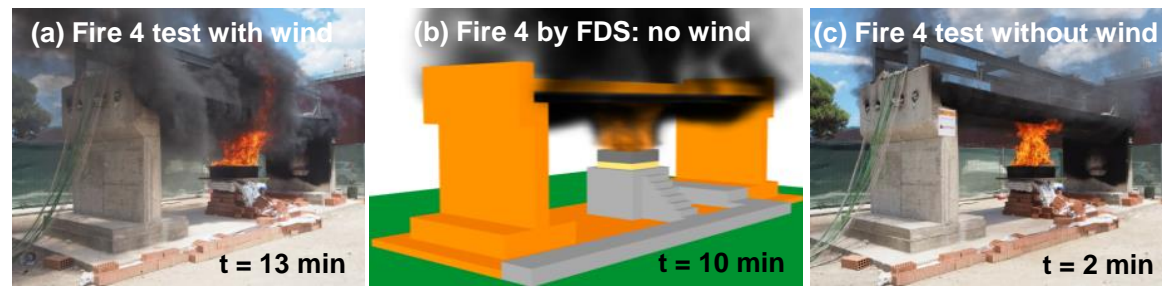

Figure 14. Different views of Fire 4 (a) Fire 4 test with wind (b) Fire 4 FDS model with no wind and (c) Fire 4 test with no wind.

Fig. 15 gives the temperatures recorded in the gas through time in the section S4 (see Fig.4) in the Central and South regions for Fires 2 and 4. These scenarios were chosen because they showed the influence of the wind on the experimental temperature recordings. Similar graphs are not provided for the other tests, since the values were similar. Table 6 contains the average temperatures given by the FDS numerical models for all the fire scenarios considered. These temperatures will be compared with the temperatures recorded during the test (see Table 2 ) in the uncertainty analysis described in Section 6.
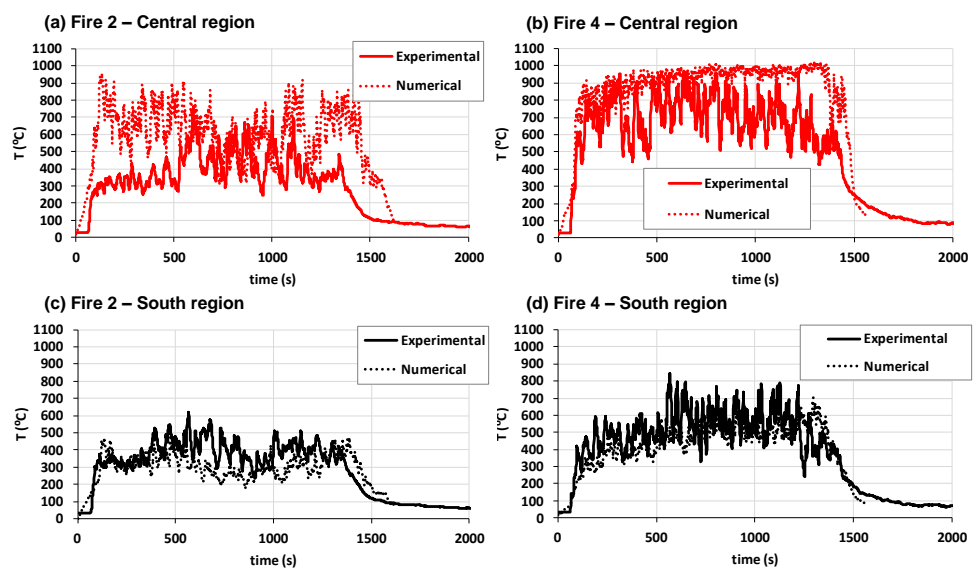

Figure 15. Time-temperature curves for the $S 4$ deck section: (a) Fire 2 - Central region, (b) Fire 4- Central region, (c) Fire 2 - South region and (d) Fire 4 - South region. The location of the section $\mathrm{S} 4$ is given in Fig. $4 \mathrm{a}$. 
Fig. 15a and Fig. 15b show how the experimental temperatures recorded by the GC4 thermocouple in the central region (for Fires 2 and 4 respectively) are equal to or lower than those predicted by the numerical model. Fig. $15 \mathrm{~b}$ is especially instructive as it clearly shows that the maximum values recorded during the Fire 4 test are very similar to the values obtained with the numerical model, which can be attributed to the lesser effect of the wind during the test. On the other hand, Fig. 15c and Fig. 15d show the temperatures recorded by the GS4 thermocouple in the South region, in which the experimental temperatures are higher than the numerical temperatures, due to the wind blowing the flames towards the South and allowing the temperature to rise in this region. This confirms that average numerical temperatures and maximum experimental temperatures in the absence of wind should be used when comparing the experimental and numerical values.

\begin{tabular}{|c|c|c|c|c|c|c|}
\hline Aver. $\mathrm{T}\left({ }^{\circ} \mathrm{C}\right)$ & $x(m)$ & South region & North region & Central region & $z(m)$ & Fire plume \\
\hline \multirow{6}{*}{ 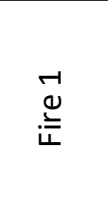 } & 0.5 & 125 & 125 & 168 & 1.73 & 470 \\
\hline & 1.5 & 125 & 125 & 198 & 1.54 & 520 \\
\hline & 2.5 & 161 & 154 & 405 & 1.24 & 609 \\
\hline & 3.5 & 150 & 148 & 322 & 0.99 & 663 \\
\hline & 4.5 & 116 & 117 & 182 & 0.65 & 799 \\
\hline & 5.5 & 124 & 123 & 158 & - & - \\
\hline \multirow{6}{*}{ 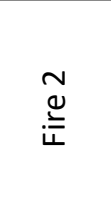 } & 0.5 & 212 & 210 & 297 & 1.73 & 768 \\
\hline & 1.5 & 233 & 239 & 389 & 1.54 & 722 \\
\hline & 2.5 & 342 & 318 & 762 & 1.24 & 728 \\
\hline & 3.5 & 303 & 287 & 615 & 0.99 & 737 \\
\hline & 4.5 & 206 & 203 & 319 & 0.65 & 746 \\
\hline & 5.5 & 200 & 197 & 257 & - & - \\
\hline \multirow{6}{*}{$\begin{array}{l}m \\
\stackrel{m}{ \pm}\end{array}$} & 0.5 & 104 & 103 & 169 & 1.95 & 462 \\
\hline & 1.5 & 82 & 81 & 191 & 1.69 & 366 \\
\hline & 2.5 & 93 & 92 & 216 & 1.41 & 386 \\
\hline & 3.5 & 123 & 121 & 253 & 1.13 & 487 \\
\hline & 4.5 & 168 & 165 & 334 & 0.85 & 755 \\
\hline & 5.5 & 241 & 240 & 643 & - & - \\
\hline \multirow{6}{*}{$\begin{array}{l}ナ \\
\stackrel{Ð}{\Perp}\end{array}$} & 0.5 & 361 & 336 & 554 & 1.89 & 661 \\
\hline & 1.5 & 355 & 338 & 736 & 1.73 & 979 \\
\hline & 2.5 & 514 & 443 & 982 & 1.54 & 983 \\
\hline & 3.5 & 522 & 454 & 970 & 1.44 & 975 \\
\hline & 4.5 & 367 & 370 & 729 & 1.25 & 791 \\
\hline & 5.5 & 396 & 372 & 544 & - & - \\
\hline
\end{tabular}

Table 6. Average temperatures (Ave. $T\left({ }^{\circ} \mathrm{C}\right)$ ) obtained from the FDS numerical simulation. Average values were calculated during the time intervals defined in Table 3. 
Finally, it is important to note that CFDs in general, and FDS models in particular, are complex to build and computationally expensive. For example, a typical simulation done with FDS of the fire that affected the I-65 overpass in Birmingham, Alabama, US - a bridge with a total length of $88.53 \mathrm{~m}$ - took three days and four hours in a computer cluster (see Alos-Moya et al. [4] for more details). Therefore, it is important to develop simplified approaches to model the effects of fires in bridges. Such approaches could be based, for example, on improvements of existing analytical methods (such as the Heskestad and Hamada's correlation) or on the development of fire curves specific for bridges. Any of them will need validation through numerical and, if possible, experimental tests, what makes the calibration of numerical models such as the one presented in this paper of major importance.

\section{Uncertainty analysis of the results obtained using CFDs.}

Differences appear when the results of a fire test are compared with those of a numerical model performed with FDS (or similar). These differences may be due to either measurement errors during the test (experimental errors, $u_{E}$ ) or to inaccuracies in the numerical model (model errors, $u_{M}$ ). The former can be attributed to incorrect measurements used as inputs in the model (e.g. mass losses and their corresponding HRR's), $u_{E 1}$, or to incorrect experimental output measurements (e.g. gas temperatures), $u_{E 2}$. The latter can be attributed to a number of reasons such as the differences between the real and modeled geometry, differences between the experimental HRR and the HRR finally employed (as can be seen in Fig.13) and the physical assumptions of the model (e.g. radiation factor and soot yield parameters). Fig. 16 summarizes the sources of error mentioned above and their application to the problem studied in this paper.

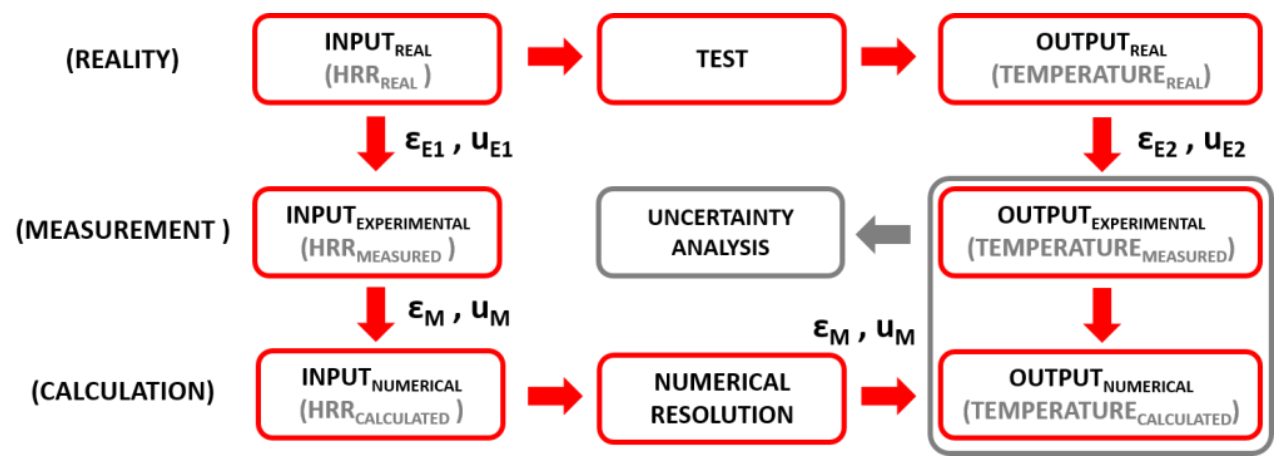

Figure 16. Sources of error and uncertainty. 
In the field of fire test validation, the concept of uncertainty is more commonly used than the concept of error. Error and uncertainty express different concepts [37]: the term "error" is used: 1) to quantify the difference between the result of a measurement and the real value, or, 2) to quantify the imperfection of the method and the device used, while the uncertainty of the measurement is a non-negative parameter that characterizes the dispersion of the values attributed to a measured variable. The following subsections detail how experimental and model uncertainties are defined and how these concepts were applied to the Valencia bridge fire tests.

\subsection{Experimental uncertainty}

According to McGrattan $[33,38]$, the experimental uncertainty of a variable that a model is trying to predict is measured by $k$ times the experimental relative standard deviation $\left(\omega_{E}\right)$ of the analyzed variable (temperature in the present study); $k$ is assumed to be equal to 2 for a $95 \%$ uncertainty interval $[33,38,39]$.

The experimental relative standard deviation $\omega_{E}$ is obtained using Eq. 10:

$$
\omega_{E}^{2}=\omega_{0}^{2}+\sum_{\mathrm{i}}^{\mathrm{n}} \mathrm{p}_{\mathrm{i}}^{2} \cdot \omega_{\mathrm{i}}^{2}
$$

Where:

$\omega_{0}$ is the relative standard deviation of the output measurements and represents the uncertainty of the device which measures the quantity (temperatures in this case) that the model is trying to predict ( $\mathrm{U}_{\mathrm{E} 2}$ defined in Fig. 16).

The expression $\sum_{\mathrm{i}}^{\mathrm{n}} \mathrm{p}_{\mathrm{i}}^{2} \cdot \omega_{\mathrm{i}}^{2}$ represents the $\mathrm{u}_{\mathrm{E} 2}$ term defined in Fig. 16. In this expression:

- $p_{i}$ are factors that represent the power dependences of the individual input parameters.

- $\omega_{\mathrm{i}}$ is the relative standard deviation of the input measurements and represents the uncertainty of the devices which measure the various input parameters required by the numerical model ( $\mathrm{u}_{\mathrm{E} 1}$ defined in Fig. 16).

- $n$ represents the number of relevant terms which affect the experimental uncertainty of the output variable under study. In the present study $n$ is equal to 1 , since the HRR is the only physical input parameter of the numerical model of the fire tests considered in the uncertainty study. 
The most important physical parameters associated with the various quantities measured in the fire experiments together with their power dependence $\left(p_{i}\right)$ are detailed in $[39,40]$.

\subsection{Model uncertainty}

To obtain the model uncertainty the following assumptions must be considered [39, 40]: (1) The experimental measurements are unbiased, and their uncertainty is assumed to be normally distributed with a constant experimental relative standard deviation, $\omega_{E}$, and (2) the model uncertainty is normally distributed about the predicted value multiplied by a bias factor, $\delta$. This bias factor $\delta$ indicates how, on average, the model over or underpredicts the experimental measurements $[38,39]$. The model relative standard deviation of the temperature distribution is denoted as $\omega_{M}$ and is used to measure the scatter of the numerical output values.

Once the experimental uncertainty has been defined (by calculating the experimental relative standard deviation $\left.\omega_{E}\right)$, and given a set of experimental measurements $\left(E_{i}\right)$, as well as a corresponding set of model predictions $\left(M_{i}\right)$, parameters $\omega_{M}$ and $\delta$, which characterize the model uncertainty, are given by Eqs. 11 and 12, respectively [33, 38].

$$
\begin{aligned}
& \omega_{M}^{2}+\omega_{E}^{2}=\frac{1}{n-1} \cdot \sum_{\mathrm{i}=1}^{\mathrm{n}}\left[\ln \left(M_{i} / E_{i}\right)-\overline{\ln (M / E)}\right]^{2} \\
& \delta=\exp \left[\overline{\ln (M / E)}+\frac{\omega_{M}^{2}}{2}-\frac{\omega_{E}^{2}}{2}\right]
\end{aligned}
$$

Where $\overline{\ln (M / E)}$ is given by Eq. 13

$$
\overline{\ln (M / E)}=\frac{1}{n} \cdot \sum_{i=1}^{n} \ln \left(M_{i} / E_{i}\right)
$$

\subsection{Application to Valencia bridge fire tests}

\subsubsection{Experimental uncertainty}

In the specific case of the Valencia bridge fire tests Eq. 10 becomes Eq. 14.

$$
\omega_{\mathrm{E}}^{2}=\omega_{\mathrm{TEMPERATURES}}^{2}+\mathrm{p}_{\mathrm{TEMPERATURE} / \mathrm{HRR}}^{2} \cdot \omega_{\mathrm{HRR}}^{2}
$$

Where:

$\omega_{E}$ is the experimental relative standard deviation $\left(\sigma_{E} / \delta\right)$

$\omega_{\text {TEMPERATURES }}$ is obtained as the combination of the uncertainties of the thermocouples and datalogger, according to Eq. 15 [41], 


$$
\omega_{\text {TEMPERATURES }}^{2}=\omega_{\text {THERMOCOUPLES }}^{2}+\omega_{\text {DATALOGGER }}^{2}
$$

$\mathrm{p}_{\text {TEMPERATURE/HRR }}^{2}$ is equal to $2 / 3$ according to $[39,40]$. This factor provides the temperature uncertainty directly attributable to the uncertainty of the HRR measurements.

$\omega_{H R R}$ is the uncertainty associated with HRR measurement.

Using the values $\omega_{\text {THERMOCOUPLES }}=0.75 \%, \omega_{\text {DATALOGGER }}=0.25 \%$ y $\omega_{H R R}=$ $15.00 \%$ provided by the manufacturers of the devices and by [40], the experimental relative standard deviation, $\omega_{E}$, is $10.03 \%$. Thus, adopting a factor $k$ equal to 2 , as explained in Section 6.1 for a 95\% uncertainty interval, the experimental relative uncertainty is $20.06 \%$.

\subsubsection{Model uncertainty}

As explained in Section 6.2, the model uncertainty requires the calculation of $\omega_{M}$ and $\delta$ from the experimental temperature values $\left(E_{i}\right)$ and from the temperatures obtained by the numerical models $\left(M_{i}\right)$.

(a) Ceiling jet temperatures

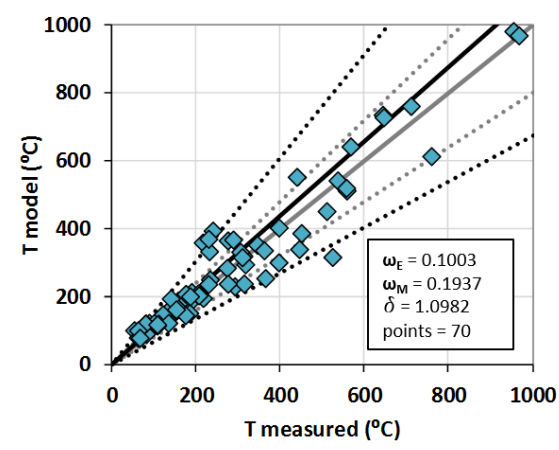

(b) Fire plume temperatures

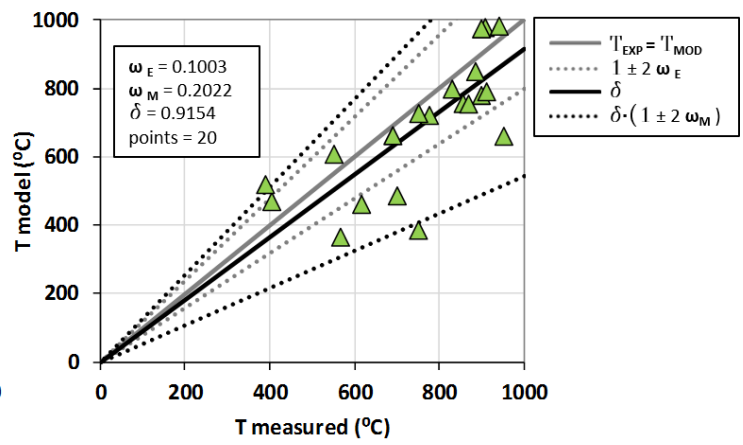

Figure 17. Scatter between measured and model temperatures for: (a) Ceiling jet and (b) Fire plume

Fig. 17 gives the dispersion between the maximum experimental temperatures and the average temperatures obtained from the numerical models for the four fire scenarios. Fig. 17a includes the values recorded by the thermocouples in the ceiling jet zone (horizontal thermocouple trees in the three regions (South, Central and North) of the bridge deck). It can be seen that the numerical model's values show a bias factor $(\delta)$ of 1.0982 with respect to the experimental values. This dispersion of the results is due to 
the assumptions of the FDS model, the uncertainties in the input parameters of the FDS model (e.g. soot yield and radiation fraction) and the effect of the wind. The latter variable, even though in theory belonging to the experimental uncertainty, could not be separated from the numerical uncertainty, simply because both its magnitude and direction keep changing with time. This phenomenon will be repeated in any future tests carried out under windy conditions. Fig. 17b gives similar data for the vertical thermocouple tree in the fire plume. In this case fewer data are used than for the ceiling jet (20 instead of 70).

Tables 7 and 8 compare the parameters used to measure the uncertainty (without and with the wind correction given in Section 5.5) with those obtained by McGrattan et al. [33] in the FDS validation tests. It should be noted that both the bias factor and the relative standard deviation of the models are closer to the parameters of McGrattan et al. [33] when maximum experimental temperatures where used. The higher uncertainties obtained in the present study can be explained by the influence of wind, a variable absent in the FDS validation work presented in [33]. Given these considerations, the authors consider the validation of the FDS model carried out is correct.

\begin{tabular}{ccccc}
\hline Ceiling jet & $\omega_{\mathrm{E}}$ & $\omega_{\mathrm{M}}$ & $\delta$ & Points \\
\hline Valencia bridge fire tests & 0.1 & 0.237 & 1.291 & 70 \\
$\begin{array}{c}\text { (Averaged temperatures) } \\
\text { Valencia bridge fire tests }\end{array}$ & 0.1 & 0.194 & 1.098 & 70 \\
(Maximum temperatures) & 0.07 & 0.14 & 1.05 & 898 \\
\hline McGrattan [32] & & & & \\
\hline
\end{tabular}

Table 7: Uncertainty parameters for ceiling jets. 70 measurements considered.

\begin{tabular}{ccccc}
\hline Fire plume & $\omega_{\mathrm{E}}$ & $\omega_{\mathrm{M}}$ & $\delta$ & Points \\
\hline Valencia bridge fire tests & 0.1 & 0.346 & 1.518 & 20 \\
$\begin{array}{c}\text { (Averaged temperatures) } \\
\text { Valencia bridge fire tests }\end{array}$ & 0.1 & 0.202 & 0.915 & 20 \\
$\begin{array}{c}\text { (Maximum temperatures) } \\
\text { McGrattan[32] }\end{array}$ & 0.07 & 0.16 & 1.18 & 107 \\
\hline
\end{tabular}

Table 8: Uncertainty parameters for fire plumes. 20 measurements considered. 


\section{Conclusions and future work}

This paper compares the experimental gas temperatures recorded in tests 2, 4, 7 and 8 of the Valencia bridge fire tests [17] with the temperatures predicted by both a simplified correlation and a computational fluid dynamics model. The comparison between the experimental data and the advanced numerical approach was conducted in two steps. Firstly, a more visual comparison was included in order to determine where the higher differences were taking place. An uncertainty analysis was then carried out to compare model uncertainties with other similar tests validated in the FDS validation guide [33]. From these analyses, the following conclusions can be drawn:

- Since the tests were carried out in the open air, they were significantly affected by the wind, unlike tests performed in furnaces or closed spaces. The wind blew the flames away from the vertical plane and also affected the ascending column of gases from the fuel pan under the deck.

- The four fire scenarios were validated with a slightly higher uncertainty than that obtained by McGrattan et al. [33]. The higher numerical dispersion can be attributed mainly to the effect of the wind during the tests carried out in the present study. In order to reduce the uncertainty values, it is recommended that a wind break should be used in any future studies of this type.

- Both the simplified and the advanced approaches provide good results when used to predict gas temperatures for the Fires 1,2 and 3 scenarios if the zero wind velocity correction justified in Section 5.5 is applied. Temperatures in the Fire 4 scenario can be accurately predicted by the FDS model, but not by the Heskestad \& Hamada correlation, as the HRR in this scenario is higher than the correlation application limits.

- Although Heskestad \& Hamada's model was initially defined for unconfined fires, it can be used for the preliminary design of future bridge fire tests with HRRs between 361 and $1130 \mathrm{~kW}$. Although gas temperatures may be underestimated by up to $30.4 \%$, it will give a good approximation of the overall shape of both peak temperatures and the expected gas temperatures around the bridge.

- The Heskestad \& Hamada correlation cannot be used to study real bridge fires as it was developed for fires with a maximum HRR of $764 \mathrm{~kW}$, which is much lower than the HRR of the fire loads involved in real bridge fires. However, given its good prediction of the overall shape of gas temperatures, it has the potential to be used as the starting point for a new simplified approach to predict gas temperatures in bridge fires.

This research work has validated the application of CFD models built with the software FDS for the study of bridge fires and has corroborated the application limits of a common 
simplified approach for ceiling jets. It is therefore an important step forward in the study of the effects of fires in bridges and improving the resilience of infrastructure networks vis-à-vis fire hazards. It has also highlighted the problems that could arise in fire tests in the open air, especially the influence of the wind. Future experimental work in this area should first consider ways of reducing wind to avoid a source of uncertainty. Then specific tests should be designed and carried out under wind controlled conditions to study wind influence. Future numerical work can be addressed towards the development of simplified approaches to model bridge fires based e.g. on improvements of existing analytical methods (such as the Heskestad and Hamada's correlation) or on the development of fire curves specific for bridges. Any of these simplified approaches will need validation through numerical and, if possible, experimental tests, what makes the work presented in this paper of major importance.

\section{Acknowledgements}

Funding for this research was provided by the Spanish Ministry of Science and Innovation (Research Project BIA 2011-27104). The authors are grateful to the Infrastructure and Safety departments of the Universitat Politècnica de València and the City of Valencia Fire Department (Cuerpo de Bomberos de Valencia), which provided crucial support in conducting the tests.

\section{References}

[1] Peris-Sayol G, Paya-Zaforteza I, Balasch-Parisi S, Alos-Moya J. Detailed Analysis of the Causes of Bridge fires and Their Associated Damage Levels. ASCE Journal of Performance and Constructed Facilities. 2016. doi:10.1061/(ASCE)CF.19435509.0000977

[2] Garlock ME, Paya-Zaforteza I, Gu L, Kodur V. Fire hazard in bridges: review, assessment and repair strategies. Engineering Structures 2012; 35:89-98.

[3] Quiel SE, Yokoyama T, Bregman LS, Mueller KA, Marjanishvili SM. A streamlined framework for calculating the response of steel-supported bridges to open-air tanker truck fires. Fire Safety Journal 2015; 73:63-65.

[4] Alos-Moya J, Paya-Zaforteza I, Garlock MEM, Loma-Ossorio E, Schiffner D, Hospitaler A. Analysis of a bridge failure due to fire using computational fluid dynamics and finite element models. Engineering Structures 2014; 68:96-110.

[5] Gong X, Agrawal AK. Numerical Simulation of Fire Damage to a Long-Span Truss Bridge.Journal Bridge Engineering 2015;20(10).doi: 10.1061/(ASCE)BE.19435592.0000707\#sthash.nhj5KqVo.dpuf 
[6] Godart B, Berthellemy J, Lucas JP. Diagnosis, assessment and repair of the Mathilde bridge close to collapse during a fire. Structural Engineering International. 2015;25(3):331-38.

[7] Peris-Sayol G, Alos-Moya J, Paya-Zaforteza I, Hospitaler-Perez A. A parametric study on the thermo-mechanical response of a multi-girder steel bridge submitted to real fires.Informes de la Construcción, 66 (Extra-1) (In Spanish).

[8] Nahid MNH, Sotelino ED, Lattimer BY. Thermo-Structural Response of Highway Bridge Structures with Tub Girders and Plate Girders. Journal of Bridge Engineering 201722 (10).

[9] Peris-Sayol G, Paya-Zaforteza I, Alos-Moya J, Hospitaler A. Analysis of the influence of geometric, modeling and environmental parameters on the fire response of steel bridges subjected to realistic fire scenarios. Computers and Structures 2015; 158:333-345.

[10] Paya-Zaforteza I, Garlock M. A numerical investigation on the fire response of a steel girder bridge. Journal of Constructional Steel Research 2012; 75: 93-103.

[11] Buchanan AH. Structural Design for Fire Safety.John Wiley \& Sons, Chichester, United Kingdom, 2002.

[12] Albero V, Saura H, Hospitaler A, Montalvà JM, Romero ML. Optimal design of prestressed concrete hollow core slabs taking into account its fire resistance. Advances in Engineering Software 2018 122: 81-92.

[13] Quiel SE, Garlock MEM, Paya-Zaforteza I. Closed Form Procedure for Predicting the Capacity and Demand of Steel Beam-Columns under Fire. ASCE Journal of Structural Engineering 2011; 137: 967-76.

[14] Rackauskaite E., Kotsovinos, P, Jeffers A., Rein G. Structural analysis of multistorey steel frames exposed to travelling fires and traditional design fires. Engineering Structures 2017 150: 271-287.

[15] Maraveas C, Vrakas A. Design of concrete tunnel linings for fire safety. Structural Engineering International 201424 (3): 319-329.

[16] Ji J, Tong Q, Wang L, Lin C, Zhang C, Gao Z, Fang J. Application of the EnKF method for real-time forecasting of smoke movement during tunnel fires. Advances in Engineering Software 2018 115: 398-412. 
[17] Alos-Moya J, Paya-Zaforteza I, Hospitaler A. Valencia bridge fire tests: Experimental study of a composite bridge under fire. Journal of Constructional Steel Research 2017 138: 538-554.

[18] Babrauskas V. Chapter 26. Heat Release rates. In: SFPE handbook of fire protection engineering, 5th ed. 2016. p. 799-904.

[19] Peris-Sayol G, Paya-Zaforteza I, Balasch-Parisi S., Alos-Moya J. Analysis of the Factors that Influence the Maximum Adiabatic Temperatures in I-girder Bridges. 9th International Conference on Structures in Fire, p. 743-50, Princeton, NJ, USA; 2016

[20] Quiel S, Zhu Z, Mueller K, Carlton A, Marjanishvili S. Performance-Based Prioritization of Fire Mitigation for Highway Bridges. 9th International Conference on Structures in Fire, p. 776-83, Princeton, NJ, USA; 2016

[21] Alpert RL. Chapter 14. Ceiling jet flows. In: SFPE handbook of fire protection engineering, 5th ed. 2016. p. 429-54.

[22] Hasemi Y, Yokobayashi S., Wakamatsu T, Ptchelintsev A. Fire Safety of Building Components Exposed to a Localized Fire: Scope and Experiments on Ceiling/Beam System Exposed to a Localized Fire. AsiaFlam 95 - 1st International Conference, p. 351, London, UK; 1995

[23] Alpert RL. Turbulent ceiling jet induced by large scale fires. Combustion Science and Technology 1975; 11:197-213.

[24] Heskestad G, Hamada T. Ceiling Jets of Strong Fire Plumes. Fire Safety Journal $1993 ; 21: 69-82$

[25] Heskestad G. Chapter 13. Fire plumes, flame height, and air entrainment. In: SFPE handbook of fire protection engineering, 5th ed. 2016. p. 396-428.

[26] KoslowskiCC and Motevalli V.Behavior of a2-Dimensional Ceiling Jet Flow: A Beamed Ceiling Configuration. Fire Safety Science - Proceedings ofthe Fourth International Symposium, p. 469, Bethesda, MD; USA;1994.

[27] Alpert RL. Calculation of Response Time of Ceiling-Mounted Fire Detectors. Fire Technology,1972:8:181. doi:10.1007/BF02590543

[28] McGrattan K, Hostikka S, McDermott R, Floyd J, Weinschenk C, Overholt K. Fire Dynamics Simulator User's Guide (version 6). User's Guide.NIST Special Publication 1019, Gaithersburg, MD, USA; 2013. 
[29] McGrattan K.B., Baum H.R., Hamins A. Thermal radiation from Large Pool Fires. NIST Report NISTIR 6546, 2000.

[30] Drysdale D. An Introduction to Fire Dynamics.John Wiley and Sons. United Kingdom; 2011

[31] Cheong MK, Spearpoint M J, Fleischmann CM. Design fires for vehicles in road tunnels. 7th International Conference on Performance-Based Codes and Fire Safety Design Methods, Auckland, New Zealand; 2008; 229-240

[32] Ingason H. Design fires in tunnels. 2nd International Symposium. Safe \& Reliable Tunnels Inovative European Achievements, Lausanne; 2006

[33] McGrattan K, Hostikka S, McDermott R, Floyd J, Weinschenk C, Overholt K. Fire Dynamics Simulator Technical Reference Guide. Volume 3: Validation (version 6). NIST Special Publication 1018-3, Gaithersburg, MD, USA; 2013.

[34] Thunderhead Engineering. Pyrosim User Manual. Included in Pyrosim version 2016.1.0425.

[35] McGrattan K, Hostikka S, McDermott R, Floyd J, Weinschenk C, Overholt K. Fire Dynamics Simulator Technical Reference Guide. Volume 1: Mathematical Model (version 6). NIST Special Publication 1018, Gaithersburg, MD, USA; 2013.

[36] Hurley MJ. Appendix 3: Fuel Properties and Combustion Data. In: SFPE handbook of fire protection engineering, 5th ed. 2016. p. 3437-3475.

[37] Centro español de la metrología. Evaluación de datos de medición. Guía para la expresión de la incertidumbre de medida. 2008

[38] McGrattan K, Steward Miles S. Chapter 32. Modeling Fires Using Computational Fluid Dynamics (CFD). In: SFPE handbook of fire protection engineering, 5th ed. 2016. p. 1034-1065.

[39] McGrattan K, Toman B. Quantifying the predictive uncertainty of complex numerical models. Metrologia. 2011; 48:173-80

[40] Hamins A. Verification and Validation of Selected Fire Models for Nuclear Power Plant. Applications. Volume 7: Experimental Uncertainty. U.S. Nuclear Regulatory Commission, Office of Nuclear Regulatory Research (RES), Rockville, MD, and Electric Power Research Institute (EPRI), NUREG-1824 and EPRI 1011999, Palo Alto, CA USA; 2006. 
[41] Gutierrez-Montes C, Sanmiguel-Rojas E, Kaiser AS, Viedma A. Numerical model and validation of atrium enclosure fire in a new fire test facility. Building and Environment 2008; 43:1912-1928.

[42] Rivkin CH. Section 21: Transportation Fire Safety. In: Fire Protection Handbook. NFPA 502, Standard for Road Tunnels, Bridges and Other Limited Access Highways, 2008. p. 502-23. 

UNIVERSIDAD
POLITECNICA
DE VALENCIA 